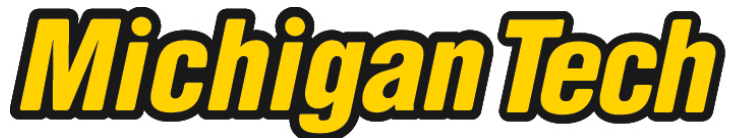 \\ Michigan Technological University Create the Future Digital Commons @ Michigan Tech
}

\section{Experimental and modeling study of the filtration and oxidation}

characteristics of a diesel oxidation catalyst and a catalyzed particulate filter

Kiran C. Premchand

Michigan Technological University

Follow this and additional works at: https://digitalcommons.mtu.edu/etds

Part of the Mechanical Engineering Commons

Copyright 2006 Kiran C. Premchand

\section{Recommended Citation}

Premchand, Kiran C., "Experimental and modeling study of the filtration and oxidation characteristics of a diesel oxidation catalyst and a catalyzed particulate filter", Master's Thesis, Michigan Technological University, 2006.

https://doi.org/10.37099/mtu.dc.etds/400

Follow this and additional works at: https://digitalcommons.mtu.edu/etds

Part of the Mechanical Engineering Commons 
An Experimental and Modeling Study of the Filtration and Oxidation Characteristics of a Diesel Oxidation Catalyst and a Catalyzed Particulate Filter

\author{
by \\ Kiran C.Premchand
}

\begin{abstract}
A Thesis
Submitted in partial fulfillment of the requirements for the degree of MASTER OF SCIENCE IN MECHANICAL ENGINEERING
\end{abstract}

MICHIGAN TECHNOLOGICAL UNIVERSITY

June 2006

Copyright ${ }^{\circledR}$ Kiran C.Premchand 2006 

This thesis, titled "An Experimental and Modeling Study of the Filtration and Oxidation Characteristics of a Diesel Oxidation Catalyst and a Catalyzed Particulate Filter" is hereby approved in partial fulfillment of the requirements for the degree of MASTER OF SCIENCE in MECHANICAL ENGINEERING.

Department: Mechanical Engineering - Engineering Mechanics

Thesis Co-advisor: $\quad$ Dr.John H.Johnson

Thesis Co-advisor: Dr.Song-Lin Yang

Department Chair: Dr.William W.Predebon

Date: 


\section{Abstract}

A diesel oxidation catalyst (DOC) with a catalyzed diesel particulate filter $(\mathrm{CPF})$ is an effective exhaust aftertreatment device that reduces particulate emissions from diesel engines, and properly designed DOC-CPF systems provide passive regeneration of the filter by the oxidation of PM via thermal and $\mathrm{NO}_{2} /$ temperature-assisted means under various vehicle duty cycles. However, controlling the backpressure on engines caused by the addition of the $\mathrm{CPF}$ to the exhaust system requires a good understanding of the filtration and oxidation processes taking place inside the filter as the deposition and oxidation of solid particulate matter (PM) change as functions of loading time.

In order to understand the solid PM loading characteristics in the CPF, an experimental and modeling study was conducted using emissions data measured from the exhaust of a John Deere 6.8 liter, turbocharged and after-cooled engine with a low-pressure loop EGR system and a DOC-CPF system (or a CCRT@ - Catalyzed Continuously Regenerating Trap $®$, as named by Johnson Matthey) in the exhaust system. A series of experiments were conducted to evaluate the performance of the DOC-only, CPF-only and DOC-CPF configurations at two engine speeds (2200 and $1650 \mathrm{rpm}$ ) and various loads on the engine ranging from 5 to $100 \%$ of maximum torque at both speeds. Pressure drop across the DOC and CPF, mass deposited in the $\mathrm{CPF}$ at the end of loading, upstream and downstream gaseous and particulate emissions, and particle size distributions were measured at different times during the experiments to characterize the pressure drop and filtration efficiency of the DOC$\mathrm{CPF}$ system as functions of loading time.

Pressure drop characteristics measured experimentally across the DOC-CPF system showed a distinct deep-bed filtration region characterized by a non-linear pressure drop rise, followed by a transition region, and then by a cake-filtration region with steadily increasing pressure drop with loading time at engine load cases with 
$\mathrm{CPF}$ inlet temperatures less than $325^{\circ} \mathrm{C}$. At the engine load cases with CPF inlet temperatures greater than $360{ }^{\circ} \mathrm{C}$, the deep-bed filtration region had a steep rise in pressure drop followed by a decrease in pressure drop (due to wall PM oxidation) in the cake filtration region. Filtration efficiencies observed during PM cake filtration were greater than $90 \%$ in all engine load cases.

Two computer models, i.e., the MTU 1-D DOC model and the MTU 1-D 2layer CPF model were developed and/or improved from existing models as part of this research and calibrated using the data obtained from these experiments. The 1-D DOC model employs a three-way catalytic reaction scheme for $\mathrm{CO}, \mathrm{HC}$ and $\mathrm{NO}$ oxidation, and is used to predict $\mathrm{CO}, \mathrm{HC}, \mathrm{NO}$ and $\mathrm{NO}_{2}$ concentrations downstream of the DOC. Calibration results from the 1-D DOC model to experimental data at 2200 and $1650 \mathrm{rpm}$ are presented. The 1-D 2-layer CPF model uses a '2-filters in series approach' for filtration, PM deposition and oxidation in the PM cake and substrate wall via thermal $\left(\mathrm{O}_{2}\right)$ and $\mathrm{NO}_{2}$ /temperature-assisted mechanisms, and production of $\mathrm{NO}_{2}$ as the exhaust gas mixture passes through the CPF catalyst washcoat. Calibration results from the 1-D 2-layer CPF model to experimental data at $2200 \mathrm{rpm}$ are presented. Comparisons of filtration and oxidation behavior of the CPF at sample load-cases in both configurations are also presented. The input parameters and selected results are also compared with a similar research work with an earlier version of the CCRTR, to compare and explain differences in the fundamental behavior of the CCRTR used in these two research studies.

An analysis of the results from the calibrated CPF model suggests that pressure drop across the CPF depends mainly on PM loading and oxidation in the substrate wall, and also that the substrate wall initiates PM filtration and helps in forming a PM cake layer on the wall. After formation of the PM cake layer of about 1-2 $\mu \mathrm{m}$ on the wall, the PM cake becomes the primary filter and performs $98-99 \%$ of PM filtration. In all load cases, most of PM mass deposited was in the PM cake 
layer, and PM oxidation in the PM cake layer accounted for 95-99\% of total PM mass oxidized during loading. Overall PM oxidation efficiency of the DOC-CPF device increased with increasing $\mathrm{CPF}$ inlet temperatures and $\mathrm{NO}_{2}$ flow rates, and was higher in the CCRTR configuration compared to the CPF-only configuration due to higher CPF inlet $\mathrm{NO}_{2}$ concentrations. Filtration efficiencies greater than $90 \%$ were observed within 90-100 minutes of loading time (starting with a clean filter) in all load cases, due to the fact that the PM cake on the substrate wall forms a very efficient filter. A good strategy for maintaining high filtration efficiency and low pressure drop of the device while performing active regeneration would be to clean the PM cake filter partially (i.e., by retaining a cake layer of 1-2 $\mu \mathrm{m}$ thickness on the substrate wall) and to completely oxidize the PM deposited in the substrate wall. The data presented support this strategy. 


\section{Acknowledgments}

This thesis is one of the latest in a long line of research works produced as a result of decades of research in the field of automotive emission control and its modeling. I would like to sincerely express acknowledgment for the effort of the following people and organizations who made this possible:

Dr.John H.Johnson, for being my academic adviser and an excellent reviewer of my work at every stage, and for being a personal inspiration for me to think logically in every aspect of research work,

Dr.Song-Lin Yang, for being my co-adviser, for helping me out with all modelrelated questions and verification and presentation of data, and for teaching me practically everything I now know about CFD and its application,

Dr.Jeffrey D.Naber and Dr.Susan T.Bagley for being on my Masters' defense committee,

Dr.Antonio P.Triana, for conducting all experimental work involved in this research and explaining every procedure involved in testing and the setup, for being personally involved above and beyond the requirements of effort in the tasks involved, and for being the primary contact I had for all questions that I had related to experimental work,

Dr.Kirby J.Baumgard, for organizing this research and guiding me through experimental data collection efforts,

John Deere Product Engineering Center, for providing a Gradute Research Assistantship and facilities needed for experimentation and personnel for conducting tests and collecting data, and the U.S. Department of Energy (DOE) for providing financial support (on contract no. DE-SC04-01AL67526) for this thesis,

All researchers who have indirectly contributed to the model development through their excellent literature in various world-renowned publications, including Dr.Athanasios Konstandopoulos, Dr.Grigorios Koltsakis, Ed Bissett, Christopher 
David Depcik, Kyoo Won Lee, Se H.Oh and James C.Cavendish. I limit names to these people only because these are the first few that come to my mind,

My colleagues Hasan Mohammed, Nishant Singh, Anand Shende, Abishek Thalagavara and Paramjot Singh for working with me on model development and data calibration, and discussions about the processes involved in filter models, and above all, being there in times I needed help and support,

ME-EM department, Grad school and IPS for providing me with the opportunity to be associated with a great school like MTU, and providing the facilities and support that I needed through these years that I've been studying and working here at $M T U$,

My friend Lakshmi, my mother (Valsalakumari Premchand), my brother Arun and his family, especially his kids Alyssa and Kochu for being in my pleasant dreams motivating me to be a responsible individual in life,

My friend, confidant and mentor Biju Patla, for all those discussions about science, religion and the beginning of the universe that I look forward to in the future too, for being the primary inspiration for me to be a better researcher, keeping me honest and accountable in what I do to study science, and inspiring me to think methodically to find the solution to any problem I had, and

My late father (Premchand Krishnan Nair), for being the greatest inspiration for me to be a Mechanical engineer, for being the first science teacher I ever had, for being my trainer and mentor in DIY projects of all kinds, and for being the provider of mental strength to handle good times and bad. I cherish every moment that we had together and I wish you were here with me to be proud of the work I have done, and intend to do in the future to add little grains of sand to the big bridge that man has been building over the ocean of unknowns for centuries. 


\section{Contents}

1 Introduction 1

2 Background and Literature Review 5

2.1 Diesel Oxidation Catalysts (DOC's) . . . . . . . . . . . 5

2.2 Catalyzed Particulate Filters (CPF's) . . . . . . . . . . . . . 9

2.2.1 Particulate Filtration Mechanisms . . . . . . . . . . . . . . . 10

2.2.2 Thermal Oxidation of Particulate Matter . . . . . . . . . . . 13

2.2.3 Catalytic Oxidation of Particulate Matter . . . . . . . . . . 13

2.2.4 $\mathrm{NO}_{2}$-assisted Oxidation of Particulate Matter . . . . . . . . 14

3 Theory and Equations Used in the DOC and CPF Models 16

3.1 Diesel Oxidation Catalyst Model . . . . . . . . . . . . . . . . 16

3.1.1 Assumptions in the DOC model . . . . . . . . . . . . . . 17

3.1.2 Chemical Reactions and Kinetic Equations . . . . . . . . . 19

3.2 Catalyzed Particulate Filter Filtration Model . . . . . . . . . . 23

3.2.1 Wall Filtration Sub-model . . . . . . . . . . . . . 26

3.2.2 Cake Filtration Sub-model . . . . . . . . . . . . . . . . 33

4 Experimental Setup and Procedures 35

4.1 Experimental Setup . . . . . . . . . . . . . . . 35

4.2 Test Cell Instrumentation _. . . . . . . . . . . . . . . . . 38 
4.3 Experimental Test Matrix . . . . . . . . . . . . . . . . . . 41

4.3.1 DOC-only Experiments . . . . . . . . . . . . . . . 41

4.3.2 CPF-only and CCRT囚 Experiments . . . . . . . . . . 42

5 Results and Discussions $\quad 45$

5.1 Experimental Results . . . . . . . . . . . . . . . . 45

5.1.1 Results from DOC-only Experiments . . . . . . . . . . . . 46

5.1.2 Results from CPF-only and CCRT囚 Experiments . . . . . 56

5.2 DOC Modeling and Experimental Results . . . . . . . . . . . 66

5.2.1 DOC Model Calibration . . . . . . . . . . . . 66

5.2.2 DOC Model - Results from Calibrated Model . . . . . . . . . 69

5.3 CPF Modeling and Experimental Results . . . . . . . . . . . . . 77

5.3.1 CPF Model Calibration - Determination of Constants and Comparison to Experimental Data . . . . . . . . . . . 77

5.3.2 CPF Model Results . . . . . . . . . . . . . . . . . 105

5.4 Discussion of CPF Modeling Results . . . . . . . . . . . . . . . . 130

5.4.1 Comparison of Calibrated Model Parameters to Previous Research Work ................... . . 131

5.4.2 Effect of $\mathrm{NO}_{2}$ Production in the CPF in CPF-only and CCRT $\mathbb{R}$ Configurations . . . . . . . . . . . . . . . . 135

6 Summary, Conclusions and Recommendations 139

6.1 Experimentation Summary . . . . . . . . . . . . . . 139

6.2 Modeling Summary . . . . . . . . . . . . . . . . . . . . . 141

6.3 Conclusions . . . . . . . . . . . . . . . . . . . 143

6.4 Recommendations for Future Research . . . . . . . . . . . . . . . . . 145

$\begin{array}{ll}\text { References } & 155\end{array}$ 
Appendices

$\begin{array}{ll}\text { A DOC Sub-models } & 156\end{array}$

A.1 PM Oxidation Kinetics in the DOC . . . . . . . . . . . 156

A.2 Mass and Energy Balance in the Gas-phase . . . . . . . . . . . 157

A.3 Mass and Energy Balance in the Solid-phase . . . . . . . . . . . . 164

A.4 Mass Transfer Calculations . . . . . . . . . . . . . . . . 167

$\begin{array}{ll}\text { B CPF Sub-models } & 168\end{array}$

B.1 CPF Mass, Momentum and Energy Balance . . . . . . . . . 168

B.2 CPF Pressure Drop Model . . . . . . . . . . . . . . . . . . . 169

B.3 CPF Oxidation Model . . . . . . . . . . . . . . . . . . 171

B.3.1 Oxidation in the Particulate Cake Layer . . . . . . . . . . 172

B.3.2 Oxidation in the Wall . . . . . . . . . . . . . . . 179

B.3.3 Wall Energy Balance . . . . . . . . . . . . . . . . . . . . 182

B.4 $\mathrm{NO}_{2}$ Production Sub-model . . . . . . . . . . . . . . . . 184

B.5 Peclet Number Calculations for CPF Model . . . . . . . . . . . 188

B.6 CPF model - Code structure and pressure drop calculations . . . . 189

C Calibration Plots from 1D DOC Model Simulations 196

D Plots from CPF Model Calibration with CPF-only and CCRT® $\begin{array}{ll}\text { Experimental Data at } 2200 \mathrm{rpm} & 210\end{array}$

E Engine Performance Curves from DOC-only Tests 223

$\begin{array}{lll}\text { F Experimental Setup - Schematics } & 227\end{array}$

G Analysis of the Particulate Filter Weight Gain Observed During Experiments 230 


\section{List of Tables}

1.1 US EPA on-road heavy-duty diesel engine emission standards . . . . . 2

1.2 Non-road Diesel engine emission standards - Tiers 1 thru 4 . . . . . 3

3.1 Adsorption equilibrium constants in oxidation catalyst modeling . . . 23

3.2 Activation energies in oxidation catalyst modeling . . . . . . . . 23

4.1 John Deere engine specifications . . . . . . . . . . . . . . 36

4.2 Dynamometer specifications . . . . . . . . . . . . 36

4.3 Fuel specifications . . . . . . . . . . . . . . . . . . 36

4.4 Diesel oxidation catalyst specifications . . . . . . . . . . . 37

4.5 Catalyzed particulate filter specifications . . . . . . . . . . . 37

4.6 SMPS specifications . . . . . . . . . . . . . . . . . 39

4.7 DOC-only tests conducted . . . . . . . . . . . . . . . 42

5.12200 rpm DOC-only - Gaseous species concentrations measured at DOC inlet and outlet $-\mathrm{CO}_{2}, \mathrm{H}_{2} \mathrm{O}, \mathrm{O}_{2}$ and $\mathrm{N}_{2} \ldots \ldots . \ldots 52$

5.22200 rpm DOC-only - Gaseous species concentrations measured at DOC inlet and outlet $-\mathrm{HC}, \mathrm{CO}, \mathrm{NO}$ and $\mathrm{NO}_{2} \ldots \ldots . . . . .53$

$5.31650 \mathrm{rpm}$ DOC-only - Gaseous species concentrations measured at DOC inlet and outlet $-\mathrm{CO}_{2}, \mathrm{H}_{2} \mathrm{O}, \mathrm{O}_{2}$ and $\mathrm{N}_{2} \ldots \ldots . \ldots 54$

5.41650 rpm DOC-only - Gaseous species concentrations measured at DOC inlet and outlet $-\mathrm{HC}, \mathrm{CO}, \mathrm{NO}$ and $\mathrm{NO}_{2} \ldots \ldots . . . . .55$ 
5.5 Engine data measured during CPF-only and CCRTß experiments . 57

5.6 Experimental values of PM deposited and percentage PM oxidized . . 64

5.7 Kinetic parameters obtained from DOC model calibration to 2200 and $1650 \mathrm{rpm}$ data . . . . . . . . . . . . . . . . . . . . . .

5.8 Comparison of experimental and model-predicted DN-DOC concentrations of $\mathrm{CO}, \mathrm{HC}, \mathrm{NO}$ and $\mathrm{NO}_{2}$ for $2200 \mathrm{rpm}$ data . . . . . . . 73

5.9 Comparison of experimental and model-predicted DN-DOC concentrations of $\mathrm{CO}, \mathrm{HC}, \mathrm{NO}$ and $\mathrm{NO}_{2}$ for $1650 \mathrm{rpm}$ data . . . . . . . . . 74

5.10 CPF model input parameters that were varied with load condition . . 79

$5.112200 \mathrm{rpm}$ - CPF model inputs - CPF geometry and physical properties 83

$5.122200 \mathrm{rpm}$ - CPF model inputs - Exhaust gas properties at CPF inlet 84

$5.132200 \mathrm{rpm}$ - CPF model inputs - Kinetic parameters used in the CPF

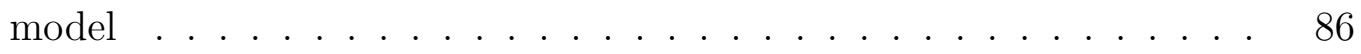

$5.142200 \mathrm{rpm}$ - CPF model inputs - Wall and PM cake properties . . . . 88

5.15 Comparison of initial pressure drops obtained from Experimental and model-predicted values in the CPF-only and CCRT@ configurations at $2200 \mathrm{rpm} \ldots \ldots \ldots \ldots$. . . . . . . . . . . . . . . . . . . . . 91

5.16 Comparison of experimental and model-predicted PM mass deposited and oxidized . . . . . . . . . . . . . . . . . . 96

5.17 Comparison of experimental and model-predicted DN-CPF PVC . . . 99

5.18 Comparison of experimental $\mathrm{NO}$ and $\mathrm{NO}_{2}$ concentration at $\mathrm{CPF}$ inlet and outlet at $2200 \mathrm{rpm} \ldots$. . . . . . . . . . . . . . 100

5.19 Comparison of $\mathrm{CO}, \mathrm{HC}, \mathrm{NO}_{x}, \mathrm{NO}$ and $\mathrm{NO}_{2}$ concentrations measured across the $\mathrm{CPF}$ at $2200 \mathrm{rpm} \ldots \ldots \ldots$. . . . . . . . . 102

5.20 Comparison of $\mathrm{NO}_{2}$ concentrations produced and consumed as obtained from the CPF model . . . . . . . . . . . . . . . 104 
5.21 Loading times at which cake efficiency equals wall efficiency for CPFonly and CCRT@ configurations at $2200 \mathrm{rpm}$. . . . . . . . . . . . . 111

5.22 Loading times required to reach 90, 95 and $98 \%$ filtration efficiency and filtration efficiencies at 4,6 and 8 hours of loading time - model data at $2200 \mathrm{rpm} \ldots \ldots \ldots \ldots$. . . . . . . . . . . . . 114

5.23 Comparison of wall and PM cake properties . . . . . . . . . . . 132

5.24 A comparison of kinetic parameters from calibrated CPF model . . . 133

5.25 Comparison of experimentally observed $\mathrm{CPF}$ inlet and outlet $\mathrm{NO}_{2}$ concentrations . . . . . . . . . . . . . . . . . . 137

5.26 Comparison of effect of $\mathrm{NO}_{2}$ production in the CPF on PM oxidation efficiency of CPF with previous research work (loading time $=8$ hours) 138

C.1 Activation energies used for DOC model calibration at $2200 \mathrm{rpm}$ and $1650 \mathrm{rpm} \ldots \ldots \ldots \ldots \ldots 7 . \ldots \ldots$

C.2 Adsorption equilibrium constants used for DOC model calibration . . 197

C.3 $2200 \mathrm{rpm}$ - CO, HC and NO pre-exponential factors . . . . . . . . . 200

C.4 Comparison of experimental and model-predicted DN-DOC concentrations of $\mathrm{CO}, \mathrm{HC}, \mathrm{NO}$ and $\mathrm{NO}_{2}$ from calibration at $2200 \mathrm{rpm}$. . . . . 201

C.5 $1650 \mathrm{rpm}$ - CO, HC and NO pre-exponential factors . . . . . . . . . . 204

C.6 Comparison of experimental and model-predicted DN-DOC concentrations of $\mathrm{CO}, \mathrm{HC}, \mathrm{NO}$ and $\mathrm{NO}_{2}$ from calibration at $1650 \mathrm{rpm}$. . . . 205

C.7 Second set of kinetic parameters . . . . . . . . . . . . . . . 208

C.8 Third set of kinetic parameters . . . . . . . . . . . . . . . 209

G.1 Estimate of filter weight gain based on number of days between measurements . . . . . . . . . . . . . . . . . . 233

G.2 Mass corrections obtained from weight gain estimates . . . . . . . . 234 


\section{List of Figures}

2.1 Typical cell structure of a DOC . . . . . . . . . . . . . 6

$2.2 \mathrm{HC}$ and $\mathrm{CO}$ conversion efficiencies of a typical DOC . . . . . . . 7

2.3 NO conversion efficiency of a typical DOC . . . . . . . . . . 8

2.4 Schematic of layout of cells in a wall-flow particulate filter . . . . . . 9

2.5 Particulate collection mechanisms in a particulate filter . . . . . . . 12

2.6 Comparison of particulate reaction rates by $\mathrm{O}_{2}$ and $\mathrm{NO}_{2} \ldots \ldots$. . . 15

3.1 A schematic representation of the coordinates used in the 1-D DOC model ........................ 17

3.2 A schematic representation of the coordinates used in the 1-D CPF

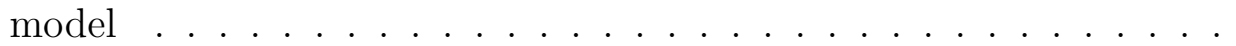

3.3 Discretization of filter wall thickness and '2-filters in series' approach used in the CPF filtration model . . . . . . . . . . . . . . 26

3.4 Schematic representation of percolation in the wall . . . . . . . . . 32

4.1 Schematic representation of the secondary dilution system . . . . . . 40

4.2 General setup of experiments . . . . . . . . . . . . . . . 41

4.3 Schematic - Test matrix for CPF-only and CCRT experiments . . . . 43

$5.12200 \mathrm{rpm}$ DOC-only - Experimental engine parameters observed . . . 46

$5.21650 \mathrm{rpm}$ DOC-only - Experimental engine parameters observed . . . 47 
$5.32200 \mathrm{rpm}$ and $1650 \mathrm{rpm}$ DOC-only - Experimental DOC pressure drops versus actual exhaust volumetric flow rates . . . . . . . . . . . . . . 47

5.42200 rpm DOC-only - Experimental DOC inlet and outlet temperatures and temperature differences (outlet - inlet) versus percentage load 48

5.51650 rpm DOC-only - Experimental DOC inlet and outlet temperatures and temperature differences (outlet - inlet) versus percentage load 48

5.6 2200 rpm DOC-only - Experimental species conversion percentages obtained versus percentage load . . . . . . . . . . . . . . . 50

5.71650 rpm DOC-only - Experimental species conversion percentages obtained versus percentage load . . . . . . . . . . . . . . 50

5.8 An overview of experimental CPF pressure drop profiles obtained at 2200 rpm in CPF-only and CCRT® configurations . . . . . . . . . 58

5.9 An overview of experimental CPF pressure drop profiles obtained at 1650 rpm in CPF-only and CCRT $\mathrm{R}$ configurations . . . . . . . . . . 59

$5.102200 \mathrm{rpm}$ and $1650 \mathrm{rpm}$ - Experimental average standard PM inlet concentrations .......................... 60

$5.112200 \mathrm{rpm}$ and $1650 \mathrm{rpm}$ - Experimental average standard exhaust volumetric flow rates . . . . . . . . . . . . . . . 61

$5.122200 \mathrm{rpm}$ and $1650 \mathrm{rpm}$ - A comparison of total PM mass entering the

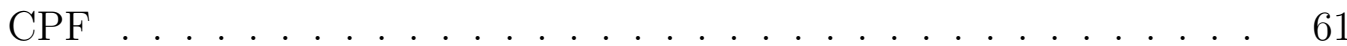

$5.132200 \mathrm{rpm}$ experiments - A comparison of percentage PM mass oxidized (corrected data) . . . . . . . . . . . . . .

$5.142200 \mathrm{rpm}$ DOC-only - A comparison of experimental and modelpredicted pressure drops across the DOC . . . . . . . . . . . 67

$5.151650 \mathrm{rpm}$ DOC-only - A comparison of experimental and modelpredicted pressure drops across the DOC . . . . . . . . . . 
5.162200 rpm DOC-only - Experimental inlet concentrations and a comparison of experimental and model-predicted outlet concentrations . . 70

5.171650 rpm DOC-only - Experimental inlet concentrations and a comparison of experimental and model-predicted outlet concentrations . . 71

5.18 Experimental and model-predicted temperature differences (outlet inlet) and their difference observed at $2200 \mathrm{rpm} \ldots \ldots$. . . . . . 76

5.19 Experimental and model-predicted temperature differences (outlet inlet) and their difference observed at $1650 \mathrm{rpm}$. . . . . . . . . 76

5.202200 rpm - PM cake layer packing density versus Peclet number . . . 87

$5.212200 \mathrm{rpm}$ CPF-only - Experimental and model-predicted pressure drop profiles versus time . . . . . . . . . . . . . . . . . 93

$5.222200 \mathrm{rpm}$ CCRTR - Experimental and model-predicted pressure drop profiles versus time . . . . . . . . . . . . . . . . . 93

5.232200 rpm CPF-only - Model-predicted versus experimental pressure drops - A point-by-point comparison . . . . . . . . . . . .

$5.242200 \mathrm{rpm}$ CCRTß - Model-predicted versus experimental pressure drops - A point-by-point comparison . . . . . . . . . . . . . . . 94

$5.252200 \mathrm{rpm}$ CPF-only - Comparison of experimental and model-predicted DN-CPF particle volume concentrations versus time . . . . . . . . . . 97

$5.262200 \mathrm{rpm}$ CCRT@ - Comparison of experimental and model-predicted DN-CPF particle volume concentrations versus time . . . . . . . . . 98

$5.2725 \%$ load at $2200 \mathrm{rpm}$ - Model-predicted pressure drop components . 106

$5.28100 \%$ load at $2200 \mathrm{rpm}$ - Model-predicted pressure drop components . 107

5.29 CPF pressure drops versus total PM mass deposited . . . . . . . . . 108

5.30 Comparison of model-predicted PM cake layer thicknesses versus time 110

5.31 Model-predicted CPF filtration efficiency distribution and CPF outlet PM concentrations versus time . . . . . . . . . . . . . . . 112 
5.32 Model-predicted filtration efficiency distribution by location versus time113

5.33 A comparison of model-predicted percentage PM mass oxidized in the CPF-only and CCRT囚) configurations at $2200 \mathrm{rpm}$ (loading time $=8$

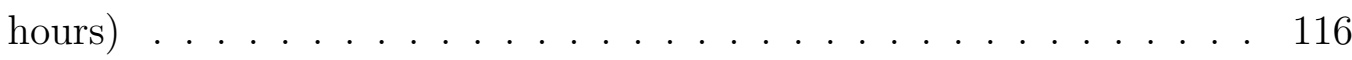

$5.342200 \mathrm{rpm}$ - Total PM oxidation rates versus time . . . . . . . . . . . 117

$5.352200 \mathrm{rpm}$ - Model wall oxidation rates versus time . . . . . . . . . 117

$5.362200 \mathrm{rpm}$ - Total and $\mathrm{NO}_{2}$ /temperature-assisted PM oxidation rates versus time . . . . . . . . . . . . . . . . . . 119

$5.372200 \mathrm{rpm}$ - Thermal PM oxidation rates versus time . . . . . . . . . 119

5.38 Comparison of model-predicted PM mass rates into, deposited, oxidized and out of PM cake layer versus time . . . . . . . . . . . . . . 121

5.39 Comparison of model-predicted PM mass rates into, deposited, oxidized and out of substrate wall versus time . . . . . . . . . . . . 123

5.40 PM mass balance at $2200 \mathrm{rpm}$ (loading time $=8$ hours) . . . . . . . . 124

5.41 PM mass balance expressed as percentage distribution of total inlet PM mass at $2200 \mathrm{rpm}$ (loading time $=8$ hours) . . . . . . . . . . . 125

5.42 Distribution of inlet PM mass by location at $2200 \mathrm{rpm}$ (loading time $=8$ hours $\ldots \ldots \ldots \ldots \ldots \ldots \ldots$

5.43 Distribution of inlet PM mass by location, expressed as percentage distribution of total deposited PM mass at $2200 \mathrm{rpm}$ (loading time =

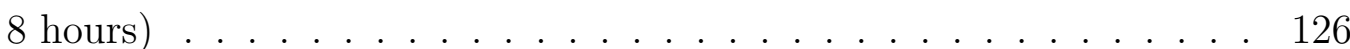

5.44 Distribution of PM mass oxidized by mechanism at $2200 \mathrm{rpm}$ (loading time $=8$ hours $) \ldots \ldots \ldots \ldots \ldots$

5.45 Distribution of PM mass oxidized by mechanism, expressed as percentage distribution of total PM mass oxidized at $2200 \mathrm{rpm}$ (loading time $=8$ hours $\ldots \ldots \ldots \ldots \ldots \ldots \ldots \ldots$ 
5.46 Distribution of PM mass oxidized by location at $2200 \mathrm{rpm}$ (loading time $=8$ hours $) \ldots \ldots \ldots \ldots$. . . . . . . . . . . 129

5.47 Distribution of PM mass oxidized by location, expressed as percentage distribution of total PM mass oxidized at $2200 \mathrm{rpm}$ (loading time $=8$

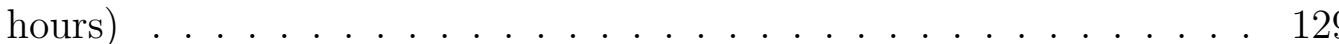

B.1 Schematic representation of the 2-layer approach used in the CPF model173

B.2 CPF filter wall discretization - computational domain for filtration . . 179

B.3 Discretization of layer 1 into sub-layers for $\mathrm{NO}_{2}$ production model . . 185

B.4 A code flowchart of the MTU 1-D 2-layer CPF model . . . . . . . . . 190

B.5 A schematic of pressure drop calculations in the CPF model . . . . . 195

C.1 2200 rpm DOC-only - Comparison of experimental and model outlet CO concentrations ..................... 198

C.2 $2200 \mathrm{rpm}$ DOC-only - Comparison of experimental and model outlet HC concentrations . . . . . . . . . . . . . . . . . . 198

C.3 2200 rpm DOC-only - Comparison of experimental and model outlet NO concentrations ....................... 199

C.4 2200 rpm DOC-only - Comparison of experimental and model outlet $\mathrm{NO}_{2}$ concentrations . . . . . . . . . . . . . . . . 199

C.5 1650 rpm DOC-only - Comparison of experimental and model outlet CO concentrations . . . . . . . . . . . . . . . . 202

C.6 1650 rpm DOC-only - Comparison of experimental and model outlet HC concentrations .................... 202

C.7 1650 rpm DOC-only - Comparison of experimental and model outlet NO concentrations ................... 203

C.8 $1650 \mathrm{rpm}$ DOC-only - Comparison of experimental and model outlet $\mathrm{NO}_{2}$ concentrations . . . . . . . . . . . . . . . 203 
C.9 Semi-log plot of kinetics obtained from 2200 and $1650 \mathrm{rpm}$ data . . . 207

C.10 Semi-log plot of kinetics obtained from 2200 and 1650 rpm data after one iteration . . . . . . . . . . . . . . . . . . . . 208

D.1 CPF inlet temperature versus loading time given as input to the CPF model ........................ . . 210

D.2 2200 rpm CPF-only - UP-CPF PSD data for CPF model calibration . 211

D.3 2200 rpm CCRTR - UP-CPF PSD data for CPF model calibration . 211

D.4 Model-predicted and experimental pressure drops versus time in the CPF-only configuration . . . . . . . . . . . . . . . . . . 213

D.5 Model-predicted and experimental pressure drops versus time in the CCRT® configuration . . . . . . . . . . . . . . 214

D.6 Mass distribution in CPF-only configuration . . . . . . . . . . . . 215

D.7 Mass distribution in CCRT® configuration . . . . . . . . . . . . . 216

D.8 Experimental average UP-CPF PSD and comparison of model and experimental DN-CPF PSD at 8 hours of loading time in CPF-only configuration ..................... . . 217

D.9 Experimental average UP-CPF PSD and comparison of model and experimental DN-CPF PSD at 8 hours of loading time in CCRTR

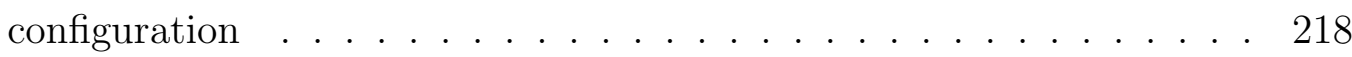

D.10 Model-predicted wall mass and CPF outlet mass versus time in the CPF-only configuration . . . . . . . . . . . . . . . . . . . . 219

D.11 Model-predicted wall mass and CPF outlet mass versus time in the CCRT $®$ configuration . . . . . . . . . . . . . . 220

D.12 Model-predicted wall mass sub-division in different 'slabs' in CPF-only

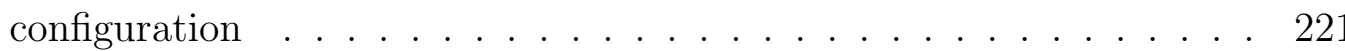

D.13 Model-predicted wall mass sub-division in different 'slabs' in CCRTß configuration 
E.1 Normalized BMEP and normalized brake power in DOC-only setup at $2200 \mathrm{rpm}$

E.2 Normalized BMEP and normalized brake power in DOC-only setup at $1650 \mathrm{rpm} \ldots \ldots \ldots \ldots \ldots \ldots$

E.3 Normalized Percentage EGR and normalized rail pressure in DOC-only

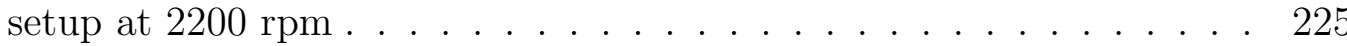

E.4 Normalized Percentage EGR and normalized rail pressure in DOC-only setup at $1650 \mathrm{rpm} \ldots \ldots . \ldots . \ldots . \ldots . . \ldots 225$

E.5 Normalized air and fuel mass flow rates and normalized air/fuel ratio against percentage load in DOC-only setup at $2200 \mathrm{rpm}$. . . . . . . . 226

E.6 Normalized air and fuel mass flow rates and normalized air/fuel ratio against percentage load in DOC-only setup at $1650 \mathrm{rpm}$. . . . . . . 226

F.1 Setup for DOC-only experiments . . . . . . . . . . . . . . . 227

F.2 Setup for CPF-only experiments . . . . . . . . . . . . . . . . . 228

F.3 Baseline setup for CPF-only experiments . . . . . . . . . . . . . 228

F.4 Setup for CCRTR experiments . . . . . . . . . . . . . . . . 229

F.5 Baseline setup for CCRT® experiments . . . . . . . . . . . . 229

G.1 CPF weight gain versus average filter temperature difference between measurements for $\mathrm{CPF} 1 \ldots \ldots . \ldots . . \ldots 231$

G.2 CPF weight gain versus average filter temperature difference between

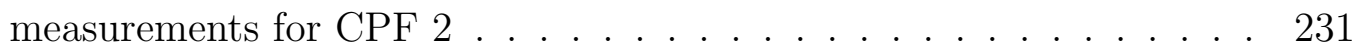

G.3 CPF weight gain versus number of days between measurements for

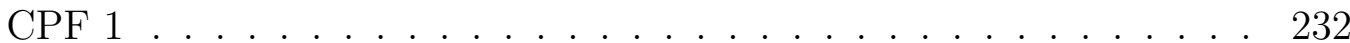

G.4 CPF weight gain versus number of days between measurements for

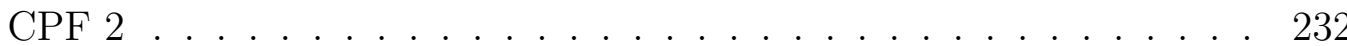




\section{List of Symbols and Abbreviations}

\section{Abbreviations}

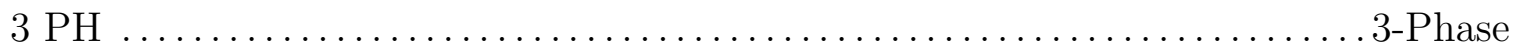

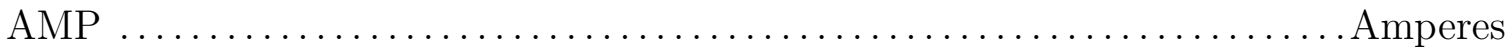

BSFC $\ldots \ldots \ldots \ldots \ldots \ldots \ldots \ldots \ldots \ldots \ldots$ Brake specific fuel consumption

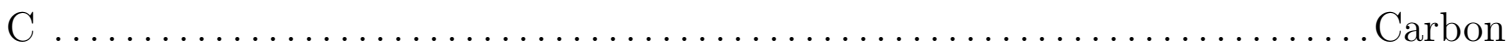

CCRT $\AA \ldots \ldots \ldots \ldots \ldots \ldots \ldots \ldots$ Catalyzed Continuously Regenerating Trap ${ }^{\circledR}$

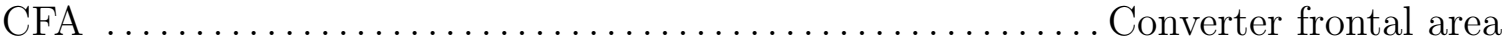

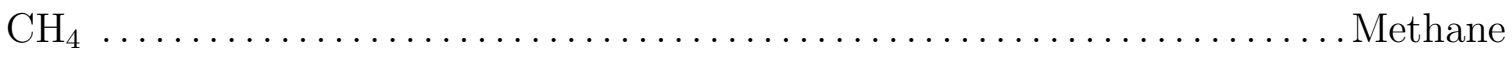

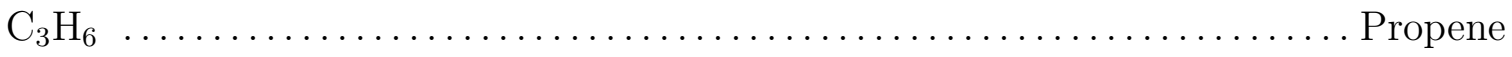

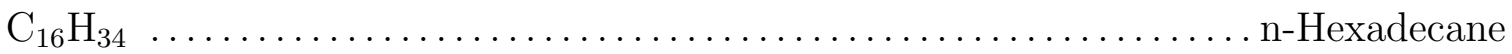

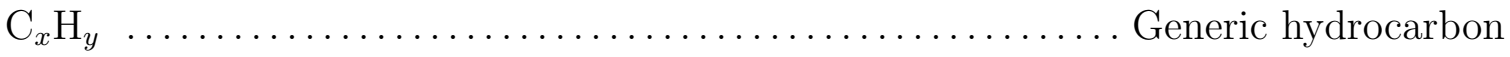

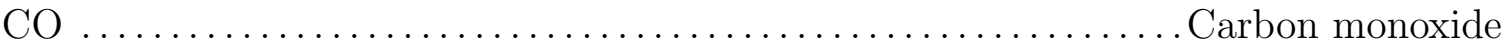

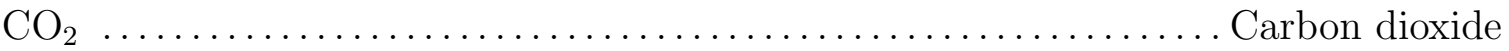

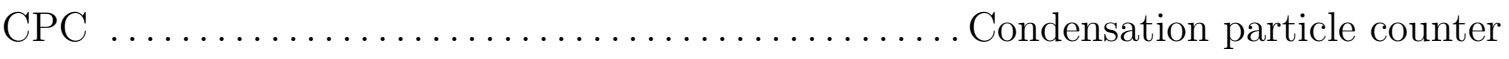

CPF $\ldots \ldots \ldots \ldots \ldots \ldots \ldots \ldots \ldots \ldots \ldots \ldots \ldots \ldots$ Catalyzed (Diesel) particulate filter

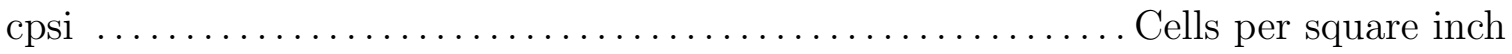

DN-CPF $\ldots \ldots \ldots \ldots \ldots \ldots \ldots$ Downstream of CPF

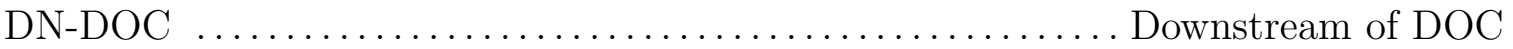

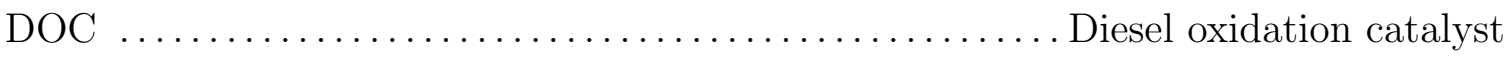


DPF $\ldots \ldots \ldots \ldots \ldots \ldots \ldots \ldots \ldots \ldots$ (Un-catalyzed) Diesel particulate filter

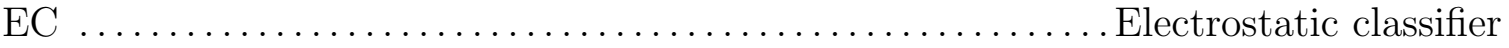

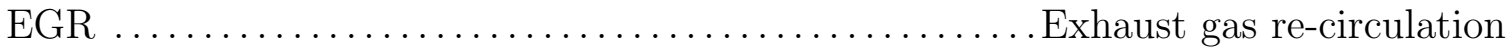

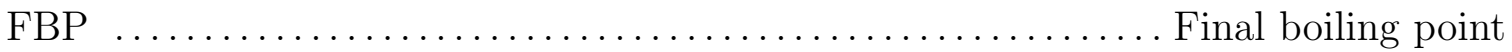

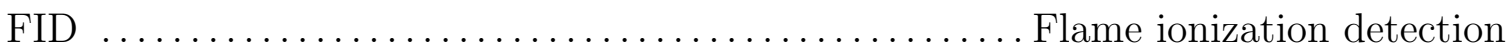

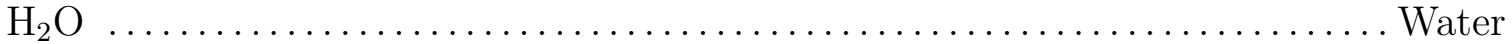

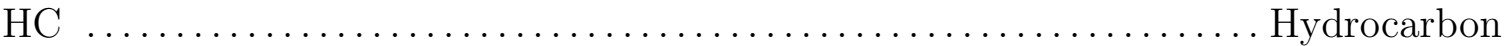

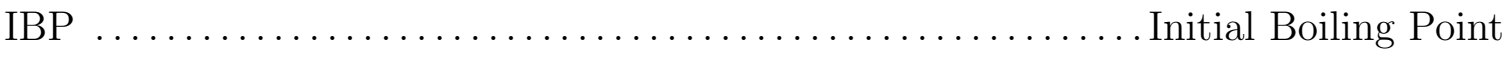

MTU ................................ Michigan Technological University

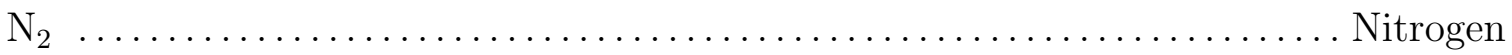

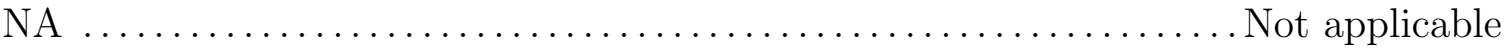

NDIR $\ldots \ldots \ldots \ldots \ldots \ldots \ldots \ldots \ldots \ldots \ldots \ldots \ldots \ldots \ldots \ldots \ldots \ldots$ Non-dispersive infrared

NMHC $\ldots \ldots \ldots \ldots \ldots \ldots \ldots \ldots \ldots \ldots \ldots \ldots$ Non-methane hydrocarbons

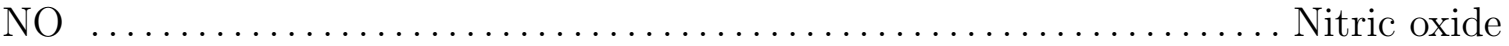

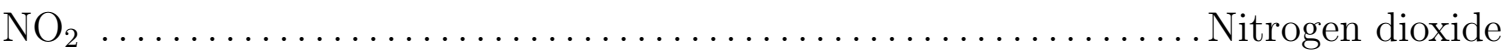

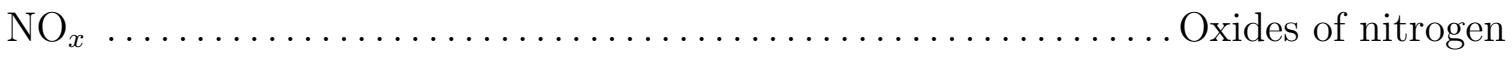

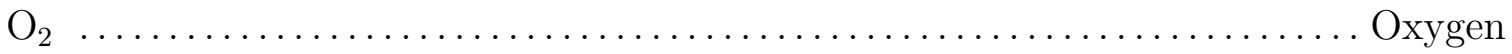

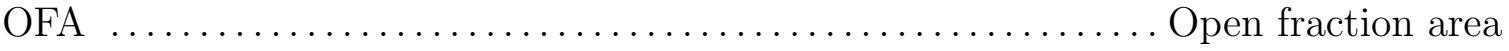

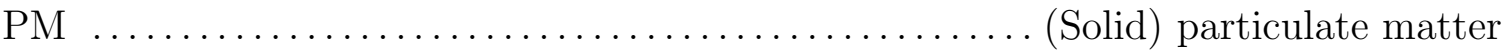

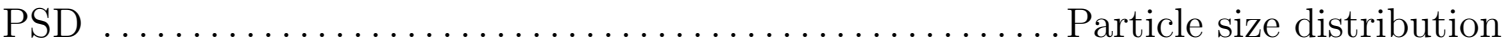

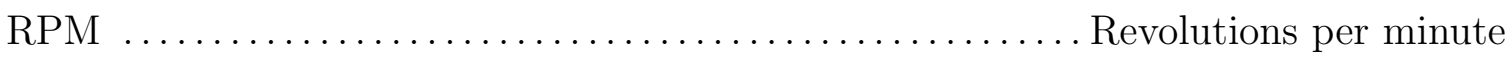

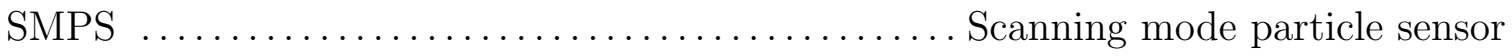

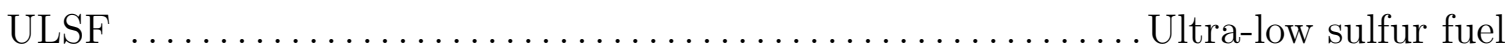

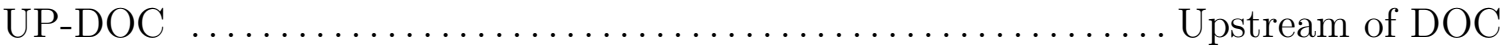

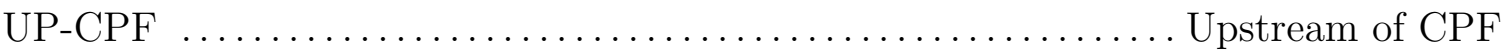




\section{Common Subscripts}

1 Inlet channel (related to) channel gas

\section{Common Symbols}

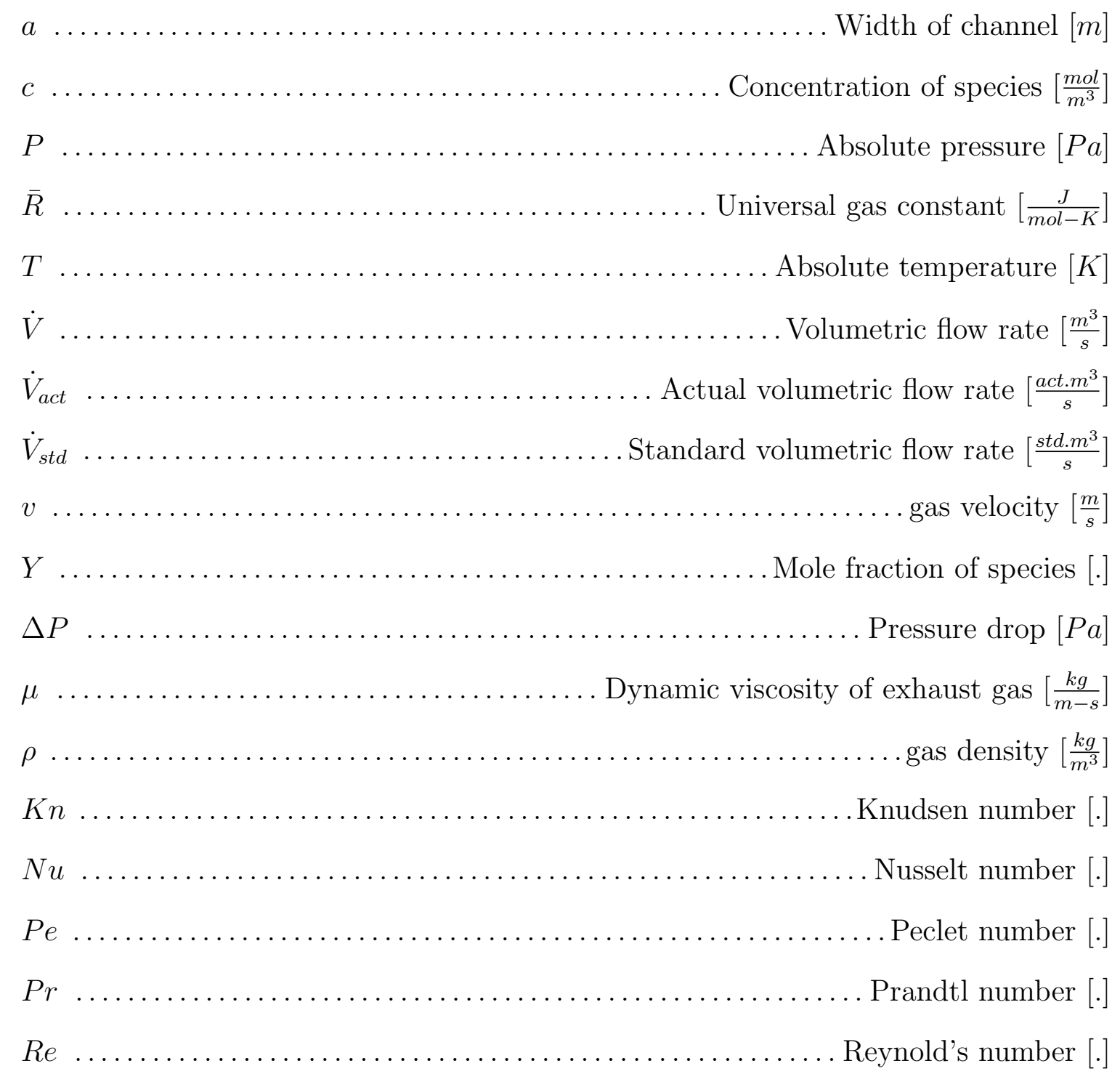




\section{DOC Symbols}

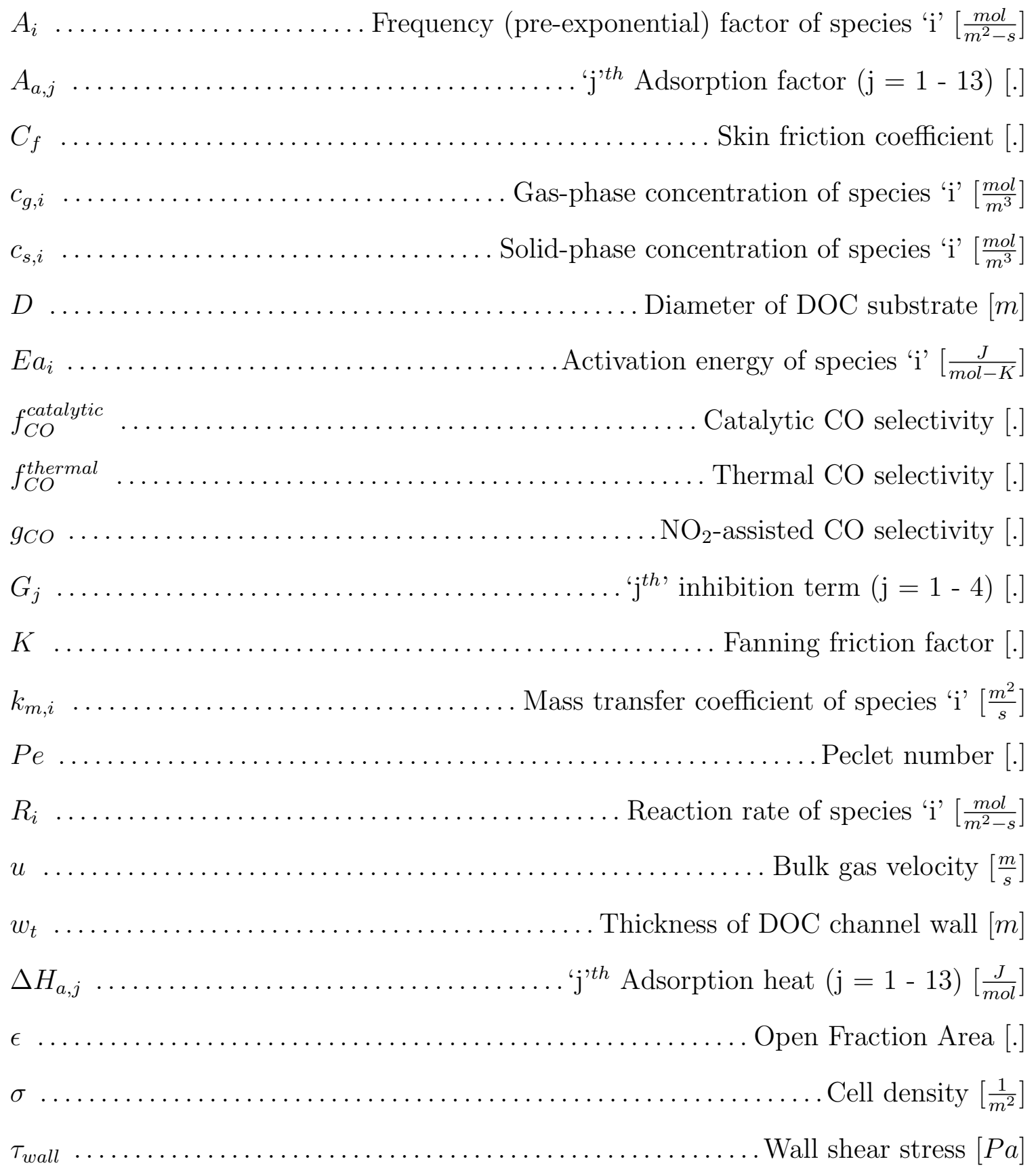




\section{CPF Symbols}

$A_{\text {cat }}$ . Frequency factor of catalytic PM oxidation $\left[\frac{m}{s-K}\right]$

$A_{N O}$ Frequency factor of $\mathrm{NO}_{2}$ production by catalyst $\left[\frac{m}{s-K^{3}}\right]$ $A_{\mathrm{NO}_{2}} \ldots \ldots \ldots$. Frequency factor of $\mathrm{NO}_{2} /$ temperature-assisted PM oxidation $\left[\frac{m}{s-K^{\frac{1}{2}}}\right]$ $A_{\mathrm{NO}_{2}, \text { wall }} \ldots \ldots \ldots$. Frequency factor of $\mathrm{NO}_{2}$-assisted PM oxidation in the wall $\left[\frac{m}{s-K^{\frac{1}{2}}}\right]$ $A_{t h} \ldots \ldots \ldots \ldots \ldots \ldots \ldots \ldots$ Frequency factor of thermal PM oxidation $\left[\frac{m}{s-K}\right]$ $A_{p} \ldots \ldots \ldots \ldots \ldots \ldots \ldots$ Surface area of particulate matter per unit mass $\left[\frac{\mathrm{m}^{2}}{\mathrm{~kg}}\right]$ $A_{\eta} \ldots \ldots \ldots \ldots \ldots \ldots \ldots \ldots \ldots \ldots \ldots \ldots \ldots \ldots \ldots$ Maximum PM cake efficiency parameter [.] $B$ Forchheimer coefficient $[$. $b$ Unit cell size $[m]$ $C \ldots \ldots \ldots \ldots \ldots \ldots \ldots \ldots \ldots \ldots$ Stokes-Cunningham slip correction factor [.]

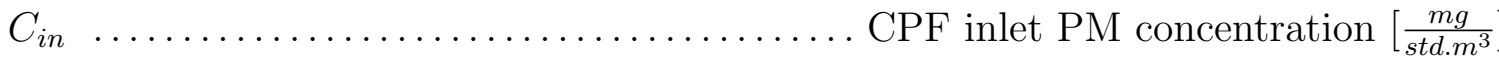
$c_{p g} \ldots \ldots \ldots \ldots \ldots \ldots \ldots \ldots \ldots \ldots \ldots \ldots \ldots \ldots \ldots \ldots+$ Specific heat of gaseous mixture $\left[\frac{J}{k g-K}\right]$

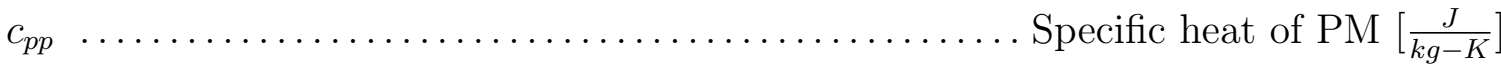
$c_{p s} \ldots \ldots \ldots \ldots \ldots \ldots \ldots \ldots \ldots \ldots \ldots \ldots \ldots \ldots \ldots \ldots$ Specific heat of substrate wall $\left[\frac{J}{k g-K}\right]$

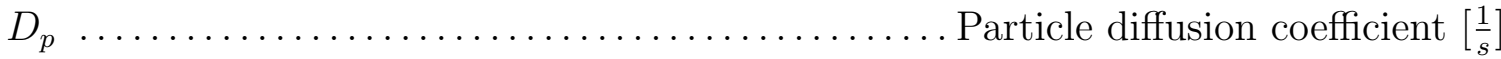
$d_{\text {aggregate }} \ldots \ldots \ldots \ldots \ldots \ldots \ldots \ldots \ldots \ldots \ldots \ldots$ Aggregate particulate diameter $[m]$ $d_{c} \ldots \ldots \ldots \ldots \ldots \ldots \ldots \ldots \ldots \ldots$ 'Loaded' filter wall unit collector diameter $[m]$ $d_{c 0} \ldots \ldots \ldots \ldots \ldots \ldots \ldots \ldots \ldots \ldots \ldots \ldots$ 'Clean' filter wall unit collector diameter $[m]$ $d_{c, \text { cake }} \ldots \ldots \ldots \ldots \ldots \ldots \ldots$ Diameter of unit collector in the PM cake layer $[m]$ $d_{c e l l, 0} \ldots \ldots \ldots \ldots \ldots \ldots \ldots \ldots \ldots \ldots \ldots \ldots \ldots \ldots$ Initial diameter of spherical cell $[m]$ $d_{\text {collector }} \ldots \ldots \ldots \ldots \ldots \ldots \ldots \ldots \ldots \ldots \ldots \ldots \ldots \ldots$ Diameter of spherical collector $[m]$

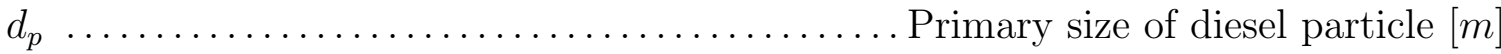
$d_{\text {pore }} \ldots \ldots \ldots \ldots \ldots \ldots \ldots \ldots \ldots \ldots \ldots \ldots \ldots \ldots \ldots$ Mean pore size of substrate wall $[m]$ $d_{\text {primary }} \ldots \ldots \ldots \ldots \ldots \ldots \ldots \ldots \ldots \ldots \ldots \ldots$ Diameter of primary soot particle $[m]$ $d h$ CPF channel width $[m]$ $E$ Overall collection efficiency of a filter wall element [.] 
$E a_{c a t} \ldots \ldots \ldots \ldots \ldots \ldots \ldots$ Activation energy of catalytic PM oxidation $\left[\frac{J}{m o l-K}\right]$ $E a_{N O} \ldots \ldots \ldots \ldots \ldots$ Activation energy of $\mathrm{NO}_{2}$ production by catalyst $\left[\frac{J}{m o l-K}\right]$ $E a_{\mathrm{NO}_{2}} \ldots \ldots$ Activation energy of $\mathrm{NO}_{2} /$ temperature-assisted PM oxidation $\left[\frac{J}{m o l-K}\right]$ $E a_{t h} \ldots \ldots \ldots \ldots \ldots \ldots \ldots$ Activation energy of thermal PM oxidation $\left[\frac{J}{m o l-K}\right]$ $\exp -\operatorname{order}_{c a t}$....... Exponential order of dependence of catalytic PM oxidation [.] $\exp -\operatorname{order}_{t h} \ldots \ldots$. Exponential order of dependence of thermal PM oxidation [.] exp-order $\mathrm{NO}_{2}$. Exponential order of dependence of $\mathrm{NO}_{2}$-assisted PM oxidation [.]

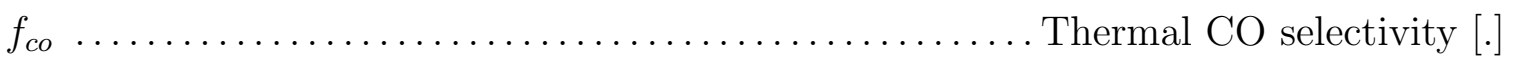

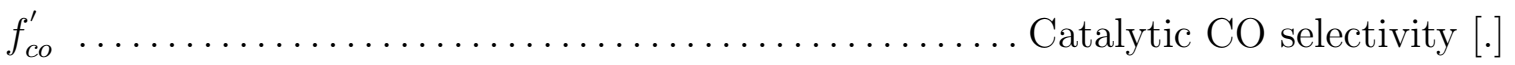
$H_{\text {cond }} \ldots \ldots \ldots \ldots \ldots \ldots \ldots \ldots$ Heat energy conducted in the axial direction $\left[\frac{J}{m^{2}-s}\right]$ $H_{\text {react }} \ldots \ldots \ldots \ldots \ldots \ldots \ldots \ldots \ldots \ldots \ldots$ Heat of reaction due to PM oxidation $\left[\frac{J}{m^{2}-s}\right]$

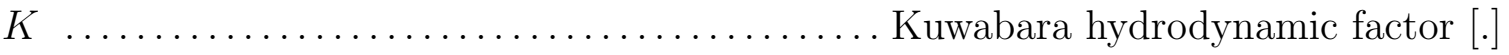
$k(0), k_{t, 0} \ldots \ldots \ldots \ldots \ldots \ldots \ldots \ldots \ldots \ldots \ldots \ldots \ldots \ldots \ldots$ 'Clean' permeability of filter wall $\left[\mathrm{m}^{2}\right]$ $k(t) \ldots \ldots \ldots \ldots \ldots \ldots \ldots \ldots$ Permeability of filter wall at time ' $\mathrm{t}$ ' $\left[\mathrm{m}^{2}\right]$ $k^{*} \ldots \ldots \ldots \ldots \ldots \ldots \ldots \ldots \ldots \ldots \ldots \ldots$ Reaction rate constant of $\mathrm{O}_{2}$ in layer $1\left[\frac{m}{s-K}\right]$

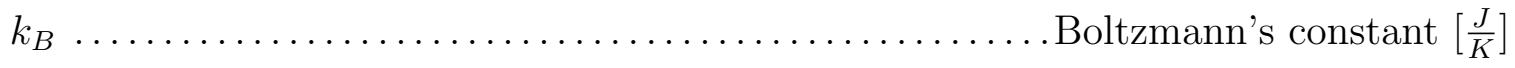
$k_{\text {cat }} \ldots \ldots \ldots \ldots \ldots \ldots$ Reaction rate constant of catalytic PM oxidation $\left[\frac{m}{s-K}\right]$ $k_{N O} \ldots \ldots \ldots \ldots \ldots$ Reaction rate constant of $\mathrm{NO}_{2}$ production by catalyst $\left[\frac{\mathrm{m}}{\mathrm{s}}\right]$ $k_{\mathrm{NO}_{2}} \ldots \ldots$ Reaction rate constant of $\mathrm{NO}_{2} /$ temperature-assisted PM oxidation $\left[\frac{\mathrm{m}}{\mathrm{s}}\right]$ $k_{\mathrm{NO}_{2}, \text { wall }} \ldots$... Reaction rate constant of $\mathrm{NO}_{2}$-assisted PM oxidation in the wall $\left[\frac{\mathrm{m}}{\mathrm{s}}\right]$ $k_{t h} \ldots \ldots \ldots \ldots \ldots \ldots$ Reaction rate constant of thermal PM oxidation $\left[\frac{m}{s}\right]$ $M_{C} \ldots \ldots \ldots \ldots \ldots \ldots \ldots \ldots \ldots \ldots \ldots$ Molecular weight of elemental carbon $\left[\frac{\mathrm{kg}}{\mathrm{kmole}}\right]$ $M_{\text {exh }} \ldots \ldots \ldots \ldots \ldots \ldots \ldots \ldots \ldots \ldots \ldots \ldots \ldots \ldots$ Molecular weight of exhaust gas $\left[\frac{\mathrm{kg}}{\mathrm{kmole}}\right]$

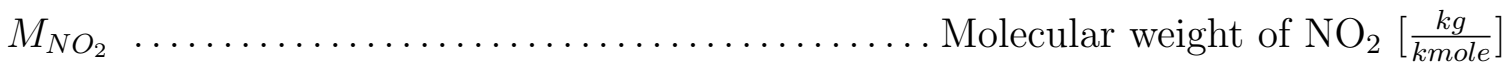
$M_{o x} \ldots \ldots \ldots \ldots \ldots \ldots \ldots \ldots \ldots \ldots \ldots \ldots \ldots$ Molecular weight of oxygen molecule $\left[\frac{\mathrm{kg}}{\mathrm{kmole}}\right]$ $M_{\text {wall }} \ldots \ldots \ldots \ldots \ldots \ldots \ldots \ldots \ldots \ldots$ Total PM mass in the substrate wall $[k g]$ $m_{i} \ldots \ldots \ldots \ldots \ldots \ldots \ldots \ldots \ldots \ldots \ldots$ PM mass in ' $\mathrm{i}$ 'th slab of the substrate wall $[k g]$ 


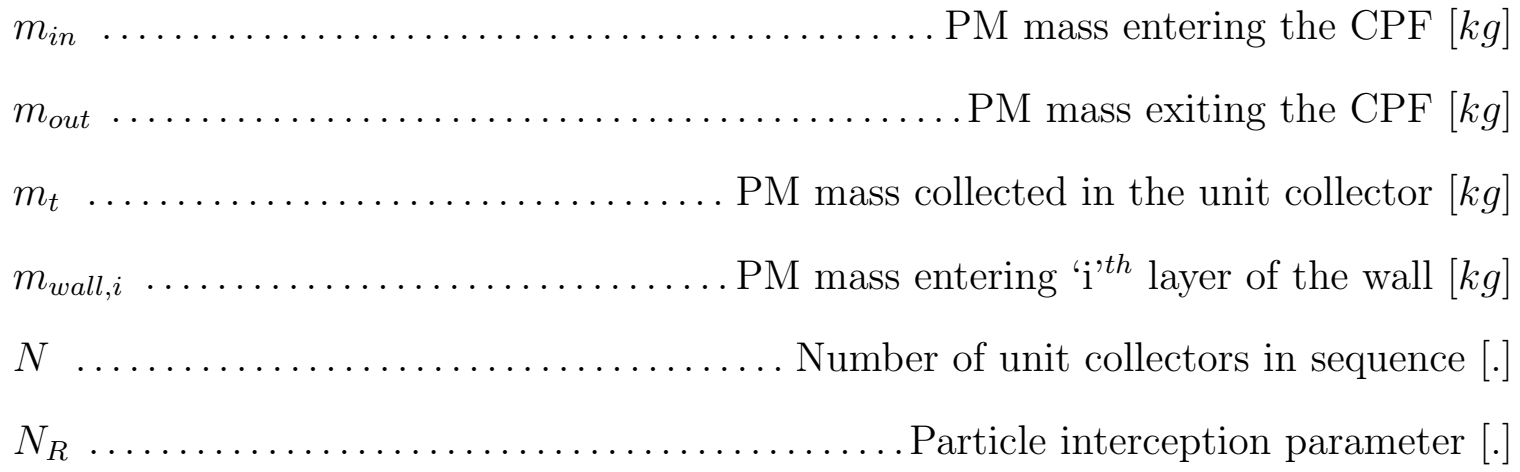

$n \ldots \ldots \ldots \ldots \ldots \ldots \mathrm{NO}_{2}$ production reaction order of dependence of $\mathrm{NO}[$. $n^{\prime} \quad \ldots \ldots \ldots \ldots$ Exponential order of dependence of $\mathrm{NO}_{2}$ production reaction [.] nlayer ............... Total number of slabs in the wall thickness direction [.] $P V C \ldots \ldots \ldots \ldots \ldots \ldots \ldots \ldots \ldots \ldots+$ Particulate volume concentration $\left[\frac{m^{3} P M}{s t d . m^{3} e x h .}\right]$

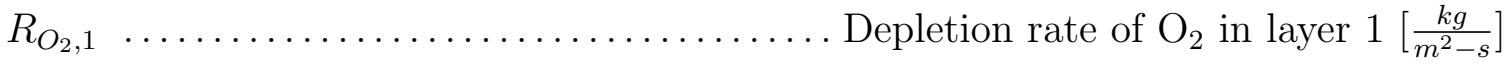
$R_{\mathrm{O}_{2}, 2} \ldots \ldots \ldots \ldots \ldots \ldots \ldots \ldots \ldots \ldots \ldots \ldots \ldots \ldots \ldots \ldots \ldots \ldots \ldots$ Detion rate of $\mathrm{O}_{2}$ in layer $2\left[\frac{\mathrm{kg}}{\mathrm{m}^{2}-\mathrm{s}}\right]$ $R_{O_{2}, \text { cat }, 1} \ldots$ Depletion rate of oxygen in layer 1 due to catalytic PM oxidation $\left[\frac{\mathrm{kg}}{\mathrm{m}^{2}-\mathrm{s}}\right]$ $R_{O_{2}, t h, 1} \ldots$ Depletion rate of oxygen in layer 1 due to thermal PM oxidation $\left[\frac{\mathrm{kg}}{\mathrm{m}^{2}-s}\right]$ $R_{\mathrm{NO}_{2}, 1} \ldots \ldots \ldots \ldots \ldots \ldots \ldots \ldots \ldots \ldots \ldots \ldots \ldots \ldots \ldots \ldots \ldots$ Detion rate of $\mathrm{NO}_{2}$ in layer $1\left[\frac{\mathrm{kg}}{\mathrm{m}^{2}-\mathrm{s}}\right]$

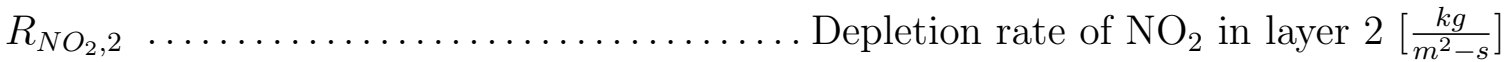
$S C F \ldots \ldots \ldots \ldots \ldots \ldots \ldots \ldots \ldots \ldots \ldots \ldots \ldots \ldots \ldots \ldots \ldots \ldots \ldots+$ Stokes-Cunningham factor $[$. $S p \quad \ldots \ldots \ldots \ldots \ldots \ldots \ldots \ldots \ldots \ldots \ldots \ldots \ldots \ldots \ldots$ Specific area of particulate matter $\left[\frac{m^{2}}{m^{3}}\right]$

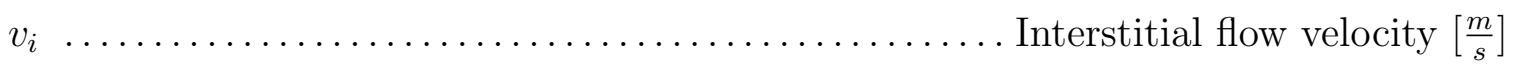

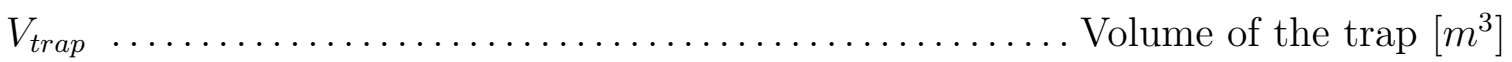

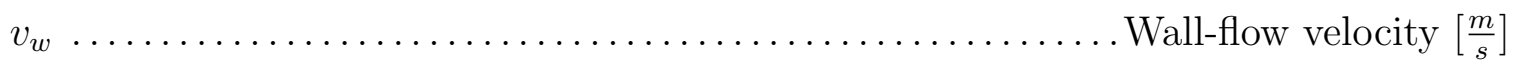

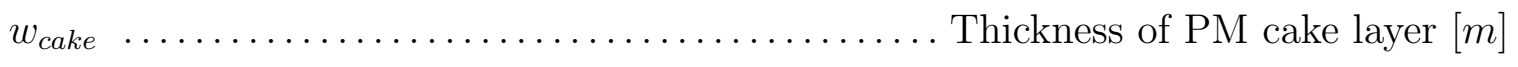

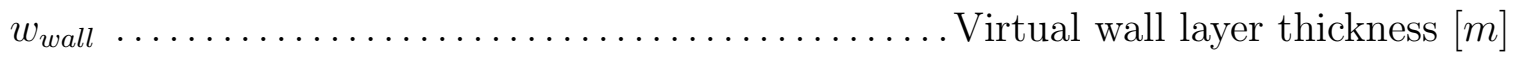

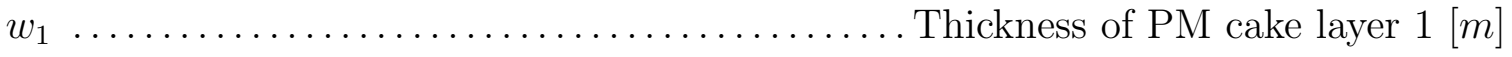

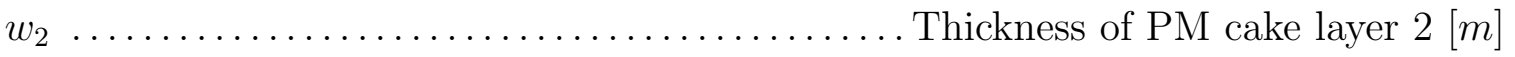
$Y_{\mathrm{NO}_{2}} \ldots \ldots \ldots \ldots \ldots \ldots \ldots \ldots \ldots \ldots \ldots \ldots \ldots \ldots \ldots$ Mass fraction of $\mathrm{NO}_{2}$ entering layer $2[$. $Y_{\mathrm{NO}_{2}, 1} \quad \ldots \ldots \ldots \ldots$ Mass fraction of $\mathrm{NO}_{2}$ exiting layer 2 and entering layer $1[$. 
$Y_{\mathrm{NO}_{2}, \text { wall }} \ldots \ldots \ldots \ldots \ldots$ Mass fraction of $\mathrm{NO}_{2}$ exiting layer 1 and entering wall [.] $Y_{w, 1} \ldots \ldots \ldots \ldots \ldots \ldots \ldots \ldots \ldots$ Mass fraction of oxygen entering layer 1 [.] $Y_{w, w a l l} \ldots \ldots \ldots \ldots \ldots \ldots \ldots$ Mass fraction of oxygen entering substrate wall [.]

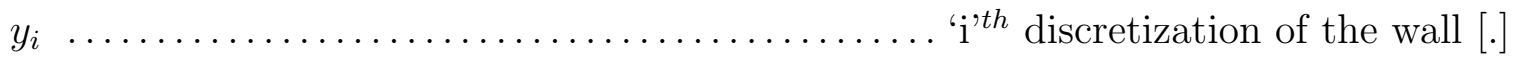

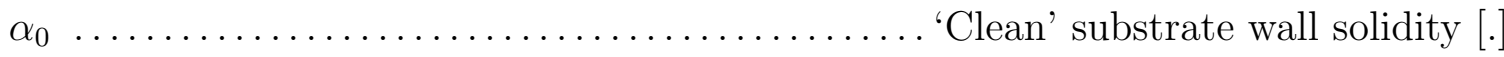

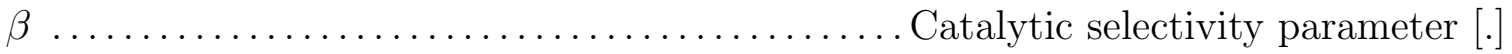
$\gamma \ldots \ldots \ldots \ldots \ldots \ldots \ldots \mathrm{NO}_{2}$ production reaction order of dependence of $\mathrm{O}_{2}[$. $\Delta H^{t h} \ldots \ldots \ldots \ldots \ldots \ldots \ldots \ldots$ Heat release due to thermal PM oxidation $\left[\frac{J}{k m o l}\right]$ $\Delta H^{\text {cat }} \quad \ldots \ldots \ldots \ldots \ldots \ldots \ldots \ldots$ Heat release due to catalytic PM oxidation $\left[\frac{\mathrm{J}}{\mathrm{kmol}}\right]$

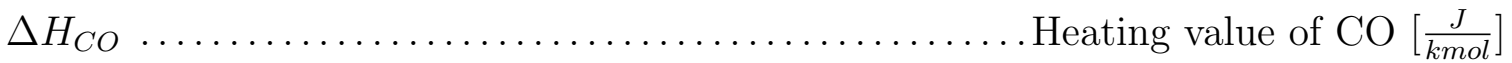

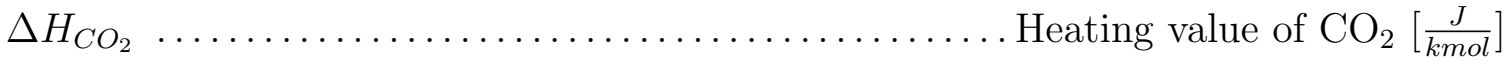
$\Delta z \ldots \ldots \ldots \ldots \ldots$ CPF channel discretization length in the axial direction $[m]$ $\Delta w_{\text {wall }} \ldots \ldots \ldots \ldots \ldots \ldots$ Specific depletion rate of virtual wall layer thickness [.]

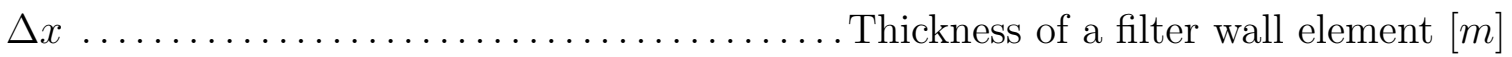

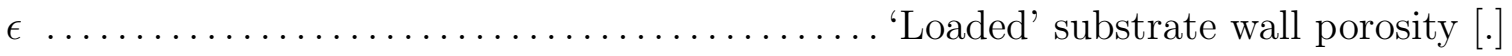

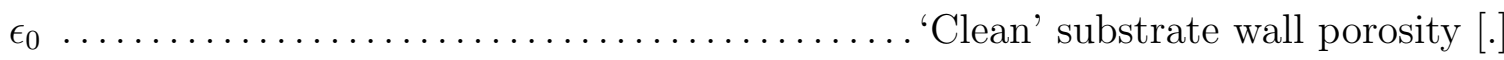

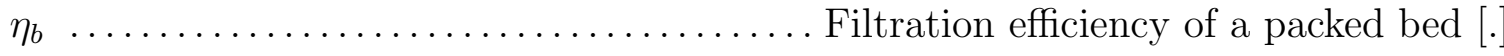
$\eta_{c} \ldots \ldots \ldots \ldots \ldots \ldots . . \ldots \ldots$ Filtration efficiency of a unit collector in the PM cake [.] $\eta_{\text {cake }} \ldots \ldots \ldots \ldots \ldots \ldots \ldots \ldots \ldots \ldots \ldots \ldots \ldots \ldots$ Filtration efficiency of PM cake layer [.] $\eta_{D} \ldots \ldots \ldots \ldots \ldots \ldots$ Collection efficiency of a unit cell by Brownian diffusion [.] $\eta_{D R} \ldots \ldots \ldots \ldots \ldots \ldots \ldots \ldots \ldots \ldots \ldots \ldots \ldots$ Overall collection efficiency of a unit cell [.] $\eta_{R} \ldots \ldots \ldots \ldots \ldots \ldots$ Collection efficiency of a unit cell by direct interception [.] $\eta_{\text {wall }, i} \ldots \ldots \ldots \ldots \ldots \ldots \ldots \ldots \ldots \ldots \ldots$ Filtration efficiency of ${ }^{\prime} \mathrm{i}$ 'th layer of the wall [.]

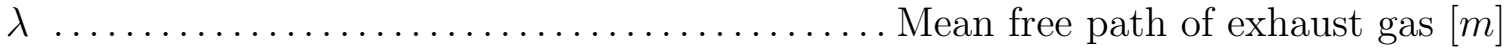

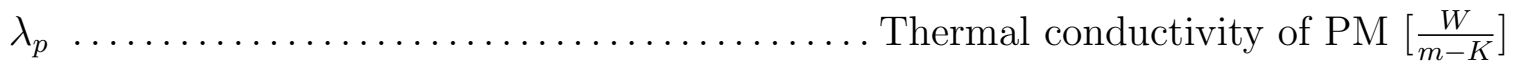
$\lambda_{s} \ldots \ldots \ldots \ldots \ldots \ldots \ldots \ldots \ldots \ldots \ldots$ Thermal conductivity of substrate wall $\left[\frac{W}{m-K}\right]$

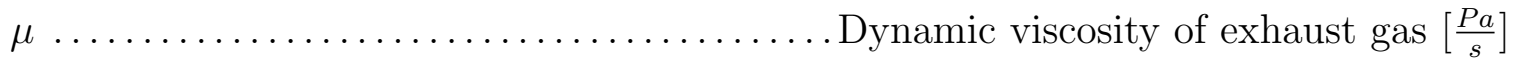




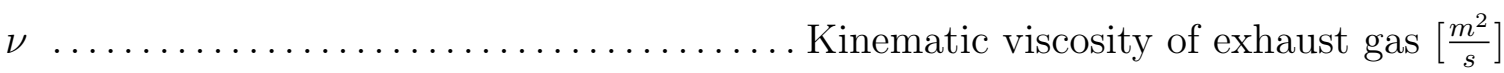

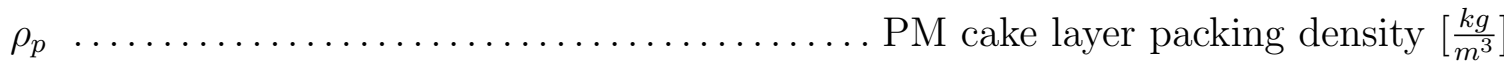

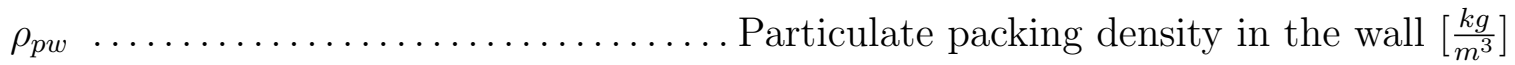

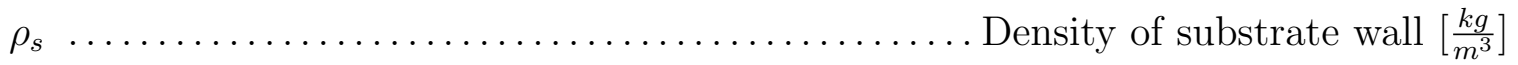

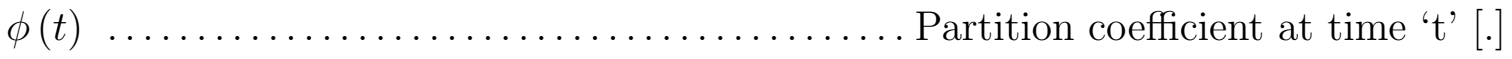

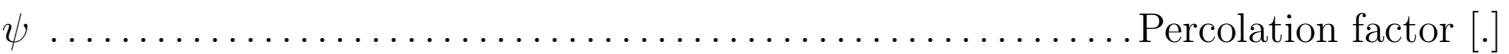




\section{Chapter 1}

\section{Introduction}

The Diesel engine, invented in 1892 by Rudolf Diesel, is still a reliable and widely-used power source for heavy-duty vehicles, marine applications and industrial applications, due to mechanical reliability, thermal efficiency and maintenance cost considerations. The principal disadvantage with this type of engine, though, is the emission levels associated with it. Compared to gasoline engines of similar performance characteristics, diesel engines generally have higher concentrations of oxides of nitrogen (commonly known as ' $\mathrm{NO}_{x}$ ') and particulate matter (in the form of black solid particulate agglomerates, commonly known as 'soot'). $\mathrm{NO}_{x}$ emissions have been proved to cause smog and respiratory illnesses, and diesel particulate matter has been established as being carcinogenic. While elimination of emissions from fossil-fuel engines may be practically impossible, considerable reductions in their overall levels can be achieved by mandating emission standards that every new vehicle has to meet.

All engine manufacturers have continuously been under emissions regulations in the United States, Europe and parts of Asia, by respective governing bodies, particularly since the past two decades. In the United States, engine emissions regulations are developed and maintained by the Environmental Protection Agency (EPA). Ta-

ble 1.1 shows the evolution of US EPA emission standards for heavy-duty on-road 
vehicles over the years; past, present and future [1].

Table 1.1: US EPA on-road heavy-duty diesel engine emission standards [1]

\begin{tabular}{|c|c|c|c|c|}
\hline Year & $\begin{array}{c}\text { NMHC } \\
\text { (g/bhp-hr })\end{array}$ & $\begin{array}{c}\text { CO } \\
\text { (g/bhp-hr })\end{array}$ & $\begin{array}{c}\text { NO }_{x} \\
\text { (g/bhp-hr })\end{array}$ & $\begin{array}{c}\text { PM } \\
\text { (g/bhp-hr })\end{array}$ \\
\hline 1990 & 1.3 & 15.5 & 6.0 & 0.6 \\
\hline 1991 & 1.3 & 15.5 & 5.0 & 0.25 \\
\hline 1994 & 1.3 & 15.5 & 5.0 & 0.1 \\
\hline 1998 & 1.3 & 15.5 & 4.0 & 0.1 \\
\hline 2002 & 0.5 & 15.5 & 2.4 & 0.1 \\
\hline 2007 & 0.14 & 15.5 & 0.2 & 0.01 \\
\hline
\end{tabular}

The PM emission standard will take full effect in the 2007 heavy-duty engine model year. The $\mathrm{NO}_{x}$ and $\mathrm{NMHC}$ standards will be phased in for diesel engines between 2007 and 2010. The phase-in would be on a percent-of-sales basis: $50 \%$ from 2007 to 2009 and 100\% in 2010 (gasoline engines are subject to these standards based on a phase-in requiring 50\% compliance in 2008 and $100 \%$ compliance in 2009).

Non-road diesel engine emissions have also been regulated, following the onroad engine emissions requirement. The first federal standards (Tier 1) for new nonroad diesel engines were adopted in 1994 for engines over $37 \mathrm{~kW}$, to be phasedin from 1996 to 2000 [2]. In 1996, a Statement of Principles (SOP) pertaining to non-road diesel engines was signed between EPA, CARB and engine makers, and on August $27^{\text {th }}, 1998$, EPA signed the final rule reflecting the provisions of the SOP. This regulation also introduced Tier 1 standards for engines under $37 \mathrm{~kW}$ with increasingly more stringent Tier 2 and Tier 3 emission standards with phase-in schedules from 2000 to 2008. Table 1.2 shows the emission standards required to be met by non-road diesel engines in the same power range as the engine studied in this research work $(187 \mathrm{~kW}$ at $2200 \mathrm{rpm}$ ). The row beginning with 4' denotes interim Tier-4 standards, which was the target for the engine studied in this research work.

Traditionally, testing of the performance of aftertreatment systems on engines involved experimentation. Conducting experiments, however, is expensive and lim- 
Table 1.2: Non-road Diesel engine emission standards - Tiers 1 thru 4 [2]

\begin{tabular}{|c|c|c|c|c|c|c|c|c|}
\hline$\stackrel{\check{\Phi}}{\stackrel{\vec{\omega}}{E}}$ & $\stackrel{\mathscr{\varpi}}{\tilde{\nabla}}$ & $\begin{array}{l}\overrightarrow{0} \\
\dot{0} \\
0 \\
0\end{array}$ & ঠ & $\underset{U}{\circlearrowright}$ & 㞯 & 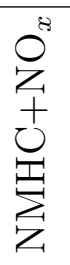 & $\stackrel{0}{z}^{x}$ & $\sum_{\Lambda_{1}}$ \\
\hline & & & 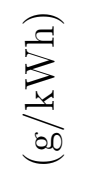 & $\underbrace{\frac{9}{3}}_{00}$ & $\underbrace{\frac{9}{3}}_{\frac{10}{31}}$ & $\frac{3}{\underbrace{30}_{10}}$ & $\underbrace{\frac{9}{3}}_{\infty}$ & $\frac{3}{\underbrace{30}_{14}}$ \\
\hline 1 & 1996 & $130-225$ & 11.4 & 1.3 & - & - & 9.2 & 0.54 \\
\hline 2 & 2003 & $130-225$ & 3.5 & - & - & 6.6 & - & 0.2 \\
\hline 3 & 2006 & $130-225$ & 3.5 & - & - & 4.0 & - & 0.2 \\
\hline $4 '$ & 2011 & $130-560$ & - & - & - & - & 2.0 & 0.02 \\
\hline 4 & 2011-14 & $130-560$ & 3.5 & - & 0.19 & - & 0.4 & 0.02 \\
\hline
\end{tabular}

ited by the capability and accuracy of the measuring equipment. Since the 1970's, computer models have been developed and used in conjunction with experimental data to conduct simulations of exhaust aftertreatment systems in order to assess their performance under different engine load conditions in a relatively inexpensive and more detailed fashion.

The objectives and goals were to:

1. Perform loading experiments on a John Deere engine to collect the experimental data required to characterize the performance of the DOC and the $\mathrm{CPF}$,

2. Develop (and/or improve existing) computer models to simulate the filtration and oxidation characteristics of the DOC and CPF in various load cases,

3. Calibrate the DOC and CPF models so as to match the model outlet values of major variables to experimentally measured values of the same, and

4. Analyze the results obtained from the calibrated models to reach conclusions about the filtration and oxidation performance of the CPF with and without the DOC at various loads. 
Two computer models are used to explain the behavior of a diesel oxidation catalyst (DOC) and a catalyzed particulate filter (CPF) respectively, under varying diesel engine load conditions at two speeds, 2200 and $1650 \mathrm{rpm}$. The CPF model was improved from an existing model developed as part of previous research at MTU [3], and the DOC model was developed as part of this research work and is based on similar models available in references $[4,5]$.

This thesis is organized into a Chapter 2 that gives an overview of DOC and CPF models in general and important processes known to take place in these two devices. This is followed by Chapter 3 that shows the equations used for developing the 1-D DOC and 1-D 2-layer CPF models. Chapter 4 details the experimental setup used for collecting data needed to calibrate the models. Chapter 5 includes all results obtained from experiments and model simulations, and Chapter 6 summarizes the findings and the conclusions drawn from the experimental data and the studies of model simulation results at various load conditions and configurations, and recommendations for future research work in aftertreatment system modeling. 


\section{Chapter 2}

\section{Background and Literature Review}

This chapter contains basic background information about the different processes taking place in the after-treatment devices being studied in this research work, namely the DOC and the CPF. The literature referred to in this chapter provide detailed information about each of the relevant individual details where they are referred to.

\subsection{Diesel Oxidation Catalysts (DOC's)}

Diesel oxidation catalysts are flow-through devices designed to oxidize gaseous species passing through the channels in order to produce less harmful gaseous species [6]. DOC's are usually cellular honeycomb structures made from a ceramic material known as cordierite $\left(2 \mathrm{MgO} .2 \mathrm{Al}_{2} \mathrm{O}_{3} .5 \mathrm{SiO}_{2}\right)$ via extrusion process, with the individual channels normally being square in cross-section. All channels are open at both ends, and positioned parallel to the exhaust gas flow direction, providing minimal exhaust flow resistance. Figure 2.1 shows the typical DOC cell structure and exhaust gas flow through the DOC schematically. DOC channels are about $1-5 \mathrm{~mm}$ in width, and the honeycomb structure provides a large surface area of contact for the oxidation reactions to take place.

Cordierite in itself does not possess any catalytic properties for aiding the 


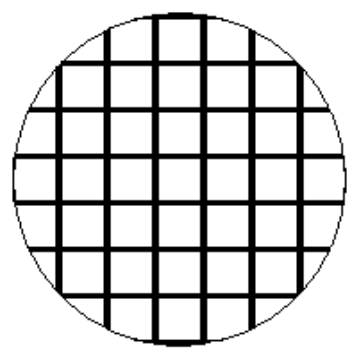

END VIEW

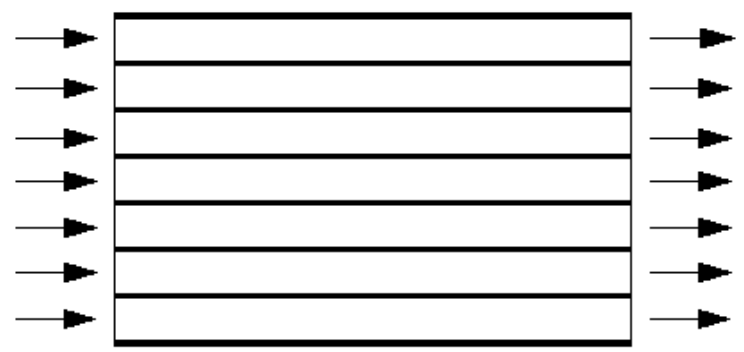

SIDE VIEW

Figure 2.1: Typical cell structure of a DOC - adapted from [7]

reactions taking place inside the DOC. A catalyst, normally a noble metal or a mixture of noble metals such as platinum (Pt), palladium $(\mathrm{Pd})$ or rhodium $(\mathrm{Rh})$ are applied onto the channels of the DOC by means of a "wash-coat" (a highly porous and highsurface-area substance like $\mathrm{Al}_{2} \mathrm{O}_{3}$ ). Typical wash-coat thicknesses are in the range of 20-100 $\mu \mathrm{m}$, depending on catalyst loading levels [6].

The major oxidation reactions taking place in the DOC $[5,8,9,10]$ are:

1. Oxidation of hydrocarbons to form carbon dioxide and water (equation 2.1),

2. Oxidation of carbon monoxide to form carbon dioxide (equation 2.2), and

3. Oxidation of nitric oxide to form nitrogen dioxide (equation 2.3).

This simplified one-step reaction scheme can be used to explain the overall kinetic behavior of the DOC, although in reality, catalyst-assisted oxidation reactions are typically multi-step with intermediate products. Figure 2.2 shows typical HC and $\mathrm{CO}$ conversion efficiencies of a DOC as functions of DOC inlet temperature, and 
Figure 2.3 shows concentrations of $\mathrm{NO}_{2}$ obtained by introducing a DOC, as compared to engine-out $\mathrm{NO}_{2}$ concentrations [6].

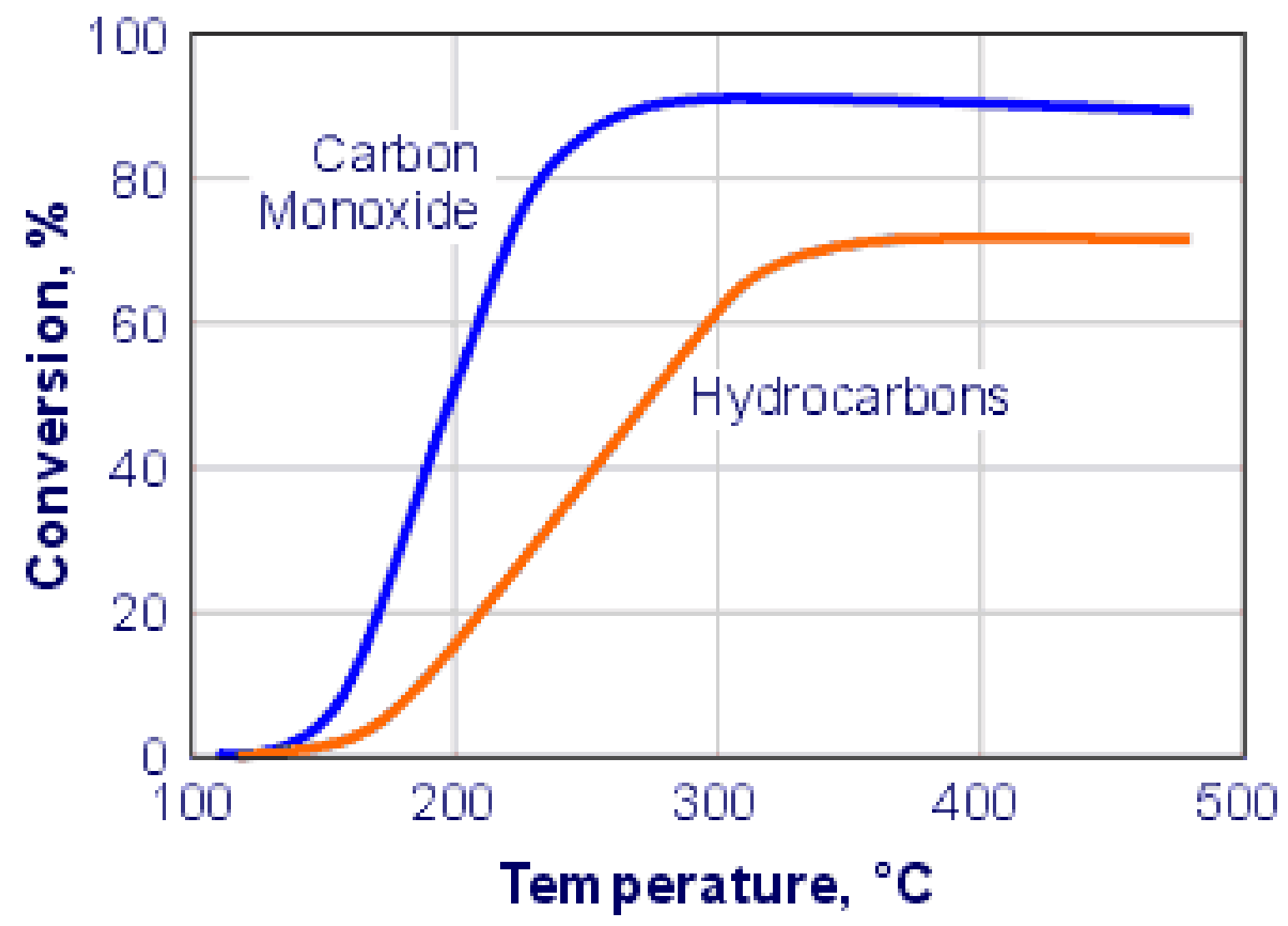

Figure 2.2: $\mathrm{HC}$ and $\mathrm{CO}$ conversion efficiencies of a typical DOC [6]

$$
\begin{aligned}
& \mathrm{C}_{x} \mathrm{H}_{y}+\left(x+\frac{y}{4}\right) \mathrm{O}_{2} \rightarrow x \mathrm{CO}_{2}+\frac{y}{2} \mathrm{H}_{2} \mathrm{O} \\
& \mathrm{CO}+\frac{1}{2} \mathrm{O}_{2} \rightarrow \mathrm{CO}_{2} \\
& \mathrm{NO}+\frac{1}{2} \mathrm{O}_{2} \rightarrow \mathrm{NO}_{2}
\end{aligned}
$$

In the CCRT $\mathrm{R}$ setup, a DOC is fitted upstream of the CPF primarily in order to oxidize HC's, CO and NO. This is beneficial to the oxidation process in the CPF because the oxidation of $\mathrm{NO}$ with $\mathrm{O}_{2}$ to form $\mathrm{NO}_{2}$ (forward reaction 2.3) in the DOC increases the concentration of $\mathrm{NO}_{2}$ entering the CPF. In the $\mathrm{CPF}$, one of the major 


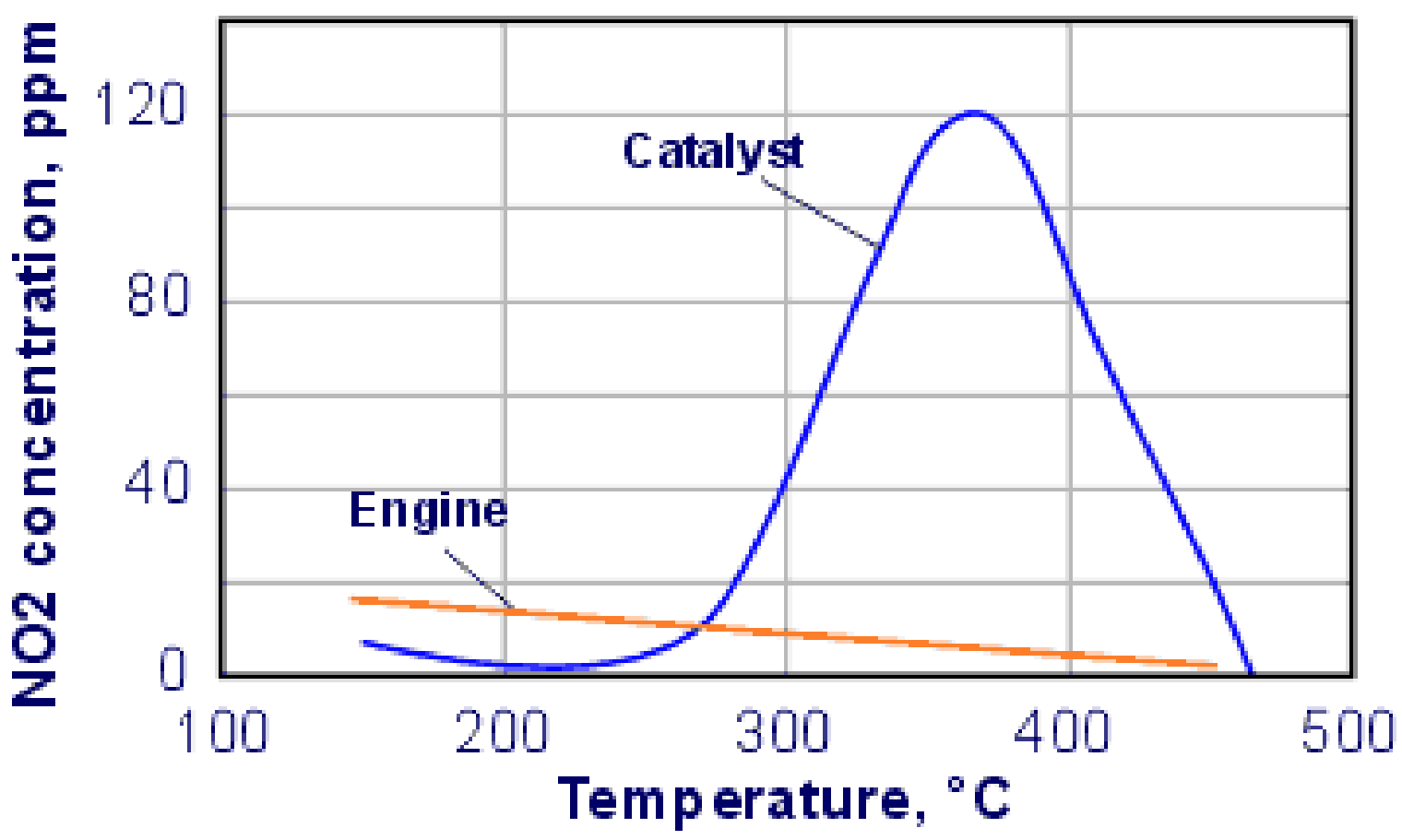

Figure 2.3: NO conversion efficiency of a typical DOC [6]

and most effective particulate oxidation mechanisms is the catalyst-assisted reaction of particulate with $\mathrm{NO}_{2}$ [11]. Thus, a DOC upstream of the CPF effectively increases the passive regeneration capability of the CPF at all temperatures.

It is notable from Figure 2.3 that below engine-out exhaust gas temperatures of about $250^{\circ} \mathrm{C}$, the reaction in equation 2.3 proceeds in the reverse direction, and $\mathrm{NO}_{2}$ is being dissociated to produce $\mathrm{NO}$ and $\mathrm{O}_{2}$, which means that at low temperatures, the DOC unit adversely affects the overall performance of the system. This, however, is not a major concern if the load-range of operation is such that engine-out temperatures are above $250^{\circ} \mathrm{C}$.

Also, all reactions taking place in the DOC are kinetics-limited in the low temperature, low flow rate regime and diffusion-limited in the high temperature, high flow rate regime $[7,12]$. So, conversion efficiencies of all gaseous species are expected to have a peak in the intermediate operating temperature range, as is evident from earlier research work $[7,13,14]$. 


\subsection{Catalyzed Particulate Filters (CPF's)}

Diesel particulate filters (PDF's) are probably one of the most effective aftertreatment devices employed to reduce internal combustion engine particulate emissions. The most common particulate filter design is the wall-flow monolith. In this design, the filter is made from a porous ceramic material such as cordierite $\left(2 \mathrm{MgO} .2 \mathrm{Al}_{2} \mathrm{O}_{3} .5 \mathrm{SiO}_{2}\right)$ by extrusion process, and opposite ends of each individual channel of the filter are plugged with an impermeable and thermally-stable material. As a result, each inlet channel in the wall-flow monolith particulate filter have four outlet channels, as shown in Figure 2.4. The particulate matter-laden exhaust gas entering the channels of the filter is thus forced to pass through the porous walls of the inlet channels, during the process of which the particulate matter gets deposited in and on the porous walls. The mechanisms of PM filtration and their relative effectiveness depend on:

- monolith wall properties such as permeability, porosity and mean pore size,

- interstitial velocity of the exhaust gas, and

- loading history of the PM in the individual 'collection sites' in the filter wall

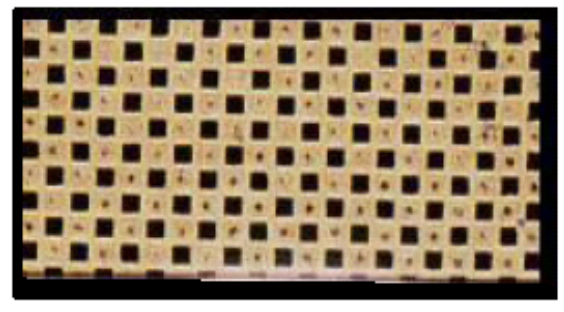

END VIEW

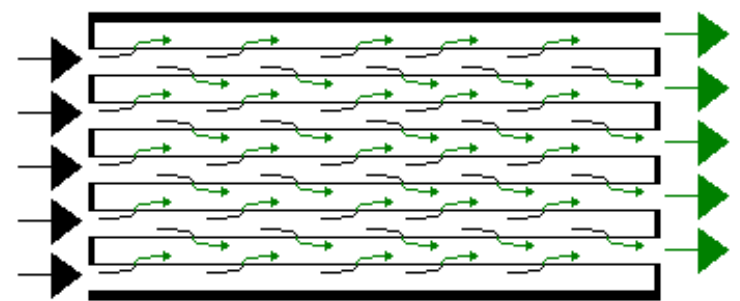

SIDE VIEW

Figure 2.4: Schematic of layout of cells in a wall-flow particulate filter - adapted from $[12]$ 
In a catalyzed particulate filter $(\mathrm{CPF})$, the individual channels are impregnated with a catalyst-laden wash-coat, similar to that used in the DOC. The catalyst, usually a combination of noble metals such as platinum (Pt), palladium $(\mathrm{Pd})$ and rhodium (Rh), promotes gaseous $\mathrm{HC}$ and $\mathrm{CO}$ oxidation (and research is also underway for catalysts that promote PM oxidation reactions) by providing high-surface-area 'catalyst sites' on which the reactant species (and intermediate species) are collected via adsorption, reacted and released via desorption. Increased wall oxidation can be expected in a $\mathrm{CPF}$, compared to a PDF.

\subsubsection{Particulate Filtration Mechanisms}

The two major filtration processes known to be occurring inside the particulate filter are deep-bed filtration and cake filtration. The two are fundamentally different in the location of PM collection. Deep-bed filtration occurs when the filter wall is clean, and particulate matter is being collected inside the filter wall. As the filter wall gets filled up with PM, a cake layer begins to form on the filter wall. Once this cake layer reaches a certain minimum thickness, this layer itself starts behaving like a filter and collects PM on top of itself. This phase is called cake filtration. In an un-catalyzed particulate filter (or in a catalyzed particulate filter without a DOC to increase the $\mathrm{NO}_{2}$ concentration levels available to the CPF), deep-bed filtration is characterized by a non-linear increase in the pressure drop across the filter with respect to loading time, and a more or less linear pressure drop increase in the cake filtration phase $[7,15,16]$.

Deep-bed filtration is characterized by collection of incoming particulate matter by the porous wall of the monolith [17]. The walls of the particulate filter are designed to provide tortuous paths which the exhaust gas passing through is required to traverse, thereby offering considerable flow-resistance to the gas streamlines. Particulate matter carried by the exhaust gases, possessing greater inertia and mass than 
the average gas molecule, gets deposited in the wall at locations where the gas path changes direction $[18,19]$.

Cake filtration is observed in almost all types of filters [20, 21, 22]. This filtration regime is associated with high filtration efficiencies, primarily due to the fact that incoming particles are captured by a filter whose 'mesh size' is comparable to that of the incoming particles themselves. However, from available literature, little is known about the actual mechanisms involved in the collection of particles by the cake layer.

In a catalyzed particulate filter, pressure drop profiles are inherently different from those for un-catalyzed particulate filters at similar engine loading conditions. The difference arises primarily from the fact that in some CPF's, the cake filtration phase has significant amount of filter-wall particulate oxidation taking place, due to which the wall pressure drop (and hence overall pressure drop) decreases with time, while the cake filters out most of the incoming PM. As a result of these phenomena, a typical pressure drop profile for a $\mathrm{CPF}[12,14]$ has an initial phase in which the pressure drop increases with time, and a second phase in which the pressure drop decreases, and then becomes fairly constant with time, depending on whether a balance between filtration and oxidation has been reached or not. This behavior is characteristic of some CPF's, especially at high loads, since wall oxidation rates are higher at higher CPF inlet temperatures.

The major collection mechanisms of PM by the filter wall [18, 23, 24, 25] collection sites are:

1. Brownian diffusion,

2. Interception, and

3. Inertial impaction.

Figure 2.5 shows a schematic description of the three particle-capture mecha- 
nisms considered.

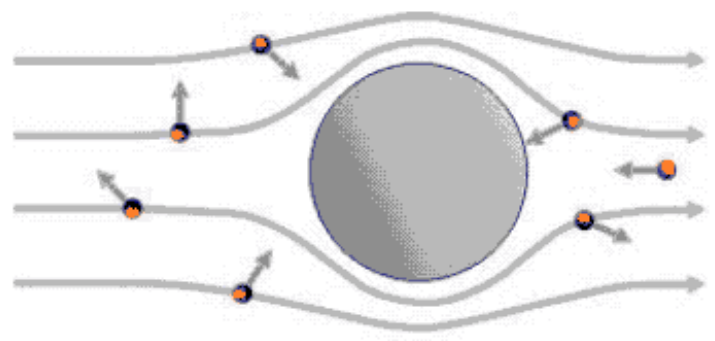

Brownian Diffusion

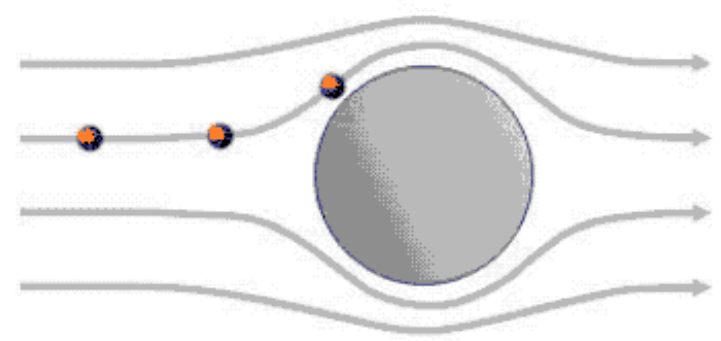

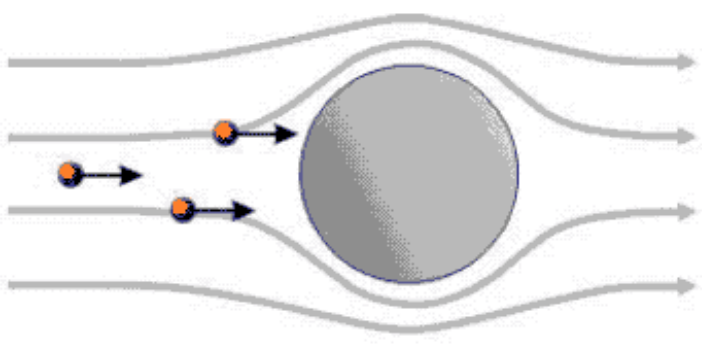

Inertial Impaction

\section{Interceptional Collection}

Figure 2.5: Particulate collection mechanisms in a particulate filter [26]

Brownian diffusion refers to the collection of particles due to random Brownian motion of small particles (less than $0.3 \mu \mathrm{m}$ in diameter). The small particles do not exactly follow the streamlines of exhaust flow; rather, they diffuse toward the collecting medium randomly and get collected.

Interception is the mechanism wherein when a fluid streamline passes close to the collecting medium (in other words, when the normal distance between the streamline and the collecting surface is less than one particle radius), the particle gets collected on the collection surface.

Inertial deposition is prominent for particles of large size (greater than $1 \mu \mathrm{m}$ in diameter). The large particles, possessing greater inertia than the average particle, tend to deviate from the flow streamline and get intercepted at the collection medium surface. Since the highest PM particle diameters encountered in this research were around $650 \mathrm{~nm}$, this mechanism would not be as relevant as the other two explained 
above.

\subsubsection{Thermal Oxidation of Particulate Matter}

Thermal oxidation refers to the direct oxidation of PM with oxygen to form carbon monoxide and carbon dioxide. Reaction equation 2.4 shows the global one-step heterogeneous reaction used to represent this reaction.

$$
C+\left(1-\frac{f_{C O}}{2}\right) O_{2} \rightarrow f_{C O} C O+\left(1-f_{C O}\right) C O_{2}
$$

Here, $\mathrm{f}_{C O}$ is a reaction parameter called the 'CO selectivity' for particulate oxidation by thermal means. The value of this parameter has been reported in earlier research work $[7,12,15]$. This reaction, however, has a light-off temperature typically in the range of $500-550^{\circ} \mathrm{C}$. This means that at typical engine temperatures encountered, which are observed to be in the range of $250-500^{\circ} \mathrm{C}$, this reaction has a low rate of reaction, so that PM mass oxidized by thermal means alone is low compared to the overall mass oxidized. At temperatures higher than $550^{\circ} \mathrm{C}$, however, thermal oxidation reaction rates increase significantly, so as to oxidize majority or all PM deposited in the filter, as is observed from recent active regeneration research [27, 28].

\subsubsection{Catalytic Oxidation of Particulate Matter}

This refers to the oxidation of PM aided by the catalyst present in the wash-coat applied to the filter wall in a catalyzed filter [12, 29, 30], as represented by the global one-step heterogeneous reaction equation 2.5:

$$
C+\left(1-\frac{f_{C O}^{\prime}}{2}\right) O_{2} \rightarrow f_{C O}^{\prime} C O+\left(1-f_{C O}^{\prime}\right) C O_{2}
$$

where $f_{C O}^{\prime}$ is the $\mathrm{CO}$ selectivity for the particulate oxidation reaction by catalytic means [31, 32]. 
The catalyst by itself does not react with PM; rather, it lowers the activation energies involved in the thermal and $\mathrm{NO}_{2}$-assisted reaction mechanisms, thus providing alternative paths for the afore-mentioned reactions to take place. The mechanism suggested for this reaction type is typical of all catalyst-aided reactions; the catalyst washcoat provides a high-surface-area reaction bed, onto which the reactant species are collected via a mechanism called 'adsorption'. The high-surface-area catalyst bed facilitates increased collision rates and collision cross-sections for the reactant molecules, thus increasing overall reaction rates. The reactant species combine to form intermediate species, which are also adsorbed on the catalyst bed, reacted further until stable products are formed and then released to the exhaust flow via a process called 'desorption'.

\subsection{4 $\mathrm{NO}_{2}$-assisted Oxidation of Particulate Matter}

The beneficial effects of nitrogen dioxide $\left(\mathrm{NO}_{2}\right)$ present in the exhaust gas reacting with PM has been reported in various research works $[11,13,33,34,35,36]$. The beneficial effects of $\mathrm{NO}_{2}$ on $\mathrm{PM}$ oxidation was first reported in the patent by Cooper, Jung and Thoss [37]. Figure 2.6 shows the $\mathrm{PM}$ reaction rates with $\mathrm{O}_{2}$ and $\mathrm{NO}_{2}$, indicated by the increase in product $\mathrm{CO}_{2}$ concentrations. It is evident that $\mathrm{NO}_{2}$-assisted reaction is significantly faster than $\mathrm{PM}-\mathrm{O}_{2}$ reaction for typical engine-out temperature conditions, since the light-off temperature for the $\mathrm{PM}-\mathrm{NO}_{2}$ is approximately $200^{\circ} \mathrm{C}$ lower than that for $\mathrm{PM}^{-\mathrm{O}_{2}}$ reaction.

The global reaction scheme originally considered by Cooper et al. [33] was the following two-step reaction.

$$
\begin{aligned}
\mathrm{NO}_{2}+\mathrm{C} & \rightarrow \mathrm{NO}+\mathrm{CO} \\
\mathrm{NO}_{2}+\mathrm{CO} & \rightarrow \mathrm{NO}+\mathrm{CO}_{2}
\end{aligned}
$$




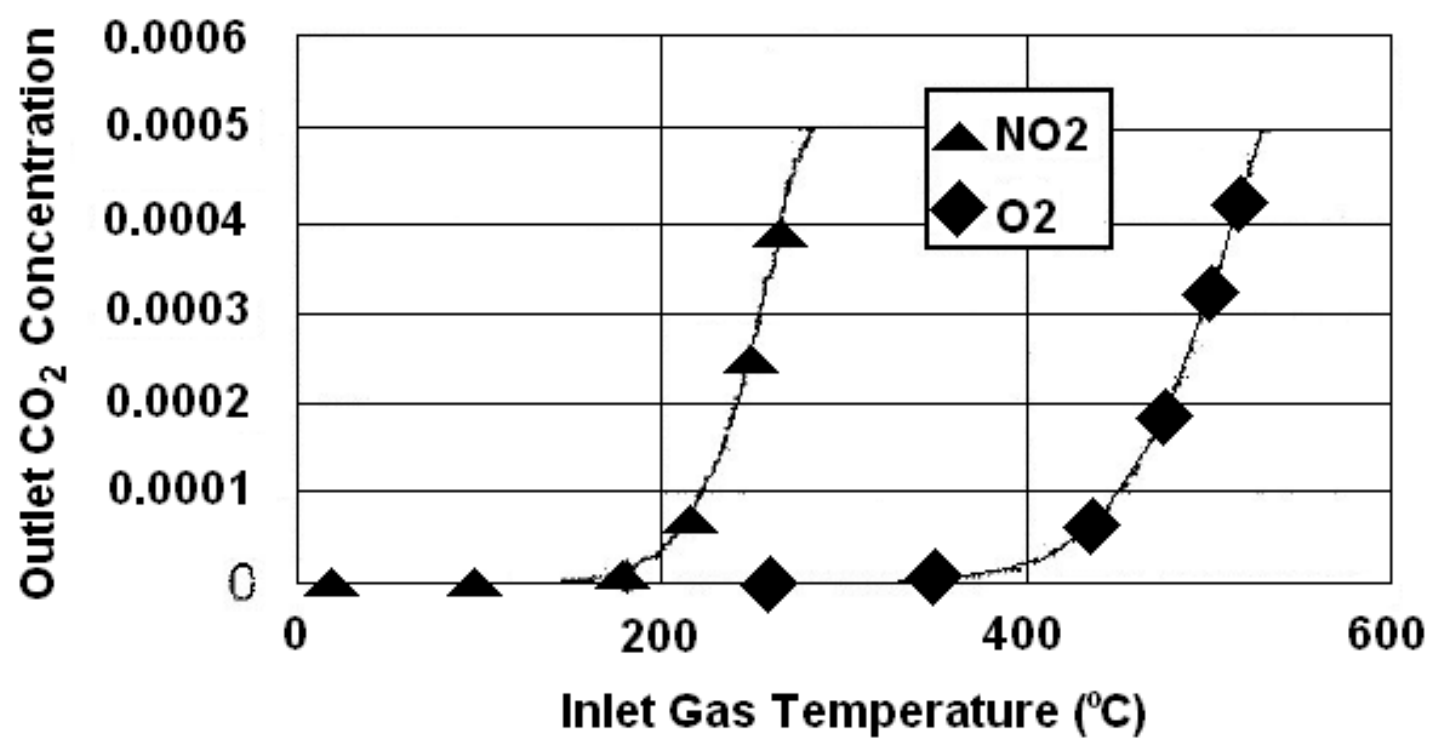

Figure 2.6: Comparison of particulate reaction rates by $\mathrm{O}_{2}$ and $\mathrm{NO}_{2}$ [38]

However, recent research [34] has also suggested alternative reaction schemes which suggests formation of different intermediate species.

$$
\begin{gathered}
\mathrm{NO}_{2}+\mathrm{C} \rightarrow \mathrm{NO}+\mathrm{CO} \\
2 \mathrm{NO}_{2}+\mathrm{C} \rightarrow 2 \mathrm{NO}+\mathrm{CO}_{2}
\end{gathered}
$$

The dominant reaction of these two (equations 2.8 and 2.9) was found out

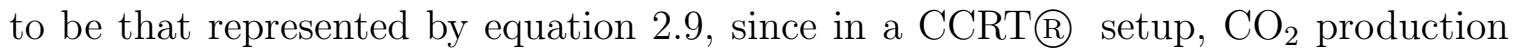
rates were observed to be much higher than $\mathrm{CO}$ production rates [12]. Other recent research work [7, 39] has also proven that the overall PM oxidation rates can be increased by increasing $\mathrm{CPF}$ inlet $\mathrm{NO}_{2}$ concentrations which occurs in a CCRT $\mathbb{R}$ due to the presence of the DOC upstream of the CPF. 


\section{Chapter 3}

\section{Theory and Equations Used in the DOC and CPF Models}

As part of the objectives of this research work, two computer models were used: a DOC model $[4,40]$ and a CPF model [3]. Both had improved sub-models incorporated into the existing models from previous research work at MTU. The DOC model is derived from the governing equations as described in detail in reference [4] and correlations for exhaust gas properties as described in reference [40], and the detailed improvements to the 1-D 2-layer CPF model are described in references [3, 7, 12]. This chapter describes the DOC and CPF models, including the reference sources for the various equations used in the models. In addition, the specific improvements to the models made during this research are described in this section.

\subsection{Diesel Oxidation Catalyst Model}

The DOC model used in this research was developed from earlier DOC models available in the literature $[4,40]$. The one-dimensional (1-D) DOC code models the transient behavior of a single channel in the diesel oxidation catalyst. A detailed description of the basic model from which the current model has been developed can be 
found in reference [4].

\subsubsection{Assumptions in the DOC model}

Figure 3.1 is a schematic representation of the coordinate system followed and the major variables used in the 1-D DOC model.

\section{DoC Single Channel Schematic}

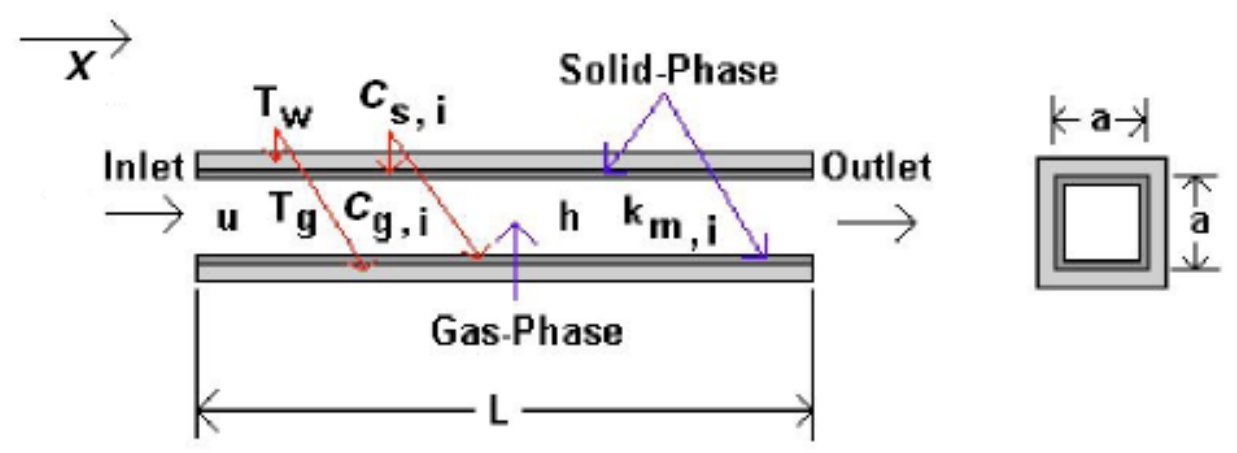

Figure 3.1: A schematic representation of the coordinates used in the 1-D DOC model - adapted from [7]

The major assumptions used in the model are as follows:

- Temperatures, species concentrations and velocities in the model are considered to be the cross-sectional averaged quantities (radial variations of the gas-phase temperatures, species concentrations and velocities within the individual channels are neglected) and hence, a bulk flow is modeled.

- Temperature gradients in the solid-phase in the transverse direction are neglected.

- Axial mass and heat diffusion in the gas-phase are neglected.

- All chemical reactions considered in the model occur only at the wall surface and at the wall temperature, except for the PM oxidation reactions which are assumed to occur in the gas-phase, at the exhaust gas temperature. 
- Oxidation of particulate matter (available in the model but not used in this research) occurs in channel gas only.

- Both quasi-steady state and unsteady state simulations are available in the model. For quasi-steady state simulation, due to the short residence time of the exhaust gases in the DOC, temporal heat and mass accumulation in the gas-phase are neglected, i.e., $\partial Y_{g, i} / \partial t=\partial T_{g} / \partial t=0$. However, for unsteady state simulation, these terms are retained and can be activated via an input flag.

- Exhaust gas properties are those of air* and varying with exhaust temperature and the mass transfer coefficients are assumed to be functions of exhaust temperature and species mole fractions.

- Heat transfer between the wall and the surroundings at the inlet and outlet are neglected.

- Heat transfer between the DOC and ambient is included and can be included in the model heat balance calculations by a heat transfer coefficient term only which is also related to the temperature difference between the channel wall and ambient.

- There are 16 species which can be considered in the model calculations, in the order of $\mathrm{CO}, \mathrm{CO}_{2}, \mathrm{PM}(\mathrm{C}), \mathrm{NO}, \mathrm{NO}_{2}, \mathrm{~N}_{2}, \mathrm{NH}_{3},\left(\mathrm{NH}_{2}\right)_{2} \mathrm{CO}$, additive ash (C), $\mathrm{H}_{2} \mathrm{O}, \mathrm{CH}_{4}, \mathrm{C}_{3} \mathrm{H}_{6}, \mathrm{C}_{16} \mathrm{H}_{34}$, lubricant ash (C), $\mathrm{SO}_{2}$ and $\mathrm{O}_{2}$, representing the diesel exhaust composition.

- All reactions are assumed to be second-order except particulate thermal and catalytic oxidation reactions [36], [33].

${ }^{*}$ Plans for future research work include calculating these properties from individual gaseous species mole fractions 
- Reaction rate constants and adsorption equilibrium constants follow the Arrhenius form.

\subsubsection{Chemical Reactions and Kinetic Equations}

There are eight (8) basic chemical reactions available in the code. They are:

1. CO oxidation

$$
\mathrm{CO}+\frac{1}{2} \mathrm{O}_{2} \rightarrow \mathrm{CO}_{2}
$$

2. $\mathrm{NO}-\mathrm{NO}_{2}$ redox reaction

$$
\mathrm{NO}+\frac{1}{2} \mathrm{O}_{2} \leftrightarrow \mathrm{NO}_{2}
$$

3. $\mathrm{C}_{3} \mathrm{H}_{6}$ oxidation

$$
\mathrm{C}_{3} \mathrm{H}_{6}+\frac{9}{2} \mathrm{O}_{2} \rightarrow 3 \mathrm{CO}_{2}+3 \mathrm{H}_{2} \mathrm{O}
$$

4. $\mathrm{CH}_{4}$ oxidation

$$
\mathrm{CH}_{4}+2 \mathrm{O}_{2} \rightarrow \mathrm{CO}_{2}+2 \mathrm{H}_{2} \mathrm{O}
$$

5. $\mathrm{C}_{16} \mathrm{H}_{34}$ oxidation

$$
\mathrm{C}_{16} \mathrm{H}_{34}+\frac{49}{2} \mathrm{O}_{2} \rightarrow 16 \mathrm{CO}_{2}+17 \mathrm{H}_{2} \mathrm{O}
$$

6. $\mathrm{NO}_{2}$-assisted PM oxidation

$$
\mathrm{C}+\left(2-g_{\mathrm{CO}}\right) \mathrm{NO}_{2} \rightarrow g_{\mathrm{CO}} \mathrm{CO}+\left(1-g_{\mathrm{CO}}\right) \mathrm{CO}_{2}+\left(2-g_{\mathrm{CO}}\right) \mathrm{NO}
$$


7. Thermal PM oxidation

$$
C+\left(1-\frac{f_{C O}^{\text {thermal }}}{2}\right) O_{2} \rightarrow f_{C O}^{\text {thermal }} C O+\left(1-f_{C O}^{\text {thermal }}\right) C_{2}
$$

8. Catalytic PM oxidation

$$
C+\left(1-\frac{f_{C O}^{\text {catalytic }}}{2}\right) O_{2} \rightarrow f_{C O}^{\text {catalytic }} C O+\left(1-f_{C O}^{\text {catalytic }}\right) C_{2}
$$

Reactions 3.1 thru 3.5 are for both solid-phase and gas-phase reactions. Reactions 3.6 thru 3.8 are for PM oxidation and are assumed to occur in channel gas only. In this research work, PM oxidation reactions in the DOC were assumed to be negligible, and therefore, these reactions were excluded from model simulations by setting the reaction rates of these reactions to be equal to zero. Also, all hydrocarbons present in the DOC were assumed to be representable using $\mathrm{C}_{3} \mathrm{H}_{6}$ (propene) [7, 12], and hence, $\mathrm{HC}$ oxidation reactions were completely represented by just one oxidation reaction, 3.3. The other hydrocarbon oxidation reactions (3.4 and 3.5) were excluded by setting the reaction rates of these reactions to zero. Also, the $\mathrm{NO}_{2}$ dissociation reaction was not used in the calibration of the DOC model, since it was found out from experimental data that the $\mathrm{NO}_{2}$ dissociation reaction was prominent in only one of each set of data at the two speeds, where DOC inlet temperatures were less than $180^{\circ} \mathrm{C}$.

The reaction rate expressions employed in the reaction scheme used were improved from simple Arrhenius-type reaction rate equations used in the original model[4]. In the current model developed during the course of this research work, these reaction rates are described using Langmuir-Hinshelwood equations of the basic form $[8],[5]$ and are as follows: 


$$
\begin{aligned}
R_{C O} & =\frac{A_{1} \cdot e^{\left(-E a_{1} / R T\right)} \cdot c_{C O} \cdot c_{O_{2}}}{G_{2}\left(T_{s}, \bar{c}\right)} \\
R_{N O} & =\frac{A_{3} \cdot e^{\left(-E a_{3} / R T\right)} \cdot c_{N O} \cdot c_{O_{2}}}{G_{4}\left(T_{s}, \bar{c}\right)} \cdot E q_{3} \\
R_{N O_{2}} & =\frac{A_{4} \cdot e^{\left(-E a_{4} / R T\right)} \cdot c_{N O_{2}}}{G_{4}\left(T_{s}, \bar{c}\right)} \cdot E q_{4} \\
R_{C_{3} H_{6}} & =\frac{A_{2} \cdot e^{\left(-E a_{2} / R T\right)} \cdot c_{C_{3} H_{6}} \cdot c_{O_{2}}}{G_{1}\left(T_{s}, \bar{c}\right) \cdot G_{3}\left(T_{s}, \bar{c}\right)}
\end{aligned}
$$

with the following expressions accounting for the inhibition terms $G_{1}$ thru $G_{4}$ :

$$
\begin{aligned}
G_{1}= & T_{s}\left(1+A_{a, 1} c_{C O}+A_{a, 2} c_{C_{3} H_{6}}\right)^{2}\left(1+A_{a, 3} c_{C O}^{2} c_{C_{3} H_{6}}^{2}\right) \\
& \left(1+A_{a, 4} c_{N O}^{0.7}\right) \\
G_{2}= & T_{s}\left(1+A_{a, 5} c_{C O}+A a, 6 c_{C_{3} H_{6}}\right)^{2}\left(1+A_{a, 7} c_{C O}^{2} c_{C_{3} H_{6}}^{2}\right) \\
& \left(1+A_{a, 8} c_{N O}^{0.7}\right) \\
G_{3}= & \left(1+A_{a, 9} c_{O_{2}}\right)^{1.5} \\
G_{4}= & T_{s}\left(1+A_{a, 10} c_{C O}+A_{a, 11} c_{C_{3} H_{6}}\right)^{2}\left(1+A_{a, 12} c_{C O}^{2} c_{C_{3} H_{6}}^{2}\right) \\
& \left(1+A_{a, 13} c_{N O}^{0.7}\right)
\end{aligned}
$$

At low temperatures, it is observed that the conditions in the DOC favor the $\mathrm{NO}-\mathrm{NO}_{2}$ redox reaction represented by equation 3.2 in the reverse direction, i.e., $\mathrm{NO}_{2}$ dissociates to produce $\mathrm{NO}$ and $\mathrm{O}_{2}$ (reduction reaction). As DOC inlet temperatures become higher than about $260^{\circ} \mathrm{C}$, the system favors the forward reaction, i.e., NO combining with $\mathrm{O}_{2}$ to produce $\mathrm{NO}_{2}$ (oxidation reaction) $[5,7]$. To account for this equilibrium, two parameters, namely $\mathrm{Eq}_{3}$ and $\mathrm{Eq}_{4}$ are introduced in rate expressions 3.10 and 3.11 respectively.

Equilibrium variables $\mathrm{Eq}_{3}$ and $\mathrm{Eq}_{4}$ can be expressed in terms of chemical 
equilibrium constants $\mathrm{K}_{p 3}$ and $\mathrm{K}_{p 4}$ as:

$$
\begin{aligned}
& E q_{3}=1-\left(\frac{c_{N O_{2}}}{c_{N O} \cdot c_{O_{2}}^{0.5} \cdot K_{p 3}(T)}\right) \\
& E q_{4}=1-\left(\frac{c_{N O} \cdot c_{O_{2}}^{0.5}}{c_{N O_{2}} \cdot K_{p 4}(T)}\right)
\end{aligned}
$$

For specific engine conditions where the $\mathrm{NO}_{2}$ reduction reaction is favored, $\mathrm{Eq}_{3}$ approaches a value of zero (0) and $\mathrm{Eq}_{4}$ approaches a value of one (1), and in cases where the NO oxidation reaction is favored, $\mathrm{Eq}_{3}$ approaches a value of one (1) and $\mathrm{Eq}_{4}$ approaches a value of zero (0). This can be achieved by calibrating the parameters $\mathrm{K}_{p 3}$ and $\mathrm{K}_{p 4}$ in each load-case.

The values of adsorption equilibrium constants $\left(A_{a, 1}\right.$ thru $\left.A_{a, 13}\right)$ used in equations 3.13 thru 3.16 are calculated from Arrhenius-type equations as follows[5, 8]:

$$
A_{a, j}=A_{a 0, j} \cdot e^{\left(\frac{\Delta H_{a, j}}{R \cdot T_{s}}\right)}, j=1 \text { to } 13
$$

The values of adsorption factors $\left(A_{a 0, j}\right)$ and adsorption heats $\left(\Delta H_{a, j}\right)$ are given in Table 3.1, as given in reference $[5]^{*}$.

The activation energy values used in equations 3.9 thru 3.11 are as given in Table 3.2, and are as given in reference [5].

The original model also included an option for including PM oxidation in the DOC, and was not used for the current research work. Mass and energy balance equations in solid-phase and gas-phase were also unchanged from those that were used in the DOC model[4]. Appendix A gives a detailed account of PM oxidation kinetics and mass and energy balance equations used in the DOC model, which were not changed from the previous model.

\footnotetext{
*Values marked by asterisks in Table 3.1 as reported in reference [5] were incorrect; they were changed to current values according to private communication with the author of the reference cited
} 
Table 3.1: Adsorption equilibrium constants in oxidation catalyst modeling [5]

\begin{tabular}{|c|c|c|}
\hline Constant & $\begin{array}{c}\text { Adsorption factor } \\
A_{a 0, j} \\
(.)\end{array}$ & $\begin{array}{c}\text { Adsorption heat } \\
\Delta H_{a, j} \\
(\mathrm{~J} / \mathrm{mol})\end{array}$ \\
\hline$A_{a, 1}$ & $65.5^{*}$ & -7990 \\
\hline$A_{a, 2}$ & $2.08 \mathrm{E}+03$ & $-3.00 \mathrm{E}+03$ \\
\hline$A_{a, 3}$ & 3.98 & -96534 \\
\hline$A_{a, 4}$ & $4 \mathrm{E}+05^{*}$ & 31036 \\
\hline$A_{a, 5}$ & $65.5^{*}$ & -7990 \\
\hline$A_{a, 6}$ & $2.08 \mathrm{E}+03$ & -3000 \\
\hline$A_{a, 7}$ & 3.98 & -96534 \\
\hline$A_{a, 8}$ & $4.79 \mathrm{E}+05$ & 31036 \\
\hline$A_{a, 9}$ & $9.00 \mathrm{E}+04^{*}$ & $0^{*}$ \\
\hline$A_{a, 10}$ & $0^{*}$ & $0^{*}$ \\
\hline$A_{a, 11}$ & $0^{*}$ & $0^{*}$ \\
\hline$A_{a, 12}$ & $3.98^{*}$ & $-96534^{*}$ \\
\hline$A_{a, 13}$ & $7 \mathrm{E}+05^{*}$ & $31036^{*}$ \\
\hline
\end{tabular}

Table 3.2: Activation energies in oxidation catalyst modeling [5]

\begin{tabular}{|c|c|}
\hline $\begin{array}{c}\text { Reaction } \\
\text { Equation } \\
\text { Number }\end{array}$ & $\begin{array}{c}\text { Activation Energy } \\
\text { Ea }_{i} \\
(\mathrm{~J} / \mathrm{mol})\end{array}$ \\
\hline 3.9 & 100000 \\
\hline 3.12 & 100000 \\
\hline 3.10 & 55000 \\
\hline 3.11 & 55000 \\
\hline
\end{tabular}

The next section describes the CPF model that was developed as part of this research work and its components.

\subsection{Catalyzed Particulate Filter Filtration Model}

The CPF model used in this research was developed from the MTU-FILTER 1-D 2-Layer model, used in previous research work at MTU, and the current model is described in reference [3]. This section covers the major development work carried out during the current research work. The sub-models of the 1-D 2-layer CPF model that were used unchanged from previous work are presented in Appendix B. For a complete 
description of the development of the mathematical model of the 1-D CPF model, the reader is advised to refer to previous research theses ([7], [12], [32]) and reference[3] which describes the model. This model uses a single-channel representation of the processes taking place inside the filter at any given inlet condition. This approach uses one inlet channel and one outlet channel separated by the porous wall, as shown in Figure 3.2, to solve for the flow, filtration, heat transfer and regeneration processes taking place in the wall-flow monolith.

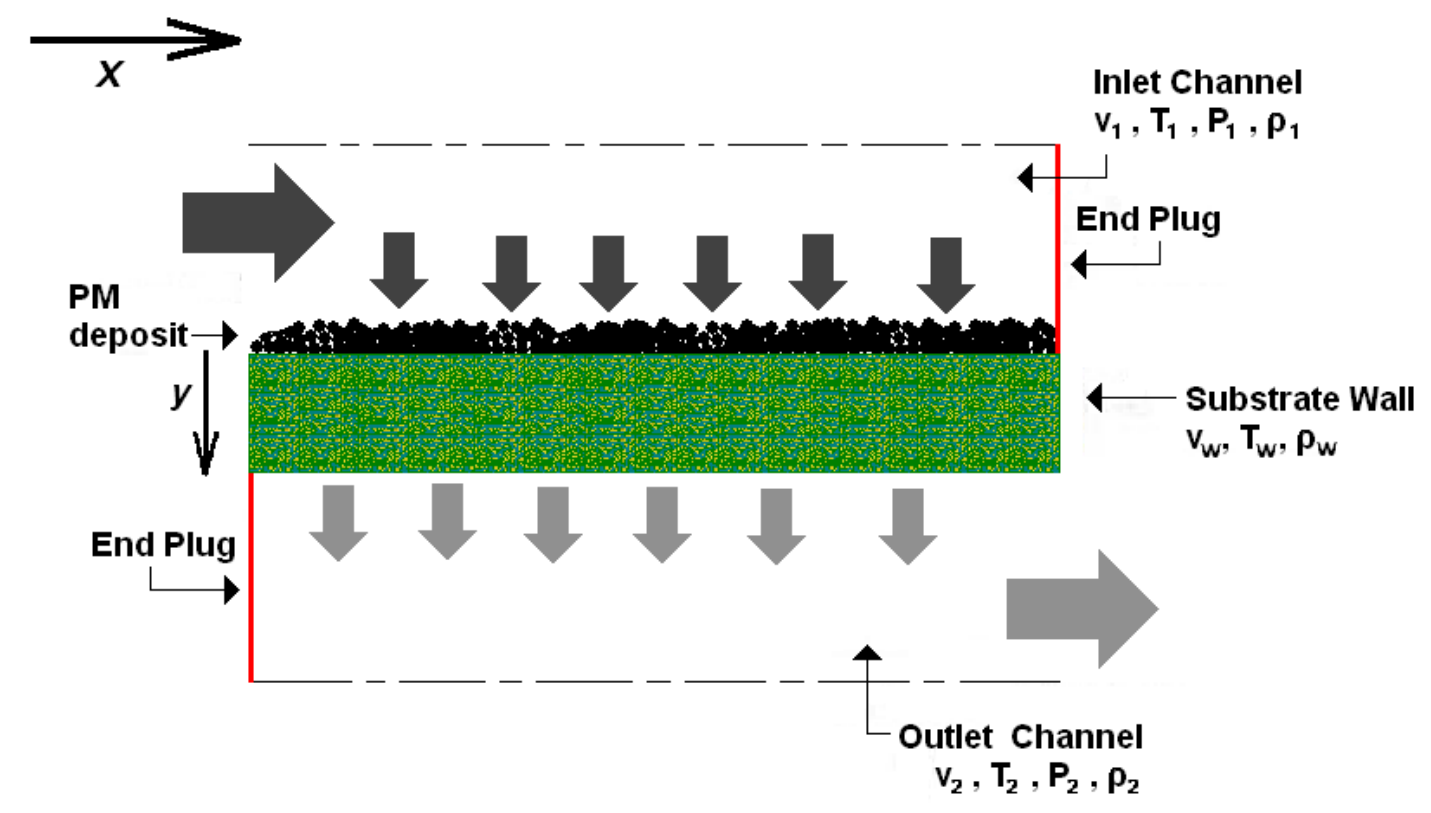

Figure 3.2: A schematic representation of the coordinates used in the 1-D CPF model - adapted from [36]

The coordinate system and discretization techniques used in the CPF 1-D model are as follows:

- The ' $x$ ' coordinate is the distance along the axial length of the filter for inlet and outlet channel of the single channel representation, $x=0$ being the inlet side of the single channel simulated. For the wall element, the ' $y$ ' co-ordinate is in the direction perpendicular to the surface of the substrate wall (This is 
the equivalent of a pseudo-dimension because for computational purposes, all governing equations for the inlet, outlet and wall elements have only ' $\frac{\partial}{\partial x}$ ' terms involved, hence making the system of equations a 1-D system).

- The thickness of the filter wall $w_{s}$ is sub-divided into a number of layers in the 'y' direction (which is user-specified, 9 in this thesis) called 'slabs' (Figure 3.3), although computationally, the filtration and oxidation processes occuring in the ' $y$ ' direction are not taken as functions of ' $y$ '.

- The axial length of the filter wall (This is the 1-D dimension in the model) is sub-divided into a number of 'sections' in the ' $\mathrm{x}$ ' direction (which is also user-specified, 120 in this thesis), as shown in Figure 3.3.

- The solution for unknown variables is carried out at the individual 'nodes' of the filter wall.

The filtration model used in this research was improved from an existing model used for previous research work at MTU[3, 12]. The '2-filters in series' approach was used to model the overall filtration characteristics of the CPF. It has been known that the particulate cake formed on the filter wall is a highly efficient filter itself, owing to the average pore size of the collected particulate being in the same size range as the incoming particulate matter[12, 36]. Initially, the filter wall does almost all of the filtration by allowing particulate matter to get into the pores of the filter wall. As a result of this particulate deposition in the wall, the permeability and porosity of the filter wall decrease, and some of the incoming particulate matter also get deposited on top of the filter wall as a layer. After a sufficiently thick particulate layer (about 0.5 to $1 \mu \mathrm{m}$ as observed from model calibration results, shown later in Chapter 5) is formed, the particulate matter cake layer filters the subsequent incoming particulate matter. A schematic representation of the '2-filters in series' approach used in the filtration model is shown in Figure 3.3. 


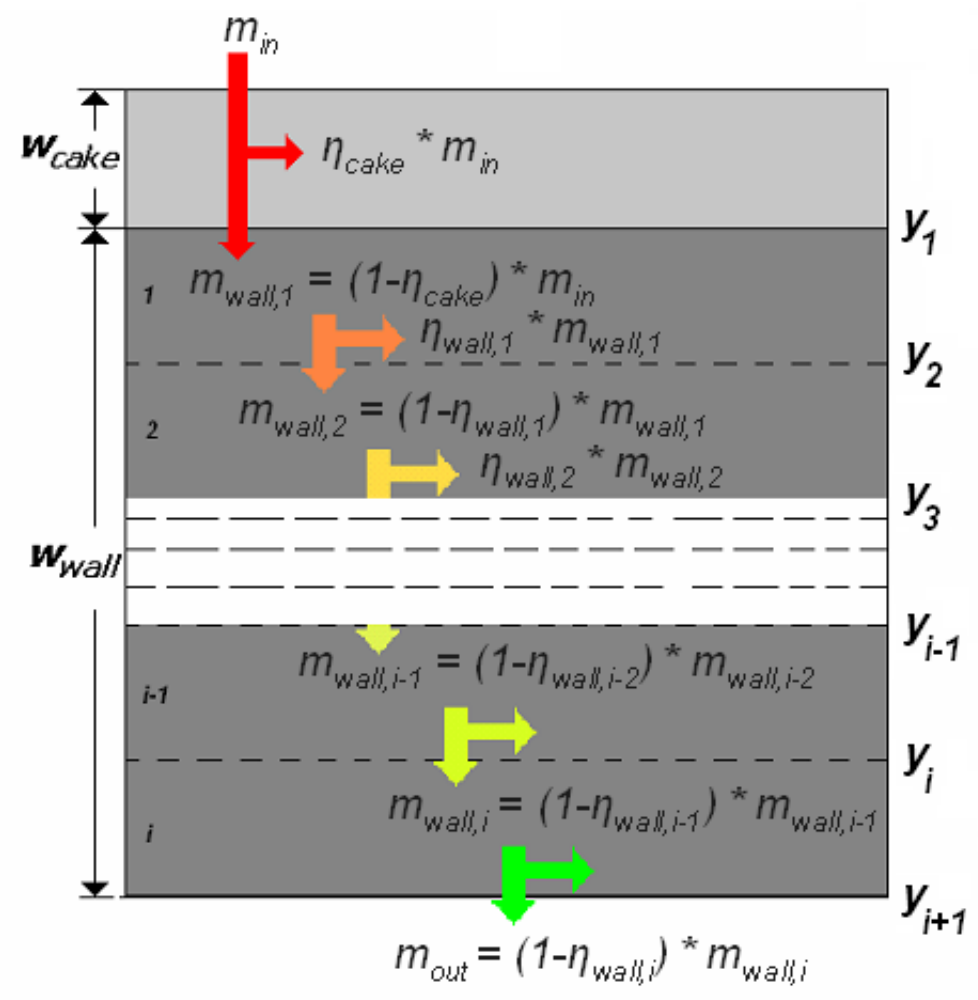

Figure 3.3: A schematic representation of the discretization of filter wall thickness in the ' $y$ ' direction and the '2-filters in series' approach used in the CPF filtration model - adapted from [12]

\subsubsection{Wall Filtration Sub-model}

The wall filtration model used in this research was unchanged from that used in previous research $[3,12]$. This model was adopted from the research work of Konstandopoulos et al.[18, 36]. The approach approximates the microstructure of the filter substrate wall by a packed bed of spherical unit cells. Each unit cell contains a single unit collector capable of collecting particulate matter by means of various particulate collection mechanisms. The volume of a unit collector is related to the volume of a unit cell such that the solid fraction in a unit cell (defined as the ratio of unit collector volume to unit cell volume) is the same as the solidity $\left(\alpha_{0}=1-\epsilon_{0}\right)$ of a clean filter wall[25]. Mathematically, 


$$
\frac{d_{c 0}^{3}}{b^{3}}=\alpha_{0}=1-\epsilon_{0}
$$

where $d_{c 0}$ is the original unit collector diameter, $b$ is the unit cell diameter and $\epsilon_{0}$ is the clean filter wall porosity (around $50 \%$ in this case).

The 'clean' unit collector diameter is related to the filter wall mean pore size and clean filter wall porosity as[18, 25, 36]:

$$
d_{c 0}=\frac{3}{2}\left(\frac{1-\epsilon_{0}}{\epsilon_{0}}\right) \cdot d_{\text {pore }}
$$

where $d_{\text {pore }}$ is the mean pore diameter and $\epsilon_{0}$ is the clean filter wall porosity. This is obtained from the assumption that in a 'bulk' sense, the void space in the substrate that makes up the wall can be approximated as being void cylinders of diameter $d_{\text {pore }}$ and that the total external area of the collectors per unit substrate volume equals the total external surface area of these void cylinders per unit substrate volume.

Particulate collection efficiency of a unit collector is determined by assuming the following:

- Small particles (less than $10 \mathrm{~nm}$ in diameter) are collected primarily due to Brownian diffusion (as described in section 2.2.1.

- Direct interception and inertial impaction are relevant for particles of larger dimensions $(10 \mathrm{~nm}-1 \mu \mathrm{m})$.

- Inertial impaction is not considered since this mechanism comes into significance only for particles greater than $2 \mu m$ in diameter.

- Gravitational settling is also not considered due to the presence of a continuous flow field in the filter.

Brownian diffusion and direct interception are considered to be two mechanisms independently collecting particles. In other words, both mechanisms contribute 
independently to the equivalent efficiency of the unit collector, which in turn translates to the equivalent efficiency of the unit cell.

The collection efficiency of a single unit collector due to Brownian diffusion and deposition is defined as the ratio of the rate at which particles diffuse (or 'stick') to the spherical surface of the collector to the rate at which particles approach a surface with an area equal to the projected area of the sphere[25, 36]. For the KuwabaraHappel flow field considered in the model, the Brownian diffusion collection efficiency of a single unit collector is given as:

$$
\eta_{D}=(3.5)\left(\frac{\epsilon}{K}\right)^{\frac{1}{3}} P e^{-\frac{2}{3}}
$$

where $\epsilon$ is the instantaneous porosity of the filter wall, $K$ is the Kuwabara's hydrodynamic factor[18, 25, 36] given by:

$$
K=2-\epsilon-\frac{9}{5}(1-\epsilon)^{\frac{1}{3}}-\frac{1}{5}(1-\epsilon)^{2}
$$

and $P e$ is the Peclet number, a dimensionless number used to determine the relative magnitudes of convective and diffusive deposition effects for a particle moving in the vicinity of a unit collector. The Peclet number is defined as:

$$
P e=\frac{v_{i} d_{c}}{D_{p}}
$$

where $v_{i}$ is the interstitial flow velocity, given by the simple relation:

$$
v_{i}=\frac{v_{w}}{\epsilon}
$$

where $v_{w}$ is the wall-flow velocity and $d_{c}$ is the diameter of the unit collector including collected particulate matter (otherwise known as 'loaded collector diameter'), and $D_{p}$ is the particle diffusion coefficient[36] defined as: 


$$
D_{p}=\frac{k_{b} T C}{3 \pi \mu d_{p}}
$$

where $k_{b}$ is the Boltzmann's constant, $\mathrm{T}$ is the absolute temperature of the gas in the wall, $\mu$ is the dynamic viscosity of the exhaust gas, $d_{p}$ is defined as the primary size of the diesel particle, and $C$ is the Stokes-Cunningham slip correction factor (or 'SCF' as it is known) used to take into account the slip conditions present in creeping flow through porous media. This becomes significant in cases where the mean free path of the exhaust gas is comparable to the mean pore size of the filter wall. The SCF is related to the local Knudsen number as:

$$
C=1+K n\left(1.257+(0.4) \cdot e^{-\frac{1.1}{K n}}\right)
$$

and the local Knudsen number is defined as:

$$
K n=\frac{2 \lambda}{d_{\text {pore }}}
$$

where $\lambda$ is the mean free path of the gas, defined as:

$$
\lambda=\frac{\mu}{P} \sqrt{\frac{\pi \bar{R} T}{2 M_{e x h}}}
$$

where $P$ is the absolute pressure of the exhaust gas, $T$ is the absolute temperature of the exhaust gas, $\bar{R}$ is the universal gas constant for the exhaust gas mixture, and $M_{\text {exh }}$ is the molecular weight of the exhaust gas mixture.

The efficiency of a unit collector due to direct interception is given[18, 25, 36] as:

$$
\eta_{R}=\frac{3}{2}\left(\frac{\epsilon}{K}\right) \frac{N_{R}}{1+N_{R}^{\frac{3-2 \epsilon}{3 \epsilon}}}
$$


where $N_{R}$ is the particle interception parameter given as:

$$
N_{R}=\frac{d_{p}}{d_{c}}
$$

The overall efficiency of a single unit collector $\eta_{D R}$ is then given as:

$$
\begin{aligned}
\eta_{D R} & =1-\left(\left(1-\eta_{D}\right)\left(1-\eta_{R}\right)\right) \\
& =\eta_{D}+\eta_{R}-\eta_{D} \cdot \eta_{R}
\end{aligned}
$$

The efficiency of a filter wall element, which is assumed as a 'packed bed' of several unit collectors, is related to the efficiency of a single unit collector as[18, 25]:

$$
E=1-e^{-\left(\frac{3(1-\epsilon) \eta_{D R} \Delta x}{2 \epsilon d_{C}}\right)}
$$

where $\Delta x$ is the thickness of the filter wall element considered. The numerical discretization used in the model employs the calculation of the filtration efficiency of the filter wall from the filtration efficiency of individual 'slabs' of thickness ' $\Delta x$ ', as shown in Figure 3.3.

Particulate mass collected in the wall elements changes the filter wall properties. In the filtration model, it is assumed that particulate mass collected in each unit collector is deposited uniformly around the spherical external surface, keeping the spherical surface of the collector intact. This is done by employing a 'constant density' $\left(\rho_{p w}\right)$ of the particulate matter deposited in the wall. The instantaneous diameter of the 'loaded' unit collector is calculated from the amount of mass deposited in the filter wall according to the following relation:

$$
d_{c}=\left[\left(\frac{d_{c 0}}{2}\right)^{3}+\frac{3}{4 \pi} \frac{m_{t}}{\rho_{p w}}\right]^{\frac{1}{3}}
$$


where $d_{c}$ is the diameter of the 'loaded' unit collector at time ' $t$ ', $d_{c 0}$ is the diameter of the 'clean' unit collector (at time ' $t=0$ '), $m_{t}$ is the mass collected in the unit collector at time ' $t$ ', and $\rho_{p w}$ is the particulate packing density in the wall. It is notable that particulate packing density in the wall is not a density in its real sense, but rather a measure of how tightly/loosely the mass collected in the wall is distributed. So, a higher value of wall packing density would mean that the mass collected in the wall is more tightly packed around the unit collector than that for a lower packing density. It can be seen from equation 3.20 and 3.34 that wall porosity evolution can be expressed as:

$$
\epsilon=1-\left(\frac{d_{c}}{d_{c 0}}\right)\left(1-\epsilon_{0}\right)
$$

With the 'clean' and 'loaded' unit collector diameters known from the equations 3.34 and 3.35 , the 'loaded' mean pore size of the filter wall $\left(d_{\text {pore }}\right)$ can be computed as:

$$
d_{\text {pore }}=\frac{2}{3}\left(\frac{\epsilon}{1-\epsilon}\right)
$$

The instantaneous permeability of the filter wall also varies with time, the evolution of which is given as[18, 25]:

$$
\frac{k(t)}{k(0)}=\left(\frac{d_{c}}{d_{c 0}}\right)^{2} \frac{K(\epsilon)}{K\left(\epsilon_{0}\right)}\left(\frac{1-\epsilon_{0}}{1-\epsilon}\right)
$$

where $K$ is the Kuwabara hydrodynamic factor defined in equation 3.23. It can be noted that the ratio $\frac{K\left(\epsilon_{t}\right)}{K\left(\epsilon_{0}\right)}$ is a smoothing factor to control the relative extent of decrease of wall permeability with decreasing wall porosity.

In the initial phase of particulate deposition, almost all of the incoming particulate matter gets deposited 'in' the filter wall, rapidly decreasing the wall porosity and wall permeability (according to equations 3.35 and 3.37 respectively). As the filter wall permeability decreases, most of the incoming particles now get deposited 'on' the filter wall, in the form of a particulate cake layer. For modeling purposes, 
a coefficient of partition of incoming PM between the wall and cake layer has been employed in the model[18]. This coefficient, called the 'partition coefficient' $\phi$, can have a value between 0 and 1 , and is used in the model as a filtration parameter to initiate the solution. The partition coefficient $\phi$ is defined as:

$$
\phi(t)=\frac{d_{c}^{2}-d_{c 0}^{2}}{(\psi b)^{2}-d_{c 0}^{2}}
$$

where $\psi(0<\psi<1)$ is a dimensionless 'percolation factor' which determines how much of the unit cell can be filled up by PM before filtration in that section of the filter is done completely by the cake layer present in that section. Figure 3.4 shows how the maximum attainable diameter of the unit collector is related to the percolation factor.

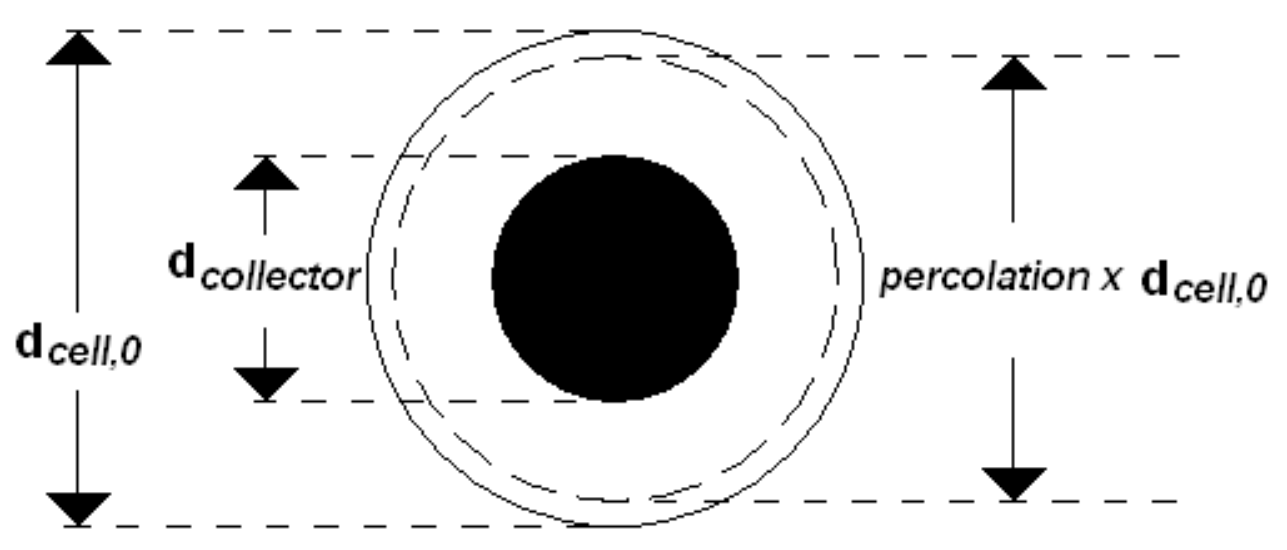

Figure 3.4: Schematic representation of percolation in the wall

In the model, the partition coefficient is used as a means to initiate the solution 
of distribution of incoming PM into PM deposited in the cake layer, and PM deposited in the filter wall. The computed value of the partition coefficient is set equal to the filtration efficiency of the cake in the initial stages of filtration. This is explained further in the next section, i.e.,3.2.2

\subsubsection{Cake Filtration Sub-model}

The particulate cake layer filtration model used in MTU 1-D 2-layer model was improved from the existing model [12] as follows:

Cake filtration efficiency was found to be exceeding a value of 1.0 (100\%) once the steady-state diffusion and interception efficiencies of the cake layer collectors were reached. SMPS data downstream of CPF and CCRTßsetup (both MTU and JD data [41]) suggest a 99.5 - 99.8\% overall particulate number reduction efficiency. According to the 2-filter approach currently used, if the efficiency of any one of the two filters reaches $100 \%$, the total efficiency is $100 \%$. This did not corroborate with what was observed from experimental DN-CPF particle size distribution data during the loading experiments. This motivated the use of a modified cake filtration efficiency calculation, as given below:

Efficiency ' $\eta_{b}$ ' of a packed bed collector consisting of ' $N$ ' collectors in sequence, each having an individual collection efficiency of ' $\eta_{c}$ ' is given as [22],[25]:

$$
\eta_{b}=\left(1-\left(1-\eta_{c}\right)^{N}\right)
$$

and in cases where the number of individual collectors becomes greater than $20, \eta_{b}$ can be approximated[22] as:

$$
\eta_{b}=\left(1-e^{-N \eta_{c}}\right)
$$

In the cake filter, the number of cake collectors in sequence, $N=\frac{w_{\text {cake }}}{d_{c, \text { cake }}}$ where $d_{c, c a k e}$ is the cake collector diameter. 
In order to include all these requirements of the cake filtration efficiency calculation, a new cake filtration calculation was adopted, which is defined as:

$$
\eta_{\text {cake }}=A_{\eta}\left(1-e^{-\eta_{c} \cdot \frac{w_{c a k e}}{d_{c, c a k e}}}\right)
$$

where $A_{\eta}$ is referred to as the 'maximum cake efficiency parameter', which was added empirically to the original packed bed filtration efficiency equation[22] so that maximum cake filtration efficiency was limited below 100\% (0.950 - 0.984 as used in the model calibration, shown later in Chapter 5, which gives a maximum cake filtration efficiency in the range of $95.0-98.4 \%$ ), and $\frac{\eta_{c}}{d_{c, c a k e}}$ is the ratio of individual cake collector efficiency to cake collector diameter and has the units $1 / \mathrm{m}$. These parameters are calibrated to fit overall pressure drop data, downstream SMPS data and outlet particulate matter concentration data.

At the beginning of loading, no PM cake layer is present (i.e., $w_{\text {cake }}=0$ ). Therefore, a cake filtration efficiency calculation using equation 3.41 would return a value of zero, and hence, all particulate matter would be directed into the wall. This would result in a cake layer initiation problem. To counter this, the partition coefficient as defined in equation 3.38, originally defined in references $[29,42]$ is used to calculate a partitioning of incoming particulate matter into 'cake fraction' and 'wall fraction'. Accordingly, a cake layer of non-zero thickness develops on the filter wall. Equation 3.41 is also used in each time-step to compute the cake filtration efficiency from cake properties alone. In order to ensure a smooth transition from using the partition coefficient to using the modified cake filtration efficiency calculation, this computed value of cake filtration efficiency is compared to the partition coefficient at every time-step of model calculations, and cake filtration efficiency is 'switched' to being calculated from equation 3.41, when the computed value from equation 3.41 is equal to or greater than that calculated from equation 3.38 . 


\section{Chapter 4}

\section{Experimental Setup and Procedures}

This chapter describes the setup for the experimental work, and the procedures that were followed in this research. All experiments for this research work were conducted at the John Deere Product Engineering Center (JD-PEC) at Waterloo, Iowa from March to April 2005.

\subsection{Experimental Setup}

The engine used for this research work was a 2004 John Deere 6-cylinder, in-line, 6.8 liters turbo-charged and after-cooled engine. Table 4.1 gives a description of the engine parameters. Table 4.2 lists the specifications of the dynamometer used in this research. The fuel used for this research work was an ultra-low sulfur fuel (ULSF) with a sulfur content of $11.6 \mathrm{ppm}$. Table 4.3 gives a listing of properties of the fuel used for the experimental work. The CCRT® unit used in this research work consisted of a 400 cpsi DOC and a 200 cpsi CPF. The DOC specifications are shown in Table 4.4 and the CPF specifications are shown in Table 4.5. 
Table 4.1: John Deere engine specifications

\begin{tabular}{|l|l|}
\hline Model & 2004 John Deere 6068H (development engine) \\
\hline Type & 4 stroke \\
\hline Cylinders & 6, in-line \\
\hline Aspiration & Turbocharged, Aftercooled \\
\hline Displacement & 6.8 liters \\
\hline Max Power observed & $187 \mathrm{~kW} @ 2200 \mathrm{rpm}$ \\
\hline Max Torque observed & $995 \mathrm{Nm} @ 1650 \mathrm{rpm}$ \\
\hline Injection Timing & Variable (Electronically Controlled) \\
\hline Fuel System & High Pressure Common-Rail \\
\hline EGR System & Cooled Low Pressure Loop EGR \\
\hline
\end{tabular}

Table 4.2: Dynamometer specifications

\begin{tabular}{|l|l|}
\hline Model & 2000 General Electric AC Dynamometer \\
\hline Rating & $750 / 700 \mathrm{HP} 1575 / 2400 \mathrm{rpm} 4 \mathrm{P} \mathrm{575} \mathrm{V} 3 \mathrm{PH}$ \\
\hline HP ABS & $750 @ 1575 / 2400 \mathrm{rpm}, 603 / 595 \mathrm{AMP}$ AC \\
\hline HP MTR & $700 @ 1575 / 2400 \mathrm{rpm}, 601 / 620 \mathrm{AMP}$ AC \\
\hline Poles & 4 \\
\hline Power Requirement & $575 \mathrm{~V} 3$ Phase @ $62.5 \mathrm{~Hz}$ \\
\hline
\end{tabular}

Table 4.3: Fuel specifications

\begin{tabular}{|l|l|}
\hline ASTM D4052 density @ $15^{\circ} \mathrm{C}\left(\mathrm{kg} / \mathrm{m}^{3}\right)$ & 841.2 \\
\hline Specific gravity @ $15^{\circ} \mathrm{C}()$. & 0.8417 \\
\hline API gravity @ $15^{\circ} \mathrm{C}()$. & 36.6 \\
\hline ASTM D445 kinematic viscosity @ $40^{\circ} \mathrm{C}\left(\mathrm{m}^{2} / \mathrm{s}\right)$ & $2.34 \mathrm{E}-06$ \\
\hline ASTM D482 ash content $(\%$ wt $)$ & $<0.001$ \\
\hline ASTM D5453 sulfur content (ppm) & 11.6 \\
\hline ASTM D613 cetane number (.) & 48.2 \\
\hline IBP $\left({ }^{\circ} \mathrm{C}\right)$ & 183 \\
\hline FBP $\left({ }^{\circ} \mathrm{C}\right)$ & 350 \\
\hline Recovered $(\% \mathrm{wt})$ & 98.0 \\
\hline Residue $(\% \mathrm{wt})$ & 0.6 \\
\hline Loss $(\% \mathrm{wt})$ & 1.4 \\
\hline
\end{tabular}


Table 4.4: Diesel oxidation catalyst specifications

\begin{tabular}{|l|l|}
\hline PARAMETER & VALUE \\
\hline Substrate material & Cordierite \\
\hline Catalyst formulation & Proprietary \\
\hline Catalyst loading & Proprietary \\
\hline Cell structure & Square \\
\hline Diameter $(\mathrm{m})$ & 0.2667 \\
\hline Channel length $(\mathrm{m})$ & 0.1524 \\
\hline Cell density $(\mathrm{cpsi})$ & 400 \\
\hline Channel width $[$ repeat distance] $(\mathrm{m})$ & $1.27 \mathrm{E}-03$ \\
\hline Channel wall thickness $(\mathrm{m})$ & $1.52 \mathrm{E}-04$ \\
\hline Washcoat thickness $(\mathrm{m})$ & $2.54 \mathrm{E}-05$ \\
\hline Frontal area $\left(\mathrm{m}^{2}\right)$ & $5.59 \mathrm{E}-02$ \\
\hline Total volume $\left(\mathrm{m}^{3}\right)$ & $8.51 \mathrm{E}-03$ \\
\hline Number of cells $()$. & 34636 \\
\hline Bulk density $\left(\mathrm{kg} / \mathrm{m}^{3}\right)$ & 440 \\
\hline Thermal conductivity $(\mathrm{W} / \mathrm{m} . \mathrm{K})$ & 1.255 \\
\hline Specific heat $(\mathrm{J} / \mathrm{kg} . \mathrm{K})$ & 836.8 \\
\hline
\end{tabular}

Table 4.5: Catalyzed particulate filter specifications

\begin{tabular}{|l|l|}
\hline PARAMETER & VALUE \\
\hline Substrate material & Cordierite \\
\hline Catalyst formulation & Proprietary \\
\hline Catalyst loading & Proprietary \\
\hline Diameter $(\mathrm{m})$ & 0.2667 \\
\hline Length $(\mathrm{m})$ & 0.3048 \\
\hline Cell density $(\mathrm{cpsi})$ & 200 \\
\hline Repeat distance $(\mathrm{m})$ & 0.0017961 \\
\hline Porous wall thickness $(\mathrm{m})$ & 0.0003048 \\
\hline Channel width $(\mathrm{m})$ & 0.0014913 \\
\hline Hydraulic diameter $(\mathrm{m})$ & 0.0014913 \\
\hline Frontal area $\left(\mathrm{m}^{2}\right)$ & 0.0558645 \\
\hline Total volume $\left(\mathrm{m}^{3}\right)$ & 0.0170275 \\
\hline Porosity $()$. & 0.52 \\
\hline Number of cells $()$. & 17318 \\
\hline Mean pore size $(\mathrm{m})$ & $1.30 \mathrm{E}-05$ \\
\hline Bulk density $\left(\mathrm{kg} / \mathrm{m}^{3}\right)$ & 390 \\
\hline Thermal conductivity $(\mathrm{W} / \mathrm{m} . \mathrm{K})$ & 1.0 \\
\hline Specific heat $(\mathrm{J} / \mathrm{kg} . \mathrm{K})$ & 1.0 \\
\hline
\end{tabular}




\subsection{Test Cell Instrumentation}

The John Deere test cell used in this research is equipped with a full emissions bench with Horiba-200 analyzers. $\mathrm{CO}$ and $\mathrm{CO}_{2}$ detection and measurement is carried out by using non-dispersive infrared detection, oxides of nitrogen (nitrogen dioxide $\mathrm{NO}_{2}$, and nitric oxide - NO) are measured and analyzed using the chemiluminescence method, hydrocarbons (HC) are measured using the heated flame ionization detection (FID) method, and oxygen $\left(\mathrm{O}_{2}\right)$ is measured using a magneto-pneumatic analyzer. The particulate sampling system uses a Sierra BG-2 partial-flow dilution system, which dilutes the exhaust gaseous sample to ratios of 7:1 to 10:1, depending on the engine operating condition. The particulate matter contained in this diluted sample is then deposited on $70 \mathrm{~mm}$ Pallflex TA60 filters by drawing the sample with a flow-rate of 110 standard liters per minute. The sampling period used in all the experiments was 15 minutes. The $70 \mathrm{~mm}$ filters were pre-baked, weighed in a temperature and humidity-controlled room (called the 'weighing room') and taken to the test-cell for sample collection. These filters were loaded into a filter-cartridge and fitted onto the sampling system, 8 at a time, and changed with another set of 8 filters when the first of 8 were loaded with PM. The loaded filters were labeled and returned to the weighing room. These filters were then weighed, and baked in a temperaturecontrolled oven for 2 hours, and weighed again. Each filter had 3 weights associated with it: pre-test, post-test and post-bake. The difference between the pre-test and the post-test weights is the amount of total PM on the filter, and the difference between the post-test and post-bake weights is the amount of volatile particulate matter present on the filter. The difference of pre-test and post-bake weights would give the amount of solid particulate matter on the filter. All temperatures were measured using K-type thermocouples. All pressures were measured with Sensotec transducers. Engine intake humidity was measured using a General Eastern dew-point meter.

Particle Size Distribution (PSD) data were collected using a TSI 3934 Scanning 
mobility particle sizer (SMPS) system, designed to detect particles in the $5-1000 \mathrm{~nm}$ range. The SMPS instrumentation specifications and settings used for collecting particle size distributions for this research are shown in Table 4.6.

Table 4.6: SMPS specifications

\begin{tabular}{|l|l|}
\hline Classifier Model & 3080 \\
\hline DMA Model & 3081 \\
\hline DMA Inner Radius (cm) & 0.00937 \\
\hline DMA Outer Radius (cm) & 0.01961 \\
\hline DMA Characteristic Length (cm) & 0.44369 \\
\hline CPC Model & 3025 High Flow \\
\hline Gas Viscosity (kg/(m.s)) & $1.82 \mathrm{E}-05$ \\
\hline Mean Free Path (m) & $6.65 \mathrm{E}-08$ \\
\hline Channels/Decade & 64 \\
\hline Multiple Charge Correction & FALSE \\
\hline Sample Settings & \\
\hline Units & dw/dlogDp \\
\hline Weight & Number \\
\hline Min Midpoint Diameter (nm) & 15.1 \\
\hline Max Midpoint Diameter (nm) & 661 \\
\hline Scan Up Time (s) & 120 \\
\hline Retrace Time (s) & 15 \\
\hline Down Scan First & FALSE \\
\hline Scans Per Sample & 1 \\
\hline Impactor Type (cm) & 0.0457 \\
\hline Sheath Flow (lpm) & 3 \\
\hline Aerosol Flow (lpm) & 0.3 \\
\hline CPC Inlet Flow (lpm) & 1.5 \\
\hline CPC Sample Flow (lpm) & 0.03 \\
\hline
\end{tabular}

The SMPS system uses an electrical mobility detection technique. An electrostatic classifier (EC) charges particles to a known charge distribution and then classifies them according to their ability to pass through an electrical field, and a condensation particle counter (CPC) measures their concentration. Size distribution plots can be obtained by using a PC with custom software from TSI to perform the data reduction [43]. Particle size distributions were collected upstream and downstream of both the CPF and of the complete DOC-CPF unit during every filter load- 
ing experiment. No particle size distribution data were collected for the DOC-only experiments, as practically no change in particle size distribution was anticipated as a consequence of introducing the DOC in the exhaust stream.

Two secondary dilution systems, consisting of four vacuum transducer pumps (two series of two), were used to dilute the sample; two for the upstream sampling and two for the downstream sampling. Figure 4.1 shows a schematic representation of the dilution system setup. The inlet orifice diameters in the ejectors were designed such that approximate iso-kinetic sampling conditions from the exhaust pipe could be obtained and that dilution ratios in the range of 10-500 to 1 depending on the sampling port could be set. A thermodenuder was installed between the dilution system and the SMPS to remove hydrocarbons $(\mathrm{HC})$ and sulfates to minimize homogeneous nucleation of nanoparticles [32].

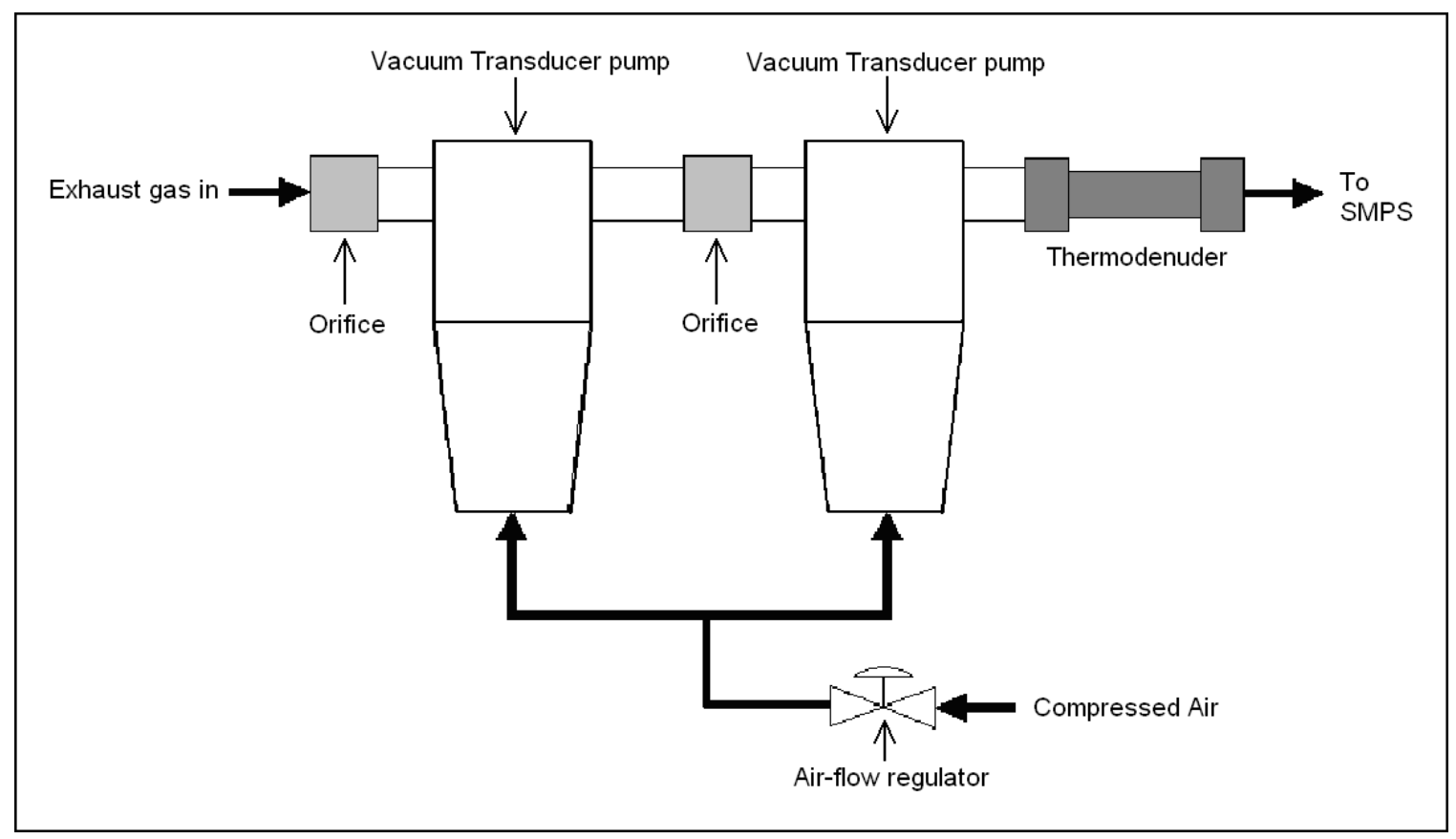

Figure 4.1: Schematic representation of the secondary dilution system 


\subsection{Experimental Test Matrix}

In order to gather the entire set of experimental data required for developing the DOC and 1D 2-layer CPF models, a test matrix was developed, a description of which is given in the following subsections.

Figure 4.2 gives a schematic depiction of the general experimental setup. The setup primarily consists of an engine coupled to a dynamometer with the appropriate after-treatment device connected to the exhaust-line, with all connections made to instruments measuring experimental variables.

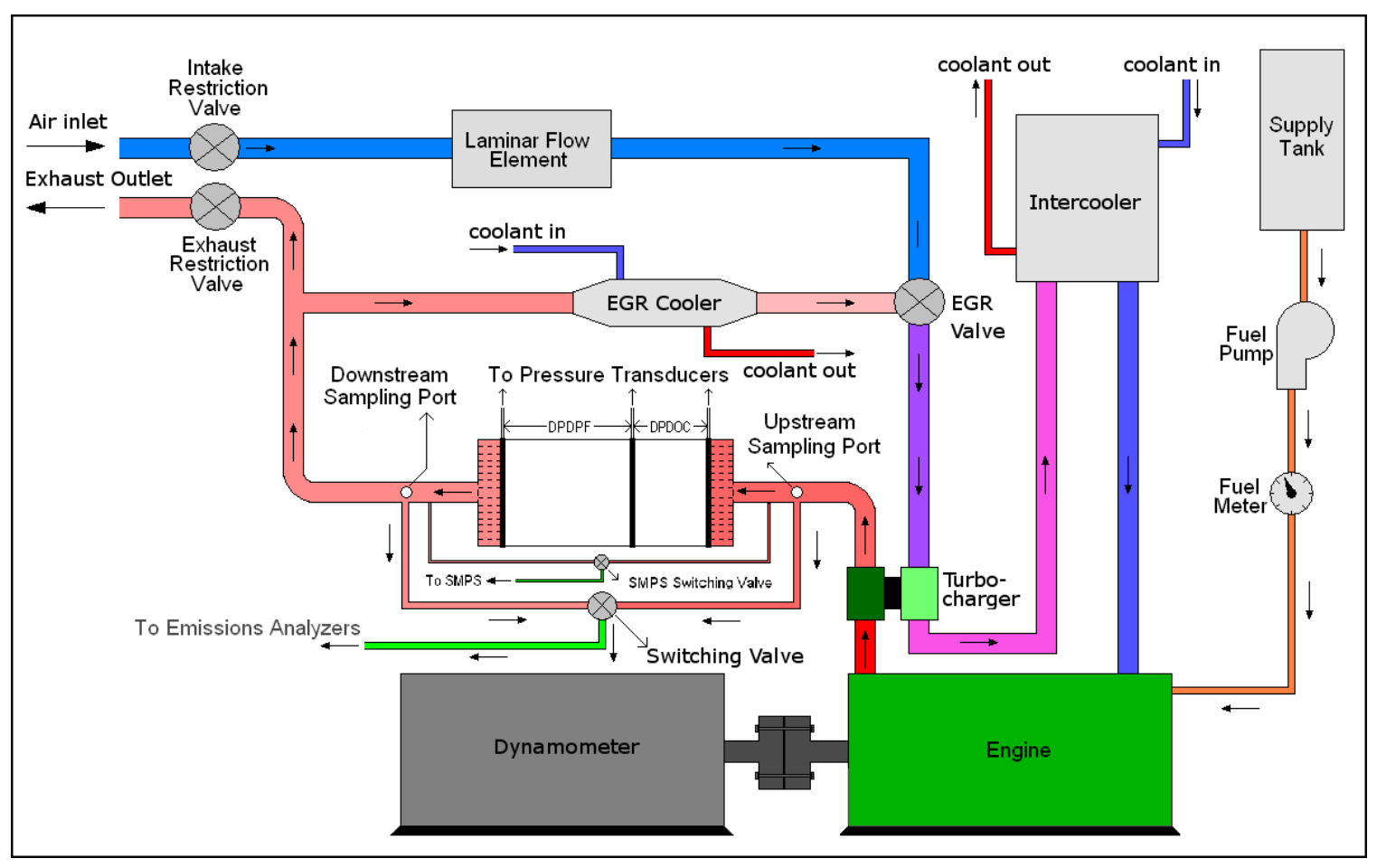

Figure 4.2: General setup of experiments

\subsubsection{DOC-only Experiments}

The DOC-only experiments were designed and conducted in order to determine the conversion efficiencies of gaseous species $\left(\mathrm{CO}, \mathrm{HC}, \mathrm{NO}\right.$ and $\left.\mathrm{NO}_{2}\right)$ due to the chemical reactions taking place in the DOC, and thereby to predict gaseous species concen- 
trations at the DOC outlet, pressure drop across the DOC and temperature at the

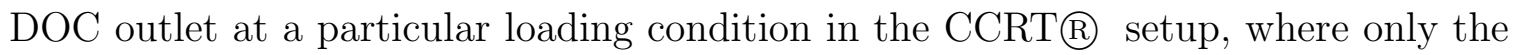
UP-DOC and DN-CPF values of species concentrations are measured. Figure F.1 in Appendix F gives a schematic layout of the DOC-only experiments conducted.

Table 4.7 outlines the DOC-only tests conducted. Two speeds were selected for the DOC-only tests - 2200 and $1650 \mathrm{rpm}$, in order to derive the DOC kinetic constants. In each test, the engine load was increased from a minimum (starting) load to a maximum (ending) load, in steps of approximately 1/20 of the maximum load. Each load-step had a step-time of about 12 minutes, and sample times in each load-step was about 2 minutes. Sampling lines were switched from 'Upstream' to 'Downstream' after taking upstream samples and sampling repeated, so as to record both UP-DOC and DN-DOC species concentrations of $\mathrm{HC}, \mathrm{CO}, \mathrm{CO} 2, \mathrm{O} 2, \mathrm{NO}$ and $\mathrm{NO}_{x}$

Table 4.7: DOC-only tests conducted

\begin{tabular}{|c|c|c|c|c|c|}
\hline No. & Speed & Starting Load & Ending Load & Step Time & Sample Time \\
\hline & $(\mathrm{RPM})$ & $(\mathrm{Nm})$ & $(\mathrm{Nm})$ & $(\mathrm{min})$ & $(\mathrm{min})$ \\
\hline 1 & 2200 & 41 & 811 & 12 & 2 \\
\hline 2 & 1650 & 50 & 955 & 12 & 2 \\
\hline
\end{tabular}

\subsubsection{CPF-only and CCRT® Experiments}

Figure 4.3 shows a schematic representation of the test matrix adopted for the CPFonly and CCRTR experiments conducted. CPF-only and CCRT tests were conducted at two speeds, 2200 and $1650 \mathrm{rpm}$ respectively, at four loads, ranging from 25 to $100 \%$ of rated torque at the respective engine speeds. In Appendix F, Figure F.2 shows a schematic of the setup for CPF-only tests conducted, and Figure F.4 shows a schematic of the CCRTß tests conducted.

Test duration for each case was either about 9 hours or when the CPF pres- 


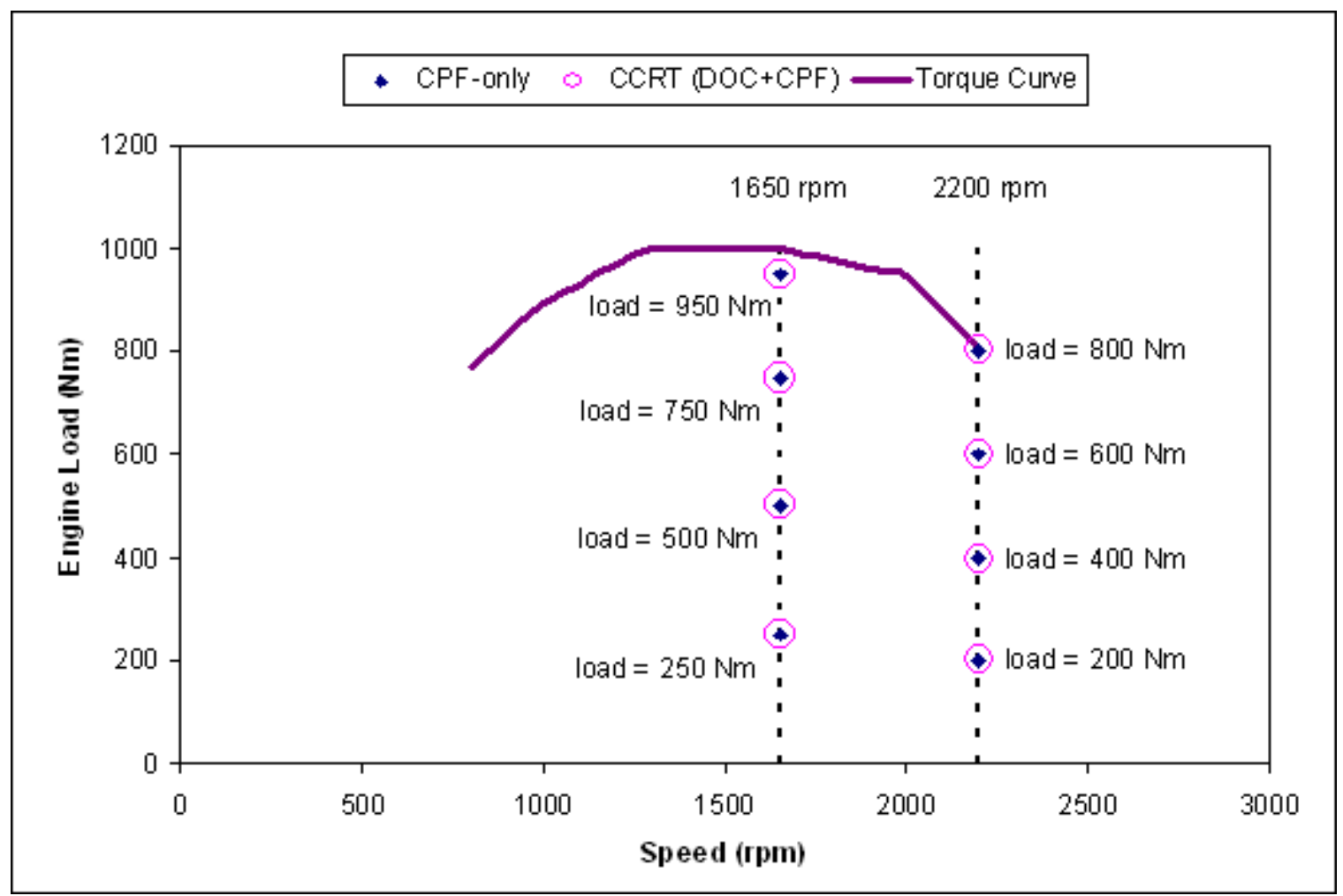

Figure 4.3: Schematic - Test matrix for CPF-only and CCRT experiments

sure drop remained constant for approximately an hour (indicating temporal balance between filtration and oxidation), whichever came first. The higher loading times required (compared to those indicated in references [12] or [7]) were mainly due to lower particulate inlet flow rates into the after-treatment device.

Accordingly, 16 experiments were conducted on CPF-only and CCRTß configurations. In addition, 3 repeat experiments were also conducted on the CPF-only setup, at the rated speed $(2200 \mathrm{rpm})$ and $25 \%$ load, to study CPF pressure drop repeatability.

Four baseline tests were also conducted to measure engine-out PM flow rates at rated speed and reduced speed. These tests were conducted at the same speeds and same load conditions as the CPF-only and CCRTß tests, without the CPF in the exhaust line. Gaseous species and PM concentrations at the engine outlet were measured during the baseline tests. Figure F.3 shows a schematic of the baseline 
test conducted for the CPF-only configuration,and Figure F.5 shows a schematic of the baseline test conducted for the CCRTß configuration. The baseline test for the CCRT@ configuration had both the DOC and the CPF in the exhaust line, so as to accurately simulate and measure species concentrations upstream of the CPF in the CCRTß setup.

Two CPF's of the same specifications were used in for all CPF-only and CCRTR tests. Each filter was blown on the 'clean' side with filtered air (for cleaning purposes), weighed before initiation of test, and filter weight was recorded on a log-sheet. After each test, the particulate filter was removed carefully from the setup, and weighed on a precision balance capable of measuring within $\pm 0.1 \mathrm{~g}$. The difference between post-test and pre-test weights gave the amount of PM deposited in the filter during the test. Afterwards, the filter was baked at $620-640^{\circ} \mathrm{C}$ for approximately 4 hours in a high-temperature oven in order to oxidize the deposited PM completely. After allowing the clean filter to cool down to approximately $250^{\circ} \mathrm{C}$, weighing was carried out again, and this (post-bake) weight was considered as the clean filter weight for the next test conducted on the same filter. This was primarily due to the observation that the porous filter gained moisture as it cooled down to room temperature before the next test, and the clean weight then would include the weight of this absorbed moisture, which would induce errors in the PM deposited calculations. Appendix $G$ has an analysis of the filter weight gain observed during the tests conducted. 


\section{Chapter 5}

\section{Results and Discussions}

This chapter presents the results obtained from the experiments conducted on the John Deere engine under study at 2200 and $1650 \mathrm{rpm}$, and results from model calibration of the MTU 1-D DOC and MTU 1-D 2-layer CPF models to the experimental data. Model results obtained from the calibrated MTU 1-D 2-layer CPF model to experimental data at $2200 \mathrm{rpm}$ are also presented. Other plots obtained from CPF model calibration at $2200 \mathrm{rpm}$ are included in Appendix D. A comparison of model calibration parameters and model results obtained in this thesis as contrasted with those from previous research using the same CPF model [14] and an earlier CCRT® are also presented.

\subsection{Experimental Results}

Experiments were conducted on the engine with three different configurations: DOConly, CPF-only and CCRT $\AA$ using the test matrix as described in sections 4.3 .1 and 4.3.2. This section provides an overview of the experimental parameters obtained from these tests, some of which were used as model input parameters. 


\subsubsection{Results from DOC-only Experiments}

To obtain an overview of the engine performance, basic engine parameters are presented in Figures 5.1 and 5.2 showing the engine parameters such as DOC inlet temperatures, \% EGR, air-fuel ratio and rail pressure obtained from measurements during the DOC-only tests conducted at 2200 and $1650 \mathrm{rpm}$ respectively. For the $2200 \mathrm{rpm}$ test, the engine load at the start of the experiment was $5 \%$ of maximum load $(811 \mathrm{Nm})$ at rated speed, and engine load was increased in steps of about $41 \mathrm{Nm}$, to $100 \%$ load at rated speed. DOC inlet temperatures were observed to be varying from $155^{\circ} \mathrm{C}$ at $5 \%$ load to $413^{\circ} \mathrm{C}$ at $100 \%$ load for the $2200 \mathrm{rpm}$ test (Figure 5.1). Start load in the $1650 \mathrm{rpm}$ experiment was $5 \%$ of maximum load in steps of $50 \mathrm{Nm}$ to an end load of 100\% (1000 Nm). DOC inlet temperatures observed varied from $145^{\circ} \mathrm{C}$ at $5 \%$ load to $500^{\circ} \mathrm{C}$ at $100 \%$ load for the $1650 \mathrm{rpm}$ test (Figure 5.2).

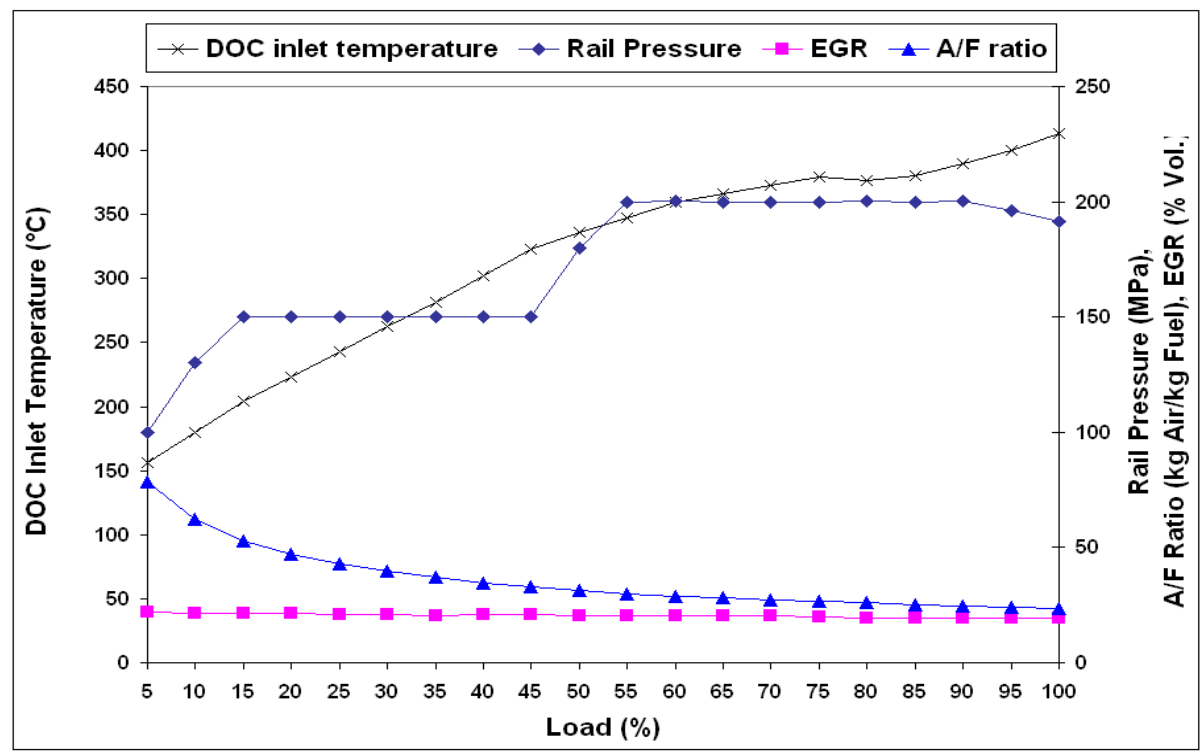

Figure 5.1: 2200 rpm DOC-only - Experimental engine parameters observed

Pressure drops across the DOC were measured during the DOC-only experiments at $2200 \mathrm{rpm}$ and $1650 \mathrm{rpm}$, as shown in Figure 5.3. DOC pressure drops in both these cases were observed to be linearly proportional to the actual exhaust volumetric flow rate through the DOC. 


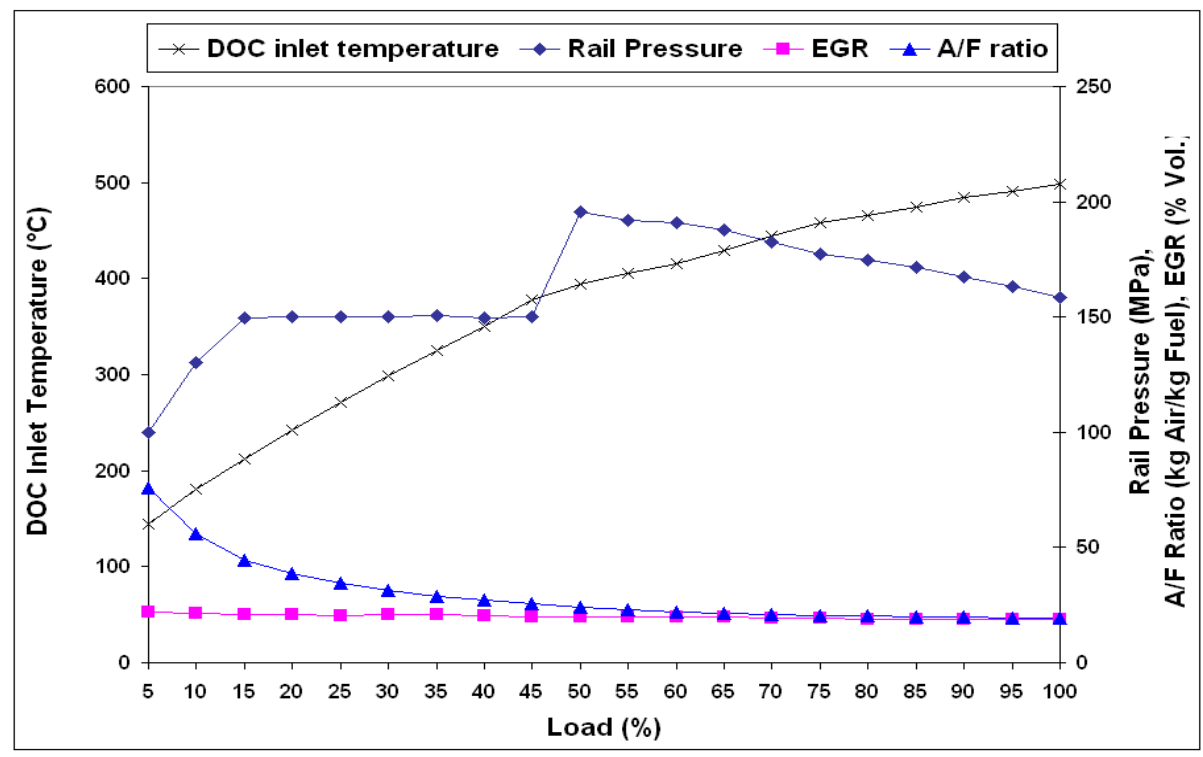

Figure 5.2: 1650 rpm DOC-only - Experimental engine parameters observed

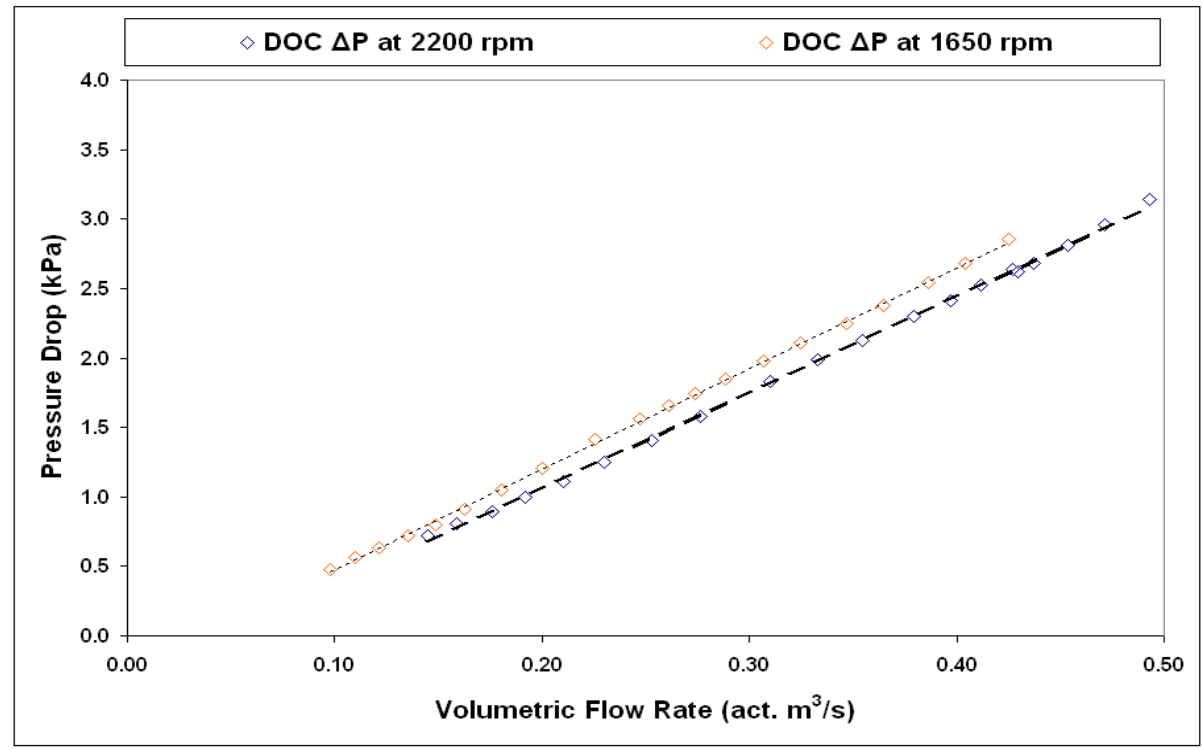

Figure 5.3: $2200 \mathrm{rpm}$ and $1650 \mathrm{rpm}$ DOC-only - Experimental DOC pressure drops versus actual exhaust volumetric flow rates

DOC inlet and outlet temperatures were measured during the DOC-only experiments, and the results from these measurements for the experiments conducted at 2200 and $1650 \mathrm{rpm}$ are shown in Figures 5.4 and 5.5 respectively.

DOC outlet temperatures observed were higher than the corresponding DOC inlet temperatures in most cases at both 2200 and $1650 \mathrm{rpm}$. This was due to the 


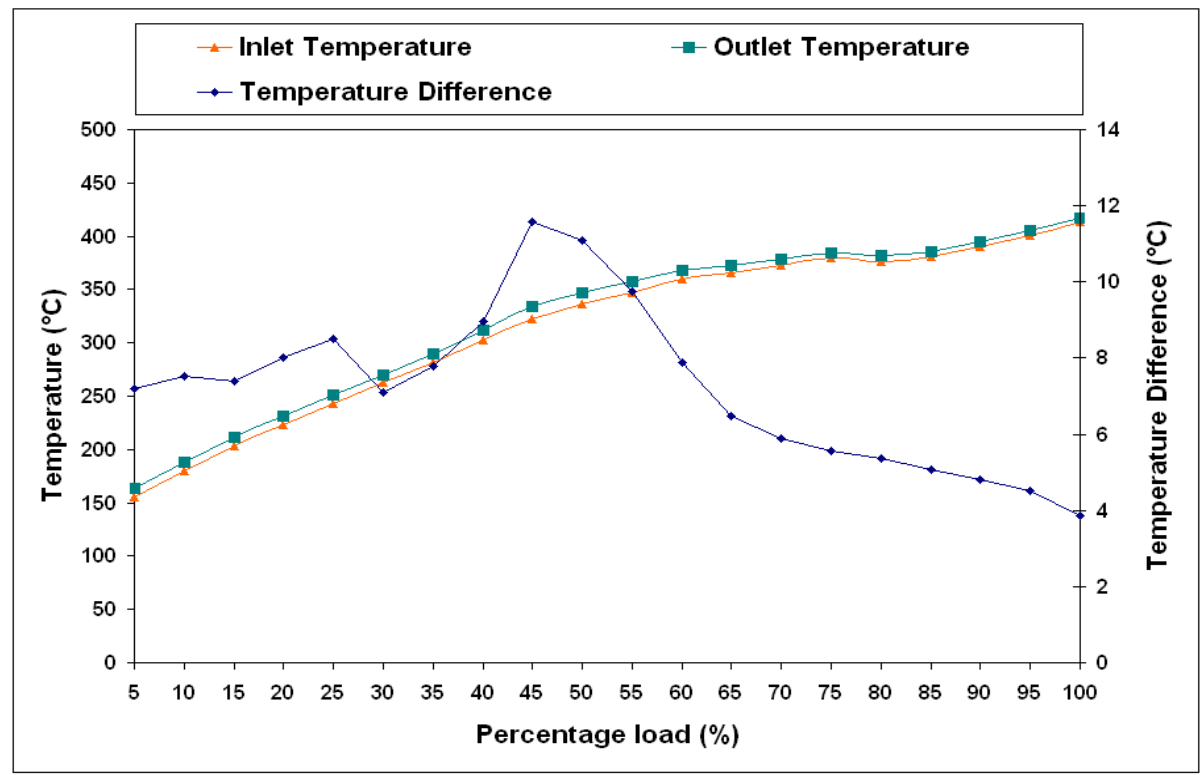

Figure 5.4: 2200 rpm DOC-only - Experimental DOC inlet and outlet temperatures and temperature differences (outlet - inlet) versus percentage load

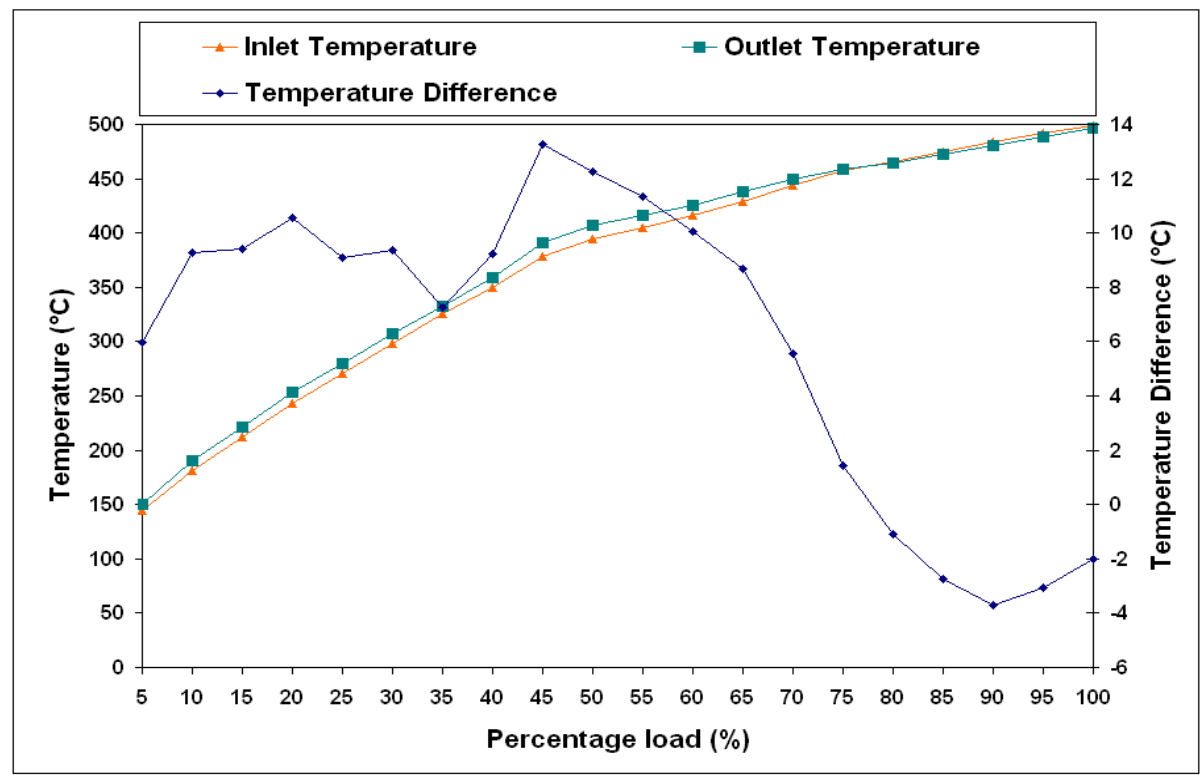

Figure 5.5: 1650 rpm DOC-only - Experimental DOC inlet and outlet temperatures and temperature differences (outlet - inlet) versus percentage load

rate of energy produced by exothermic oxidation reactions taking place inside the DOC being higher than the heat transfer losses from the DOC to the ambient. It was also observed that at a given speed, the temperature difference between DOC inlet and outlet increased with increasing load (as can be seen from the 'temperature 
difference' curves in Figures 5.4 and 5.5), and after a certain point (45\% load at 2200 and $1650 \mathrm{rpm}$ ), the temperature difference decreased. For instance, in the 80, 85, 90, 95 and $100 \%$ load at $1650 \mathrm{rpm}$, the outlet DOC temperatures were lower than inlet DOC temperatures, indicating that in these cases, the temperature increase due to oxidation reactions was less than the temperature decrease due to heat transfer to the ambient.

The other data needed to determine the performance of the DOC is the inlet and outlet concentrations of hydrocarbons (HC), carbon monoxide (CO), nitric oxide (NO) and nitrogen dioxide $\left(\mathrm{NO}_{2}\right)$ as functions of load at a given speed. These data are used to calibrate the DOC model kinetic parameters so as to match model-predicted values of outlet species concentrations to those observed from the experiments. Figure 5.6 shows the conversion efficiencies of hydrocarbons $(\mathrm{HC})$, carbon monoxide $(\mathrm{CO})$, nitric oxide (NO) and nitrogen dioxide $\left(\mathrm{NO}_{2}\right)$ observed across the DOC at all engine loads in the DOC-only test at $2200 \mathrm{rpm}$. CO conversion efficiencies were greater than $90 \%$ from 5 to $75 \%$ load, and decreased afterwards to about $75 \%$, from 80 to $100 \%$ load at $2200 \mathrm{rpm}$. HC conversion efficiencies were observed to be in the range of 85 to $70 \%$ at all loads at $2200 \mathrm{rpm}$. NO conversion efficiencies increased with increasing load to about $73 \%$ at $35 \%$ load, and decreased afterwards with increasing load to about $35 \%$ at $100 \%$ load at $2200 \mathrm{rpm}$.

It was observed that conversion efficiencies of $\mathrm{NO}$ and $\mathrm{NO}_{2}$ at the first data points (5\% load) at both speeds were not following the trend that was observed in the other load conditions because at this load, unlike the others, the inlet exhaust conditions $\left(150{ }^{\circ} \mathrm{C}\right.$ DOC inlet temperature) favored $\mathrm{NO}_{2}$ dissociation. Therefore, only in these load conditions (i.e., $5 \%$ load at $2200 \mathrm{rpm}$ and $1650 \mathrm{rpm}$ ), $\mathrm{NO}_{2}$ concentration at the DOC outlet was observed to be less than that at the DOC inlet, and correspondingly, an increased NO concentration was observed at the DOC outlet compared to the DOC inlet. Figure 5.7 shows the percentage conversion of $\mathrm{HC}, \mathrm{CO}, \mathrm{NO}$ and $\mathrm{NO}_{2}$ 


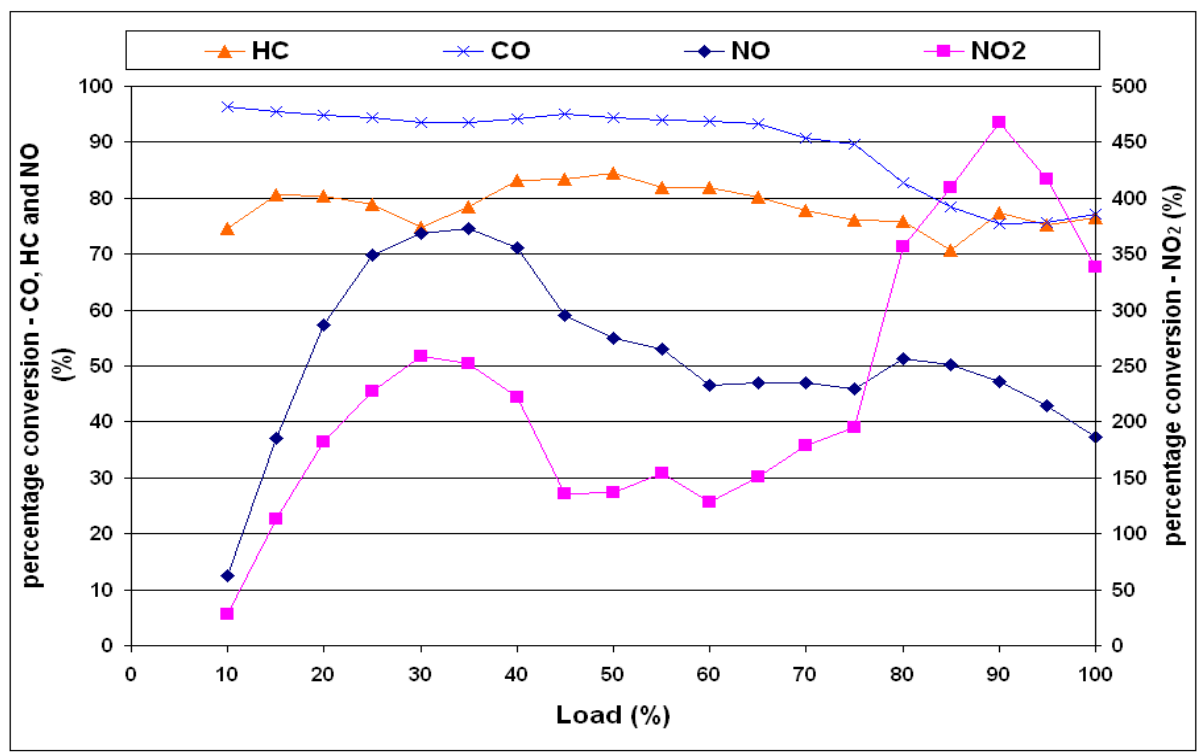

Figure 5.6: 2200 rpm DOC-only - Experimental species conversion percentages obtained versus percentage load

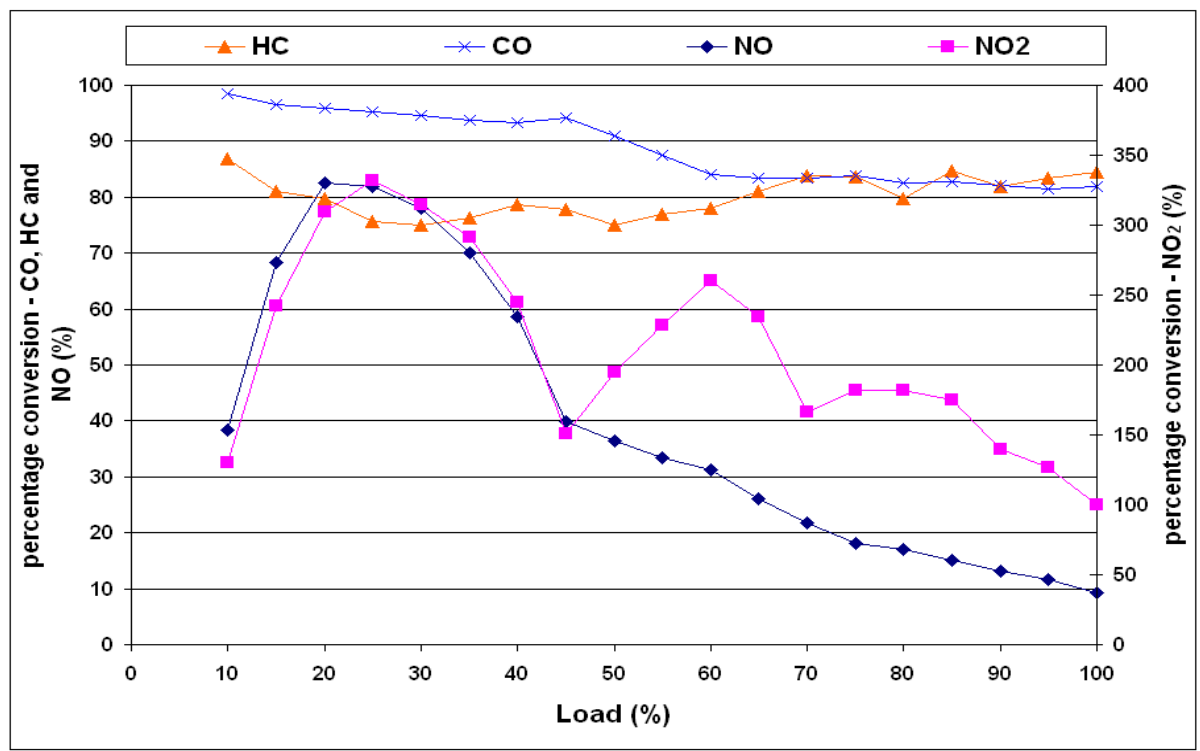

Figure 5.7: 1650 rpm DOC-only - Experimental species conversion percentages obtained versus percentage load

observed during the $1650 \mathrm{rpm}$ DOC-only experiment. Conversion efficiencies of CO at all loads at $1650 \mathrm{rpm}$ were in the range of 97 to $82 \%$, and in general, showed a decreasing trend with increasing load. HC conversion efficiencies at all loads at 1650 rpm were in the $75-85 \%$ range. NO conversion efficiencies showed similar trends to 
those at $2200 \mathrm{rpm}$, increasing with increasing load to about $83 \%$ at $20 \%$ load, and decreasing afterward to $10 \%$ at $100 \%$ load at $1650 \mathrm{rpm}$.

Tables 5.1 and 5.2 and Tables 5.3 and 5.4 show the inlet and outlet concentrations of the 8 gaseous species measured during the DOC-only experiments at 2200 and $1650 \mathrm{rpm}$ respectively. 


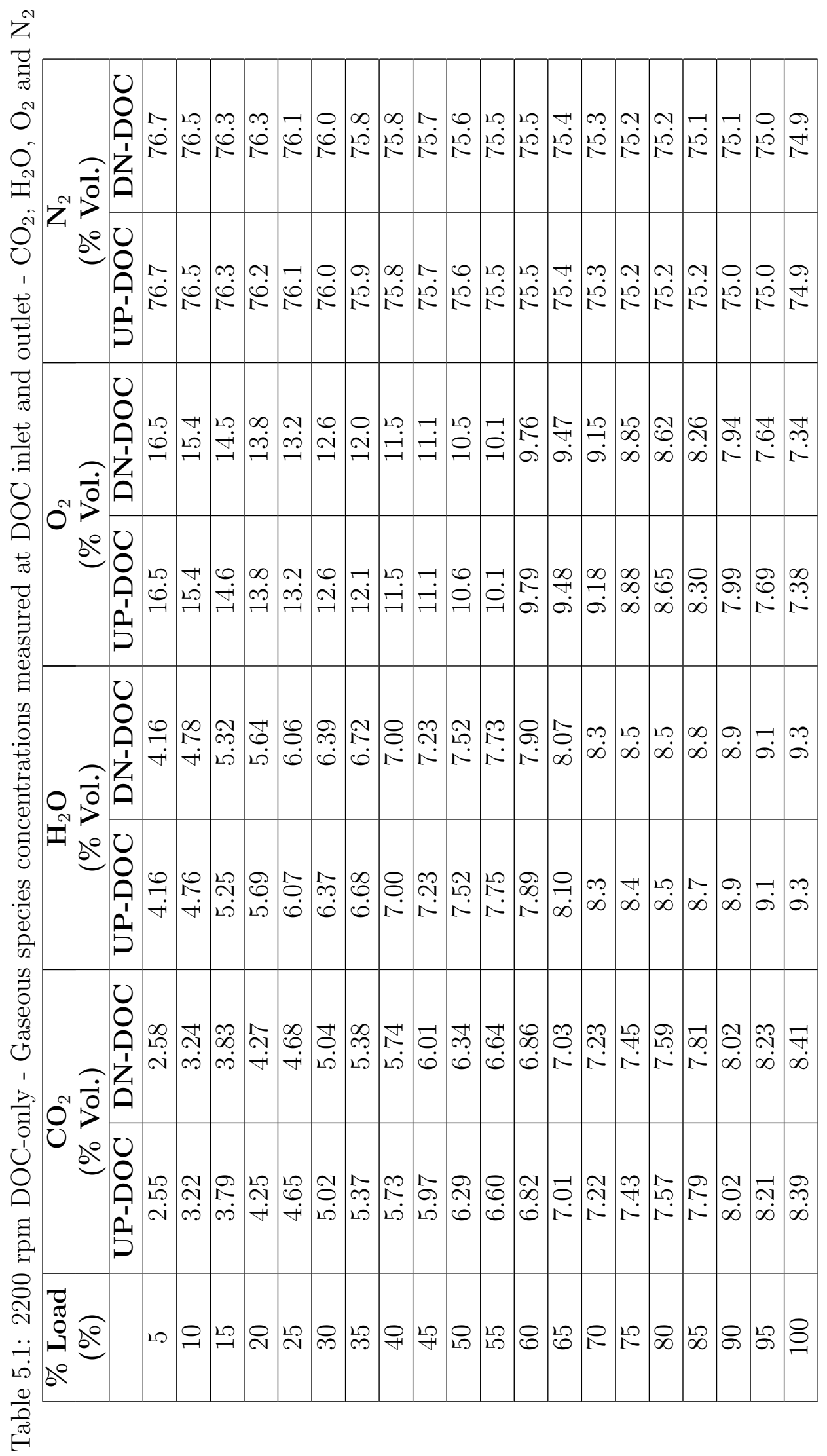




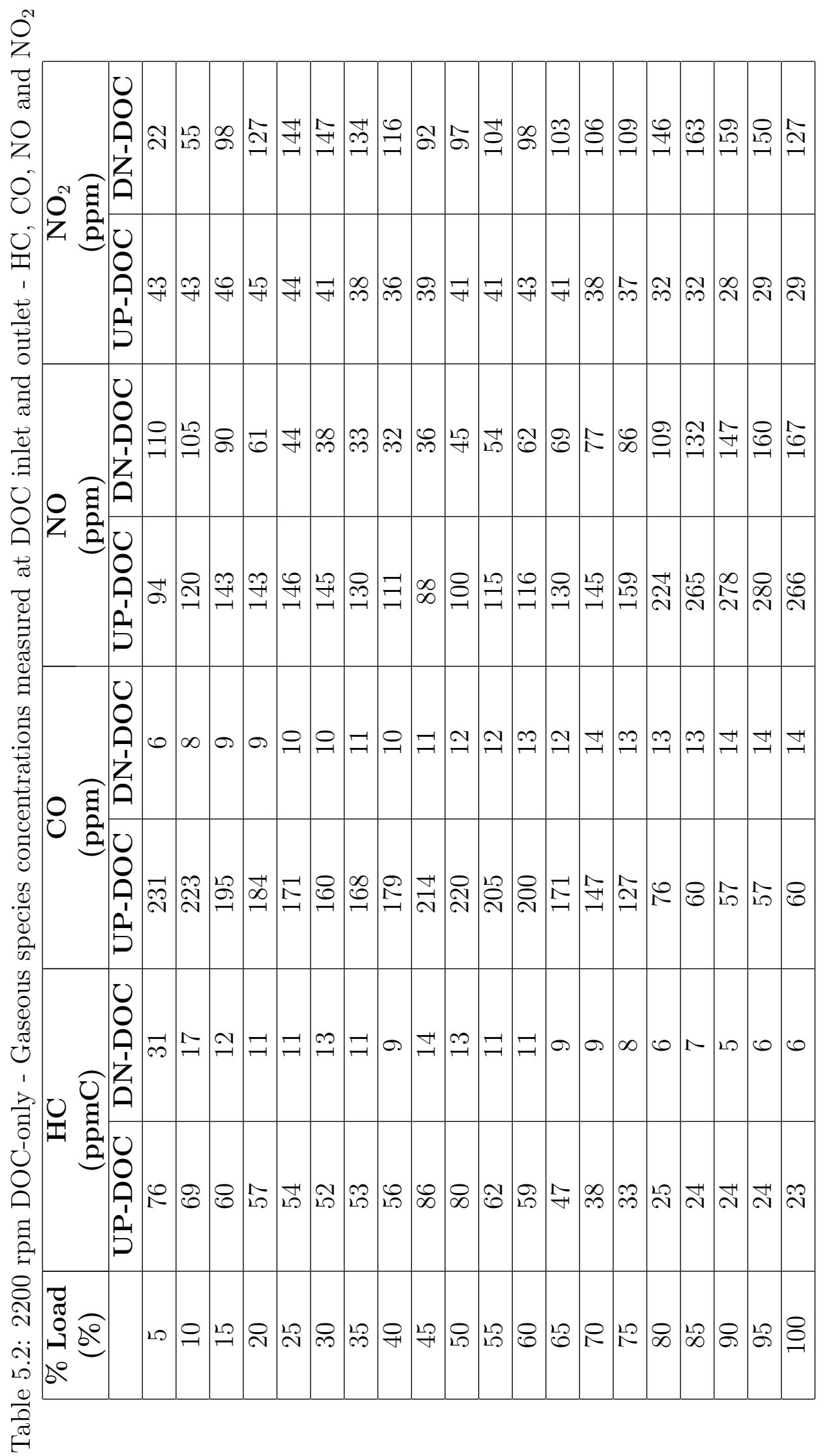




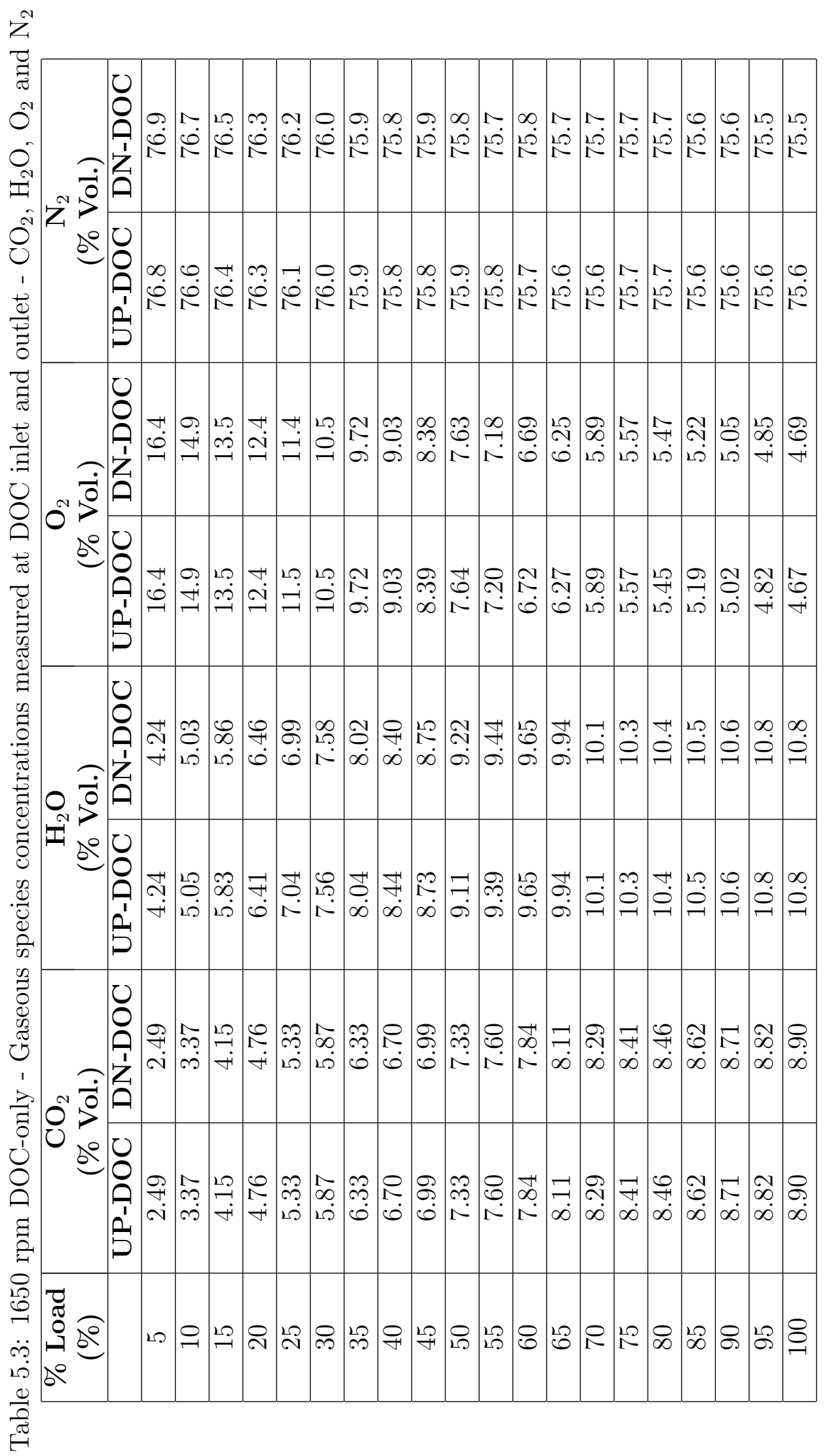




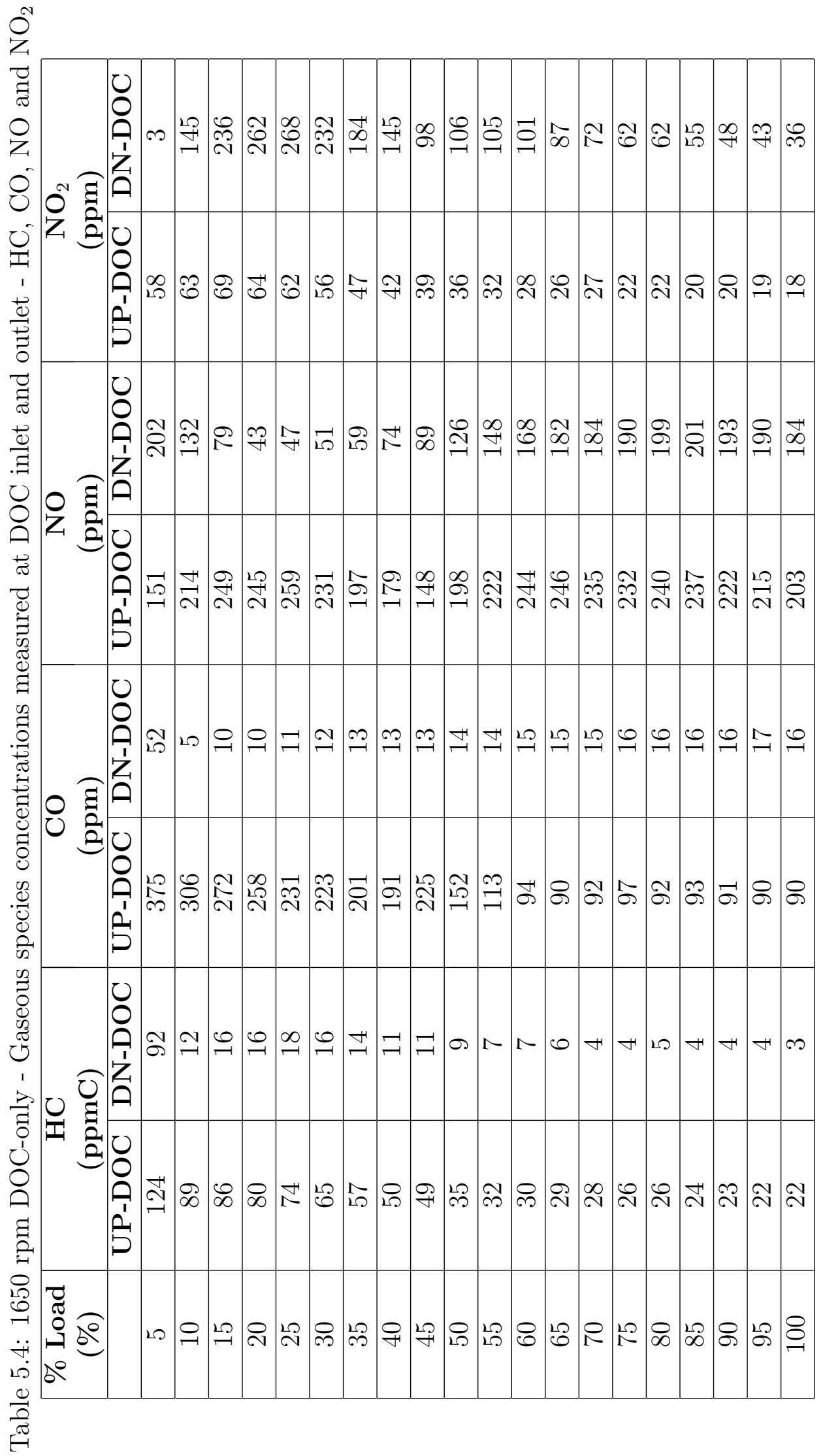




\subsubsection{Results from CPF-only and CCRT® Experiments}

Table 5.5 summarizes the average engine parameters measured during the CPF-only and CCRTR experiments. Average A/F ratios for similar loading conditions were different (up to $\pm 1.4 \%$ in the $100 \%$ load case) owing to day-to-day differences in the experiments. Average BSFC observed at $2200 \mathrm{rpm}$ was $45 \%$ of maximum BSFC at $25 \%$ load in the CCRT@ configuration, and the minimum BSFC observed was $37 \%$ of maximum BSFC at $100 \%$ load in CPF-only configuration. BSFC in the $1650 \mathrm{rpm}$ data set was $51 \%$ of maximum in the $25 \%$ load CCRTß configuration, and the minimum was $47 \%$ of maximum in the $100 \%$ CCRTR configuration. It was also observed that $\mathrm{CPF}$ inlet temperatures in the CCRTß configuration were approximately 15$25{ }^{\circ} \mathrm{C}$ higher than corresponding values in the CPF-only configuration, due to the temperature increase from the exothermic oxidation reactions of $\mathrm{HC}$ and $\mathrm{CO}$ taking place inside the DOC.

In all CPF-only and CCRTß experiments, pressure drop across the CPF were recorded against loading time of the experiment. Figures 5.8 and 5.9 summarize all CPF pressure drop profiles obtained for experiments conducted at 2200 and $1650 \mathrm{rpm}$ in CPF-only and CCRTß configurations. It may be noted that the loading times for all experiments were not equal. Loading times in each case were considered to be the total time between the time at which the engine speed and dynamometer torque became steady after turning the engine on and the time at which the engine was turned off. Maximum value of CPF pressure drop observed at $2200 \mathrm{rpm}$ was 11.26 $\mathrm{kPa}$ in the $100 \%$ load case in CPF-only configuration and $12.20 \mathrm{kPa}$ in the $100 \%$ load case in CCRTR configuration, and corresponding values for $1650 \mathrm{rpm}$ were 16.59 $\mathrm{kPa}$ in the $100 \%$ load case in CPF-only configuration and $18.84 \mathrm{kPa}$ in the $100 \%$ load case in CCRT $\cap$ configuration. 


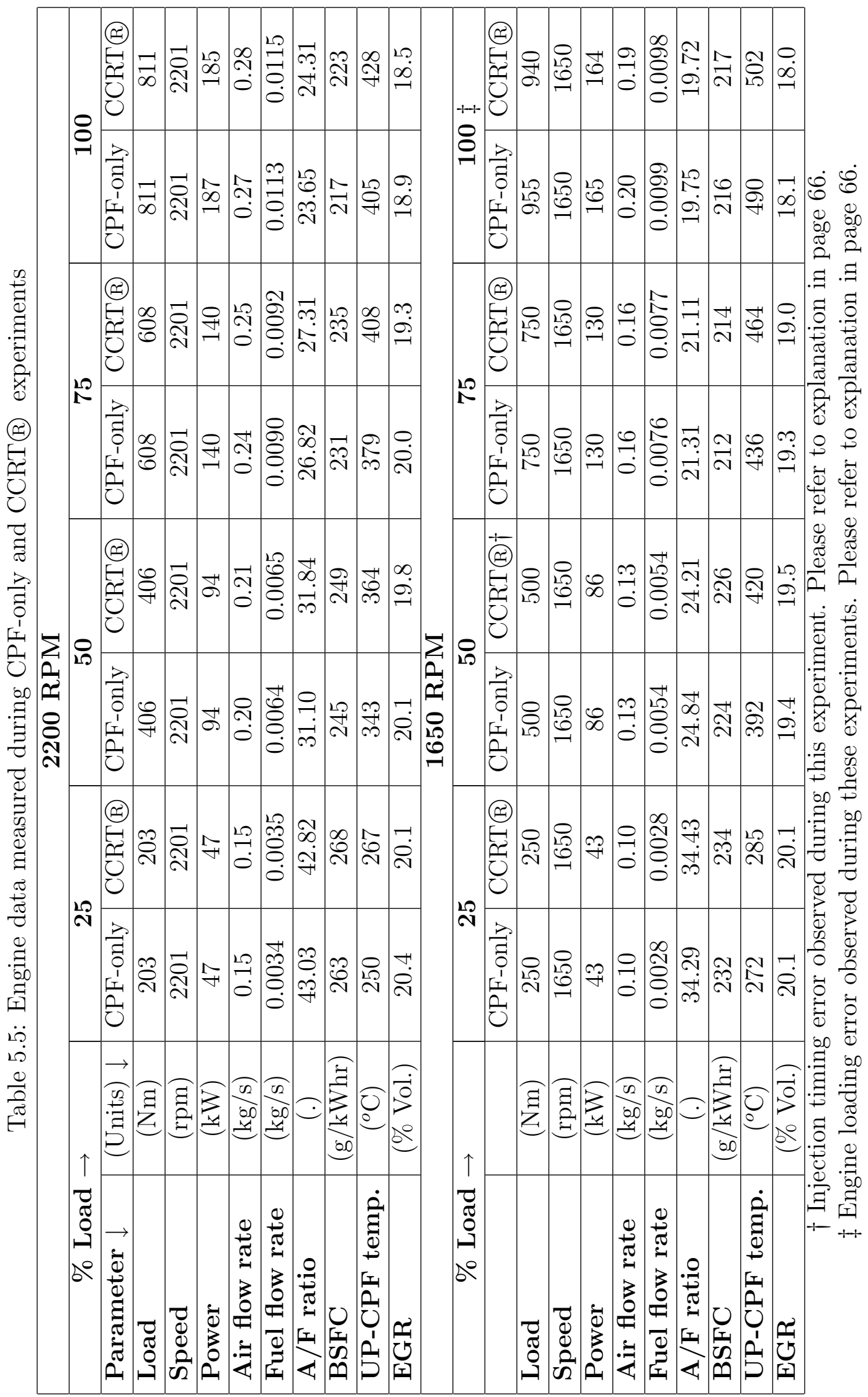




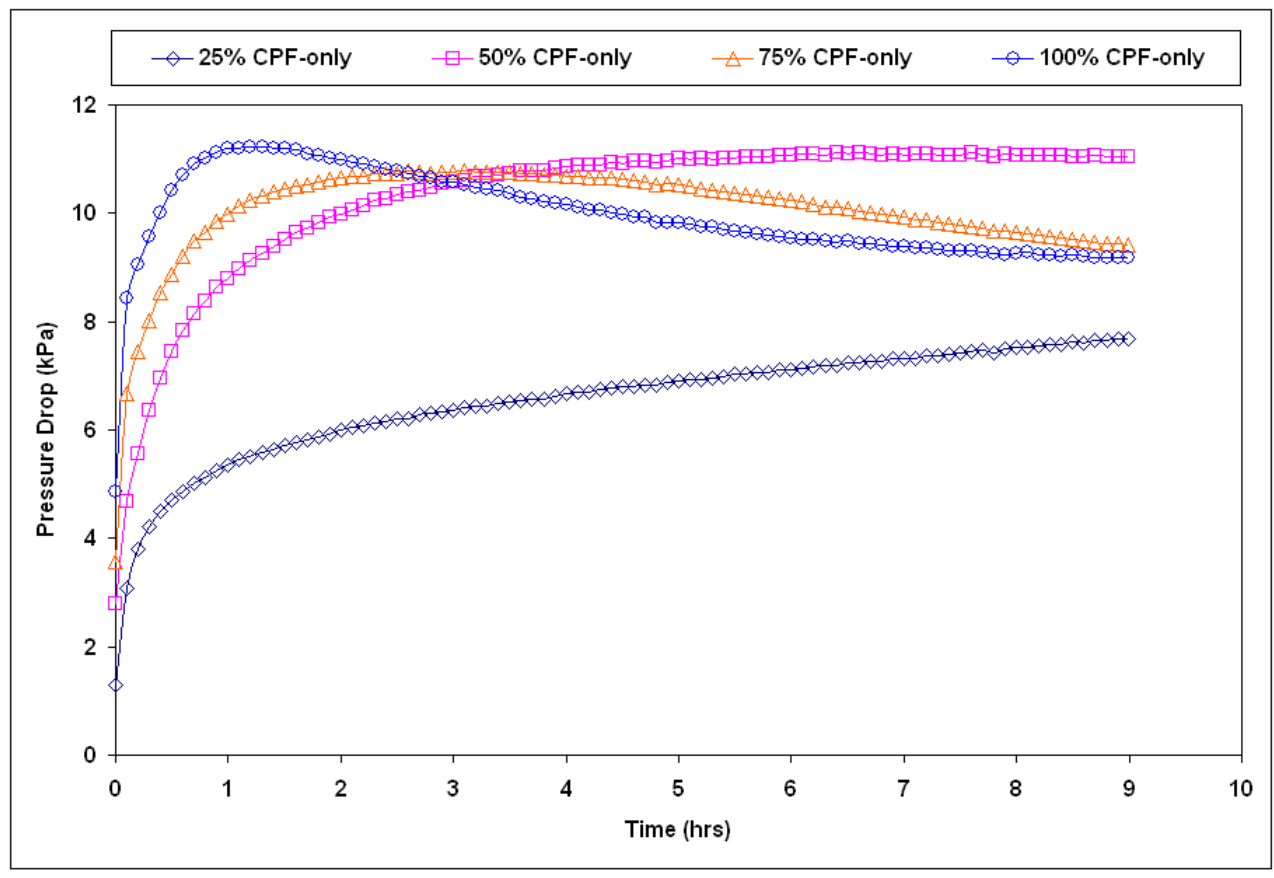

(a) 2200 rpm CPF-only

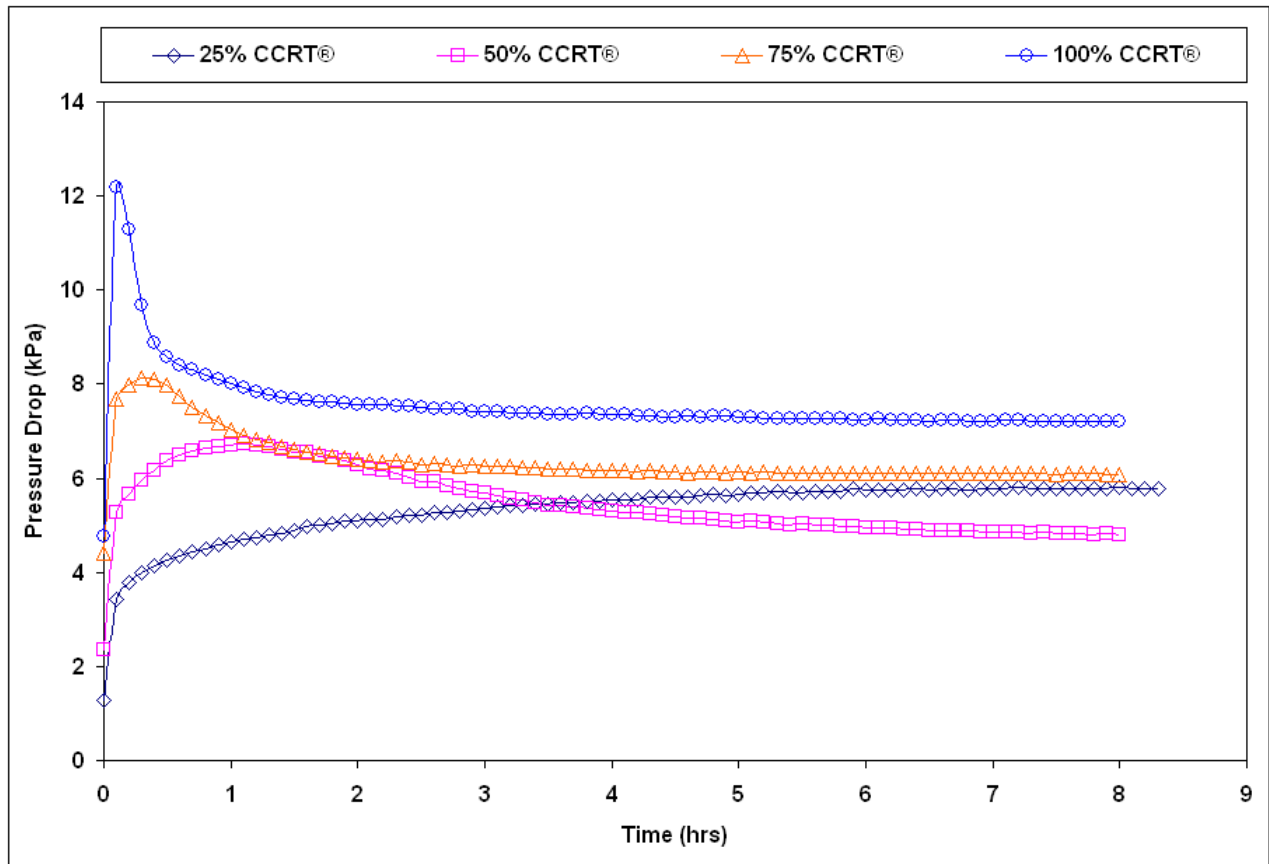

(b) $2200 \mathrm{rpm}$ CCRT $\AA$

Figure 5.8: An overview of experimental CPF pressure drop profiles obtained at 2200 rpm in CPF-only and CCRTR configurations 


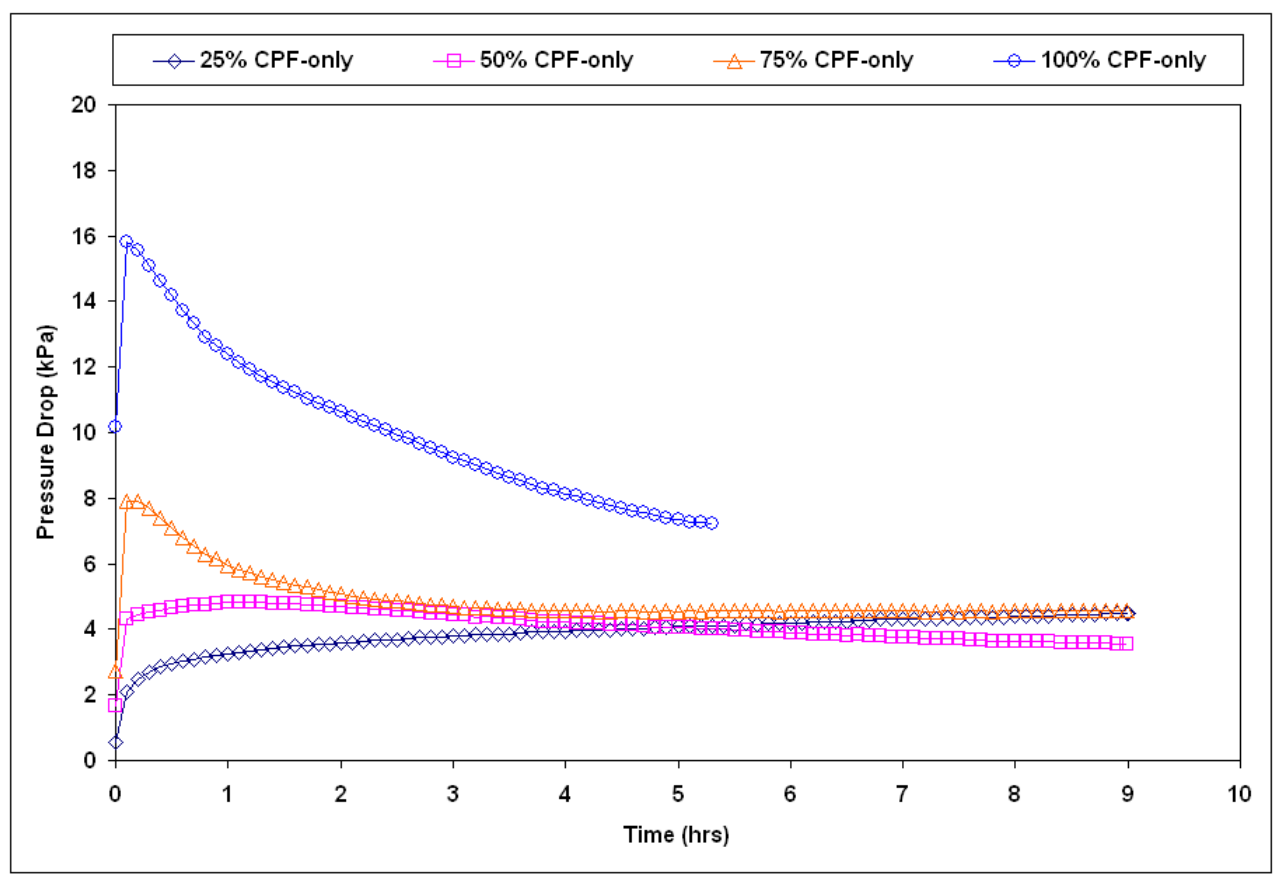

(a) 1650 rpm CPF-only

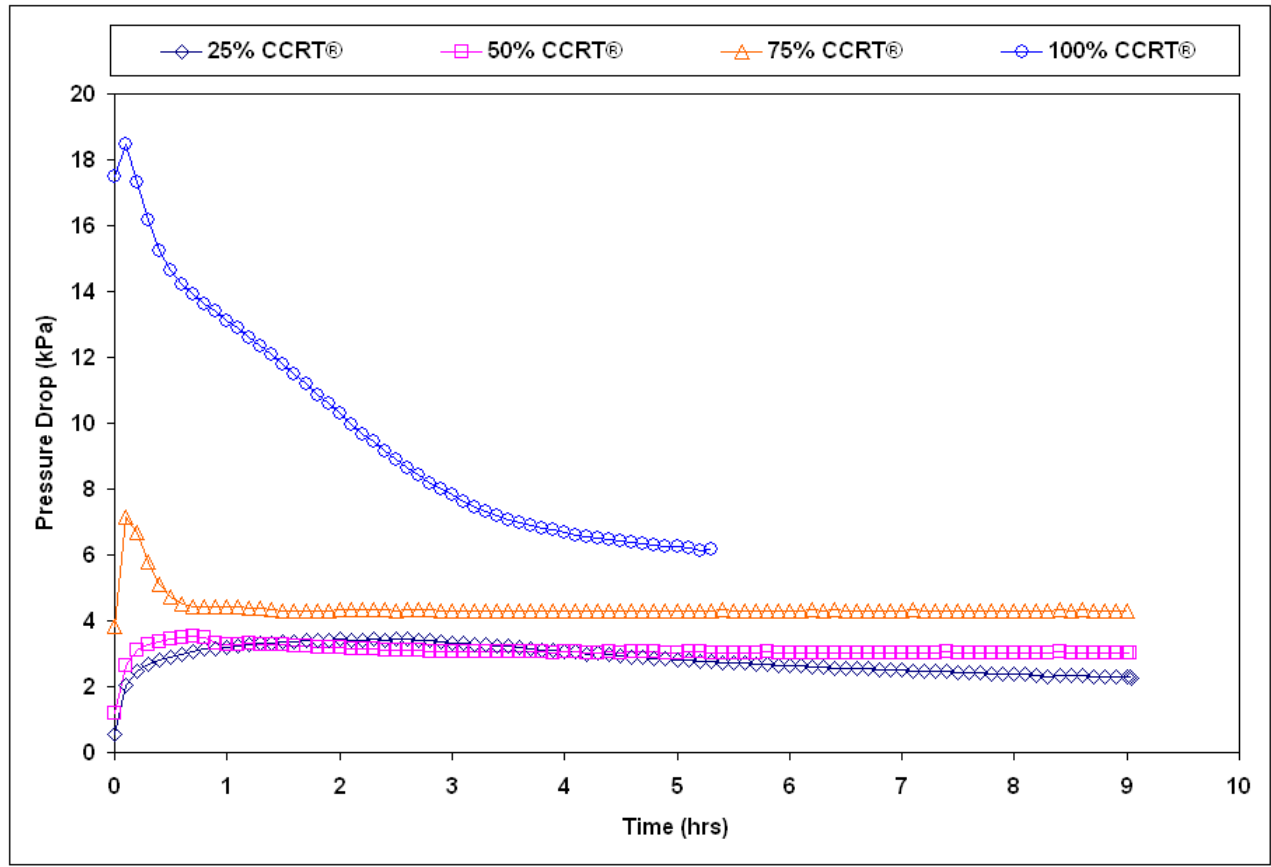

(b) $1650 \mathrm{rpm}$ CCRT $\AA$

Figure 5.9: An overview of experimental CPF pressure drop profiles obtained at 1650 rpm in CPF-only and CCRTR configurations 
Standard inlet PM concentrations (Figure 5.10) and standard exhaust volumetric flow rates (Figure 5.11) were calculated from engine baseline tests conducted

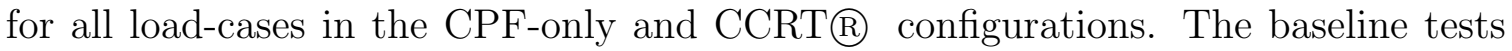
were conducted without the CPF in the exhaust-line, and PM concentrations were calculated from pre-test and post-test weights of PM sampling system (50 mm Pallflex) filters.

From these measurements, total inlet PM mass in each load-case was calculated as:

$$
m_{P M}=C_{\text {in }} \dot{V}_{\text {std }} t_{\text {loading }} \cdot \frac{3600}{1000}
$$

where $m_{P M}$ is the total inlet PM mass entering the CPF during the entire duration of the test (expressed in grams), $C_{i n}$ is the standard PM inlet concentration (expressed in $\left.\mathrm{mg} / \mathrm{std} . \mathrm{m}^{3}\right), \dot{V}_{\text {std }}$ is the standard exhaust volumetric flow rate (expressed in $s t d . \mathrm{m}^{3} / \mathrm{s}$ ), and $t_{\text {loading }}$ is the loading time (expressed in $h r s$ ). The calculated values of total inlet PM mass for all load-cases in the CPF-only and CCRT® tests at $2200 \mathrm{rpm}$ and 1650 rpm are shown in Figure 5.12.

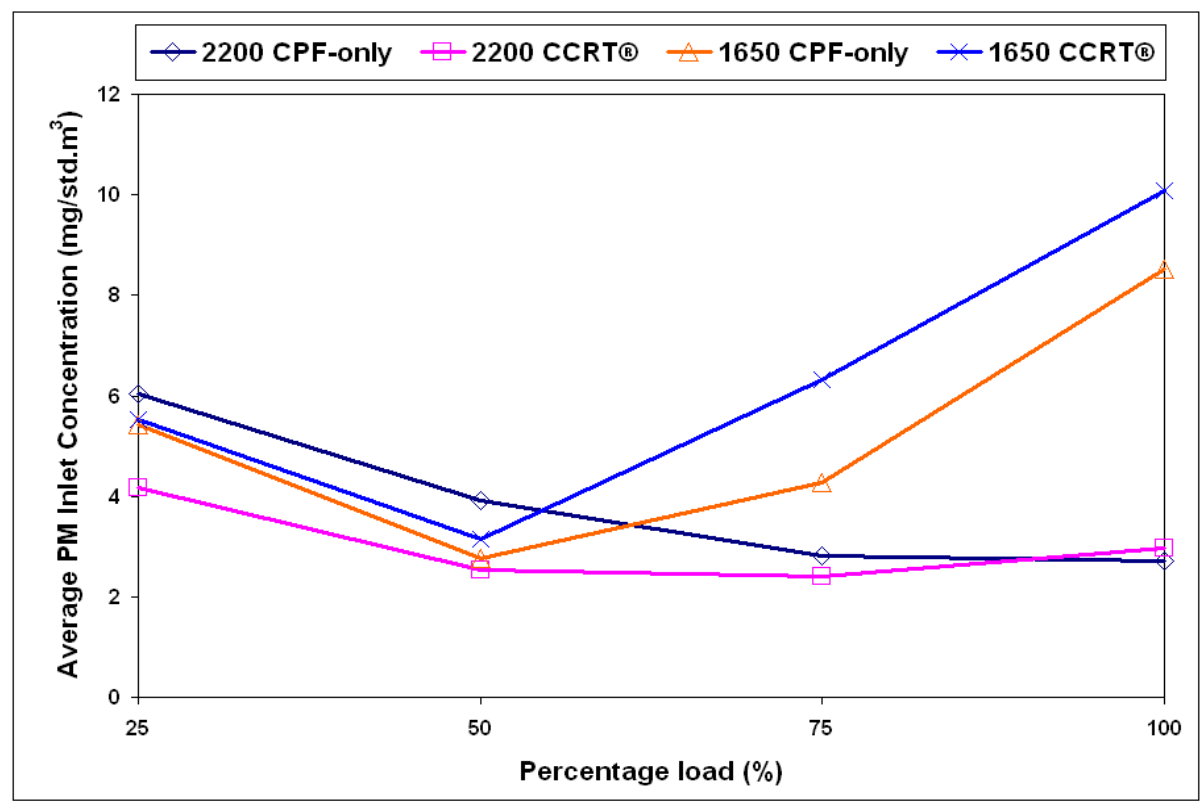

Figure 5.10: $2200 \mathrm{rpm}$ and $1650 \mathrm{rpm}$ - Experimental average standard PM inlet concentrations 


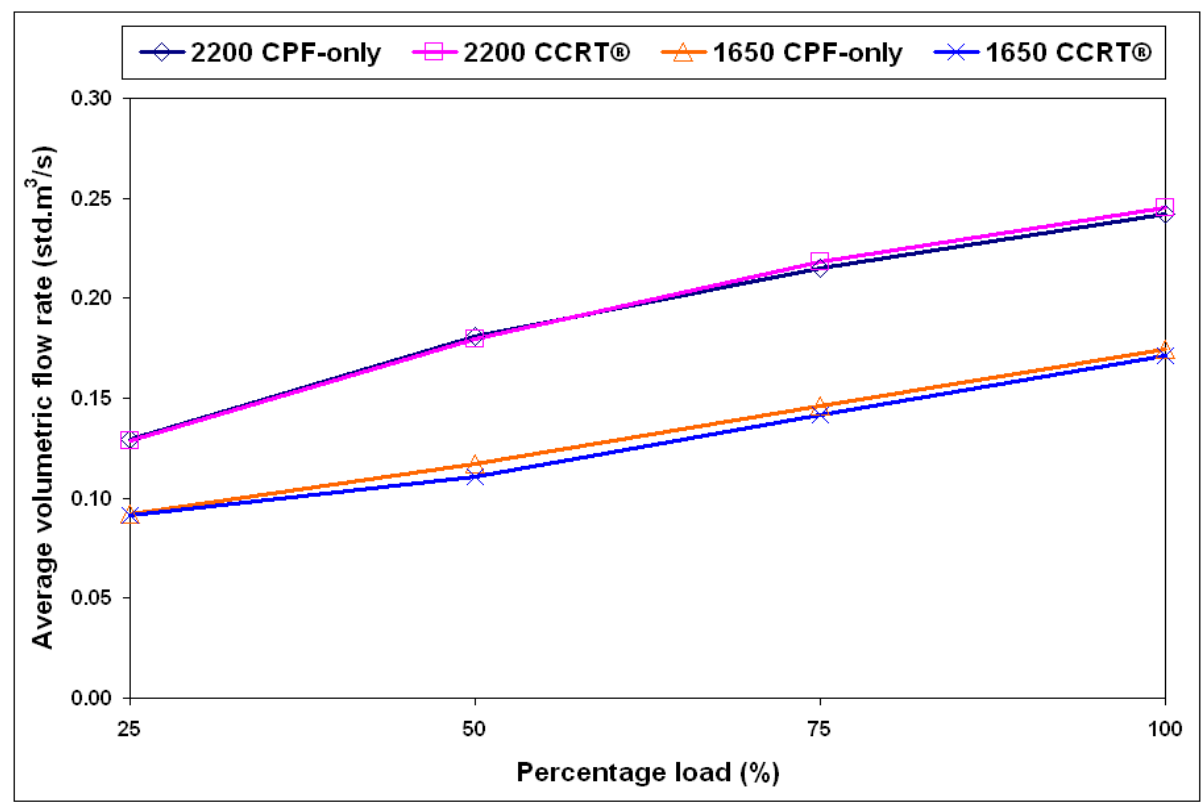

Figure 5.11: $2200 \mathrm{rpm}$ and $1650 \mathrm{rpm}$ - Experimental average standard exhaust volumetric flow rates

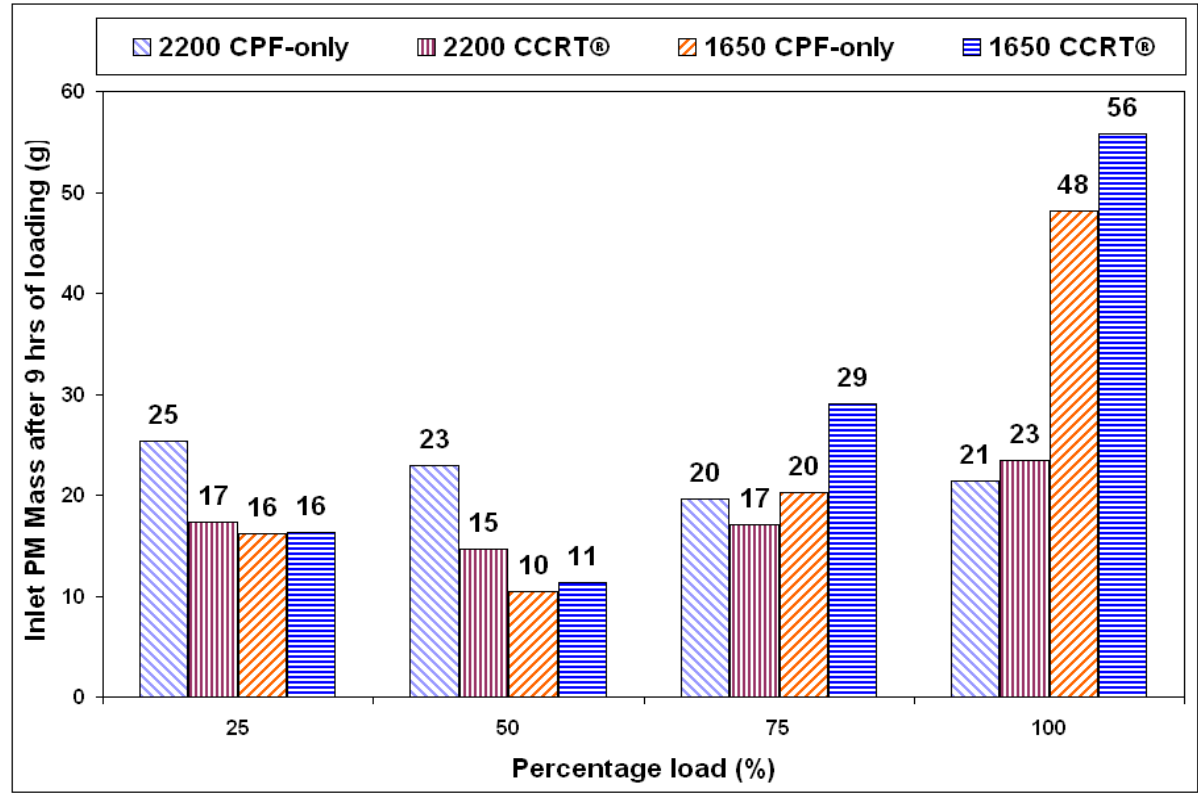

Figure 5.12: $2200 \mathrm{rpm}$ and $1650 \mathrm{rpm}$ - A comparison of total PM mass entering the $\mathrm{CPF}$

The weights of the CPF's that were used in all load-cases in the CPF-only and CCRTß experiments were measured before and after the tests. The difference between the corresponding 'clean' and 'loaded' weights of a particular test was taken 
to be the experimentally determined 'PM mass deposited' in the CPF during the test. In the 25\% CPF-only, 25\% CCRT@ and 50\% CPF-only cases, the PM mass deposited values were corrected (in order to account for absorbed moisture), from estimates of absorbed moisture on the filter substrate obtained from an analysis done on CPF weight gain, given in Appendix G. The mass oxidized was determined as the difference between the total inlet PM mass 'available for filtration/oxidation' (assuming a time-averaged overall cumulative filtration efficiency of 99\%, from [12], and calculating this as $\left.m_{\text {available }}=0.99 m_{P M}\right)$ and the PM mass deposited.

Table 5.6 shows the measured values of PM mass deposited in the filter at the end of loading, with the corrected values obtained from corrections applied to each from weight gain estimates described in Appendix G. The percentage PM mass oxidized in all load-cases at 2200 and $1650 \mathrm{rpm}$ calculated from the procedure described are as shown in Table 5.6.

The mass oxidation efficiency of the device increased with load (increased UPCPF temperatures as shown in Table 5.6) in the same configuration, and was higher in the CCRTR configuration than in the CPF-only configuration (owing to higher inlet temperatures and inlet $\mathrm{NO}_{2}$ concentrations as shown in Table 5.6), except in 2 cases:

1. $50 \%$ load in CCRTR configuration at $1650 \mathrm{rpm}$ : the percentage PM oxidized was observed to be $90.1 \%$ which was unusually high according to the trend expected from the general behavior of the CPF. This was due to an error in the experimental setup for the first 0.80 hours of loading, where the injection timing angle was different from the required value at $50 \%$ load, which is believed to have changed the PM oxidation during this experiment. The exhaust temperature at the CPF inlet for the first 1 hour of loading in this experiment was about $15-17^{\circ} \mathrm{C}$ greater than the steady-state value of CPF inlet temperature (about $420^{\circ} \mathrm{C}$ ) once the correction was made. Hence, PM oxidation rate in the first 1 
hour time must have been greater than that if the temperature were maintained at steady-state.

2. $100 \%$ load at $1650 \mathrm{rpm}(\mathrm{CPF}$-only and CCRTR configurations): where the CPF-only configuration had a percentage PM oxidized of $33.6 \%$ while the CCRTR configuration showed a percentage PM oxidized of $96.0 \%$. The percentage PM oxidized in the 100\% load CPF-only configuration at $1650 \mathrm{rpm}$ was lower than that for the $75 \%$ load CPF-only configuration at $1650 \mathrm{rpm}(33.6 \%$ compared to $75.0 \%$ ), which was contrary to what was expected, due to the CPF inlet exhaust temperature in the former being $490^{\circ} \mathrm{C}$ compared to $436^{\circ} \mathrm{C}$ in the latter. This was because in the 100\% CPF-only and CCRTß experiments conducted at $1650 \mathrm{rpm}$, data obtained regarding PM mass deposited was not reliable due to an engine loading error due to calibration discrepancies during the initiation of these experiments. The engine, in these experiments, emitted much higher PM emissions than were expected from estimates for the same obtained from baseline data (this was confirmed by visible smoking from the engine during the initial 5-10 minutes of both loading experiments), and thus, is believed to have changed the loading of the CPF in a transient manner. Thus, a steady loading of the CPF in these cases could not be considered. 


\begin{tabular}{|c|c|c|c|c|c|c|}
\hline 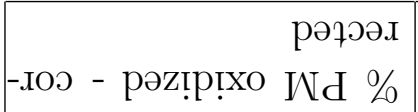 & 2 & $\mid \begin{array}{cccc}0 & m & 0 & 0 \\
\dot{\rho} & \ddot{\rho} & \dot{\infty} & \dot{0} \\
\sim & \infty & \infty\end{array}$ & 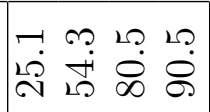 & 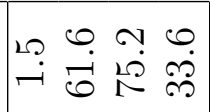 & 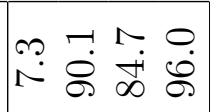 & \\
\hline 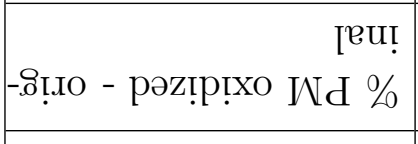 & 2 & 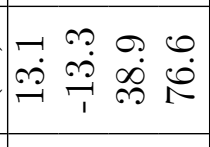 & 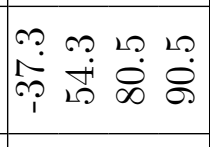 & 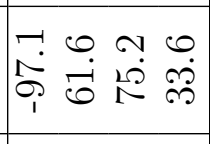 & 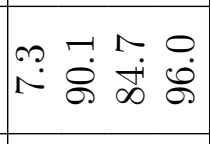 & \\
\hline 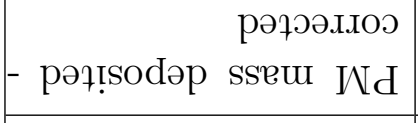 & 20 & 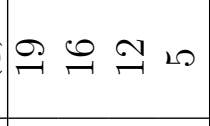 & $\stackrel{N}{\sim} \infty m$ & $\stackrel{0}{-1}$ म & $\forall \neg \forall N$ & \\
\hline 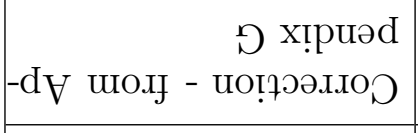 & 80 & 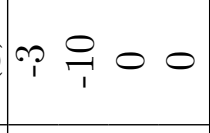 & 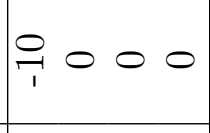 & $\underset{1}{0}{ }_{1}^{0} 000$ & 0000 & \\
\hline 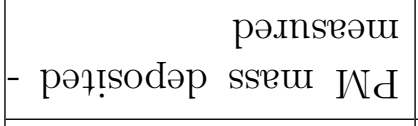 & 20 & $\stackrel{\sim}{\sim} \stackrel{\sim}{\sim}\llcorner$ & 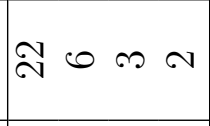 & कै & 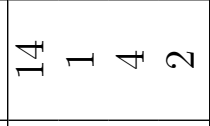 & \\
\hline $\begin{array}{r}\text { рә7ет } \\
\text {-nәгеә - ұә[u! sseu } \mathrm{Nd}\end{array}$ & 20 & 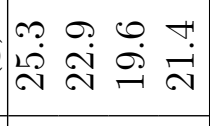 & 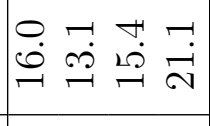 & 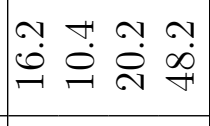 & 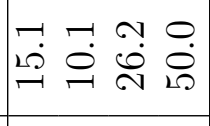 & \\
\hline әшт̣ 8ит̣реот & $\overparen{\mathscr{D}}$ & 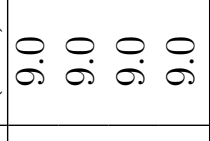 & $\begin{array}{llll}\infty & -1 & 0 & 0 \\
\infty & \infty & \infty & \infty \\
& & & \end{array}$ & 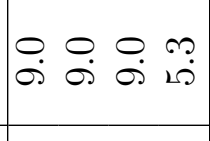 & 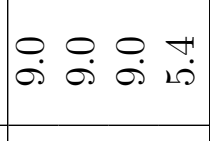 & \\
\hline${ }^{7} \mathrm{ON}$ Ұə[UI & हa & $\infty$ \& & 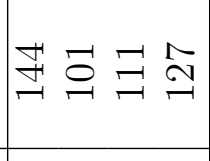 & 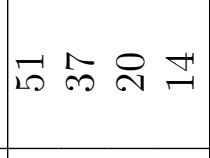 & 고용 & \\
\hline ә.пұеләdшәұ ұә[Uі & 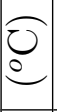 & 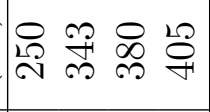 & 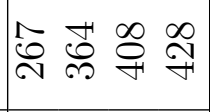 & 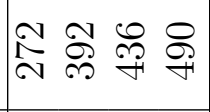 & 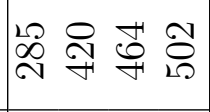 & \\
\hline peot & 2 & 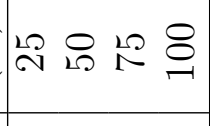 & $\stackrel{1}{2}$ & 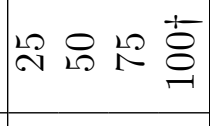 & 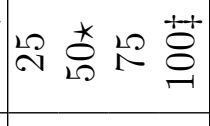 & \\
\hline uǫฺ̣.xn.8уuop & & 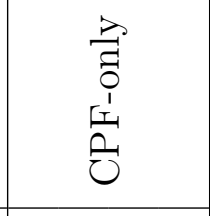 & 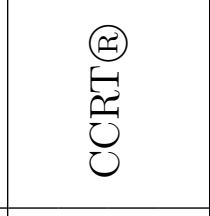 & 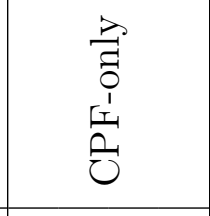 & 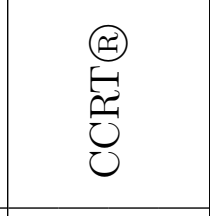 & \\
\hline рәәdS & 离 & 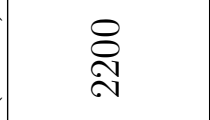 & 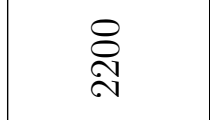 & $\begin{array}{l}0 \\
10 \\
0 \\
\end{array}$ & $\begin{array}{l}0 \\
10 \\
0 \\
-1\end{array}$ & \\
\hline
\end{tabular}


Figure 5.13 shows the corrected percentage PM mass oxidized obtained from experiments at $2200 \mathrm{rpm}$, after corrections were made to the PM mass deposited, from Table G.2. The corrected data shows higher percentage PM oxidized for the same configuration with increasing load due to higher CPF inlet temperatures and higher inlet $\mathrm{NO}_{2}$ flow rates, and higher percentage PM oxidized in the CCRTß configuration than in the CPF-only configuration for the same load, due to the additional $\mathrm{NO}_{2}$ produced from NO by the DOC upstream of the CPF. It can also be observed that at low CPF inlet temperatures $\left(250-270{ }^{\circ} \mathrm{C}\right)$, the DOC was not effective in increasing the PM oxidation efficiency of the CPF, as can be seen from the PM oxidation efficiency of the CPF at $25 \%$ load in CPF-only (25\%) and CCRTß (25\%) configurations in Figure 5.13.

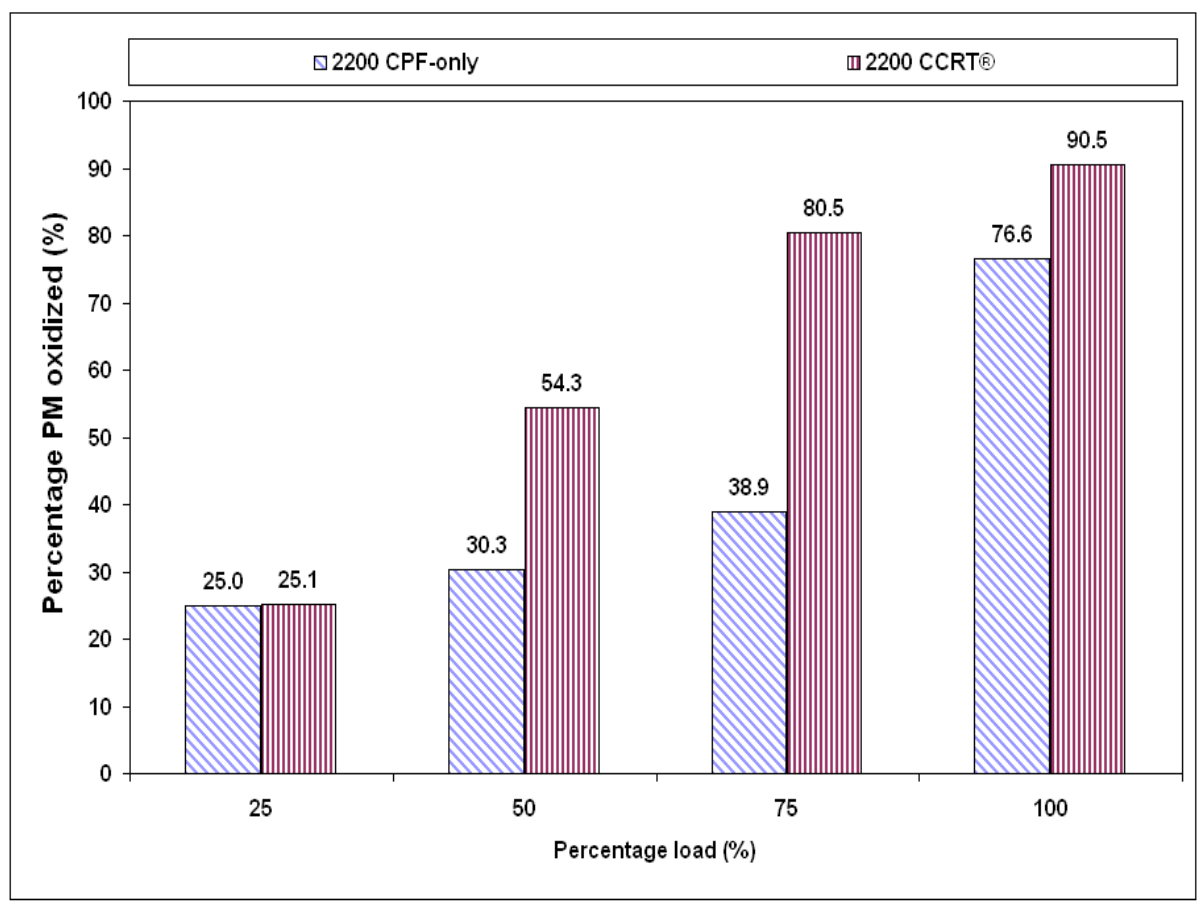

Figure 5.13: 2200 rpm experiments - A comparison of percentage PM mass oxidized (corrected data) 


\subsection{DOC Modeling and Experimental Results}

A 1-D model of a DOC was developed as part of this thesis, as detailed in Chapter 3 and Appendix A. This section focuses on the process of the calibration of the 1-D DOC model, and the results obtained from the calibrated model as compared to the experimental data as detailed in Section 5.2.2.

\subsubsection{DOC Model Calibration}

The 1-D DOC model was calibrated from the data obtained from experiments in the DOC-only configuration at 2200 and $1650 \mathrm{rpm}$. The relevant experimental variables measured to use for model calibration were:

- DOC pressure drops, and

- Individual species concentrations of carbon monoxide(CO), hydrocarbons(HC), nitric oxide $(\mathrm{NO})$ and nitrogen dioxide $\left(\mathrm{NO}_{2}\right)$ upstream and downstream of the DOC

- DOC inlet temperatures, and

- Exhaust flow rates.

Pressure drop across the DOC was modeled based on the frictional flow resistance encountered by fully-developed laminar flow through a square channel, and depends on the dynamic viscosity (denoted by $\mu_{g}$ ) and volumetric flow rate (denoted by $\dot{V}$ ) of the exhaust gas mixture, as given by equation A.15.

Figure 5.14 shows a comparison of DOC pressure drops obtained from model calibration with experimentally obtained values of DOC pressure drop at $2200 \mathrm{rpm}$. It was determined that the ratio of experimental DOC pressure drops to corresponding model-predicted values was a constant. The average value of this constant, denoted as ' $C$ ' in the pressure drop equation in Figure 5.14, was found out to be 2.00. This 
constant accounts for all inlet/outlet losses and DOC inlet baffle losses which have not been accounted for in the DOC pressure drop model. The value of ' $C$ ' was determined to be 2.00 for the model calibration at $1650 \mathrm{rpm}$ also (as shown in Figure 5.15).

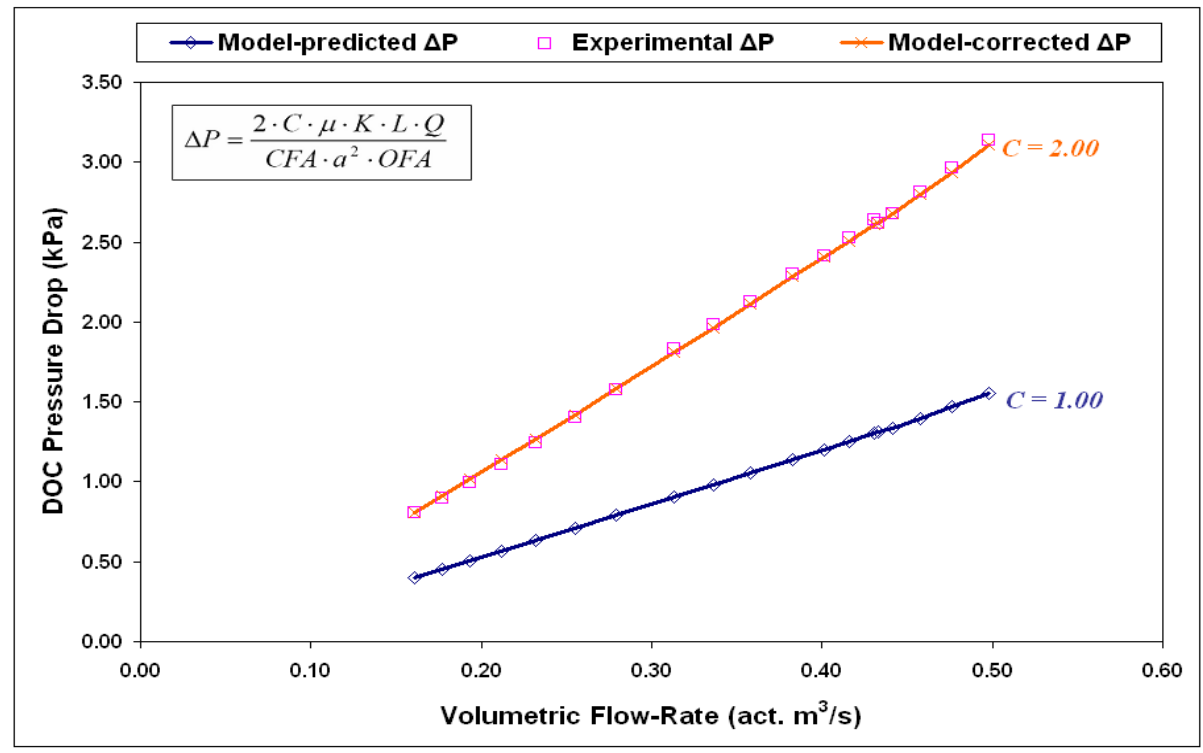

Figure 5.14: 2200 rpm DOC-only - A comparison of experimental and model-predicted pressure drops across the DOC

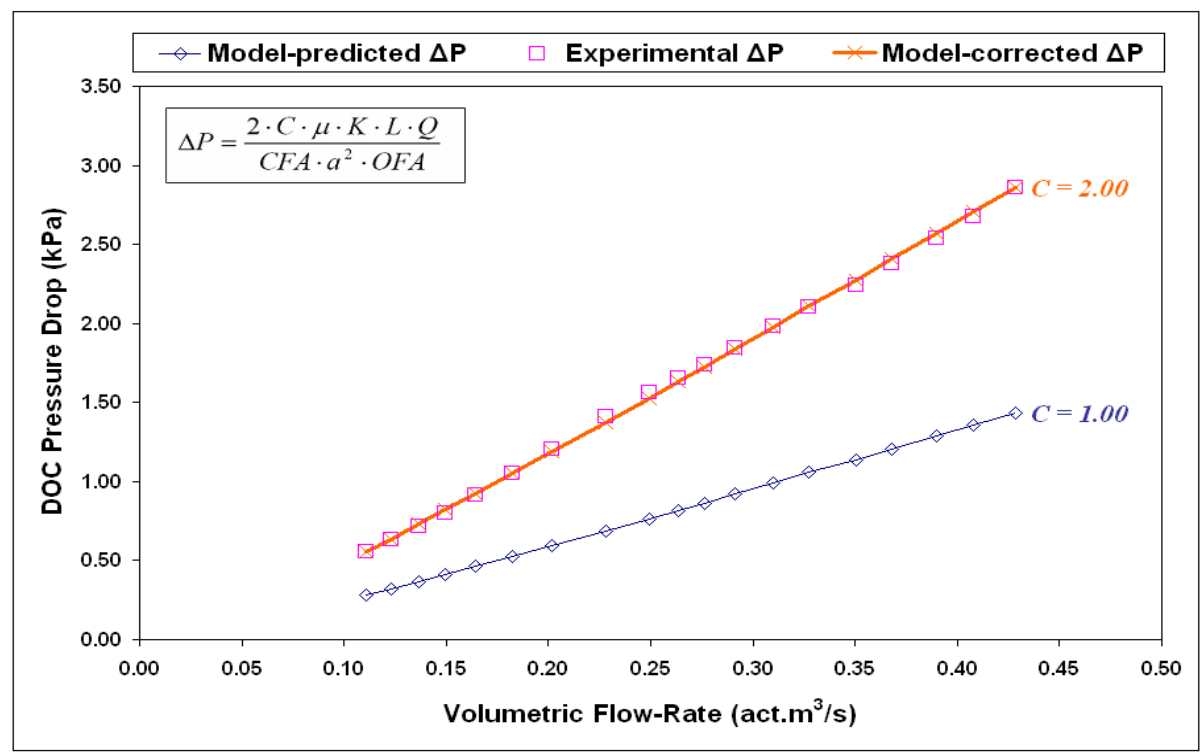

Figure 5.15: 1650 rpm DOC-only - A comparison of experimental and model-predicted pressure drops across the DOC 
Therefore, equation 5.2 is able to predict the pressure drop of the DOC used in this research work, at various load conditions at 2200 and $1650 \mathrm{rpm}$.

$$
\begin{gathered}
\Delta P=C\left(\frac{2 \mu_{g} K L \dot{V}}{\epsilon(C F A) D_{h}^{2}}\right) \\
\text { where } \\
C=2.00
\end{gathered}
$$

In order to predict downstream species concentrations and conversion percentages of $\mathrm{HC}, \mathrm{CO}, \mathrm{NO}$ and $\mathrm{NO}_{2}$ in the $\mathrm{DOC}$ at 2200 and $1650 \mathrm{rpm}$ using a minimum number of kinetic parameters, the downstream concentrations of these four species as predicted by the 1-D DOC model were calibrated to match experimentally observed values of the same, as explained in Appendix C. The maximum deviation of the downstream concentrations from the experimental values was $2.7 \mathrm{ppm}$ for $\mathrm{NO}$ at $2200 \mathrm{rpm}$ (refer to Table C.4) and $5.5 \mathrm{ppm}$ for NO at $70 \%$ load at $1650 \mathrm{rpm}$ (refer to Table C.4) for the first step in the calibration using the pre-determined values of the activation energies from the literature.

The pre-exponential factors for the calibrated model at $2200 \mathrm{rpm}$ (as shown in Table C.3) and $1650 \mathrm{rpm}$ (as shown in Table C.5) were then used in conjunction with the corresponding activation energy values (as shown in Table C.1) to calculate reaction rate constants, using equation C.1. These rate constants were then plotted on a semi-log plot versus the inverse of the absolute bulk temperature at the DOC inlet (as shown in Figure C.9), to get new values of the activation energies and pre-exponential factors for each of the three reactions; namely $\mathrm{CO}, \mathrm{HC}$ and $\mathrm{NO}$ oxidation. These values are shown in Table C.7. These kinetic parameters were then used back in the model to re-calculate the DN-DOC concentrations of CO, $\mathrm{HC}, \mathrm{NO}$ and $\mathrm{NO}_{2}$. The new values of activation energies (from Table C.7) were 
kept constant and pre-exponential factors were varied case-by-case to get another set of pre-exponential factors for 2200 and $1650 \mathrm{rpm}$ data. Semi-log plots of the rate constants obtained thus were constructed for all the data at both speeds and a new set of pre-exponential factors and activation energies (as shown in Table C.8) were derived. These kinetic parameters were finally used back in the DOC model to predict downstream concentrations of $\mathrm{CO}, \mathrm{HC}, \mathrm{NO}$ and $\mathrm{NO}_{2}$, and are presented in the next sub-section (Section 5.2.2).

\subsubsection{DOC Model - Results from Calibrated Model}

The 'apparent' kinetic parameters obtained from calibration of the DOC model to experimental data using semi-log plots were as shown in Table C.8, and are re-produced below in Table 5.7 for convenience.

This set of kinetic parameters was then used in the DOC model to predict the DOC outlet concentrations of $\mathrm{CO}, \mathrm{HC}, \mathrm{NO}$ and $\mathrm{NO}_{2}$ for the $2200 \mathrm{rpm}$ and 1650 rpm data. The results from this model calibration are presented in Figures 5.16(a), 5.16(b), 5.16(c) and 5.16(d) for $2200 \mathrm{rpm}$ data and in Figures 5.17(a), 5.17(b), 5.17(c) and 5.17(d) for 1650 rpm data.

Table 5.7: Kinetic parameters obtained from DOC model calibration to 2200 and $1650 \mathrm{rpm}$ data

\begin{tabular}{|c|c|c|}
\hline Reaction & Pre-exponential factor & Activation Energy \\
\hline & $\left(\mathrm{mol} / \mathrm{m}^{2} . \mathrm{s}\right)$ & $(\mathrm{J} / \mathrm{mol})$ \\
\hline $\mathrm{CO}$ & $1.82 \times 10^{19}$ & 102821 \\
\hline $\mathrm{HC}$ & $1.95 \times 10^{24}$ & 95260 \\
\hline $\mathrm{NO}$ & $2.08 \times 10^{12}$ & 87312 \\
\hline
\end{tabular}



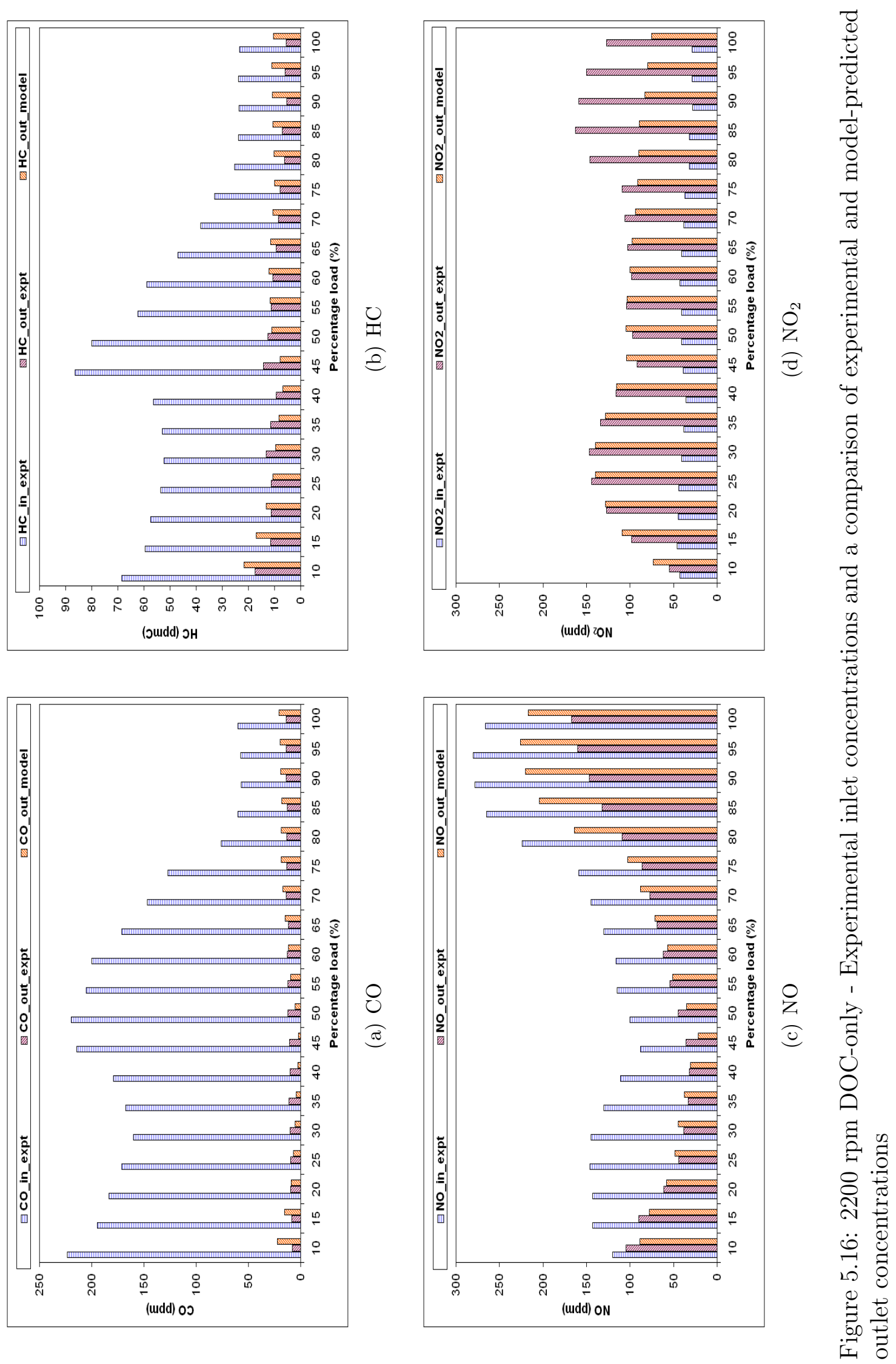

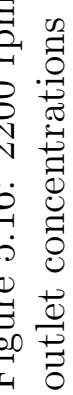



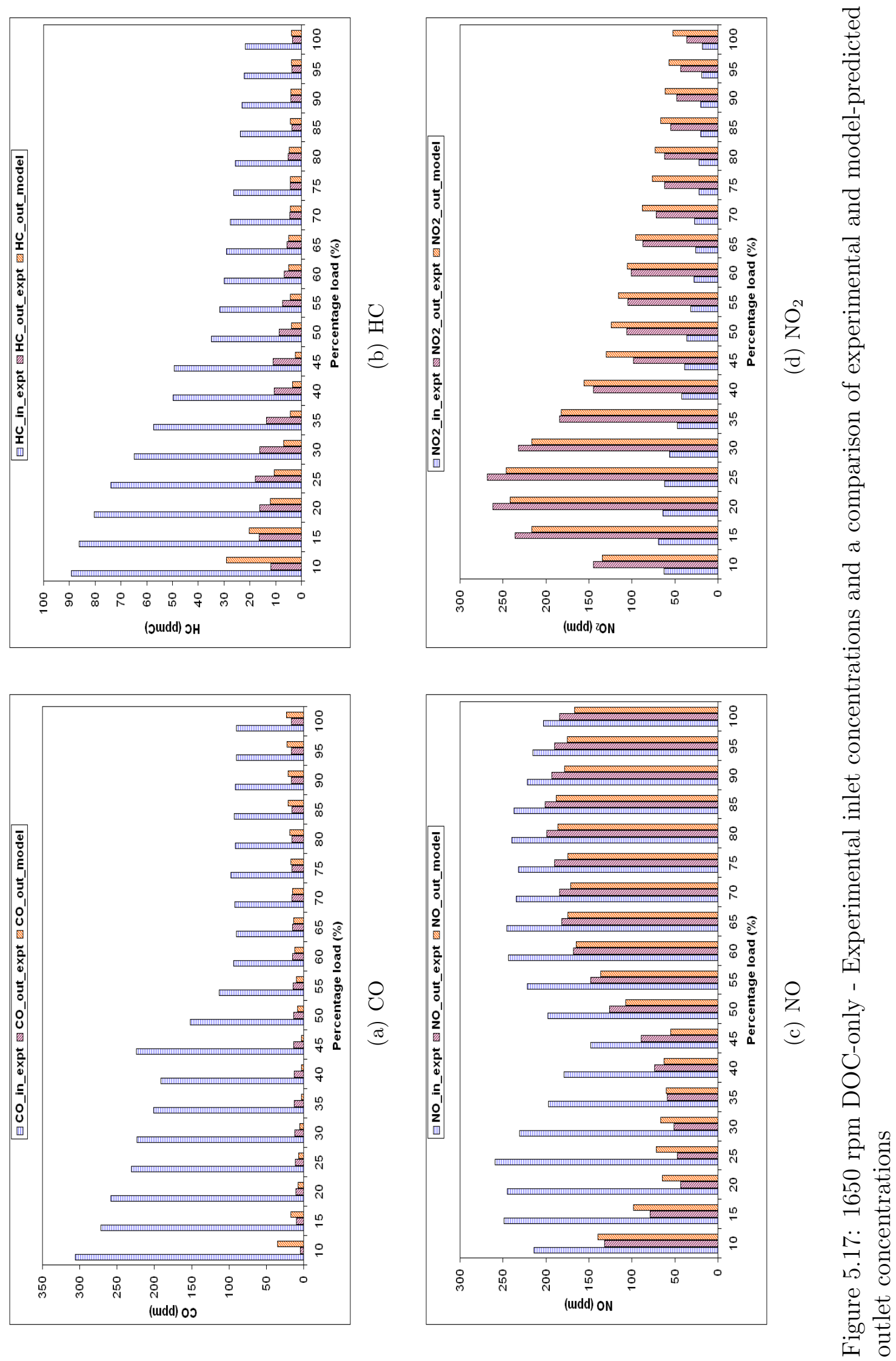
Tables 5.8 and 5.9 summarize the percentage differences between experimental and model-predicted DN-DOC concentrations of CO, HC, $\mathrm{NO}$ and $\mathrm{NO}_{2}$ at $2200 \mathrm{rpm}$ and $1650 \mathrm{rpm}$ respectively.

Tables 5.8 and 5.9 show that there were significant differences in the modelpredicted outlet concentrations as compared to the experimental data, especially for the $80 \%$ to $100 \%$ load cases at 2200 rpm where the errors in DN-DOC $\mathrm{NO}_{2}$ concentrations predicted were greater than $40 \%$. High percentage differences can be expected for prediction of low DOC outlet concentrations of $\mathrm{CO}$ and $\mathrm{HC}(3-18 \mathrm{ppm})$. The reasons for this discrepancy are:

1. Lack of availability of a good set of adsorption equilibrium constants to explain the adsorption characteristics of each species - this data can be collected by obtaining bench flow reactor study data for a DOC similar to that used in this thesis, where the main objective of data collection is to observe the change in reactor conversion efficiency with changing concentrations of each reactant species involved. The values of adsorption equilibrium constants from published literature (Koltsakis et al.) [5] were found to be not accurate in predicting the adsorption characteristics of the DOC used in this research. This is true from a catalyst perspective also, since the adsorption characteristics are device-specific and also vary with factors like aging.

2. Linearization of reaction rate constants which is an exponential function of the inverse of absolute bulk temperature $\left(k_{i}=A_{i} e^{\frac{E^{a_{i}}}{R T}}\right)$ using a semi-log plot approach causes large errors in the actual values of pre-exponential factors for relatively small amounts of differences of the same in a semi-log plot. Also, an error in the predicted kinetics of NO causes errors to manifest in the prediction of downstream concentrations of $\mathrm{CO}$ and $\mathrm{HC}$ because of the interdependence in reaction rates caused by inhibition terms involved in reaction rate expressions (Equations 3.13, 3.14 and 3.15). 


\begin{tabular}{|c|c|c|c|c|c|c|c|c|c|c|c|c|c|c|c|c|c|c|c|}
\hline \multirow{4}{*}{$\begin{array}{l}0 \\
Z\end{array}$} & " & & & $\tilde{\sigma}$ & -1 & 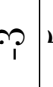 & P & +4 & & $\rightarrow$ & $\infty$ & $\infty$ & $2 p$ & $\frac{7}{1}$ & $\begin{array}{c}0 \\
-1 \\
1\end{array}$ & 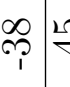 & & 采 & F \\
\hline & $\begin{array}{l}\text { ұәғрпо } \\
\text { [әрош }\end{array}$ & (udd) & 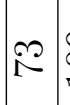 & & 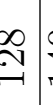 & & & & & 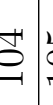 & & & $\infty$ & or & $\sigma$ & & $\ddot{\infty}$ & $\infty$ & 12 \\
\hline & 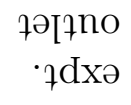 & (udd) & $20 \%$ & $\infty$ & $\vec{v}$ & $\exists$ & & 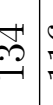 & 0 & $\bar{\sigma} \cdot$ & $\bar{s}$ & 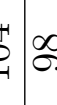 & $\stackrel{\mathscr{\theta}}{=}$ & $\stackrel{8}{0}$ & $\stackrel{8}{2}$ & $\underset{1}{0}$ & & 2 & $\stackrel{N}{\Xi}$ \\
\hline & $\begin{array}{l}\text { नә[U! } \\
\text { ·7dxə }\end{array}$ & (udd) & 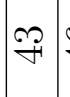 & क्: & (9) & 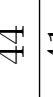 & $F$ & $\infty$ & 8 & s: & $F=$ & 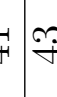 & $F$ & $\infty$ & $\widehat{\omega}$ & ๙ิ & $a^{\infty}$ & $\stackrel{2}{2}$ & 尺ి \\
\hline \multirow{4}{*}{ Z } & 'Ш!Р \% & $e^{2}$ & $\frac{20}{7}$ & 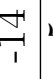 & $i$ & $\exists:$ & $=$ & , 10 & i & 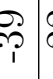 & 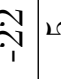 & $p$ & 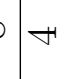 & $\nexists$ & $\overparen{\sim}$ & 80 & 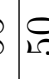 & $F$ & \% \\
\hline & $\begin{array}{l}\text { ұә[рпо } \\
\text { [әрош }\end{array}$ & (udd) & $\infty$ & $\infty$ & $\infty$ & & +8 & & 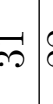 & 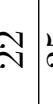 & 2 & 51 & た & $\infty$ & $\approx$ & త્| & & $\stackrel{\mathscr{N}}{N}$ & $\stackrel{N}{\sim}$ \\
\hline & 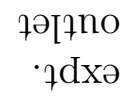 & (udd) & $\stackrel{2}{\circ}$ & 8 & 6 & 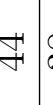 & $\infty$ & 2 & $\therefore$ & $0^{1}:$ & 8 & 5 & 8 & $\hat{\imath}$ & $\infty$ & $\stackrel{8}{\stackrel{2}{2}}$ & & 8 & $\stackrel{1}{6}$ \\
\hline & $\begin{array}{l}\text { 7ə[U] } \\
\text { •7dxə }\end{array}$ & (udd) & $\stackrel{\stackrel{\sim}{\sim}}{二}$ & $\stackrel{P}{*}$ & $\mathscr{P}$ & F: & 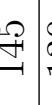 & 8 & $\exists$ & $\infty$ & 8 & $=0$ & $\stackrel{8}{9}$ & $\stackrel{29}{\rightrightarrows}$ & $\stackrel{8}{10}$ & $\underset{N}{*}$ & & \& & $\stackrel{\circ}{\circ}$ \\
\hline \multirow{4}{*}{ U. } & • サ!Р \% & 8 & 2 & $F$ & $A$ & is & $\underset{1}{*}$ & 趈 & 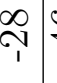 & fil; & $7-$ & $H$ & $\stackrel{2}{*}$ & $\stackrel{2}{N}$ & $\hat{N}$ & $\infty$ & & $\infty$ & $\sigma$ \\
\hline & $\begin{array}{l}\text { ұә[рпо } \\
\text { гәрош }\end{array}$ & (Dudd) & ลี & E & 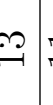 & $F$ & 0 & $\infty 1$ & $\wedge$ & $\infty ;$ & $=\cong$ & 2 & $=$ & $\exists$ & 0 & 의 $=$ & $=$ & $=$ & $=$ \\
\hline & 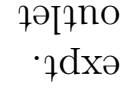 & (गudd) & $\approx$ & $\approx$ & $\exists$ & $\exists$ & $\theta$ & $\exists$ & & \pm & $=$ & $=$ & 0 & 0 & $\infty$ & 01 & 25 & 0 & 0 \\
\hline & 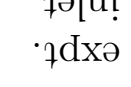 & (১udd) & 8 & 81 & is i & 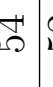 & $\begin{array}{c}* 10 \\
i 0\end{array}$ & : & 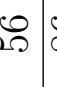 & $\infty$ & 8 & ji & 年 & $\infty$ & $\because 2$ & $\stackrel{2}{\sim}$ & $\vec{\sigma}$ & $\stackrel{\leftrightarrow}{\sim}$ & $\approx$ \\
\hline \multirow{4}{*}{0} & •Ш!P \% & & i & e. & 1 & $P$ & 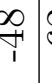 & $\begin{array}{l}1 \\
\\
\end{array}$ & $\frac{9}{1}$ & $\begin{array}{l}0 \\
0 \\
0 \\
1\end{array}$ & $\stackrel{5}{s}$ & 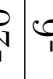 & $\stackrel{\infty}{\infty}$ & $\stackrel{2}{N}$ & $\mathscr{F}$ & $\stackrel{F}{F}=$ & 4 & $\stackrel{F}{F}$ & iิ \\
\hline & $\begin{array}{l}\text { tə[†по } \\
\text { Iәрош }\end{array}$ & (udd) & $\stackrel{N}{:}$ & . & 0.1 & $N$ & . & + . & $\infty$ & 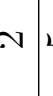 & S & I & $\stackrel{20}{-10}$ & $\bumpeq$ & 9 & $\stackrel{\alpha}{a}$ & 0 & $\stackrel{2}{2}$ & $\approx$ \\
\hline & 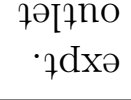 & (udd) & $\infty$ & 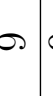 & os: & $\theta$ & $\theta$ & $\exists$ & $0:$ & $\exists$ & 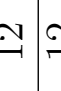 & 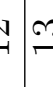 & $\stackrel{7}{7}$ & $\nexists$ & $\stackrel{9}{-1}$ & $\stackrel{\rightarrow}{\rightarrow}$ & 8 & $\mathbb{H}$ & $\nexists$ \\
\hline & $\begin{array}{l}\text { ఫə[U] } \\
\cdot 7 \mathrm{dx}\end{array}$ & (udd) & $\stackrel{\curvearrowright}{\curvearrowright}$ & 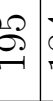 & $\infty$ & $E$ & 8 & 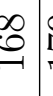 & 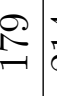 & $\frac{1}{2}$ & ָָे & 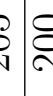 & I & 会 & $\stackrel{N}{A}$ & 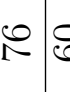 & & 512 & 8 \\
\hline 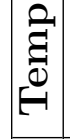 & & 0 & $\begin{array}{l}\infty \\
\infty \\
-\rightarrow\end{array}$ & : & $\stackrel{\$}{*}$ & 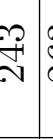 & $\stackrel{2}{8}$ & 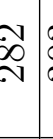 & $\underset{\infty}{2}$ & $\stackrel{2}{0}$ & $0 \frac{1}{\sigma}$ & 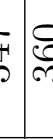 & : & $\underset{\substack{N \\
\infty}}{N}$ & 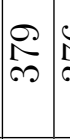 & 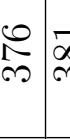 & $\stackrel{m}{0}$ & 宗 & $\vec{F}$ \\
\hline $\begin{array}{l}\tilde{z} \\
0 \\
0 \\
\end{array}$ & & & $\circ$ & 8 & 8 & & 8 & ת. & Fals & Fi & 82 & 5 & 38 & R & & $\infty \stackrel{2}{\infty}$ & & 38 & $\underset{-\infty}{8}$ \\
\hline
\end{tabular}




\begin{tabular}{|c|c|c|c|c|c|c|c|c|c|c|c|c|c|c|c|c|c|c|c|c|c|c|}
\hline \multirow{4}{*}{$\begin{array}{l}0 \\
Z\end{array}$} & •サ!P \% & 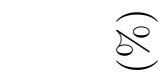 & $\Gamma_{1}$ & $\infty$ & $\infty$ & $\infty$ & $\Gamma_{1}$ & 7 & $-1 \propto$ & $\infty$ & 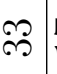 & $\stackrel{\sim}{\sim}$ & $\stackrel{0}{-1}$ & 20 & $\stackrel{\circ}{\circ}$ & $\stackrel{\sim}{\sim}$ & $\Re$ & $\stackrel{\infty}{=-}$ & $\vec{N}$ & $\stackrel{\sim}{2}$ & ๙ิ & $\stackrel{20}{7}$ \\
\hline & $\begin{array}{l}\text { ұәғпоо } \\
\text { тәрош }\end{array}$ & (udd) & 觜 & $\stackrel{N}{\sim}$ & $\stackrel{\mathcal{N}}{\stackrel{N}{N}}$ & $\stackrel{0}{\stackrel{0}{N}}$ & $\stackrel{N}{\sim}$ & $\infty$ & $\begin{array}{lll}0 & 6 \\
& 5 & 5\end{array}$ & $b$ & $\stackrel{8}{\oplus}$ & $\underset{\sim}{\stackrel{N}{-}}$ & $\begin{array}{l}0 \\
- \\
-\end{array}$ & $\stackrel{8}{Ð}$ & ڤ & $\infty$ & 0 & $\Re$ & 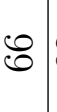 & ஸै & 占o & กิ \\
\hline & $\begin{array}{l}\text { 7әтұno } \\
\cdot \text { tdxə }\end{array}$ & (udd) & $\stackrel{29}{\underset{7}{+}}$ & 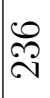 & ڤै & $\stackrel{\infty}{\stackrel{\leftrightarrow}{N}}$ & $\stackrel{\sim}{\approx}$ & $\infty$ & $\begin{array}{l}5 \\
5 \\
-1\end{array}$ & $\underset{T}{q}$ & $\infty$ & 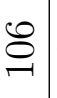 & $\stackrel{2}{0}$ & $\stackrel{\vec{\sigma}}{=}$ & $\infty$ & $\stackrel{N}{N}$ & ชै & $\begin{array}{lll}3 & 2 \\
0 & 2\end{array}$ & 20 & $\stackrel{\infty}{+}$ & $\underset{7}{+}$ & @ \\
\hline & $\begin{array}{l}\text { ұə[U! } \\
\cdot 7 \mathrm{dxə}\end{array}$ & (udd) & שֶ & 0 & है & ช్ & 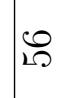 & 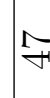 & $5 \%$ & $\begin{array}{l}y \\
y\end{array}$ & ले & 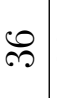 & กิ & $\stackrel{\infty}{\sim}$ & $\stackrel{\leftrightarrow}{\sim}$ & $\stackrel{N}{N}$ & ฟิ & $\stackrel{\overbrace{}}{\sim}$ & $\stackrel{\curvearrowright}{\curvearrowright}$ & 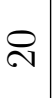 & 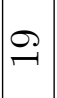 & $\infty$ \\
\hline \multirow{4}{*}{$\begin{array}{l}0 \\
Z\end{array}$} & •Ш!Р \% & $\sqrt{2}$ & 0 & $\stackrel{H}{N}$ & 20 & i⿱⺈ & $\sigma$ & $\sim$ & 5 & $\begin{array}{c}2 \\
\\
1\end{array}$ & $\begin{array}{l}\infty \\
\infty \\
p\end{array}$ & $\stackrel{20}{\longrightarrow}$ & $\infty$ & $\Upsilon_{1}$ & $\vec{r}$ & $T_{1}$ & $\infty_{1}^{\infty} 1$ & $r_{1}$ & $\varphi_{1}$ & $\infty$ & $\infty$ & $\theta_{i}$ \\
\hline & $\begin{array}{l}\text { ұәғпо } \\
\text { јәрош }\end{array}$ & (udd) & $\stackrel{\infty}{\infty}$ & $\infty$ & 0 & N & 6 & $\stackrel{8}{6}$ & $b$ ç & 8 & 20 & $\stackrel{\infty}{0}$ & $\stackrel{n}{\infty}$ & $\stackrel{10}{0}$ & 咅 & I & $\stackrel{10}{12}$ & 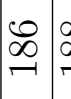 & $\begin{array}{l}\infty \\
\infty \\
-1\end{array}$ & $\begin{array}{l}\infty \\
\simeq \\
\sim\end{array}$ & 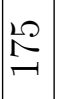 & $\stackrel{1}{6}$ \\
\hline & $\begin{array}{l}\text { ұə[†nо } \\
\cdot 7 \mathrm{dx}\end{array}$ & (udd) & के & $R$ & $\mathscr{P}$ & $\stackrel{N}{\gamma}$ & $\sqrt{20}$ & 8 & 3 & E & $\infty$ & 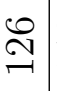 & $\stackrel{\infty}{ \pm}$ & $\begin{array}{l}\infty \\
0 \\
-1\end{array}$ & $\begin{array}{c}\infty \\
\infty \\
=-1\end{array}$ & 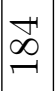 & 8 & $\stackrel{8}{2}$ & 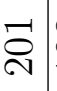 & $\mathscr{m}$ & 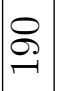 & $\underset{\infty}{\infty}$ \\
\hline & $\begin{array}{l}7 \partial[ \\
\cdot 7 \mathrm{dx}\end{array}$ & (udd) & $\underset{\sim}{\vec{N}}$ & $\stackrel{\text { 亗 }}{\mathrm{N}}$ & $\stackrel{10}{\stackrel{2}{N}}$ & 昰 & $\vec{\sim}$ & 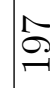 & 5 & -19 & $\stackrel{\infty}{\underset{f}{\sim}}$ & $\begin{array}{l}\infty \\
\Omega \\
\sim\end{array}$ & ָิ & $\underset{\sim}{\stackrel{H}{\sim}}$ & $\begin{array}{l}0 \\
\stackrel{1}{N}\end{array}$ & $\begin{array}{l}\stackrel{2}{2} \\
\stackrel{2}{N}\end{array}$ & ๙ิ & 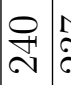 & $\stackrel{\sim}{\stackrel{\sim}{\sim}}$ & $\stackrel{\stackrel{N}{N}}{\stackrel{N}{N}}$ & $\frac{10}{\sim N}$ & $\stackrel{\leftrightarrow}{\stackrel{\sim}{*}}$ \\
\hline \multirow{4}{*}{ U } & •サ!P \% & $\sqrt{2}$ & $\underset{\sim}{\stackrel{\infty}{+}}$ & $\stackrel{+}{\sim}$ & $\stackrel{\mathscr{L}}{\sim}$ & $\underset{i}{\stackrel{F}{*}}$ & $\mid \begin{array}{l}\infty \\
\stackrel{1}{i}\end{array}$ & $\begin{array}{l}\infty \\
0 \\
1\end{array}$ & $p$ & $\begin{array}{lll}8 & 0 \\
1 & 1\end{array}$ & $\begin{array}{c}\infty \\
1\end{array}$ & $\begin{array}{l}0 \\
\stackrel{0}{0} \\
\stackrel{1}{*}\end{array}$ & $\underset{1}{\stackrel{P}{+}}$ & 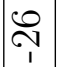 & $\underset{1}{-1}$ & $T_{1}$ & $\sim_{1}$ & $\begin{array}{ll}0 \\
\\
\end{array}$ & $\vec{N}$ & 0 & $N$ & 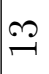 \\
\hline & $\begin{array}{l}\text { ұәғпо } \\
\text { әәрош }\end{array}$ & (Dudd) & ล & จ & $\stackrel{\sim}{\sim}$ & 二 & $\Lambda$ & $\nabla$ & $+\mathrm{r}$ & 0 & $N$ & $\nabla$ & $\nabla$ & 20 & 10 & $\forall$ & $\nabla 1$ & 100 & $\nabla$ & $\nabla$ & $\forall$ & $\nabla$ \\
\hline & $\begin{array}{l}\text { 7ә[ұno } \\
\cdot 7 \mathrm{dx}\end{array}$ & (Dudd) & $\stackrel{\sim}{\beth}$ & 0 & $\stackrel{0}{-1}$ & $\infty$ & $\stackrel{0}{-1}$ & $\nexists$ & 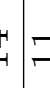 & -1 & 二 & $\sigma$ & $\Lambda$ & 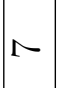 & 0 & $\nabla$ & $F 1$ & 100 & $\forall$ & $\nabla 1$ & $\forall$ & $\infty$ \\
\hline & $\begin{array}{l}\text { 7ə[U! } \\
\cdot 7 \mathrm{dx}\end{array}$ & (Dudd) & $\infty$ & $\infty$ & $\infty$ & 亲 & 6 & 10 & 58 & b & g & ח & กิ & คి & $\stackrel{\sim}{N}$ & $\stackrel{\infty}{\sim}$ & $\stackrel{\sim}{\sim}$ & 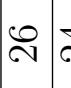 & $\stackrel{\Delta}{\Delta}$ & $\stackrel{\Re}{\sim}$ & $\stackrel{\sim}{\sim}$ & $\approx$ \\
\hline \multirow{4}{*}{ U } & • & & $\begin{array}{c}0 \\
6 \\
6\end{array}$ & $\infty$ & $\underset{\sim}{0}$ & $\stackrel{\sim}{\rho_{i}}$ & $\overbrace{i}$ & $N_{1}^{0}$ & $\stackrel{1}{1}$ & $\tau \delta$ & $\begin{array}{c}\infty \\
\infty \\
1\end{array}$ & $\underset{\mathfrak{T}}{\mathcal{F}}$ & $\stackrel{\mathscr{P}_{i}}{\mathscr{P}_{i}}$ & $\underset{\sim}{\stackrel{\sim}{1}}$ & $\underset{F}{\vec{T}}$ & $L_{P}$ & $\stackrel{\circ}{-}$ & $\stackrel{\infty}{-1}$ & 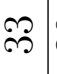 & $\stackrel{\circ}{\circ}$ & m & $\stackrel{\sim}{\forall}$ \\
\hline & $\begin{array}{l}\text { ұәтұno } \\
\text { әәрош }\end{array}$ & (udd) & ח & 득 & $\infty$ & $\Lambda$ & ס & $\infty$ & $D$ o & 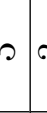 & $\infty$ & $\infty$ & $\stackrel{0}{\circ}$ & $\stackrel{\sim}{\sim}$ & $\infty$ & 100 & 드. & $\stackrel{9}{-1}$ & $\vec{N}$ & $\vec{N}$ & $\stackrel{\sim}{\sim}$ & $\stackrel{9}{\sim}$ \\
\hline & $\begin{array}{l}\text { 7ә[тnо } \\
\cdot 7 \mathrm{dx}\end{array}$ & (udd) & 20 & $\stackrel{ }{-1}$ & $\stackrel{0}{-1}$ & 二 & $\stackrel{\mathcal{Z}}{\sim}$ & $m$ & $\begin{array}{ll}9 \\
-1\end{array}$ & 2 & $\underset{-1 .}{-\infty}$ & $\Xi$ & 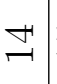 & 10 & 20 & 100 & 0 & 0 & $\stackrel{0}{-1}$ & $\stackrel{0}{-1}$ & $\approx$ & $\underset{0}{0}$ \\
\hline & $\begin{array}{l}7 \partial[\mathrm{U} ! \\
\cdot 7 d x \partial\end{array}$ & (udd) & $\begin{array}{c}0 \\
0 \\
\infty \\
\infty\end{array}$ & $\stackrel{N}{\stackrel{N}{N}}$ & $\begin{array}{l}\infty \\
\stackrel{1}{N} \\
\sim\end{array}$ & $\ddot{\sim}$ & $\stackrel{\Re}{N}$ & ఠ) & 5 & -1 & $\stackrel{\stackrel{2}{N}}{\mathrm{~N}}$ & 疍 & $\stackrel{\infty}{=}$ & $\vec{\sigma}$ & 8 & ๙ & 今。 & 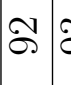 & $\mathscr{\sigma}$ & $\vec{\sigma}$ & 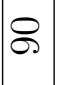 & ఠ \\
\hline$\sum_{\substack{||}}$ & & e & $\infty$ & $\stackrel{\sim}{\sim}$ & $\stackrel{\Re}{\sim}$ & $\stackrel{ }{N}$ & $\stackrel{\infty}{\mathscr{N}}$ & $\begin{array}{l}0 \\
\text { N } \\
\approx\end{array}$ & 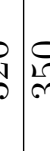 & 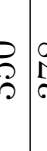 & $\begin{array}{c}\infty \\
\stackrel{\infty}{\infty} \\
\infty\end{array}$ & 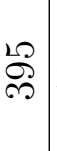 & 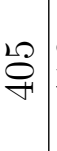 & $\stackrel{0}{\stackrel{0}{\forall}}$ & 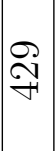 & $\underset{\sharp}{\sharp}$ & $\mid \begin{array}{c}\infty \\
2 \\
\stackrel{2}{+} \\
9\end{array}$ & 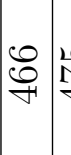 & $\begin{array}{l}\stackrel{2}{⿰} \\
\stackrel{7}{7}\end{array}$ & 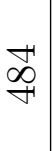 & $\vec{\sigma}$ & $\underset{\sim}{\stackrel{\mathscr{H}}{ }}$ \\
\hline$\frac{2}{2}$ & & 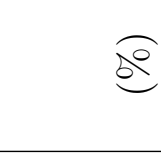 & 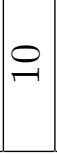 & $\stackrel{20}{-1}$ & ๙ & $\stackrel{12}{N}$ & คి & $\stackrel{100}{\infty}$ & $b \subsetneq$ & Fis & $\stackrel{\operatorname{Lig}}{\rightarrow}$ & 유 & 20 & 8 & 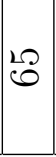 & $?$ & $\stackrel{10}{1}$ & 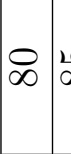 & $\stackrel{12}{\infty}$ & ఠ & $\stackrel{20}{\Omega}$ & $\stackrel{8}{\circ}$ \\
\hline
\end{tabular}


DOC outlet gas temperatures were also obtained from the DOC model. The model simulations were carried out with the heat transfer to the ambient set to zero (by setting $h_{\infty}$ as described in Appendix A to zero). This assumption was made for the purpose of simplifying the calculations. Figures 5.18 and 5.19 show comparisons of model-predicted DOC outlet temperatures versus experimentally measured values of DOC outlet temperatures at the corresponding load conditions for 2200 and 1650 rpm respectively. It was observed that DOC outlet temperatures at all loads for both speeds followed similar trends as experimentally observed values of DOC outlet temperatures, but the model-predicted values of DOC outlet temperatures were lower than experimental DOC outlet temperatures in most cases.

The other aspect that can be causing the difference in model-predicted and experimental temperature differences is the potential error in the DOC inlet and outlet temperatures. The temperatures measured upstream and downstream of the DOC could be another reason for the experimental results being higher than modelpredicted values. This can occur if the DN-DOC thermocouple were over-predicting the DOC outlet temperature or if the UP-DOC were under-predicting the DOC inlet temperature. The steps to be taken to improve the DOC model are discussed later in the conclusions section in Chapter 6 of this thesis. 


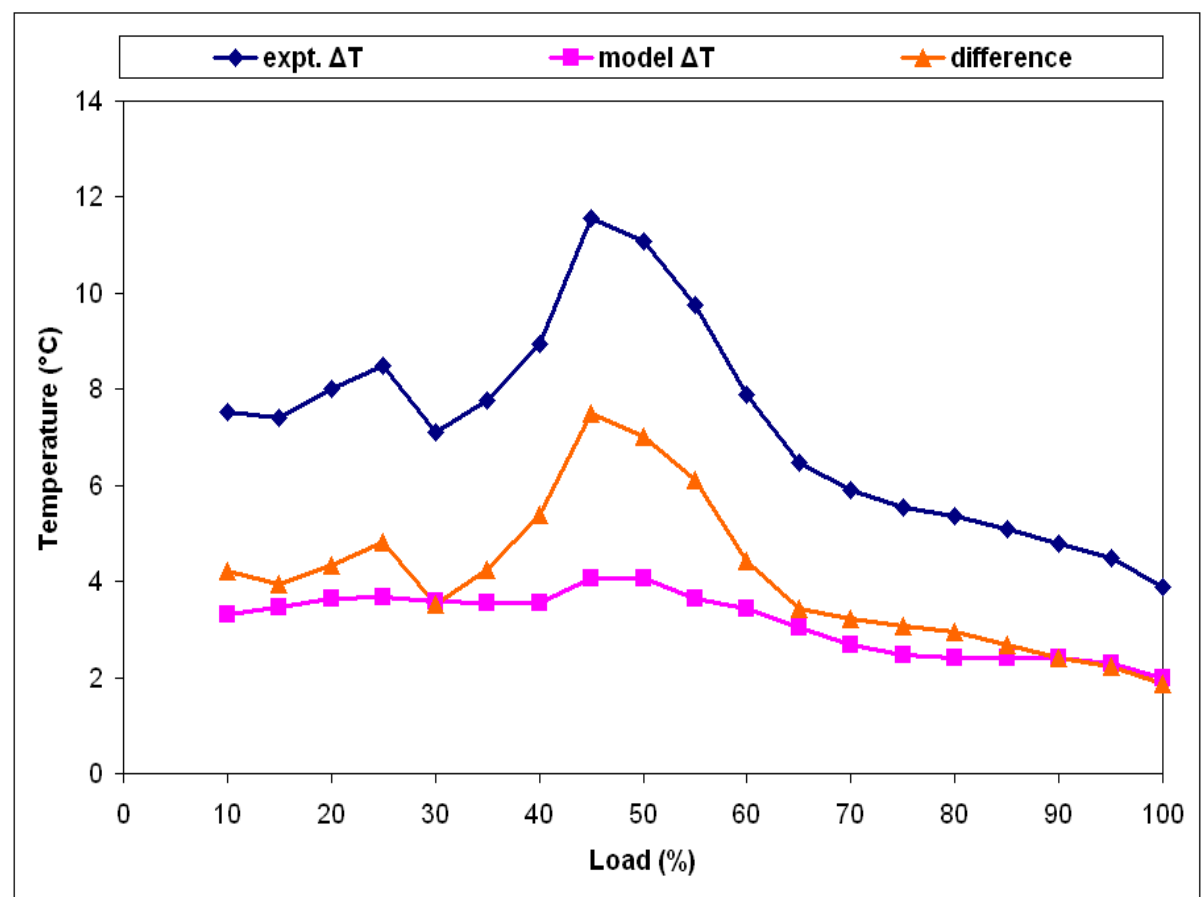

Figure 5.18: Experimental and model-predicted temperature differences (outlet inlet) and their difference observed at $2200 \mathrm{rpm}$

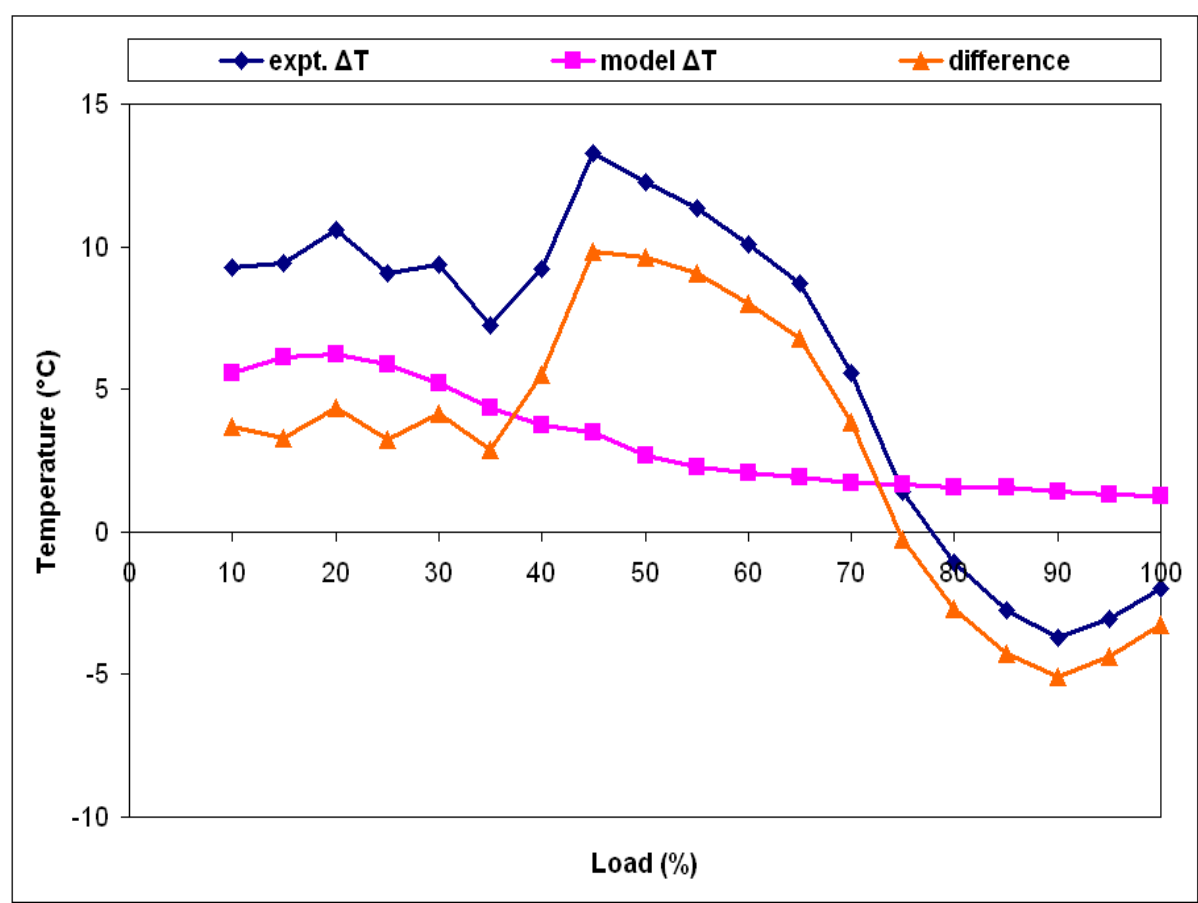

Figure 5.19: Experimental and model-predicted temperature differences (outlet inlet) and their difference observed at $1650 \mathrm{rpm}$ 


\subsection{CPF Modeling and Experimental Results}

This section discusses calibration of the MTU 1-D 2-layer CPF model and a detailed study of the filtration and oxidation characteristics based on the results obtained from the calibrated model at 25 and $100 \%$ load at $2200 \mathrm{rpm}$, the former being the load with the lowest PM oxidation rates, and the latter being the highest oxidation rate case. Results from both $\mathrm{CPF}$-only and CCRTR configurations are presented to

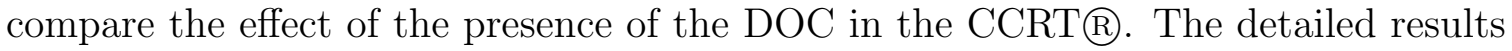
obtained at other loading conditions (50 and 75\% load) at $2200 \mathrm{rpm}$ are presented in Appendix D. A comparison of calibrated model input parameters obtained in this thesis work to those obtained in a previous research work (Hasan et al.) [14] using the same CPF model for a different set of experimental data is also presented.

\subsubsection{CPF Model Calibration - Determination of Constants and Comparison to Experimental Data}

The MTU 1-D 2-layer CPF model was calibrated to the given set of experimental data at $2200 \mathrm{rpm}$, in both CPF-only and CCRTR configurations. Generally, a given steady-state loading condition has a set of parameters that were fit to match the model-predicted values of pressure drop across the CPF versus time, clean pressure drop, mass deposited in the CPF after the loading, DN-CPF particulate concentration and DN-CPF PSD data. In addition, these input parameters are compared to those observed in previous research work at MTU $[12,14]$, using the same CPF model on a different engine and using an earlier produced CCRTR.

The guiding principle behind calibration of the model is that there exists a solution of the numerical problem for which the model predicts the experimental variables measured (which are: clean pressure drops, CPF pressure drops versus time, PM mass deposited, outlet PM concentrations, DN-CPF PSD data with time and DN- 
$\mathrm{CPF} \mathrm{NO}_{2}$ concentrations) within a given percentage of accuracy (usually $\pm 5 \%$ ), and this solution is attainable using a particular set of values for the input parameters used for the model. The general method of conducting calibration of the model at a given loading condition includes simulation of the given loading condition with trial values of input parameters, viewing model results, comparing with measured values of experimental variables, re-adjusting the values of CPF model input parameters and repeating the cycle of processes described above until satisfactory degree of fit is achieved for all the experimental data being used to compare with the model data. Changes in the values of these input parameters as a function of the engine load at a given speed follows particular trends as will be discussed later in this chapter. A number of parameters are held constant for all loads.

Input parameters needed for the MTU 1-D 2-layer CPF model can be classified into four categories in general as follows:

1. CPF substrate geometry and physical property specification parameters,

2. CPF inlet exhaust gas properties and species concentrations corresponding to each load condition,

3. Kinetic parameters, and

4. Properties of particulate in wall and cake.

Table 5.10 shows the parameters that were determined for each load condition to match model-predicted values of variables to experimental values of the same variables.

The detailed procedure for calibration (which involves iterating to a better solution of the loading simulation by re-adjusting the values of model input parameters) was as follows: 
Table 5.10: CPF model input parameters that were varied with load condition

\begin{tabular}{|c|c|c|c|}
\hline Sl. No. & Parameter & Notation & Units \\
\hline \multicolumn{4}{|c|}{ Substrate Properties } \\
\hline 1 & Clean wall permeability & $k_{t, 0}$ & $\left(m^{2}\right)$ \\
\hline 2 & Percolation factor & $\psi$ & $()$. \\
\hline \multicolumn{4}{|c|}{ Particulate properties in wall and cake } \\
\hline 3 & Particulate packing density in the wall & $\rho_{p, w}$ & $\left(\frac{\mathrm{kg}}{\mathrm{m}^{3}}\right)$ \\
\hline 4 & PM cake layer permeability & $k_{p}$ & $\left(m^{2}\right)$ \\
\hline 5 & PM cake layer packing density & $\rho_{p}$ & $\left(\frac{\mathrm{kg}}{\mathrm{m}^{3}}\right)$ \\
\hline 6 & Maximum cake efficiency parameter & $A_{\eta}$ & (.) \\
\hline 7 & Cake collector efficiency ratio parameter & $\frac{\eta_{c}}{d_{c, c a k e}}$ & $\left(\frac{1}{m}\right)$ \\
\hline \multicolumn{4}{|c|}{ Kinetic Parameters } \\
\hline 8 & Freq. factor for thermal PM oxidation & $A_{t h}$ & $\left(\frac{m}{s-K}\right)$ \\
\hline 9 & Freq. factor for catalytic PM oxidation & $A_{c a t}$ & $\left(\frac{m}{s-K}\right)$ \\
\hline 10 & Freq. factor for $\mathrm{NO}_{2}$-assisted oxidation & $A_{\mathrm{NO}_{2}}$ & $\left(\frac{m}{s-K^{\frac{1}{2}}}\right)$ \\
\hline 11 & Freq. factor for $\mathrm{NO}_{2}$-assisted oxidation in wall & $A_{\mathrm{NO}_{2}, \text { wall }}$ & $\left(\frac{m}{s-K^{\frac{1}{2}}}\right)$ \\
\hline 12 & Freq. factor for $\mathrm{NO}_{2}$ production & $A_{N O}$ & $\left(\frac{m}{s-K^{3}}\right)$ \\
\hline
\end{tabular}

1. Clean wall permeability $\left(k_{t, 0}\right)$ was adjusted to match the initial point in the experimental pressure drop data with that which the model predicts. However, as can be seen from the later comparison of the experimental and model clean pressure drops, exact matches for initial pressure drop points as predicted by the model with experimental data could not be achieved at all load cases, even with varying clean trap permeability $\left(k_{t, 0}\right)$ values, since it was found out that the initial pressure drop (which is a function of $k_{t, 0}$ ), affected the overall pressure drop, especially for the 25 and $50 \%$ load cases in CPF-only and CCRT $\mathbb{R}$ configurations, and even with higher wall PM loadings, accurate fits for overall pressure drops could not be achieved. This means that the filter was loaded to some extent in all the load cases before the 'initial' point at which pressure drop data was recorded, since the experimental setup was such that the exhaust gas passed through the CPF right from the point where the engine was started up. This issue is discussed further in the text explaining the data later in this section and the solution to overcome this issue is discussed in the Recommendations 
Section (Section 6.4) in Chapter 6 of this thesis.

2. Percolation factor $(\psi)$ was adjusted to change the initial rate of increase in cake filtration efficiency with time. This variable is used to calculate partition coefficient (as defined in Equation 3.38), which is in turn assigned as cake filtration efficiency during the initial stages of filtration. Other parameters, namely, $A_{\eta}$ and $\frac{\eta_{c}}{d_{c, \text { cake }}}$ are also used to compute parametric cake filtration efficiency at each time step during model simulation (as per Equation 3.41), and compared with the partition coefficient calculated from $\psi$, and the model uses the parametric cake filtration efficiency equation once these values exceed partition coefficients for the corresponding axial location in the channel. A higher percolation factor generally translates to a faster rise in cake filtration efficiency during the initial stage of filtration.

3. The maximum cake filtration efficiency parameter $\left(A_{\eta}\right)$ was adjusted to match model-predicted values of DN-CPF particulate volume concentration to those obtained from SMPS data at steady-state at all load-cases in both configurations. $A_{\eta}$ also has an effect on the pressure drop versus time data since $\left(1-A_{\eta}\right)$ is directly related to the PM mass that exits the PM cake layer and enters the wall.

4. Particulate packing density in the wall $\left(\rho_{p, w}\right)$ determines the rate of increase of volume of the wall collectors for unit amount of PM deposited. In other words, a lower particulate packing density in the wall means that the wall collectors would be larger than for another case having higher particulate packing density in the wall, for the same amount of PM deposited in the wall in both cases. It has been observed from model calibration that for all other factors remaining the same, an increase in $\rho_{p, w}$ decreases the sensitivity of wall pressure drop to the PM mass deposited in the wall. 
5. PM cake layer permeability $\left(k_{p}\right)$ was adjusted to control the contribution of the PM cake layer to overall pressure drop (since $\Delta P_{\text {cake }} \propto \frac{w_{\text {cake }}}{k_{p}}$ ). An increase in $k_{p}$ decreases the pressure drop due to the cake layer, and hence this parameter generally controls the rate of increase/decrease of the pressure drop in the cake filtration regime. It has also been observed from previous research work for similar modeling studies that $k_{p}$ increased with increase in actual volumetric flow rates (or Peclet numbers) [7], [29], which is consistent with what was observed in this research work.

6. The frequency factor for $\mathrm{NO}_{2} /$ temperature-assisted PM oxidation $\left(A_{\mathrm{NO}_{2}}\right)$ was adjusted to match experimental values of overall PM mass deposited in the filter at the end of loading. An increase in $A_{\mathrm{NO}_{2}}$ increases the rate of the $\mathrm{NO}_{2}$ /temperature-assisted PM oxidation reaction and consequently, results in a decrease in the mass deposited in the filter at the end of loading.

7. Frequency factor for thermal PM oxidation reaction $\left(A_{t h}\right)$ was the same as that used in previous research work at MTU[12].

8. Frequency factor for $\mathrm{NO}_{2} /$ temperature-assisted $\mathrm{PM}$ oxidation in the wall $\left(A_{\mathrm{NO}_{2}, \text { wall }}\right)$ was adjusted to match wall pressure drop gradients, especially in the initial loading phase (the first 1-2 hours of loading).

9. Frequency factor for $\mathrm{NO}_{2}$ production in the $\mathrm{CPF}\left(A_{N O}\right)$ was calibrated so as to match DN-CPF $\mathrm{NO}_{2}$ concentrations.

Table 5.11 shows the CPF geometry and physical properties supplied to the model, corresponding to technical specifications data [41] for the CPF substrate used in this research: 10.5 in. diameter x 12 in. length, 200 cpsi, mean pore diameter $\left(d_{\text {pore }}\right)$ of $11 \mu \mathrm{m}$ and a clean porosity $\left(\epsilon_{0}\right)$ of $50 \%$.

Table 5.12 shows the exhaust properties, species concentrations and actual volumetric flow rates at each loading condition at $2200 \mathrm{rpm}$. These input data are 
based on the measured values for the individual loading condition (PM concentrations are from baseline tests). The gaseous emission data are the average values of the experimental data taken during the test. Exhaust PM concentrations were measured from baseline experiments conducted at the same speed and load conditions as the individual loading test. 


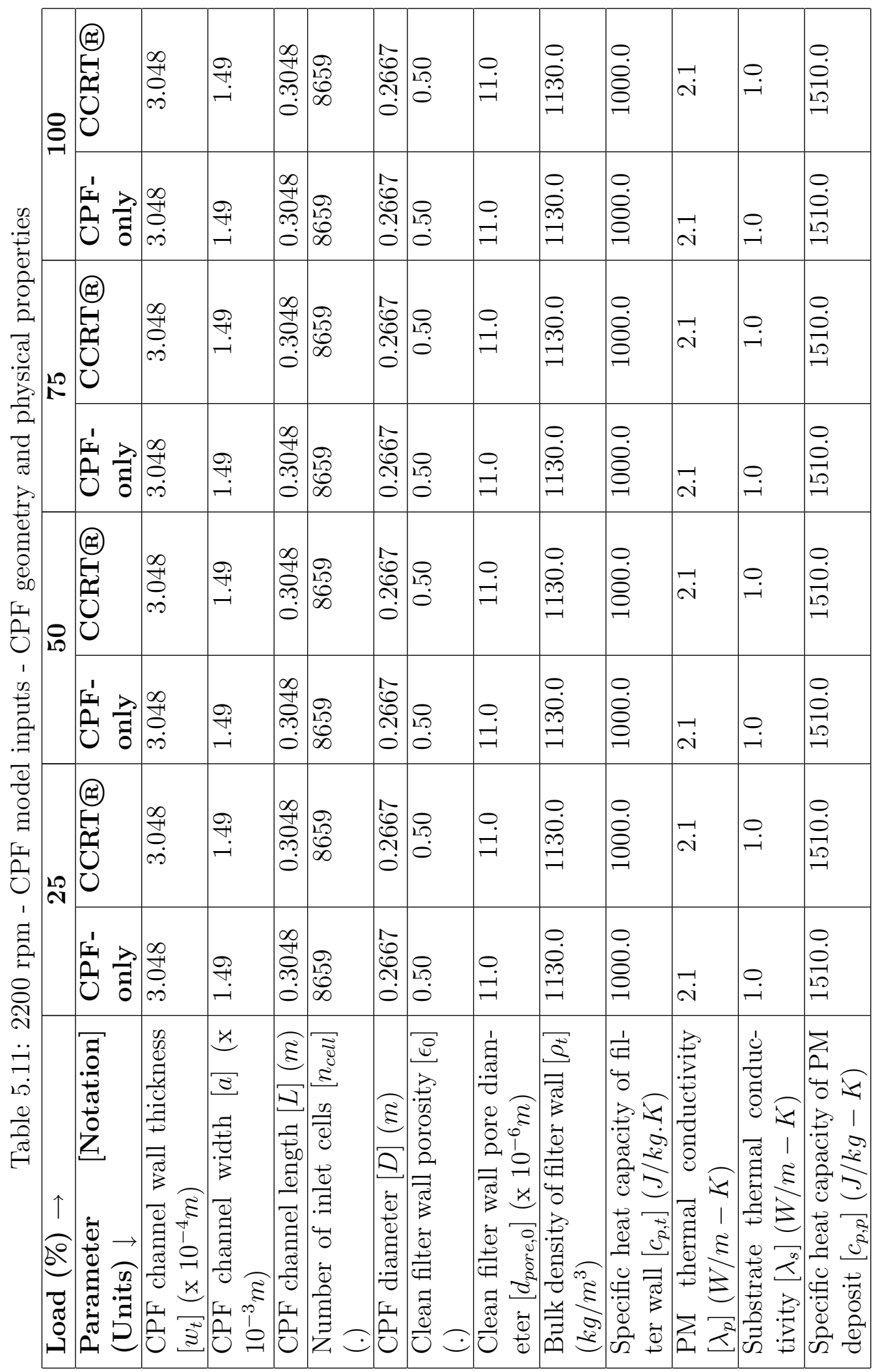




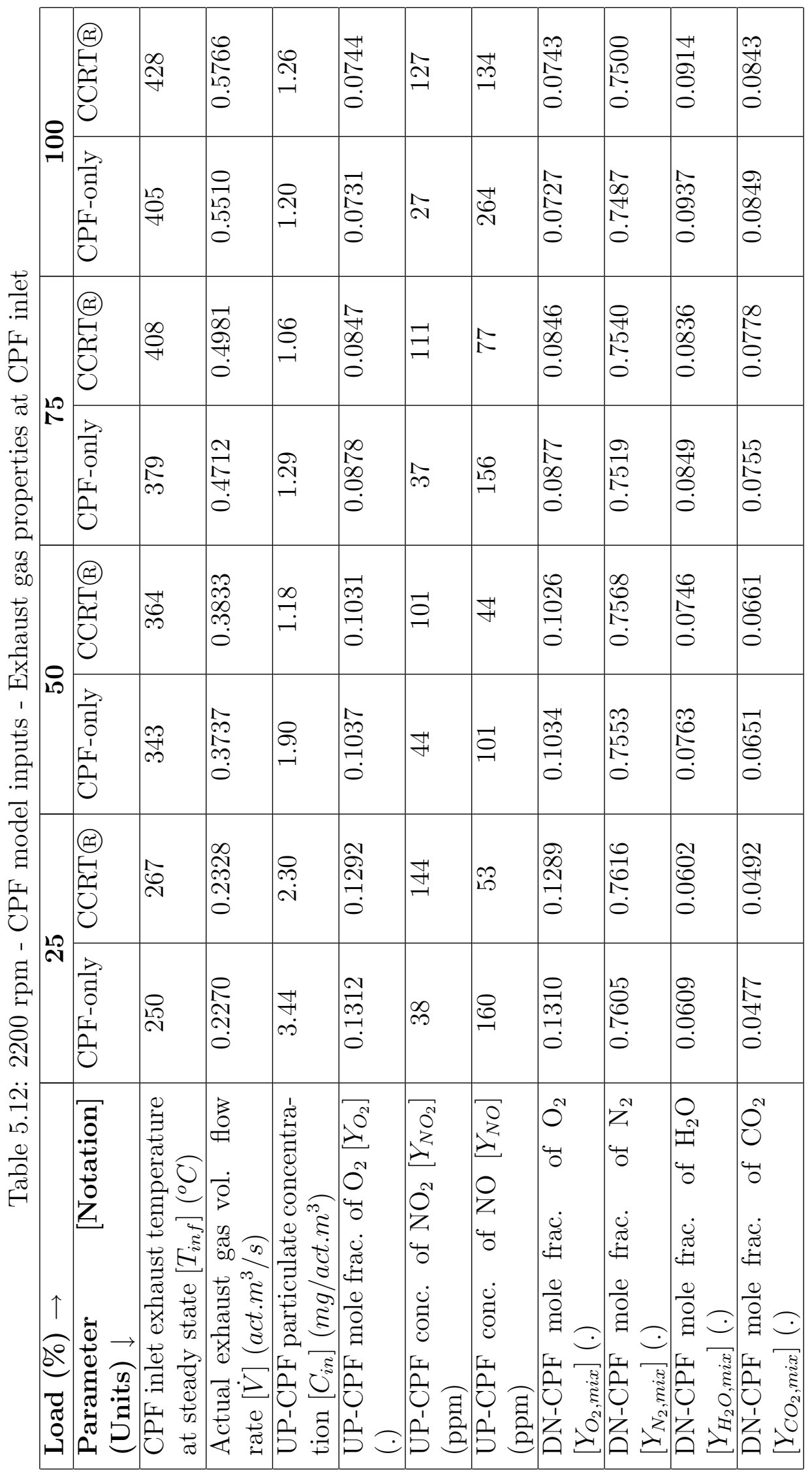


In addition to the exhaust gas properties in Table 5.12, CPF inlet temperatures as a function of loading time and average upstream particle size distribution are also required by the CPF model. Figure D.1 in Appendix D shows the CPF inlet temperatures given as inputs to the CPF model for model calibration at all load conditions at $2200 \mathrm{rpm}$.

Upstream particle size distribution data were collected during the loading experiments, and the average values of UP-CPF PSD were used as model inputs for calibration. Figures D.2 and D.3 show the CPF inlet PSD data used as inputs for CPF model calibration in CPF-only and CCRTß configurations at $2200 \mathrm{rpm}$ respectively.

Table 5.13 shows the third set of CPF model input parameters, namely kinetic parameters that were determined from the calibration of the model. All activation energy values used for the model were consistently kept constant, and pre-exponential factors of the individual reactions had to be adjusted to get the reaction rate needed for a given load condition. 


\begin{tabular}{|c|c|c|c|c|c|c|c|c|c|c|}
\hline$\oslash$ & 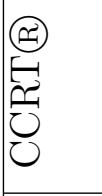 & 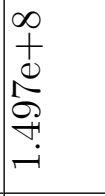 & 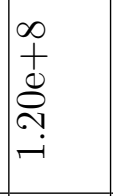 & $\begin{array}{l}\infty \\
+ \\
0 \\
0 \\
\infty \\
\tilde{N} \\
0\end{array}$ & $\begin{array}{l}\infty \\
+ \\
0 \\
0 \\
0 \\
8 \\
0 \\
0 \\
\end{array}$ & 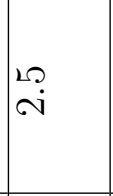 & $\stackrel{0}{0}$ & ユ & $\stackrel{0}{0}$ & 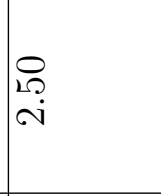 \\
\hline$=$ & $\begin{array}{c}\vec{z} \\
\vec{a} \\
0 \\
\frac{1}{12} \\
0 \\
0 \\
0\end{array}$ & 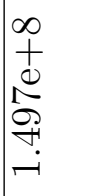 & $\begin{array}{l}\infty \\
+ \\
0 \\
0 \\
\stackrel{N}{+} \\
- \\
-\end{array}$ & 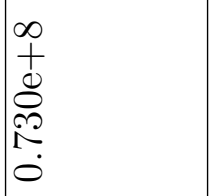 & $\begin{array}{l}\infty \\
+ \\
0 \\
0 \\
0 \\
0 \\
0 \\
0\end{array}$ & $\begin{array}{l}20 \\
\sim \\
\sim\end{array}$ & $\stackrel{0}{0}$ & $\begin{array}{l}\sim \\
\infty \\
\infty\end{array}$ & $\begin{array}{l}0 \\
\infty \\
\infty\end{array}$ & 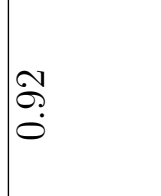 \\
\hline 1 & 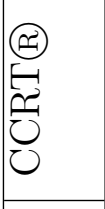 & 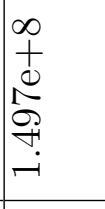 & 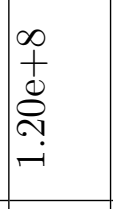 & 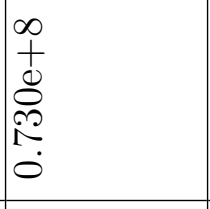 & $\begin{array}{l}\infty \\
+ \\
0 \\
0 \\
0 \\
\delta \\
0 \\
0\end{array}$ & $\begin{array}{l}10 \\
\sim \\
\sim\end{array}$ & $\stackrel{0}{0}$ & $\underset{r}{0}$ & $\begin{array}{l}0 \\
0\end{array}$ & $\begin{array}{l}8 \\
0 \\
i\end{array}$ \\
\hline & $\begin{array}{l}\overrightarrow{3} \\
\overrightarrow{0} \\
1 \\
\frac{1}{2} \\
\hat{0} \\
0\end{array}$ & 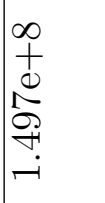 & 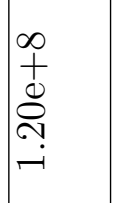 & $\begin{array}{l}\infty \\
+ \\
+ \\
0 \\
\stackrel{\infty}{0} \\
\stackrel{0}{0} \\
0 \\
0\end{array}$ & $\begin{array}{l}\infty \\
+ \\
0 \\
0 \\
0 \\
0 \\
0 \\
0\end{array}$ & $\begin{array}{l}10 \\
\sim \\
\sim\end{array}$ & $\stackrel{0}{0}$ & $\underset{r}{0}$ & $\begin{array}{l}0 \\
0\end{array}$ & $\begin{array}{l}\stackrel{0}{0} \\
\dot{0}\end{array}$ \\
\hline & 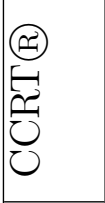 & 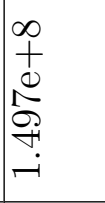 & 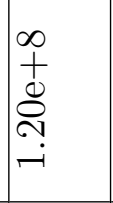 & $\begin{array}{l}\infty \\
+ \\
0 \\
0 \\
\infty \\
1 \\
0 \\
0\end{array}$ & $\begin{array}{l}\infty \\
+ \\
0 \\
0 \\
0 \\
0 \\
0 \\
0\end{array}$ & $\begin{array}{l}10 \\
\sim \\
\sim\end{array}$ & $\stackrel{0}{0}$ & $\stackrel{\sim}{\sim}$ & $\stackrel{0}{0}$ & $\underset{\sim}{\infty}$ \\
\hline D & $\begin{array}{l}\vec{z} \\
\vec{a} \\
0 \\
1 \\
\underline{1} \\
0 \\
0 \\
0\end{array}$ & 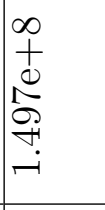 & 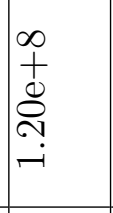 & \begin{tabular}{l}
$\infty$ \\
+ \\
+ \\
0 \\
$\infty$ \\
\multirow{2}{0}{} \\
0 \\
0
\end{tabular} & 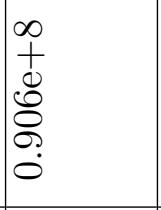 & $\begin{array}{l}10 \\
i \\
\sim\end{array}$ & $\stackrel{0}{0}$ & ــ & $\stackrel{0}{0}$ & $\stackrel{N}{\stackrel{N}{0}}$ \\
\hline & 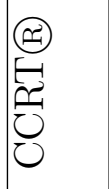 & 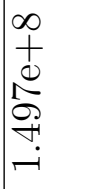 & $\begin{array}{l}\infty \\
+ \\
0 \\
\stackrel{0}{0} \\
\stackrel{\sim}{+} \\
-1\end{array}$ & 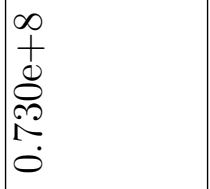 & $\begin{array}{l}\infty \\
+ \\
0 \\
0 \\
0 \\
0 \\
0 \\
0 \\
0\end{array}$ & $\begin{array}{l}10 \\
\sim \\
\sim\end{array}$ & $\stackrel{0}{0}$ & $\stackrel{100}{\forall}$ & $\stackrel{0}{0}$ & i? \\
\hline $\mathrm{N}$ & $\begin{array}{l}\vec{z} \\
\vec{a} \\
0 \\
1 \\
\underline{1} \\
0 \\
0\end{array}$ & 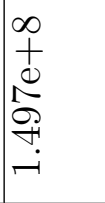 & 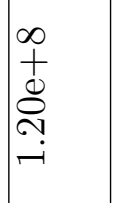 & 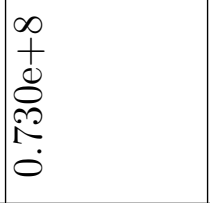 & 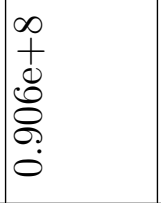 & $\begin{array}{l}10 \\
\sim \\
\sim\end{array}$ & $\stackrel{0}{0}$ & $\stackrel{2}{12}$ & $\stackrel{0}{0}$ & $\begin{array}{l}8 \\
\infty \\
0\end{array}$ \\
\hline 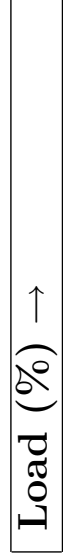 & 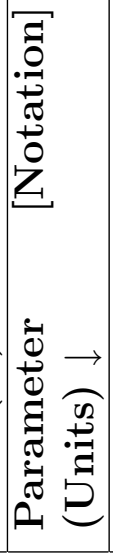 & 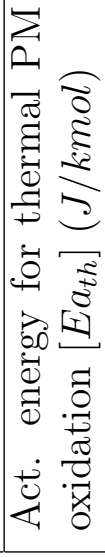 & 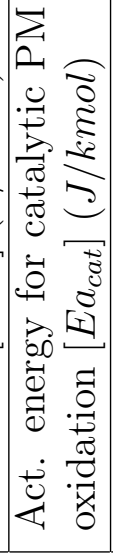 & 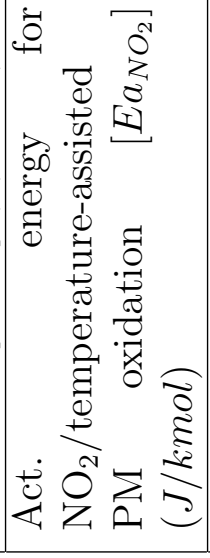 & 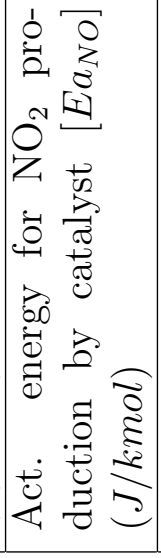 & 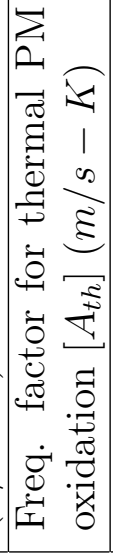 & 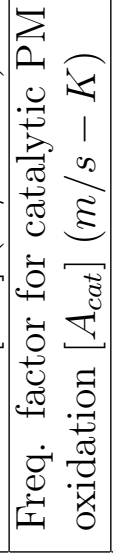 & 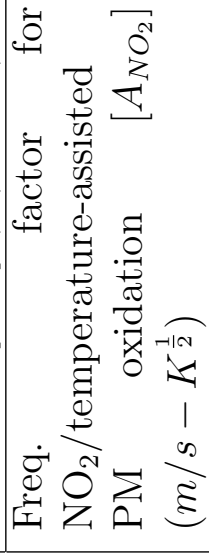 & 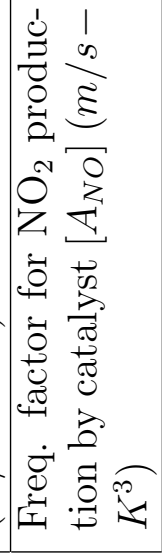 & 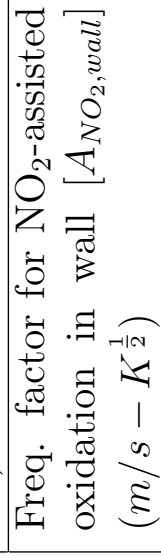 \\
\hline
\end{tabular}


Table 5.14 shows the substrate wall and PM cake properties determined from the calibration of the CPF model to experimental data at $2200 \mathrm{rpm}$. PM cake layer packing density at a particular loading condition was arrived at using a basic relation to the average Peclet number $(\mathrm{Pe})$, and was obtained in the form of a plot of PM cake layer packing density versus Peclet number[29]. The average Peclet numbers calculated from the different load conditions were used to determine the PM cake layer packing density values from Figure 5.20. The average Peclet number for each load condition is calculated according to the equations given in Appendix B (section B.5).

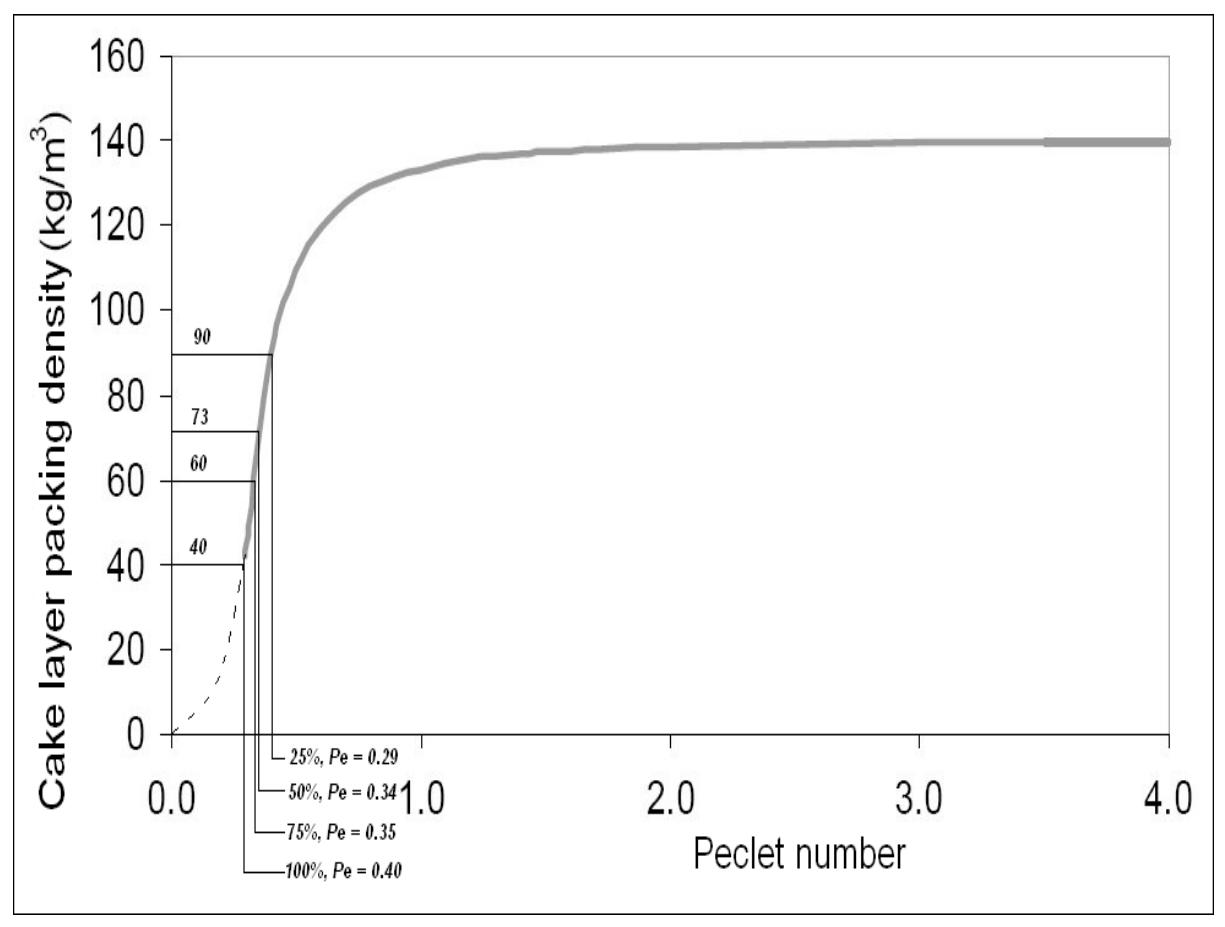

Figure 5.20: 2200 rpm - PM cake layer packing density versus Peclet number 


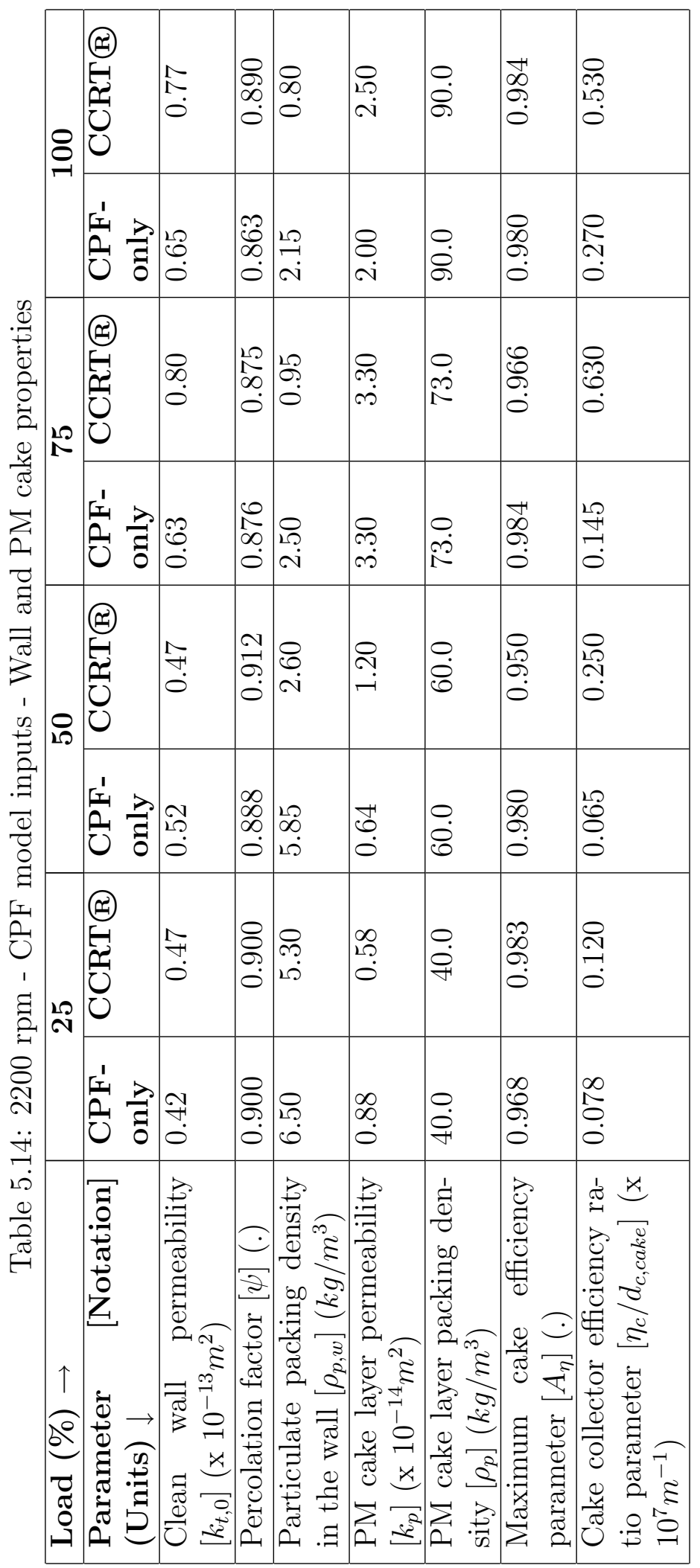


From the parameters in Tables 5.13 and 5.14 obtained from calibration of the model to $2200 \mathrm{rpm}$ CPF-only and CCRTß data, the following observations can be made:

- Clean wall permeability values $\left(k_{t, 0}\right)$ increased with increasing load in both configurations $\left(0.42 \mathrm{e}-13-0.65 \mathrm{e}-13 \mathrm{~m}^{2}\right.$ in the CPF-only configuration and $0.47 \mathrm{e}-$ $13-0.77 \mathrm{e}-13 \mathrm{~m}^{2}$ in the CCRTR configuration). Clean wall permeability values for each case needed to be varied from case to case, since the experiments were conducted in such a way that the filter wall was always 'partially loaded' at the initiation of measurement of pressure drop data.

- Percolation factor values $(\psi)$ decreased with increasing load in both configurations $(0.900-0.863$ in the CPF-only configuration and $0.900-0.875$ in the CCRT囚 configuration), except for the $50 \%$ CCRTß load. In this case, average value of percolation factor used was 0.912 , in order to correctly model the cake efficiency evolution.

- Activation energies for thermal PM oxidation $\left(E a_{t h}\right)$,catalytic PM oxidation $\left(E a_{c a t}\right), \mathrm{NO}_{2} /$ temperature-assisted oxidation reaction $\left(E a_{\mathrm{NO}_{2}}\right)$ and $\mathrm{NO}_{2}$ production reaction $\left(E a_{N O}\right)$ were maintained constant with loads in both configurations. The values used were $1.497 \mathrm{e}+08 \mathrm{~J} / \mathrm{kmol}, 1.20 \mathrm{e}+08 \mathrm{~J} / \mathrm{kmol}, 0.730 \mathrm{e}+08$ $\mathrm{J} / \mathrm{kmol}$, and $0.906 \mathrm{e}+08 \mathrm{~J} / \mathrm{kmol}$ respectively.

- Frequency factor for thermal oxidation reaction $\left(A_{t h}\right)$ was maintained constant at $2.5 \mathrm{~m} / \mathrm{s}-K$ for all loads in both configurations.

- Frequency factor for catalytic oxidation reaction $\left(A_{\text {cat }}\right)$ was maintained constant at zero $(0) m / s-K$, since this reaction mechanism was found out to be not necessary to be included for explaining the oxidation behavior of a CCRT $\mathbb{R}$ $[3,12]$. The effect of a catalyst on the CPF substrate wall would, instead, 
be manifested as increased oxidation efficiencies of $\mathrm{NO}_{2} /$ temperature-assisted oxidation mechanism in layer 1 and the wall.

- Frequency factors for $\mathrm{NO}_{2} /$ temperature-assisted PM oxidation reaction $\left(A_{\mathrm{NO}_{2}}\right)$ were found to decrease with increasing loads in both configurations $(7.5-3.2$ $\mathrm{m} / \mathrm{s}-K^{\frac{1}{2}}$ in CPF-only configuration and $4.50-1.1 \mathrm{~m} / \mathrm{s}-K^{\frac{1}{2}}$ in CCRTß configuration).

- Frequency factor for $\mathrm{NO}_{2}$ production by catalyst $\left(A_{N O}\right)$ was calibrated for one load case (100\% CPF-only) at $2200 \mathrm{rpm}$ in which the $\mathrm{NO}_{2}$ production was more than $\mathrm{NO}_{2}$ consumption by $\mathrm{NO}_{2}$ /temperature-assisted PM oxidation reaction, and the value used in this load case was $80 \frac{m}{s-K^{3}}$. In all other load cases, $A_{N O}$ was set to $0.0 \frac{m}{s-K^{3}}$, due to non-availability of data regarding $\mathrm{NO}_{2}$ production in the $\mathrm{CPF}$. The reliability of these values and $\mathrm{NO}_{2}$ production due to the values of $A_{N O}$ used are discussed later in this section.

- Frequency factors for $\mathrm{NO}_{2}$-PM reaction in the wall $\left(A_{N_{2}, \text { wall }}\right)$ showed a general trend of decreasing with increasing load in both configurations, although from $75 \% \mathrm{CPF}$-only to $100 \% \mathrm{CPF}$-only case, the values of $A_{\mathrm{NO}_{2} \text {,wall }}$ increased (from 0.6 to $\left.0.922 \mathrm{~m} / \mathrm{s}-K^{\frac{1}{2}}\right)$.

- Cake layer permeability values $\left(k_{p}\right)$ were found to increase with increasing load from $25 \%$ to $75 \%$ and then decrease for $100 \%$ load cases in both configurations.

- Cake packing density values for both CPF-only and CCRT® configurations at $2200 \mathrm{rpm}$ were obtained from the Peclet number correlation [29] (as shown in Figure 5.20), and were found to increase with increasing load (and hence, increasing Peclet number).

- Particulate packing density in the wall $\left(\rho_{p, w}\right)$ decreased with increasing load in both configurations $\left(6.5-2.15\right.$ in CPF-only configuration and $5.3-0.8 \mathrm{~kg} / \mathrm{m}^{3}$ 
in CCRT $\AA$ configuration). It was also observed by comparing corresponding load-cases in both configurations that wall packing densities in the CPF-only configuration were consistently higher than corresponding values of the same in the CCRT $\mathrm{R}$ configuration.

- The cake collector efficiency ratio parameter $\left(\eta_{c} / d_{c, c a k e}\right)$ showed a general trend of increasing with increasing load in both configurations $(0.08 \mathrm{E}+07-0.26 \mathrm{E}+07$

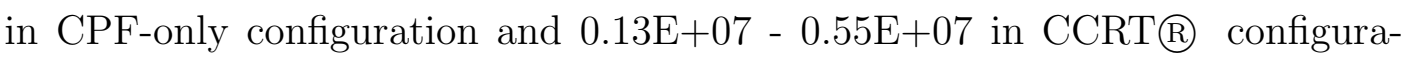
tion), except for the 50\% CPF-only and 75\% CCRTß configurations.

Pressure drop profiles across the CPF predicted by the model were calibrated

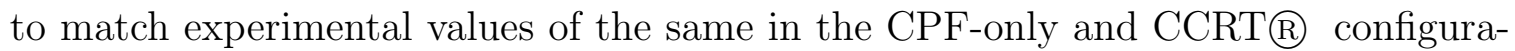
tions. Table 5.15 shows a comparison between the initial pressure drops obtained from model calibration and experimentally obtained values. Experimental values considered here are the averages of the pressure drops (frequency of measurement was once in every 5 seconds) for the first 1 minute, due to a sharp increase $(0.8-1.2 \mathrm{kPa})$ in the pressure drop in the first minute. It was observed that using the 1-D 2-layer CPF model, initial pressure drops could be predicted within a maximum percentage error of $49 \%$ (in the $25 \%$ CPF-only load case) of the experimental values. The deviation of the calibrated model results could be due to the following reasons:

Table 5.15: Comparison of initial pressure drops obtained from Experimental and model-predicted values in the CPF-only and CCRTR configurations at $2200 \mathrm{rpm}$

\begin{tabular}{|c|c|c|c|c|c|c|c|c|}
\hline Load $\downarrow$ & \multicolumn{4}{|c|}{ CPF-only } & \multicolumn{4}{c|}{ CCRTR } \\
\hline & expt. & model & diff. & \% diff. & expt. & model & diff. & \% diff. \\
\hline $\mathbf{( \% )}$ & $\mathbf{( k P a )}$ & $\mathbf{( k P a )}$ & $\mathbf{( k P a )}$ & $\mathbf{( \% )}$ & $\mathbf{( k P a )}$ & $\mathbf{( k P a )}$ & $\mathbf{( k P a )}$ & $\mathbf{( \% )}$ \\
\hline 25 & 1.63 & 2.43 & 0.80 & 49 & 1.83 & 2.53 & 0.71 & 39 \\
\hline 50 & 3.25 & 4.32 & 1.07 & 33 & 2.90 & 3.00 & 0.10 & 3 \\
\hline 75 & 4.48 & 4.62 & 0.14 & 3 & 5.20 & 4.75 & -0.45 & -9 \\
\hline 100 & 5.98 & 5.66 & -0.32 & -5 & 6.56 & 4.83 & -1.73 & -26 \\
\hline
\end{tabular}


1. Clean wall permeability values $\left(\mathrm{k}_{t, 0}\right)$ given as input to the 1-D CPF model were not constant for all load-cases. This was because the experimental setup was designed with a single exhaust line to which the CPF was always connected, and exhaust gas passed through the CPF from the instant the engine was started. Because of this, at the starting point of recording CPF pressure drop values (which was typically between 2 to 5 minutes from the time the engine was started), the filter was not completely clean. Therefore, clean wall permeability values obtained from calibration of the 1-D CPF model indicate the corresponding instantaneous permeability values of the loaded $\mathrm{CPF}$ at the particular instant of time at which measurement was started.

2. Since CPF wall temperatures were not measured, they were assumed to be the average of the inlet and outlet gas temperatures. This assumption, although simple and straight-forward, may not hold good due to the fact that temperatures at the CPF inlet and outlet were still increasing in a non-linear fashion, and the thermal inertia of the substrate was not taken into consideration while calculating the $\mathrm{CPF}$ wall temperature at the initial point $\left(t_{w, 0}\right)$. The contribution of this effect to the initial pressure drop, however, was considered secondary to that of clean wall permeability values.

Figures 5.21 and 5.22 show the CPF pressure drop profiles obtained from calibration of the model against the corresponding experimental profiles measured for the CPF-only and CCRT $\AA$ configurations respectively.

A point-by-point comparison of the experimental and model pressure drop data indicated that the model pressure drops were fit to within $0.85 \mathrm{kPa}$ of the experimental values, except for the $100 \%$ CCRT@ load-case, where the initial 'steep' part of the pressure drop rise was predicted to within $1.22 \mathrm{kPa}$. Figures 5.23 and 5.24 show point-by-point comparisons of the model-predicted and experimental pressure drops for the eight load-cases looked at in this section, which shows good agreement 


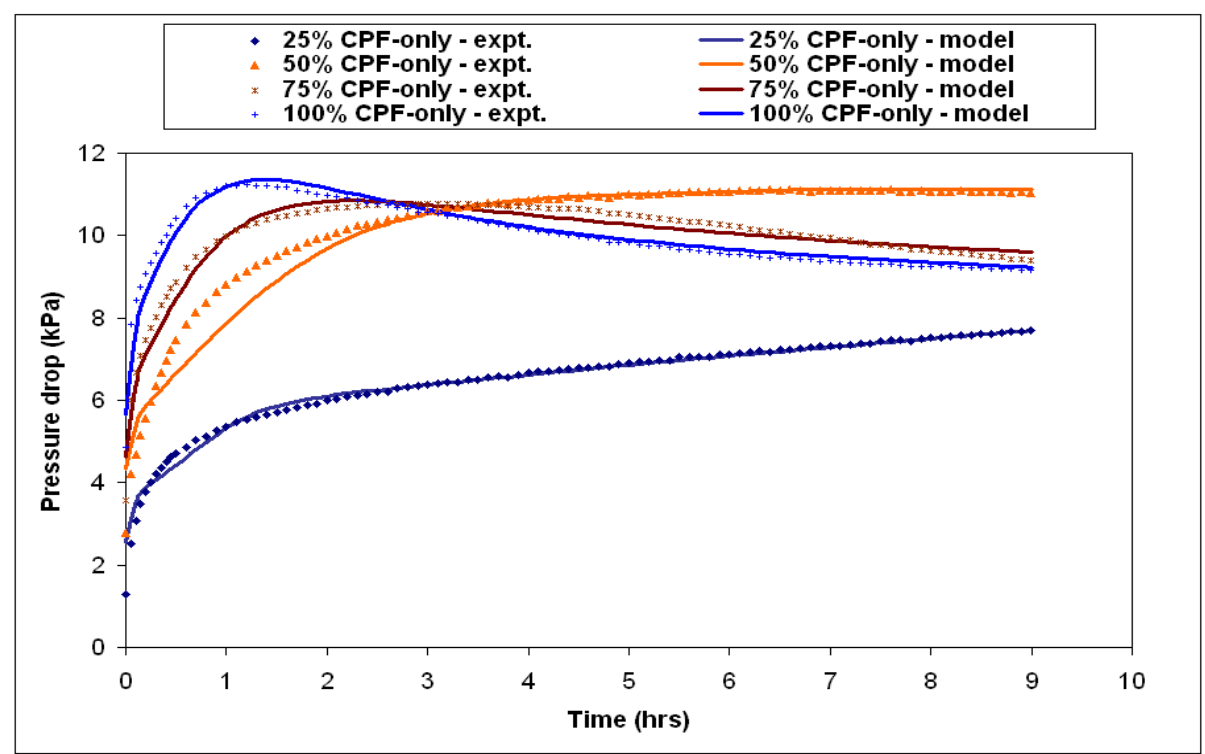

Figure 5.21: 2200 rpm CPF-only - Experimental and model-predicted pressure drop profiles versus time

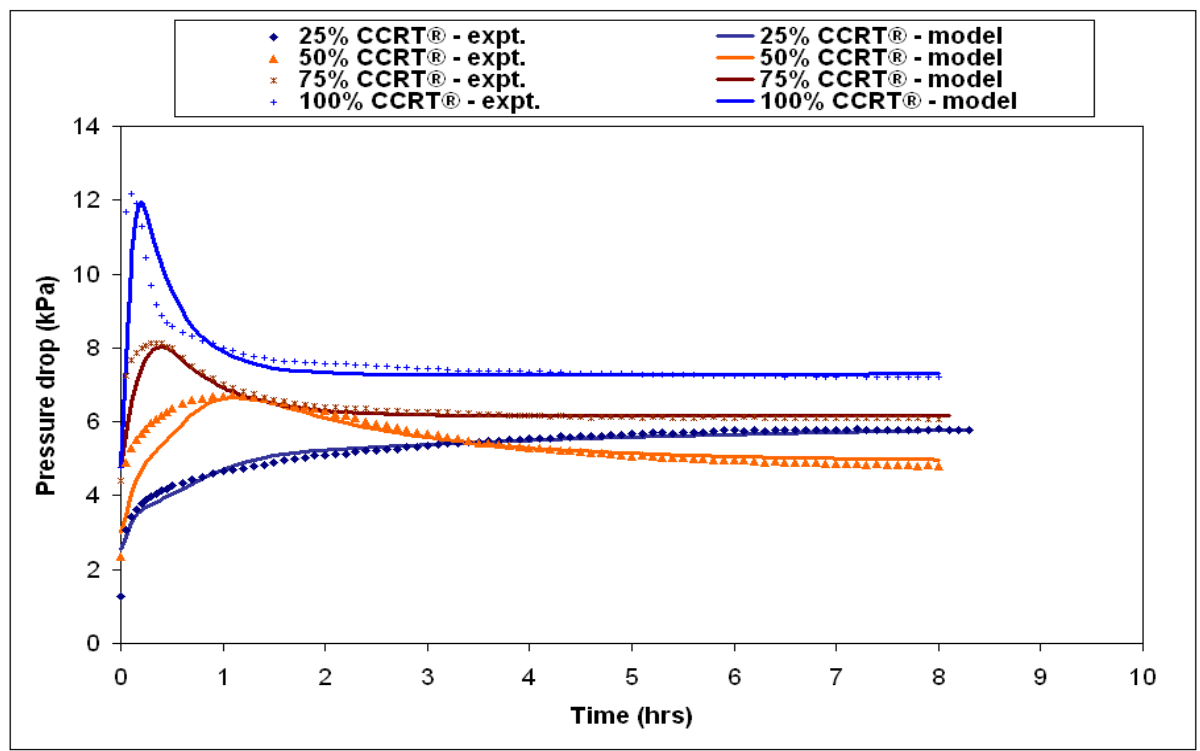

Figure 5.22: 2200 rpm CCRTß - Experimental and model-predicted pressure drop profiles versus time

(minimum value of least squares fit coefficient $R^{2}=0.95$ ) for all cases, except for the

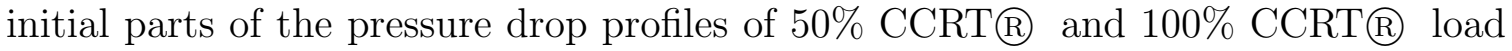
cases.

Oxidation characteristics of the CPF at different loads in CPF-only and 


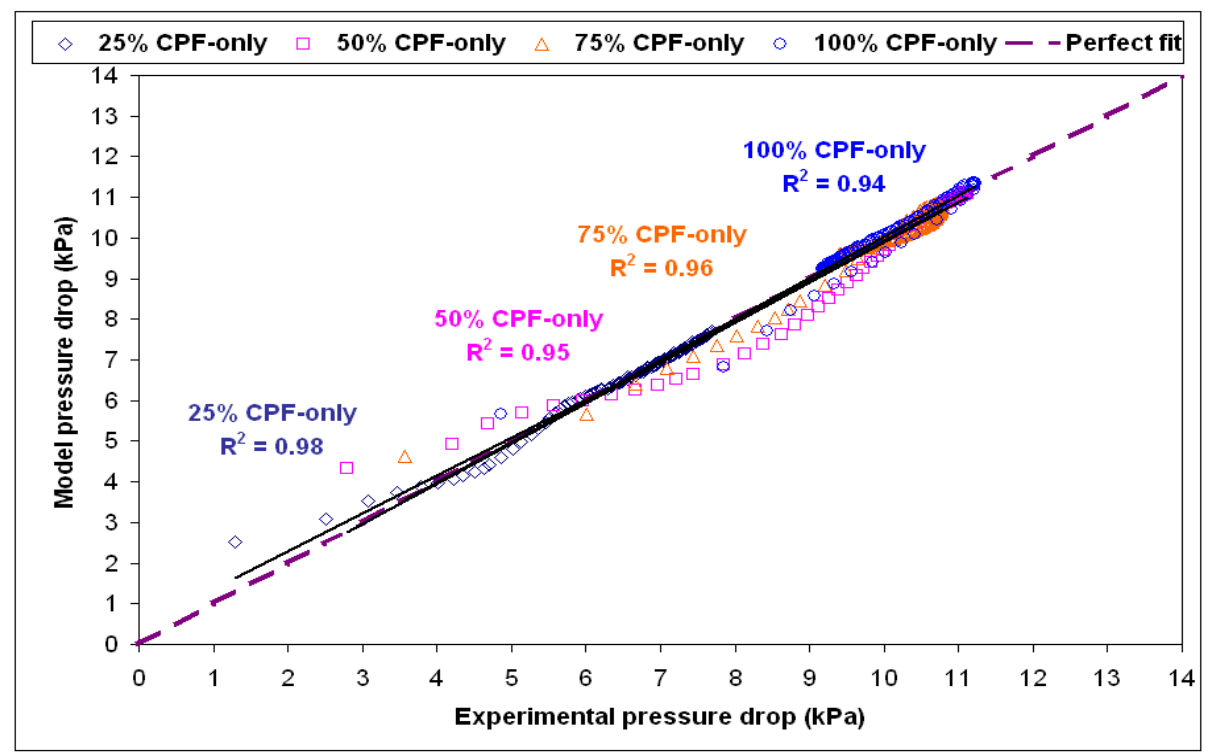

Figure 5.23: 2200 rpm CPF-only - Model-predicted versus experimental pressure drops - A point-by-point comparison

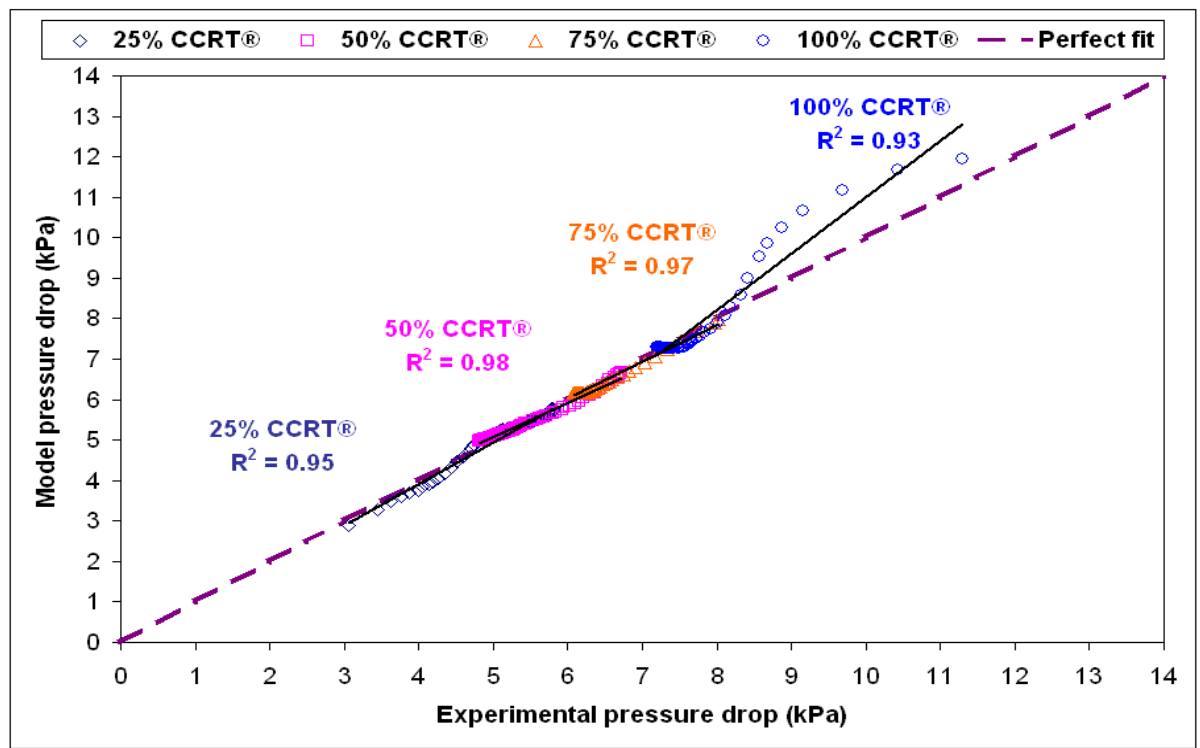

Figure 5.24: 2200 rpm CCRTß - Model-predicted versus experimental pressure drops - A point-by-point comparison

CCRTR configurations were studied by using PM mass balance simulation results from the calibrated 1-D 2-layer CPF model. Table 5.16 gives an overview of the percentage oxidation of CPF inlet PM in both CPF-only and CCRT $\mathrm{R}$ configurations. Model-predicted values of PM mass deposited were within $14.1 \%$ of experimental 
values and model-predicted PM mass oxidized were within $8.9 \%$ of values calculated from experimental data. It was also observed during experimental data analysis that experimental values of PM mass deposited obtained from measurement of CPF weights were either unreliable or inaccurate at certain loading conditions in the 2200 rpm experiments (specifically, 25\% CPF-only, 25\% CCRTß and 50\% CPF-only). For understanding the cause behind these apparent errors, a CPF weight gain analysis was conducted on the CPF weight data, and the results are presented in Appendix G. The values in the column labeled 'Experimental PM mass deposited' in these cases are the corrected values based on the data presented in Table 5.6.

CPF outlet efficiencies at all loads in CPF-only and CCRT@ configurations were studied using DN-CPF PSD data, since CPF outlet PM concentration measurements using the DN-CPF PM sampling system (50mm filters) were not accurate. For comparing the particulate filtering efficiency of the CPF, the total particulate volume concentration obtained from the CPF model as a function of time was compared to the particulate volume concentration obtained from different experimental samples taken at different times into the loading experiment. Total particulate volume concentration is calculated as:

$$
P V C=\sum_{n=1}^{106} n_{i} \frac{4}{3}\left(\frac{d_{p, i}}{2}\right)^{3}
$$

where $P V C$ is expressed in $m^{3} P M / s t d-m^{3} e x h . n_{i}$ are the individual particulate numbers in number $/$ std. $m^{3}$, and $d_{i}$ are the corresponding mean particulate diameters expressed in $m$. The experimental values are computed from the downstream PSD data, and model-predicted values are output as a function of loading time.

Figures 5.25 and 5.26 show comparisons between experimental and modelpredicted values of total particulate volume concentration downstream of the CPF (DN-CPF) versus time for CPF-only and CCRTR configurations respectively. 
Table 5.16: Comparison of experimental and model-predicted PM mass deposited and oxidized

\begin{tabular}{|c|c|c|c|c|c|c|c|c|c|c|c|}
\hline & & & & zne & zen & & & or & & & \\
\hline 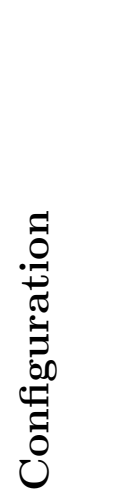 & 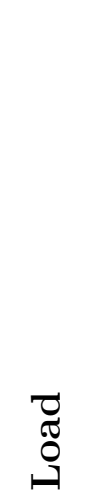 & 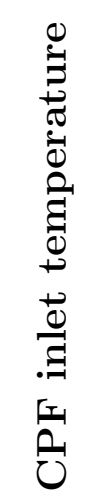 & 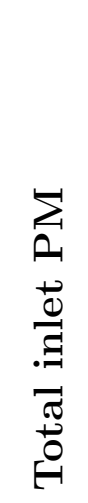 & 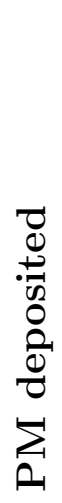 & 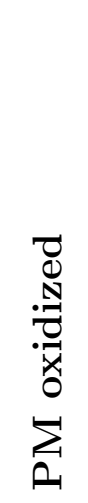 & 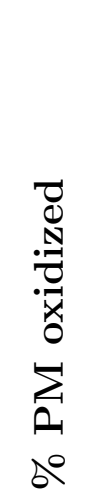 & $\begin{array}{l}0 \\
0 \\
.0 \\
0 \\
0 \\
0 \\
0 \\
0 \\
0 \\
\sum_{1}\end{array}$ & 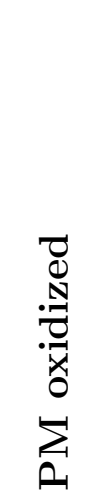 & 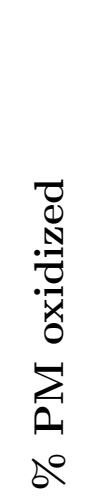 & 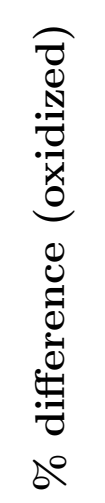 & 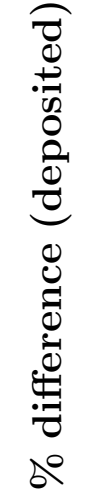 \\
\hline & $(\%)$ & $\left({ }^{o} \mathbf{C}\right)$ & $(\mathrm{g})$ & (g) & $(\mathrm{g})$ & $(\%)$ & $(\mathrm{g})$ & $(\mathrm{g})$ & $(\%)$ & $(\%)$ & $(\%)$ \\
\hline & 25 & 250 & 25.3 & 19 & 6.1 & 25.0 & 19.3 & 5.6 & 22.1 & 1.7 & -2.9 \\
\hline & 50 & 343 & 23.0 & 16 & 6.8 & 30.3 & 15.8 & 6.7 & 29.3 & -1.1 & -1.0 \\
\hline$x \geq$ & 75 & 379 & 19.7 & 12 & 7.5 & 38.9 & 12.2 & 7.2 & 36.3 & 1.9 & -2.6 \\
\hline$\tilde{0}$ & 100 & 405 & 21.4 & 5 & 16.2 & 76.6 & 5.4 & 15.7 & 73.1 & 8.0 & -3.5 \\
\hline & 25 & 267 & 16.0 & 12 & 3.9 & 25.2 & 10.3 & 5.5 & 34.1 & -14.1 & 8.9 \\
\hline$(\approx)$ & 50 & 364 & 14.0 & - & 7.8 & 57.1 & 5.9 & 8.0 & 56.9 & 1.7 & -0.2 \\
\hline 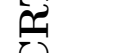 & 75 & 408 & 15.4 & 3 & 12.2 & 80.5 & 3.0 & 12.1 & 78.7 & 1.6 & -1.8 \\
\hline 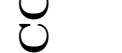 & 100 & 428 & 21.6 & 2 & 19.4 & 90.7 & 2.2 & 19.1 & 88.6 & 12.0 & -2.1 \\
\hline
\end{tabular}



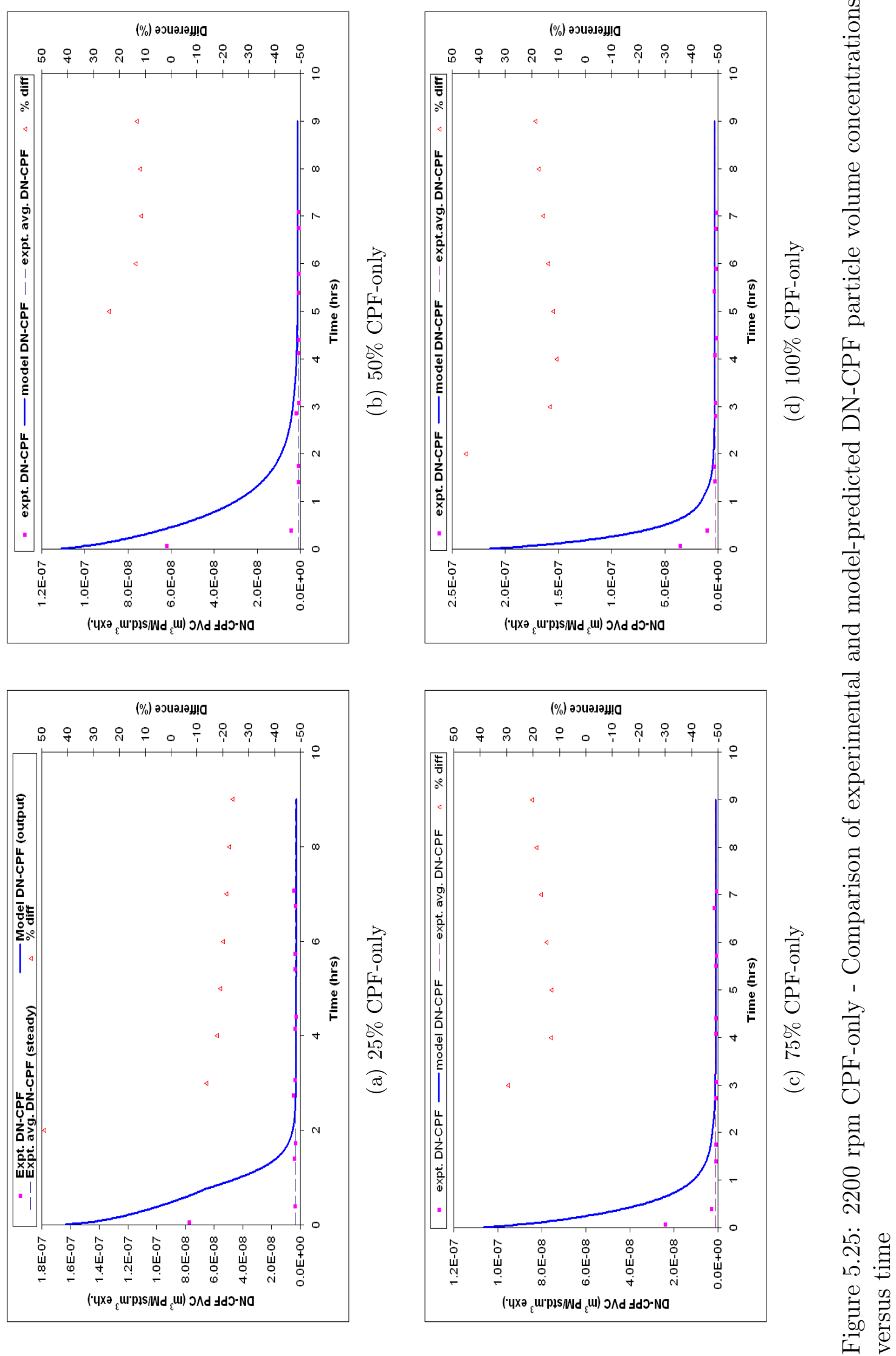

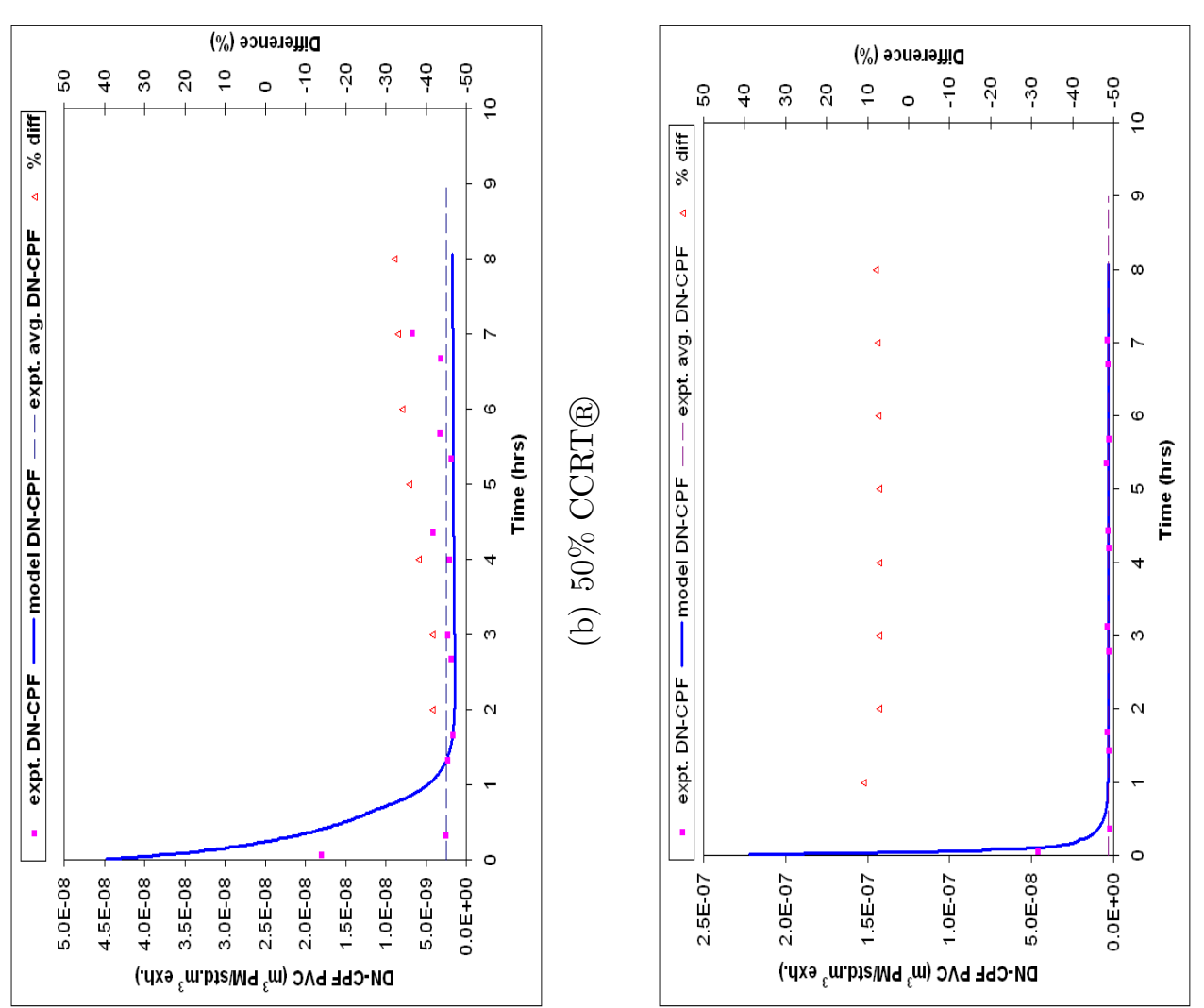

0
0
0
0
0
0
0
0
0
0
0
0
0
0
0
0
0
0
0
0
0
1
1
0
0
0
0
0
0
0
1
0
0
0
0
0
0
0
0
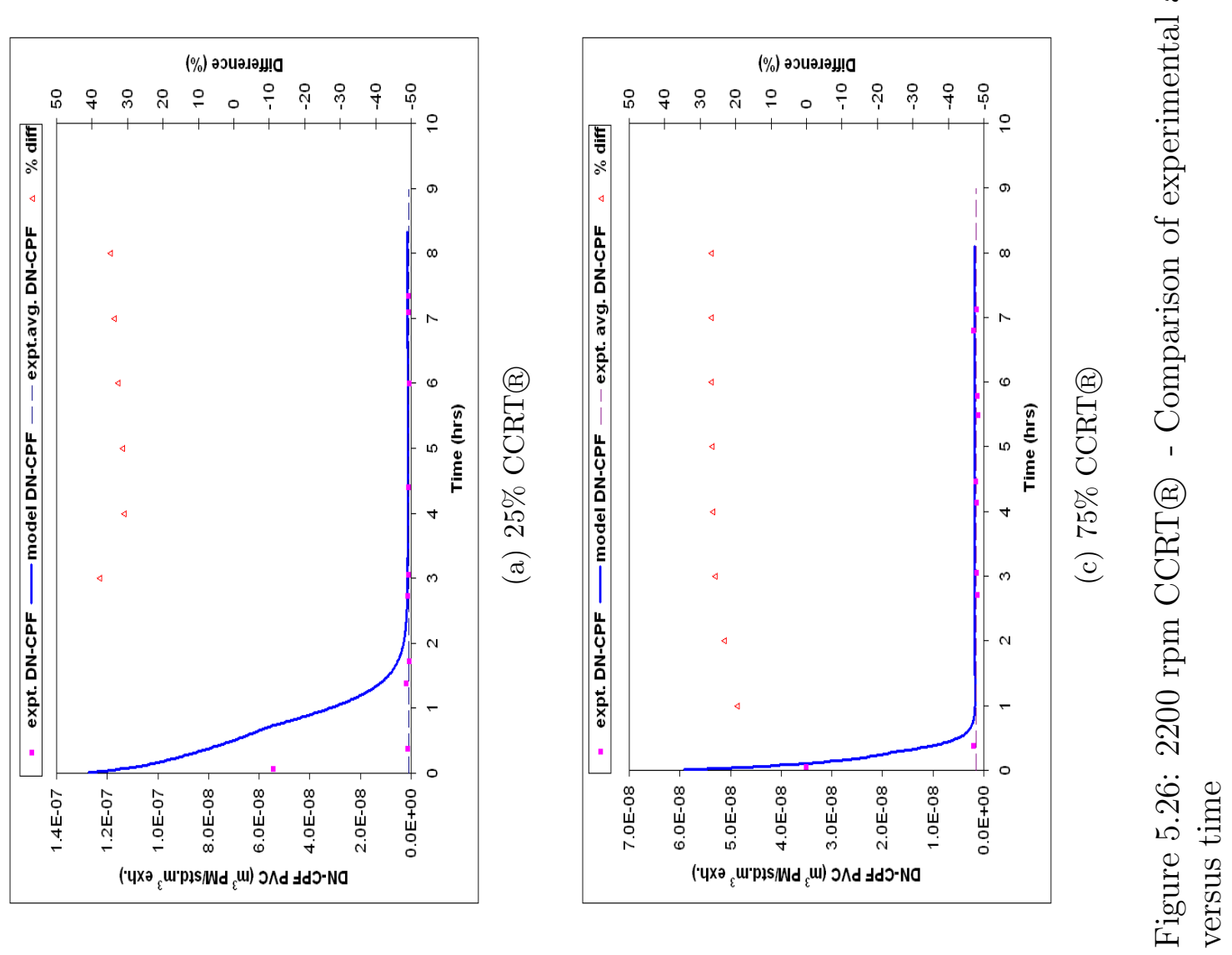
Table 5.17 shows a comparison of DN-CPF particulate volume concentrations calculated from SMPS data and those predicted by the CPF model, at 4,6 and 8 hours of loading time. The experimental outlet particle volume concentrations shown are average values, excluding the first two SMPS samples taken at 4 minutes and 24 minutes from the start of loading time. Hence, the experimental PVC shown in Table 5.17 are 'steady-state' values, attained after PM cake layer becomes the primary filter. Downstream PVC values were matched within $\pm 40 \%$ of the experimental values for all load cases, by adjusting the $A_{\eta}$ values input to the CPF model.

Table 5.18 shows a comparison of $\mathrm{NO}$ and $\mathrm{NO}_{2}$ concentrations upstream and downstream of the CPF in both CPF-only and CCRT $\AA$ configurations at $2200 \mathrm{rpm}$. $\mathrm{NO}_{2}$ concentrations were found to be decreasing from inlet to outlet in all cases except the $100 \%$ load in CPF-only configuration. This observation was contrary to findings from recent research work on an earlier CCRT® [12] and a comparison between observed $\mathrm{NO}_{2}$ concentrations in this thesis and previous research[12] is discussed in Section 5.4.2. The possible reasons for reduction in $\mathrm{NO}_{2}$ concentration as the exhaust

Table 5.17: Comparison of experimental and model-predicted DN-CPF PVC

\begin{tabular}{|c|c|c|c|c|c|c|c|c|}
\hline & \multicolumn{4}{|c|}{ CPF-only } & \multicolumn{4}{|c|}{ CCRTß } \\
\hline 莡 & 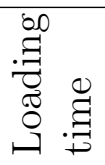 & 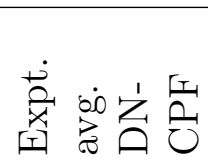 & 苞光至 & Diff. & 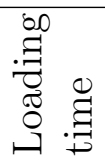 & 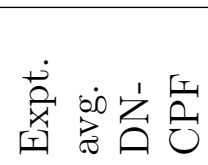 & 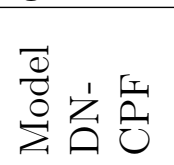 & Diff. \\
\hline$(\%)$ & (hrs) & $\left(\frac{m^{3}}{s t d \cdot m^{3}}\right)$ & $\left(\frac{m^{3}}{s t d . m^{3}}\right)$ & $(\%)$ & (hrs) & $\left(\frac{m^{3}}{s t d \cdot m^{3}}\right)$ & $\left(\frac{m^{3}}{s t d . m^{3}}\right)$ & $(\%)$ \\
\hline \multirow{3}{*}{25} & 4 & $3.60 \mathrm{E}-09$ & $2.97 \mathrm{E}-09$ & -17.7 & 4 & $1.02 \mathrm{E}-09$ & $1.33 \mathrm{E}-09$ & 30.9 \\
\hline & 6 & 3.60E-09 & $2.88 \mathrm{E}-09$ & -20.1 & 6 & $1.02 \mathrm{E}-09$ & $1.35 \mathrm{E}-09$ & 32.7 \\
\hline & 8 & $3.60 \mathrm{E}-09$ & 2.80E-09 & -22.4 & 8 & $1.02 \mathrm{E}-09$ & $1.37 \mathrm{E}-09$ & 34.9 \\
\hline \multirow{3}{*}{50} & 4 & $1.09 \mathrm{E}-09$ & 1.30E-09 & 19.6 & 4 & $2.49 \mathrm{E}-09$ & $1.54 \mathrm{E}-09$ & -38.1 \\
\hline & 6 & 1.09E-09 & $1.24 \mathrm{E}-09$ & 13.7 & 6 & $2.49 \mathrm{E}-09$ & 1.64E-09 & -34.1 \\
\hline & 8 & 1.09E-09 & $1.22 \mathrm{E}-09$ & 12.2 & 8 & $2.49 \mathrm{E}-09$ & $1.68 \mathrm{E}-09$ & -32.2 \\
\hline \multirow{3}{*}{75} & 4 & $9.33 \mathrm{E}-10$ & $1.06 \mathrm{E}-09$ & 13.3 & 4 & $1.45 \mathrm{E}-09$ & $1.83 \mathrm{E}-09$ & 26.5 \\
\hline & 6 & $9.33 \mathrm{E}-10$ & 1.07E-09 & 15.0 & 6 & $1.45 \mathrm{E}-09$ & $1.84 \mathrm{E}-09$ & 26.8 \\
\hline & 8 & $9.33 \mathrm{E}-10$ & 1.11E-09 & 18.8 & 8 & $1.45 \mathrm{E}-09$ & $1.84 \mathrm{E}-09$ & 27.0 \\
\hline \multirow{3}{*}{100} & 4 & $2.85 \mathrm{E}-09$ & $3.16 \mathrm{E}-09$ & 10.8 & 4 & $3.09 \mathrm{E}-09$ & $3.31 \mathrm{E}-09$ & 7.2 \\
\hline & 6 & $2.85 \mathrm{E}-09$ & $3.25 \mathrm{E}-09$ & 14.0 & 6 & 3.09E-09 & 3.31E-09 & 7.3 \\
\hline & 8 & $2.85 \mathrm{E}-09$ & 3.35E-09 & 17.4 & 8 & 3.09E-09 & 3.33E-09 & 7.9 \\
\hline
\end{tabular}


mixture passes through the $\mathrm{CPF}$ are:

1. $\mathrm{NO}_{2}$ /temperature-assisted PM oxidation,

2. Dissociation of $\mathrm{NO}_{2}$ to produce $\mathrm{NO}$ and $\mathrm{O}_{2}$,

3. Oxidation reactions of $\mathrm{CO}$ and $\mathrm{HC}$ with $\mathrm{NO}_{2}$ (as mentioned in reference [5]), and

4. Experimental errors involved in measuring $\mathrm{NO}_{2}$ concentrations.

Table 5.18: Comparison of experimental $\mathrm{NO}$ and $\mathrm{NO}_{2}$ concentration at $\mathrm{CPF}$ inlet and outlet at $2200 \mathrm{rpm}$

\begin{tabular}{|c|c|c|c|c|c|c|c|c|}
\hline \multirow[t]{2}{*}{ 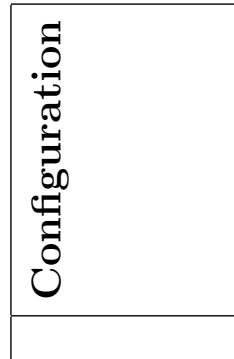 } & 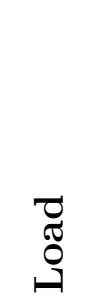 & 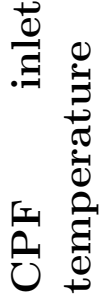 & 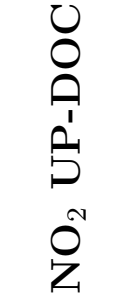 & 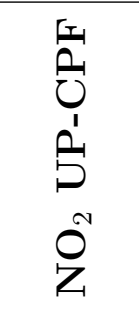 & 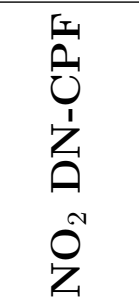 & $\begin{array}{l}0 \\
0 \\
9 \\
\rho^{\prime} \\
\vdots \\
0 \\
0 \\
Z\end{array}$ & $\begin{array}{l}\frac{1}{1} \\
0 \\
0 \\
1 \\
\rho_{1}^{\prime} \\
\vdots \\
0 \\
Z \\
Z\end{array}$ & 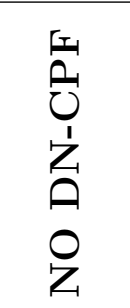 \\
\hline & $(\%)$ & $\left({ }^{o} \mathbf{C}\right)$ & (ppm) & (ppm) & (ppm) & (ppm) & (ppm) & $(\mathrm{ppm})$ \\
\hline \multirow{4}{*}{ CPF-only } & 25 & 250 & NA & 38 & 12 & NA & 160 & 185 \\
\hline & 50 & 343 & NA & 44 & 21 & NA & 101 & 126 \\
\hline & 75 & 379 & NA & 37 & 19 & NA & 156 & 174 \\
\hline & 100 & 405 & NA & 27 & 33 & NA & 264 & 259 \\
\hline \multirow{4}{*}{ CCRT@ } & 25 & 267 & 44 & 144 & 125 & 154 & 46 & 72 \\
\hline & 50 & 364 & 45 & 101 & 65 & 99 & 44 & 81 \\
\hline & 75 & 408 & 39 & 111 & 74 & 149 & 80 & 114 \\
\hline & 100 & 428 & 29 & 127 & 91 & 230 & 145 & 170 \\
\hline
\end{tabular}

$\mathrm{NO}_{2}$ production was observed to be taking place in the CPF simultaneously with $\mathrm{NO}_{2}$ consumption in the $100 \% \mathrm{CPF}$-only case with high $\mathrm{CPF}$ inlet temperature and low $\mathrm{CPF}$ inlet $\mathrm{NO}_{2}$ concentrations since there was an increase in $\mathrm{NO}_{2}$ concentrations observed across the $\mathrm{CPF}$. The outlet concentration of $\mathrm{NO}_{2}$ is determined by the balance between these 'competing' reactions, to consume and produce $\mathrm{NO}_{2}$. In order to study the possible causes of $\mathrm{NO}_{2}$ consumption in CPF-only and CCRT $囚$ configurations, experimental species concentration data at $2200 \mathrm{rpm}$ was analyzed. 
Table 5.19 shows the $\mathrm{CO}, \mathrm{HC}, \mathrm{NO}_{x}, \mathrm{NO}$ and $\mathrm{NO}_{2}$ concentrations observed at 25, 50, 75 and $100 \%$ load in CPF-only and CCRTß configurations at $2200 \mathrm{rpm}$. Note that here, the UP-CPF values in the CCRT $\AA$ configuration were estimated from

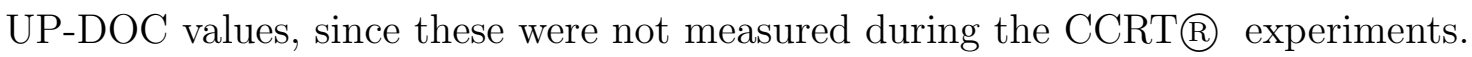

From Table 5.19, the following were observed:

- $\mathrm{NO}_{x}$ concentrations in CPF-only and CCRTR configurations were conserved in all UP-CPF and DN-CPF measurements within $\pm 2 \mathrm{ppm}$. This means that the measurements made in the ' $\mathrm{NO}_{x}$ ' mode were accurate.

- Decrease in $\mathrm{NO}_{2}$ concentrations between UP-CPF and DN-CPF measurements were equal to increase in NO concentrations measured between the same locations in the CPF-only configuration (within $\pm 2 \mathrm{ppm}$ ). This means that $\mathrm{NO}_{2}$ consumption in the CPF produced equal amount of NO in these load cases, indicating that $\mathrm{NO}_{2}$ dissociation to form $\mathrm{NO}$ and $\mathrm{O}_{2}$ is the most probable reaction mechanism in these cases.

- Decrease in $\mathrm{CO}$ and $\mathrm{HC}$ concentrations were not proportional to decrease in $\mathrm{NO}_{2}$ concentrations, and consumption of $\mathrm{CO}$ and $\mathrm{HC}$ did not correlate to $\mathrm{NO}_{2}$ consumption in both configurations. Therefore, reaction of $\mathrm{CO}$ and $\mathrm{HC}$ with $\mathrm{NO}_{2}$ was found to not be a probable reason to explain the $\mathrm{NO}_{2}$ consumption in the CPF.

- Differences in NO increase and $\mathrm{NO}_{2}$ decrease (Table 5.19) were found out to be more (6 ppm at the $25 \%$ load to -10 ppm at $100 \%$ load) in the CCRT $\mathrm{R}$ configuration (where UP-CPF $\mathrm{NO}_{2}$ concentrations were higher) than in the CPF-only configuration $( \pm 2 \mathrm{ppm})$. This difference could be due to the fact that the UP-CPF measurements were estimated from UP-DOC measurements, using data from DOC-only experiments. This difference could also be due to errors involved in the method of measurement of $\mathrm{NO}_{2}$ concentrations. 


\begin{tabular}{|c|c|c|c|}
\hline & ${ }^{z} \mathrm{ON}$ & 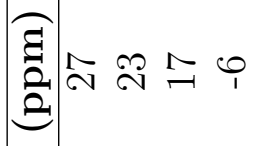 & 악 ㄱ \\
\hline & әsеә.лวu! ON & קי & $\stackrel{\circ}{\circ}$ \\
\hline & HdO-Nब & Э & 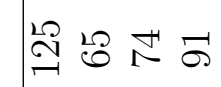 \\
\hline & HdO-d $\Omega$ & 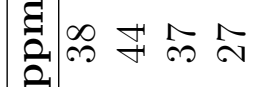 & 骂哭 \\
\hline & गOब-d $\Omega$ & 艺艺苔艺 & 本染学 \\
\hline & adP-nd & Lo & $\stackrel{i}{\infty} \vec{\sharp}$ \\
\hline & HdO-d $\Omega$ & 部 & $\forall \infty$ \\
\hline & गOब-d $\Omega$ & 艺艺艺艺 & 菬 8 \& \\
\hline & HdO-NA & 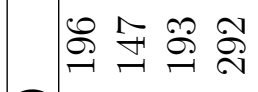 & 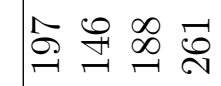 \\
\hline & HdO-d & 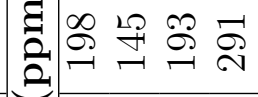 & 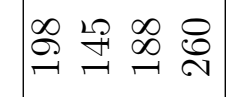 \\
\hline & गоब-d & 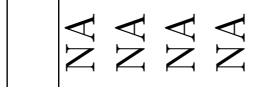 & 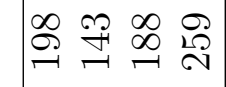 \\
\hline & HdO-NG & 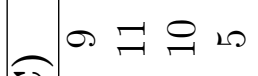 & $\cong \cong \Im$ \\
\hline & HdO-d $\Omega$ & 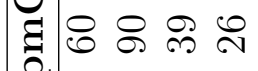 & 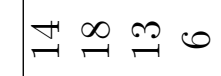 \\
\hline & गОब-d & 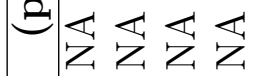 & $\infty \exists \mathbb{g}$ \\
\hline & HdO-NA & $\exists \cong \stackrel{\Xi}{\exists}$ & $\ominus \cong$ \\
\hline & HdO-d $\Omega$ & 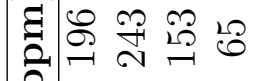 & $\dddot{2} \stackrel{2}{\rightarrow} 9$ \\
\hline & गоđ-d & 启岩岁艺 & 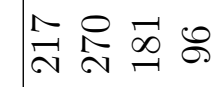 \\
\hline & реот & 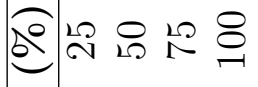 & 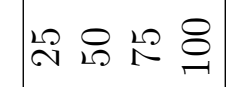 \\
\hline & 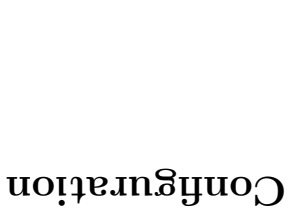 & \begin{tabular}{l}
$\vec{\partial}$ \\
$\vec{z}$ \\
1 \\
\multicolumn{1}{|c}{} \\
0 \\
0
\end{tabular} & $\stackrel{(a)}{E}$ \\
\hline
\end{tabular}


Therefore, in order to predict the DN-CPF $\mathrm{NO}_{2}$ concentrations observed in this thesis accurately, the CPF model should include a dissociation reaction of $\mathrm{NO}_{2}$ to form $\mathrm{NO}$ and $\mathrm{O}_{2}$, as the exhaust mixture passes through the substrate wall. Also, in future work, during experiments conducted in the CCRTß configuration, $\mathrm{NO}$ and $\mathrm{NO}_{2}$ concentrations should be measured in the UP-CPF location in addition to UP-DOC and DN-CPF locations to ensure that the $\mathrm{NO}$ and $\mathrm{NO}_{2}$ concentration measurements and the trends observed are accurate, since these data were not available in this thesis. Also, since the ' $\mathrm{NO}_{x}$ ' mode measurements were found out to be accurate, the errors involved (if any) could arise from the 'NO' mode measurements (especially in cases where the UP-CPF NO concentrations are low [30-50 ppm]).

In order to compare model-predicted values of $\mathrm{DN}-\mathrm{CPF} \mathrm{NO}_{2}$ concentrations obtained to experimental values, model simulations were done to study the amount of $\mathrm{NO}_{2}$ consumed by $\mathrm{NO}_{2}$ /temperature-assisted PM oxidation and the concentration of $\mathrm{NO}_{2}$ produced from the $\mathrm{NO}_{2}$ production model. This was achieved by comparing model-predicted DN-CPF $\mathrm{NO}_{2}$ concentrations with and without $\mathrm{NO}_{2}$ production at all load cases at $2200 \mathrm{rpm}$ at 8 hours of loading time, as shown in Table 5.20. The difference between $\mathrm{DN}-\mathrm{CPF} \mathrm{NO}_{2}$ concentrations with and without $\mathrm{NO}_{2}$ production gives the value of $\mathrm{NO}_{2}$ produced. As can be seen from Table 5.20, the only load case where the the $\mathrm{CPF}$ model was able to predict $\mathrm{DN}-\mathrm{CPF} \mathrm{NO}_{2}$ concentration to reasonable accuracy was the $100 \%$ CPF-only load case, where the $\mathrm{NO}_{2}$ produced (8.7 ppm) was greater than the $\mathrm{NO}_{2}$ consumed by $\mathrm{PM}$ reaction $(4.5 \mathrm{ppm})$. The prominent reactions in this case are the consumption of $\mathrm{NO}_{2}$ by $\mathrm{NO}_{2}$ /temperatureassisted PM oxidation reaction and the production of $\mathrm{NO}_{2}$ from oxidation of $\mathrm{NO}$ with $\mathrm{O}_{2}$. In all the other load cases, the $\mathrm{NO}_{2}$ consumed by PM reaction was lower than the actual $\mathrm{NO}_{2}$ consumed as observed from experimental data. Also, $\mathrm{NO}_{2}$ produced in all load cases except $100 \%$ CPF-only load case was 0.0 , since $A_{N O}$ was set to 0.0 during calibration of the CPF model in these load cases, since effectively, no $\mathrm{NO}_{2}$ 
production was observed at these cases. Hence it is confirmed that in order to be able to predict $\mathrm{DN}-\mathrm{CPF} \mathrm{NO}_{2}$ concentration values observed in this thesis, the CPF model should also include a reaction mechanism for the dissociation of $\mathrm{NO}_{2}$ to form $\mathrm{NO}$ and $\mathrm{O}_{2}$ at $\mathrm{UP}-\mathrm{CPF}$ temperatures below $405^{\circ} \mathrm{C}$.

Table 5.20: Comparison of $\mathrm{NO}_{2}$ concentrations produced and consumed as obtained from the CPF model

\begin{tabular}{|c|c|c|c|c|c|c|c|}
\hline \multirow[t]{2}{*}{ 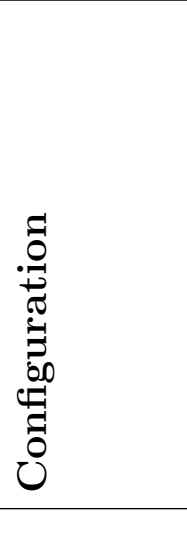 } & 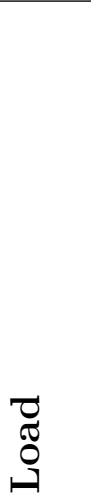 & 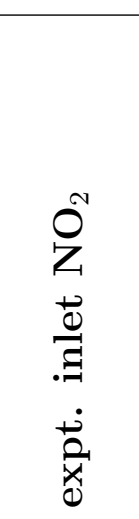 & $\begin{array}{l}0 \\
Z \\
0 \\
0 \\
\overrightarrow{0} \\
0 \\
\dot{0} \\
\dot{0} \\
0\end{array}$ & 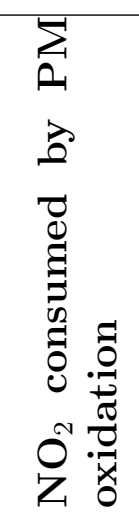 & 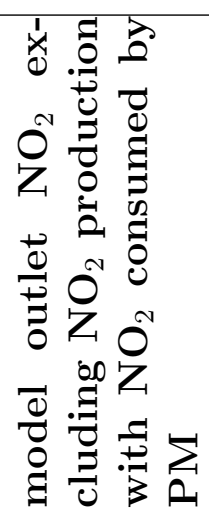 & 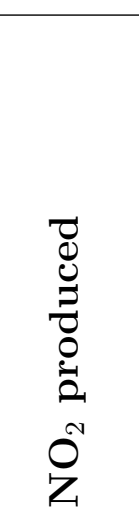 & 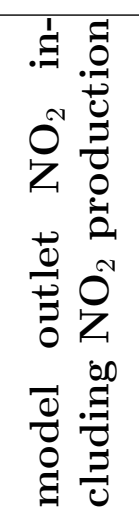 \\
\hline & $(\%)$ & (ppm) & (ppm) & (ppm) & (ppm) & (ppm) & (ppm) \\
\hline \multirow{4}{*}{ CPF-only } & 25 & 38 & 12 & 3.2 & 35 & 0.0 & 35 \\
\hline & 50 & 44 & 21 & 5.5 & 39 & 0.0 & 39 \\
\hline & 75 & 37 & 19 & 3.5 & 34 & 0.0 & 34 \\
\hline & 100 & 27 & 32 & 4.5 & 23 & 8.7 & 31 \\
\hline \multirow{4}{*}{ CCRTß } & 25 & 144 & 125 & 7.8 & 136 & 0.0 & 136 \\
\hline & 50 & 101 & 65 & 6.7 & 94 & 0.0 & 94 \\
\hline & 75 & 111 & 74 & 4.9 & 106 & 0.0 & 106 \\
\hline & 100 & 127 & 91 & 8.8 & 118 & 0.0 & 118 \\
\hline
\end{tabular}




\subsubsection{CPF Model Results}

In this section, results from a study of the effect of load and configuration on the filtration and regeneration characteristics are presented. For this purpose, model results from four load-cases - 25\% CPF-only, 25\% CCRTß, 100\% CPF-only and 100\% CCRTß are compared. In order to compare model results at a common loading time, PM oxidation results are shown at 8 hours of loading time.

In addition to overall pressure drop data versus time, the CPF model also predicts the distribution of the total CPF pressure drop based on location (wall, cake and channel). Figures 5.27(a), 5.27(b), 5.28(a) and 5.28(b) show the pressure drop components and the overall pressure drops in the 25\% CPF-only, 25\% CCRTß, 100\% CPF-only and 100\% CCRTß configurations respectively. For all the four cases, it was observed that the greatest contribution to the overall pressure drop was from the substrate wall. The PM cake layer formed on top of the substrate wall was less permeable than the wall (permeability values for the PM cake obtained from model calibration ranged from $0.58 \times 10^{-14}$ to $3.30 \times 10^{-14} \mathrm{~m}^{2}$, compared to $0.42 \times 10^{-13}$ - $0.80 \times 10^{-13} \mathrm{~m}^{2}$ for the wall), but the substrate wall was thicker $(304.8 \mu \mathrm{m})$ than the cake layer (26.9-1.6 $\mu \mathrm{m}$, depending on load), and since pressure drops encountered by laminar fluid flow through porous media are directly proportional to the ratio of media thickness to permeability[44], higher thickness of the wall would lead to higher contributions by the wall to the overall pressure drop. The effect of increasing load on overall pressure drop was to make the pressure drop decrease more rapidly, and

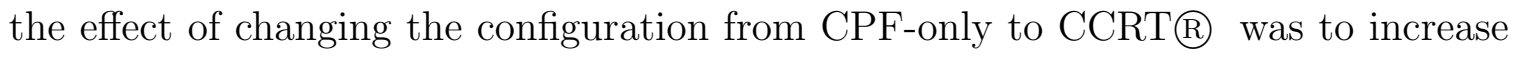
the pressure drop gradients further, and this effect was more pronounced at higher loads than at lower loads. Both of these effects are due to increased PM oxidation rates in the wall.

Figure 5.29 shows CPF pressure drops plotted versus total PM mass deposited (cake+wall) in the CPF, as obtained from model output. The main observation here 


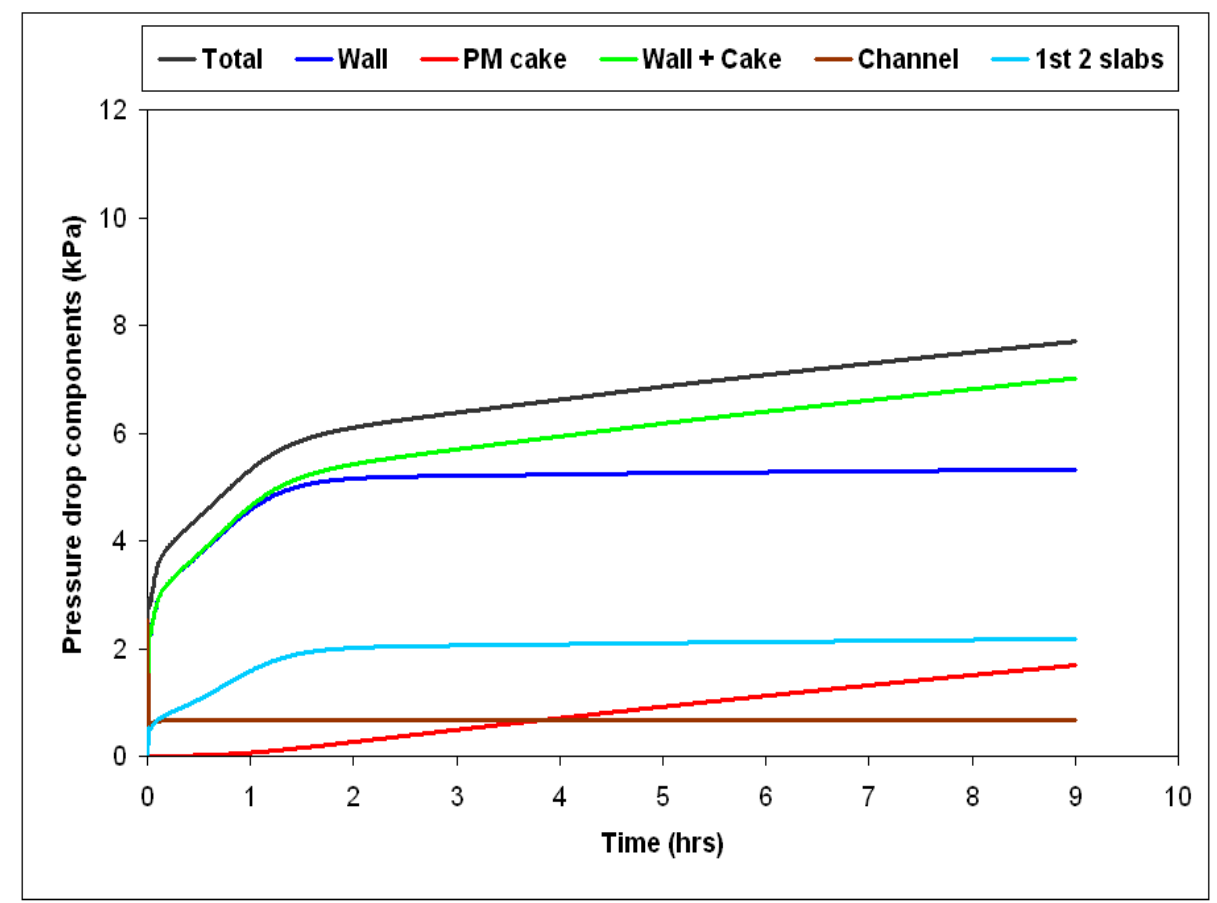

(a) $25 \%$ CPF-only

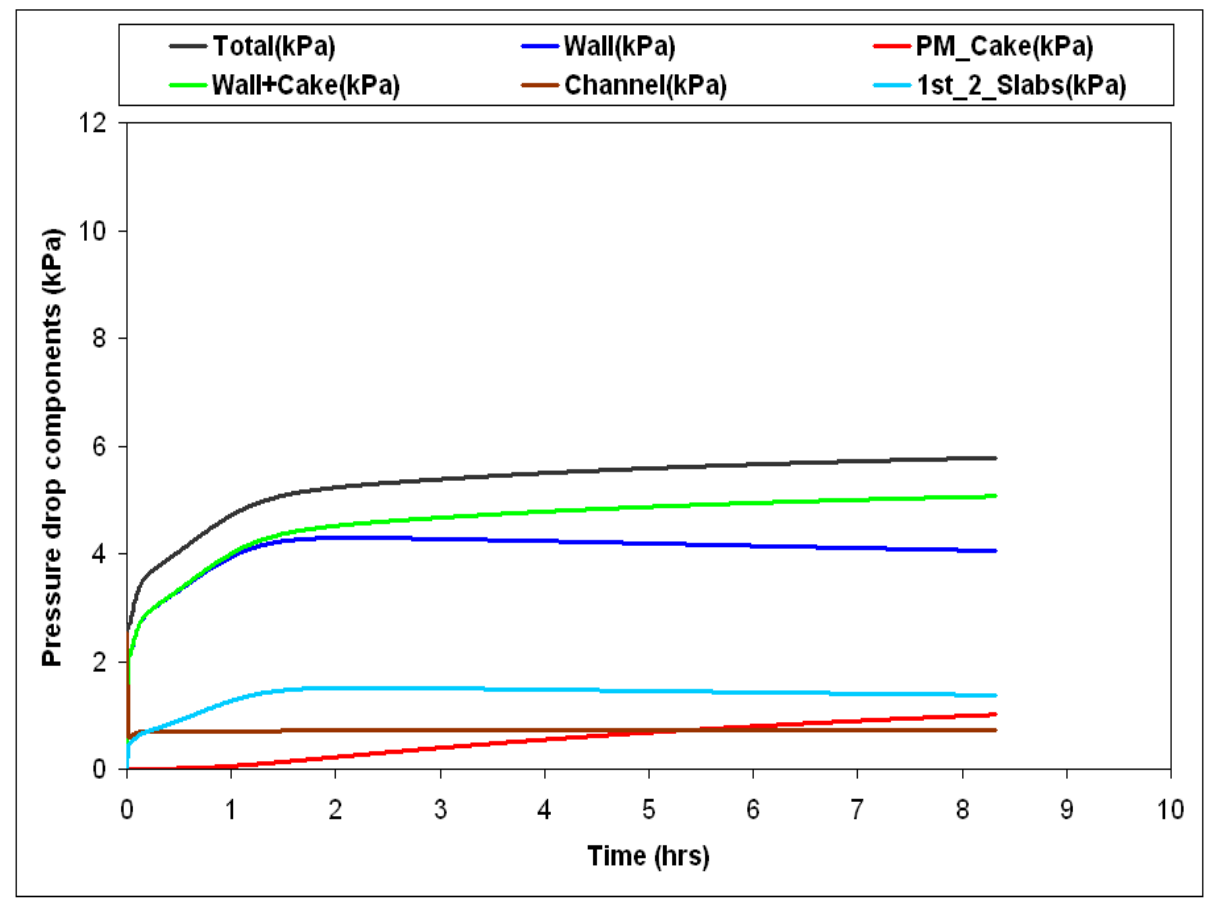

(b) $25 \%$ CCRT $\AA$

Figure 5.27: 25\% load at $2200 \mathrm{rpm}$ - Model-predicted pressure drop components 


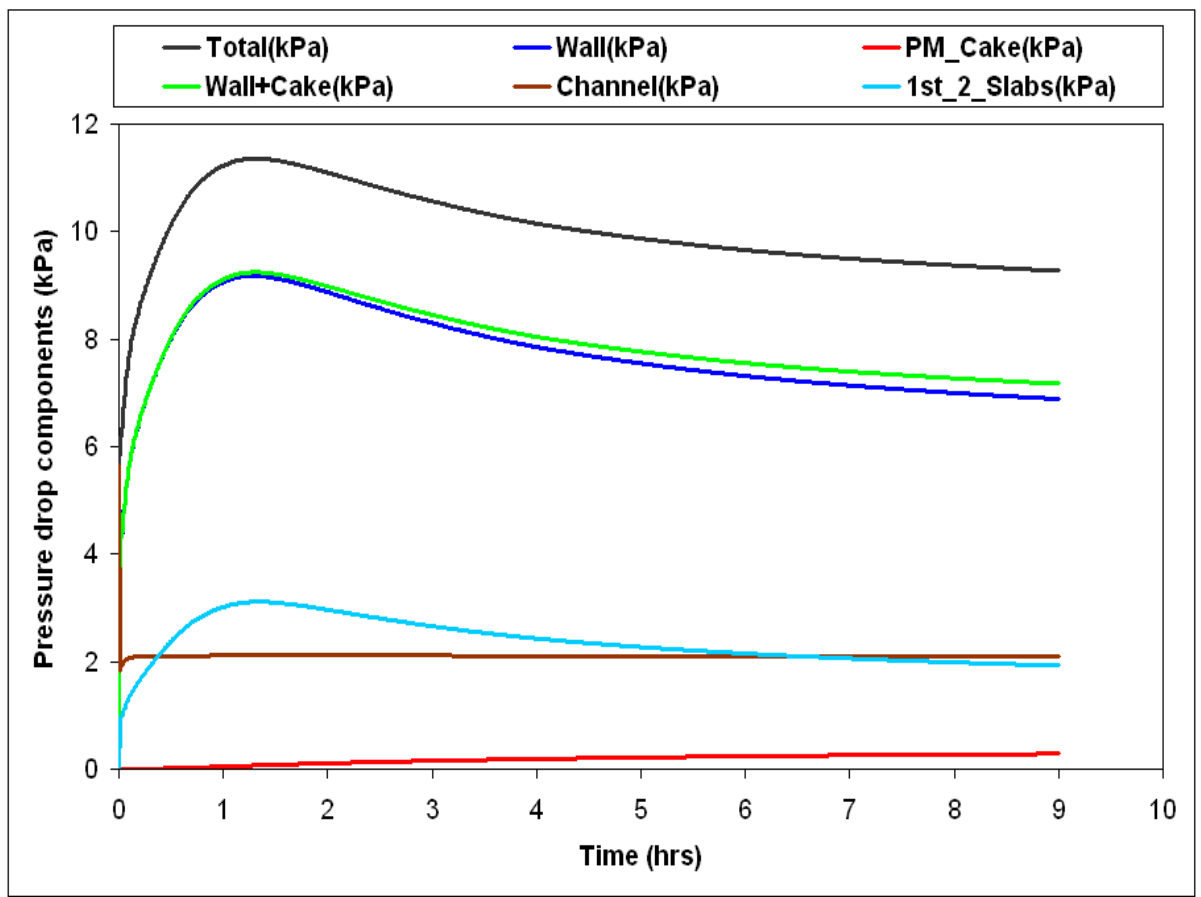

(a) $100 \%$ CPF-only

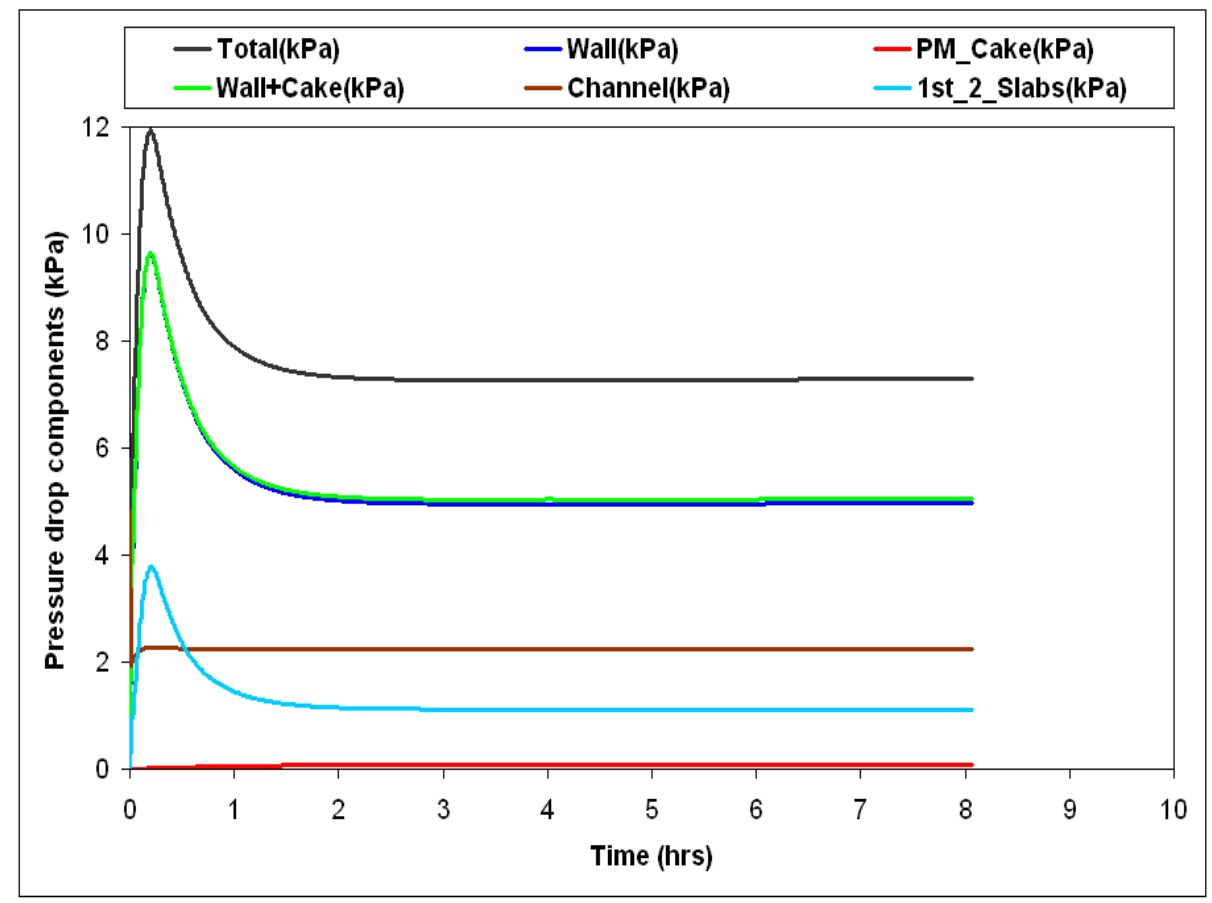

(b) $100 \%$ CCRT $\AA$

Figure 5.28: 100\% load at $2200 \mathrm{rpm}$ - Model-predicted pressure drop components 
is that the pressure drop in the $100 \%$ load case do not show a direct linear relationship with the total PM mass deposited in the filter. The distribution of PM mass between the PM cake and wall is different in corresponding load-cases between configurations, contributing to the difference in the pressure drops versus mass curves, The $25 \%$ load data shows a linear relation after the first 3-4 grams of mass which mainly fills the wall, and all PM coming into the CPF after that gets deposited in the PM cake layer. Also, higher pressure drops observed at 100\% load in both configurations compared to the $25 \%$ load cases are mainly due to the higher exhaust volumetric flow rates.

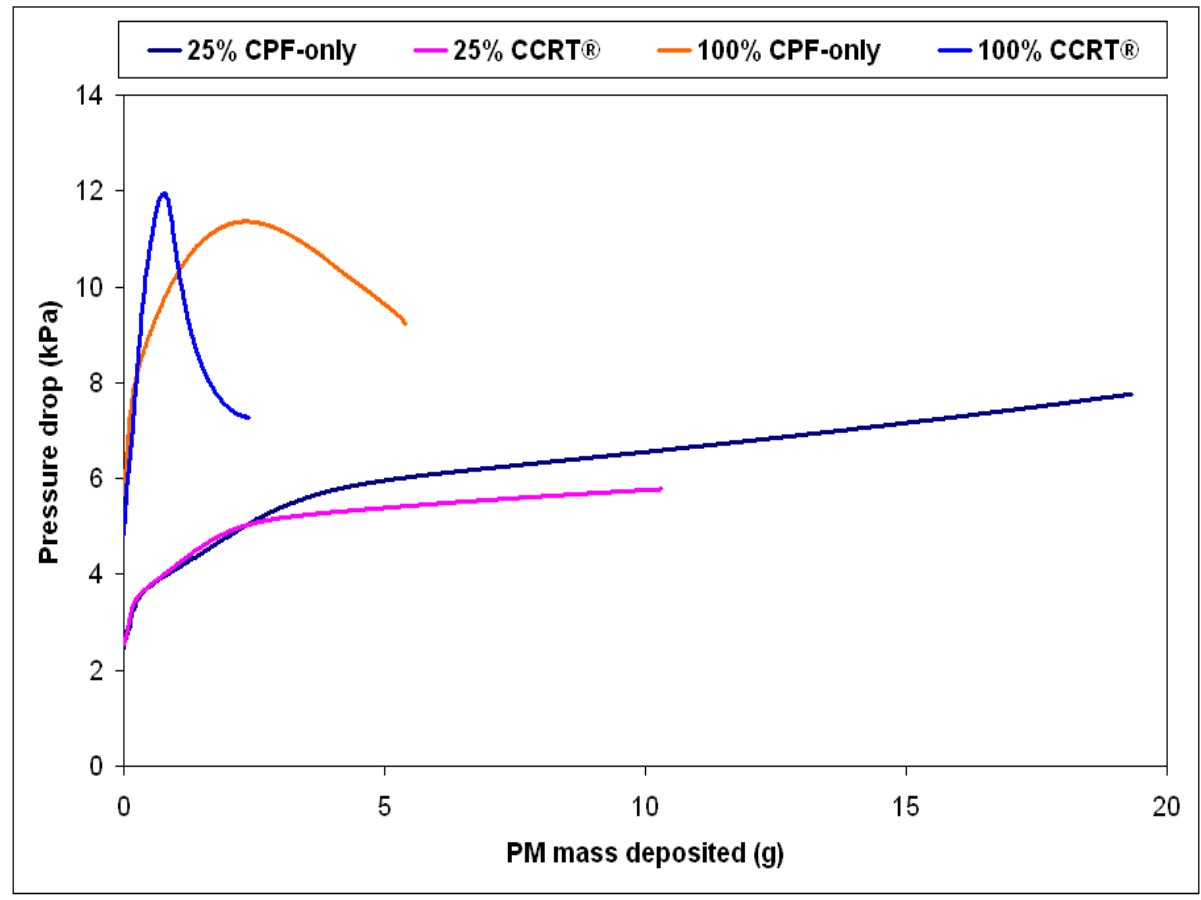

Figure 5.29: CPF pressure drops versus total PM mass deposited

Figure 5.30 shows PM cake layer thicknesses at the midpoint of the CPF channel and PM cake filtration efficiencies versus loading time in the 4 cases studied. From Figure 5.30, it can be seen that the cake layer efficiency increases faster with increasing load, and the increase in cake efficiency is faster for the CCRTß configuration than for the CPF-only configuration for similar loads. In the $100 \%$ CCRT@ configuration, while high wall oxidation rates decreased the efficiency of the wall from a 
peak of $82.5 \%$ at 12 minutes of loading time to $70.5 \%$ at 8 hours of loading time, it affects the overall efficiency by less than $2.7 \%$, because the PM cake was still present in this case, and had a $98.4 \%$ filtration efficiency until the end of loading. A particulate cake layer was present at the end of all load conditions, as can be observed from Figure 5.30. Thickness of the PM cake layer was observed to become constant and later on, decrease with time (in the 100\% CCRTß configuration). This could be important in terms of designing a good strategy for active regeneration of the $\mathrm{CPF}$, where the objective is to maintain an acceptable CPF pressure drop (and hence, the engine back-pressure), while maintaining the high filtration efficiency obtained from the CPF when a PM cake layer is present on the filter substrate wall. This is discussed further in the Recommendations section (Section 6.4) in Chapter 6 of this thesis. 

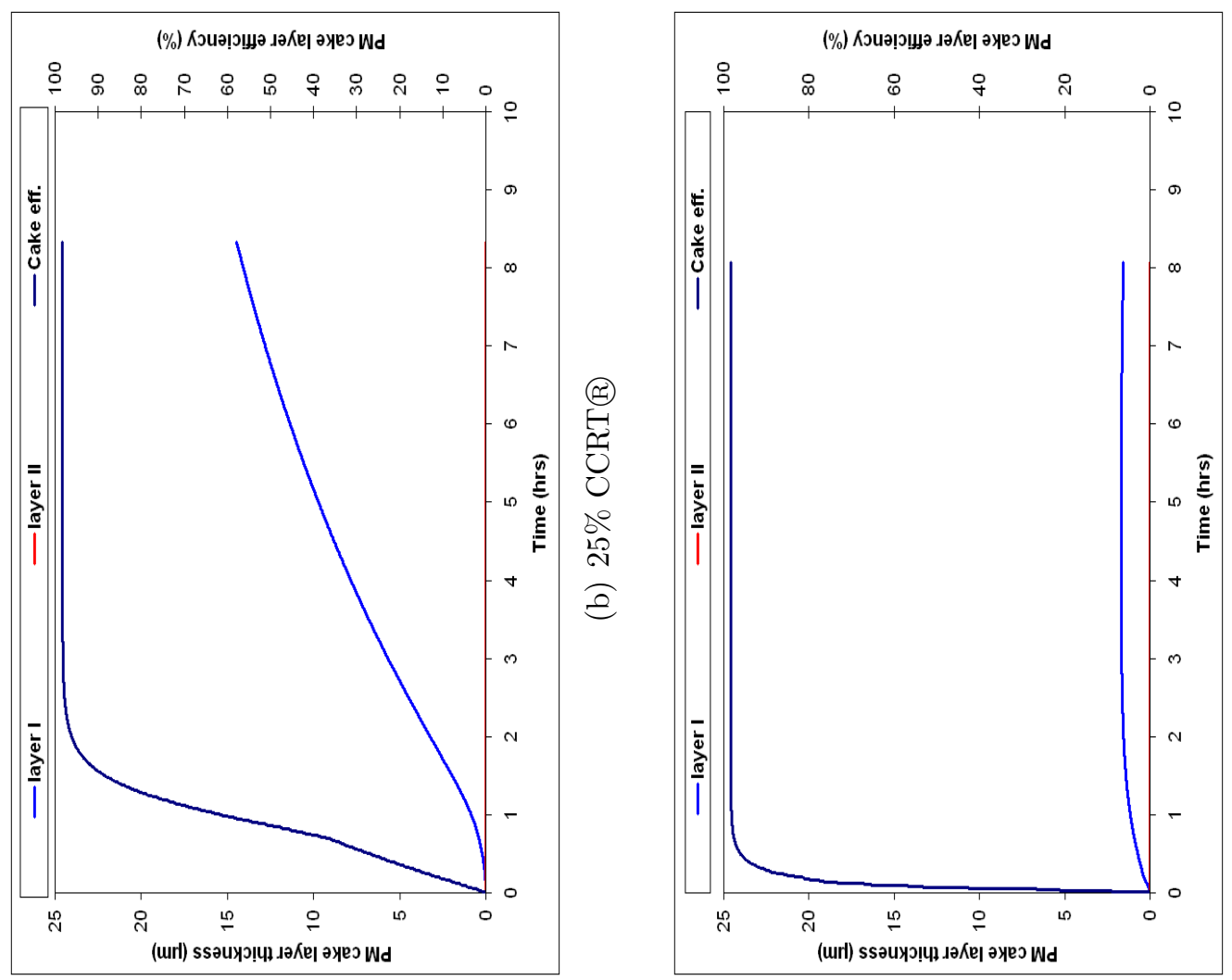

(ㅇ)
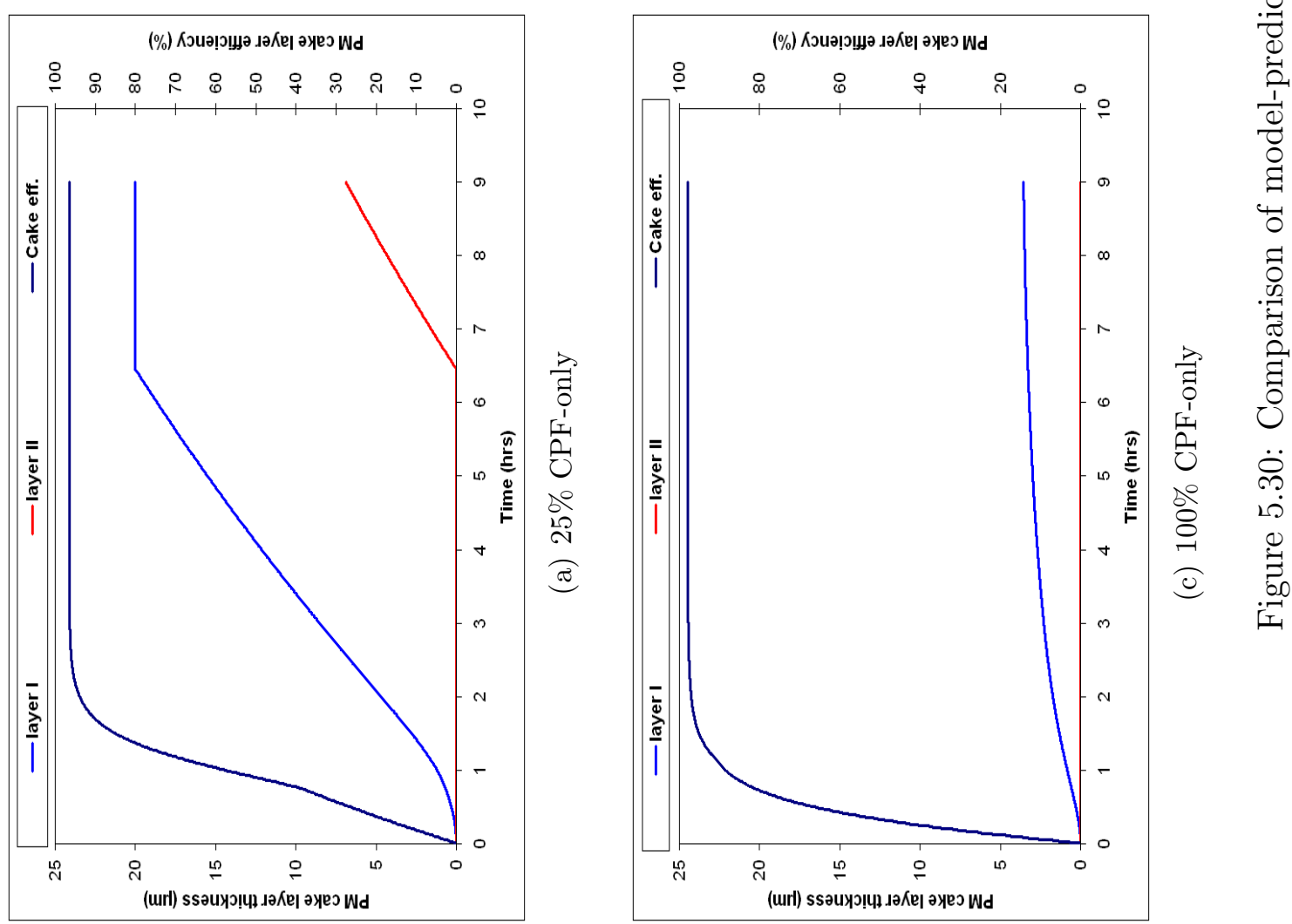
Figure 5.31 provides an overview of distribution of filtration efficiencies and CPF outlet PM mass concentrations obtained from the model versus time. Figure 5.32 shows the PM cake and wall filtration efficiencies for all 4 load-cases. It can be observed that the PM cake contributes to the majority of the particulate filtration efficiency of the $\mathrm{CPF}$, once it is formed. Since the cake efficiency at initiation of loading is 0 and becomes higher than wall efficiency, there is a certain time at which cake efficiency is equal to wall efficiency. After this time, the cake is more efficient than the wall. Table 5.21 presents these times from the model data at $2200 \mathrm{rpm}$ in CPF-only and CCRT $\AA$ configurations. As can be observed from this table, the time at which PM cake efficiency equals wall efficiency increased with increasing load from $25 \%$ to $50 \%$ load and decreased with further increasing load in the CPF-only configuration, and decreased with increasing load in the CCRTß configuration, and is less for the CCRT $\AA$ than in the CPF-only configuration in the same load-case. Also, the individual efficiency at this time as shown in Table 5.21 decreased with increasing load and was less in the CCRT $\AA$ configuration than in the CPF-only configuration.

Table 5.21: Loading times at which cake efficiency equals wall efficiency for CPF-only and CCRT@ configurations at $2200 \mathrm{rpm}$

\begin{tabular}{|c|c|c|c|c|c|}
\hline \multirow[t]{2}{*}{ 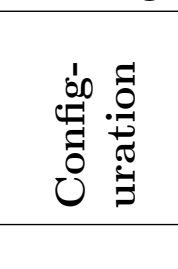 } & 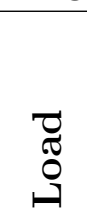 & 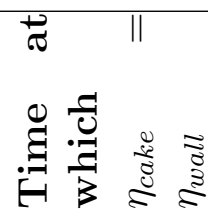 & 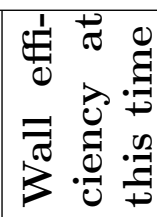 & 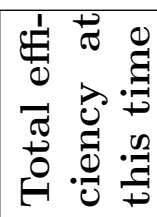 & 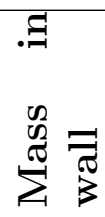 \\
\hline & $(\%)$ & (min) & $(\%)$ & $(\%)$ & (g) \\
\hline \multirow{4}{*}{ CPF-only } & 25 & 105 & 91.0 & 99.2 & 2.1 \\
\hline & 50 & 135 & 88.7 & 98.7 & 2.0 \\
\hline & 75 & 59 & 82.3 & 96.9 & 0.8 \\
\hline & 100 & 41 & 78.1 & 95.2 & 0.6 \\
\hline \multirow{4}{*}{ CCRT $\AA$} & 25 & 90 & 88.6 & 98.7 & 1.3 \\
\hline & 50 & 92 & 92.2 & 99.4 & 0.7 \\
\hline & 75 & 25 & 80.3 & 96.2 & 0.4 \\
\hline & 100 & 12 & 81.7 & 96.8 & 0.3 \\
\hline
\end{tabular}



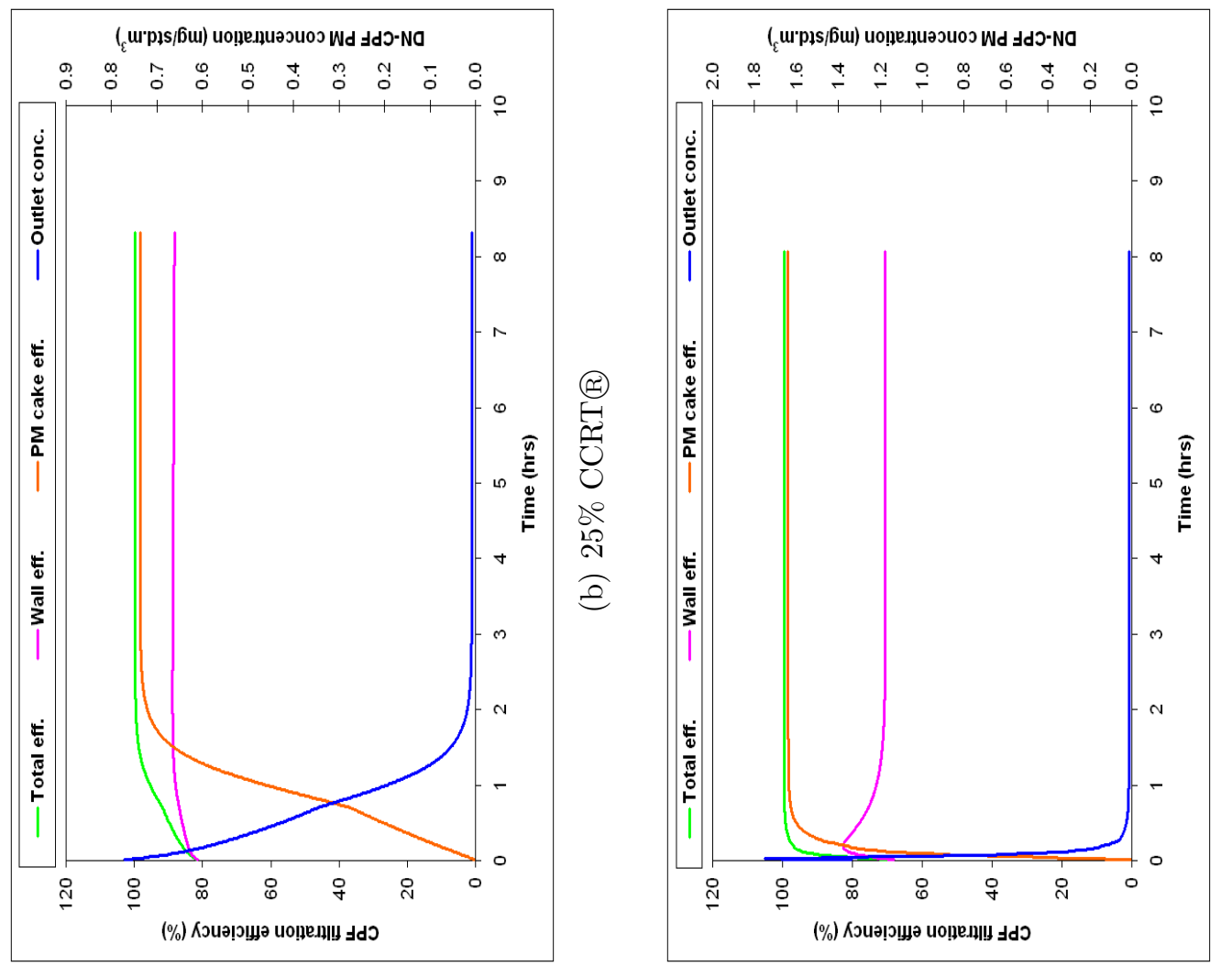

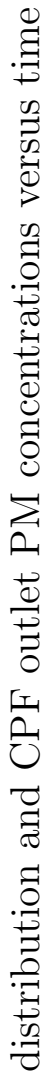
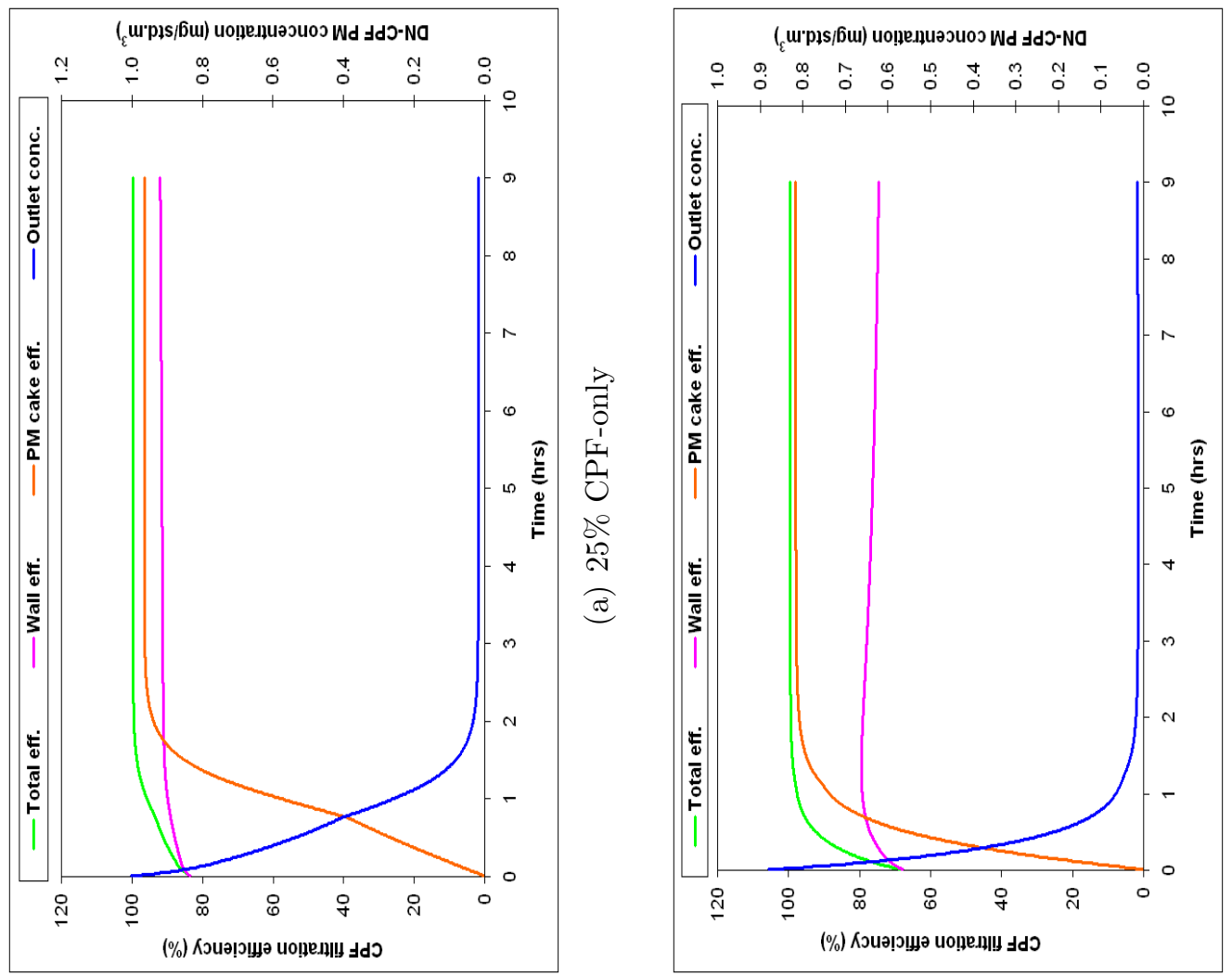

告 


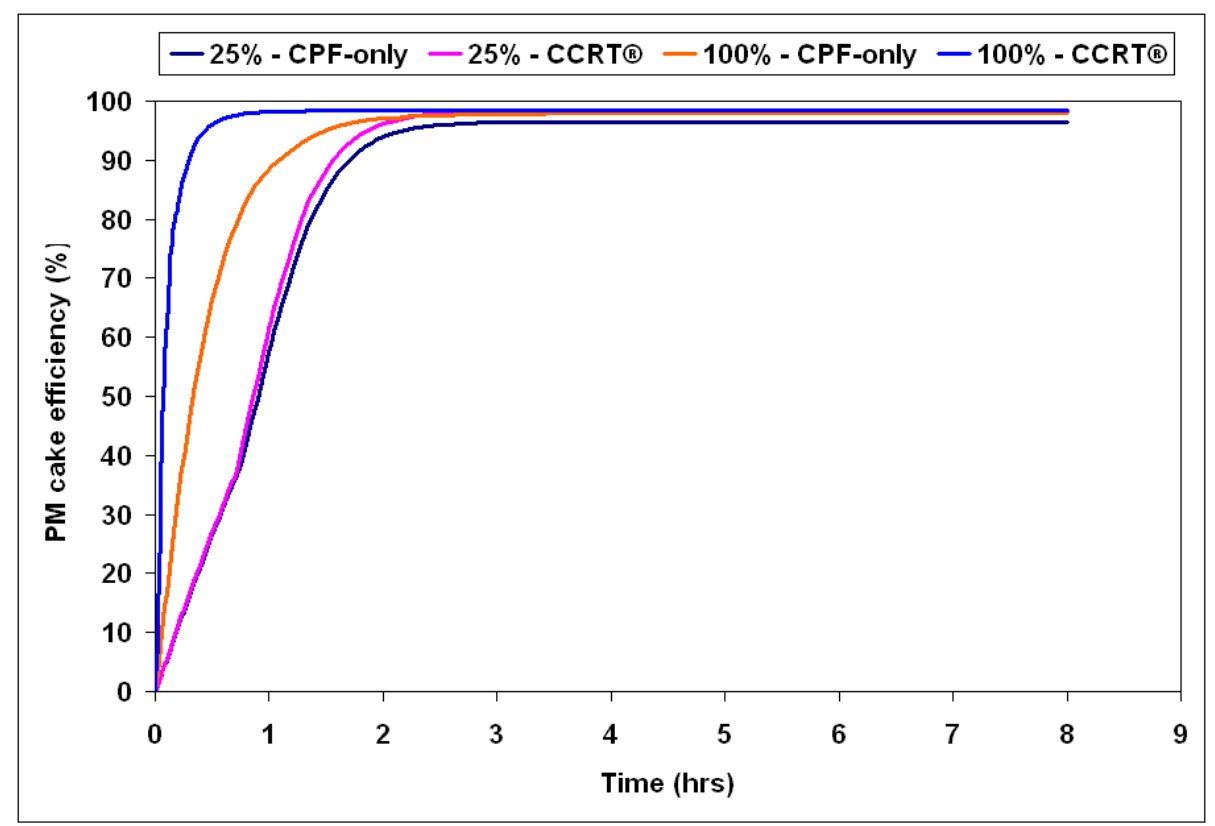

(a) PM cake

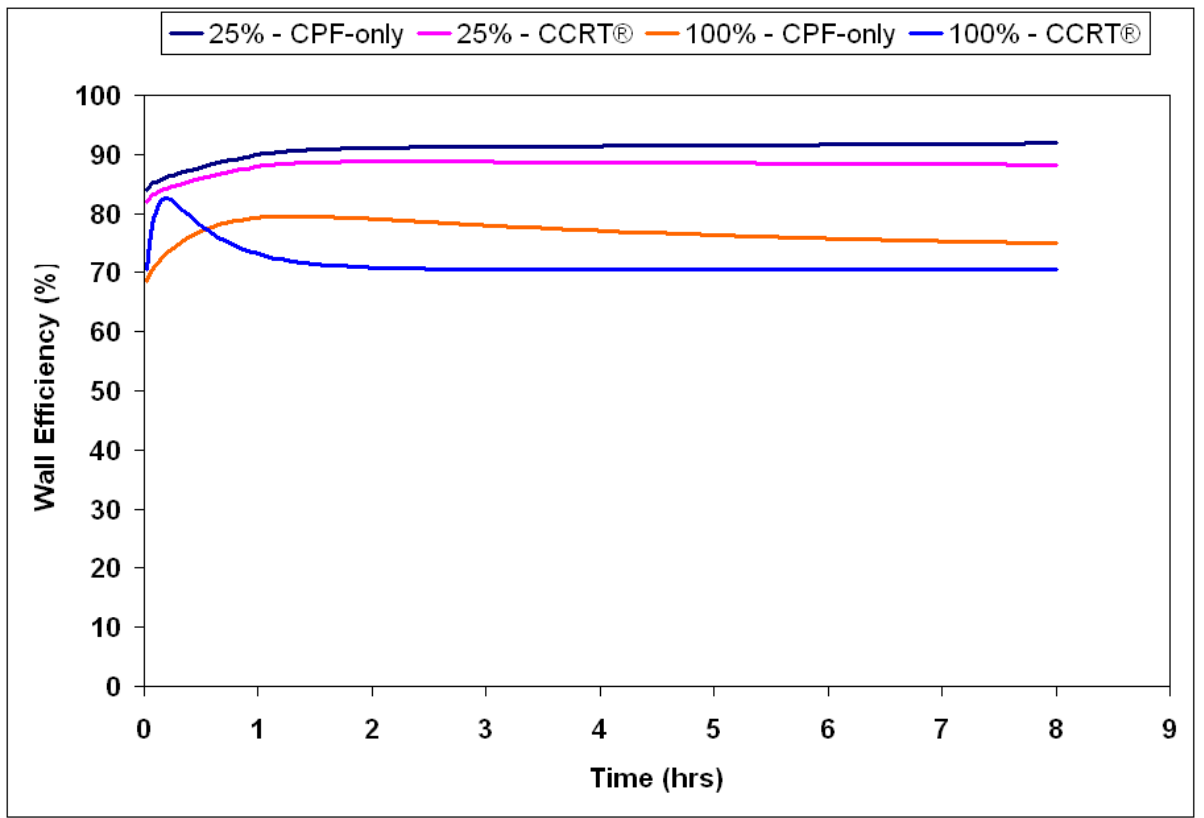

(b) Wall

Figure 5.32: Model-predicted filtration efficiency distribution by location versus time

From Figure 5.32(b), it is also observed that the wall efficiency was lower for higher loads and lower for CCRTß configuration than for CPF-only configuration 
for the same load percentage. This is because the wall filtration efficiency depends on the cumulative PM loading in the wall (that is, a 'clean' wall is less efficient than a 'loaded' wall), and in higher loads, higher oxidation rates in the wall cause a cleaner wall than in lower load cases, which is less efficient in filtration. For the same reason, the wall in CCRT $\AA$ configuration is less efficient than in CPF-only configuration for similar loads.

A comparison of loading times required by the CPF to reach $90 \%, 95 \%$ and $98 \%$ filtration efficiency is shown in Table 5.22, as well as total PM filtration efficiencies at 4,6 , and 8 hours of loading time in the 8 load cases at $2200 \mathrm{rpm}$. Loading times required for the filter to reach 90, 95 and $98 \%$ filtration efficiency were found to be decreasing with increasing loads (due to increasing PM cake layer efficiencies at higher loads), the only exception being the $50 \% \mathrm{CPF}$-only load case, which took longer to reach corresponding efficiency values compared to the $25 \%$ CPF-only configuration. This was due to the substrate wall in the $50 \%$ CPF-only load case being filled up slower than for the 25\% CPF-only load case. This effect is noticeable from the pressure drop curve for the 50\% CPF-only case (as shown in Figure 5.21), where the deep-bed filtration region extends for a longer time than for the $25 \% \mathrm{CPF}$-only load case.

Table 5.22: Loading times required to reach 90, 95 and $98 \%$ filtration efficiency and filtration efficiencies at 4,6 and 8 hours of loading time - model data at $2200 \mathrm{rpm}$

\begin{tabular}{|c|c|c|c|c|c|c|c|}
\hline & Load & \multicolumn{3}{|c|}{ Loading times for: } & \multicolumn{3}{|c|}{ Filtration efficiency at: } \\
& & $90 \%$ eff. & $95 \%$ eff. & $98 \%$ eff. & 4 hrs & 6 hrs & 8 hrs \\
\hline & $(\%)$ & (min) & $($ min $)$ & $($ min) & $(\%)$ & $(\%)$ & $(\%)$ \\
\hline \multirow{5}{*}{ CPF-only } & 25 & 24 & 56 & 80 & 99.7 & 99.7 & 99.7 \\
& 50 & 33 & 66 & 110 & 99.7 & 99.8 & 99.8 \\
& 75 & 27 & 46 & 72 & 99.7 & 99.7 & 99.7 \\
& 100 & 24 & 40 & 66 & 99.5 & 99.5 & 99.5 \\
\hline \multirow{5}{*}{ CCRT® } & 25 & 32 & 58 & 80 & 99.8 & 99.8 & 99.8 \\
& 50 & 9 & 30 & 54 & 99.5 & 99.5 & 99.5 \\
& 75 & 13 & 22 & 32 & 99.2 & 99.2 & 99.2 \\
& 100 & 5 & 8 & 17 & 99.5 & 99.5 & 99.5 \\
\hline
\end{tabular}


It was also observed that after 4 hours of loading time, the CPF in all load cases had filtration efficiency greater than $99 \%$. This was true even for the $100 \%$ CCRT® load case at 8 hours of loading time, where the PM mass in the wall was only $0.01 \mathrm{~g}$ (which means that the substrate wall was practically clean, and the wall filtration efficiency at this time (70.5\%) returned close to the 'clean' value (68.1\%)), indicating the fact that the PM cake layer is very efficient (filtration efficiency of the PM cake layer at this time was $98.4 \%$ and corresponding PM cake layer thickness at the midpoint of the inlet channel was $1.6 \mu \mathrm{m}$ ) in filtering out the incoming PM even when the substrate wall is cleaned due to wall PM oxidation.

Figure 5.33 shows the percentage PM mass oxidized in the CPF-only and CCRTß configurations at $25 \%$ and $100 \%$ loads, obtained from model results at 8 hours of loading time. It can be deduced from the data that:

1. Percentage PM mass oxidized increases with increasing load, due to higher PM oxidation rates caused by higher $\mathrm{CPF}$ inlet temperatures and $\mathrm{NO}_{2}$ flow rates.

2. In terms of percentage PM mass oxidized, the CCRT® configuration is beneficial compared to the $\mathrm{CPF}$-only configuration at all loading conditions at $2200 \mathrm{rpm}$. This is clearly due to a combination of increased thermal and $\mathrm{NO}_{2}$ /temperature-assisted oxidation rates encountered in CCRTß configuration compared to the CPF-only configuration at the same loading conditions.

PM oxidation rates from 0 to 8 hours of model simulation time obtained from the calibrated model were compared for 25 and $100 \%$ loads for CPF-only and CCRT® configurations. Figure 5.34 shows the total PM inlet and oxidation rates and Figure 5.35 shows the wall oxidation rates from all 4 cases considered for this study, i.e., 25\% CPF-only, 25\% CCRT $\AA, 100 \%$ CPF-only and 100\% CCRT®. As expected, total PM oxidation rates increased with increasing load, and were higher in the CCRT® configuration compared to CPF-only configuration, owing to higher 


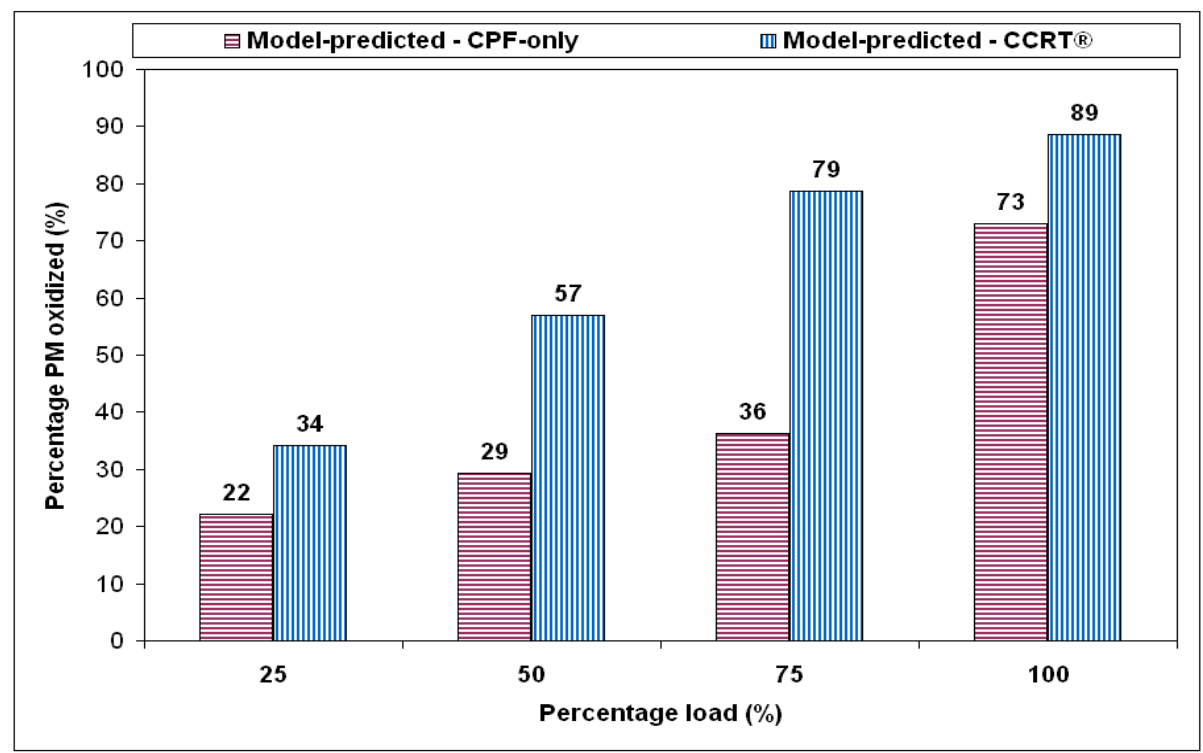

Figure 5.33: A comparison of model-predicted percentage PM mass oxidized in the $\mathrm{CPF}$-only and CCRT® configurations at $2200 \mathrm{rpm}$ (loading time $=8$ hours)

$\mathrm{NO}_{2}$ /temperature-assisted oxidation rates. Wall oxidation rates for the $25 \%$ load-case in both configurations were not significantly different, but wall oxidation rates in the $100 \%$ load in the CCRT $\AA$ configuration were steeper than that for the CPF-only configuration. The wall oxidation rates in the $100 \%$ load case were observed to peak at the time at which the cake layer efficiency took control of the overall filtration efficiency, and afterwards to decrease due to decreasing overall PM available for oxidation in the wall. In the $100 \%$ CCRTß case, where the highest overall oxidation rates were observed, the wall oxidation rate became constant after about 4 hours of loading time, suggesting that wall oxidation rate and wall outlet rate balanced with wall inlet rate (as can be seen later in this section in Figure 5.39).

In Figure 5.34, the oxidation rate curve for the 100\% CCRT $\AA$ case does not follow a smooth non-linear curve with loading time, since the reactions are temperature-dependent, and model input temperatures were varying as observed from temperature-time data for the individual experiments. As expected, the highest total PM oxidation rate was observed in the $100 \%$ CCRT $\AA$ configuration, because of the highest $\mathrm{CPF}$ inlet temperature and $\mathrm{NO}_{2}$ concentration. In the $100 \% \mathrm{CCRT} \AA$ 


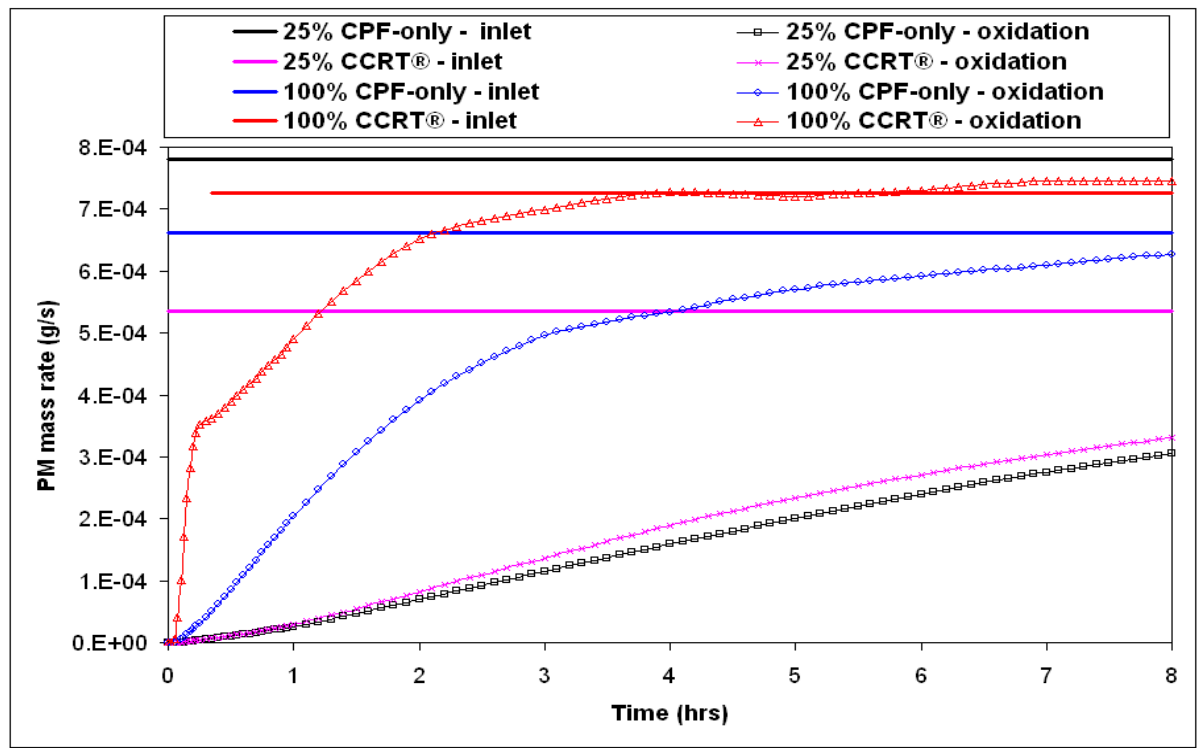

Figure 5.34: 2200 rpm - Total PM oxidation rates versus time

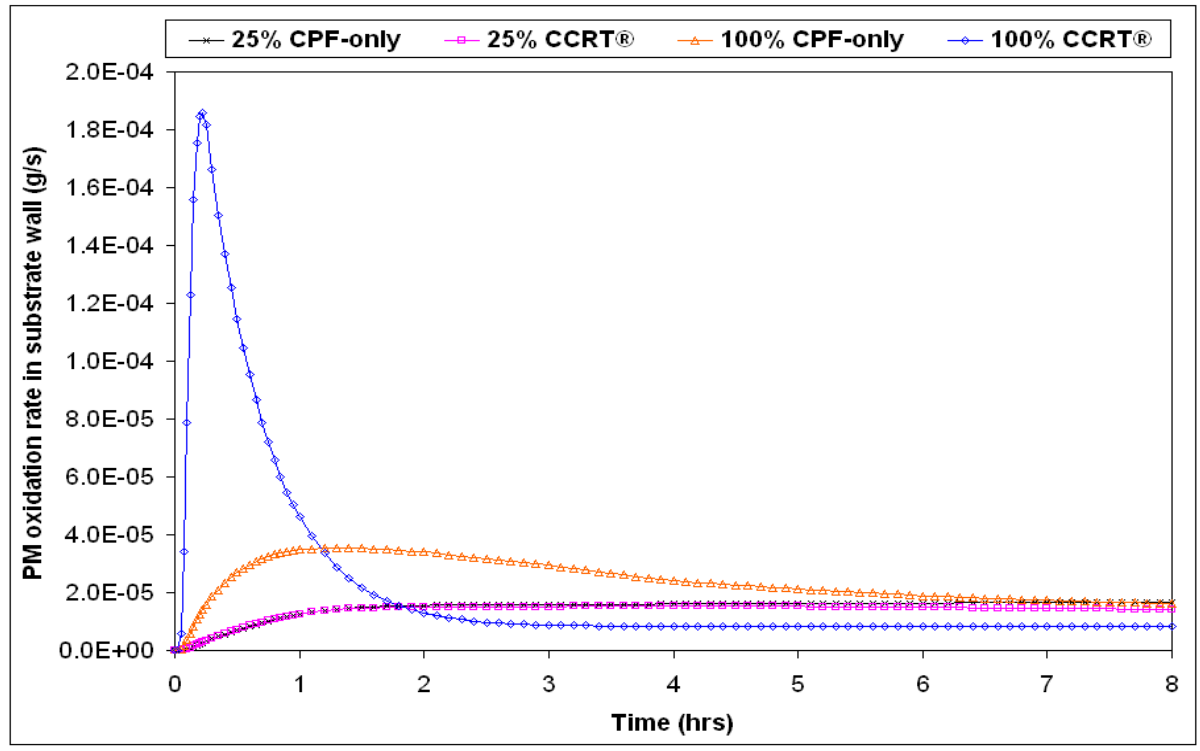

Figure 5.35: 2200 rpm - Model wall oxidation rates versus time

load case, the oxidation rate exceeds inlet PM rate after about 6 hours of loading. However, CPF pressure drop in this case remains fairly constant (within $0.2 \mathrm{kPa}$ ), as can be seen from Figure 5.22. This is because the PM mass oxidized after the 6 hour time-mark in this case is entirely from the PM cake, and since the cake layer does not contribute much to the overall pressure drop, the change in the pressure drop is 
also minimal.

It was also observed from a comparison of wall oxidation rates (as shown in Figure 5.35) that the highest wall oxidation rate occurred in the $100 \%$ CCRT@ configuration, and also that higher rates of change in wall oxidation rates resulted in higher overall pressure drop changes as function of time. This supports the observation that wall oxidation dynamics play a major role in pressure drop characteristics observed in the CPF-only and CCRT $\mathrm{R}$ experiments.

Figures 5.36 and 5.37 show the PM oxidation rates by the two different mechanisms of PM oxidation considered in the 1-D 2-layer CPF model: $\mathrm{NO}_{2} /$ temperatureassisted and thermal. Figure 5.36 also shows the total PM oxidation rates along with the $\mathrm{NO}_{2} /$ temperature-assisted PM oxidation rates. At the $25 \%$ load cases in both configurations, the total PM oxidation rates were almost entirely contributed to by $\mathrm{NO}_{2}$ /temperature-assisted PM oxidation rates, due to higher temperatures being needed for the thermal PM oxidation mechanism to be effective compared to the $\mathrm{NO}_{2}$ /temperature-assisted PM oxidation reaction. At the $100 \%$ load cases also, the principal contribution to the total PM oxidation rate was from $\mathrm{NO}_{2}$ /temperatureassisted PM oxidation rate, although thermal oxidation rates accounted for 5.5$6.3 \%$ of the total PM oxidation rates, due to higher $\mathrm{CPF}$ inlet temperatures (in the range of $400-450{ }^{\circ} \mathrm{C}$ ). Clearly, thermal oxidation rates in Figure 5.37 are less than $\mathrm{NO}_{2}$ /temperature-assisted oxidation rates for the same load-case in Figure 5.36, confirming the fact that the $\mathrm{NO}_{2}$ /temperature-assisted PM oxidation mechanism dominates the PM oxidation at all CPF inlet conditions in this research.

This can also be looked at from kinetics point of view, where the activation energy for the thermal PM oxidation reaction obtained from references [7] and [14] $(1.50 \mathrm{e}+08 \mathrm{~J} / \mathrm{kmole})$ were more than twice as much as the activation energy for $\mathrm{NO}_{2}$ /temperature-assisted PM oxidation reaction $(0.730 \mathrm{e}+08 \mathrm{~J} / \mathrm{kmole})$, indicating that the temperature for the $\mathrm{NO}_{2}$ /temperature-assisted mechanism to be effective is 
much lower than that for the thermal mechanism. Hence, at any given CPF inlet temperature, the $\mathrm{NO}_{2}$ /temperature-assisted mechanism would be the more dominant oxidation mechanism, provided $\mathrm{CPF}$ inlet $\mathrm{NO}_{2}$ concentrations are sufficient for the $\mathrm{NO}_{2}$ /temperature-assisted PM oxidation reaction to occur.

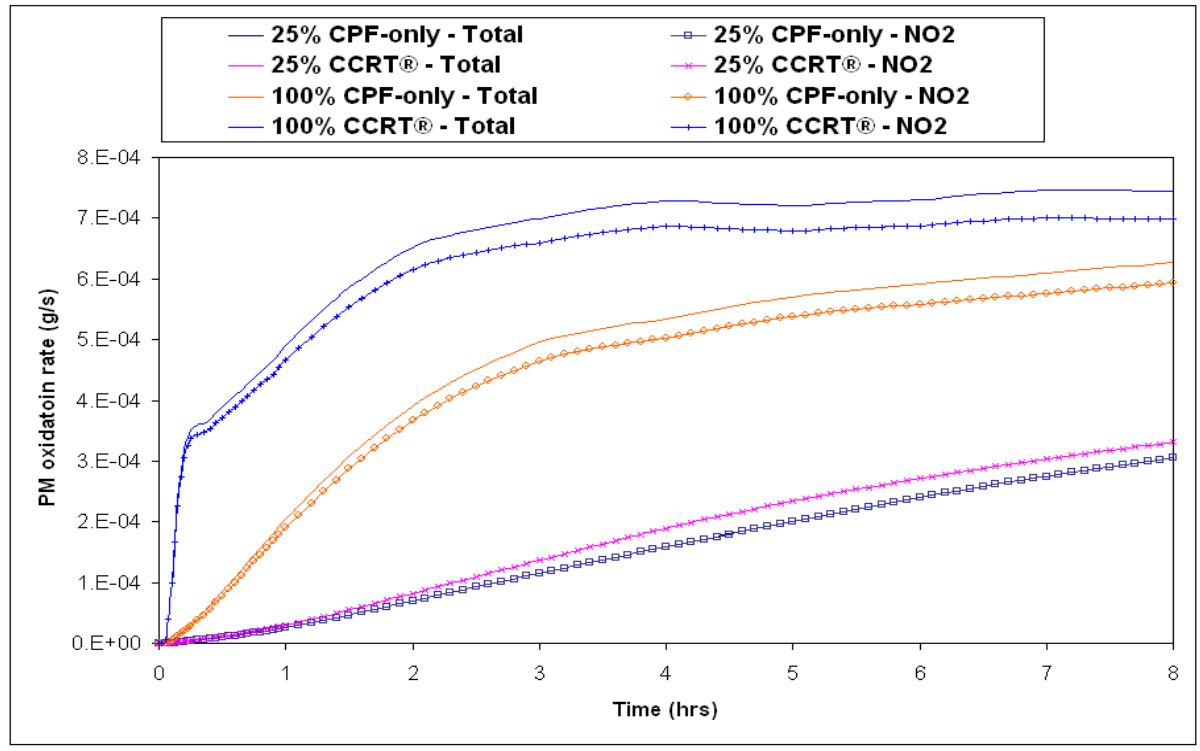

Figure 5.36: $2200 \mathrm{rpm}$ - Total and $\mathrm{NO}_{2}$ /temperature-assisted PM oxidation rates versus time

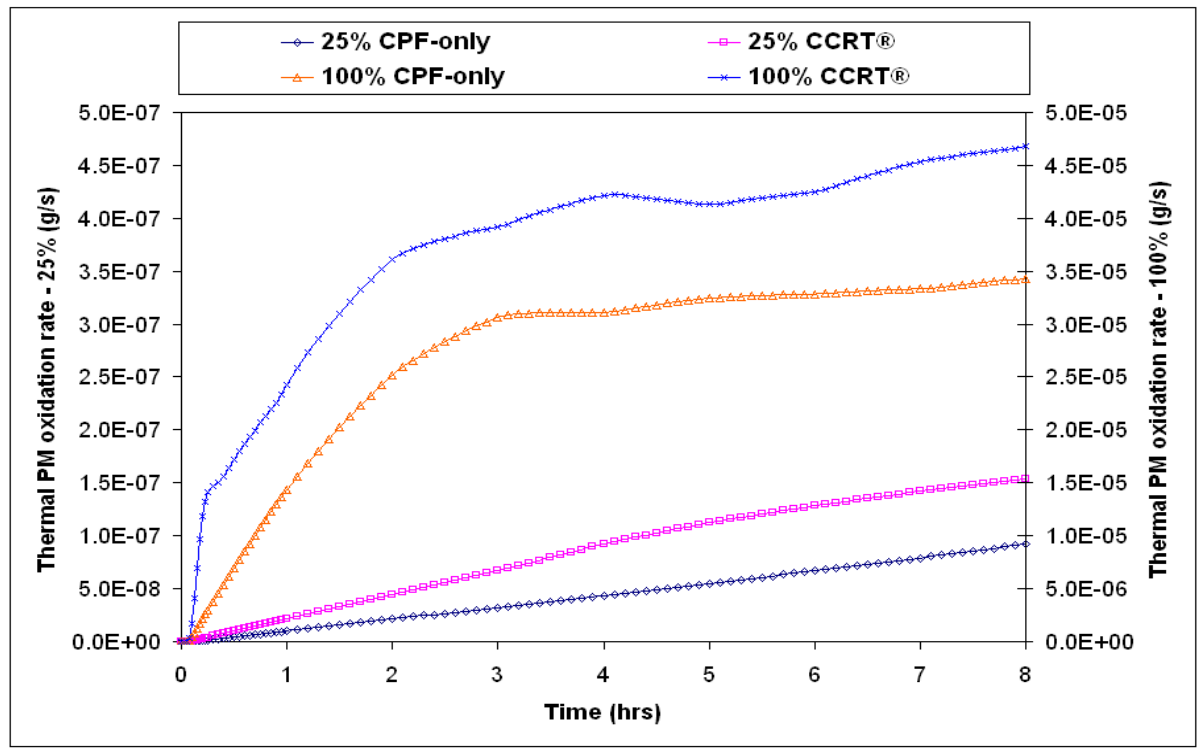

Figure 5.37: 2200 rpm - Thermal PM oxidation rates versus time 
The 1-D 2-layer CPF model also has outputs to show the PM mass rate balance of the PM cake layer and the substrate wall versus loading time. The mass rate curve for the PM cake at 25\% CPF-only, 25\% CCRTß, 100\% CPF-only and 100\% CCRTß load cases is shown in Figure 5.38.

From Figure 5.38, it can be observed that inlet PM mass rate into the PM cake layer is a constant for all cases, depending on the individual PM mass rate of the load case, calculated from the product of the standard volumetric flow rate and the CPF inlet PM concentration. The exception to this was the first 17 minutes of loading time in the $100 \%$ CCRTß load case, where the PM inlet concentrations were considered as varying, due to high load on the engine. PM deposition rates in the PM cake layer in all load cases showed similar trend of increasing first, and then

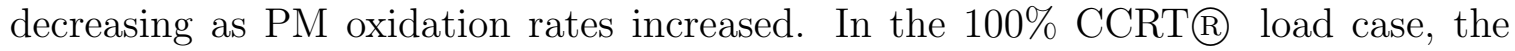
oxidation rate of $\mathrm{PM}$ in the cake layer was equal to and even slightly greater than the inlet PM rate, indicating that the PM cake layer was being depleted in this case after about 6 hours of loading time. The PM cake outlet PM mass rate in all load cases decreased from a value equal to the PM cake inlet PM mass rate at the start of loading (since the cake was not collecting any PM, due to the cake layer not being formed at the start of loading), to a low value and becoming constant at later times. This means that the wall inlet mass rate (which is equal to the PM cake outlet mass rate) after the formation of the PM cake filter was constant, since the cake filtering efficiency was constant and equal to $A_{\eta}$. 

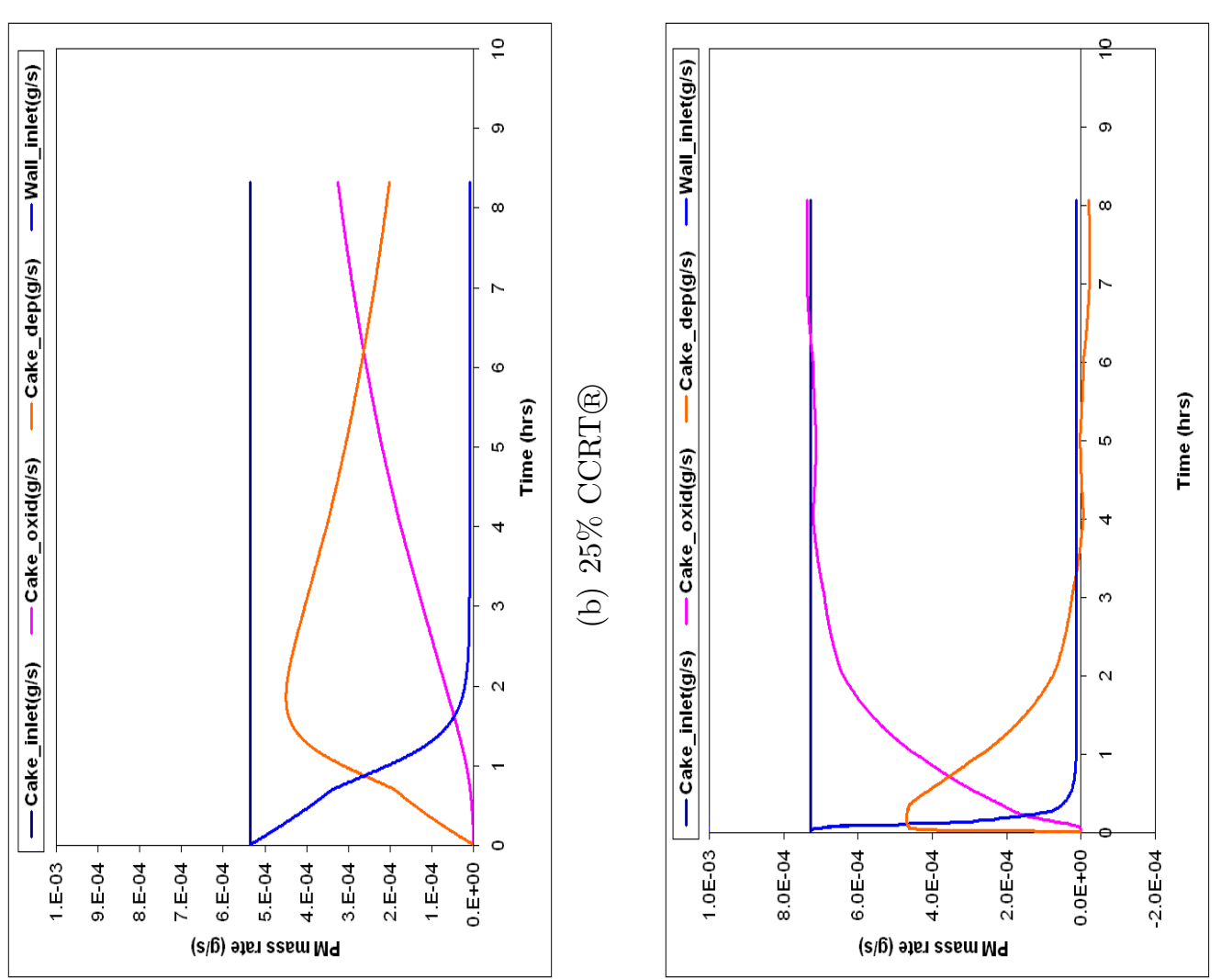

马્コ
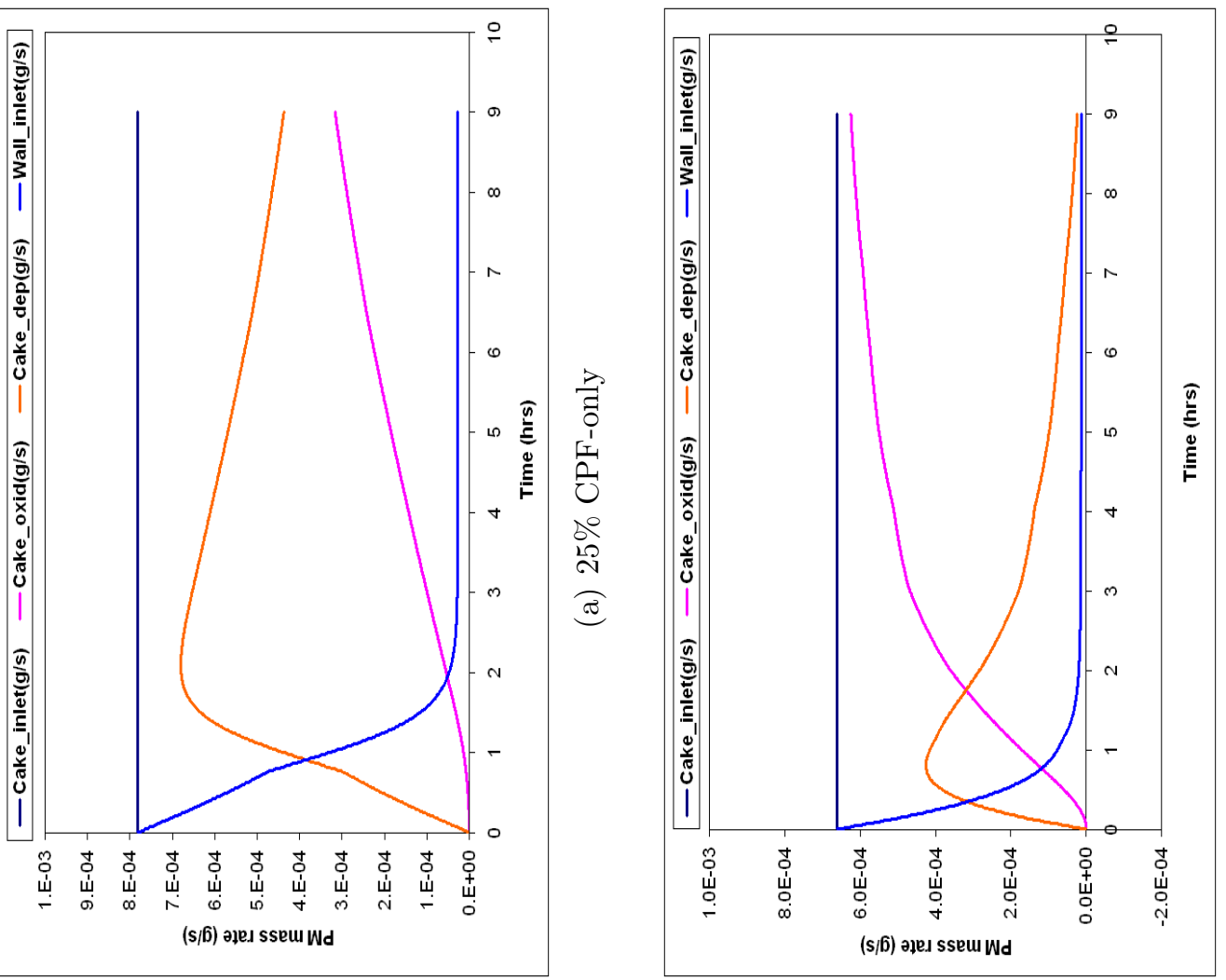

(2)

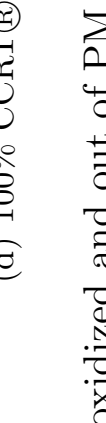

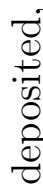

茵

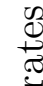

ปี

穴

0
0
0
0
0
0
1
0
0
0
0
$\vdots$
4
0
0
0
0
0
0
0
0
0

$\ddot{\infty}$

0
0
0
0
0 
The mass rate curve for the substrate wall at 25\% CPF-only, 25\% CCRTß, 100\% CPF-only and 100\% CCRT@ load cases is shown in Figure 5.39. As can be seen from Figure 5.39, the wall deposition rates in the 100\% CPF-only and 100\% CCRT $\AA$ cases went to negative values after the formation of the cake layer, indicating the fact that the PM in the wall in these cases was being partially to completely oxidized ('cleaned'), while the PM cake layer performed filtration of the incoming PM into the CPF. The PM oxidation rates in the wall in the $100 \%$ load case in both cases decreased with time (after about 1 hour in the 100\% CPF-only load case and 10 minutes in the $100 \%$ CCRT $\AA$ load case), due to the overall PM available for oxidation decreasing. In the 100\% CCRT@ load case, after about 3 hours of loading time, the wall inlet PM rate becomes equal to the sum of PM oxidation rate in the wall and wall outlet PM mass rate, and hence the deposition rate is zero, indicating that almost $100 \%$ of the incoming PM into the wall is either being oxidized or being let out, and none of the PM is being deposited in the wall. The total PM in the CPF wall at 8 hours of loading time was $0.01 \mathrm{~g}$, showing that the filter wall was practically clean towards the end of the loading experiment. Even at this point, DN-CPF SMPS data showed $99 \%$ filtration efficiency. This can be explained only by the capability of the PM cake layer in filtration.

This is important from the aspect of explaining the pressure drops across CPF, because it is clear from the analysis of mass rates that the wall pressure drop and hence, the overall pressure drop encountered in a $\mathrm{CPF}$ in a particular load case is directly related to the wall PM deposition rate at that load condition. The analysis also shows that it is also important to have a certain minimum PM cake layer thickness on the $\mathrm{CPF}$ substrate wall at all times to maintain high filtration efficiency (greater than 90\%) of the device. This aspect is discussed further in Chapter 6 of this thesis. 

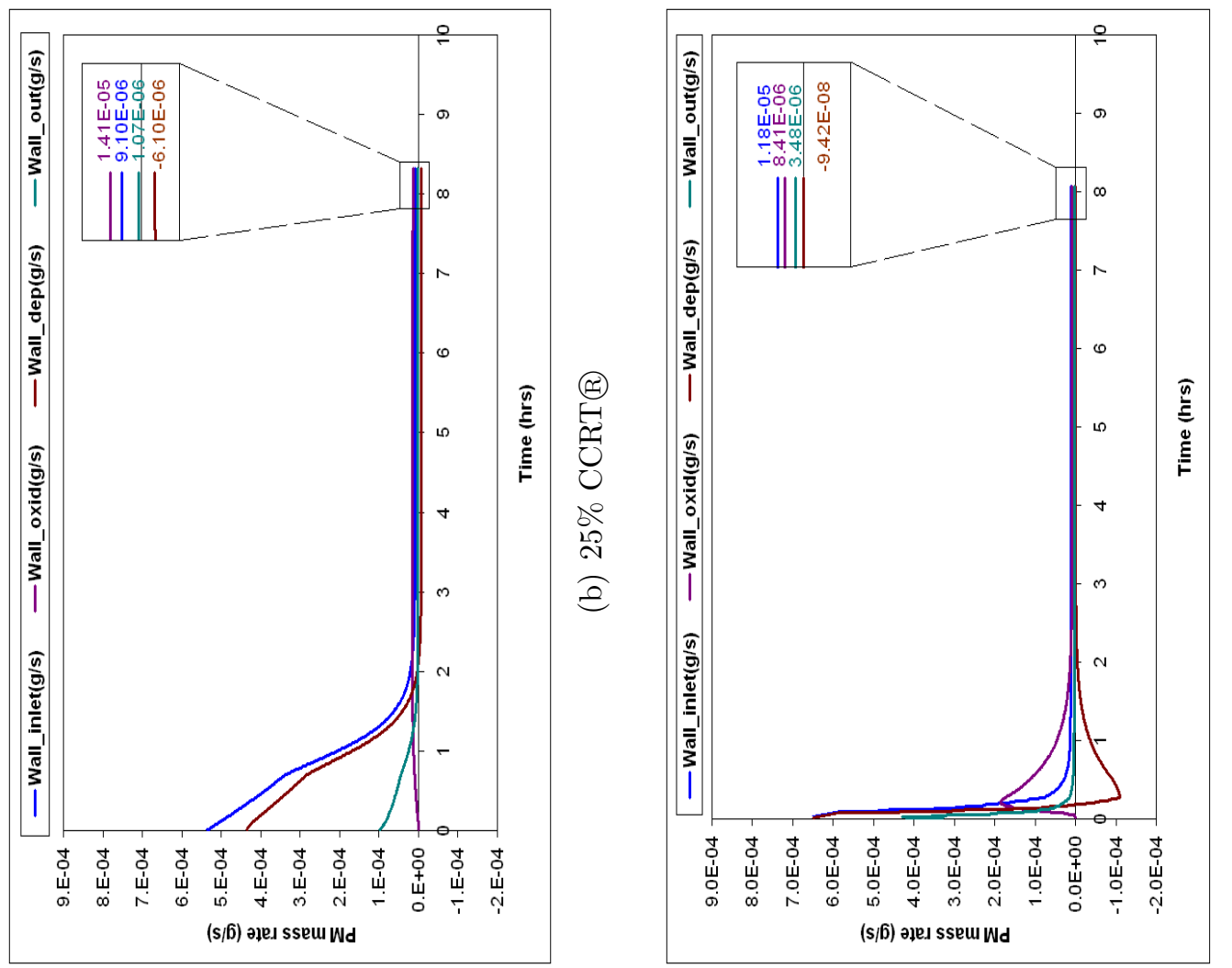

東
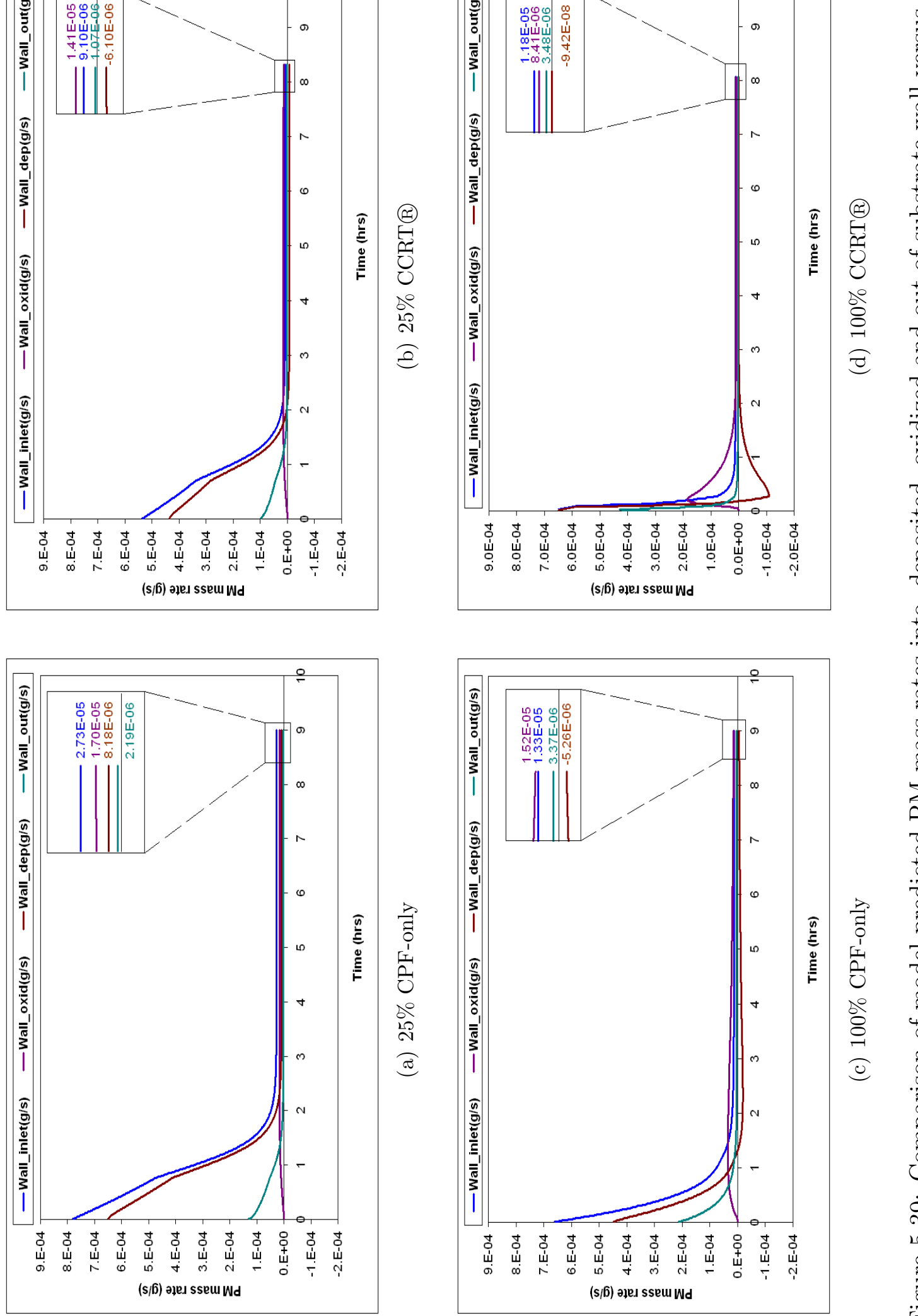

.

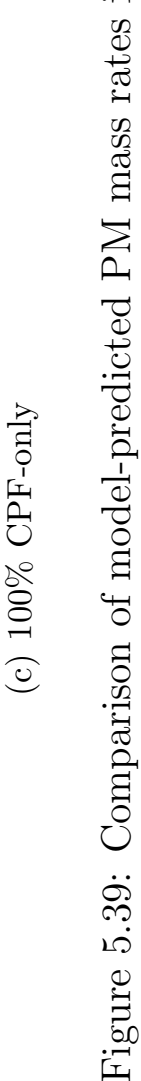


Figures 5.40 and 5.41 show cumulative PM mass balance of all 4 cases under study at the same loading time ( 8 hours), illustrating the fact that higher load cases exhibit higher PM oxidation percentages (due to higher CPF inlet temperatures), as can be seen by comparing the $25 \%$ CPF-only with the $100 \%$ CPF-only $(20 \%$ and $70 \%$ respectively) and the $25 \%$ CCRT@ with the $100 \%$ CCRTß $(33 \%$ and $89 \%$ respectively) due to higher $\mathrm{CPF}$ inlet temperatures.

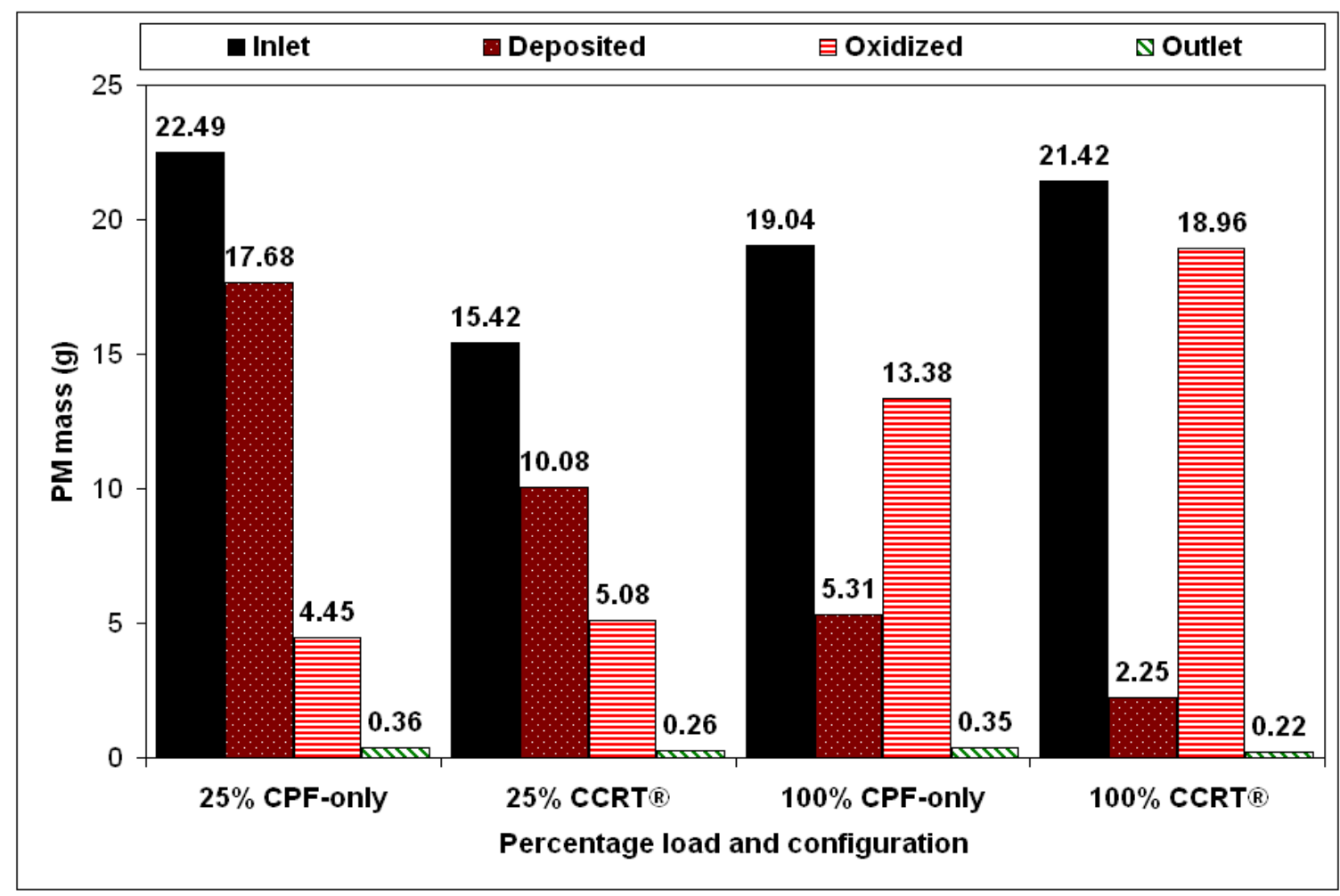

Figure 5.40: PM mass balance at $2200 \mathrm{rpm}$ (loading time $=8$ hours)

It was also observed that the CCRT $\cap$ configuration increased the PM oxidation percentage in any given load case from that of the CPF-only configuration, as can be seen by comparing the $25 \%$ CPF-only with the $25 \%$ CCRT@ (20\% and $33 \%$ respectively) and the $100 \%$ CPF-only with the $100 \%$ CCRT@ (70\% and $89 \%$ respectively). This is clearly due to the additional $\mathrm{NO}_{2}$ concentration available at the CPF inlet due to the oxidation of $\mathrm{NO}$ to $\mathrm{NO}_{2}$ by the DOC present in the CCRT $\mathrm{R}$. 


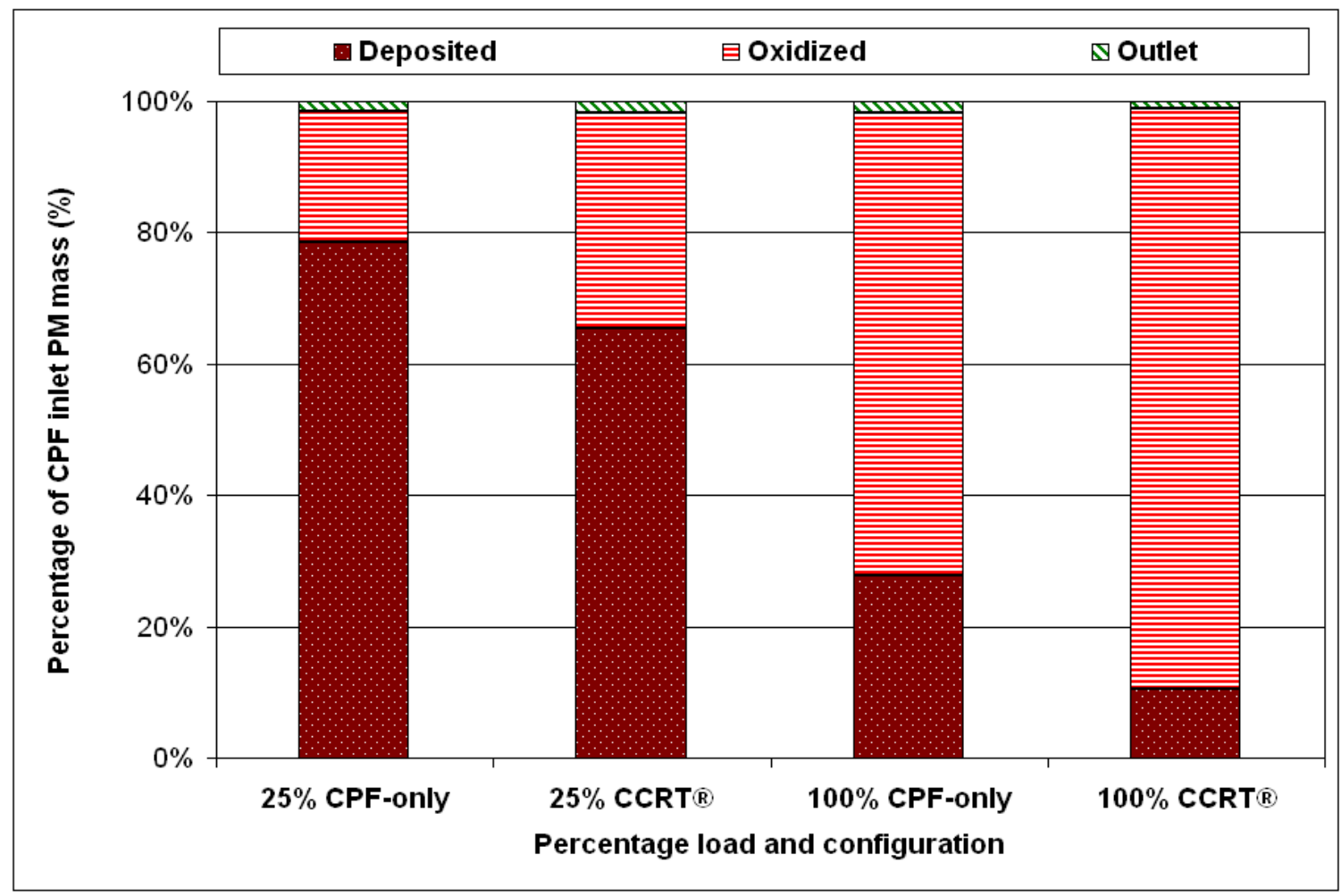

Figure 5.41: PM mass balance expressed as percentage distribution of total inlet PM mass at $2200 \mathrm{rpm}$ (loading time $=8$ hours)

Figures 5.42 and 5.43 show the distribution of the PM mass deposited between the PM cake and wall at 8 hours of loading time, showing that the majority of PM deposited in the CPF in all load cases is in the PM cake layer (86\% in 25\% CPF-only to $99 \%$ in the $100 \%$ CCRTß case), and that percentage of PM deposited in the cake at equal loading times increased with higher loads ( $86 \%$ in the $25 \%$ CPF-only compared to $93 \%$ in the $100 \%$ CPF-only and $88 \%$ in the $25 \%$ CCRTß compared to 99\% in the $100 \%$ CCRTR load case). Also, the percentage PM deposited in the cake was higher in the CCRT $\AA$ configuration compared to the CPF-only configuration in a given load case, due to higher inlet PM flow rates and higher wall oxidation rates in the CCRTR configuration compared to the CPF-only configuration. 


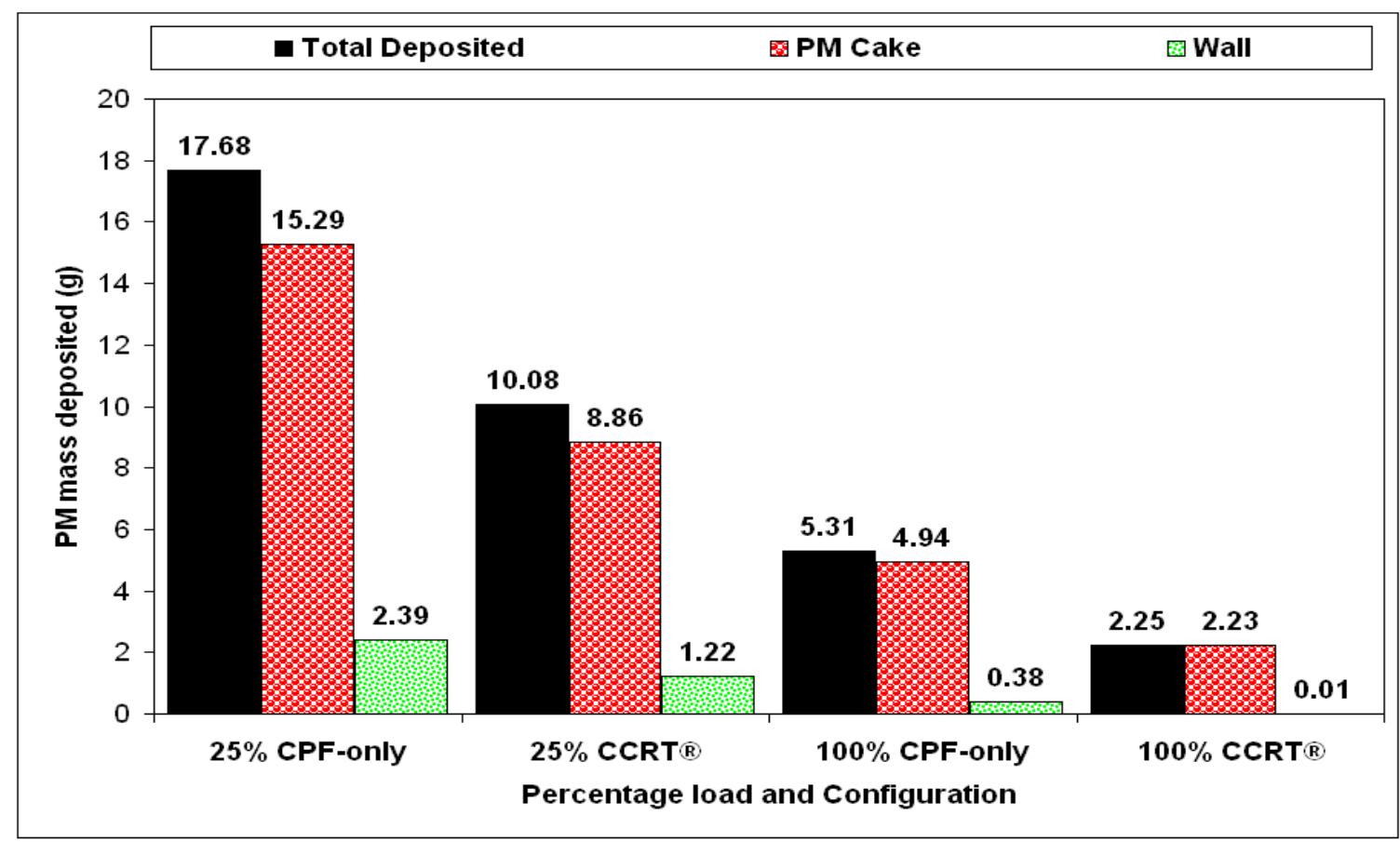

Figure 5.42: Distribution of inlet PM mass by location at $2200 \mathrm{rpm}$ (loading time = 8 hours)

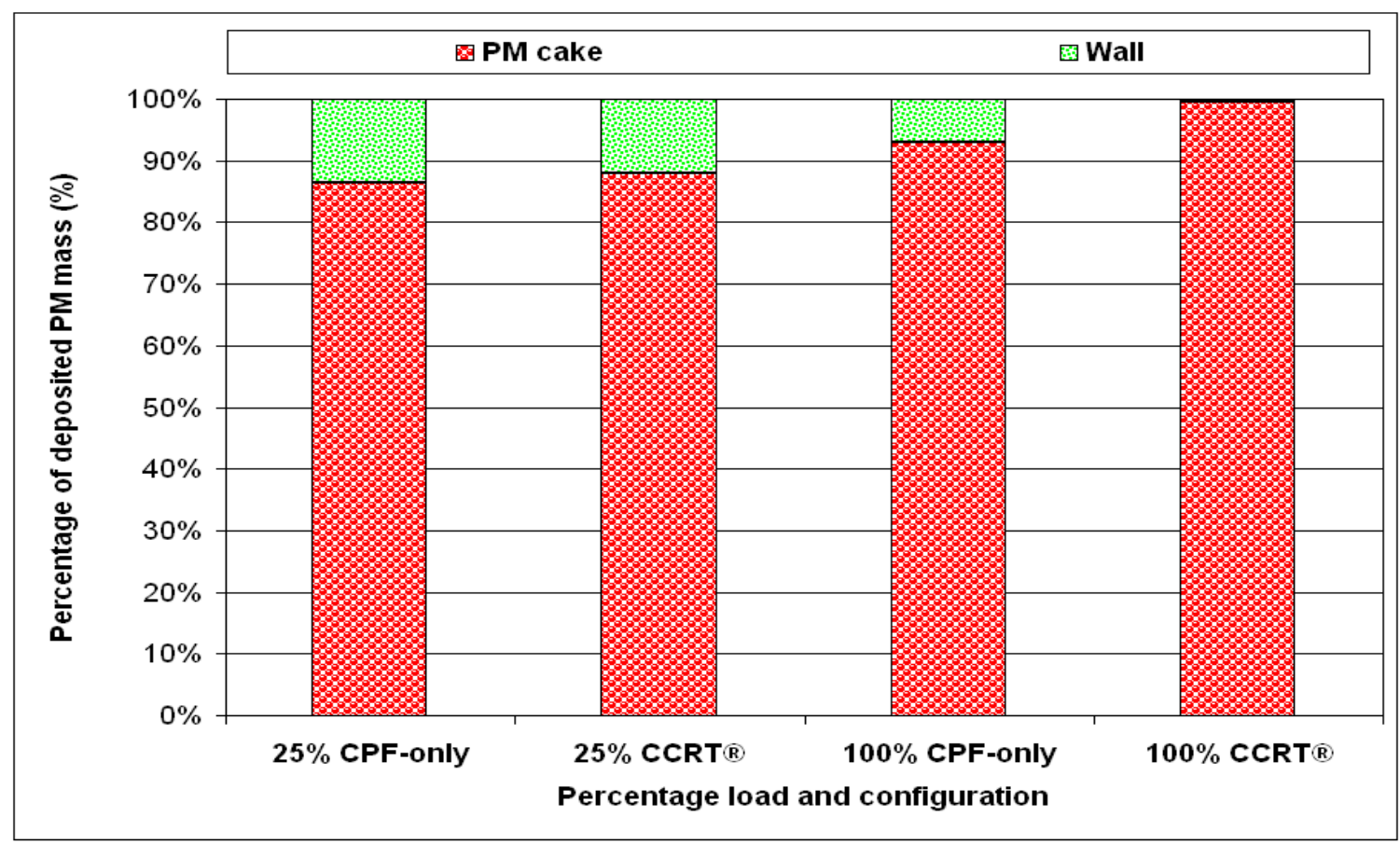

Figure 5.43: Distribution of inlet PM mass by location, expressed as percentage distribution of total deposited PM mass at $2200 \mathrm{rpm}$ (loading time $=8$ hours) 
Figures 5.44 and 5.45 show the distribution of PM mass oxidized by mechanism, and Figures 5.46 and 5.47 show the distribution of PM mass oxidized by location (PM cake layers 1 and 2, and the substrate wall). From Figure 5.45, it was observed that at $25 \%$ load case in both configurations, the $\mathrm{NO}_{2} /$ temperature-assisted mechanism contributed entirely to the total amount of PM oxidized, while at $100 \%$ load case, the $\mathrm{NO}_{2}$ /temperature-assisted mechanism contributed to about $94 \%$ of the total PM oxidized. Although a higher percentage of PM oxidized was expected from the CCRT@) configuration at $100 \%$ load (due to higher inlet $\mathrm{NO}_{2}$ concentrations in the CCRTR configuration), the percentage PM oxidized turned out to be about the same, due to higher inlet PM rates in the 100\% CCRTß load case compared to the $100 \%$ CPF-only load case. Figure 5.44, however, showed higher values of PM oxidized via the $\mathrm{NO}_{2}$ temperature-assisted as well as thermal mechanisms in the $100 \%$ CCRTß load case compared to the $100 \%$ CPF-only load case.

Figures 5.46 and 5.47 show that majority of PM oxidized in all load cases was in PM cake layer 1 (87\% in 25\% CPF-only, $92 \%$ in $25 \%$ CCRT@ , $95 \%$ in $100 \%$ CPF-only and $97 \%$ in 100\% CCRTß configurations). In the $25 \%$ CCRTß , 100\% CPF-only and 100\% CCRTß load cases, PM oxidized in PM cake layer 2 was zero, because layer 2 was not formed in these cases. All PM deposited in the PM cake layer in these load cases was in PM cake layer 1 (a maximum thickness of $20 \mu \mathrm{m}$ ). 


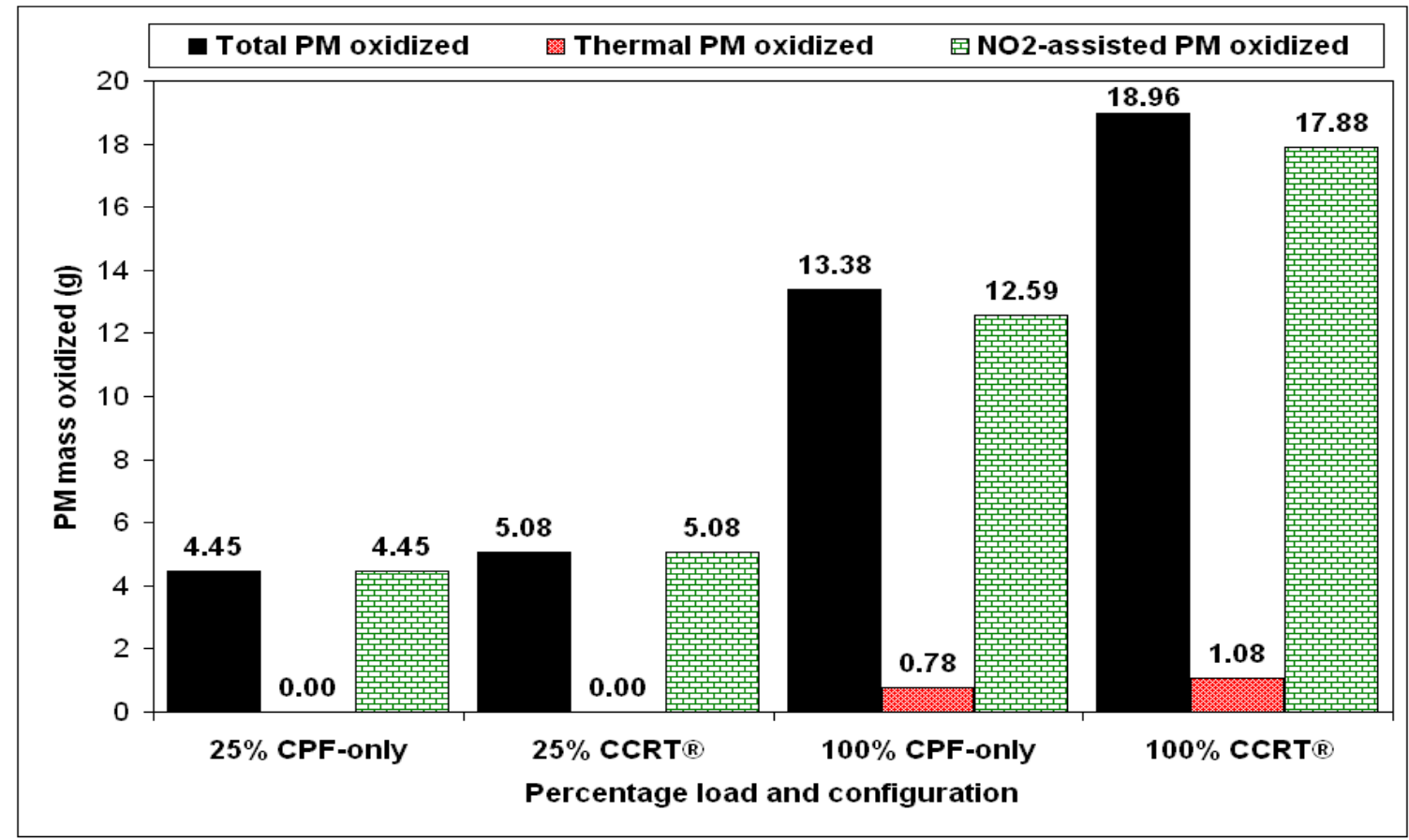

Figure 5.44: Distribution of PM mass oxidized by mechanism at $2200 \mathrm{rpm}$ (loading time $=8$ hours $)$

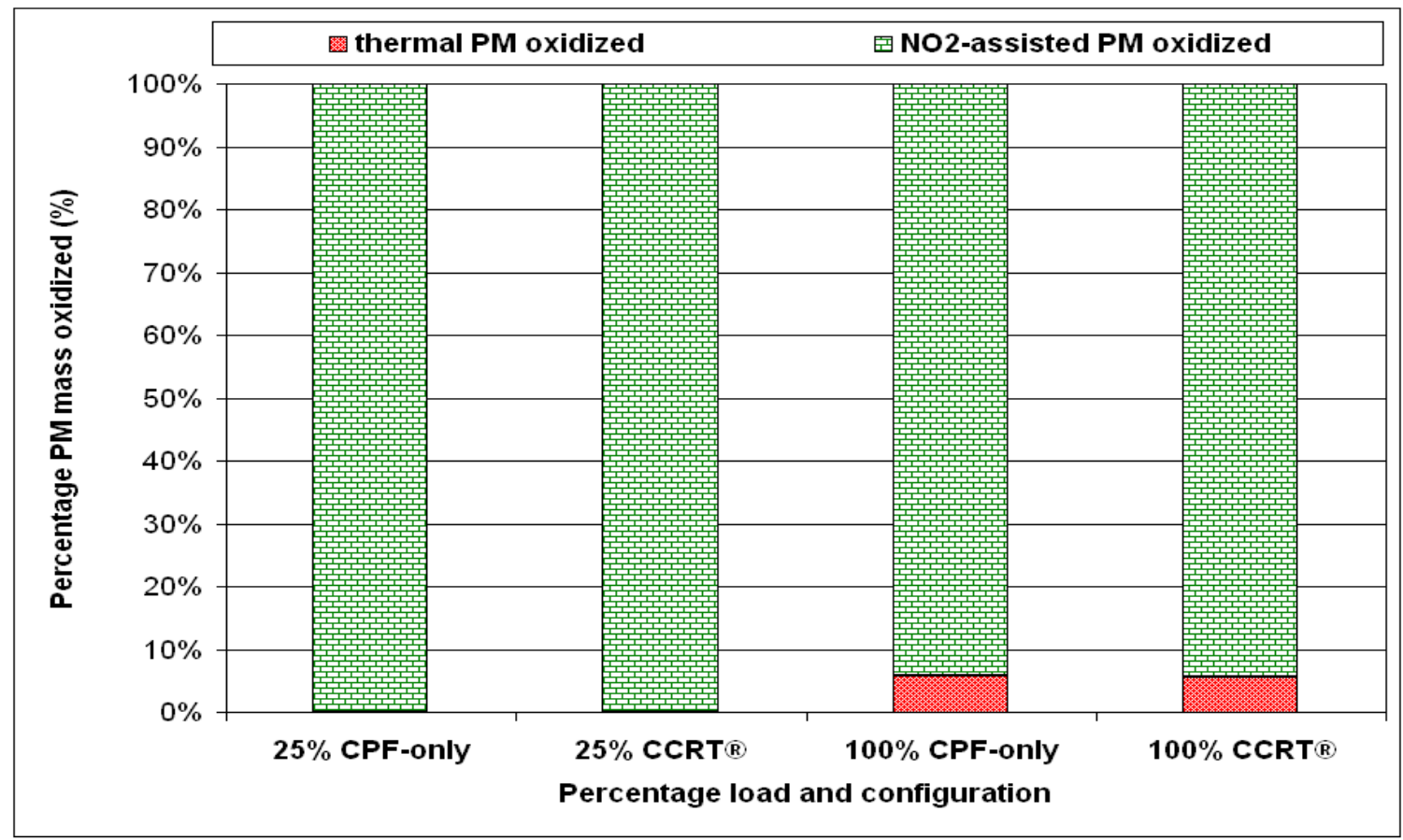

Figure 5.45: Distribution of PM mass oxidized by mechanism, expressed as percentage distribution of total PM mass oxidized at $2200 \mathrm{rpm}$ (loading time $=8$ hours) 


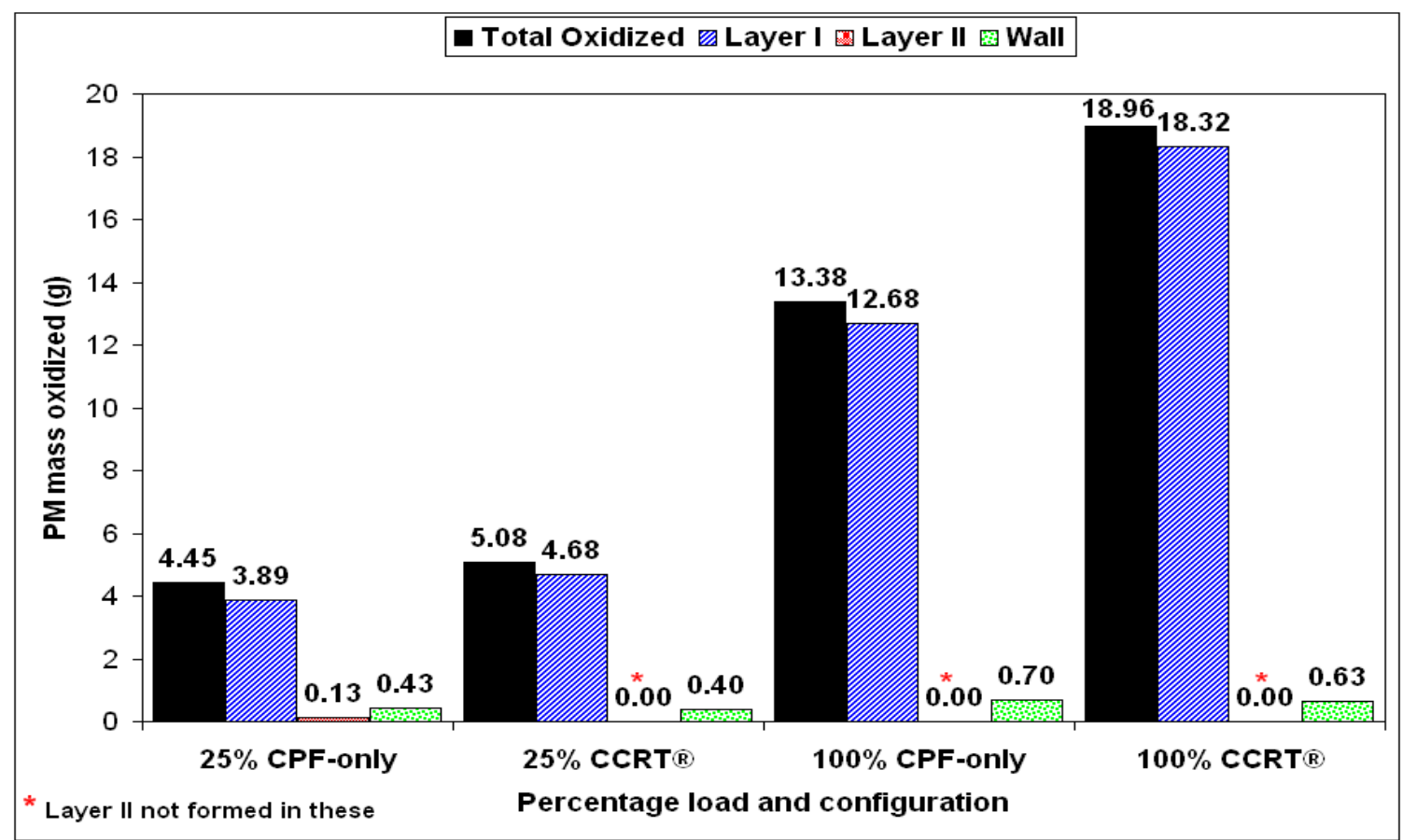

Figure 5.46: Distribution of PM mass oxidized by location at $2200 \mathrm{rpm}$ (loading time $=8$ hours $)$

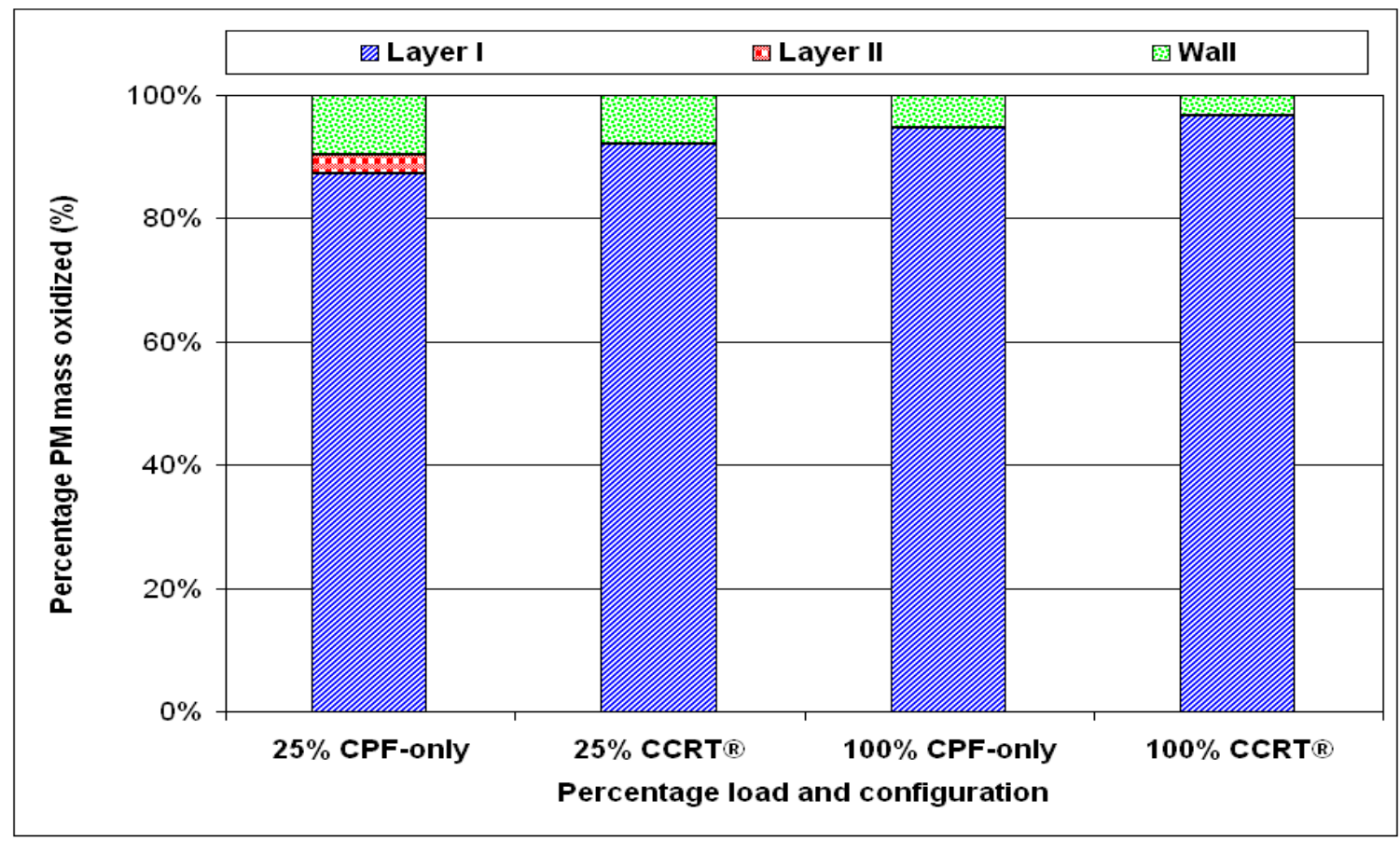

Figure 5.47: Distribution of PM mass oxidized by location, expressed as percentage distribution of total PM mass oxidized at $2200 \mathrm{rpm}$ (loading time $=8$ hours) 
A summary of the processes happening in the CPF with progression of loading time can be made as follows:

- PM accumulation in substrate wall of the CPF,

- PM cake formation on the substrate wall due to the filling up of voids in the wall,

- PM cake becoming the first filter with the wall as the second filter sequentially,

- In lower temperature load cases where CPF inlet temperatures are in the 250$280^{\circ} \mathrm{C}$ range, wall PM mass remains constant after PM cake formation, therefore, wall pressure drop remains constant, while PM cake pressure drop steadily builds up due to PM accumulation in PM cake layer, and

- In high temperature load cases where CPF inlet temperatures are in the 450$500^{\circ} \mathrm{C}$ range, wall $\mathrm{PM}$ mass gets depleted due to high wall $\mathrm{PM}$ oxidation rate while PM cake layer continues to be an efficient PM filter, and under favorable conditions, the PM in the wall gets almost completely oxidized while the CPF still performs at a high filtration efficiency, thus effectively explaining the steady pressure drop curves after 4 hours of loading times at 100\% load in CCRTR. configuration at $2200 \mathrm{rpm}$.

\subsection{Discussion of CPF Modeling Results}

This section presents a discussion of modeling results obtained from this thesis as compared to previous research at MTU [14] involving an earlier CCRTß. Although overall filtration and oxidation characteristics observed experimentally in the two cases were similar, some fundamental differences were observed between the two. In this section the result of the CPF model are used to explain these differences. 


\subsubsection{Comparison of Calibrated Model Parameters to Previ- ous Research Work}

Tables 5.23 and 5.24 show comparisons of calibrated model input parameters obtained from this research work, to those from previous research work at MTU [14] where the same CPF model was used to calibrate emissions data from a heavy duty 10.8 liter, 6-cylinder in-line engine having a rated power of $246 \mathrm{~kW}$ at $2300 \mathrm{rpm}$, at a rated speed of $2100 \mathrm{rpm}$ with a high pressure cooled electronically controlled EGR system. Ultra Low sulfur fuel (ULSF - sulfur content of 0.20 - 0.30 ppm and a cetane index

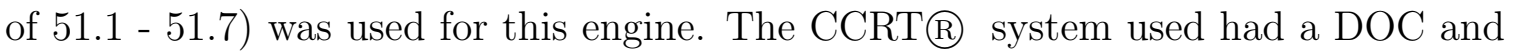
CPF having the same dimensions as the ones used in the current research work (as given in Tables 4.4 and 4.5), but the catalyst loading and/or formulation in the DOC and CPF were likely different. 


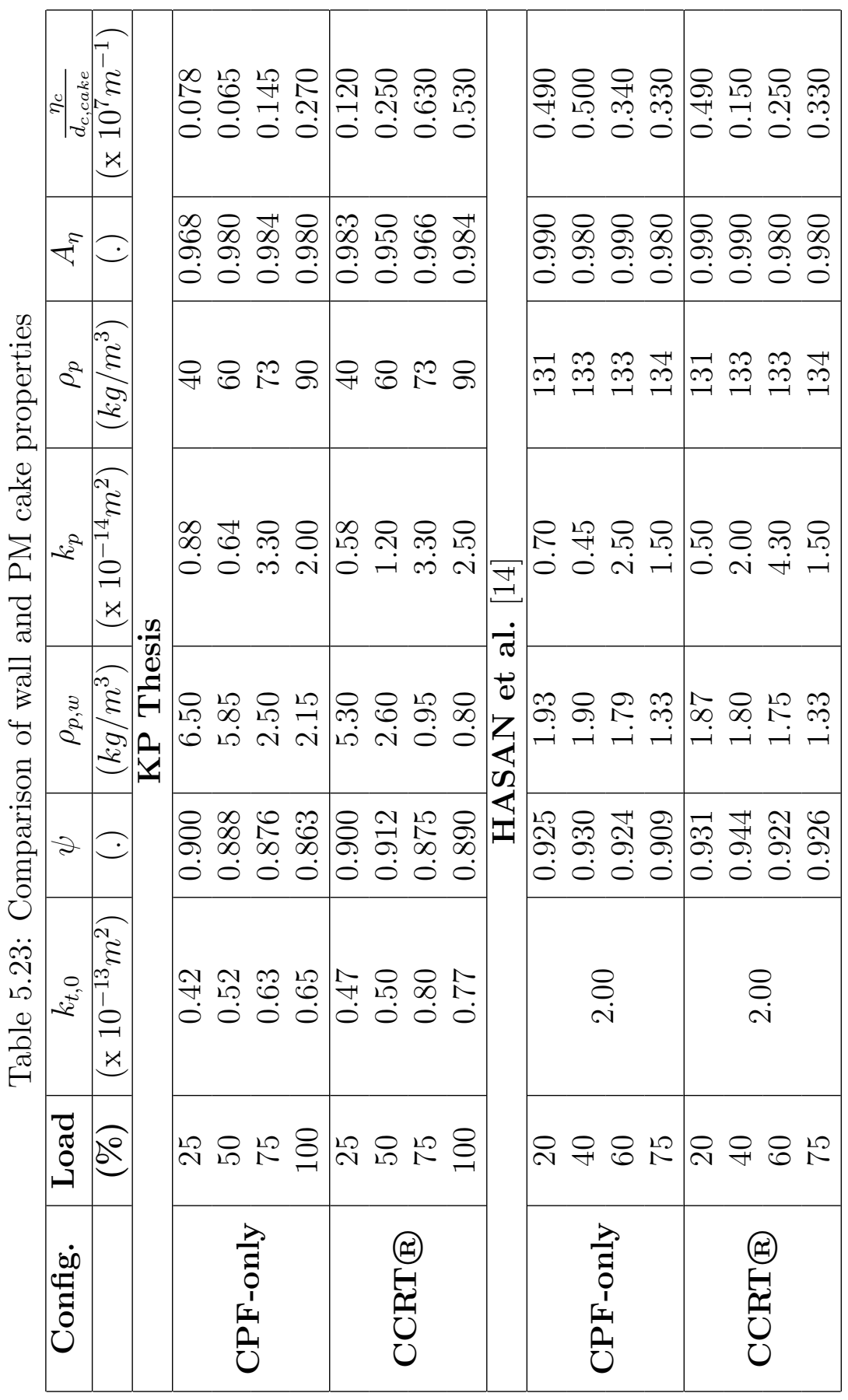




\begin{tabular}{|c|c|c|c|c|c|c|}
\hline - & 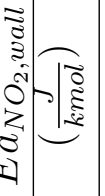 & $\begin{array}{l}\infty \\
0 \\
+ \\
+1 \\
⿱ ㇒ \\
0 \\
0 \\
0\end{array}$ & 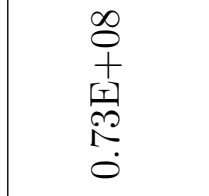 & & 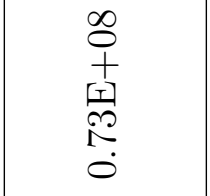 & $\begin{array}{c}\infty \\
0 \\
+ \\
+1 \\
0 \\
0 \\
0 \\
0\end{array}$ \\
\hline 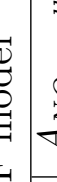 & 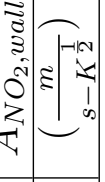 & 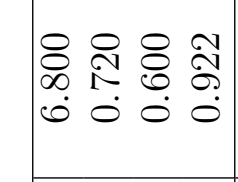 & 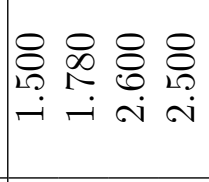 & & 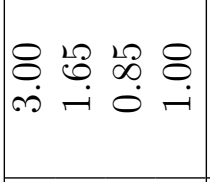 & 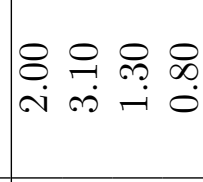 \\
\hline & 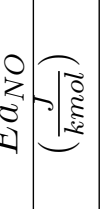 & $\begin{array}{l}\infty \\
0 \\
+ \\
+1 \\
0 \\
0 \\
0 \\
0\end{array}$ & $\begin{array}{l}\infty \\
0 \\
+ \\
+ \\
1 \\
\sigma \\
0 \\
0\end{array}$ & & 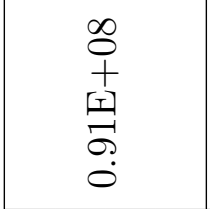 & $\begin{array}{l}\infty \\
0 \\
+ \\
1 \\
\vdots \\
0 \\
0\end{array}$ \\
\hline & $\begin{array}{c}0 \\
z_{1}\end{array}$ & $0 \begin{array}{lll}0 & 0 & \infty\end{array}$ & 0000 & & 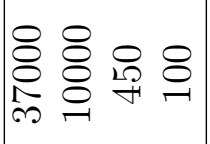 & 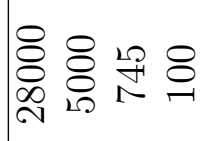 \\
\hline & 至 & $\begin{array}{c}\infty \\
0 \\
+ \\
+1 \\
01 \\
0 \\
0 \\
0\end{array}$ & 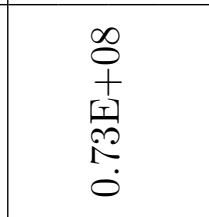 & 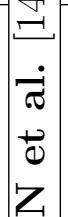 & 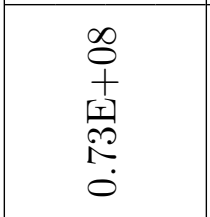 & 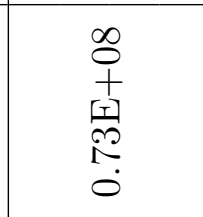 \\
\hline & 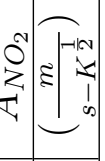 & 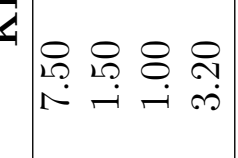 & 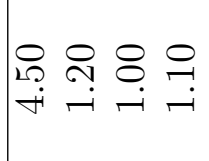 & 在 & $\underset{-}{\&}$ & $\underset{-}{\&}$ \\
\hline & 可 & $\begin{array}{c}\infty \\
0 \\
+ \\
+1 \\
0 \\
0 \\
10 \\
-1\end{array}$ & 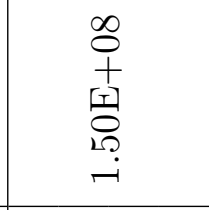 & & 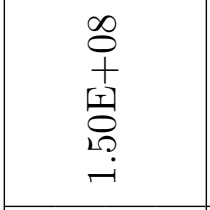 & 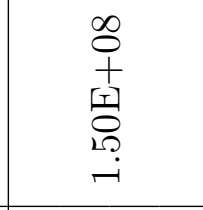 \\
\hline & 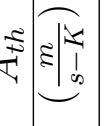 & 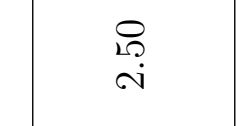 & $\begin{array}{l}0 \\
\stackrel{1}{0} \\
\text { i }\end{array}$ & & $\begin{array}{l}0 \\
\text { in } \\
\text { in }\end{array}$ & $\begin{array}{l}0 \\
\stackrel{1}{0} \\
\text { i }\end{array}$ \\
\hline & $\underset{7}{\overparen{2}}$ & 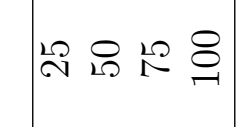 & 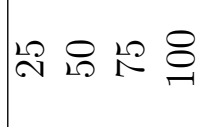 & & 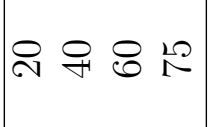 & 웡아 용 \\
\hline & ঠֶ. & $\begin{array}{l}\frac{\lambda}{3} \\
0 \\
0 \\
1 \\
\frac{1}{0} \\
0 \\
0\end{array}$ & 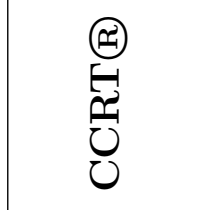 & & $\begin{array}{l}\vec{Z} \\
0 \\
0 \\
\frac{1}{1} \\
0 \\
0 \\
0\end{array}$ & 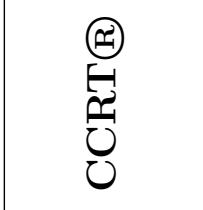 \\
\hline
\end{tabular}


From Table 5.23, the major differences between the calibration parameters in this thesis and previous research [14] are:

1. Clean trap permeability $k_{t, 0}$ values in this thesis were varied $\left(0.42-0.80 x 10^{-13}\right.$ $\left.\mathrm{m}^{2}\right)$ while it was maintained constant $\left(2 x 10^{-13} \mathrm{~m}^{2}\right)$ in reference [14]. This was due to a fundamental difference in the experimental setup (explained in section $5.3 .1)$.

2. Wall packing density values $\left(\rho_{p, w}\right)$ were generally higher for this thesis compared to previous research[14]. The general trend remained the same, that is, to decrease with increasing load.

3. Cake layer packing density values $\left(\rho_{p}\right)$ were lower for this thesis than for previous research[14]. This was because the cake layer packing densities were obtained in both cases as functions of the global Peclet numbers, and the global Peclet numbers encountered in the current work were different (lower) from that for previous research.

4. Maximum cake efficiency parameter values $\left(A_{\eta}\right)$ were in a wider range of values for this thesis $(0.950-0.984)$, while they were varied between 0.98 and 0.99 for the previous research[14]. This was due to the fact that the filter model was not accurately calibrated to DN-CPF particulate volume concentrations from the SMPS data in reference [14].

Table 5.24 shows the kinetic parameters used in the CPF model in this thesis and previous research [14]. From Table 5.24, the major changes in kinetic parameters between this thesis and previous research [14] are:

1. Values of frequency factors for $\mathrm{NO}_{2}$ /temperature-assisted oxidation in the PM cake were generally observed to be higher $\left(7.5,1.5,1.0\right.$ and $3.2 \frac{m}{s-K^{\frac{1}{2}}}$ for CPF- 
only configuration and $4.5,1.2,1.0$ and $1.1 \frac{m}{s-K^{\frac{1}{2}}}$ for CCRT $\mathrm{C}$ configuration) than 1.0, the value used for the same in previous research.

2. Frequency factors for the $\mathrm{NO}_{2}$ production in the wall $\left(\mathrm{A}_{N O}\right)$ were different (80 $\frac{m}{s-K^{3}}$ for the $100 \% \mathrm{CPF}$-only load case and 0.0 for the other 7 load-cases) compared to the values for the same from previous research [14]. This is due to fundamentally different $\mathrm{NO}_{2}$ production characteristics of the CPF catalysts used in the two different CCRTß) units (discussed in section 5.4.2).

\subsubsection{Effect of $\mathrm{NO}_{2}$ Production in the CPF in CPF-only and CCRT® Configurations}

Table 5.25 shows a comparison of experimental UP-CPF and DN-CPF $\mathrm{NO}_{2}$ concentrations measured in this thesis work to those from Hasan et al.[14]. It can be observed here that the CPF used in reference [14] had a much higher $\mathrm{NO}_{2}$ conversion efficiency than the CPF used in this research work (where an effective consumption of $\mathrm{NO}_{2}$ was observed in most cases), especially in the CPF-only configuration. Table 5.26 shows the percentage PM oxidized by the additional $\mathrm{NO}_{2}$ produced in the $\mathrm{CPF}$, as predicted by the model in both CPF-only and CCRT $R$ configurations, at a common loading time of 8 hours, and corresponding values as reported in reference [14]. These data were obtained by simulating the calibrated model at the same load with and without a production of $\mathrm{NO}_{2}$ in the $\mathrm{CPF}$ ('no $\mathrm{NO}_{2}$ production' achieved by setting $A_{N O}=0$ ), and taking the difference in the PM oxidized (at the same loading time) between both cases to be equal to the PM oxidized by the additional $\mathrm{NO}_{2}$ produced in the filter.

Percentage PM oxidized due to the additional $\mathrm{NO}_{2}$ produced in all load cases in the CPF-only and CCRTR configurations in this thesis was zero, except in the $100 \%$ CPF-only load case (6.7\%). Correspondingly, DN-CPF $\mathrm{NO}_{2}$ concentrations in 
the $100 \%$ CPF-only case (which showed highest percentage PM oxidized by $\mathrm{NO}_{2}$ generated) was higher than the UP-CPF value of the same (32 ppm DN-CPF compared to 27 ppm UP-CPF, as is shown in Table 5.25). This shows that $\mathrm{NO}_{2}$ production and PM oxidation due to $\mathrm{NO}_{2}$ may be taking place at certain load conditions, albeit at a much slower rate than corresponding rates observed from previous research work at MTU [14]. Clearly, the additional $\mathrm{NO}_{2}$ produced in the $\mathrm{CPF}$ used in this thesis contributes only a fraction (maximum of about $7 \%$ ) of the total PM oxidation efficiency of the CPF, and is beneficial in the $100 \%$ CPF-only load case, where the UP-CPF $\mathrm{NO}_{2}$ concentrations are low (due to the DOC not being present upstream of the $\mathrm{CPF}$ ), and hence the additional $\mathrm{NO}_{2}$ produced $(8.7 \mathrm{ppm}$, as shown in Table 5.20) in the CPF is significant compared to the CPF inlet $\mathrm{NO}_{2}$ concentration in the CPF-only configuration (27 ppm).

Evidently, the CPF used in reference [14] had higher conversion efficiency of $\mathrm{NO}$ to $\mathrm{NO}_{2}$ in all load-cases compared to the one used in this research work, and correspondingly, greater $\% \mathrm{PM}$ oxidation due to $\mathrm{NO}_{2}$ production effect was observed in the previous research work[14]. This could be due to a different reactivity of the catalyst to NO oxidation reaction between the CPF's used in both cases, probably due to differences in overall catalyst loadings and/or catalyst formulation. This is noticeable from the high values of NO production pre-exponential factors observed in reference [14], compared to the corresponding values obtained from model calibration in this thesis (as shown in Table 5.26). The values of frequency factors for $\mathrm{NO}_{2}$ production obtained from this thesis were able to predict $\mathrm{DN}-\mathrm{CPF} \mathrm{NO}_{2}$ concentrations accurately for only 1 load case (100\% CPF-only). Consumption of $\mathrm{NO}_{2}$ across the $\mathrm{CPF}$ has also been observed in recent research work [5], although at lower UP-CPF temperatures than were observed in this thesis. The most probable reason for the consumption of $\mathrm{NO}_{2}$ in the $\mathrm{CPF}$ was found out to be due to a dissociation reaction of $\mathrm{NO}_{2}$ to form $\mathrm{NO}$ and $\mathrm{O}_{2}$. 
Table 5.25: Comparison of experimentally observed CPF inlet and outlet $\mathrm{NO}_{2}$ concentrations

\begin{tabular}{|c|c|c|c|c|}
\hline \multirow[t]{2}{*}{ Config. } & \multirow{2}{*}{$\begin{array}{c}\text { Load } \\
(\%)\end{array}$} & \multicolumn{2}{|c|}{$\mathrm{NO}_{2}$ concentration } & \multirow{2}{*}{$\begin{array}{c}\text { \% conversion } \dagger \\
(\%)\end{array}$} \\
\hline & & $\begin{array}{c}\text { UP-CPF } \\
(\mathrm{ppm})\end{array}$ & $\begin{array}{c}\text { DN-CPF } \\
(\mathrm{ppm})\end{array}$ & \\
\hline \multicolumn{5}{|c|}{ KP Thesis } \\
\hline \multirow{4}{*}{ CPF-only } & 25 & 38 & 12 & -68.4 \\
\hline & 50 & 44 & 21 & -52.3 \\
\hline & 75 & 37 & 19 & -48.6 \\
\hline & 100 & 27 & 32 & 22.2 \\
\hline \multirow{4}{*}{ CCRTß } & 25 & 144 & 125 & -13.2 \\
\hline & 50 & 101 & 65 & -33.0 \\
\hline & 75 & 111 & 74 & -32.1 \\
\hline & 100 & 127 & 91 & -28.3 \\
\hline \multicolumn{5}{|c|}{ Hasan et al. [14] } \\
\hline \multirow{4}{*}{ CPF-only } & 20 & 35 & 71 & 102.9 \\
\hline & 40 & 22 & 96 & 336.4 \\
\hline & 60 & 24 & 111 & 362.5 \\
\hline & 75 & 13 & 90 & 592.3 \\
\hline \multirow{4}{*}{ CCRTß } & 20 & 105 & 113 & 7.6 \\
\hline & 40 & 136 & 132 & -2.9 \\
\hline & 60 & 103 & 113 & 9.7 \\
\hline & 75 & 63 & 86 & 36.5 \\
\hline
\end{tabular}

$\dagger+$ ve values of $\%$ conversion indicate a net production of $\mathrm{NO}_{2}$, and -ve values indicate consumption. 
Table 5.26: Comparison of effect of $\mathrm{NO}_{2}$ production in the CPF on PM oxidation efficiency of CPF with previous research work (loading time $=8$ hours)

\begin{tabular}{|c|c|c|c|c|}
\hline \multirow[t]{2}{*}{ 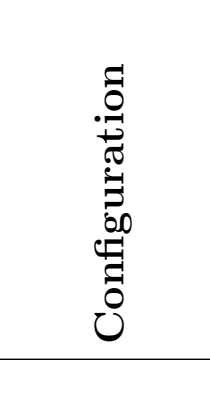 } & 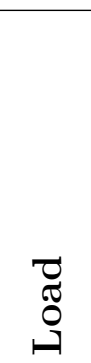 & 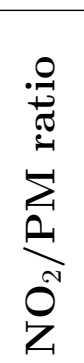 & 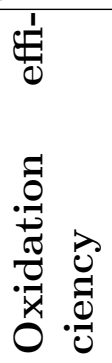 & 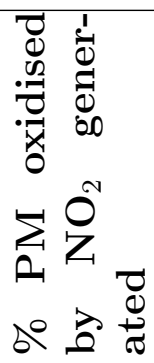 \\
\hline & $(\%)$ & $()$. & $(\%)$ & $(\%)$ \\
\hline \multicolumn{5}{|c|}{ KP Thesis } \\
\hline \multirow{4}{*}{ CPF-only } & 25 & 11.5 & 22.1 & 0.0 \\
\hline & 50 & 17.1 & 29.3 & 0.0 \\
\hline & 75 & 20.5 & 36.3 & 0.0 \\
\hline & 100 & 15.2 & 73.1 & 6.7 \\
\hline \multirow{4}{*}{ CCRTR } & 25 & 20.4 & 34.1 & 0.0 \\
\hline & 50 & 34.2 & 56.9 & 0.0 \\
\hline & 75 & 30.8 & 78.7 & 0.0 \\
\hline & 100 & 19.1 & 88.6 & 0.0 \\
\hline \multicolumn{5}{|c|}{ HASAN et al. [14] } \\
\hline \multirow{4}{*}{ CPF-only } & 20 & 3.1 & 4.9 & 42.1 \\
\hline & 40 & 1.8 & 18.9 & 75.9 \\
\hline & 60 & 3.1 & 33.8 & 66.9 \\
\hline & 75 & 2.3 & 68.2 & 27.6 \\
\hline \multirow{4}{*}{ CCRT® } & 20 & 12.8 & 9.5 & 5.9 \\
\hline & 40 & 13.8 & 33.6 & 5.9 \\
\hline & 60 & 13.9 & 71.3 & 9.6 \\
\hline & 75 & 13.1 & 82.4 & 3.9 \\
\hline
\end{tabular}




\section{Chapter 6}

\section{Summary, Conclusions and \\ Recommendations}

This chapter provides a summary of the experimental and simulation work carried out as part of this thesis. Conclusions from the experimental and model simulation results presented in Chapter 5 are summarized. Recommendations for conducting future research work are also developed.

\subsection{Experimentation Summary}

A series of experiments was carried out on the John Deere engine with a DOCCPF system (commercially known as 'CCRT®') in the DOC-only, CPF-only and CCRT $\AA$ configurations to evaluate the performance of the DOC and the CPF in these configurations at two engine speeds, 2200 and $1650 \mathrm{rpm}$ and various engine loads.

Experiments conducted in the DOC-only configuration were intended to evaluate the $\mathrm{CO}, \mathrm{HC}$ and $\mathrm{NO}$ oxidation efficiencies and the $\mathrm{NO}_{2}$ conversion efficiency of the DOC at the two speeds. DOC inlet temperatures observed during the experiments were in the range of $150-414^{\circ} \mathrm{C}$ for the $2200 \mathrm{rpm}$ experiment and $160-499^{\circ} \mathrm{C}$ for 
the $1650 \mathrm{rpm}$ experiment. CO conversion efficiencies observed varied between 97 and $75 \%$ for $2200 \mathrm{rpm}$ and 98 and $82 \%$ for $1650 \mathrm{rpm}$, always decreasing with increasing load on the engine. HC conversion efficiencies of $70-85 \%$ were observed at 2200 and $1650 \mathrm{rpm}$. NO conversion efficiencies observed at $2200 \mathrm{rpm}$ increased from 12 (at $10 \%$ load) to $74 \%$ (at $35 \%$ load) and then decreased to $37 \%$ (at 100\% load), and at $1650 \mathrm{rpm}$, NO conversion efficiencies increased from 38\% (at 10\% load) to $83 \%$ (at $15 \%$ load) and then decreased to $10 \%$ (at $100 \%$ load). Maximum $\mathrm{NO}_{2}$ conversion efficiencies observed were $460 \%$ at $90 \%$ load at $2200 \mathrm{rpm}$ and $330 \%$ at $25 \%$ load at $1650 \mathrm{rpm}$. The DOC used in this research assisted the $\mathrm{NO}_{2}$ dissociation reaction (or the 'reverse reaction') at DOC inlet temperatures less than $180^{\circ} \mathrm{C}(5 \%$ load) at 2200 and $1650 \mathrm{rpm}$, and $\mathrm{NO}_{2}$ at the inlet was therefore consumed in these cases. The DOC also showed more than $100 \% \mathrm{NO}_{2}$ conversion efficiencies for DOC inlet temperatures greater than $200^{\circ} \mathrm{C}$.

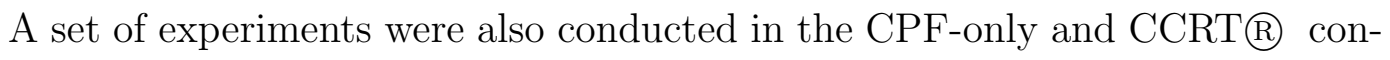
figurations at 25, 50, 75 and $100 \%$ load at 2200 and $1650 \mathrm{rpm}$. These experiments were intended to characterize the pressure drop and oxidation and filtration efficiencies of the CPF in both configurations (i.e. with and without the DOC) and at various engine loads (at various inlet temperatures).

Pressure drop across the CPF varied with loading time at steady load condition for all load cases. The maximum pressure drop observed at $2200 \mathrm{rpm}$ in the CPFonly configuration was $11.3 \mathrm{kPa}$ (in the $100 \%$ load case), and that for the CCRTR) configuration was $12.2 \mathrm{kPa}$ (in the $100 \%$ load case). Corresponding values for 1650 rpm were $16.6 \mathrm{kPa}$ in the CPF-only configuration and $18.8 \mathrm{kPa}$ in the CCRT $\mathbb{R}$ configuration, both at the $100 \%$ load case.

Cumulative PM oxidation efficiency of the CPF varied from 25 to $77 \%$ in the CPF-only configuration and 25 to $91 \%$ in the CCRT@ configuration at $2200 \mathrm{rpm}$,

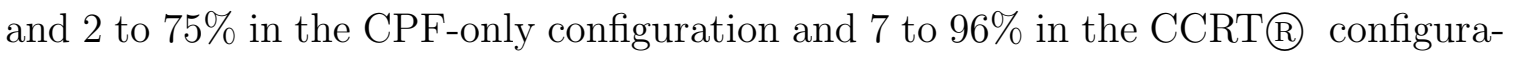


tion at $1650 \mathrm{rpm}$. The general trend observed was increasing PM oxidation efficiencies with increasing load at the same speed, due to increased CPF inlet temperatures and therefore higher PM oxidation rates via the temperature $/ \mathrm{NO}_{2}$-assisted and thermal PM oxidation mechanisms, and higher PM oxidation percentages for the CCRT $\mathbb{R}$ configuration compared to the CPF-only configuration at the same load and speed, due to the DOC present in the CCRTR configuration upstream of the CPF converting $\mathrm{NO}$ to $\mathrm{NO}_{2}$, thereby providing more $\mathrm{NO}_{2}$ for the $\mathrm{PM}$ in the $\mathrm{CPF}$ to get oxidized via the $\mathrm{NO}_{2}$ /temperature-assisted mechanism.

Outlet PM mass concentrations measured were unreliable/inaccurate, probably due to PM mass collected on the $50 \mathrm{~mm}$ filters being in the same range as the filter weight loss between post-test weighing and post-bake weighing. Therefore, UP-CPF and DN-CPF SMPS data were used to assess the filtration efficiency of the CPF at all load cases. Filtration efficiencies of the CPF calculated from UP-CPF and DN-CPF SMPS data for all load-cases showed greater than $99 \%$ overall efficiency in the cake filtration region.

\subsection{Modeling Summary}

Two models (the MTU 1-D DOC model and the MTU 1-D 2-layer CPF model) were further developed from previous models and used at MTU. The models were first calibrated using experimental data collected, and results from the models were analyzed to study the performance of the CPF with and without the DOC.

The MTU 1-D DOC model was developed from previous models as detailed in references $[4,40]$ and calibrated to experimental data using a single set of kinetic parameters for 2200 and $1650 \mathrm{rpm}$. Having one set of kinetic parameters for different speeds enhances the portability of the model to different data using the same DOC, minimizing or eliminating the need for further model calibration. The calibration, 
however, has to be verified using further experimental data. It was also observed that adsorption equilibrium constants for the DOC at various loads and speeds have to be determined more accurately, using reactor study data. This is important because the adsorption and kinetic constants are DOC-specific and can also depend on other factors like aging of the DOC.

As part of this thesis, the MTU 1-D 2-layer CPF model was improved from a previous version of the model developed at MTU. The technical approach to the current model is available in the published literature[3]. The major improvement in the 1-D 2-layer CPF model was the development of a cake filtration model using a parametric equation, which is important to explain the filtration performance of the $\mathrm{CPF}$, especially in cases with high PM oxidation rates. Improvements were also made so as to include the PM mass rate balance of the PM cake layer and substrate wall in the model outputs. The CPF model was calibrated to experimental data at 2200 rpm in both CPF-only and CCRT@ configurations. Calibration of the CPF model involved matching model-predicted values of clean pressure drop, pressure drop versus loading time, mass deposited in the filter at the end of loading, DN-CPF particle volume concentrations (calculated from DN-CPF PSD data) versus loading time, $\mathrm{NO}_{2}$ production in the $\mathrm{CPF}$ and average $\mathrm{DN}-\mathrm{CPF} \mathrm{NO}$ concentrations to corresponding experimentally measured variables. The results obtained from the calibrated model were then used to study the filtration and oxidation behavior of the CPF.

Clean pressure drop data as predicted by the model were fit to within $49 \%$ of the experimental values measured at $2200 \mathrm{rpm}$. Pressure drop versus time data were within an absolute difference of $0.85 \mathrm{kPa}$ from the experimental pressure drop data. Also, the minimum least squares fit coefficient calculated for all 8 calibrated cases was 0.95 . PM mass deposited in the filter at the end of loading were fit to the experimental data within 14\%. DN-CPF PVC were within $38 \%$ of calculated values of the same from experimental data. $\mathrm{NO}_{2}$ concentrations measured downstream of 
the CPF were matched within $5 \%$ at one load case (100\% CPF-only). At all the other load cases, a dissociation reaction of $\mathrm{NO}_{2}$ to form $\mathrm{NO}$ and $\mathrm{O}_{2}$ was observed to take place, which was not included in the CPF model. The current 1-D 2-layer CPF model accounts for the amount of $\mathrm{NO}_{2}$ consumed by PM oxidation reaction, but experimentally observed $\mathrm{NO}_{2}$ consumption was more than the result of this effect alone. Hence, in order to predict $\mathrm{NO}_{2}$ outlet concentrations more accurately for all load cases, the $\mathrm{NO}_{2}$ dissociation reaction should be included in the CPF model (this is planned as part of future CPF model development work).

\subsection{Conclusions}

Major conclusions that can be drawn from pressure drop profiles obtained from CPF model simulation are as follows:

- CPF pressure drop in the $25 \%$ load case in both configurations increased steadily after PM cake layer efficiency exceeded 90\%, due to low wall and PM cake oxidation rates. In the $100 \%$ load case, however, the CPF pressure drop increased to a high value (12.2 $\mathrm{kPa}$ in CCRT@ configuration) after about 6 minutes of loading (due to wall filling), and later on decreased to a 'steady' value of 7.2 $\mathrm{kPa}$, due to wall mass balance, i.e., wall PM inlet rate equals the sum of wall PM oxidation rate and wall PM outlet rate, and

- In cases where the CPF pressure drop stabilized to a steady value with time (specifically, in the $100 \%$ load case in CPF-only and CCRTß configurations at $2200 \mathrm{rpm}$ ), the substrate wall PM deposition rate approached zero, which means that the PM cake was performing 98-99\% of filtration in these cases. Observing the PM inlet, deposition, oxidation and outlet mass rates for the PM cake layer and substrate wall thus helps in understanding the PM deposition and oxidation in the cake and wall. 
Regarding the PM mass oxidation efficiency, the following conclusions can be made:

- Percentage PM oxidized by the CPF increased with increasing load, due to higher temperatures and higher $\mathrm{NO}_{2}$ flow rates.

- Catalytic PM oxidation mechanism was not necessary to model CPF oxidation behavior.

- $\mathrm{NO}_{2}$ production in the $\mathrm{CPF}$ was observed to be less than $\mathrm{NO}_{2}$ consumption due to a possible dissociation reaction of $\mathrm{NO}_{2}$ to form $\mathrm{NO}$ and $\mathrm{O}_{2}$ in all load cases except the $100 \%$ CPF-only load case (maximum $\mathrm{NO}_{2}$ production in this load case was $8.7 \mathrm{ppm}$, as estimated from the model).

The following conclusions can be made about the filtration efficiency of the CPF:

- Overall CPF filtration efficiency was higher than 99\% after PM cake layer formation (3.3-0.7 $\mu \mathrm{m}$ in thickness, depending on load).

- The PM cake layer was the primary filter in the CPF after it was formed. Filtration efficiencies greater than $90 \%$ were observed from model simulations when average PM cake layer thickness was 0.6 - $2.0 \mu \mathrm{m}$ in all load cases at 2200 rpm, and the overall efficiencies approached $99 \%$.

- Wall filtration efficiency decreases with increasing wall oxidation. For instance, in the $100 \%$ load case at $2200 \mathrm{rpm}$ in the CCRTß configuration, wall filtration efficiency decreased from $83 \%$ when the wall PM mass was 0.3 g, to $71 \%$ when the wall PM mass was oxidized to zero mass. However, this change did not significantly affect overall filtration efficiency because of the presence of the PM cake as the primary filter. 


\subsection{Recommendations for Future Research}

This section summarizes the important recommendations for future research based on the challenges faced in this thesis and conclusions drawn thereof.

\section{DOC Model:}

1. $\mathrm{NO}_{2}$ dissociation reaction needs to be considered at all load cases in the DOC model. The equilibrium constants for $\mathrm{NO}$ oxidation and $\mathrm{NO}_{2}$ dissociation reactions should be calculated in the DOC model as functions of DOC inlet temperatures, and necessary changes to species conservation equations of $\mathrm{NO}, \mathrm{NO}_{2}$ and $\mathrm{O}_{2}$ should also be incorporated in the DOC model.

2. The adsorption equilibrium constants used in the DOC model need to be determined more accurately, since values of the same from published literature were found to be insufficient to explain the kinetics of the DOC used in this research.

3. Air property correlations used in the DOC model should be replaced with properties calculated from actual exhaust gas species mole fractions.

4. Pre-constructed numerical subroutines used for setting up and solution of the system of governing equations for the DOC should be replaced by generic algorithms, to facilitate use of ordinary fortran compilers to compile and execute the DOC model program.

\section{CPF Experiments:}

The recommendations to CPF loading experiments that can be suggested based on experimental data collected in this thesis are as follows:

1. Determination of clean pressure drop of the CPF at the start of each loading experiment is important for calibration of the initial pressure drop and overall 
pressure drop versus time data of the 1-D 2-layer CPF model. The addition of a 'baseline' in the experimental setup and by-passing the exhaust gas from the CPF until load and speed conditions stabilize to steady values will eliminate the discrepancies in clean pressure drop values measured from experiments observed in this research. This will also enable the use of a single value of clean trap permeability for the CPF model at all load conditions.

2. Discrepancies in the outlet PM concentrations measured during CPF loading experiments were observed, owing to low PM emissions downstream of the CPF during loading (which was, in turn, due to high filtration efficiencies of the CPF) and also due to PM mass loss from the filters used in the PM sampling system, as observed in recent research at MTU[27]. The weighing procedure can be improved by using the procedure outlined in MTU[28].

3. An effective consumption of $\mathrm{NO}_{2}$ was observed across the CPF in most of the load cases at $2200 \mathrm{rpm}$ in this research, as opposed to effective $\mathrm{NO}_{2}$ production observed in recent research work with an earlier CCRTß [12]. Also, the consumption of $\mathrm{NO}_{2}$ was more than what would be needed for oxidation of PM in the CPF. In order to confirm this observation, the causes and mechanisms for $\mathrm{NO}_{2}$ consumption in the $\mathrm{CPF}$ has to be studied further and included in the CPF model. Also, a study of the reliability of 'NO' mode measurements should be conducted to ensure that the measurements taken as part of this thesis were accurate.

\section{CPF Model:}

1. Individual species conservation equations for all exhaust species considered should be included in the 1-D 2-layer CPF model, in order to include more reactions (like $\mathrm{HC}$ and $\mathrm{CO}$ oxidation in the gas-phase and $\mathrm{NO}_{2}$ dissociation 
in the wall) in the model in future work. This will help in accounting for all gaseous species in the exhaust mixture passing through the CPF.

2. The next step in CPF modeling should be to extend the current framework of the model to include active regeneration. Simulation of an active regeneration scenario requires several improvements to the current model, including the gaseous velocity solver method, the regeneration (PM oxidation) model and including the capability to simulate transient inlet conditions.

3. PM oxidation in the gas-phase, in the inlet and outlet channels of the CPF is another important phenomenon that should be included in the CPF model. This effect will be important to explain PM oxidation during active regeneration simulations.

4. $\mathrm{HC}$ and $\mathrm{CO}$ oxidation in the gas-phase should be included in the CPF model, as these are important reactions that take place in the CPF during active regeneration by means of $\mathrm{HC}$ injection upstream of the DOC in the CCRTR configuration.

5. $\mathrm{NO}_{2}$ dissociation in the wall is another important reaction to be included in the CPF model, and this reaction can also be considered similar to the $\mathrm{NO}-\mathrm{NO}_{2}$ reversible reaction to be included in the DOC model (explained earlier). This reaction, in conjunction with the species conservation equation, will enable the prediction of DN-CPF $\mathrm{NO}_{2}$ concentrations accurately.

6. A multi-channel representation of the CPF should be developed in order to predict radial temperature gradients observed during active regeneration, as given in reference [27], as opposed to the single-channel representation currently used in the 1-D 2-layer CPF model.

7. Current findings about retaining a PM cake layer for maintaining high filtration 
efficiency of the CPF should be verified in future research. This would require collection and analysis of experimental data regarding PM filtration efficiency of the $\mathrm{CPF}$ in cases where the CPF model currently predicts very low substrate wall PM loading and a partial PM cake loading (corresponding to a PM cake thickness of 1-2 $\mu \mathrm{m})$. 


\section{References}

[1] Dieselnet online resource. http://www.dieselnet.com/standards/us/hd.html. Jan. 2005.

[2] Dieselnet online resource. http://www.dieselnet.com/standards/us/offroad.html. Jan. 2005.

[3] H.Mohammed, A.P.Triana, S.L.Yang, and J.H.Johnson. An Advanced 1D 2-layer Catalyzed Diesel Particulate Filter Model to Simulate : Filtration by the Wall and Particulate Cake, Oxidation in the Wall and Particulate Cake by $\mathrm{NO}_{2}$ and $\mathrm{O}_{2}$, and Regeneration by Heat Addition - Paper No. 2006-01-0467. SAE, 2006.

[4] H.Oh and J.C.Cavendish. Transients of Monolithic Catalytic Converters: Response to Step Changes in Feedstream Temperature as Related to Controlling Automobile Emissions. Ind. Eng. Chem. Prod. Res. Dev., 21:29-37, 1982.

[5] G.C.Koltsakis, O.A.Haralampous, C.K.Dardiotis, Z.C.Samaras, C.D.Vogt, E.Ohara, Y.Watanabe, and T.Mizutani. Performance of catalyzed particulate filters without upstream oxidation catalyst - Paper No. 2005-01-0952. SAE, 2005.

[6] Dieselnet online resource. http://www.dieselnet.com/tech/cat_doc.html. Dec. 2005.

[7] A.P.Triana. Development of Models to Study the Emissions, Flow and Kinetic 
Characteristics from Diesel Oxidation Catalysts and Particulate Filters. PhD thesis, Michigan Technological University, January 2005.

[8] A.P.E.York, J.P.Cox, T.C.Watling, A.P.Walker, D.Bergeal, R.Allanson, and M.Lavenius. Development and Validation of a One-Dimensional Computational Model of the Continuously Regenerating Diesel Particulate Filter (CR-DPF) system - Paper No. 2005-01-0954. SAE, 2005.

[9] G.C.Koltsakis, P.A.Konstantinidis, and A.M.Stamatelos. Development and Application Range of Mathematical Models for 3-Way Catalytic Converters. Applied Catalysis B : Environmental, 12, 1997.

[10] I.P.Kandylas, G.C.Koltsakis, and A.M.Stamatelos. Mathematical Modeling of Precious Metals Catalytic Converters for Diesel NOx Reduction. Proceedings of the Institution of Mechanical Engineers, 213, 1999.

[11] A.Setiabudi, M.Makkee, and J.A.Moulijn. The Role of $\mathrm{NO}_{2}$ and $\mathrm{O}_{2}$ in the Accelerated Combustion of Soot in Diesel Exhaust Gases. Applied Catalysis B : Environmental, 50, 2004.

[12] H.Mohammed. The Filtration and Oxidation Characteristics of a Diesel Oxidation Catalyst and a Catalyzed Particulate Filter: Development of a 1-D 2-Layer Model. Master's thesis, Michigan Technological University, May 2005.

[13] I.P.Kandylas and G.C.Koltsakis. NO2-assisted Regeneration of Diesel Particulate Filters : A Modeling Study. Industrial Engineering Chemistry Research, 41, 2002.

[14] H.Mohammed, V.R.Lakkireddy, J.H.Johnson, and S.T.Bagley. An Experimental and Modeling Study of a Diesel Oxidation Catalyst and a Catalyzed Diesel Particulate Filter Using a 1D 2-layer Model - Paper No. 2006-01-0466. SAE, 2006. 
[15] A.S.Shende. A Study of the Filtration and Particulate Matter Oxidation Characteristics of Two Catalyzed Wall-Flow Diesel Particulate Filters : Experimental and 1D 2-Layer Model Results. Master's thesis, Michigan Technological University, 2003.

[16] A.S.Shende, J.H.Johnson, S.L.Yang, S.T.Bagley, and A.M.Thalagavara. The Filtration and Particulate Matter Oxidation Characteristics of a Catalyzed WallFlow Diesel Particulate Filter : Experimental and 1D 2-Layer Model Results Paper No. 2005-01-0949. SAE, 2005.

[17] S.M.Kau and D.F.Lawler. Dynamics of Deep-Bed filtration : Velocity, Depth and Inertia . Journal of Environmental Engineering, 1995.

[18] A.G.Konstandopoulos and J.H.Johnson. Wall-Flow Diesel Particulate Filters Their Pressure Drop and Collection Efficiency - Paper No. 890405. SAE, 1989.

[19] G.G.Muntean, D.Rector, D.Herling, and D.Lessor amd M.Khaleel. LatticeBoltzmann Diesel Particulate Filter Sub-Grid Modeling - a Progress Report Paper No. 2003-01-0835. SAE, 2003.

[20] G.D.Dickey. Filtration. Reinhold Publishing Corporation, NY, 1961.

[21] Clyde Orr. Filtration : Principles and Practices - Part 1. Chemical Processing and Engineering, Marcel Drekker Incorporated, NY, 1981.

[22] Kenneth Wark, Cecil.F.Warner, and Wayne.T.Davis. Air Pollution - Its Origin and Control. Addison - Wesley Publishing Company, 2002.

[23] A.G.Konstandopoulos. Deposit Growth Dynamics : Particle Sticking and Scattering Phenomena. Powder Technology, 109, 2000.

[24] K.W.Lee, L.D.Reed, and J.A.Geiseke. Pressure Drop across Packed Beds in the Low Knudsen Number Regime. J. Aerosol Science, 9, 1978. 
[25] K.W.Lee and J.A.Geiseke. Collection of Aerosol Particles by Packed Beds. Environmental Science and Technology, 13(4), 1979.

[26] Dieselnet online resource. http://www.dieselnet.com/tech/dpf_top.html. Dec. 2005.

[27] P.A.Singh. An Experimental Study of Active Regeneration of an Advanced Catalyzed Particulate Filter by Diesel Fuel Injection Upstream of an Oxidation Catalyst. Master's thesis, Michigan Technological University, January 2006.

[28] P.A.Singh, A.M.Thalagavara, J.Naber, J.H.Johnson, and S.T.Bagley. An Experimental Study of Active Regeneration of an Advanced Catalyzed Particulate Filter by Diesel Fuel Injection Upstream of an Oxidation Catalyst - Paper No. 2006-01-0879. SAE, 2006.

[29] A.G.Konstandopoulos, E.Skaperdas, and M.Masoudi. Microstructural Properties of Soot Deposits in Diesel Particulate Traps - Paper No. 2002-01-1015. SAE, 2002.

[30] E.Kladopoulou, S.L.Yang, J.H.Johnson, G.G.Parker, and A.G.Konstandopoulos. A Study Describing the Performance of Diesel Particulate Filters During Loading and Regeneration A Lumped Parameter Model for Control Applications - Paper No. 2003-01-0842. SAE, 2003.

[31] A.G.Konstandopoulos and M.Kostoglou. Periodically Reversed Flow Regeneration of Diesel Particulate Traps - Paper No. 1999-01-0469. SAE, 1999.

[32] C.T.Huynh. A Study of the Filtration and Regeneration Characteristics of a Catalyzed Wall Flow Diesel Particulate Filter: One Dimensional Model Calibrated and Validated with Experimental Data. Master's thesis, Michigan Technological University, 2002. 
[33] B.J.Cooper and J.E.Thoss. Role of NO in Diesel Particulate Emission Control Paper No. 890404. SAE, 1989.

[34] F.Jacquot, V.Logie, J.F.Brilhac, and P.Gilot. Kinetics of the Oxidation of Carbon Black by $\mathrm{NO}_{2}$ : Influence of the presence of water and oxygen. Carbon, 40, 2002.

[35] B.R.Stanmore, J.F.Brilhac, and P.Gilot. The Oxidation of Soot : a Review of Experiments, Mechanisms and Models. Carbon, 39, 2001.

[36] A.G.Konstandopoulos, M.Kostoglou, E.Skaperdas, E.Papaioannou, D.Zarvalis, and E.Kladopoulou. Fundamental Studies of Diesel Particulate Filters : Transient Loading, Regeneration and Aging - Paper No. 2000-01-1016. SAE, 2000.

[37] B.J.Cooper, H.J.Jung, and J.E.Thoss. Treatment of diesel exhaust gases. US Patent No. 4902487, 1990.

[38] I.P.Kandylas and G.C.Koltsakis. Simulation of Continuously Regenerating Diesel Particulate Filters in Transient Driving Cycles. Proceedings of the Institution of Mechanical Engineers Part D J Automobile Enginerring, 216(7), 2002.

[39] A.P.Triana, J.H.Johnson, S.L.Yang, and K.J.Baumgard. An Experimental and Numerical Study of the Performance Characteristics of the Diesel Oxidation Catalyst in a Continuously Regenerating Diesel Particulate Filter - Paper No. 2003-01-3176. SAE, 2003.

[40] P.M.Laing, M.D.Shane, Son, Seha, A.A.Adamczyk, and P.Li. A Simplified Approach to Modeling Exhaust System Emissions - SIMTWC - Paper No. 1999-013476. SAE, 1999.

[41] John Deere PEC. CPF and CCRT® Experimental Data. Technical report, John Deere - Product Engineering Center, 2005. 
[42] M.Masoudi, A.G.Konstandopoulos, M.S.Nikitidis, E.Skaperdas, D.Zarvalis, E.Kladopoulou, and C.Altiparmakis. Validation of a Model and Development of a Simulator for Predicting the Pressure Drop of Diesel Particulate Filters Paper No. 2001-01-0911. SAE, 2001.

[43] TSI. Aerosol Instrument Manager@Software for SMPS : Instruction Manual. TSI Incorporated, 1930038 edition, October 2002.

[44] Bird.B.R., Stewart.W.E., and Lightfoot.E.N. Transport Phenomena. John Wiley and Sons, 1960.

[45] S.E.Voltz, C.R.Morgan, D.Liederman, and S.M.Jacob. Kinetic Study of Carbon Monoxide and Propylene Oxidation on Platinum Catalysts. Ind. Eng. Chem. Prod. Res. Dev., 12(4), 1973.

[46] M.J.Murphy, L.J.Hillenbrand, D.A.Trayser, and J.H.Wasser. Assessment of Diesel Particulate Control - Direct and Catalytic Oxidation - Paper No. 810112. SAE, 1981.

[47] Houghen.O.A. and Watson.K.M. Chemical Process Principles - Part 3. Wiley, New York, N.Y., 1947.

[48] E.Bissett. Mathematical Model of the Thermal Regeneration of a Wall-Flow Monolith Diesel Particulate Filter. Chemical Engineering Science, 39, 1983.

[49] E.Bissett and F.Shadman. Thermal Regeneration of Diesel Particulate Monolithic Filters. AIChE Journal, 31, 1984.

[50] C.N.Davies. Air Filtration. Academic Press, 1973.

[51] A.G.Konstandopoulos, E.Skaperdas, and M.Masoudi. Inertial Contributions to the Pressure Drop of Diesel Particulate Filters - Paper No. 2001-01-0909. SAE, 2001. 
[52] A.G.Konstandopoulos. Flow Resistance Descriptors for Diesel Particulate Filters: Definitions, Measurements and Testing - Paper No. 2003-01-0846. SAE, 2003

[53] A.B.Palotas, L.C.Rainey, A.F.Sarofim, J.B.VanderSande, and P.Ciambelli. Effect of Oxidation on the Microstructure of Carbon Blacks. Energy and Fuels, 10, 1996.

[54] Z.Du, A.F.Sarofim, and J.P.Longwell. Kinetic Measurement and Modeling of Carbon Oxidation. Energy and Fuels, 5, 1991.

[55] J.P.A.Neeft, O.P.vanPruissen, M.Makee, and J.A.Mouljin. Catalysts for the Oxidation of Soot from Diesel Exhaust Gases II - Contact between Soot and Catalyst under Practical Conditions. Applied Catalysis B : Environmental, 12, 1997. 


\section{Appendix A}

\section{DOC Sub-models}

\section{A.1 PM Oxidation Kinetics in the DOC}

Thermal and catalytic PM oxidation reactions are assumed to follow a first-order heterogeneous oxidation reaction, but with different ' $\mathrm{CO}$ selectivity' for carbon oxidation. The reactions are assumed to have a temperature dependence of the following form [36]:

$$
\begin{aligned}
r_{c}^{\text {thermal }} & =k_{c}^{\text {thermal }} Y_{O_{2}} \\
r_{c}^{\text {catalytic }} & =k_{c}^{\text {catalytic }} Y_{O_{2}} \\
f_{C O}^{\text {thermal }} & =\frac{1}{1+k_{f 1} Y_{O_{2}}^{\mu_{1}} e^{\left(E T_{f 1} / T\right)}} \\
f_{C O}^{\text {catalytic }} & =\frac{1}{1+k_{f 2} Y_{O_{2}}^{\mu_{2}} e^{\left(E T_{f 2} / T\right)}}
\end{aligned}
$$

along with a modified Arrhenius form of reaction constants[36]:

$$
\begin{aligned}
& k_{c}^{\text {thermal }}=A_{\text {thermal }} T e^{\left(-E T_{\text {thermal }} / T\right)} \\
& k_{c}^{\text {catalytic }}=A_{\text {catalytic } T e^{\left(-E T_{\text {catalytic }} / T\right)}}
\end{aligned}
$$


For the second-order $\mathrm{NO}_{2}$-assisted particulate oxidation reaction 3.6 as given in Chapter 3, the 'CO selectivity', $\mathrm{g}_{C O}$, is also assumed to have a similar form [36]:

$$
\begin{gathered}
r_{\mathrm{NO}_{2} \text {-assisted }}=k_{\mathrm{NO}_{2}-\text { assisted }} Y_{\mathrm{C}} Y_{\mathrm{NO}_{2}} \\
g_{\mathrm{CO}}=\frac{1}{1+k_{f 3} Y_{\mathrm{O}_{2}} e^{\left(E_{f 3} / R T\right)}}
\end{gathered}
$$

The reaction rate constant for $\mathrm{NO}_{2}$-assisted particulate oxidation reaction is assumed to have an Arrhenius form [36]:

$$
k_{\mathrm{NO}_{2}-\text { assisted }}=A_{\mathrm{NO}_{2}-\text { assisted }} e^{\left(-E T_{N O_{2}-\text { assisted }} / T\right)}
$$

The $\mathrm{O}_{2}$ consumption rate is obtained by assuming stoichiometric reaction of all chemical reactions involving $\mathrm{O}_{2}$, and is given by[36]:

$$
\begin{aligned}
r_{\mathrm{O}_{2}}=0.5 r_{N O}+0.5 r_{C O}+2 r_{C H_{4}}+4.5 r_{C_{3} H_{6}}+24.5 r_{r_{C_{16} H_{34}}}+ \\
\left(1-\frac{f_{C O}^{\text {thermal }}}{2}\right) \cdot r_{C}^{\text {thermal }}+\left(1-\frac{f_{C O}^{\text {catalytic }}}{2}\right) \cdot r_{C}^{\text {catalytic }}
\end{aligned}
$$

\section{A.2 Mass and Energy Balance in the Gas-phase}

The conservation of mass for the unsteady one-dimensional model is:

$$
\frac{\partial \rho_{g}}{\partial t}+\frac{\partial\left(\rho_{g} u\right)}{\partial x}=0
$$

where $\rho_{g}$ is the density of the exhaust gas, $u$ is the gas flow velocity, and $x$ represents the axial coordinate of the DOC channel. For steady or quasi-steady state, equation A.11 reduces to: 


$$
\frac{\partial\left(\rho_{g} u\right)}{\partial x}=0
$$

This equation can be solved for the velocity in a single square channel. However, for a 1D bulk flow model, velocity can simply be expressed as:

$$
u=\frac{4 \dot{V}}{\pi D^{2} \epsilon}
$$

where $\dot{V}$ is the volumetric flow rate in $\mathrm{m}^{3} / \mathrm{s}, D$ and $\epsilon$ are the properties of the DOC monolith. $D$ is the diameter and $\epsilon$ represents the open frontal area (OFA) of the monolith (also known as the 'void fraction') [40] given by:

$$
\epsilon=\left(1-w_{t} \sqrt{\sigma}\right)^{2}
$$

where $\sigma$ is the cell density and $\mathrm{w}_{t}$ is the wall thickness.

The pressure drop across the DOC was determined by using the pressure drop model developed from the mass and momentum balances for fully-developed laminar flow in a square channel [7] and is expressed as:

$$
\begin{aligned}
\Delta P & =\frac{1}{\epsilon}\left(\frac{2 \mu_{g} K L \dot{V}}{(C F A) D_{h}^{2}}\right) \\
K & =\operatorname{Re} C_{f} \\
C_{f} & =\frac{\tau_{\text {wall }}}{\frac{1}{2} \rho u^{2}}
\end{aligned}
$$

where $R e$ is the Reynolds number, $C_{f}$ is the skin friction coefficient, $K$ is the fanning friction factor and has a value of 14.23 for a square channel cross-section, $\mu_{g}$ is the exhaust gas viscosity, $L$ is the length of the channels, $a$ is the width of a single channel, and $C F A$ is the converter frontal area. For a cylindrical DOC, CFA is expressed as:

$$
C F A=\frac{\pi}{4} D^{2}
$$


This model is commonly used for catalytic converter monoliths of honeycomb structure, as discussed in reference [45].

The conservation of energy for the channel gas flow is:

$$
\epsilon \rho_{g} c_{p g} \frac{\partial T_{g}}{\partial t}=-\epsilon \rho_{g} c_{p g} u \frac{\partial T_{g}}{\partial x}+\operatorname{Gah}_{g}\left(T_{w}-T_{g}\right)+S p\left(\sum_{i=1}^{3}\left(-\Delta H_{i}\right) r_{i}\right)
$$

or

$$
\frac{\partial T_{g}}{\partial t}=-u \frac{\partial T_{g}}{\partial x}+\frac{G a h_{g}}{\epsilon \rho_{g} c_{p g}}\left(T_{w}-T_{g}\right)+\frac{S p}{\epsilon \rho_{g} c_{p g}}\left(\sum_{i=1}^{3}\left(-\Delta H_{i}\right) r_{i}\right)
$$

where $\rho_{g}$ is the mixture gas density, $c_{p g}$ is the gas specific heat, $T_{g}$ is the gas temperature, $T_{w}$ is the solid wall temperature, $h_{g}$ is the convective heat transfer coefficient, Ga represents the geometric surface area $\left(\mathrm{m}^{2} / \mathrm{m}^{3}\right)$ [40], and is given by:

$$
G a=4\left(1-w_{t} \sqrt{\sigma}\right) \sqrt{\sigma}
$$

and $\mathrm{Sp}$ is the specific area $(1 / m)$ of diesel particulate and can, in general, be written as the product of the surface area of particulate $\left(A_{\text {soot }}, \mathrm{m}^{2} / \mathrm{kg}\right)$ and its density $\left(\rho_{\text {soot }}, \mathrm{kg} / \mathrm{m}^{3}\right)$ :

$$
S p=\rho_{\text {soot }} A_{\text {soot }}
$$

where $A_{\text {soot }}$ has a value of $1.0 \mathrm{E}+05 \mathrm{~m}^{2} / \mathrm{kg}$ and the soot bulk density $\rho_{\text {soot }}$ is assumed as $75 \mathrm{~kg} / \mathrm{m}^{3}$ [46].

The channel exhaust gas specific heat, $c_{p g}(J / k g . K)$, viscosity, $\mu_{g}\left(N . s / m^{2}\right)$ and thermal conductivity $\lambda_{g}(W / s . K)$, are treated as functions of exhaust gas temperature 
$T_{g}$ and are calculated based on the following correlation equations for air* [40]:

$$
\begin{aligned}
c_{p g} & =962.097+0.1507 T_{g} \\
\mu_{g} & =\left(0.00268 T_{g}+1.384\right) \cdot 10^{-5} \\
\lambda_{g} & =8.459 E-03+5.7 E-05 . T_{g}
\end{aligned}
$$

The convective heat transfer coefficient $h_{g}$ is obtained from the Reynolds number $R e_{g}$, Prandtl number $P r_{g}$, and Nusselt number $N u_{g}$.

$$
\begin{aligned}
R e_{g} & =\frac{\dot{m} D_{h}}{\epsilon \cdot C F A \mu_{g}} \\
P r_{g} & =\frac{\mu_{g} c_{p g}}{\lambda_{g}} \\
N u_{g} & =2.709\left(R e_{g} P r_{g}\right)^{0.179} \\
h_{g} & =\frac{N u_{g} \lambda_{g}}{D_{h}}
\end{aligned}
$$

where $\dot{m}$ is the exhaust gas mass flow rate (expressed in $\mathrm{kg} / \mathrm{s}$ ) and $D_{h}$ is the hydraulic diameter of the channel (expressed in $m$ ), and is given by:

$$
D_{h}=\frac{1}{\sqrt{\sigma}}\left(1-w_{t} \sqrt{\sigma}\right)
$$

The last term on the RHS of equations A.19 and A.20 is the heat addition due to PM oxidation. Summing over the three reactions described in equations 3.6, 3.7 and 3.8 (as given in Chapter 3 of this thesis):

*Air properties are presently used for DOC model - plans are to update code to the actual exhaust properties based on species mole fractions as used in the CPF model - Appendix B 


$$
\begin{aligned}
& S p\left(\sum_{i=1}^{3}\left(-\Delta H_{i}\right) r_{i}\right)=S p\left[(-\Delta H)_{N_{2}-\text { assisted }} r_{N O_{2}-\text { assisted }}\right]+ \\
& S p\left[(-\Delta H)_{\text {thermal }} r_{\text {thermal }}\right]+S p\left[(-\Delta H)_{\text {catalytic }} r_{\text {catalytic }}\right]
\end{aligned}
$$

where the heating values (heats of combustion) are:

$$
\begin{aligned}
(-\Delta H)_{N O_{2}-\text { assisted }} & =g_{C O}\left(\Delta h_{f}^{0}\right)_{C O}+\left(1-g_{C O}\right)\left(\Delta h_{f}^{0}\right)_{C O_{2}} \\
& +\left(2-g_{C O}\right)\left(\Delta h_{f}^{0}\right)_{N O} \\
& -\left(2-g_{C O}\right)\left(\Delta h_{f}^{0}\right)_{N O_{2}} \\
(-\Delta H)_{\text {thermal }} & =f_{C O}^{\text {thermal }}\left(\Delta h_{f}^{0}\right)_{C O} \\
& +\left(1-f_{C O}^{\text {thermal }}\right)\left(\Delta h_{f}^{0}\right)_{C O_{2}} \\
& =f_{C O}^{\text {catalytic }}\left(\Delta h_{f}^{0}\right)_{C O} \\
(-\Delta H)_{\text {catalytic }} & +\left(1-f_{C O}^{\text {catalytic }}\right)\left(\Delta h_{f}^{0}\right)_{C O_{2}}
\end{aligned}
$$

in which $\left(\Delta h_{f}^{0}\right)_{m}$ is the specific heat (enthalpy) of formation of species ' $m$ ' at standard reference state (expressed in $\mathrm{J} / \mathrm{mol}$ ).

For quasi-steady state assumption, the unsteady term is dropped from equation A.19, and the energy balance in the gas-phase can be re-arranged as:

$$
\epsilon \rho_{g} c_{p g} u \frac{\partial T_{g}}{\partial x}=\operatorname{Gah}_{g}\left(T_{w}-T_{g}\right)+S p\left(\sum_{i=1}^{3}\left(-\Delta H_{i}\right) r_{i}\right)
$$

Expanding the convection term and using equation A.12,

$$
\frac{\partial T_{g}}{\partial x}=\left(\frac{G a}{\epsilon \rho_{g} c_{p g} u}\right) h_{g}\left(T_{w}-T_{g}\right)+\left(\frac{S p}{\epsilon \rho_{g} c_{p g} u}\right)\left(\sum_{i=1}^{3}\left(-\Delta H_{i}\right) r_{i}\right)
$$


The individual species conservation equation system is:

$$
\epsilon \frac{\partial c_{g, i}}{\partial t}=-\epsilon u \frac{\partial c_{g, i}}{\partial x}-G a k_{m, i}\left(c_{g, i}-c s, i\right)+S p\left(\sum_{i=1}^{3}\left(\zeta_{i} r_{i}^{\text {soot-oxidation })}\right)\right)
$$

or

$$
\frac{\partial c_{g, i}}{\partial t}=-u \frac{\partial c_{g, i}}{\partial x}-\frac{G a k_{m, i}}{\epsilon}\left(c_{g, i}-c_{s, i}\right)+\frac{S p}{\epsilon}\left(\sum_{i=1}^{3}\left(\zeta_{i} r_{i}^{\text {soot-oxidation }}\right)\right)
$$

where $c_{g, i}$ (expressed in $\mathrm{mol} / \mathrm{m}^{3}$ ) are the concentrations of the $i^{\text {th }}$ species in gasphase, $k_{m, i}$ is the mass transfer coefficient of the $i^{t h}$ species (expressed in $\mathrm{m}^{2} / \mathrm{s}$ ), $c_{s, i}$ (expressed in $\mathrm{mol} / \mathrm{m}^{3}$ ) is the concentration of the $i^{\text {th }}$ species in solid-phase, and $\zeta_{i}$ are the stoichiometric coefficients for the $i^{\text {th }}$ soot oxidation reaction. All the species concentrations used in the model are expressed in $\mathrm{mol} / \mathrm{m}^{3}$.

Similar to the energy conservation equation, the unsteady term from the individual species conservation equation system can be dropped for the quasi-steady and steady cases, and re-written as:

$$
\epsilon u \frac{\partial c_{g, i}}{\partial x}=G a k_{m, i}\left(c_{s, i}-c_{g, i}\right)+S p\left(\sum_{i=1}^{3} \zeta_{i} r_{i}^{\text {soot-oxidation }}\right)
$$


Accordingly, for steady or quasi-steady state simulation, the species conservation equations are:

$$
\begin{aligned}
& \frac{\partial c_{g, C O}}{\partial x}=\frac{G a k_{m, C O}}{\epsilon u}\left(c_{s, C O}-c_{g, C O}\right) \\
& +\frac{S p}{\epsilon u}\left[f_{C O}^{\text {thermal }} r_{C}^{\text {thermal }}\right]+\frac{S p}{\epsilon u}\left[f_{C O}^{\text {catalytic }} r_{C}^{\text {catalytic }}\right] \\
& +\frac{S p}{\epsilon u}\left[g_{C O} r_{\mathrm{NO}_{2}-\text { assisted }}\right] \\
& \frac{\partial c_{g, N O}}{\partial x}=\frac{G a k_{m, N O}}{\epsilon u}\left(c_{s, N O}-c_{g, N O}\right) \\
& +\frac{S p}{\epsilon u}\left[\left(2-g_{C O}\right) r_{N_{2}-a s s i s t e d}\right] \\
& \frac{\partial c_{g, C_{3} H_{6}}}{\partial x}=\frac{G a k_{m, C_{3} H_{6}}}{\epsilon u}\left(c_{s, C_{3} H_{6}}-c_{g, C_{3} H_{6}}\right) \\
& \frac{\partial c_{g, C H_{4}}}{\partial x}=\frac{G a k_{m, C H_{4}}}{\epsilon u}\left(c_{s, C H_{4}}-c_{g, C H_{4}}\right) \\
& \frac{\partial c_{g, C_{16} H_{34}}}{\partial x}=\frac{G a k_{m, C_{16} H_{34}}}{\epsilon u}\left(c_{s, C_{16} H_{34}}-c_{g, C_{16} H_{34}}\right) \\
& \frac{\partial c_{g, O_{2}}}{\partial x}=\frac{G a k_{m, O_{2}}}{\epsilon u}\left(c_{s, O_{2}}-c_{g, O_{2}}\right)-\frac{S p}{\epsilon u}\left[\left(1-\frac{f_{C O}^{\text {thermal }}}{2}\right) r_{C}^{\text {thermal }}\right] \\
& -\frac{S p}{\epsilon u}\left[\left(1-\frac{f_{C O}^{\text {catalytic }}}{2}\right) r_{C}^{\text {catalytic }}\right] \\
& \frac{c_{g, C O_{2}}}{\partial x}=\frac{G a}{\epsilon u}\left(3 r_{C_{3} H_{6}}+r_{C H_{4}}+16 r_{C_{16} H_{34}}+r_{C O}\right) \\
& +\frac{S p}{\epsilon u}\left[\left(1-f_{C O}^{\text {thermal }}\right) r_{C}^{\text {thermal }}\right] \\
& +\frac{S p}{\epsilon u}\left[\left(1-f_{C O}^{\text {catalytic }}\right) r_{C}^{\text {catalytic }}\right] \\
& +\frac{S p}{\epsilon u}\left[\left(1-g_{C O}\right) r_{N_{2}-a s s i s t e d}\right] \\
& \frac{\partial c_{g, H_{2} O}}{\partial x}=\frac{G a}{\epsilon u}\left(3 r_{C_{3} H_{6}}+2 r_{C H_{4}}+17 r_{C_{16} H_{34}}\right) \\
& \frac{\partial c_{g, N O_{2}}}{\partial x}=\frac{G a}{\epsilon u} r_{N O}-\frac{S p}{\epsilon u}\left(2-g_{C O}\right) r_{N O_{2}-\text { assisted }} \\
& \frac{\partial c_{C}}{\partial x}=-\frac{S p}{\epsilon u}\left[\frac{1}{1-\frac{f_{C O}^{\text {thermal }}}{2}} r_{C}^{\text {thermal }}\right] \\
& +\frac{S p}{\epsilon u}\left[\frac{1}{1-\frac{f_{C O}^{\text {catalytic }}}{2}} r_{C}^{\text {catalytic }}\right]+\frac{S p}{\epsilon u}\left[\frac{1}{2-g_{C O}} r_{N O_{2} \text {-assisted }}\right]
\end{aligned}
$$


Similar species conservation equations can be written for the unsteady case, including the temporal derivatives of the individual species concentrations in the gasphase.

\section{A.3 Mass and Energy Balance in the Solid-phase}

The rate of transport of species from the exhaust gases to the wall must be equal to the rate of disappearance of species due to the wall reaction and are assumed to occur at the wall temperature. This can be expressed by the following equation:

$$
(1-\epsilon) \frac{\partial c_{s, i}}{\partial t}=-G a k_{m, i}\left(c_{s, i}-c_{g, i}\right)-G_{c a} r_{i}
$$

where $G_{c a}$ is the catalytic surface area per unit volume $\left(m^{2} / m^{3}\right)$. In this research work, $G_{c a}$ has been approximated to be equal to $G a$. For steady or quasi-steady state, equation A.50 reduces to:

$$
k_{m, i}\left(c_{s, i}-c_{g, i}\right)=-r_{i}
$$

Accordingly, for steady or quasi-steady state simulation, equations describing the wall reactions are:

$$
\begin{aligned}
k_{m, C O}\left(c_{s, C O}-c_{g, C O}\right) & =-r_{C O} \\
k_{m, N O}\left(c_{s, N O}-c_{g, N O}\right) & =-r_{N O} \\
k_{m, C_{3} H_{6}}\left(c_{s, C_{3} H_{6}}-c_{g, C_{3} H_{6}}\right) & =-r_{C_{3} H_{6}} \\
k_{m, C H_{4}}\left(c_{s, C H_{4}}-c_{g, C H_{4}}\right) & =-r_{C H_{4}} \\
k_{m, C_{16} H_{34}}\left(c_{s, C_{16} H_{34}}-c_{g, C_{16} H_{34}}\right) & =-r_{C_{16} H_{34}} \\
k_{m, O_{2}}\left(c_{s, O_{2}}-c_{g, O_{2}}\right) & =-r_{O_{2}}
\end{aligned}
$$


Similar wall reaction equations can be written for the unsteady case, including the temporal derivatives of the individual species concentrations in the solid-phase.

The wall energy balance equation is expressed as follows:

$$
\begin{aligned}
(1-\epsilon) \rho_{w} c_{p, w} \frac{\partial T_{w}}{\partial t}=-G a h_{g}\left(T_{w}-T_{g}\right)-S_{e x t} h_{\infty}\left(T_{w}-T_{\infty}\right)+ \\
\lambda_{w}(1-\epsilon) \frac{\partial^{2} T_{w}}{\partial x^{2}}+G_{c a}\left(\sum_{i=1}^{n}\left(-\Delta H_{i}\right) r_{i}\right)
\end{aligned}
$$

where $S_{\text {ext }}(1 / m)$ is the DOC external surface to volume ratio, $n$ is the number of reactions considered, and the subscript $\infty$ refers to the ambient condition. For a cylindrical DOC,

$$
S_{\text {ext }}=\frac{\pi D_{\text {can }}}{\frac{1}{4} \pi D_{\text {can }}^{2}}
$$

where $D_{\text {can }}(m)$ is the external diameter of the DOC can. The DOC channel wall specific heat $c_{p, w}(J / k g . K)$ and thermal conductivity $\lambda_{w}(W / s . K)$ are treated as functions of channel wall absolute temperature $T_{w}(K)$ and are calculated based on the following correlation equations [40]:

$$
\begin{aligned}
c_{p, w} & =1071.0+(0.156) T_{w}-\frac{3.435 E+07}{T_{w}^{2}} \\
\lambda_{w} & =(3.0 E-06) T_{w}^{2}-(0.0037) T_{w}+2.0553
\end{aligned}
$$

The external heat transfer coefficient $h_{\infty}$ is obtained from the following relation:

$$
h_{\infty}=h_{a m b} \frac{N u_{\infty} \lambda_{\infty}}{D_{c a n}}
$$

where $h_{a m b}$ is an augmentation factor [40] that can be used to account for:

1. forced convection, or

2. increased internal heat transfer due to pulsating exhaust flow, pipe bends, etc. and is a user-input parameter. The external Nusselt number $N u_{\infty}$ and ambient air 
thermal conductivity $\lambda_{\infty}$ are calculated from:

$$
\begin{aligned}
N u_{\infty} & =0.53\left(G r_{\infty} P r_{\infty}\right)^{0.25} \\
P r_{\infty} & =\frac{\mu_{\infty} c_{p \infty}}{\lambda_{\infty}} \\
c_{p \infty} & =c_{p g}\left(T_{\infty}\right) \\
\mu_{\infty} & =\mu_{g}\left(T_{\infty}\right) \\
\lambda_{\infty} & =\lambda_{g}\left(T_{\infty}\right) \\
G r_{\infty} & =\frac{g \beta\left(T_{w}-T_{\infty}\right) D_{c a n}^{3} \lambda_{\infty}}{\mu_{\infty}^{2}} \\
g & =9.807 \\
\beta & =\frac{1}{T_{\infty}}
\end{aligned}
$$

Unlike what was assumed for the gas-phase energy balance equation for the steady or quasi-steady state, the temporal derivatives in the solid-phase energy balance equation are significant due to all the reactions taking place on the wall, and therefore, the unsteady term needs to be considered in the solid-phase (wall) energy balance equation for the steady or quasi-steady state also.

The RHS of equation A.58 includes the convective heat transfer with the exhaust gases, heat transfer between the DOC and ambient, the axial heat conduction in the monolith wall, and the reaction energy produced by all the reactions considered 3.1 - 3.5, which can be expressed as:

$$
\begin{aligned}
G_{c a}\left(\sum_{i=1}^{5}-\Delta H_{i} r_{i}\right) & =G_{c a}\left[(-\Delta H)_{C O} r_{C O}\right] \\
& +G_{c a}\left[(-\Delta H)_{N O} r_{N O}\right] \\
& +G_{c a}\left[(-\Delta H)_{C_{3} H_{6}} r_{C_{3} H_{6}}\right] \\
& +G_{c a}\left[(-\Delta H)_{C H_{4}} r_{C H_{4}}\right] \\
& +G_{c a}\left[(-\Delta H)_{C_{16} H_{34}} r_{C_{16} H_{34}}\right]
\end{aligned}
$$


The mass transfer coefficients $k_{m, i}$ are calculated based on the following relations, as given in reference [44]:

\section{A.4 Mass Transfer Calculations}

Binary Diffusion Coefficients, $D_{i j}$ are calculated from the equations[44]:

$$
D_{i j}=C_{i j} \frac{T^{B}}{P}
$$

where $D_{i j}$ is in $\mathrm{cm}^{2} / \mathrm{s}, T$ is in $K$ and $P$ is in atm [44].

Coefficients, $C_{i j}$ are calculated from the following equations[44]:

$$
C_{i j}=A\left(P_{c, i} P_{c, j}\right)^{\frac{1}{3}}\left(T_{c, i} T_{c, j}\right)^{\left(\frac{5}{12}-\frac{B}{2}\right)}\left(\frac{1}{M W_{i}}+\frac{1}{M W_{j}}\right)^{\frac{1}{2}}
$$

where $M W_{i}$ is the molecular weight of the $i^{t h}$ species, $A=2.745 \mathrm{E}-04$ and $B=1.823$ for non-polar gas-pairs, and $\mathrm{B}=2.334$ for $\mathrm{H}_{2} \mathrm{O}$ with a non-polar gas [44], $P_{c, i}(\mathrm{~atm})$ and $T_{c, i}(K)$ are the critical pressure and critical temperature of the $i^{\text {th }}$ species [47].

Molecular Diffusivities, $D m_{i}$ are obtained from the following[44]:

The molecular diffusivity for component $i$ is:

$$
D m_{i}=\frac{1-Y_{i}}{\sum_{j=2}^{n} \frac{Y_{j}}{D_{i j}}}
$$

where $Y_{i}$ is the mole fraction of the $i^{\text {th }}$ species.

Mass Transfer Coefficients, $k_{m, i}$ are calculated as[44]:

$$
k_{m, i}=\frac{S h_{\infty} D m_{i}}{D_{h}}
$$

where $k_{m, i}$ is the mass transfer coefficient of the $i^{\text {th }}$ species in $\mathrm{cm}^{2} / \mathrm{s}, S h_{\infty}=3.167$ is the limiting Sherwood number, and $D_{h}$ is the hydraulic diameter. 


\section{Appendix B}

\section{CPF Sub-models}

\section{B.1 CPF Mass, Momentum and Energy Balance}

This section provides a brief overview of the mass, momentum and energy balance equations used for the exhaust gas in the filter channels. For more detailed derivations on these, the reader is advised to refer to previous literature [7, 12, 48, 49].

Mass balance for the inlet and outlet channel in the single channel framework can be expressed as[48]:

$$
\begin{aligned}
& \frac{\partial\left(\rho_{1} v_{1}\right)}{\partial x}=-\frac{4}{a} \rho_{w} v_{w} \\
& \frac{\partial\left(\rho_{2} v_{2}\right)}{\partial x}=\frac{4}{a} \rho_{w} v_{w}
\end{aligned}
$$

where $a$ is the width of the channel, $v$ is the velocity of the exhaust gas, $\rho$ is the density of the exhaust gas, and subscripts 1,2 and $w$ refer to inlet channel, outlet channel and wall respectively.

The momentum equation for the exhaust gas in the inlet channel and outlet 
channel can be expressed as[48]:

$$
\begin{aligned}
& \frac{\partial P_{1}}{\partial x}+\frac{\partial\left(\rho_{1} v_{1}^{2}\right)}{\partial x}=-F \frac{\mu\left(T_{1}\right) v_{1}}{a^{2}} \\
& \frac{\partial P_{2}}{\partial x}+\frac{\partial\left(\rho_{2} v_{2}^{2}\right)}{\partial x}=-F \frac{\mu\left(T_{1}\right) v_{2}}{a^{2}}
\end{aligned}
$$

where $P_{1}$ is the absolute pressure of the exhaust gas in the inlet channel, $P_{2}$ is the absolute pressure of the exhaust gas in the outlet channel and $\mu$ is the exhaust gas dynamic viscosity. The RHS terms in equations B.2a and B.2b represent the viscous drag loss along the length of the channel ( $z$ direction), since gas velocity at the wall in $z$ direction is zero. The numerical solution of these equations gives the friction losses in the inlet and outlet channels.

Energy balance of an elemental volume of exhaust gas in the inlet and outlet channels can be expressed as[48]:

$$
\begin{aligned}
c_{p, g} \rho_{1} v_{1} \frac{\partial T_{1}}{\partial x} & =\frac{4}{a} h_{1}\left(T_{w}-T_{1}\right) \\
c_{p, g} \rho_{2} v_{2} \frac{\partial T_{2}}{\partial x} & =\frac{4}{a}\left[h_{2}+c_{p, g} \rho_{w} v_{w}\right]\left(T_{w}-T_{2}\right)
\end{aligned}
$$

where $c_{p, g}$ is the specific heat of the exhaust gas, $T$ is the absolute temperature of the exhaust gas and $h_{1}$ and $h_{2}$ are heat transfer coefficients in the inlet channel and outlet channel respectively. Note that the temperature of the exhaust gas entering the filter wall is assumed to be at temperature $T_{1}$ and not at $T_{w}$ as originally proposed by Bissett et al.[48], and the temperature of the exhaust gas leaving the filter wall is assumed to be at temperature $T_{w}$.

\section{B.2 CPF Pressure Drop Model}

The pressure drop across the filter is directly proportional to the flow resistance encountered by the exhaust gas as it passes through the monolith walls $[21,50]$. The 
total pressure drop across the filter is the result of the following elements: inlet channel contraction losses, inlet and outlet channel frictional losses, pressure drop due to particulate cake, pressure drop due to filter wall, and outlet channel expansion losses.

The total pressure drop due to contraction in the inlet channel and expansion in the outlet channel is given as $[51,52]$ :

$$
\Delta P_{\text {con }+\exp }=\frac{2 \zeta \dot{V}^{2} \rho\left(a+w_{s}\right)^{4}}{V_{\text {trap }}^{2} a^{2}}\left(\frac{L}{a}\right)^{2}
$$

where $\zeta$ is the contraction/expansion inertial loss coefficient. This effect is prominent, however, at very high exhaust gas flow rates. Hence, this effect is neglected from the pressure drop model.

There are friction losses occurring in the filter as the exhaust flows through first the inlet channels, and then the outlet channels. The usual Reynolds numbers encountered in the filter are less than 1000[12], which imply that the flow can be considered to be laminar and viscous. The total frictional losses in the inlet and outlet channels (combined) is given as $[36,52]$ :

$$
\Delta P_{\text {friction }}=\frac{4}{3} \frac{F L^{2} \mu \dot{V}\left(a+w_{s}^{2}\right)}{V_{\text {trap }} a^{2}}
$$

where:

$$
F=2 c_{f} R e
$$

and $c_{f} R e$ is equal to 14.227 for square-type channel geometry.

Pressure drop across the loaded filter wall can be represented by using D'arcy's law, including a second-order Forchheimer term[52]:

$$
\Delta P_{w a l l}=\frac{\mu}{k_{t}} v_{w} w_{s}+B \rho v_{w}^{2} w_{s}
$$


where $\mu$ is the dynamic viscosity of the exhaust gas, $v_{w}$ is the wall-flow velocity, $k_{t}$ is the instantaneous permeability of the filter wall, and $w_{s}$ is the thickness of the filter wall. The second term on the RHS of equation B.7, called the Forchheimer coefficient, is an inertial term, and has been shown to be significant only for highly porous substrates (such as those in foam filters) operating at high flow rates. Since this study has been done on a $50 \%$ porous cordierite filter at moderate flow rates ( 0.1 to 0.4 actual $\mathrm{m}^{3} / \mathrm{s}$ ), this term can be neglected.

Pressure drop across the PM cake layer can also be approximated by a D'arcy flow resistance balance equation as follows:

$$
\Delta P_{\text {cake }}=\frac{\mu}{k_{p}} v_{w} w=\frac{\mu}{k_{p}} v_{w}\left(w_{1}+w_{2}\right)
$$

where $k_{p}$ is the permeability of the particulate cake, and $w_{1}$ and $w_{2}$ are the instantaneous computed thickness values of layer 1 and layer 2 respectively.

The particulate cake and filter wall in each axial section of the filter can actually be visualized as two sequential flow resistance elements, each offering its characteristic flow resistance to the exhaust gas stream flowing through it. Hence, the overall pressure drop model used in the CPF model can be summarized mathematically as:

$$
\begin{aligned}
\Delta P_{\text {total }} & =\Delta P_{\text {friction }}+\Delta P_{\text {cake }}+\Delta P_{\text {wall }} \\
& =\frac{4}{3} \frac{\mu \dot{V}\left(a+w_{s}^{2}\right) F L^{2}}{V_{\text {trap }}^{2} a^{4}}+\frac{\mu}{k_{p}} v_{w} w+\frac{\mu}{k_{s}} v_{w} w_{s}
\end{aligned}
$$

\section{B.3 CPF Oxidation Model}

Oxidation of particulate matter in the filter is an important phenomenon in a particulate filter. Depending on the type of filter used and inlet exhaust gas conditions, a variety of oxidation mechanisms determine the oxidation of particulate matter collected in the filter. In the filter model, the equivalent oxidation in the filter was 
considered to be taking place in two locations: in the filter wall, and in the particulate cake layer. Accordingly, there are two sub-models in the CPF model; the following sub-sections describe these in detail.

\section{B.3.1 Oxidation in the Particulate Cake Layer}

The particulate cake layer oxidation model used in the MTU 1D model employs the 2layer theory put forward by Konstandopoulos et al.[31] as shown in Figure B.1, which is based on the regeneration framework of Bissett[48]. This approach uses the concept of two assumed layers of particulate cake, and the oxidation mechanisms in each layer assumed to be by different combinations of the individual oxidation mechanisms. In a typical case where cake layer thickness is growing with time, all particulate matter deposited in the cake layer is assumed to be only in one layer (layer 1), as long as the thickness of the cake layer is less than the assumed thickness of layer 1, and in cases where thickness of the cake layer is greater than the assumed thickness of layer 1 , two layers are considered; layer 1 containing particulate matter for the full assumed thickness, and layer 2 containing the rest of particulate matter. Mathematically,

$$
\begin{aligned}
& w_{1}=w_{\text {cake }}, \text { if } w_{\text {cake }} \leq w_{1} \\
& w_{1}=w_{1, \text { cat }} \& w_{2}=w_{\text {cake }}-w_{1}, \text { if } w_{\text {cake }}>w_{1}
\end{aligned}
$$

where $w_{1}$ is the thickness of layer $1, w_{2}$ is the thickness of layer $2, w_{\text {cake }}$ is the total thickness of the PM cake layer $\left(w_{1}+w_{2}\right)$ and $w_{1, \text { cat }}$ is the assumed maximum layer 1 thickness (20 $\mu \mathrm{m}$ in this thesis).

The 2-layer model uses a total of three mechanisms to explain the overall oxidation in the cake layer. They are:

1. Thermal oxidation,

2. Catalytic oxidation, and 


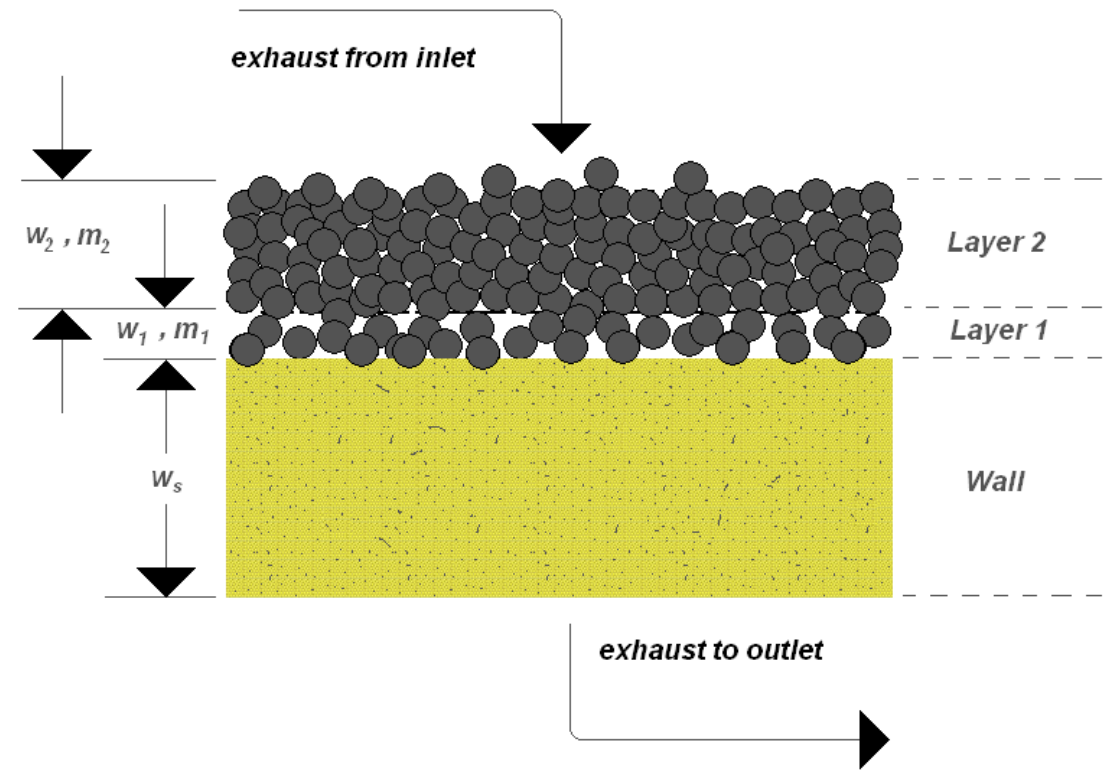

Figure B.1: Schematic representation of the 2-layer approach used in the CPF model [18]

3. $\mathrm{NO}_{2}$-assisted oxidation.

Thermal oxidation refers to the direct oxidation of particulate matter, which is principally carbon, by oxygen at elevated temperatures. Catalytic oxidation refers to the oxidation of particulate matter by oxygen in the presence of the catalyst present in the washcoat applied to the filter wall, and is assumed to be taking place only in a limited spatial region of 10-30 $\mu m$ thickness. In addition to these two conventional mechanisms, an additional $\mathbf{N O}_{2}$-assisted oxidation of the particulate matter, caused by the $\mathrm{NO}_{2}$ entering the filter was recognized and incorporated into the overall oxidation scheme by previous researchers[7, 12].

The catalytic oxidation mechanism is assumed to be taking place in layer 1 only, and the thickness of layer 1 is given as a user-defined input to the model. In the current set of simulations, a maximum layer 1 thickness value of $20 \mu m$ has been used, as defined and used in a previous research work[12] at MTU. So, a brief overview of the layers and oxidation mechanisms employed in each would look like: 
- Layer 1: Thermal + Catalytic $+\mathrm{NO}_{2}$-assisted

- Layer 2: Thermal $+\mathrm{NO}_{2}$-assisted

Oxygen mass fraction, $Y_{w}$, entering the particulate cake layer is kept track of by balancing convective transport through the layer considered, and reaction kinetics in the layer considered, assuming that diffusive transport is negligible compared to convective transport. Thus, the oxygen balance equation for layer 2 can be expressed as:

$$
\frac{\partial\left(\rho_{w} v_{w} Y_{w}\right)}{\partial x}=-S_{p} \rho_{w} Y_{w} k_{t h}\left(T_{w}\right)\left(1-\frac{f_{C O}}{2}\right)
$$

where $f_{C O}$ is the thermal $C O$ selectivity parameter (section 2.2.2), $k_{t h}$ is the thermal oxidation reaction rate constant, and $S_{p}$ is the specific area of the particulate matter, defined as:

$$
S_{p}=A_{p} \cdot \rho_{p}
$$

where $A_{p}$ is the surface area of particulate per unit mass, and has been reported to be approximately $100 \mathrm{~m}^{2} / \mathrm{g}[29,35]$, and $\rho_{p}$ is the particulate cake layer packing density, which is related to peclet numbers as reported by Konstandopoulos et al.[29].

Assuming that the exhaust gas density and wall-flow velocity remain constant as it flows through the particulate cake layer, equation B.11 can be integrated across layer 2 and the resulting oxygen depletion rate expressed as:

$$
R_{O_{2}, 2}=\rho_{w} v_{w} Y_{w}\left(1-e^{\left(\frac{-S_{p} k_{t h}\left(1-\frac{f_{C O}}{2}\right) w_{2}}{v_{w}}\right)}\right)
$$

where $w_{2}$ is the thickness of layer 2 . The oxygen mass fraction leaving layer 2 and entering layer 1 can be computed as:

$$
Y_{w, 1}=Y_{w} \cdot e^{\left(\frac{-S_{p} k_{t h}\left(1-\frac{f_{C O}}{2}\right) w_{2}}{v_{w}}\right)}
$$


Oxygen entering layer 1, however, follows 2 reaction paths: a catalytic path and a thermal path. The fractional distribution of oxygen concentration engaging in each reaction is expressed by a single parameter, $\beta$. Hence, the catalytic path is defined as having a 'selectivity' of $(\beta)$ and the thermal path, $(1-\beta)$. Accordingly, the oxygen species balance equation for layer 1 can be defined as:

$$
\begin{aligned}
\frac{\partial\left(\rho_{w} v_{w} Y_{w, 1}\right)}{\partial x}= & -S_{p} \rho_{w} Y_{w, 1} \\
& \left(k_{t h}\left(T_{w}\right)\left(1-\frac{f_{C O}}{2}\right)(1-\beta)+k_{c a t}\left(T_{w}\right)\left(1-\frac{f_{C O}^{\prime}}{2}\right)(\beta)\right)
\end{aligned}
$$

where $f_{C O}^{\prime}$ is the catalytic CO selectivity(section 2.2.3), $k_{t h}$ and $k_{\text {cat }}$ are rate constants for particulate oxidation by thermal and catalytic means respectively. These reaction rate constants are expressed as modified Arrhenius functions of the form[31, 48]:

$$
\begin{gathered}
k_{t h}\left(T_{w}\right)=A_{t h} \cdot T_{w}^{e x p-o r d e r_{t h}} \cdot e^{-\frac{E a_{t h}}{\bar{R} T_{w}}} \\
k_{c a t}\left(T_{w}\right)=A_{c a t} \cdot T_{w}^{e x p-o r d e r_{c a t}} \cdot e^{-\frac{E a_{c a t}}{\bar{R} T_{w}}}
\end{gathered}
$$

where $A_{t h}$ and $A_{c a t}$ are pre-exponential factors for the oxidation of particulate matter by thermal and catalytic means respectively, which are determined by calibrating the model to experimentally determined values of mass oxidized in the particulate filter for a given amount of time, exp-order $r_{t h}$ and $e x p-o r d e r_{c a t}$ are the exponential orders for the temperature dependence of thermal and catalytic oxidation reactions, and both have been assumed to be equal to a value of 1 in this research work as well as previous research work[12]. Hence, the degree of dependence of the thermal and catalytic reaction rate constants on absolute filter wall temperature is 1. Also, $E a_{t h}$ and $E a_{c a t}$ are the activation energy values for thermal and catalytic oxidation reactions respectively.

Integrating equation B.15 across the thickness of layer 1 gives the total deple- 
tion rate of oxygen in layer 1.

$$
R_{O_{2}, 1}=\rho_{w} v_{w} Y_{w, 1}\left(1-e^{\left(-\frac{S_{p} k^{*} w_{1}}{v_{w}}\right)}\right)
$$

where:

$$
k^{*}=k_{t h}\left(T_{w}\right)\left(1-\frac{f_{C O}}{2}\right)(1-\beta)+k_{c a t}\left(T_{w}\right)\left(1-\frac{f_{C O}^{\prime}}{2}\right)(\beta)
$$

and $w_{1}$ is the thickness of layer 1 .

The thermal and catalytic contributions to the total oxygen depletion rate can be derived as:

$$
\begin{aligned}
& R_{O_{2}, t h, 1}=R_{O_{2}, 1}\left(\frac{k_{t h}\left(T_{w}\right)\left(1-\frac{f_{C O}}{2}\right)(1-\beta)}{k^{*}}\right) \\
& R_{O_{2}, c a t, 1}=R_{O_{2}, 1}\left(\frac{k_{c a t}\left(T_{w}\right)\left(1-\frac{f_{C O}^{\prime}}{2}\right)(\beta)}{k^{*}}\right)
\end{aligned}
$$

A major assumption used in calculating the evolution of the particulate cake layer thickness with time is that particulate cake layer packing density remains constant, in other words, the particulate cake layer is incompressible. Although there have been reports of changing particulate microstructure with oxidation $[53,54,55]$, this is still a good assumption due to lack of data on a pre-determined relation between particulate cake morphology changes and oxidation rates, and also due to computational simplicity. Another assumption is that the specific area of particulate $S_{p}$ remains constant. Given these, the evolution of particulate cake layer thickness with time due to particulate oxidation by thermal and catalytic means can be derived 
as:

$$
\begin{aligned}
& \frac{\partial\left(\rho_{p} w_{2}\right)}{\partial t}=-\frac{M_{C}}{M_{o x}}\left(\frac{R_{O_{2}, 2}}{1-\frac{f_{C O}^{\prime}}{2}}\right) \\
& \frac{\partial\left(\rho_{p} w_{1}\right)}{\partial t}=-\frac{M_{C}}{M_{o x}}\left(\frac{R_{O_{2}, t h, 1}}{1-\frac{f_{C O}}{2}}+\frac{R_{O_{2}, c a t, 1}}{1-\frac{f_{C O}^{\prime}}{2}}\right)
\end{aligned}
$$

The $\mathrm{NO}_{2}$ mass fraction, $\mathrm{YNO}_{2}$ entering layer 2 is balanced by convective transport and reaction kinetics (ignoring diffusion transport). Assuming that $\mathrm{NO}_{2}$-assisted oxidation is first-order heterogeneous (as described in section 2.2.4), $\mathrm{NO}_{2}$ balance equation for layer 2 is as follows[7, 12]:

$$
\frac{\partial\left(\rho_{w} v_{w} Y_{N_{2}}\right)}{\partial x}=-S_{p} \rho_{w} Y_{N O_{2}} k_{N O_{2}}\left(T_{w}\right)\left(2-g_{C O}\right)
$$

where $g_{C O}$ is the $\mathrm{CO}$ selectivity for the particulate oxidation by $\mathrm{NO}_{2}$ (section 2.2.4), and $k_{\mathrm{NO}_{2}}$ is the reaction rate constant for the $\mathrm{NO}_{2}$-assisted oxidation, and is assumed to be a modified Arrhenius-type function of the following form:

$$
k_{\mathrm{NO}_{2}}\left(T_{w}\right)=A_{\mathrm{NO}_{2}} T_{w}^{e x p-\operatorname{order}_{N O_{2}}} e^{\left(\frac{E a_{N O_{2}}}{\bar{R} T_{w}}\right)}
$$

where $A_{\mathrm{NO}_{2}}$ and $E a_{\mathrm{NO}_{2}}$ are the pre-exponential factor and activation energy for $\mathrm{NO}_{2}$ assisted particulate oxidation respectively.

Assuming that exhaust gas density $\rho_{w}$ and wall-flow velocity $v_{w}$ remain constant as the gas flows through the particulate cake layer, equation B.21 can be integrated across layer 2 to obtain the $\mathrm{NO}_{2}$ depletion rate in layer 2 as[7, 12, 18]:

$$
R_{N O_{2}, 2}=\rho_{w} v_{w} Y_{N O_{2}}\left(1-e^{\left(-\frac{S_{p} k_{N O_{2}}\left(2-g_{C O}\right) w_{2}}{v_{w}}\right)}\right)
$$

The $\mathrm{NO}_{2}$ mass fraction exiting layer 2 and entering layer $1\left(Y_{\mathrm{NO}_{2}, 1}\right)$ can be 
obtained from equations B.22 and B.23 as:

$$
Y_{\mathrm{NO}_{2}, 1}=Y_{\mathrm{NO}_{2}} e^{\left(-\frac{S_{p} k_{N O_{2}}\left(2-g_{C O}\right) w_{2}}{v_{w}}\right)}
$$

The $\mathrm{NO}_{2}$ conservation equation for layer 1 is:

$$
\frac{\partial\left(\rho_{w} v_{w} Y_{N O_{2}, 1}\right)}{\partial x}=-S_{p} \rho_{w} Y_{N O_{2}, 1} k_{N O_{2}}\left(T_{w}\right)\left(2-g_{C O}\right)
$$

Integrating equation B.25 across layer 1, the $\mathrm{NO}_{2}$ depletion rate in layer 1 can be found out as:

$$
R_{N O_{2}, 1}=\rho_{w} v_{w} Y_{N O_{2}, 1}\left(1-e^{\left(-\frac{S_{p} k_{N O_{2}}\left(2-g_{C O}\right) w_{1}}{v_{w}}\right)}\right)
$$

From equations B.25 and B.26, the $\mathrm{NO}_{2}$ mass fraction exiting layer 1 and entering the wall $\left(Y_{\mathrm{NO}_{2} \text {,wall }}\right)$ can be determined as:

$$
Y_{N O_{2}, \text { wall }}=Y_{N_{2}, 1} e^{\left(-\frac{S_{p} k_{N O_{2}}\left(2-g_{C O}\right) w_{1}}{v_{w}}\right)}
$$

Therefore, from equations B.20a and B.20b, the evolution of thickness of layer $2\left(w_{2}\right)$ and layer $1\left(w_{1}\right)$ due to oxidation by $\mathrm{NO}_{2}$ and $\mathrm{O}_{2}$ can be described by:

$$
\begin{aligned}
& \frac{\partial\left(\rho_{p} w_{2}\right)}{\partial t}=-\frac{M_{C}}{M_{o x}}\left(\frac{R_{O_{2}, 2}}{1-\frac{f_{C O}}{2}}\right)-\frac{M_{C}}{M_{N O_{2}}}\left(\frac{R_{N O_{2}, 2}}{2-g_{C O}}\right) \\
& \frac{\partial\left(\rho_{p} w_{1}\right)}{\partial t}=-\frac{M_{C}}{M_{o x}}\left(\frac{R_{O_{2}, t h, 1}}{1-\frac{f_{C O}}{2}}+\frac{R_{O_{2}, c a t, 1}}{1-\frac{f_{C O}^{\prime}}{2}}\right)-\frac{M_{C}}{M_{N O_{2}}}\left(\frac{R_{N O_{2}, 1}}{\left(2-g_{C O}\right)}\right)
\end{aligned}
$$

Equations B.28a and B.28b explain the evolution of the particulate cake layer, including oxidation by thermal, catalytic and $\mathrm{NO}_{2}$-assisted means. These equations are solved in the CPF model using Runge-Kutta method of the $4^{\text {th }}$ order. 


\section{B.3.2 Oxidation in the Wall}

The original monolith particulate filter regeneration model developed by Bissett[48] and the subsequent particulate filter model by Konstandopoulos et al.[36] excluded the phenomenon of particulate oxidation in the filter wall. In a catalyzed particulate filter, however, oxidation in the wall becomes significant, especially at high exhaust temperatures (greater than $400^{\circ} \mathrm{C}$ ), due to which the overall pressure drop across the filter decreases with time[12] in the cake-filtration regime. The decrease is more rapid at higher temperatures, suggesting that more and more mass in the wall is getting oxidized. Since the 'wall pressure drop' plays an important part in determining the overall shape of the pressure drop curve, it is impossible to model pressure drop curves from a catalyzed particulate filter setup without a wall oxidation model. To this effect, a wall oxidation model was developed at MTU[3, 12].

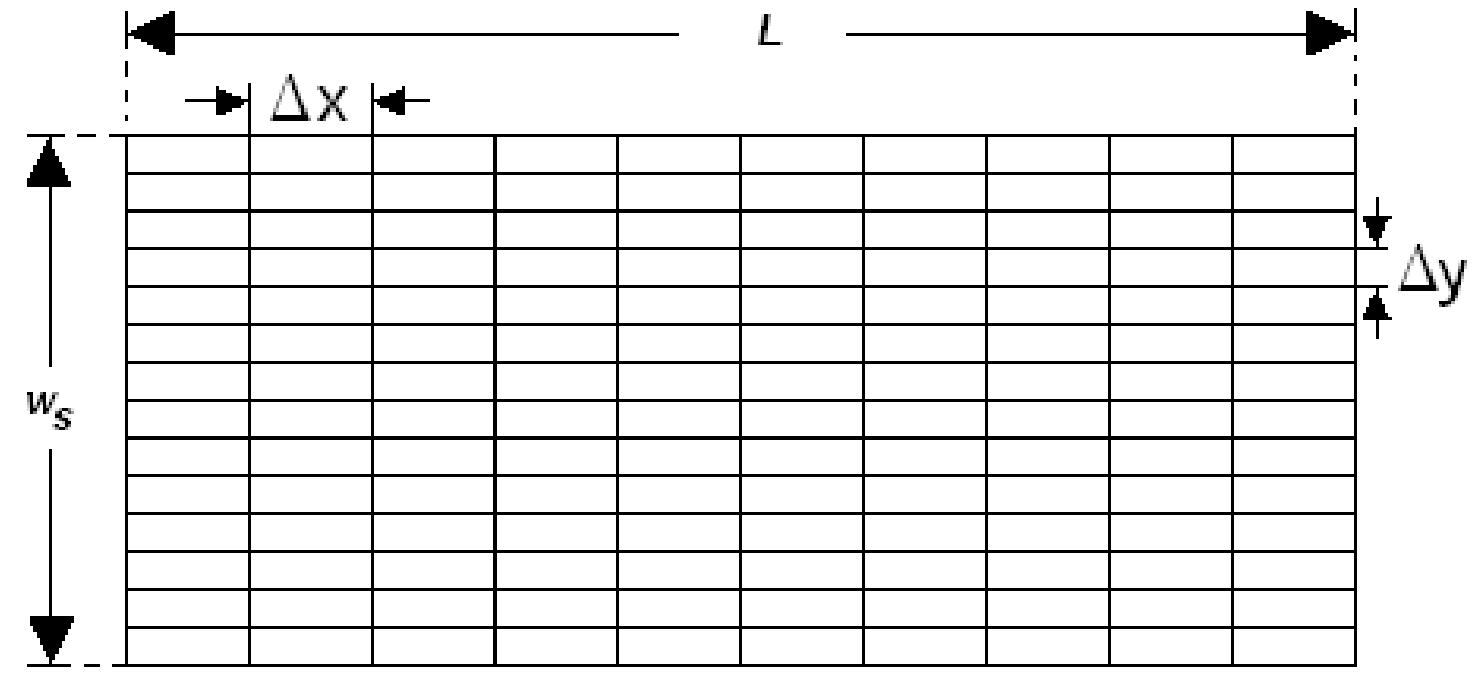

Figure B.2: CPF filter wall discretization - computational domain for filtration adapted from $[12]$

Figure B.2 shows the discretization of the CPF wall as used in the model. The total length of the wall $(L)$ is sub-divided into a number of elements of length $\Delta x$, and the wall thickness $\left(w_{s}\right)$ is sub-divided into a number of layers, called 'slabs' hereafter, 
each having a width of $\Delta y$. Hence, the computational unit in the model for the wall are 'cells', each of dimensions a $x \Delta x x \Delta y$. Each of these cells contains a number of unit collectors, depending upon the volume of a single unit cell. The mass collected by each slab in the wall in each time-step is related to the mass exiting the previous slab, and the instantaneous particulate capture efficiency of the slab in consideration calculated from the wall filtration model 3.2.1, as shown in Figure 3.3.

The concept of virtual wall layers is used to compute oxidation rates in each discretized location of the filter wall. The mass of each virtual wall layer discretized axially is given as:

$$
M_{\text {wall }}=\sum_{i=1}^{\text {nlayer }} m_{i}
$$

where $m_{i}$ is the mass of particulate matter present in the $i^{\text {th }}$ slab, and nlayer is the number of slabs in $x$ (wall thickness) direction.

To determine the thickness of the virtual wall layer such that under similar conditions, same amount of particulate mass present in the wall and cake would be oxidized by the same rate, a particulate density equal to that of the particulate in the cake layer is assumed for the wall also[3, 12]. Specific area of particulate $\left(S_{p}\right)$ is also assumed to be equal to that in the cake layer. Given these simplifying assumptions, the virtual wall layer thickness can be defined as:

$$
w_{\text {wall }}=\frac{M_{\text {wall }}}{\rho_{p} d h \Delta x}
$$

where $d h$ is the CPF channel width and $\Delta x$ is the discretization length in the axial direction, and $S_{p}$ is defined as:

$$
S_{p}=A_{p} \rho_{p}
$$

where $A_{p}$ is the surface area of particulate (assumed as $100 \mathrm{~m}^{2} / \mathrm{g}$ ) [31, 35], and $\rho_{p}$ is the particulate packing density in the particulate cake layer[29]. 
Given equation B.30, Oxygen species conservation for the wall can be expressed as:

$$
\frac{\partial\left(\rho_{w} v_{w} Y_{w, w a l l}\right)}{\partial x}=-S_{p} \rho_{w} Y_{w, w a l l} k_{t h}\left(T_{w}\right)\left(1-\frac{f_{C O}}{2}\right)
$$

where $Y_{w, w a l l}$ is the mass fraction of oxygen entering the wall. This is similar to equation B.51b:

$$
\begin{aligned}
Y_{w, w a l l} & =Y_{w} e^{\frac{-S_{p} k_{t h}\left(1-\frac{f_{C O}}{2}\right) w_{2}}{v_{w}}} e^{\frac{-S_{p} k^{*} w_{1}}{v_{w}}} \\
k^{*} & =k_{t h}\left(T_{w}\right)\left(1-\frac{f_{C O}}{2}\right)(1-\beta)+k_{c a t}\left(T_{w}\right)\left(1-\frac{f_{C O}^{\prime}}{2}\right)(\beta)
\end{aligned}
$$

Oxygen depletion in the wall can be computed by integrating equation B.32 across the virtual wall thickness $w_{\text {wall }}$ :

$$
R_{O_{2}, \text { wall }}=\rho_{w} v_{w} Y_{w, w a l l}\left(1-e^{\left(\frac{-S_{p} k_{t h}\left(1-\frac{f_{C O} O}{2}\right) w_{w a l l}}{v_{w}}\right)}\right)
$$

Similarly, $\mathrm{NO}_{2}$ species conservation equation in the wall can now be expressed as:

$$
\frac{\partial\left(\rho_{w} v_{w} Y_{N O_{2}, w a l l}\right)}{\partial x}=-S_{p} \rho_{w} Y_{N_{2}, w a l l} k_{N O_{2}}\left(T_{w}\right)\left(2-g_{C O}\right)
$$

where $Y_{\mathrm{NO}_{2} \text {,wall }}$ is the mass fraction of $\mathrm{NO}_{2}$ entering the filter wall, which is related to the mass fraction of $\mathrm{NO}_{2}$ entering the $\mathrm{CPF}$, and depletion rates of $\mathrm{NO}_{2}$ in layer 2 and layer 1, and is defined as:

$$
Y_{\mathrm{NO}_{2}, \text { wall }}=Y_{\mathrm{NO}_{2}, 1} e^{\left(\frac{-S_{p} k_{N O_{2}}\left(2-g_{\mathrm{CO}}\right) w_{1}}{v_{w}}\right)}
$$

$\mathrm{NO}_{2}$ depletion equation in the wall can be computed by integrating B.35 across 
the virtual wall thickness $w_{\text {wall }}$, and expressed as:

$$
R_{N O_{2}, \text { wall }}=\rho_{w} v_{w} Y_{N O_{2}}\left(1-e^{\left(\frac{-S_{p} k_{N O_{2}}\left(2-g_{C O}\right) w_{w a l l}}{v_{w}}\right)}\right)
$$

Accordingly, the temporal evolution of virtual wall layer thickness due to particulate oxidation by $\mathrm{O}_{2}$ and $\mathrm{NO}_{2}$ can be expressed as:

$$
\frac{\partial\left(\rho_{p} w_{\text {wall }}\right)}{\partial t}=-\frac{M_{C}}{M_{o x}}\left(\frac{1}{1-\frac{f_{C O}}{2}} R_{O_{2}, \text { wall }}\right)-\frac{M_{C}}{M_{N O_{2}}}\left(\frac{1}{2-g_{C O}} R_{N O_{2}, \text { wall }}\right)
$$

The specific depletion rate of the virtual wall layer thickness can now be computed as:

$$
\Delta w_{\text {wall }}=\frac{\left(\left(w_{\text {wall }}\right)_{n-1}-\left(w_{\text {wall }}\right)_{n}\right)}{\left(w_{\text {wall }}\right)_{n-1}}
$$

where the subscript $\mathrm{n}$ denotes the $n^{\text {th }}$ iteration time-wise. Assuming that all cells in the layers in the wall have the same reaction rates,

$$
\left(m_{i}\right)_{n}=\left(m_{i}\right)_{n-1}\left(1-\Delta w_{w a l l}\right)
$$

\section{B.3.3 Wall Energy Balance}

The rate of energy accumulation in the filter wall is equal to: rate at which energy is transported from the inlet channel - rate of energy loss to the outlet channel + rate of energy production due to particulate oxidation - rate of energy conduction in the axial direction[48]. So, the energy balance in the wall can be expressed as:

$$
\begin{aligned}
\left(\rho_{p} c_{p p} w+\rho_{s} c_{p s} w_{s}\right) \frac{\partial T_{w}}{\partial t}=-h_{1}\left(T_{1}-\right. & \left.T_{w}\right)-h_{2}\left(T_{2}-T_{w}\right) \\
& +H_{\text {react }}+H_{\text {cond }}+c_{p g} \rho_{w} v_{w}\left(T_{1}-T_{w}\right)
\end{aligned}
$$


where $c_{p p}, c_{p s}$ and $c_{p g}$ are the specific heats of the particulate, filter wall substrate and exhaust gas respectively, $w$ and $w_{s}$ are the thickness of the particulate cake and filter wall respectively, $\rho_{s}$ is the density of the filter wall substrate and $H_{\text {react }}$ and $H_{\text {cond }}$ refer to the heat of combustion of particulate oxidation and axial conduction in the filter wall respectively. Heat of conduction in the axial direction is given by[48]:

$$
H_{\text {cond }}=-\lambda_{p} \frac{\partial}{\partial x}\left(w \frac{\partial\left(T_{w}\right)}{\partial x}\right)-\lambda_{s} w_{s} \frac{\partial^{2}\left(T_{w}\right)}{\partial x^{2}}
$$

where $\lambda_{p}$ and $\lambda_{s}$ are the thermal conductivities of the particulate and filter wall substrate respectively.

The heat of combustion of particulate oxidation is dependent on the oxygen depletion in layers 1 and 2 due to particulate oxidation[48] as follows:

$$
H_{\text {react }}=\frac{\Delta H^{t h}}{M_{C}}\left(\frac{M_{C}}{M_{o x}} \frac{1}{1-\frac{f_{C O}}{2}} R_{O_{2}^{t h}}\right)+\frac{\Delta H^{c a t}}{M_{C}}\left(\frac{M_{C}}{M_{o x}} \frac{1}{1-\frac{f_{C O}^{\prime}}{2}} R_{O_{2}, c a t, 1}\right)
$$

where $R_{\mathrm{O}_{2}}^{\text {th }}$ is the total oxygen depletion rate due to thermal oxidation, given as:

$$
R_{O_{2}}^{t h}=R_{O_{2}, 2}+R_{O_{2}, t h, 1}
$$

The thermal and catalytic heats of reaction depend on their respective $\mathrm{CO}$ selectivities, $f_{C O}$ and $f_{C O}^{\prime}$ as follows:

$$
\begin{gathered}
\Delta H^{t h}=f_{C O} \Delta H_{C O}+\left(1-f_{C O}\right) \Delta H_{C O_{2}} \\
\Delta H^{c a t}=f_{C O}^{\prime} \Delta H_{C O}+\left(1-f_{C O}^{\prime}\right) \Delta H_{C O_{2}}
\end{gathered}
$$




\section{B.4 $\quad \mathrm{NO}_{2}$ Production Sub-model}

This section gives a brief overview of the $\mathrm{NO}_{2}$ production sub-model used in the $1 \mathrm{D}$ CPF model in this research. For detailed derivations of the equations involved and explanations for the logic followed, the reader is advised to refer to [12]. Previous research at MTU[3, 12] resulted in the development of this sub-model, which incorporates the production of additional $\mathrm{NO}_{2}$ with the aid of the catalyst wash-coat applied to the filter wall. As $\mathrm{NO}$ passes through the filter monolith wall, it is oxidized by $\mathrm{O}_{2}$ to form $\mathrm{NO}_{2}$. This additional $\mathrm{NO}_{2}$ would also oxidize particulate matter on its way through the wall.

Since in the original model framework developed by Konstandopoulos et al.[31], the catalyst effect was assumed to be limited to layer 1 of the particulate cake, the $\mathrm{NO}_{2}$ production is also assumed to be occurring in layer 1 . The kinetics of this reaction scheme can be represented by[33, 36]:

$$
\frac{d y_{N O_{2}}}{d t}=k_{N O} y_{O_{2}}^{\gamma} y_{N O}^{n}
$$

where $\gamma$ and $n$ are exponents representing variable reaction orders[33]. These exponents are reported to be dependent on space velocities of the exhaust gas in the device. Also, a space velocity of $42000 h r^{-1}$ is reported to be a low space velocity, and $373000 h r^{-1}$ is reported as a high space velocity. The dependence of the reaction exponents on space velocities is given as:

$$
\begin{aligned}
& \gamma=0.22^{*}, \\
& n=0.5^{\dagger}, \\
& n=1.4^{\ddagger},
\end{aligned}
$$

and $k_{N O}$ is the reaction rate constant for the $\mathrm{NO}+\mathrm{O}_{2} \rightarrow \mathrm{NO}_{2}$ reaction

\footnotetext{
*for all space velocities

† for low space velocities

${ }^{\ddagger}$ for high space velocities
} 
assumed to follow a modified Arrhenius function as[36]:

$$
k_{N O}\left(T_{w}\right)=A_{N O} T_{w}^{n^{\prime}} e^{\left(\frac{-E a_{N O}}{\bar{R} T_{w}}\right)}
$$

where $n^{\prime}$ is the temperature order for the reaction and $A_{N O}$ and $E a_{N O}$ are the pre-exponential factor and activation energy for the $\mathrm{NO}+\mathrm{O}_{2} \rightarrow \mathrm{NO}_{2}$ reaction respectively. $E a_{N O}$ has been experimentally determined[36] to be equal to $0.906 \mathrm{E}+08$, and used in previous research works $[7,12] . A_{N O}$ is determined from calibration of the model with experimental data at various loadings.

Figure B.3 shows the discretization technique used for layer 1 for the $\mathrm{NO}_{2}$ production sub-model.

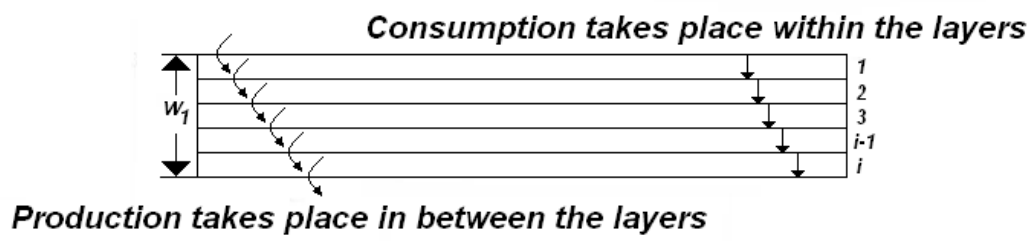

Figure B.3: Discretization of layer 1 into sub-layers for $\mathrm{NO}_{2}$ production model adapted from $[12]$

In order to calculate depletion rates of $\mathrm{NO}_{2}$ and $\mathrm{O}_{2}$ in layer 1 due to the oxidation reaction taking place from the additional $\mathrm{NO}_{2}$ produced in layer $1, \mathrm{NO}_{2}$ and $\mathrm{O}_{2}$ concentrations entering layer 1 are to be known. These are calculated from CPF inlet concentrations of $\mathrm{NO}_{2}$ and $\mathrm{O}_{2}$ and depletion rates for the same in layer 2, as given in equations B.24 and B.14. Particulate cake thickness in layer 1 reduces due to oxidation of particulate by $\mathrm{NO}_{2}$ and $\mathrm{O}_{2}$, and the evolution of layer 1 thickness 
can be defined mathematically as:

$$
\begin{array}{r}
\frac{\partial\left(\rho_{p} w_{e}\right)}{\partial t}=-\frac{M_{C}}{M_{o x}}\left(\frac{1}{1-\frac{f_{C O}}{2}} R_{O_{2}, t h, e}+\frac{1}{1-\frac{f_{C O}^{\prime}}{2}} R_{O_{2}, c a t, e}\right) \\
\quad-\frac{M_{C}}{M_{N O_{2}}}\left(\frac{1}{\left(2-g_{C O}\right)} R_{N_{2}, e}\right)
\end{array}
$$

where the subscript $e$ denotes the individual sub-layers in layer 1.

The thermal, catalytic and $\mathrm{NO}_{2}$ depletion rates in the individual sub-layers of layer 1 are given by:

$$
\begin{aligned}
R_{O_{2}, t h, e} & =R_{O_{2}, \text { total }, e}\left(\frac{k_{t h}\left(T_{w}\right)\left(1-\frac{f_{C O}}{2}\right) \beta}{k^{*}}\right) \\
R_{O_{2}, \text { cat }, e} & =R_{O_{2}, \text { total }, e}\left(\frac{k_{c a t}\left(T_{w}\right)\left(1-\frac{f_{C O}^{\prime}}{2}\right)(1-\beta)}{k^{*}}\right) \\
R_{N O_{2}, e} & =\rho_{w} v_{w} Y_{N O_{2}, 1}\left(1-e^{\left(\frac{-S_{p} k_{N O_{2}}\left(2-g_{C O}\right) w_{e}}{v_{w}}\right)}\right)
\end{aligned}
$$

where the total oxygen depletion rate due to thermal and catalytic means, $R_{O_{2}, \text { total,e }}$ is given by:

$$
R_{O_{2}, t o t a l, e}=\rho_{w} v_{w} Y_{w, 1}\left(1-e^{\left(\frac{-S_{p} k^{*} w_{e}}{v_{w}}\right)}\right)
$$

From equations B.49, $\mathrm{NO}_{2}$ and $\mathrm{O}_{2}$ mass fractions leaving individual layers in layer 1 can be computed as:

$$
\begin{aligned}
Y_{N O_{2}, e} & =Y_{N O_{2}, 1}\left(1-e^{\left(\frac{S_{p} k_{N O_{2}}\left(2-g_{C O}\right) w_{e}}{v_{w}}\right)}\right) \\
Y_{w, e} & =Y_{w, 1}\left(1-e^{\left(\frac{-S_{p} k^{*} w_{e}}{v_{w}}\right)}\right)
\end{aligned}
$$

where the subscript $e$ denotes the mass fractions exiting the particulate layers. These depletion rates, however, are due to the oxidation reaction by the 'normal' wall inlet 
$\mathrm{NO}_{2}$ and $\mathrm{O}_{2}$. An effect additional to this is due to the $\mathrm{NO}_{2}$ production as $\mathrm{NO}$ and $\mathrm{O}_{2}$ pass through the wall layers (or layer 1 sub-layers as is assumed in this model), as represented by the reaction scheme $\mathrm{NO}+\frac{1}{2} \mathrm{O}_{2} \rightarrow \mathrm{NO}_{2}$. As is evident, this results in an increase in $\mathrm{NO}_{2}$ concentrations and a decrease in $\mathrm{NO}$ and $\mathrm{O}_{2}$ concentrations. The $N O$ mole fractions exiting the particulate cake layer can be calculated from a conservation of nitrogen atoms relation as:

$$
y_{\mathrm{NO}, e}=y_{\mathrm{NO}}+y_{\mathrm{NO}_{2}}-y_{\mathrm{NO}_{2}, e}
$$

where $\mathrm{NO}$ and $\mathrm{NO}_{2}$ are the mole fractions of $\mathrm{NO}$ and $\mathrm{NO}_{2}$ entering the particulate cake layer. These are assumed equal to inlet-CPF $\mathrm{NO}$ and $\mathrm{NO}_{2}$ mole fractions, as all reactions are assumed to be taking place in the particulate cake and filter wall, and not in the inlet channels. $y_{\mathrm{NO}_{2}, e}$ is the mole fraction of $\mathrm{NO}_{2}$ leaving the particulate cake (more specifically, layer 1), and can be calculated from the mass fraction of $\mathrm{NO}_{2}$ exiting layer $1 Y_{\mathrm{NO}_{2}, \mathrm{e}}$ B.51a by the simple relation:

$$
y_{\mathrm{NO}_{2}, e}=Y_{\mathrm{NO}_{2}, e}\left(\frac{M_{e x h}}{M_{\mathrm{NO}_{2}}}\right)
$$

where $\mathrm{M}_{\mathrm{NO}_{2}}$ is the molecular weight of $\mathrm{NO}_{2}(46.05 \mathrm{~kg} / \mathrm{kmole}), M_{\text {exh }}$ is the molecular weight of the exhaust gas mixture $(28.5$ - $28.8 \mathrm{~kg} / \mathrm{kmole}$, depending on exhaust conditions and composition).

Using a similar relation, mole fraction of $\mathrm{O}_{2}$ exiting layer $1\left(y_{w, e}\right)$ can also be calculated from $Y_{w, e}$ as given in equation B.51b as:

$$
y_{w, e}=Y_{w, e}\left(\frac{M_{e x h}}{M_{o x}}\right)
$$

where $M_{o x}$ is the molecular weight of oxygen $(31.9988 \mathrm{~kg} / \mathrm{kmole})$

The additional depletion of oxygen due to production of $\mathrm{NO}_{2}$ can be derived 
now from a conservation of oxygen atoms as:

$$
y_{\mathrm{O}_{2}}=y_{w, e}-0.5\left(y_{\mathrm{NO}_{2}, g e n}-y_{\mathrm{NO}_{2}, e}\right)
$$

where $y_{\mathrm{NO}_{2}, \text { gen }}$ is the additional mole fraction of $\mathrm{NO}_{2}$ generated in the layers.

For solution of this method, layer 1 was divided into 'nlayer 1 ' sub-layers, and all species involved in the reaction kept track of in each sub-layer, namely $\mathrm{C}, \mathrm{O}_{2}, \mathrm{NO}$, and $\mathrm{NO}_{2}$. So, total thickness of layer 1 is obtained as the sum of depleted thicknesses of each sub-layer, and can be expressed mathematically as:

$$
w_{1, \text { dep }}=\sum_{i=1}^{\text {nlayer } 1} w_{e, d e p}
$$

where $w_{1, \text { dep }}$ is the total thickness of layer 1 after depletion, and $w_{e, d e p}$ are the depleted thicknesses of individual sub-layers.

\section{B.5 Peclet Number Calculations for CPF Model}

The Peclet number $(P e)$ is computed for each CPF load condition as [29]:

$$
P e=\frac{u_{w} d_{\text {primary }}}{D_{p}}
$$

where $u_{w}$ is the average wall-flow velocity, $d_{\text {primary }}$ is the primary particulate diameter, and $D_{p}$ is the soot aggregate-based diffusion coefficient, computed as:

$$
D_{p}=\frac{k_{B} T}{3 \pi \mu d_{\text {aggregate }}} S C F
$$

where $d_{\text {aggregate }}$ is the aggregate particulate diameter, $k_{B}$ is the Boltzmann's constant, $T$ is the average temperature, $\mu$ is the dynamic viscosity of the exhaust gas, and $S C F$ is the Stokes-Cunningham factor which is basically a correction factor applied 
to correct for deviations of $D_{p}$ from continuum behavior. $S C F$ is expressed as a function of the Knudsen number $(K n)$ as:

$$
S C F=1+K n\left(1.257+0.4 e^{-1.1 / K n}\right)
$$

and the Knudsen number is given as:

$$
K n=\frac{2 \lambda}{d_{\text {aggregate }}}
$$

where $\lambda$ is the gas mean free path, expressed as:

$$
\lambda=\nu \sqrt{\frac{\pi M W}{2 R T}}
$$

where $M W$ is the molecular weight of exhaust gas, $R$ is the universal gas constant, and $\nu$ is the kinematic viscosity of the exhaust gas.

\section{B.6 CPF model - Code structure and pressure drop calculations}

This section gives a brief description of the FORTRAN MTU 1-D 2-layer CPF model code and the procedure followed in solving the system of equations describing the flow, filtration and oxidation processes in the CPF taking place as functions of loading time. Figure B.4 shows a diagrammatic representation of the algorithm (flowchart) used in the FORTRAN CPF model code. Here, the part shown enclosed by dotted lines is the time loop and this section is repeated for every time step in model simulations.

The various sub-routines used in the model and their functions are as follows:

1. rinput_1d reads input data from the input files. The input data consists of filter specifications, exhaust gas conditions, kinetics-related parameters, PM 


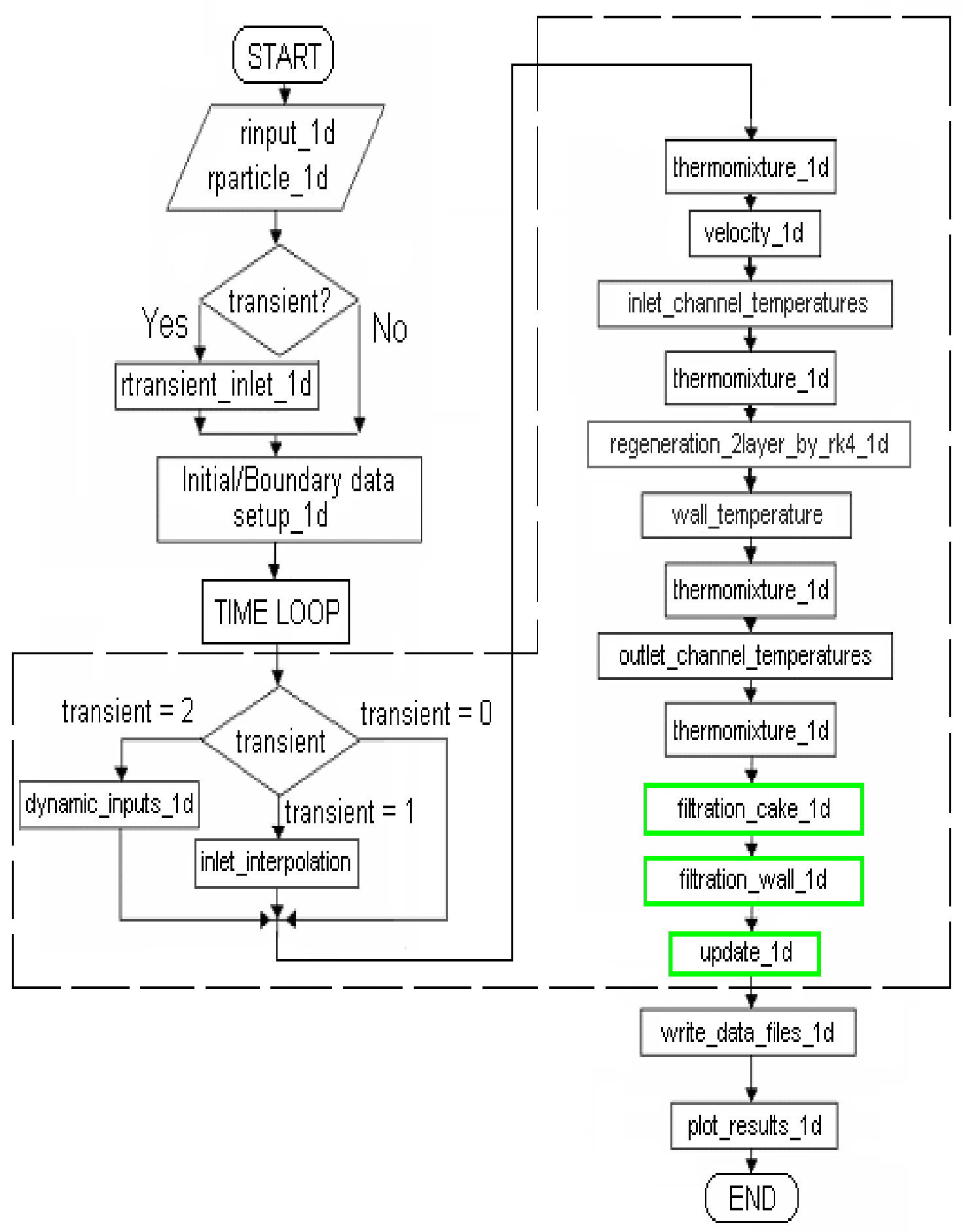

Figure B.4: A code flowchart of the MTU 1-D 2-layer CPF model 
cake and substrate wall particulate matter properties, initial conditions, and numerics-related parameters.

2. rparticle_1d reads the average UP-CPF particle size distribution data.

3. setup_1d sets the boundary and initial conditions from the input data and converts them into the units chosen for the model calculations. It also determines the clean filter velocity field, clean pressure drop and initial filtration parameters.

4. thermomixture_1d calculates the exhaust gas properties (density, specific heat, thermal conductivity, dynamic viscosity, and heat transfer coefficient) based on input parameters such as UP-CPF temperature, pressure, and filter geometry. This subroutine is used to update the exhaust gas mixture properties in the inlet channel, wall and outlet channel, after calculating the inlet channel, wall and outlet channel temperatures respectively.

5. velocity_1d solves the velocity field for the inlet and outlet channel flow velocities as well as for the wall flow velocity. This sub-routine solves the system of boundary value problem ordinary differential equations using the shooting method along with a Runge-Kutta $4^{\text {th }}$ order formulation. Aitken's interpolation technique is also used to obtain the estimated initial slope through three trial values.

6. inlet_channel_temperatures solves the energy balance for the inlet channel (gas phase). The inlet channel gas temperature at each spatial step from inlet to end plug of the filter is obtained in this sub-routine using $4^{\text {th }}$ order RungeKutta explicit formulation by 'marching' the solution in space from the inlet $\operatorname{boundary}(x=0)$ to the end $\operatorname{plug}(x=L)$.

7. regeneration_2layer_by_rk4_1d solves the regeneration process involving 
thermal and $\mathrm{NO}_{2}$ /temperature-assisted PM oxidation mechanisms, and $\mathrm{NO}_{2}$ production in the sub-layers of the filter wall. It uses a $4^{\text {th }}$ order Runge-Kutta technique to determine the particulate layer thickness shrinkage for the layer and for the effective wall thickness. It calculates the rate coefficients involved, CO selectivities and the PM deposit evolution.

8. wall_temperature solves the energy balance for the wall. The wall temperature is determined using a Crank-Nicolson implicit scheme, which involves a tridiagonal system solver subroutine.

9. outlet_channel_temperatures solves the energy balance for the outlet channel gas phase temperature. Similar to the technique through which the inlet channel gas temperature is computed, the outlet channel gas temperature is solved using a $4^{\text {th }}$ order Runge-Kutta explicit formulation by 'marching' the solution in space from the end $\operatorname{plug}(x=0)$ to the exit of the channel $(x=L)$.

10. filtration_cake_1d computes the filtration efficiency of the PM cake layer as a function of time. It also conducts a comparison of the partition coefficient to the parametric cake efficiency calculated from the local PM cake layer thickness, and calculates all PM cake filtration parameters.

11. filtration_wall_1d computes the filtration efficiency of the loaded substrate wall as a function of time. This sub-routine also calculates all filtration parameters required to determine the wall efficiency and updates the wall properties and determines the pressure drop across the filter.

12. update_1d updates the PM mass evolution 'in' and 'on' the filter wall after the filtration process.

13. write_data_files_1d writes the desired output data to various ASCII text files which can later be processed or plotted using plotting software. 
14. plot_results_1d is an optional sub-routine which plots various output variables in Matlab.

In order to calculate the pressure drop encountered by the exhaust gas mixture as it passes through the CPF, the individual components of the pressure drop have to be calculated. These components of the pressure drop are:

1. Frictional pressure loss in the CPF inlet channel,

2. Pressure drop due to flow resistance offered by the PM cake layer,

3. Pressure drop due to flow resistance offered by the loaded substrate wall, and

4. Frictional pressure loss in the CPF outlet channel.

Frictional pressure drop losses in the CPF inlet and outlet channels are given by equation B.5, pressure drop due to the loaded substrate wall is given by equation B.7 and pressure drop due to the PM cake layer is given by equation B.8. In order to compute these, inlet, outlet and wall velocities of the exhaust gas have to be known beforehand. This is done by the velocity solver sub-routine (velocity_1d from Figure B.4), using the mass conservation equations for inlet and outlet channel elements. Also, the instantaneous equivalent permeability values of the cake and wall elements $\left(k_{p}\right.$ and $\left.k(t)\right)$ and local PM cake layer thickness $\left(w_{\text {cake }}\right)$ have to be known. PM cake permeability is assumed constant in the model and the value is an input parameter. Instantaneous equivalent wall permeability values are obtained from the individual permeability values of all sub-layers of the wall (which are calculated in the filtration_wall_1d sub-routine) and individual sub-layer thicknesses. PM cake layer thicknesses are obtained from the regeneration sub-routine, regeneration_2layer_by_rk4_1d.

Pressure drop calculations begin with the absolute pressure at the CPF outlet being assumed equal to the ambient pressure (also a user input parameter). Absolute 
pressure of each outlet channel element is calculated by 'marching' the pressure drop calculations in the axial (' $\mathrm{x}$ ') direction from the exit of the outlet channel $(x=L)$ to the end plug $(x=0)$, adding the outlet channel pressure drop due to the individual outlet channel wall element at each step. Next, pressure drop due to loaded filter wall and PM cake at each axial location are calculated and added to the absolute outlet channel pressures calculated previously to obtain absolute pressures at the inlet to the PM cake layer at each axial element. Finally, the pressure drop due to inlet channel friction loss is calculated using the inlet channel pressure drop equation and added to the absolute pressure at the inlet to the PM cake layer, to obtain the absolute pressure in each inlet channel element. The total pressure drop encountered by the exhaust gas mixture gas while passing through the CPF will then be the difference between the absolute pressure at the first inlet channel ( $x=0$, inlet channel) and the absolute pressure at the last outlet channel $(x=L$, outlet channel). Figure B.5 shows a schematic representation of the calculations involved in the pressure drop sub-model. 


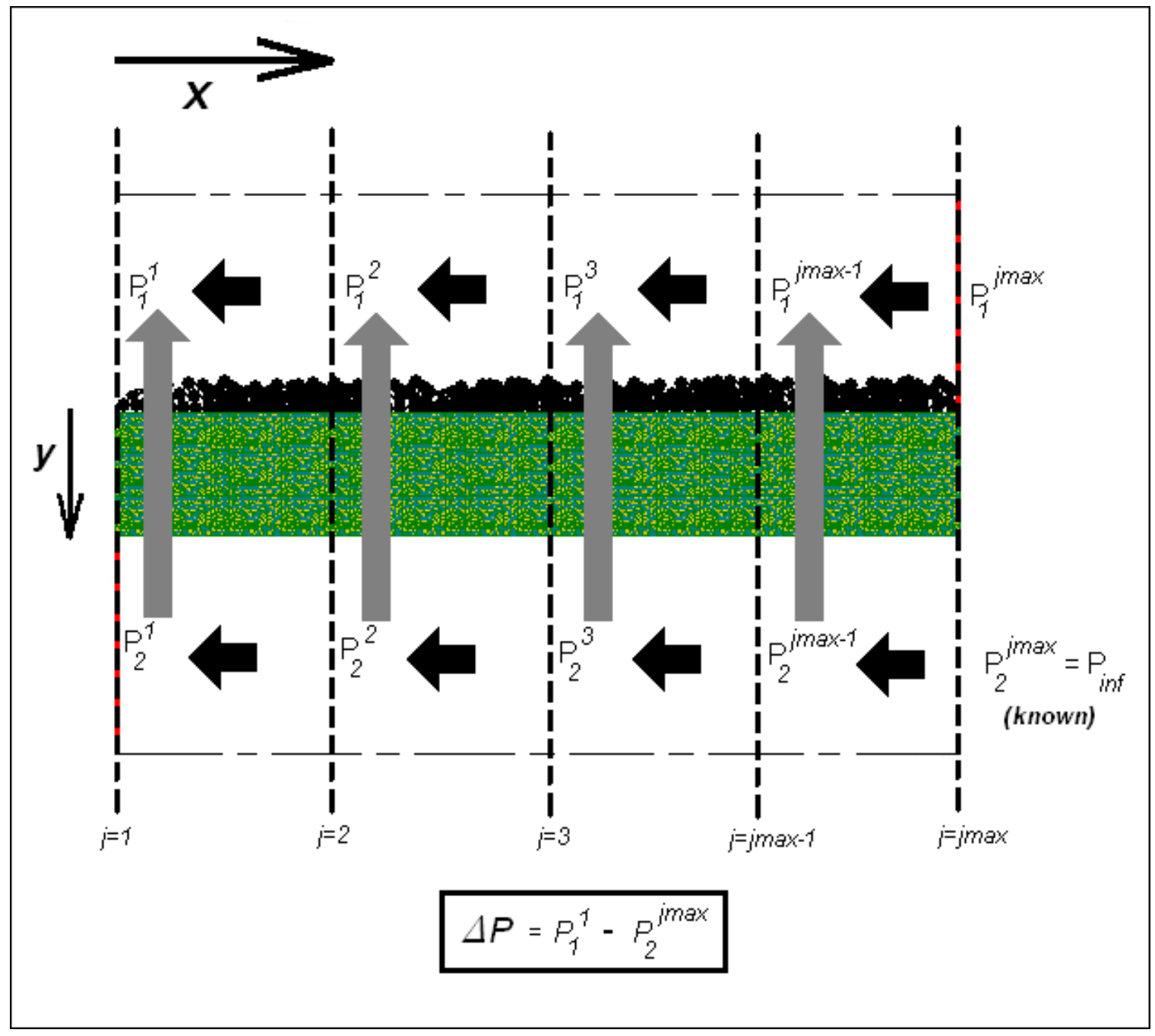

Figure B.5: A schematic of pressure drop calculations in the CPF model 


\section{Appendix C}

\section{Calibration Plots from 1D DOC}

\section{Model Simulations}

The main objective of DOC model calibration was to determine a single set of kinetic parameters (pre-exponential factors and activation energies) of $\mathrm{CO}\left(A_{1}, E a_{1}\right.$ in Equation 3.9), $\mathrm{HC}\left(A_{2}, E a_{2}\right.$ in Equation 3.12) and $\mathrm{NO}\left(A_{3}, E a_{1}\right.$ in Equation 3.10) oxidation reactions for the different load conditions at $2200 \mathrm{rpm}$ and $1650 \mathrm{rpm}$.

The first step toward this was to match the model-predicted values of outlet concentrations of $\mathrm{CO}, \mathrm{HC}$ and $\mathrm{NO}$ by keeping the model input values of activation energies of $\mathrm{CO}, \mathrm{HC}$ and $\mathrm{NO}$ at pre-determined values (from [5])as shown in Table C.1, and using the adsorption equilibrium constants from Table C.2, and adjusting the input values of pre-exponential factors of $\mathrm{CO}, \mathrm{HC}$ and $\mathrm{NO}$ oxidation reactions. It should be noted that the hydrocarbons ( $\mathrm{HC}$ ) in the exhaust line were modeled as propene $\left(\mathrm{C}_{3} \mathrm{H}_{6}\right)$, although the actual carbon numbers of exhaust HC's usually measured in diesel engine exhaust lie in the $\mathrm{C}_{9}-\mathrm{C}_{12}$ range. This is because of the low HC concentrations measured in this research, which would result in even smaller concentrations if they were modeled using higher carbon number molecular formulas. Figures C.1, C.2, C.3 and C.4 show the results obtained from the DOC 
model calibration at $2200 \mathrm{rpm}$ and Figures C.5, C.6, C.7 and C.8 show the results obtained from the DOC model calibration at $1650 \mathrm{rpm}$. Tables C.3 and C.5 show the pre-exponential factors obtained thus at $2200 \mathrm{rpm}$ and $1650 \mathrm{rpm}$ respectively.

Table C.1: Activation energies used for DOC model calibration at $2200 \mathrm{rpm}$ and $1650 \mathrm{rpm}$

\begin{tabular}{|c|c|}
\hline Reaction & $\begin{array}{c}\text { Activation Energy } \\
(\mathrm{J} / \text { gmole })\end{array}$ \\
\hline $\mathrm{CO}$ & $1.00 \mathrm{E}+05$ \\
$\mathrm{HC}$ & $1.00 \mathrm{E}+05$ \\
$\mathrm{NO}$ & $5.50 \mathrm{E}+04$ \\
\hline
\end{tabular}

Table C.4 shows the experimental UP-DOC concentrations and a comparison of experimental and model-predicted DN-DOC concentrations of $\mathrm{CO}, \mathrm{HC}, \mathrm{NO}$ and $\mathrm{NO}_{2}$ respectively, obtained from calibration of the DOC model at $2200 \mathrm{rpm}$. The maximum difference observed in this set of data were $-0.3 \mathrm{ppm}$ for $\mathrm{CO},-0.2 \mathrm{ppm}$ for $\mathrm{HC}, 2.7 \mathrm{ppm}$ for $\mathrm{NO}$ and $-0.5 \mathrm{ppm}$ for $\mathrm{NO}_{2}$ respectively.

Table C.2: Adsorption equilibrium constants used for DOC model calibration

\begin{tabular}{|c|c|c|}
\hline Constant & $\begin{array}{c}\text { Adsorption } \\
\text { factor } \\
(.)\end{array}$ & $\begin{array}{c}\text { Adsorption } \\
\text { heat } \\
(\mathrm{J} / \text { gmole })\end{array}$ \\
\hline$A_{a, 1}$ & 65.5 & -7990 \\
\hline$A_{a, 2}$ & $2.08 \times 10^{3}$ & -3000 \\
\hline$A_{a, 3}$ & 3.98 & -96534 \\
\hline$A_{a, 4}$ & $4 \times 10^{5}$ & 85000 \\
\hline$A_{a, 5}$ & 65.5 & -7990 \\
\hline$A_{a, 6}$ & 2080 & -3000 \\
\hline$A_{a, 7}$ & 3.98 & -96534 \\
\hline$A_{a, 8}$ & $4.79 \times 10^{5}$ & 85000 \\
\hline$A_{a, 9}$ & $9 \times 10^{4}$ & 0 \\
\hline$A_{a, 10}$ & 0 & 0 \\
\hline$A_{a, 11}$ & 0 & 0 \\
\hline$A_{a, 12}$ & 3.98 & -96534 \\
\hline$A_{a, 13}$ & $7 \times 10^{5}$ & 85000 \\
\hline
\end{tabular}




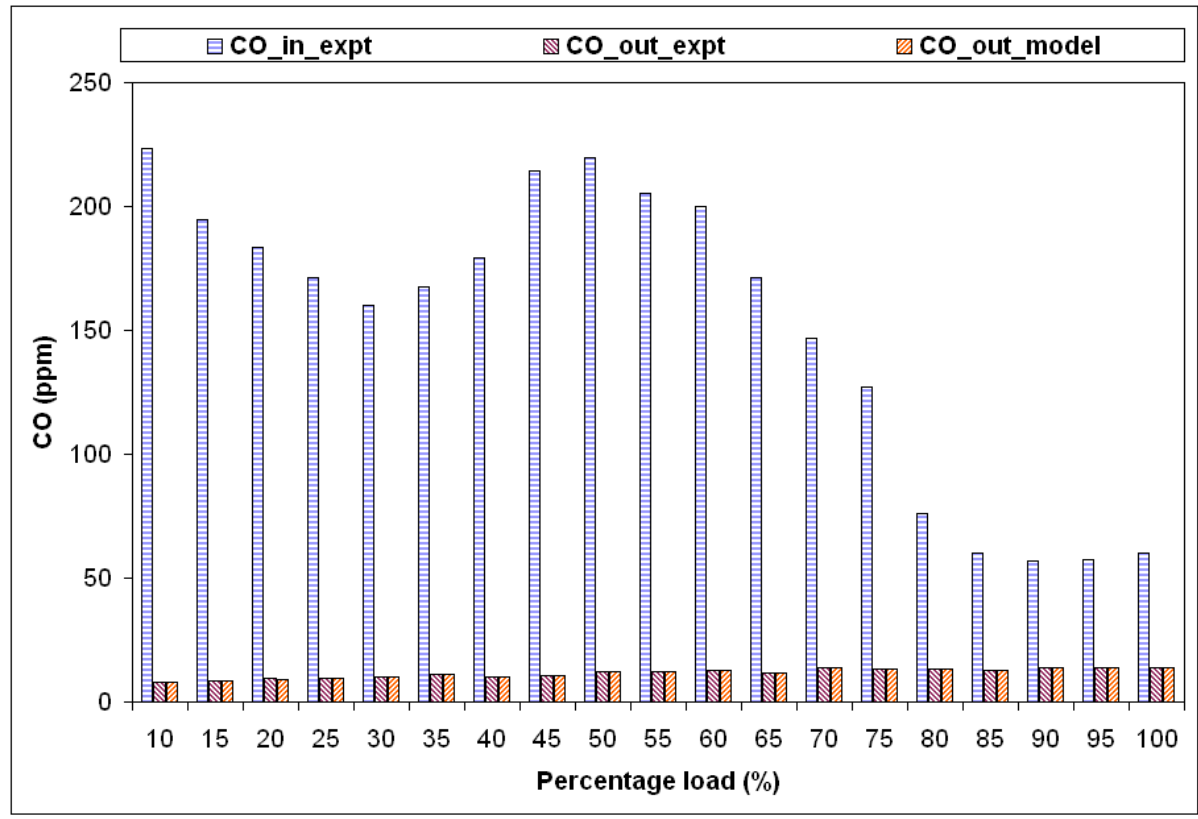

Figure C.1: 2200 rpm DOC-only - Comparison of experimental and model outlet CO concentrations

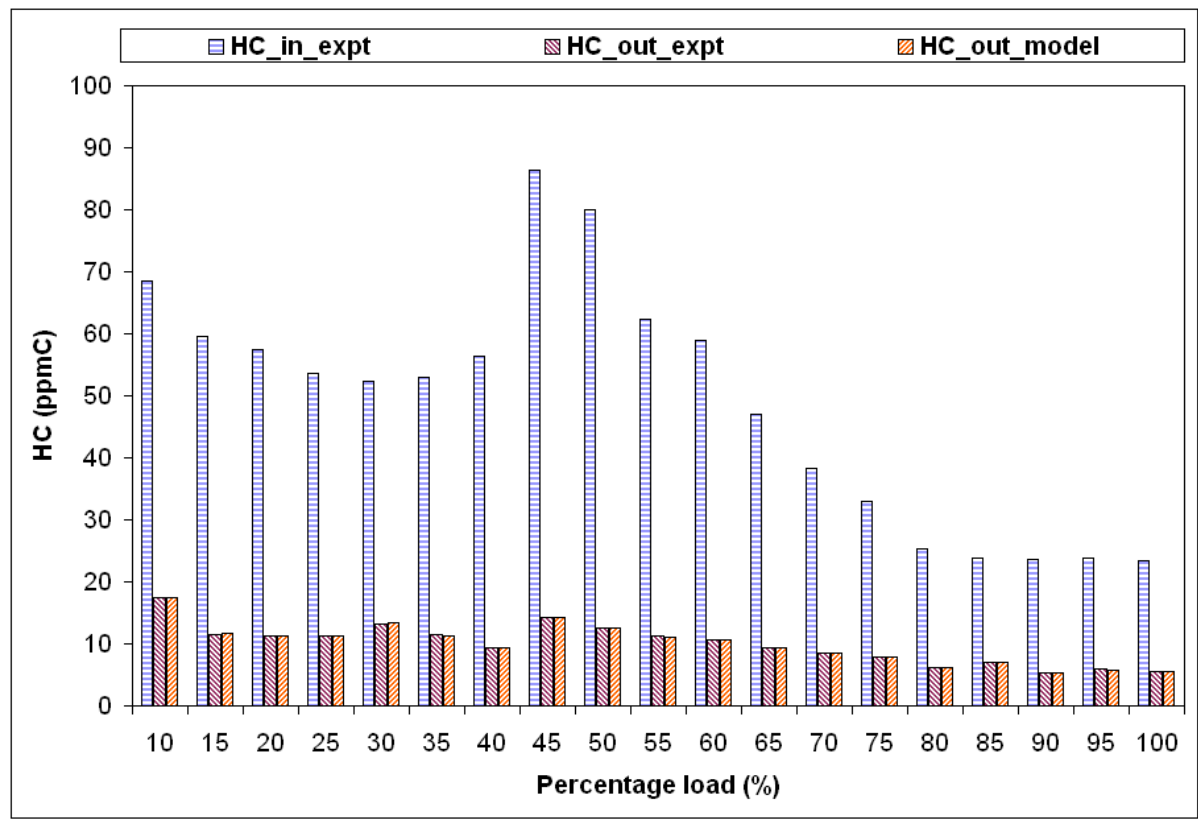

Figure C.2: 2200 rpm DOC-only - Comparison of experimental and model outlet $\mathrm{HC}$ concentrations 


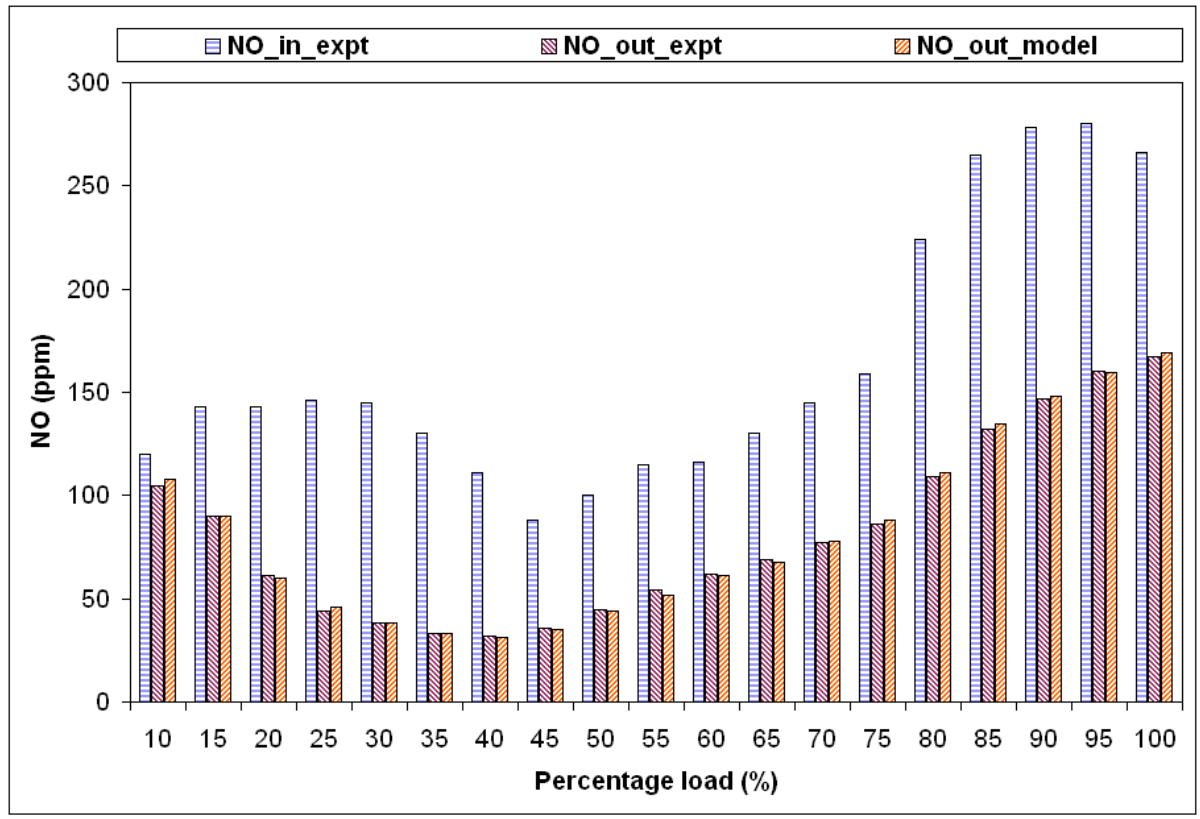

Figure C.3: 2200 rpm DOC-only - Comparison of experimental and model outlet NO concentrations

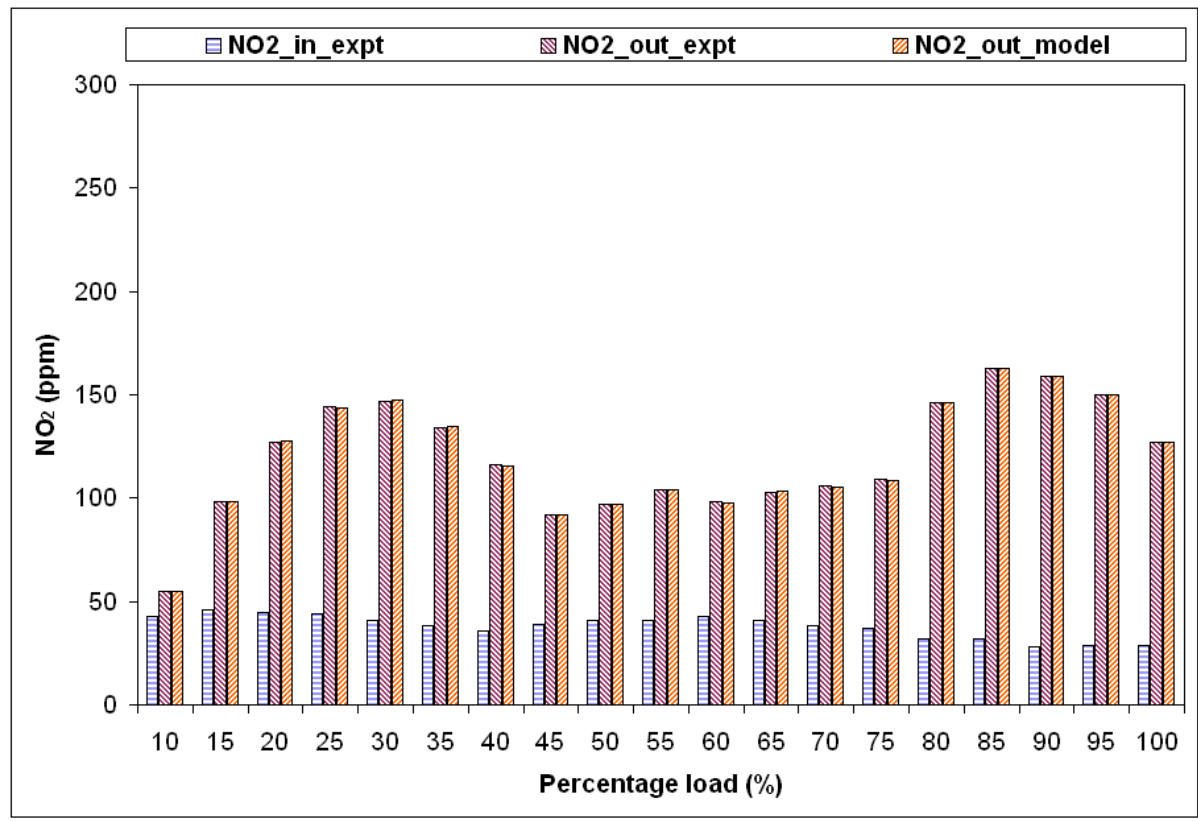

Figure C.4: 2200 rpm DOC-only - Comparison of experimental and model outlet $\mathrm{NO}_{2}$ concentrations 
Table C.3: $2200 \mathrm{rpm}$ - CO, HC and NO pre-exponential factors

\begin{tabular}{|c|c|c|c|}
\hline & \multicolumn{3}{|c|}{ pre-exponential factors } \\
\hline Temperature & $\mathrm{CO}$ & $\mathrm{HC}$ & $\mathrm{NO}$ \\
\hline$\left({ }^{\circ} \mathrm{C}\right)$ & $\left(\mathrm{gmole} / \mathrm{m}^{2}\right.$-s $)$ & $\left(\mathrm{gmole} / \mathrm{m}^{2}-\mathrm{s}\right)$ & $\left(\mathrm{gmole} / \mathrm{m}^{2}-\mathrm{s}\right)$ \\
\hline 180.08 & $1.35 \mathrm{E}+19$ & $8.80 \mathrm{E}+24$ & $1.60 \mathrm{E}+08$ \\
\hline 203.83 & $1.16 \mathrm{E}+19$ & $8.94 \mathrm{E}+24$ & $5.10 \mathrm{E}+08$ \\
\hline 223.53 & $9.50 \mathrm{E}+18$ & $7.00 \mathrm{E}+24$ & $8.70 \mathrm{E}+08$ \\
\hline 243.13 & $8.40 \mathrm{E}+18$ & $5.80 \mathrm{E}+24$ & $1.23 \mathrm{E}+09$ \\
\hline 262.58 & $7.63 \mathrm{E}+18$ & $4.50 \mathrm{E}+24$ & $1.68 \mathrm{E}+09$ \\
\hline 281.68 & $7.16 \mathrm{E}+18$ & $4.50 \mathrm{E}+24$ & $2.10 \mathrm{E}+09$ \\
\hline 302.60 & $7.14 \mathrm{E}+18$ & $4.65 \mathrm{E}+24$ & $2.50 \mathrm{E}+09$ \\
\hline 322.85 & $7.87 \mathrm{E}+18$ & $4.60 \mathrm{E}+24$ & $2.40 \mathrm{E}+09$ \\
\hline 336.28 & $8.90 \mathrm{E}+18$ & $5.30 \mathrm{E}+24$ & $3.05 \mathrm{E}+09$ \\
\hline 347.38 & $1.01 \mathrm{E}+19$ & $5.30 \mathrm{E}+24$ & $4.05 \mathrm{E}+09$ \\
\hline 359.80 & $1.09 \mathrm{E}+19$ & $5.50 \mathrm{E}+24$ & $4.30 \mathrm{E}+09$ \\
\hline 365.95 & $1.18 \mathrm{E}+19$ & $5.50 \mathrm{E}+24$ & $5.40 \mathrm{E}+09$ \\
\hline 372.38 & $1.17 \mathrm{E}+19$ & $5.50 \mathrm{E}+24$ & $6.30 \mathrm{E}+09$ \\
\hline 379.10 & $1.24 \mathrm{E}+19$ & $5.50 \mathrm{E}+24$ & $7.37 \mathrm{E}+09$ \\
\hline 376.25 & $1.20 \mathrm{E}+19$ & $6.60 \mathrm{E}+24$ & $1.08 \mathrm{E}+10$ \\
\hline 380.55 & $1.24 \mathrm{E}+19$ & $6.36 \mathrm{E}+24$ & $1.30 \mathrm{E}+10$ \\
\hline 389.70 & $1.22 \mathrm{E}+19$ & $7.94 \mathrm{E}+24$ & $1.48 \mathrm{E}+10$ \\
\hline 400.58 & $1.33 \mathrm{E}+19$ & $7.80 \mathrm{E}+24$ & $1.61 \mathrm{E}+10$ \\
\hline 413.60 & $1.44 \mathrm{E}+19$ & $7.80 \mathrm{E}+24$ & $1.58 \mathrm{E}+10$ \\
\hline & & & \\
\hline
\end{tabular}




\begin{tabular}{|c|c|c|c|c|c|c|c|c|c|c|c|c|c|c|c|c|c|c|c|c|c|}
\hline \multirow{4}{*}{$\begin{array}{l}0 \\
7\end{array}$} & サ!P & (udd) & $\stackrel{0}{0}$ & $\stackrel{N}{0}$ & $\ddot{0}$ & 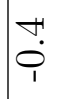 & $\ddot{\infty}$ & $\ddot{0}$ & $\stackrel{m}{\infty}$ & $\ddot{\infty}$ & $\stackrel{m}{0}$ & 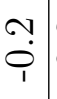 & $\begin{array}{l}\stackrel{1}{0} \\
0 \\
1\end{array}$ & $\begin{array}{r}r \\
0\end{array}$ & $\mid$ & $\mid$ & 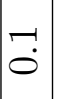 & 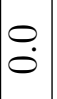 & $\stackrel{m}{0}$ & $\ddot{0}$ & $\stackrel{0}{0}$ \\
\hline & $\begin{array}{l}\text { ұәтұno } \\
\text { гәрош }\end{array}$ & (udd) & 120 & $\infty$ & $\stackrel{N}{\sim}$ & $\underset{+}{+}$ & $\stackrel{N}{\vec{H}}$ & 票 & $\stackrel{0}{=}$ & $\approx$ & $\widehat{\sigma}$ & $\underset{⿱}{\vec{O}}$ & $\infty$ & $\stackrel{\overrightarrow{0}}{\stackrel{-}{\prime}}$ & $\stackrel{0}{0}$ & $\stackrel{8}{0}$ & $\stackrel{0}{\stackrel{0}{\sim}}$ & $\underset{3}{0}$ & $\stackrel{\Omega}{20}$ & $\stackrel{0}{20}$ & $\stackrel{\sim}{\sim}$ \\
\hline & $\begin{array}{l}\text { 7әтұno } \\
\cdot 7 \mathrm{dx}\end{array}$ & (udd) & \begin{tabular}{|l|}
120 \\
120
\end{tabular} & $\infty$ & $\stackrel{\mathfrak{N}}{\stackrel{N}{\sim}}$ & $\underset{+}{+}$ & $\stackrel{N}{\exists}$ & $\stackrel{+}{-1}$ & $\stackrel{0}{=}$ & $\approx$ & $\hat{\sigma}$ & $\underset{\Xi}{+}$ & $\infty$ & $\ddot{\theta}$ & 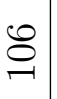 & $\stackrel{g}{\varrho}$ & $\stackrel{0}{\stackrel{0}{2}}$ & ्ְर & 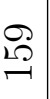 & 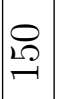 & $\stackrel{\sim}{\mathcal{I}}$ \\
\hline & $\begin{array}{l}\text { ૧ӘЧU! } \\
\cdot 7 \mathrm{dx} \partial\end{array}$ & (udd) & $\mathscr{m}$ & $\stackrel{0}{\rightarrow}$ & $\stackrel{20}{7}$ & 吕 & $F$ & $\infty$ & m & ले & $F$ & $F$ & $\mathscr{P}$ & $F$ & $\mid$ & $\hat{\infty}$ & $\therefore$ & $\therefore$ & $\stackrel{\infty}{\sim}$ & 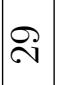 & $\stackrel{2}{2}$ \\
\hline \multirow{4}{*}{$\begin{array}{l}0 \\
7\end{array}$} & サ!р & (udd) & $\hat{\sim}$ & $\begin{array}{l}-1 \\
\dot{0}\end{array}$ & $\stackrel{\longrightarrow}{\longrightarrow}$ & $\stackrel{\sim}{\sim}$ & $\stackrel{0}{0}$ & $\stackrel{\sim}{0}$ & $\begin{array}{l}\infty \\
0 \\
1\end{array}$ & $\begin{array}{l}0 \\
0 \\
1\end{array}$ & $\begin{array}{l}\infty \\
0 \\
1\end{array}$ & $\begin{array}{l}0 \\
\dot{T} \\
1\end{array}$ & $\begin{array}{l}0 \\
\dot{i} \\
\end{array}$ & $\mid \begin{array}{c}0 \\
\dot{i} \\
1\end{array}$ & $\ddot{0}$ & $\stackrel{0}{a}$ & $\infty$ & $\mid$ & $\stackrel{+}{-}$ & $\begin{array}{c}-1 \\
0 \\
1\end{array}$ & $\stackrel{+}{\sim}$ \\
\hline & $\begin{array}{l}\text { ұәтұnо } \\
\text { гррош }\end{array}$ & (udd) & 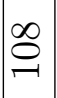 & 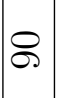 & 8 & $\stackrel{0}{7}$ & $\infty$ & ñ & $\ddot{\infty}$ & 12 & $\stackrel{F}{\sharp}$ & กิ่ & 6 & $\sqrt{6}$ & $\infty$ & $\infty$ & $\exists$ & 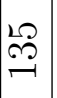 & $\stackrel{\infty}{ \pm}$ & $\underset{0}{0}$ & g. \\
\hline & $\begin{array}{l}\text { 7әтұnо } \\
\cdot 7 \mathrm{dxə}\end{array}$ & [d) & $\stackrel{20}{\stackrel{0}{1}}$ & \& & $\overline{6}$ & $\exists$ & $\infty$ & ñ & ๓ิ & @ి & $\stackrel{\sim 2}{7}$ & है & ชै & 8 & N & $\stackrel{\infty}{\infty}$ & $\stackrel{8}{\circ}$ & $\stackrel{\sim}{\oplus}$ & 告 & $\begin{array}{c}0 \\
0 \\
-1 \\
\end{array}$ & 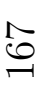 \\
\hline & 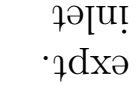 & (udd) & 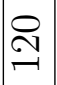 & $\stackrel{\oplus}{\rightleftarrows}$ & $\stackrel{\infty}{\rightleftarrows}$ & $\stackrel{0}{\stackrel{0}{1}}$ & $\stackrel{20}{+}$ & 里 & 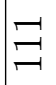 & $\infty$ & $\underset{8}{\varrho}$ & $\stackrel{20}{=}$ & $\begin{array}{c}0 \\
\stackrel{1}{F}\end{array}$ & @ & $\stackrel{20}{ \pm}$ & $\stackrel{0}{20}$ & ir & $\left|\begin{array}{l}10 \\
\varrho \\
\sim \\
N\end{array}\right|$ & $\frac{\infty}{N}$ & $\underset{\substack{\infty \\
N}}{\infty}$ & $\stackrel{\bullet}{\stackrel{\leftrightarrow}{\sim}}$ \\
\hline \multirow{4}{*}{$\underline{U}$} & サ!P & (Dudd) & $\stackrel{0}{0}$ & $\ddot{0}$ & $\ddot{0}$ & $\stackrel{1}{0}$ & $\ddot{0}$ & $\mid \begin{array}{r}-1 \\
0 \\
1\end{array}$ & $\ddot{1}_{1}$ & $\stackrel{0}{0}$ & $\stackrel{0}{0}$ & $\begin{array}{l}\stackrel{0}{0} \\
\mathfrak{1}\end{array}$ & $\stackrel{0}{0}$ & $\ddot{0}$ & $\ddot{0}$ & $\begin{array}{l}0 \\
0\end{array}$ & $\ddot{0}$ & $\begin{array}{c}-1 \\
\dot{0} \\
1\end{array}$ & $\breve{0}$ & $\begin{array}{l}\mathfrak{r} \\
\dot{p} \\
1\end{array}$ & ְ. \\
\hline & $\begin{array}{l}\text { ұə[łno } \\
\text { әәрош }\end{array}$ & (Dudd) & $\approx$ & $\stackrel{\sim}{=}$ & 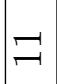 & 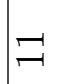 & 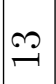 & 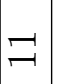 & os & 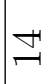 & $\stackrel{\sim}{\sim}$ & $\exists$ & $\exists$ & 0 & 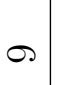 & $\infty$ & 0 & $N$ & D & 0 & 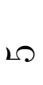 \\
\hline & $\begin{array}{l}\text { 7әtนno } \\
\cdot 7 d x ә\end{array}$ & (Dudd) & 든 & $\stackrel{\sim}{\sim}$ & 二 & 二 & $\infty$ & 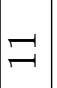 & 0 & 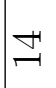 & $\stackrel{m}{-1}$ & $\exists$ & 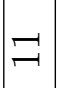 & $\infty$ & 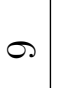 & $\infty$ & 0 & $\sim$ & 10 & 0 & 0 \\
\hline & $\begin{array}{l}\text { ұə[U! } \\
\cdot 7 \mathrm{dx}\end{array}$ & (Dudd) & 8 & 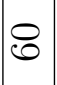 & 10 & 20 & กิ่ & is & $\begin{array}{l}0 \\
10\end{array}$ & $\infty$ & $\infty$ & $\overparen{ఠ}$ & 20 & $\stackrel{N}{y}$ & $\infty$ & $\infty$ & $\stackrel{\stackrel{\sim}{\sim}}{\sim}$ & $\vec{N}$ & $\stackrel{\leftrightarrow}{\sim}$ & $\stackrel{H}{\sim}$ & $\stackrel{\Re}{\sim}$ \\
\hline \multirow{4}{*}{ ৩ } & • Ш!P & d) & $\begin{array}{c}-1 \\
0 \\
1\end{array}$ & $\ddot{0}$ & 占 & $\ddot{O}$ & $\begin{array}{l}-1 \\
0 \\
1\end{array}$ & $\stackrel{0}{0}$ & $\ddot{0}$ & $\stackrel{0}{0}$ & $\ddot{0}$ & $\begin{array}{l}m \\
\stackrel{9}{q}\end{array}$ & $\ddot{0}$ & $\stackrel{0}{0}$ & $\mid \begin{array}{l}-1 \\
0 \\
1\end{array}$ & $\stackrel{0}{0}$ & $\stackrel{0}{0}$ & $\begin{array}{l}\Upsilon \\
0 \\
1\end{array}$ & $\ddot{\circ}$ & $\begin{array}{l}0 \\
\vdots \\
1 \\
1\end{array}$ & $\ddot{\circ}$ \\
\hline & $\begin{array}{l}\text { ұәтұnо } \\
\text { гррош }\end{array}$ & dd) & $\infty$ & 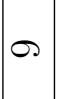 & $\sigma$ & $\underset{1}{0}$ & $\underset{-1}{-1}$ & $二$ & $\stackrel{0}{-1}$ & $\underset{1}{\circ}$ & $\stackrel{\sim}{\beth}$ & $\stackrel{\mathcal{V}}{\sim}$ & 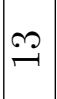 & $\stackrel{\sim}{\sim}$ & 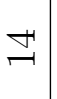 & 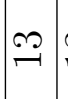 & $m$ & $\infty$ & $\rightleftarrows$ & $\exists$ & $\rightleftarrows$ \\
\hline & $\begin{array}{l}\text { 7әtұno } \\
\cdot 7 \mathrm{dx}\end{array}$ & (udd) & $\infty$ & 0 & 0 & $\stackrel{0}{-1}$ & $\stackrel{0}{-1}$ & 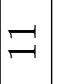 & $\stackrel{0}{-1}$ & $\exists$ & $\stackrel{\sim}{\sim}$ & $\stackrel{\simeq}{\sim}$ & $\infty$ & $\stackrel{\sim}{\sim}$ & 岌 & $m$ & $m$ & $m$ & 巳 & $\exists$ & $\Xi$ \\
\hline & $\begin{array}{l}\text { ұə[u! } \\
\cdot 7 \mathrm{dx}\end{array}$ & (udd) & 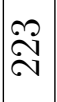 & 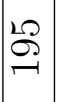 & $\underset{\infty}{\infty}$ & $\stackrel{I}{r}$ & $\stackrel{8}{6}$ & $\mid$ & $\stackrel{R}{1}$ & $\underset{A}{\sharp}$ & $\stackrel{\curvearrowright}{\stackrel{\sim}{\sim}}$ & $\stackrel{2}{\stackrel{N}{N}}$ & 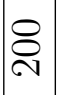 & 든 & $\underset{\sim}{\sim}$ & $\stackrel{N}{\stackrel{N}{-1}}$ & $\begin{array}{l}0 \\
1\end{array}$ & 8 & مَ & 12 & 8 \\
\hline 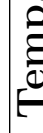 & & రి & $\infty$ & 穴 & $\underset{\sim}{\stackrel{H}{N}}$ & $\stackrel{m}{\stackrel{2}{H}}$ & 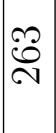 & $\begin{array}{c}\stackrel{1}{\infty} \\
\sim \\
\sim\end{array} \mid$ & $\stackrel{m}{\infty}$ & $\underset{\sim}{\approx}$ & 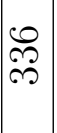 & 祭 & $\begin{array}{l}8 \\
\stackrel{0}{0} \\
\infty\end{array}$ & $\left|\begin{array}{c}0 \\
0 \\
\infty \\
0\end{array}\right|$ & $\underset{\infty}{\mathbb{N}}$ & $\begin{array}{c}\Omega \\
N \\
\infty\end{array}$ & $\begin{array}{c}0 \\
N \\
m\end{array}$ & $\vec{\infty}$ & 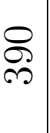 & $\underset{ }{\circ}$ & $\underset{\forall}{\rightleftarrows}$ \\
\hline $\begin{array}{l}0 \\
6 \\
0 \\
0 \\
1\end{array}$ & & & $\stackrel{\ominus}{=}$ & 20 & $\stackrel{\sim}{\sim}$ & $\stackrel{12}{N}$ & ৫ & ח & 와 & $\stackrel{20}{7}$ & 8 & | & 8 & 10 & $R$ & $\frac{10}{1}$ & 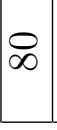 & $\infty$ & ๑ & $\mathscr{2}$ & $\stackrel{8}{8}$ \\
\hline
\end{tabular}




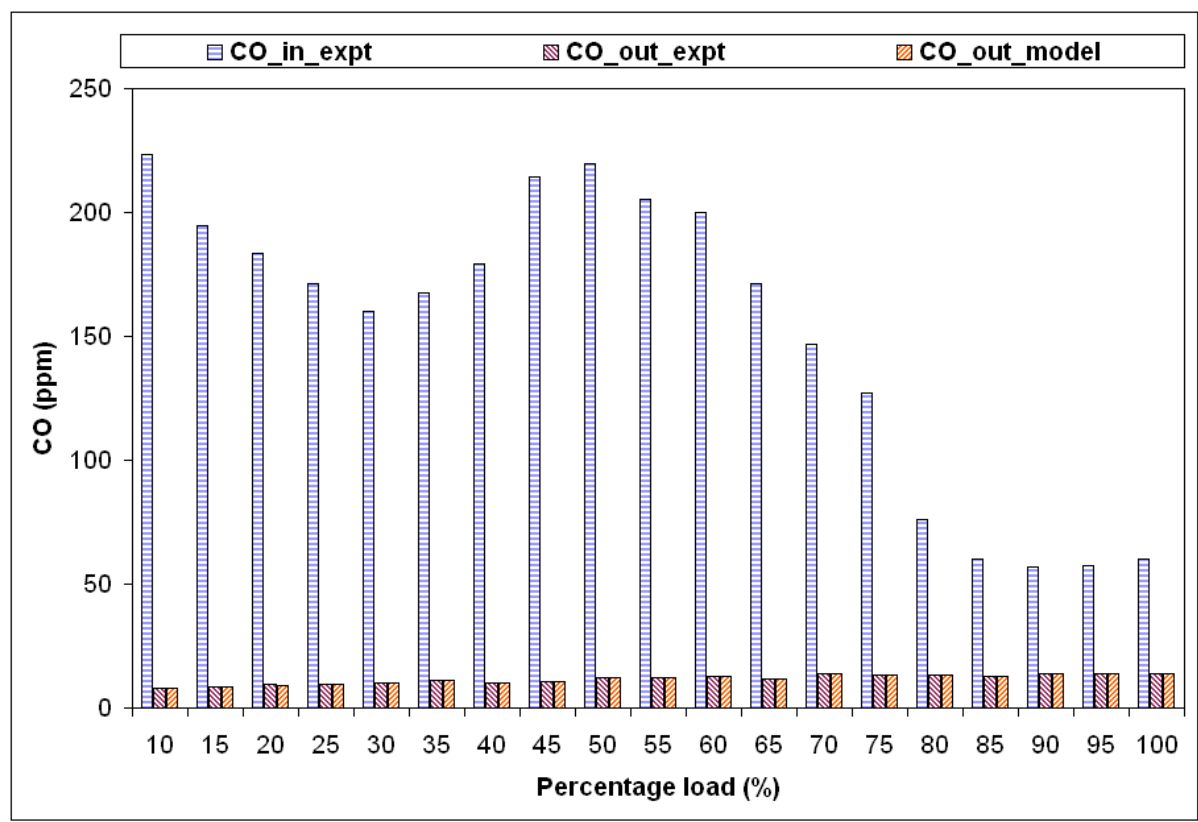

Figure C.5: 1650 rpm DOC-only - Comparison of experimental and model outlet CO concentrations

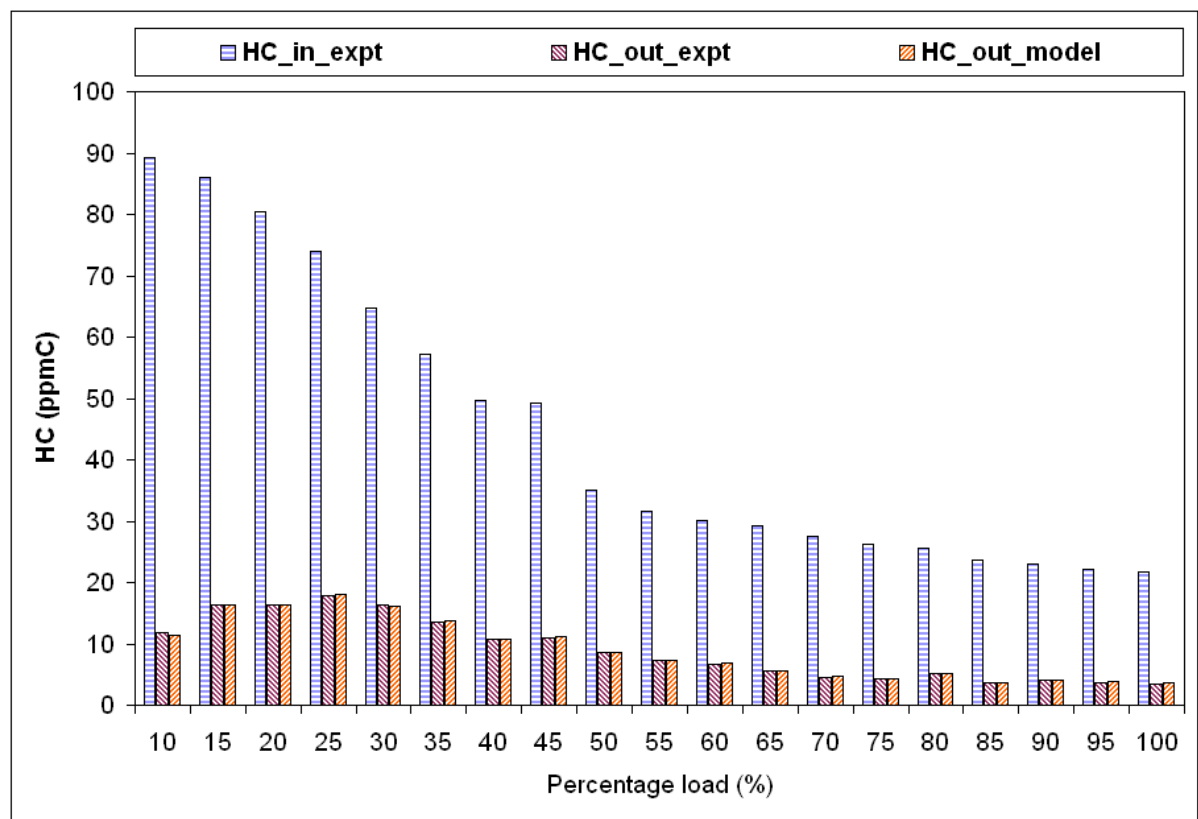

Figure C.6: 1650 rpm DOC-only - Comparison of experimental and model outlet $\mathrm{HC}$ concentrations 


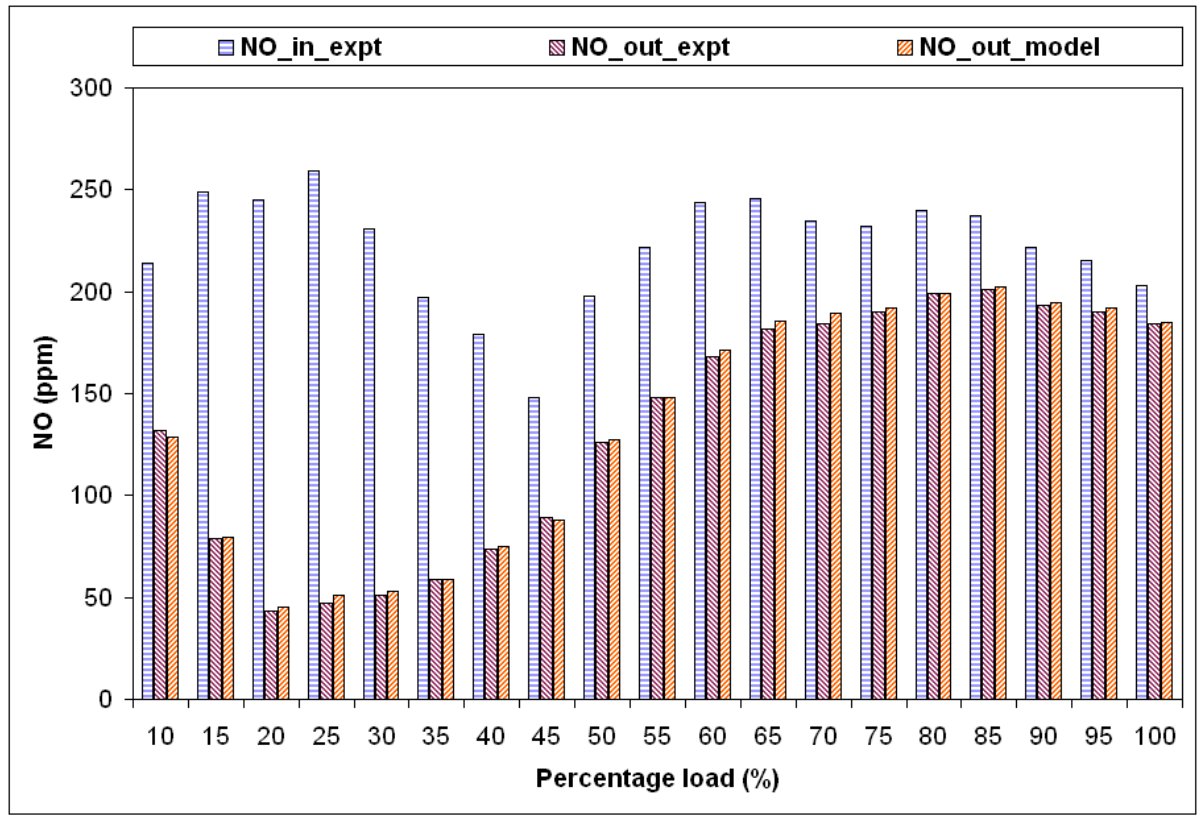

Figure C.7: 1650 rpm DOC-only - Comparison of experimental and model outlet NO concentrations

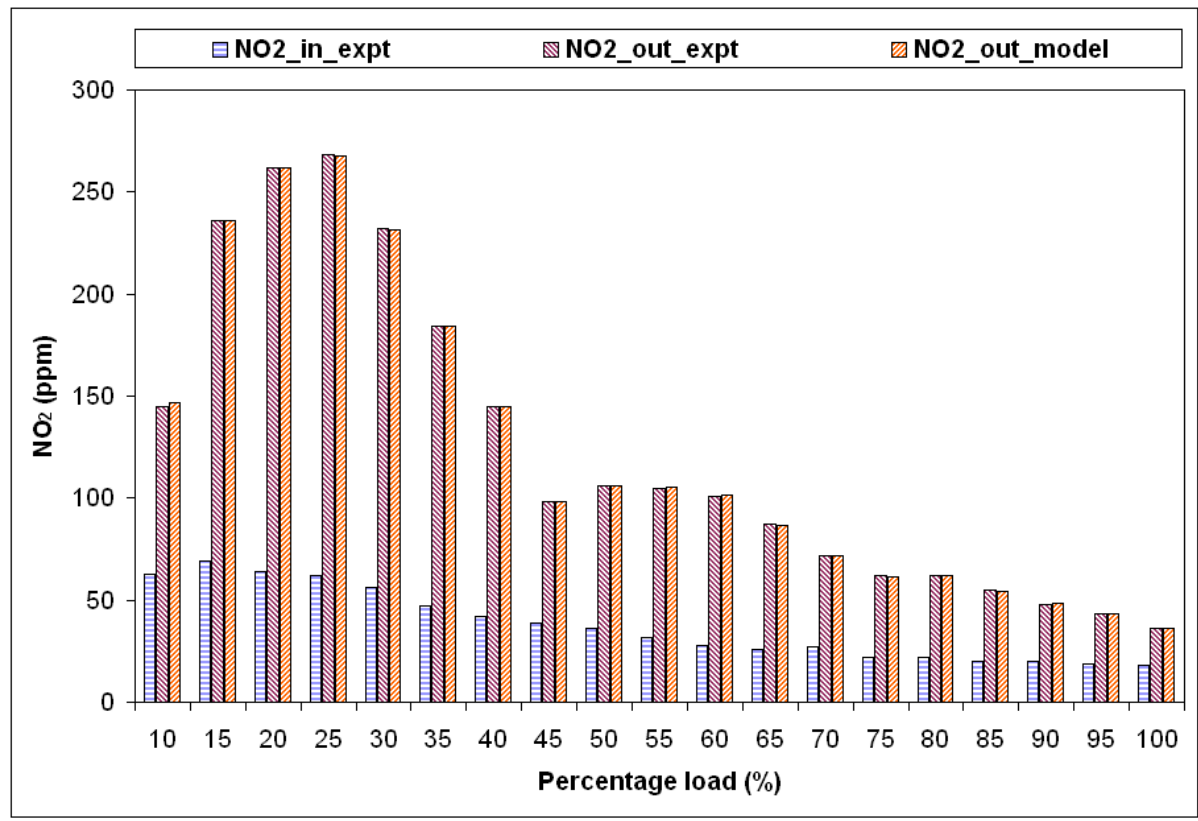

Figure C.8: 1650 rpm DOC-only - Comparison of experimental and model outlet $\mathrm{NO}_{2}$ concentrations 
Table C.5: $1650 \mathrm{rpm}$ - CO, HC and NO pre-exponential factors

\begin{tabular}{|c|c|c|c|}
\hline & \multicolumn{3}{|c|}{ pre-exponential factors } \\
\hline Temperature & $\mathrm{CO}$ & $\mathrm{HC}$ & $\mathrm{NO}$ \\
\hline$\left({ }^{\circ} \mathrm{C}\right)$ & $\left(\mathrm{gmole} / \mathrm{m}^{2}\right.$-s $)$ & $\left(\mathrm{gmole} / \mathrm{m}^{2}-\mathrm{s}\right)$ & $\left(\mathrm{gmole} / \mathrm{m}^{2}-\mathrm{s}\right)$ \\
\hline 181.05 & $1.60 \mathrm{E}+19$ & $1.15 \mathrm{E}+25$ & $5.35 \mathrm{E}+08$ \\
\hline 212.33 & $1.04 \mathrm{E}+19$ & $6.80 \mathrm{E}+24$ & $9.10 \mathrm{E}+08$ \\
\hline 242.80 & $8.00 \mathrm{E}+18$ & $4.57 \mathrm{E}+24$ & $1.40 \mathrm{E}+09$ \\
\hline 271.15 & $8.00 \mathrm{E}+18$ & $3.80 \mathrm{E}+24$ & $1.99 \mathrm{E}+09$ \\
\hline 298.15 & $7.60 \mathrm{E}+18$ & $3.20 \mathrm{E}+24$ & $2.66 \mathrm{E}+09$ \\
\hline 325.58 & $7.13 \mathrm{E}+18$ & $2.92 \mathrm{E}+24$ & $3.30 \mathrm{E}+09$ \\
\hline 349.95 & $7.55 \mathrm{E}+18$ & $3.05 \mathrm{E}+24$ & $3.69 \mathrm{E}+09$ \\
\hline 378.05 & $8.40 \mathrm{E}+18$ & $2.82 \mathrm{E}+24$ & $3.35 \mathrm{E}+09$ \\
\hline 394.75 & $9.75 \mathrm{E}+18$ & $3.15 \mathrm{E}+24$ & $4.94 \mathrm{E}+09$ \\
\hline 404.85 & $9.80 \mathrm{E}+18$ & $3.55 \mathrm{E}+24$ & $6.00 \mathrm{E}+09$ \\
\hline 415.88 & $1.02 \mathrm{E}+19$ & $3.80 \mathrm{E}+24$ & $7.10 \mathrm{E}+09$ \\
\hline 429.03 & $1.10 \mathrm{E}+19$ & $4.30 \mathrm{E}+24$ & $7.30 \mathrm{E}+09$ \\
\hline 444.30 & $1.16 \mathrm{E}+19$ & $4.47 \mathrm{E}+24$ & $6.90 \mathrm{E}+09$ \\
\hline 457.63 & $1.28 \mathrm{E}+19$ & $4.48 \mathrm{E}+24$ & $7.50 \mathrm{E}+09$ \\
\hline 466.00 & $1.33 \mathrm{E}+19$ & $4.20 \mathrm{E}+24$ & $8.70 \mathrm{E}+09$ \\
\hline 474.70 & $1.45 \mathrm{E}+19$ & $4.85 \mathrm{E}+24$ & $8.70 \mathrm{E}+09$ \\
\hline 484.35 & $1.45 \mathrm{E}+19$ & $4.40 \mathrm{E}+24$ & $8.40 \mathrm{E}+09$ \\
\hline 491.40 & $1.50 \mathrm{E}+19$ & $4.40 \mathrm{E}+24$ & $8.30 \mathrm{E}+09$ \\
\hline 498.93 & $1.57 \mathrm{E}+19$ & $4.50 \mathrm{E}+24$ & $7.40 \mathrm{E}+09$ \\
\hline & & & \\
\hline
\end{tabular}




\begin{tabular}{|c|c|c|c|c|c|c|c|c|c|c|c|c|c|c|c|c|c|c|c|c|c|}
\hline \multirow{4}{*}{$\begin{array}{l}0 \\
7\end{array}$} & サ!P & (udd) & $\infty$ & 0 & $\begin{array}{r}-1 \\
\dot{0}\end{array}$ & $\begin{array}{l}\mathfrak{r} \\
\stackrel{0}{1} \\
1\end{array}$ & $\begin{array}{l}20 \\
0 \\
1 \\
1\end{array}$ & $\ddot{0}$ & $\ddot{1}$ & $\ddot{0}$ & $\ddot{0}$ & $\ddot{+}$ & $\ddot{0}$ & $\begin{array}{l}N \\
0 \\
1\end{array}$ & & $\begin{array}{l}+ \\
0 \\
1\end{array}$ & $\ddot{0}$ & $\begin{array}{l}\ddot{1} \\
\dot{Q} \\
1\end{array}$ & $\stackrel{\sim}{0}$ & $\stackrel{\sim}{0}$ & $\stackrel{20}{\circ}$ \\
\hline & $\begin{array}{l}\text { ұәтұno } \\
\text { гәрош }\end{array}$ & (udd) & $\stackrel{\sim}{\vec{F}}$ & 命 & 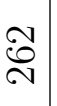 & $\begin{array}{l}\infty \\
0 \\
\sim\end{array}$ & 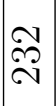 & $\infty$ & $\stackrel{20}{+}$ & $\infty$ & $\stackrel{\bullet}{0}$ & $\stackrel{2}{0}$ & $\stackrel{0}{0}$ & $\infty$ & $\mathfrak{N}$ & ชै & ชै & $\begin{array}{ll}120 \\
120\end{array}$ & $\stackrel{\infty}{+}$ & $\stackrel{P}{*}$ & డి \\
\hline & $\begin{array}{l}\text { 7әтұnо } \\
\cdot 7 \mathrm{dxә}\end{array}$ & (udd) & $\stackrel{2}{\underset{7}{7}}$ & 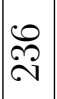 & $\begin{array}{l}\mathcal{O} \\
\stackrel{\nu}{ }\end{array}$ & $\begin{array}{l}\infty \\
\stackrel{\infty}{\sim} \\
\mathcal{N}\end{array}$ & $\underset{\tilde{\approx}}{\tilde{\sim}}$ & $\mid \begin{array}{l}+ \\
\infty \\
-1\end{array}$ & $\stackrel{10}{\rightarrow}$ & $\infty$ & $\stackrel{0}{\varrho}$ & $\stackrel{2}{\circ}$ & $\vec{\sigma}$ & $\infty$ & $\mathbb{N}$ & ชิ & ชै & 20 & $\stackrel{\infty}{+}$ & $\stackrel{\circledast}{+}$ & 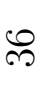 \\
\hline & $\begin{array}{l}\text { ૧ӘЧU! } \\
\cdot 7 \mathrm{dx} \partial\end{array}$ & (udd) & 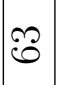 & 8 & ठै। & ชै & 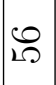 & Fr & F & ले & 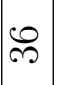 & กิ & $\stackrel{\infty}{\sim}$ & $\stackrel{\circ}{\sim}$ & $\hat{N}$ & $\stackrel{\curvearrowright}{\curvearrowright}$ & ลे & $\stackrel{\curvearrowright}{\sim}$ & $\stackrel{\overbrace{}}{\curvearrowright}$ & $\stackrel{\Omega}{-1}$ & $\stackrel{\infty}{-1}$ \\
\hline \multirow{4}{*}{$\begin{array}{l}0 \\
Z\end{array}$} & サ!Р & (udd) & po & $\infty$ & $\begin{array}{l}0 \\
\stackrel{v}{1}\end{array}$ & $\underset{+}{+}$ & 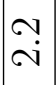 & $\stackrel{0}{0}$ & $\infty$ & $\mid \begin{array}{l}\infty \\
\dot{0}\end{array}$ & $\stackrel{-}{-}$ & $\stackrel{\Upsilon}{0}$ & is & $\hat{r}$ & 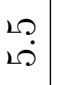 & $\underset{-}{-}$ & $\ddot{0}$ & $\stackrel{\sim}{-}$ & $\stackrel{\sim}{\sim}$ & $\infty$ & $\stackrel{0}{-}$ \\
\hline & $\begin{array}{l}\text { ұәтұnо } \\
\text { гррош }\end{array}$ & (udd) & $\begin{array}{l}\infty \\
\stackrel{\sim}{-} \\
-1\end{array}$ & $\infty$ & $\stackrel{20}{\rightarrow}$ & 둥 & 20 & 28 & 10 & $\infty$ & $\stackrel{\mathfrak{N}}{\stackrel{\sim}{二}}$ & $\stackrel{\infty}{+}$ & 닫 & $\begin{array}{c}0 \\
\infty \\
-1\end{array}$ & $\stackrel{\Xi}{\square}$ & $\stackrel{\sigma}{\sigma}$ & $\stackrel{\mathscr{g}}{\mathscr{2}}$ & 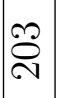 & $\stackrel{20}{2}$ & 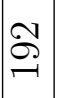 & 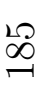 \\
\hline & $\begin{array}{l}\text { 7әтұnо } \\
\cdot 7 \mathrm{dxə}\end{array}$ & (udd) & ๙ิ & $R$ & $\stackrel{m}{\sim}$ & $\stackrel{N}{\forall}$ & $\sqrt{20}$ & $\Omega$ & 兄 & $\infty$ & 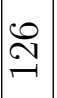 & $\stackrel{\infty}{\underset{\sim}{\sim}}$ & $\begin{array}{l}\infty \\
0 \\
-1\end{array}$ & $\begin{array}{c}1 \\
\infty \\
-1\end{array}$ & $\begin{array}{l}+ \\
-\infty \\
-1\end{array}$ & $\stackrel{8}{\circledR}$ & $\stackrel{\mathscr{\rho}}{-1}$ & ఠ) & $\mathscr{2}$ & $\underset{8}{\mathscr{\Omega}}$ & $\underset{\infty}{+\infty}$ \\
\hline & 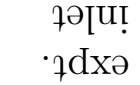 & (udd) & $\underset{H}{\vec{N}}$ & 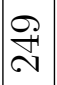 & 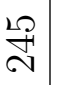 & $\begin{array}{l}\stackrel{\Omega}{2} \\
\stackrel{2}{\sim}\end{array}$ & $\overparen{\sim}$ & $\stackrel{N}{\Omega}$ & I & $\stackrel{\infty}{\rightleftharpoons}$ & \begin{tabular}{l}
$\infty$ \\
0 \\
\hdashline \\
\end{tabular} & ָิ & $\underset{\sim}{\stackrel{H}{\sim}}$ & $\stackrel{0}{\stackrel{1}{N}}$ & $\begin{array}{l}\stackrel{L}{\curvearrowright} \\
\stackrel{2}{2}\end{array}$ & ๙ิ & $\stackrel{\circ}{\stackrel{4}{\sim}}$ & 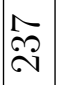 & $\stackrel{\sim}{N}$ & $\frac{20}{\stackrel{N}{N}}$ & $\stackrel{\infty}{\stackrel{\sim}{N}}$ \\
\hline \multirow{4}{*}{$\underline{Z}$} & •サ!P & (Dudd) & $\begin{array}{l}+ \\
\dot{0} \\
\dot{1}\end{array}$ & $\stackrel{0}{0}$ & $\begin{array}{l}0 \\
0\end{array}$ & $\stackrel{-1}{0}$ & $\stackrel{0}{0}$ & $\ddot{0}$ & $\stackrel{7}{\circ}$ & $\stackrel{?}{o}$ & $\stackrel{0}{0}$ & $\ddot{\circ}$ & $\stackrel{?}{0}$ & $\stackrel{0}{0}$ & $\stackrel{\sim}{O}$ & $\stackrel{0}{0}$ & $\stackrel{0}{0}$ & $\ddot{0}$ & $\stackrel{0}{0}$ & $\stackrel{\Upsilon}{o}$ & $\stackrel{?}{0}$ \\
\hline & $\begin{array}{l}\text { ұə[łno } \\
\text { әәрош }\end{array}$ & (Dudd) & 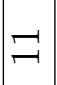 & $\stackrel{0}{-1}$ & $\stackrel{0}{-1}$ & $\infty$ & $\stackrel{0}{=}$ & 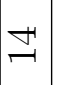 & $\exists$ & $\exists$ & 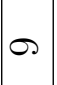 & $\sim$ & $\Lambda$ & 0 & 10 & 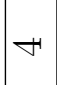 & 10 & $\forall$ & 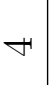 & $\forall$ & $\nabla$ \\
\hline & $\begin{array}{l}\text { ғәтио } \\
\cdot 7 \mathrm{dxә}\end{array}$ & (Dudd) & $\stackrel{\sim}{\sim}$ & 0 & 0 & $\infty$ & 0 & 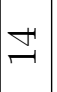 & 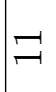 & 二 & $\sigma$ & $\Lambda$ & $N$ & 0 & $\nabla$ & $\nabla$ & 20 & $\nabla$ & 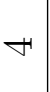 & 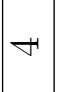 & $\infty$ \\
\hline & $\begin{array}{l}\text { ұə[U! } \\
\cdot 7 \mathrm{dx}\end{array}$ & (Dudd) & $\infty$ & $œ$ & $\infty$ & 只 & 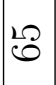 & 10 & 온 & 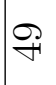 & 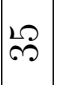 & กิ & ৫) & ๙ & $\stackrel{\infty}{\sim}$ & $\stackrel{\bullet}{\sim}$ & $\stackrel{\leftrightarrow}{\sim}$ & $\vec{\sim}$ & $\stackrel{\sim}{\sim}$ & $\stackrel{\sim}{\sim}$ & $\stackrel{\sim}{\sim}$ \\
\hline \multirow{4}{*}{ ৩ } & • Ш!Р & d) & $\begin{array}{l}0 \\
0 \\
0 \\
1\end{array}$ & $\stackrel{0}{0}$ & $\begin{array}{l}-1 \\
0 \\
0\end{array}$ & $\stackrel{\sim}{O}$ & $\stackrel{0}{0}$ & $\stackrel{0}{0}$ & $\ddot{0}$ & 节 & $\begin{array}{l}-1 \\
0 \\
1\end{array}$ & $\begin{array}{l}-1 \\
\vdots \\
0\end{array}$ & $\begin{array}{l}\mathfrak{N} \\
\vdots \\
1\end{array}$ & $\stackrel{0}{0}$ & $\ddot{0}$ & $\begin{array}{l}-1 \\
0 \\
1\end{array}$ & $\ddot{0}$ & $\begin{array}{c}-1 \\
0 \\
1\end{array}$ & $\stackrel{0}{0}$ & $\begin{array}{c}-1 \\
0 \\
1\end{array}$ & †. \\
\hline & $\begin{array}{l}\text { ұәтұnо } \\
\text { гррош }\end{array}$ & dd) & 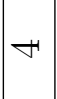 & $\underset{-1}{-1}$ & $\stackrel{\circ}{\rightarrow}$ & 二 & $\stackrel{N}{\sim}$ & $\stackrel{\sim}{\sim}$ & $\stackrel{m}{-1}$ & $\infty$ & 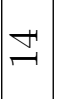 & $\underset{\Xi}{\Xi}$ & $\stackrel{10}{-1}$ & $\stackrel{20}{-1}$ & $\underset{0}{0}$ & $\stackrel{0}{-1}$ & $\stackrel{0}{-1}$ & $\stackrel{0}{-1}$ & 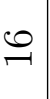 & 0 & 0 \\
\hline & $\begin{array}{l}\text { 7әtұno } \\
\cdot 7 \mathrm{dx}\end{array}$ & (udd) & 20 & $\stackrel{-}{-1}$ & $\stackrel{ }{-1}$ & 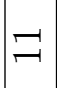 & $\stackrel{\sim}{\sim}$ & $m$ & $m$ & $\infty$ & $\vec{J}$ & $\Xi$ & 10 & 100 & $\stackrel{L 2}{\longrightarrow}$ & $\stackrel{0}{-}$ & $\underset{1}{-1}$ & $\underset{0}{-1}$ & $\underset{-1}{0}$ & $\stackrel{\sim}{\sim}$ & $\stackrel{0}{0}$ \\
\hline & $\begin{array}{l}\text { ұə[u! } \\
\cdot 7 \mathrm{dx}\end{array}$ & (udd) & 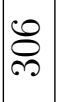 & $\stackrel{N}{N}$ & $\begin{array}{l}\infty \\
\stackrel{\infty}{\sim} \\
\stackrel{2}{\sim}\end{array}$ & $\stackrel{\mathscr{2}}{\sim}$ & $\stackrel{\check{N}}{\stackrel{\sim}{\sim}}$ & $\underset{\sim}{\stackrel{\sim}{*}}$ & $\vec{\sigma}$ & $\stackrel{\stackrel{\sim}{\mathcal{N}}}{\stackrel{\mathrm{N}}{2}}$ & $\begin{array}{l}\stackrel{1}{10} \\
-1\end{array}$ & $\stackrel{\infty}{=}$ & $\vec{O}$ & ஓ & 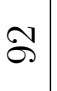 & $\hat{\sigma}$ & ๙ิ & $\approx$ & $\vec{\sigma}$ & 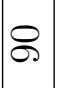 & ஓ \\
\hline 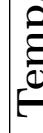 & & 0 & $\underset{\infty}{-1}$ & $\stackrel{N}{\stackrel{N}{N}}$ & 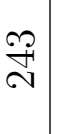 & $\stackrel{\sim}{\sim}$ & $\begin{array}{l}\infty \\
\stackrel{N}{\infty}\end{array}$ & \begin{tabular}{l}
0 \\
\multirow{N}{*}{} \\
\multirow{\infty}{*}{}
\end{tabular} \mid & $\begin{array}{l}0 \\
\stackrel{1}{2} \\
\text { ก }\end{array}$ & $\underset{\infty}{\infty}$ & $\begin{array}{l}20 \\
2 \\
2\end{array}$ & $\begin{array}{l}\stackrel{2}{O} \\
\stackrel{7}{7}\end{array}$ & $\begin{array}{l}0 \\
\Rightarrow \\
\forall\end{array}$ & $\underset{\sim}{\stackrel{乛}{*}}$ & $\underset{f}{\stackrel{f}{*}}$ & $\begin{array}{l}\infty \\
20 \\
\stackrel{2}{\sim}\end{array}$ & \begin{tabular}{l}
0 \\
0 \\
\hdashline
\end{tabular} & $\begin{array}{l}10 \\
\stackrel{F}{F}\end{array}$ & $\underset{+}{+1}$ & $\overrightarrow{\sigma_{F}}$ & $\stackrel{\curvearrowright}{\stackrel{\leftrightarrow}{+}}$ \\
\hline ס & & & $\stackrel{\ominus}{=}$ & $\stackrel{20}{-1}$ & $\curvearrowright$ & $\stackrel{\llcorner O}{\sim}$ & 尺 & ח & 와 & $\stackrel{20}{7}$ & 8 & | & 8 & 10 & $R$ & $\frac{12}{12}$ & $\infty$ & $\begin{array}{ll}12 \\
\infty\end{array}$ & ๑ & $\mathscr{2}$ & $\stackrel{8}{8}$ \\
\hline
\end{tabular}


The pre-exponential factors for each of the three oxidation reactions $(\mathrm{CO}, \mathrm{HC}$ and NO respectively) at $2200 \mathrm{rpm}$ and $1650 \mathrm{rpm}$ were then combined together in a semi-log plot, aimed at obtaining a single set of pre-exponential factors and activation energies to predict downstream concentrations of $\mathrm{CO}, \mathrm{HC} \mathrm{NO}$ and $\mathrm{NO}_{2}$. Figure C.9 shows the semi-log plot obtained thus, where the Y co-ordinate values represent the natural logarithms of the reaction rate constants obtained from calibrating the concentrations of $\mathrm{CO}, \mathrm{HC}, \mathrm{NO}$ and $\mathrm{NO}_{2}$ to experimentally observed values of the same at 2200 and $1650 \mathrm{rpm}$, and the X co-ordinate values are the inverse values of absolute DOC inlet temperatures. Since reaction rate constant is the product of the pre-exponential factor and the exponential term (containing the activation energy), a semi-log plot of reaction rate constants for any device has to follow a linear relation ship with the inverse of the absolute bulk temperature. Mathematically,

$$
\begin{aligned}
k_{i} & =A_{i} \cdot e^{\left(\frac{-E a_{i}}{R T}\right)} \\
\ln \left(k_{i}\right) & =\ln \left(A_{i}\right)+\left(\frac{-E a_{i}}{R T}\right) \\
& \text { or } \\
\ln \left(k_{i}\right) & =\ln \left(A_{i}\right)+\left(\frac{-E a_{i}}{R}\right) \cdot\left(\frac{1}{T}\right)
\end{aligned}
$$

where $k_{i}$ is the reaction rate of reaction ' $i$ ' $(i=1,2,3$ denotes $\mathrm{CO}, \mathrm{HC}$ and NO oxidation reactions respectively), $A_{i}$ are the pre-exponential factors, $E a_{i}$ are the activation energies, $R$ is the universal gas constant and $T$ is the absolute bulk temperature at which the reaction takes place.

Equation C.2 is the equation of a straight line in semi-log co-ordinates:

$$
y=m x+c
$$


where $m$ is the slope of the line and $\mathrm{c}$ is the $\mathrm{Y}$ intercept of the line. Comparing coefficients of equations C.2 and C.3,

$$
\begin{aligned}
& m=-\frac{E a_{i}}{R} \\
& \text { and } \\
& c=\ln \left(A_{i}\right)
\end{aligned}
$$

where

$$
y=\ln \left(k_{i}\right)
$$

and

$$
x=\frac{1}{T}
$$

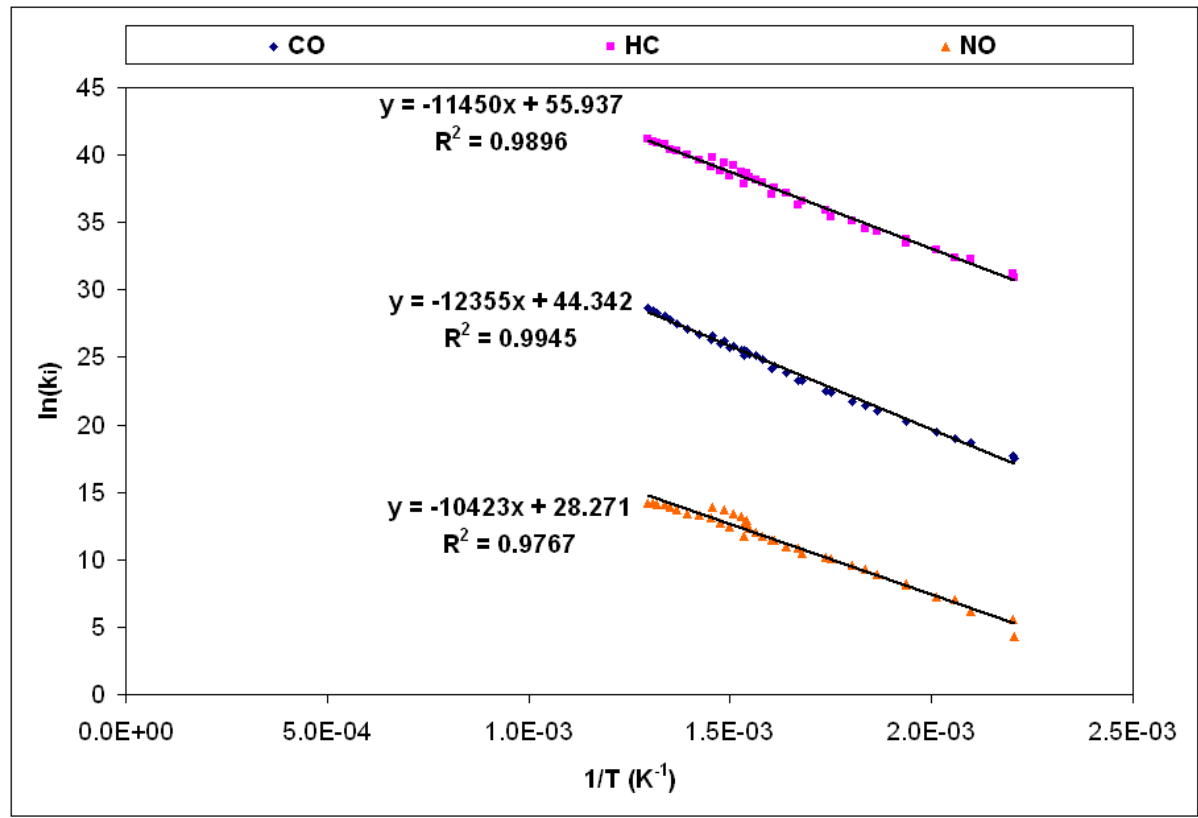

Figure C.9: Semi-log plot of kinetics obtained from 2200 and $1650 \mathrm{rpm}$ data

As shown in Figure C.9, trendlines were constructed for the semi-log plots of $\mathrm{CO}, \mathrm{HC}$ and $\mathrm{NO}$ reaction rate constants to obtain the single set of pre-exponential factors and activation energies, according to equations C.5 and C.4. Table C.7 shows 
the kinetic parameters obtained thus.

These kinetic parameters were input into the DOC model, and another iteration of calibration was conducted to get better values of the kinetic parameters. This was done by keeping the activation energies constant at the new values obtained (as shown in Table C.7), and varying the pre-exponential factors to get exact match between the model-predicted and experimental values of DN-DOC concentrations of $\mathrm{CO}, \mathrm{HC}, \mathrm{NO}$ and $\mathrm{NO}_{2}$. Semi-log plots of the new set of reaction rate constants obtained thus were plotted, and trend lines constructed for these semi-log plots. The semi-log plots obtained thus are shown in Figure C.10, and Table C.8 shows the kinetic parameters obtained thus.

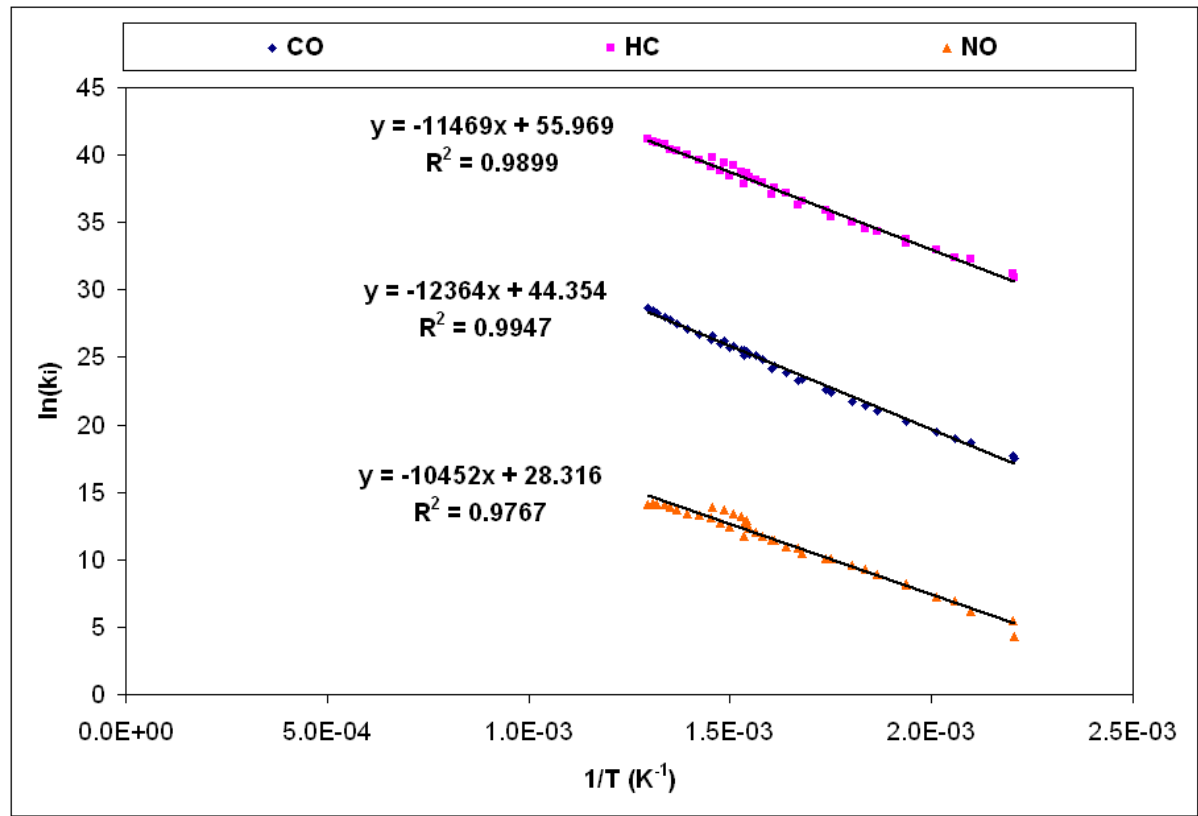

Figure C.10: Semi-log plot of kinetics obtained from 2200 and $1650 \mathrm{rpm}$ data after one iteration

Table C.7: Second set of kinetic parameters

\begin{tabular}{|c|c|c|}
\hline Reaction & Pre-exp. & Act. E \\
\hline & $\left(\right.$ gmole $\left./ \mathrm{m}^{2} . \mathrm{s}\right)$ & $(\mathrm{J} / \mathrm{gmole})$ \\
\hline $\mathrm{CO}$ & $1.81 \times 10^{19}$ & 102724 \\
\hline $\mathrm{HC}$ & $1.96 \times 10^{24}$ & 95200 \\
\hline $\mathrm{NO}$ & $1.90 \times 10^{12}$ & 86661 \\
\hline
\end{tabular}


Table C.8: Third set of kinetic parameters

\begin{tabular}{|c|c|c|}
\hline Reaction & Pre-exp. & Act. E \\
\hline & $\left(\right.$ gmole $\left./ \mathrm{m}^{2} . \mathrm{s}\right)$ & $(\mathrm{J} / \mathrm{gmole})$ \\
\hline $\mathrm{CO}$ & $1.82 \times 10^{19}$ & 102821 \\
\hline $\mathrm{HC}$ & $1.95 \times 10^{24}$ & 95260 \\
\hline $\mathrm{NO}$ & $2.08 \times 10^{12}$ & 87312 \\
\hline
\end{tabular}

These values of kinetic parameters were then used back in the model to predict $\mathrm{DN}-\mathrm{CPF}$ concentrations of $\mathrm{CO}, \mathrm{HC}, \mathrm{NO}$ and $\mathrm{NO}_{2}$, the results from which are presented in Section 5.2.2. 


\section{Appendix D}

\section{Plots from CPF Model Calibration with CPF-only and CCRT® Experimental Data at $2200 \mathrm{rpm}$}

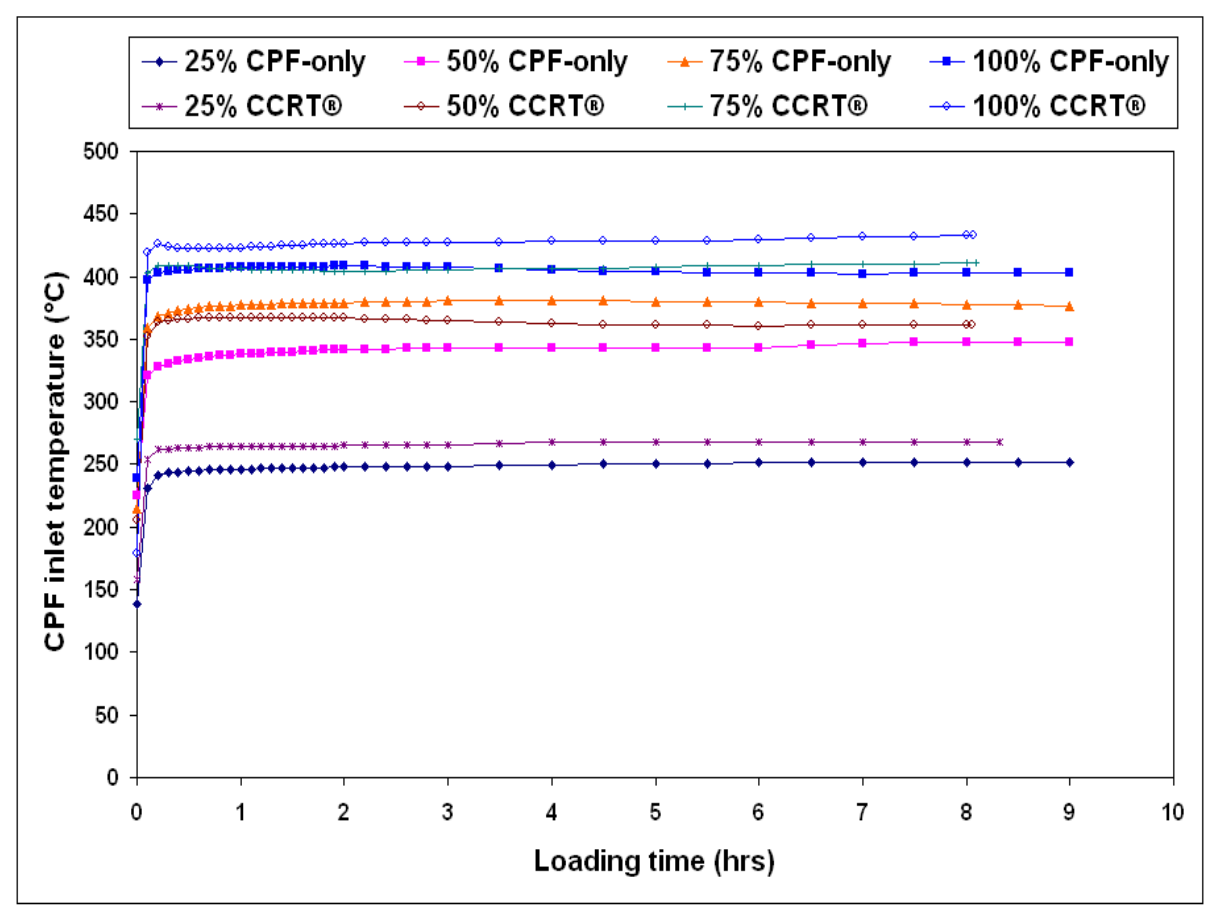

Figure D.1: CPF inlet temperature versus loading time given as input to the CPF model 


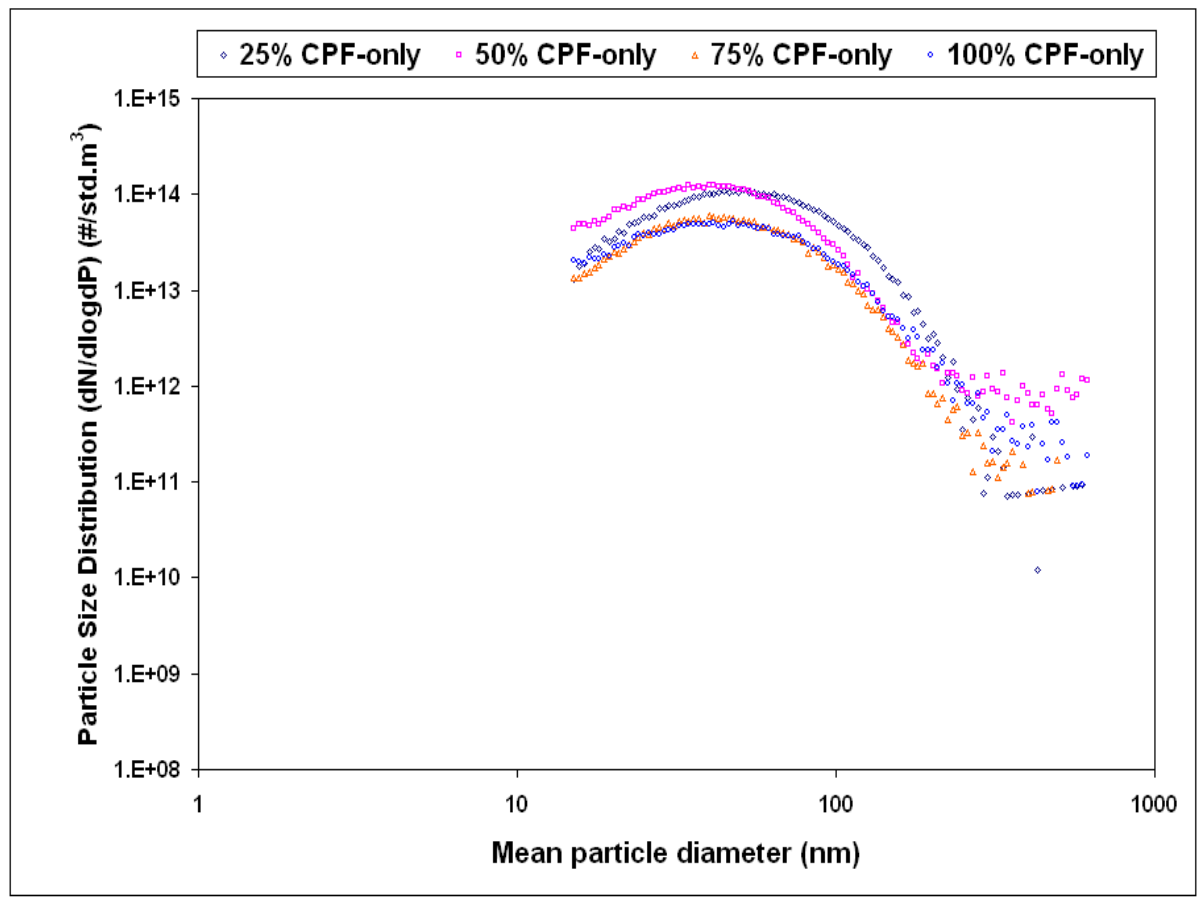

Figure D.2: 2200 rpm CPF-only - UP-CPF PSD data used for CPF model calibration

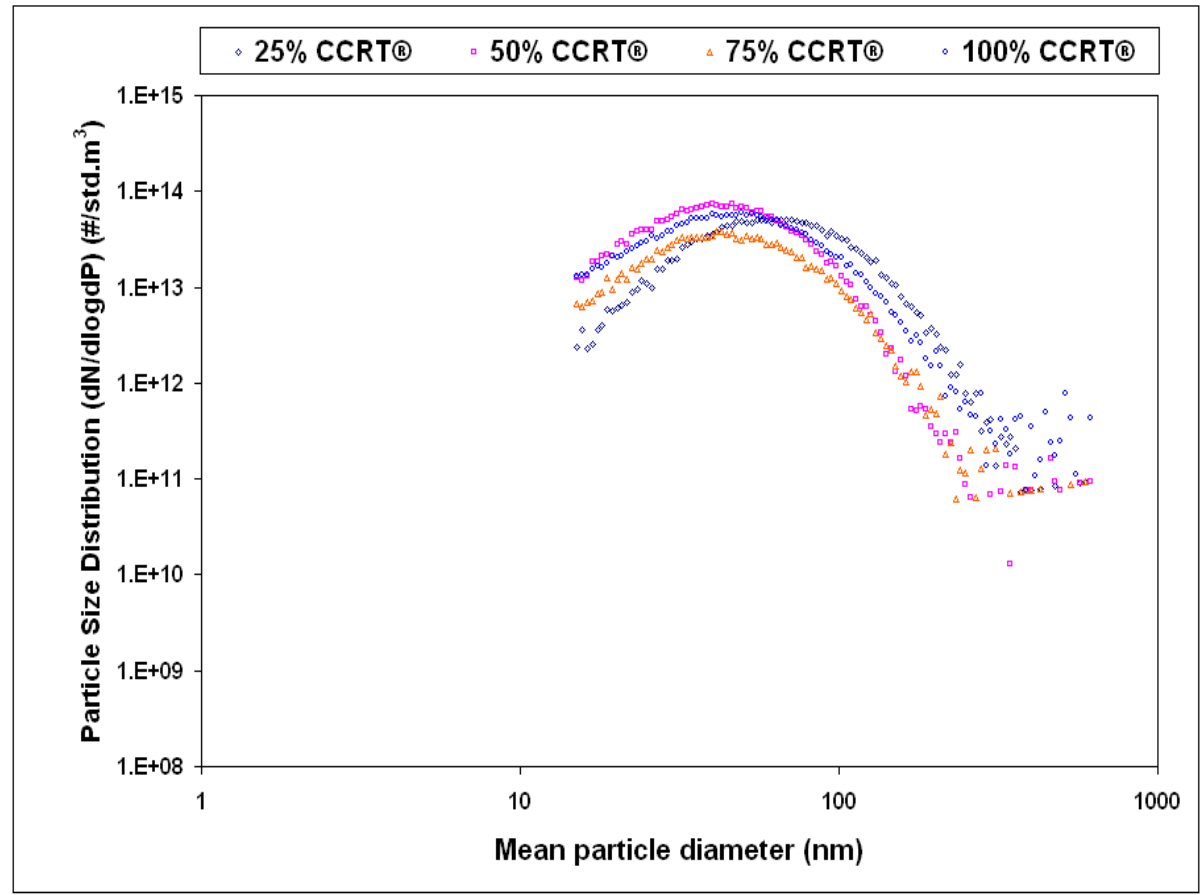

Figure D.3: 2200 rpm CCRTß - UP-CPF PSD data used for CPF model calibration 
Figures D.4 and D.5 show the plots from CPF-only and CCRTß pressure drop data calibration at $2200 \mathrm{rpm}$. Figures D.6 and D.7 show the plots from CPFonly and CCRTß PM mass data calibration at 2200 rpm. Figures D.8 and D.9 show the PSD plots from calibration of CPF-only and CCRT R data calibration at 2200 rpm. Figures D.10 and D.11 show the CPF (cumulative) wall mass and outlet mass versus time. Figures D.12 and D.13 show individual slab PM mass versus time. 

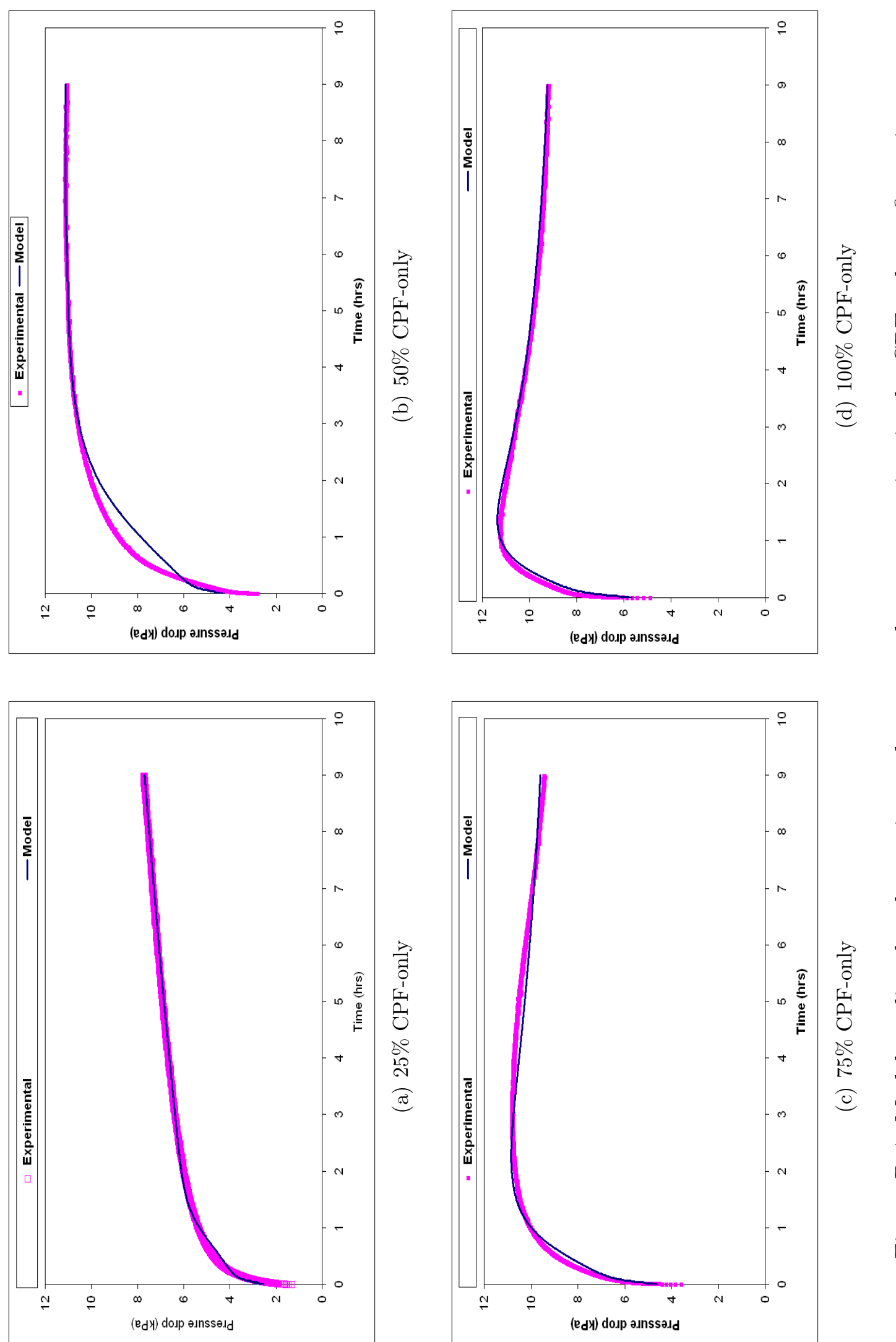

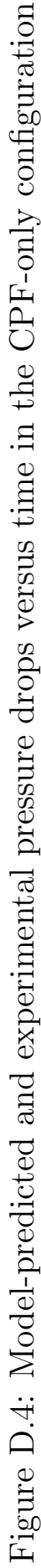



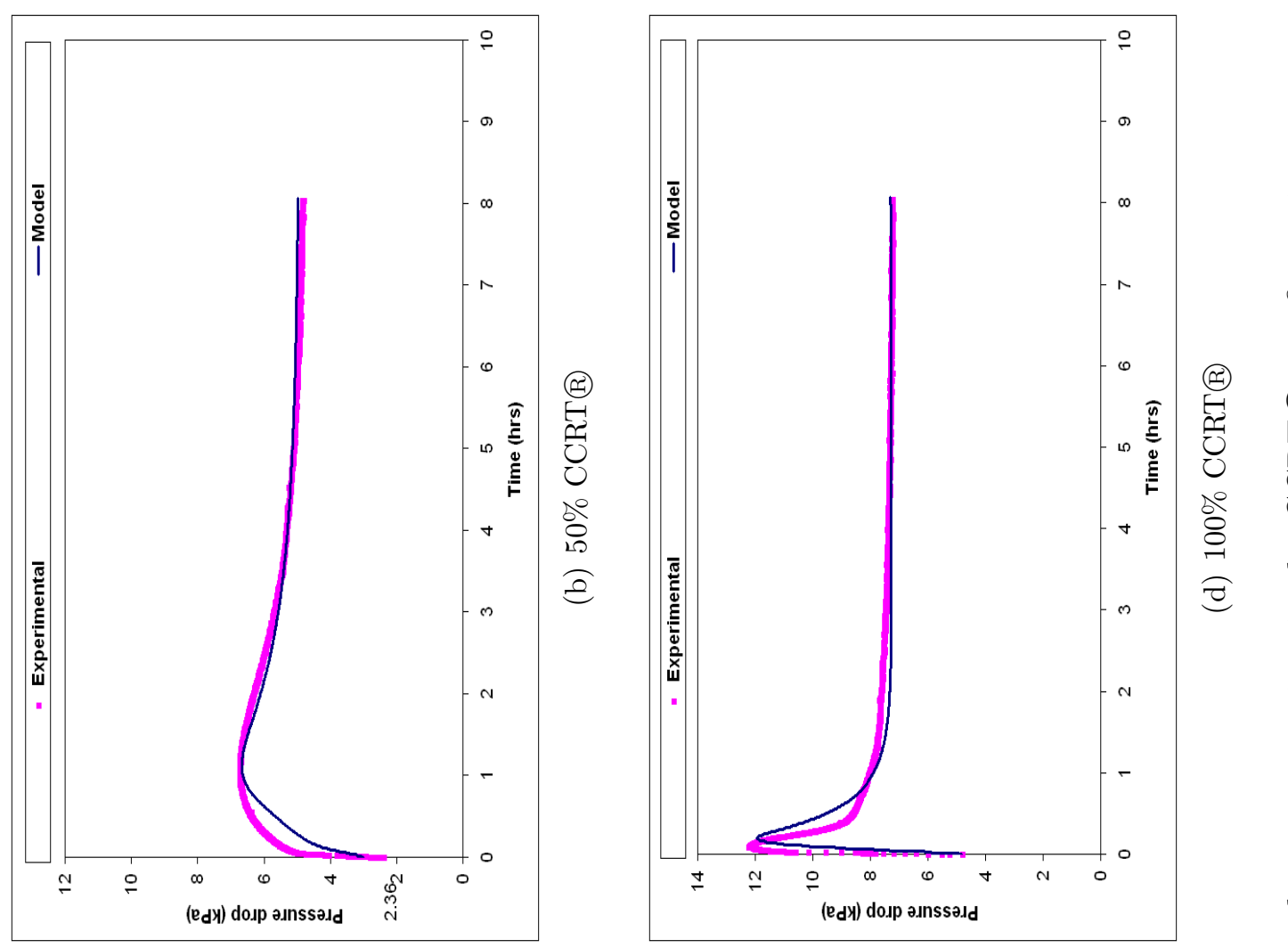

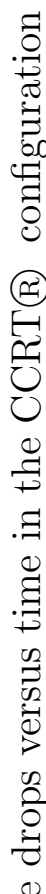
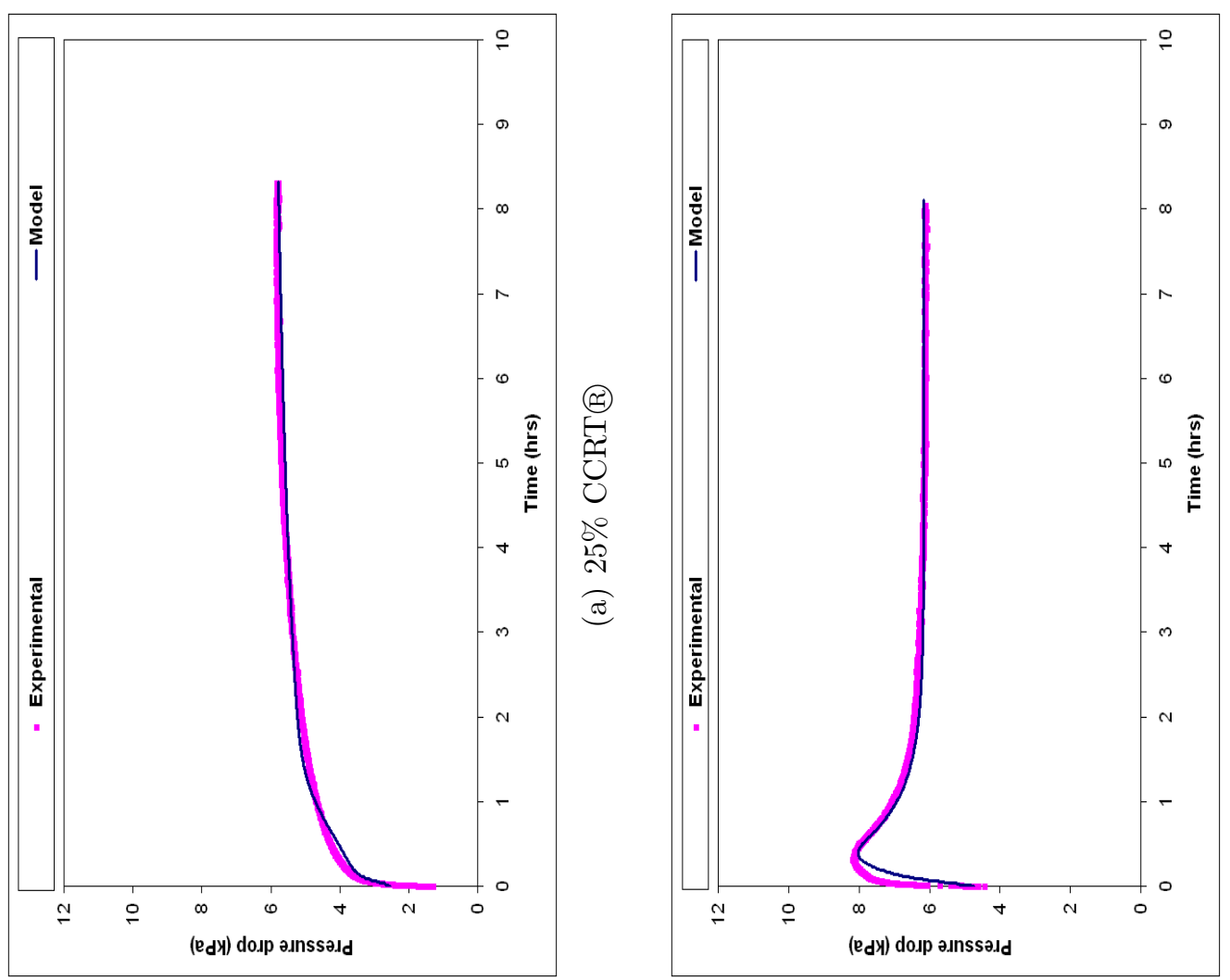

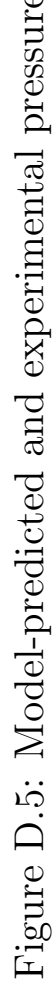



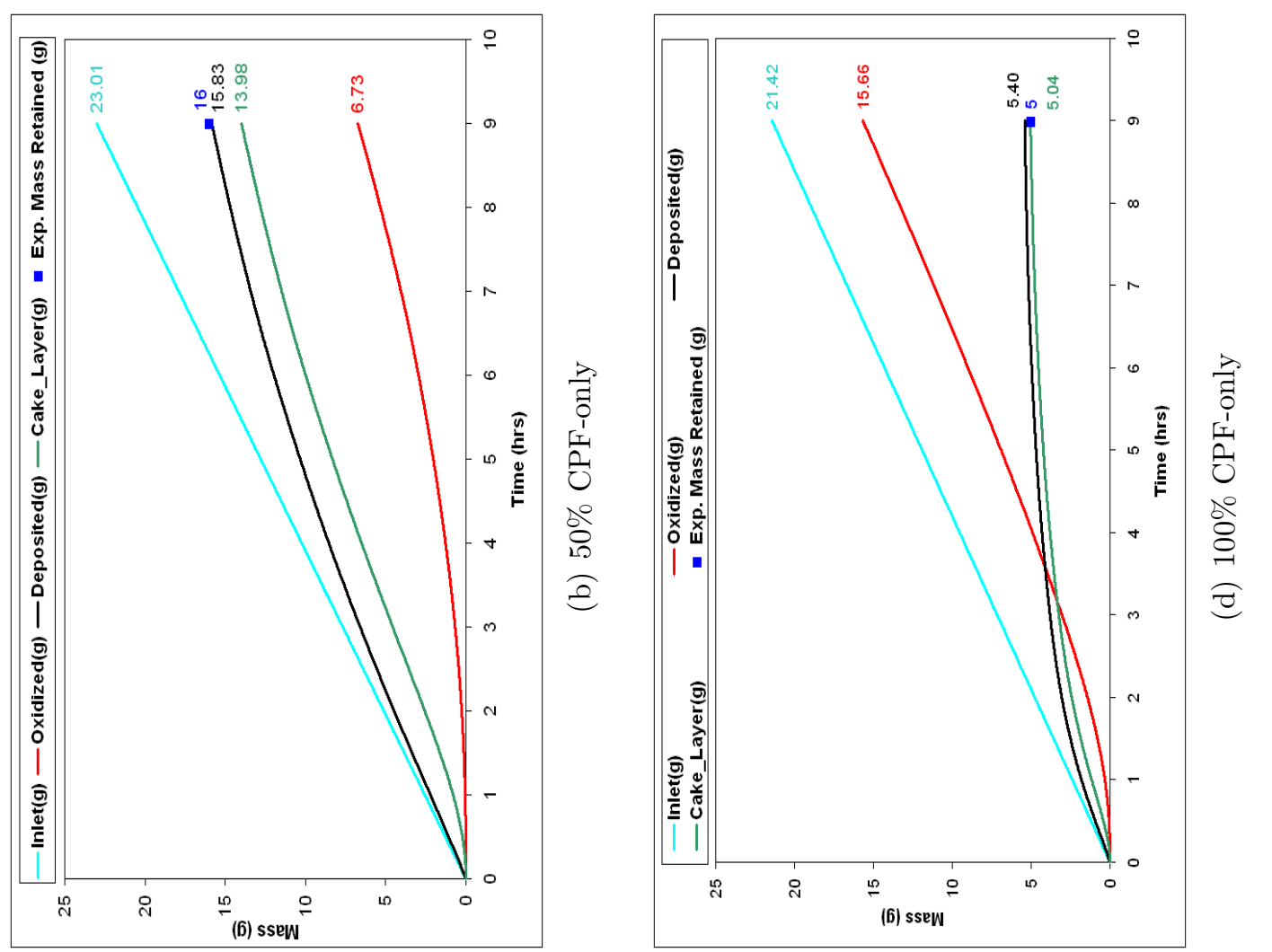

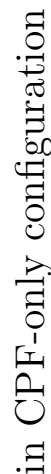
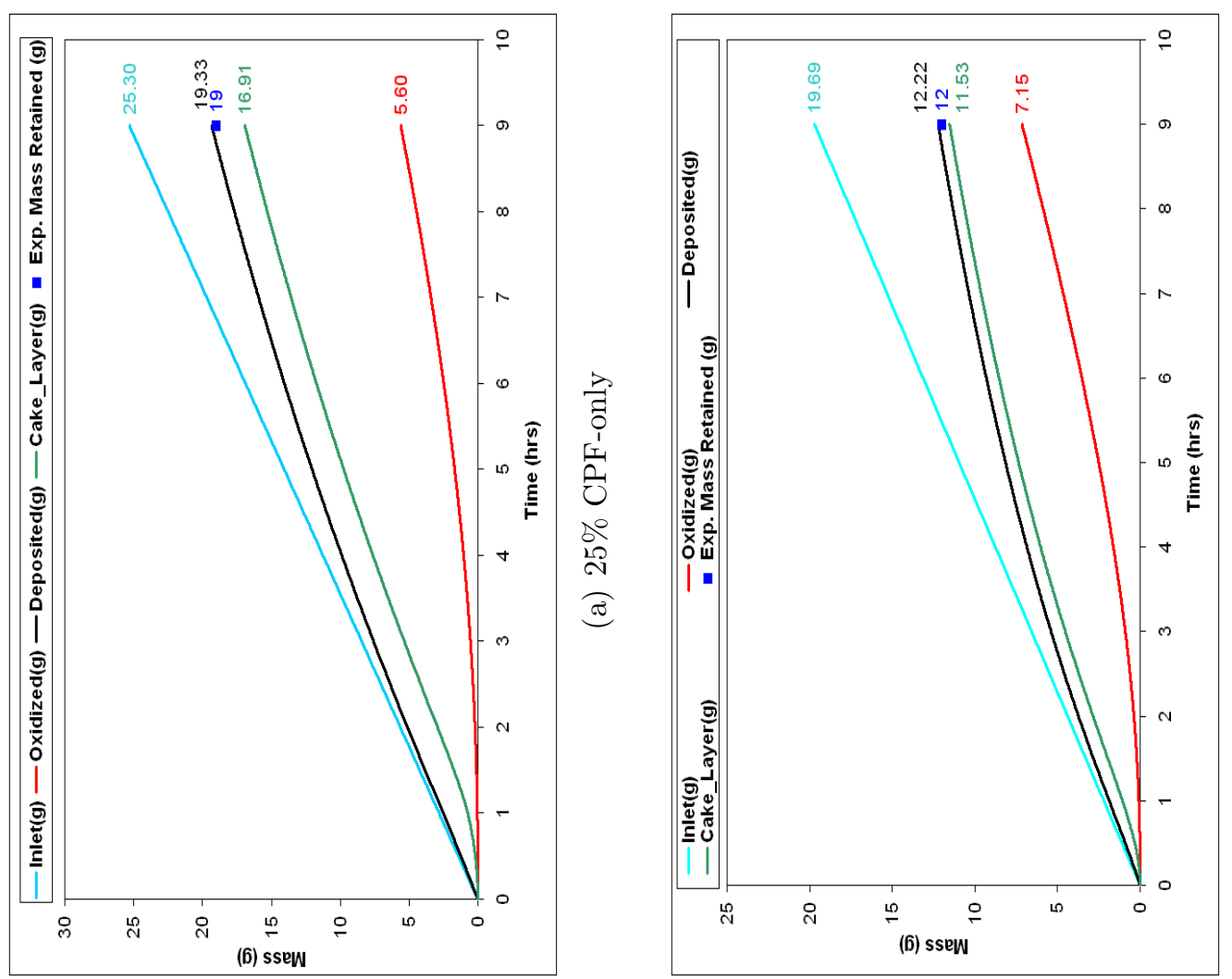

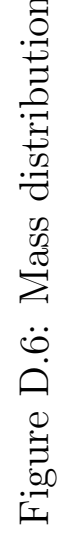



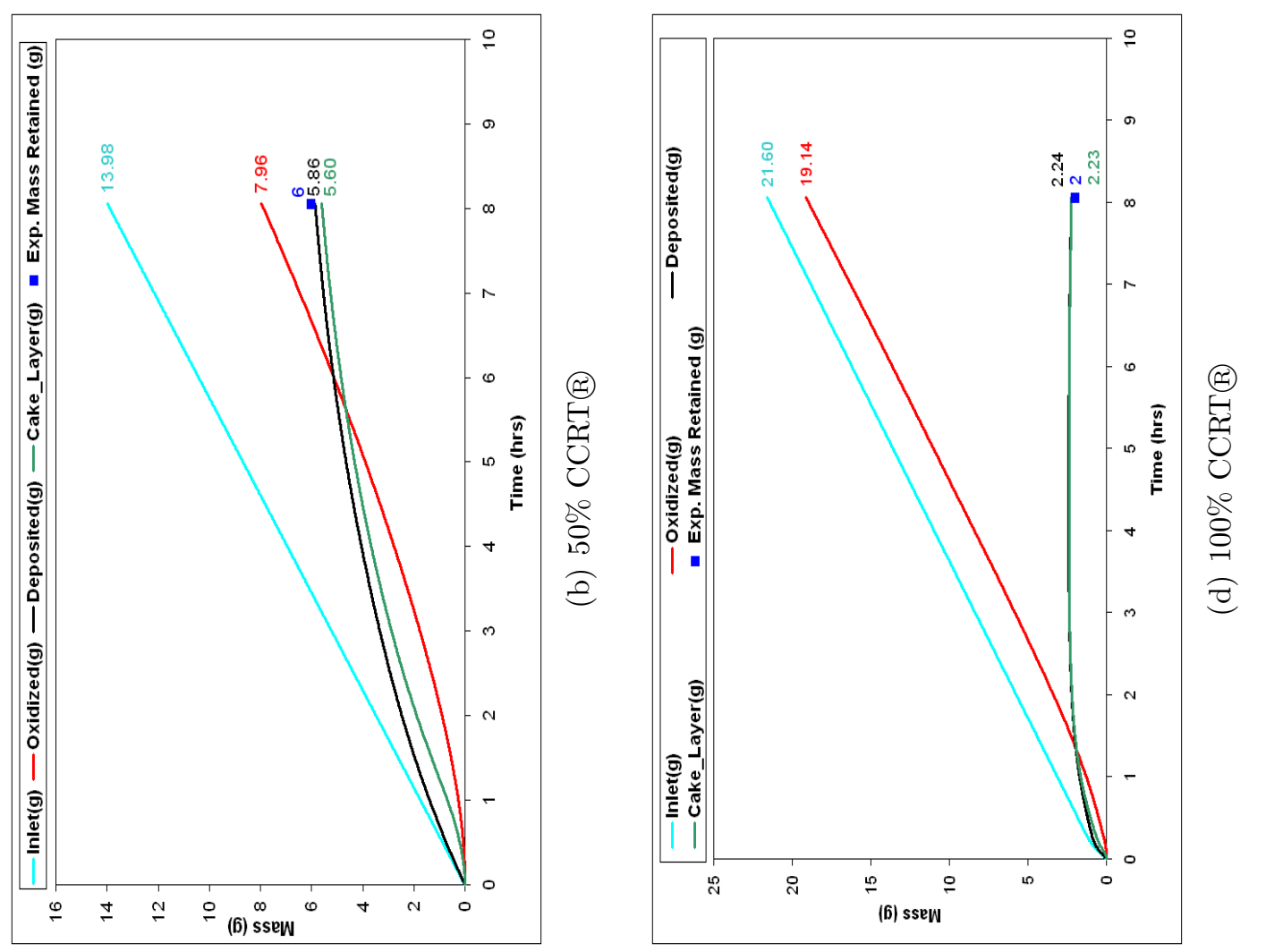

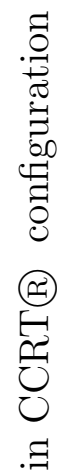
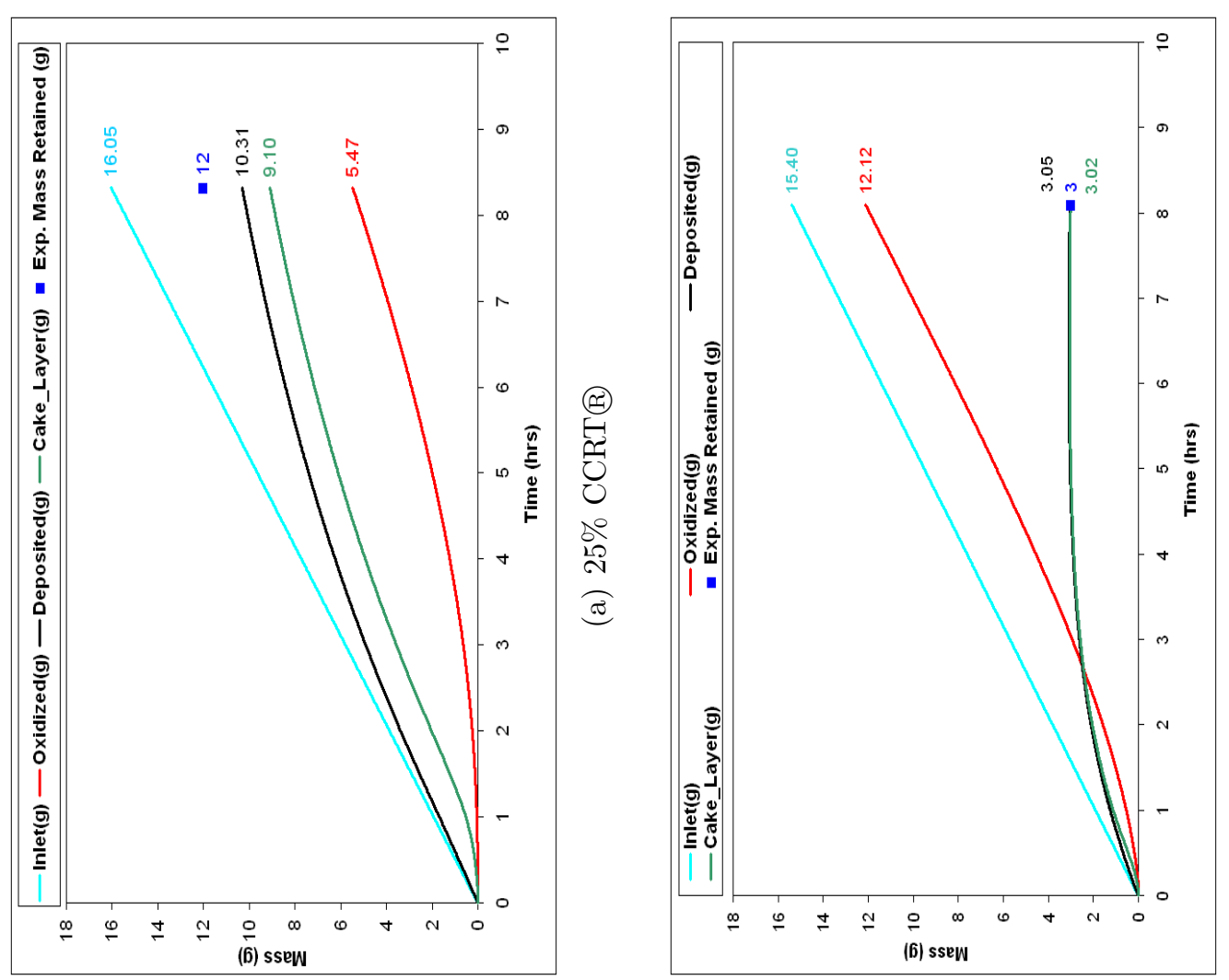

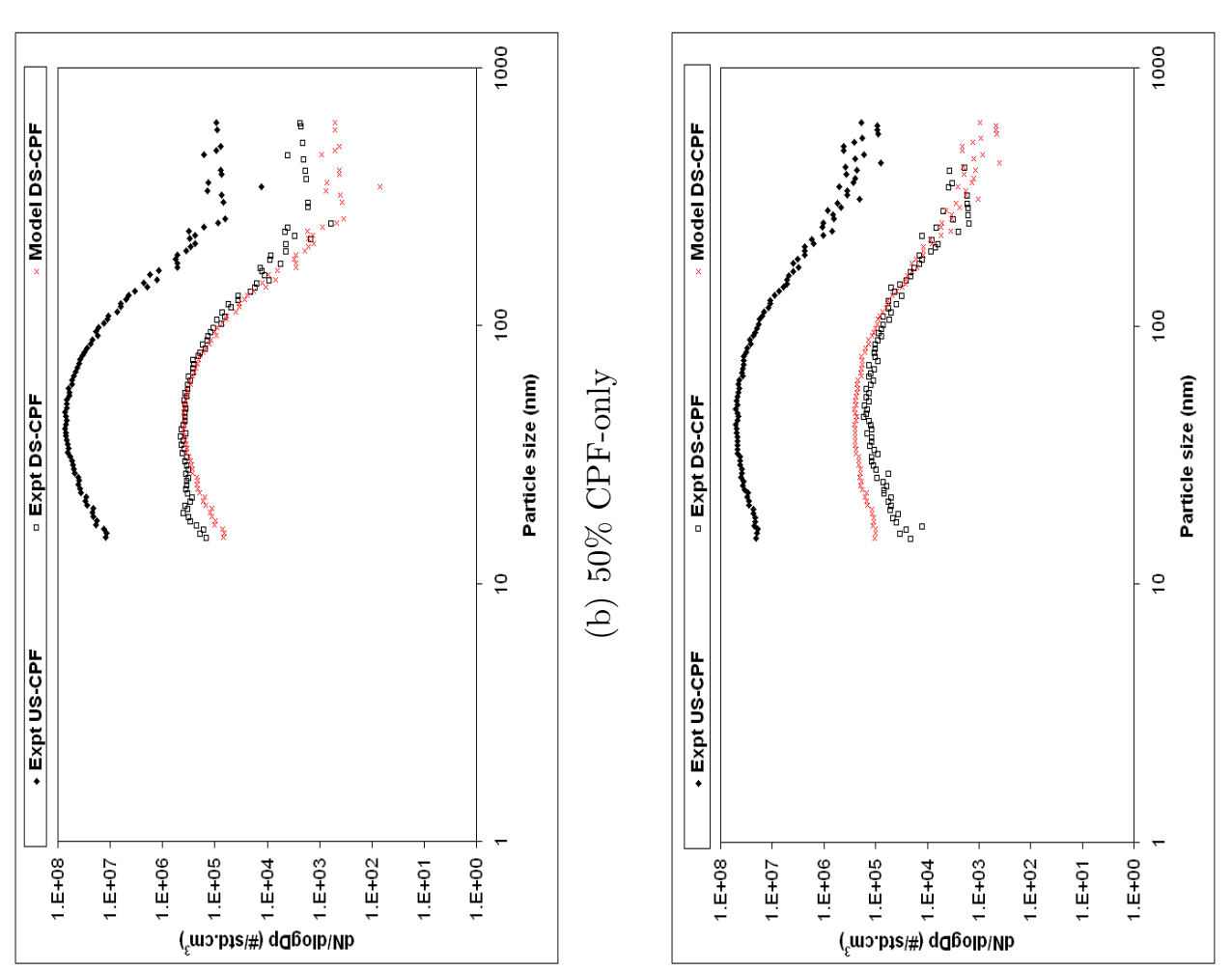

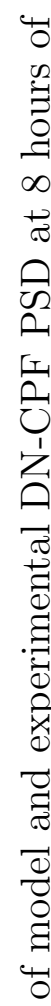
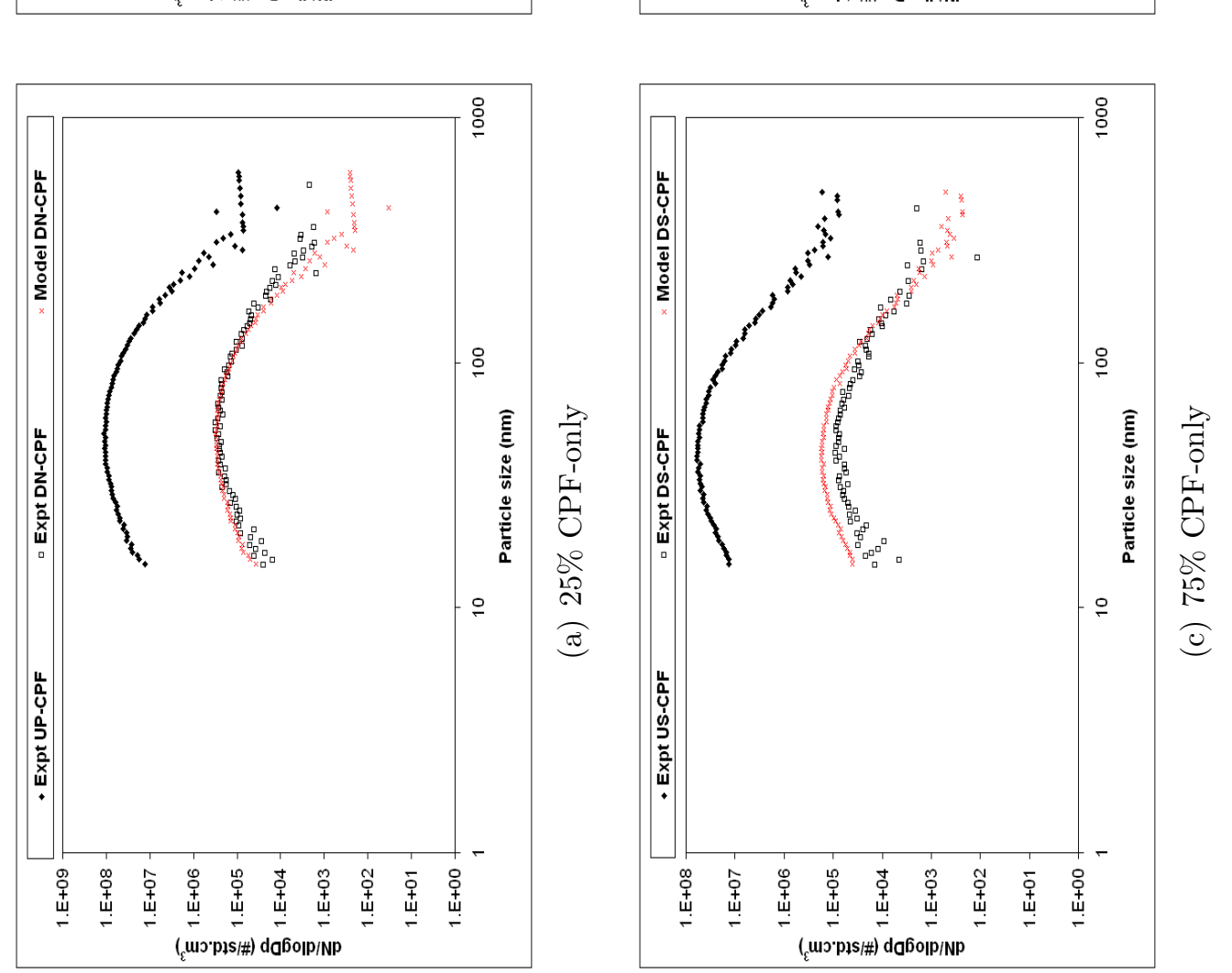

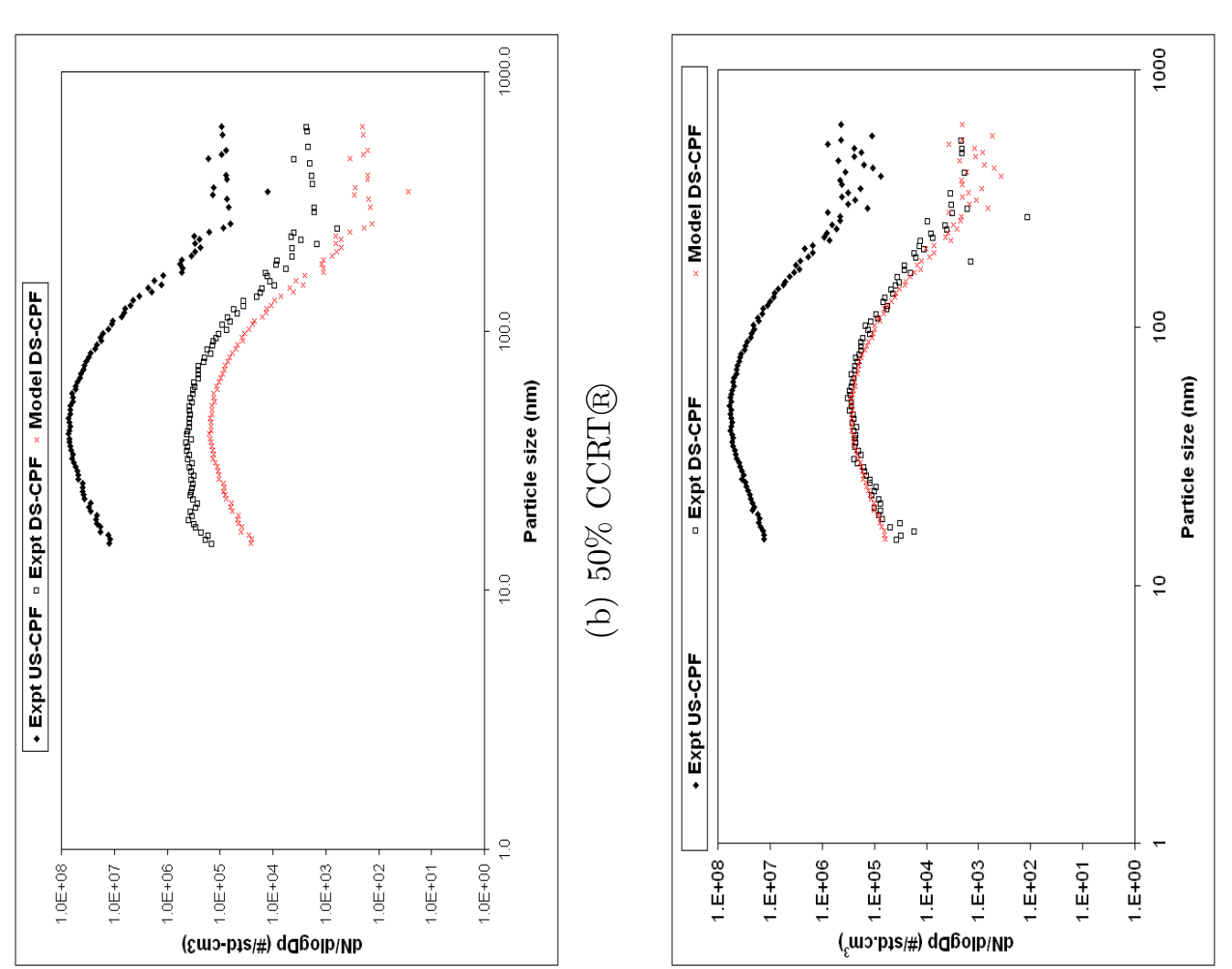

(⿸丆口广
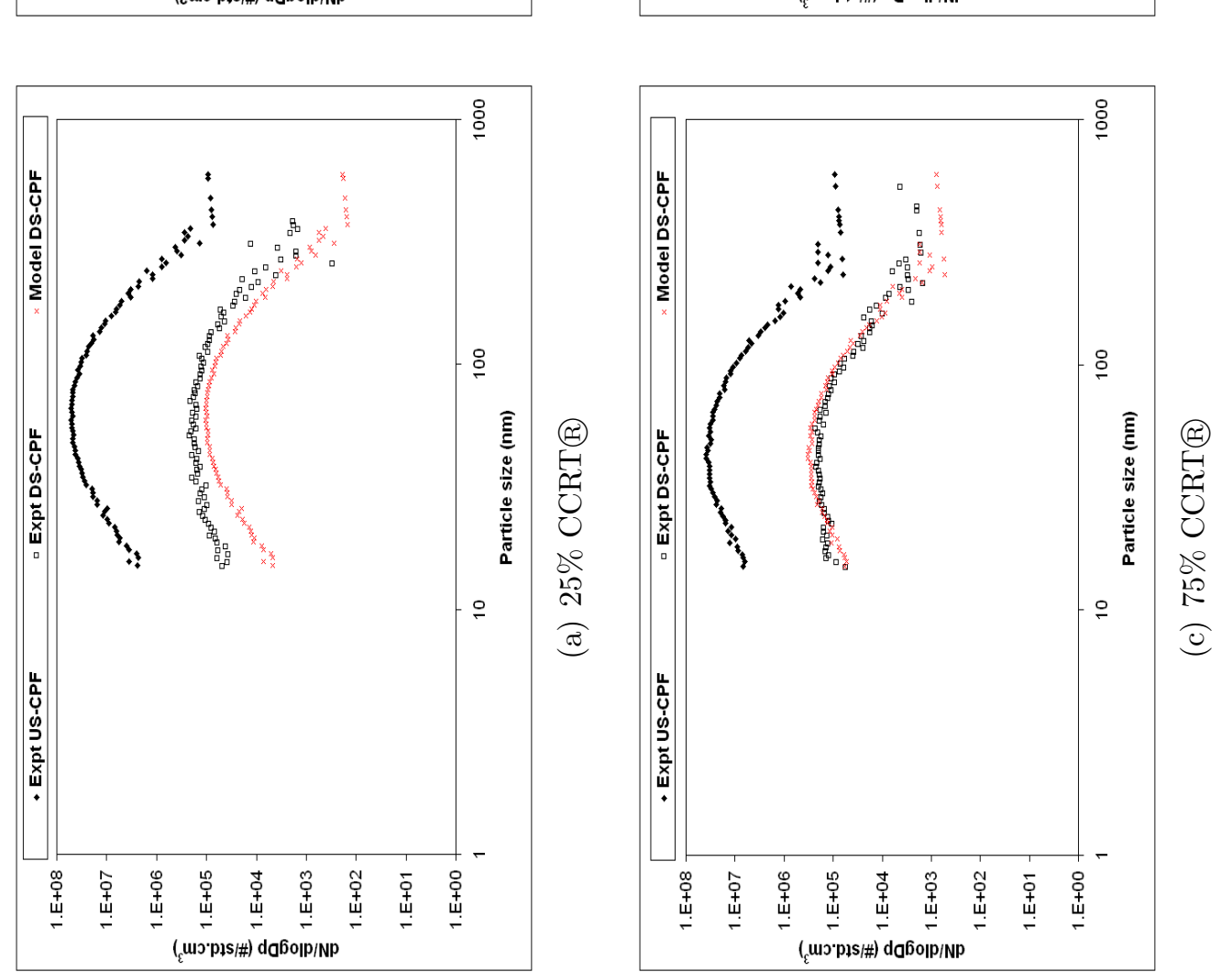

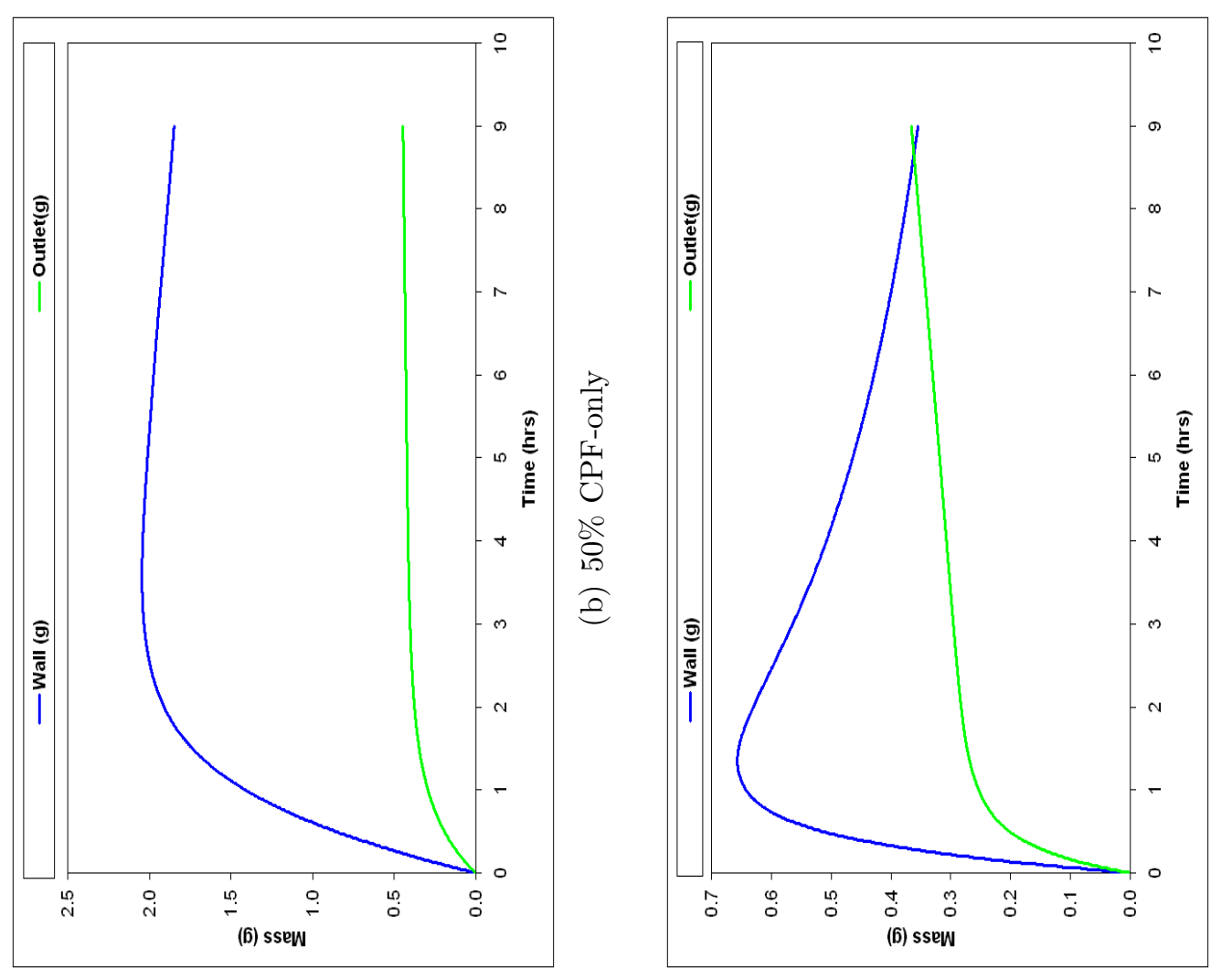

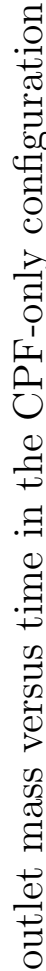
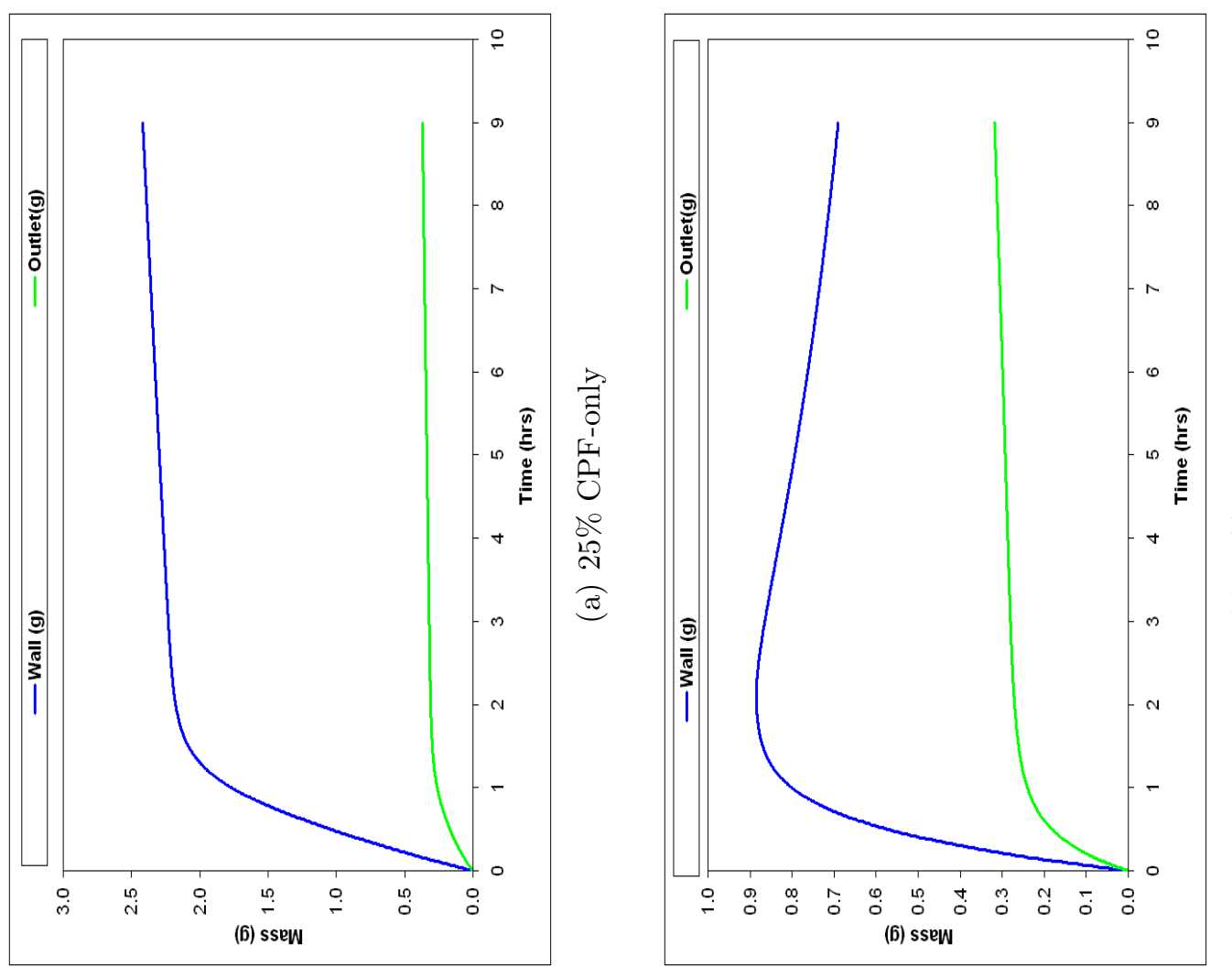

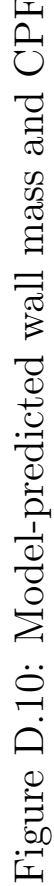



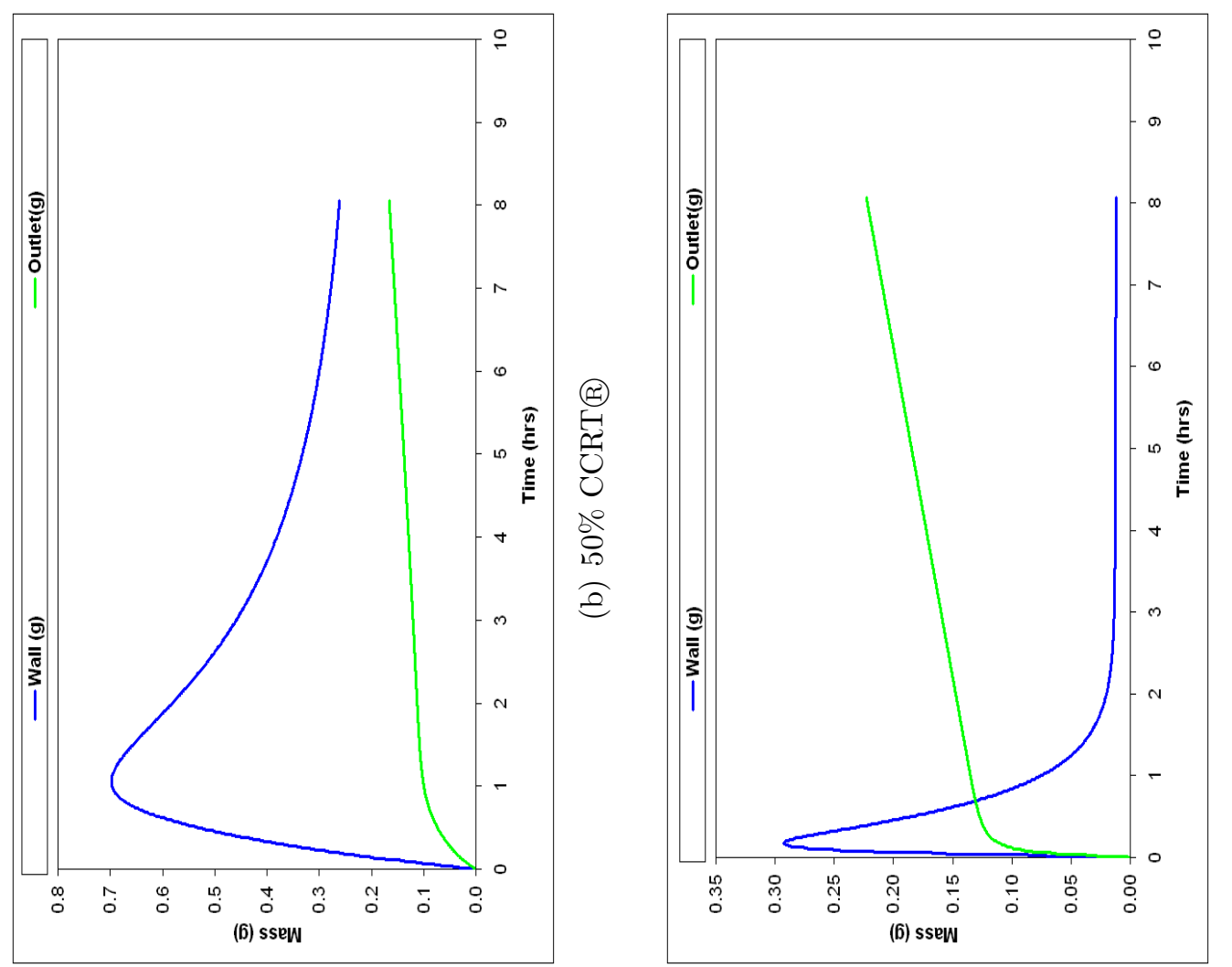

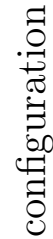

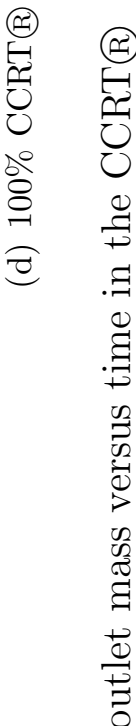
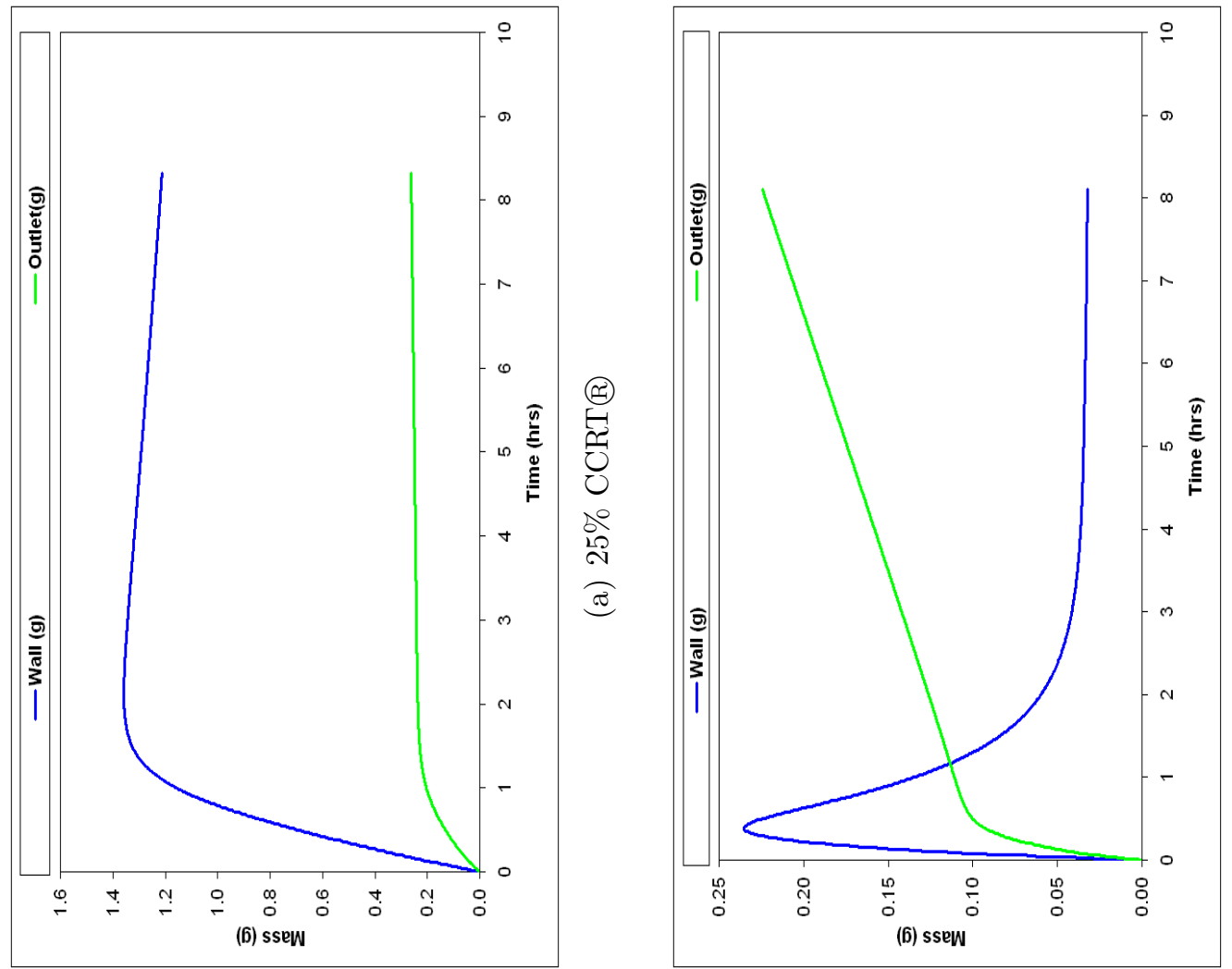

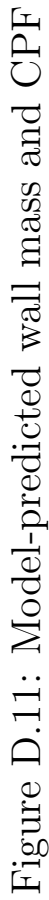



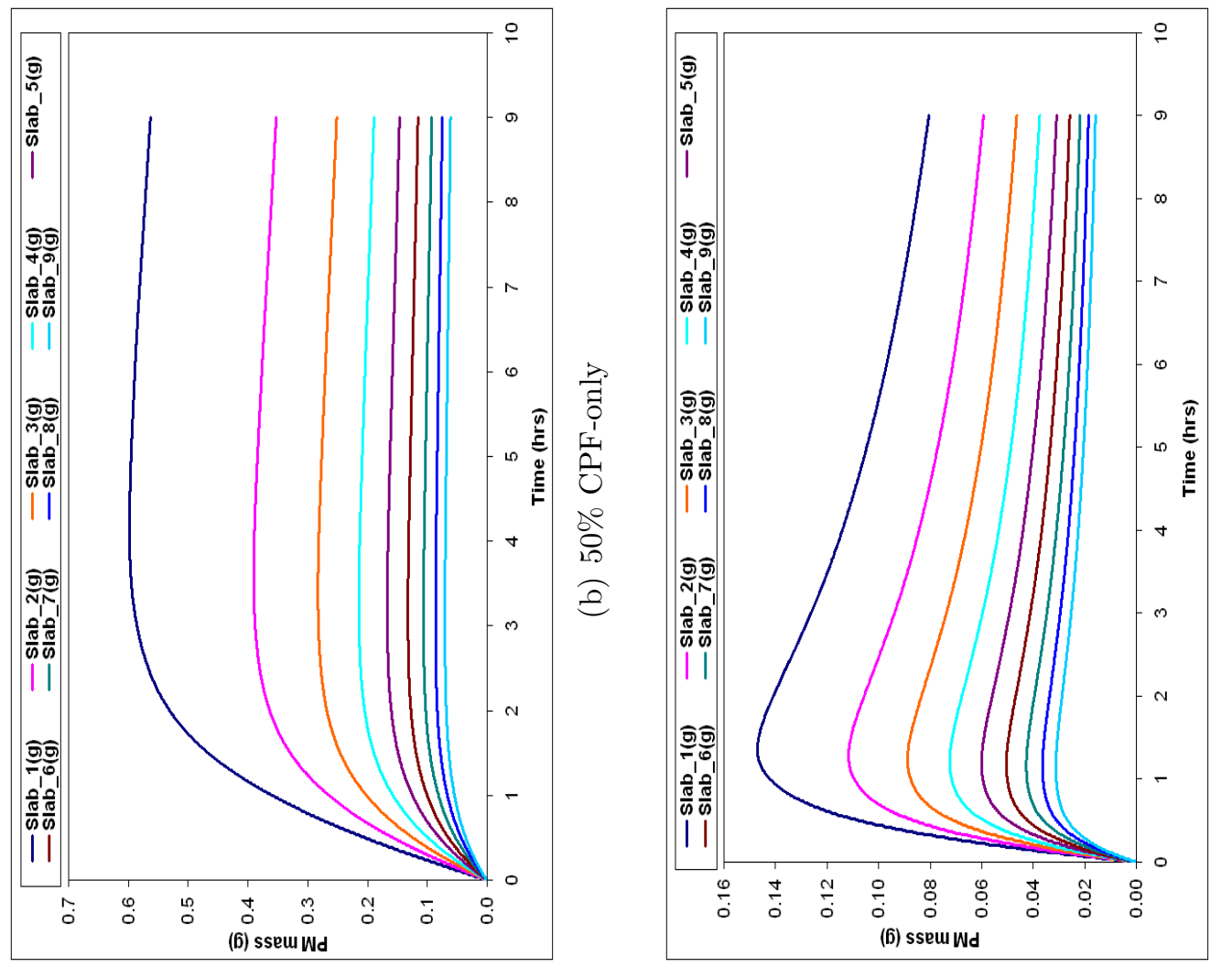

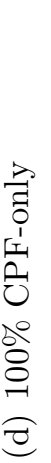

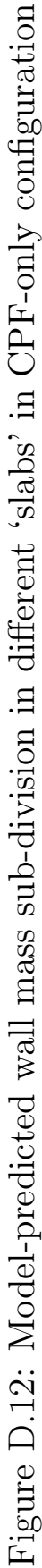
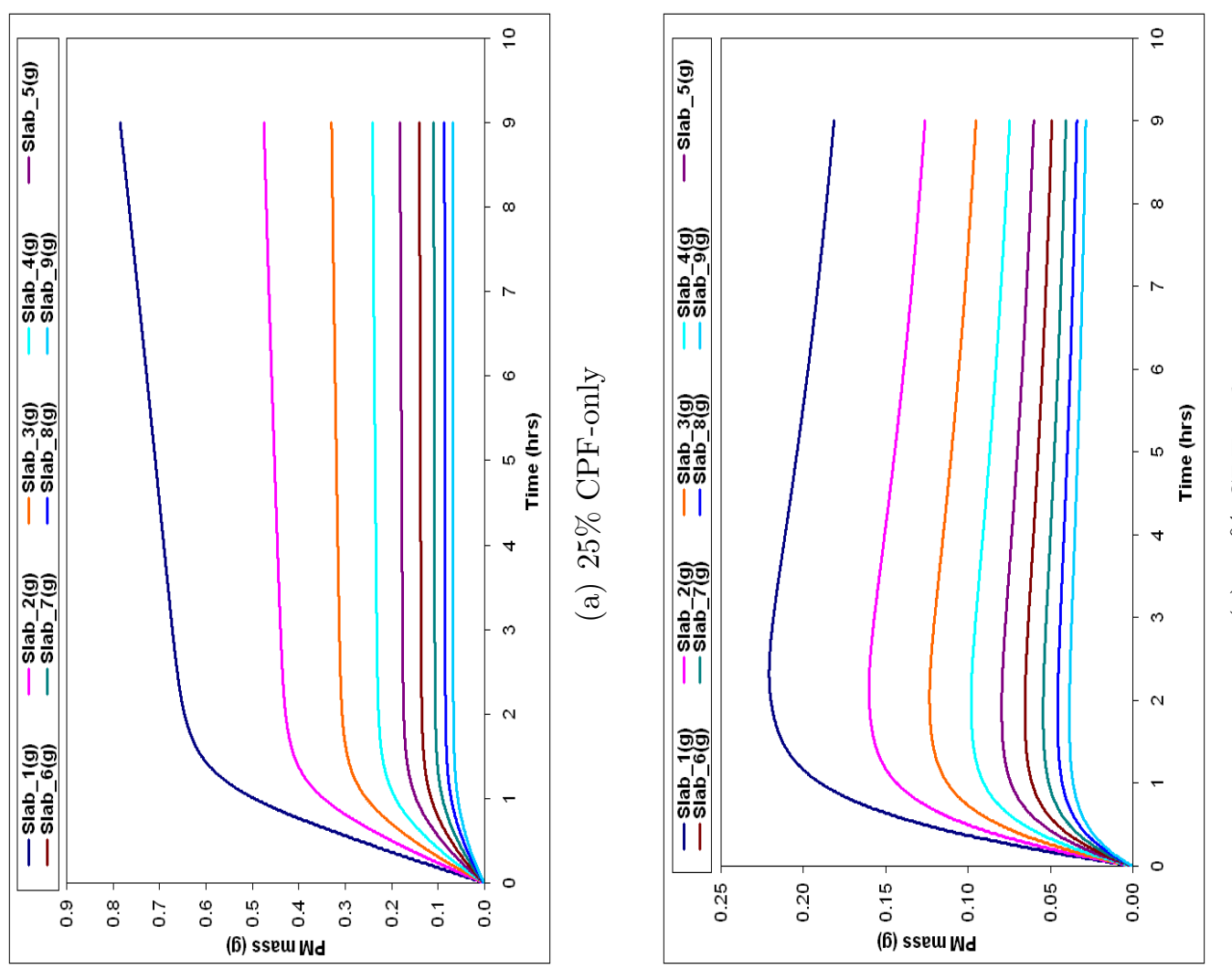

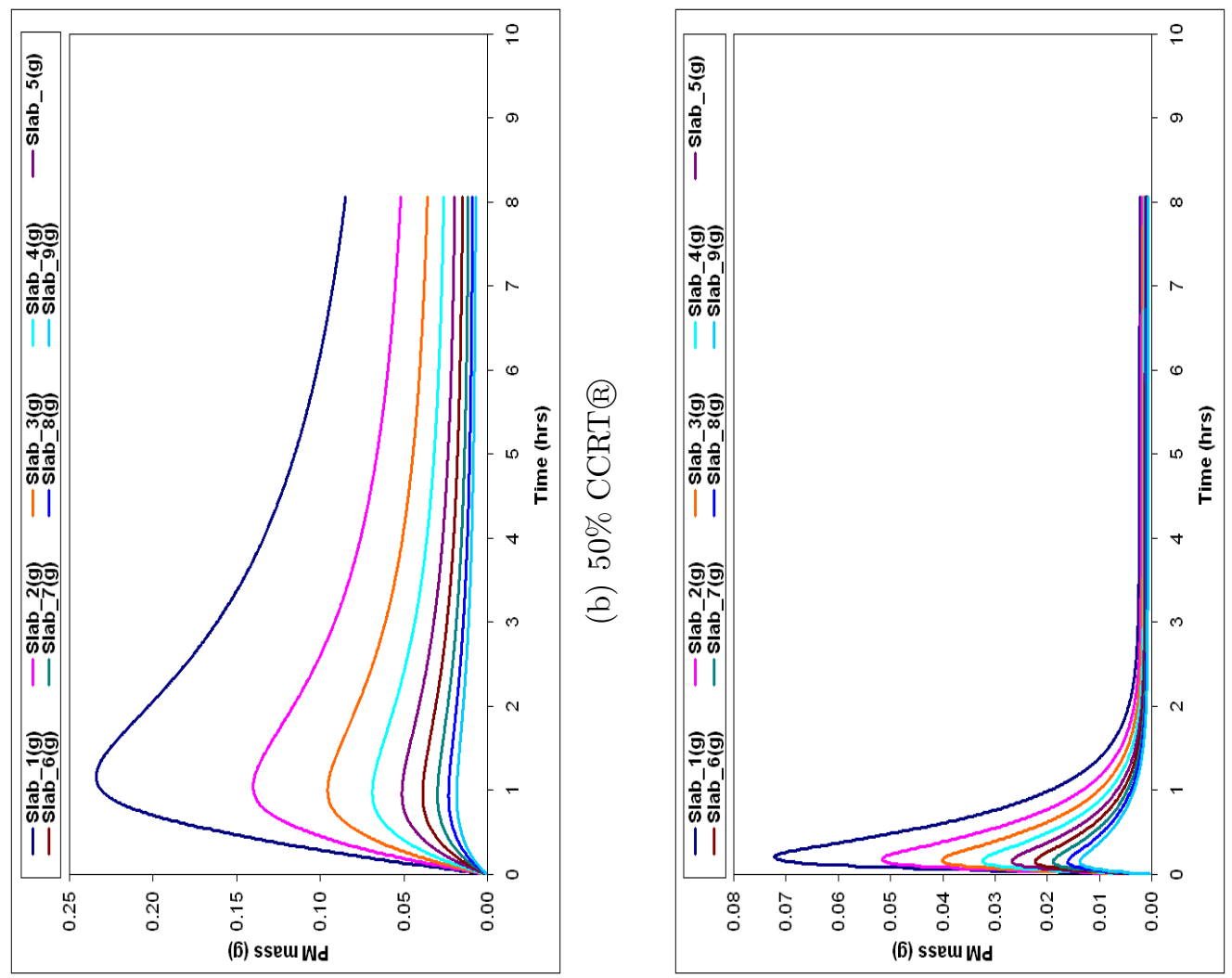

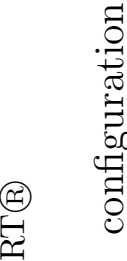

$E=1$
0
0
0
0
0
อ
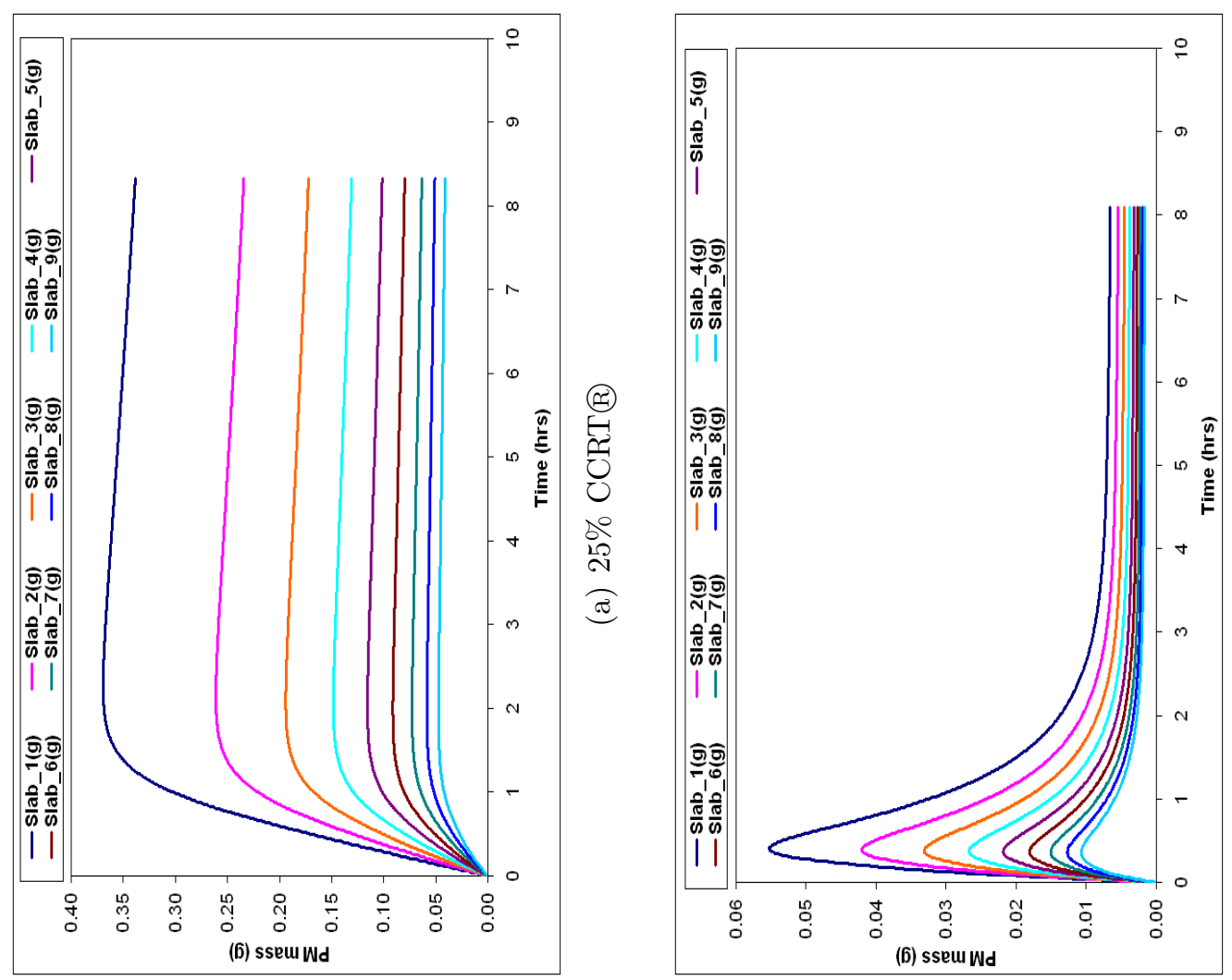

(2) ᄋ ङ्ञ.

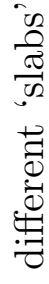

.$\Xi$

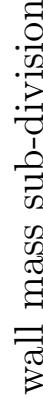

(2)

車

$\begin{array}{ll}0 & 0 \\ 0 & 0 \\ 0\end{array}$

然

() $\ddot{\sim}$ 


\section{Appendix E}

\section{Engine Performance Curves from DOC-only Tests}

This section shows the engine performance curves obtained from the experiments conducted on the John Deere engine in the DOC-only configuration at 2200 and 1650 $\mathrm{rpm}$. Since in these experiments, the engine load was varied from 5 to $100 \%$ of the maximum torque on the engine, the performance curves also gives an idea of the relative magnitudes of the major engine variables at the rated speed and reduced speed. All curves show relative values normalized to the maximum value of the variable measured, since the engine involved is in the development stages and hence, major engine variables have not been made available to publish. 


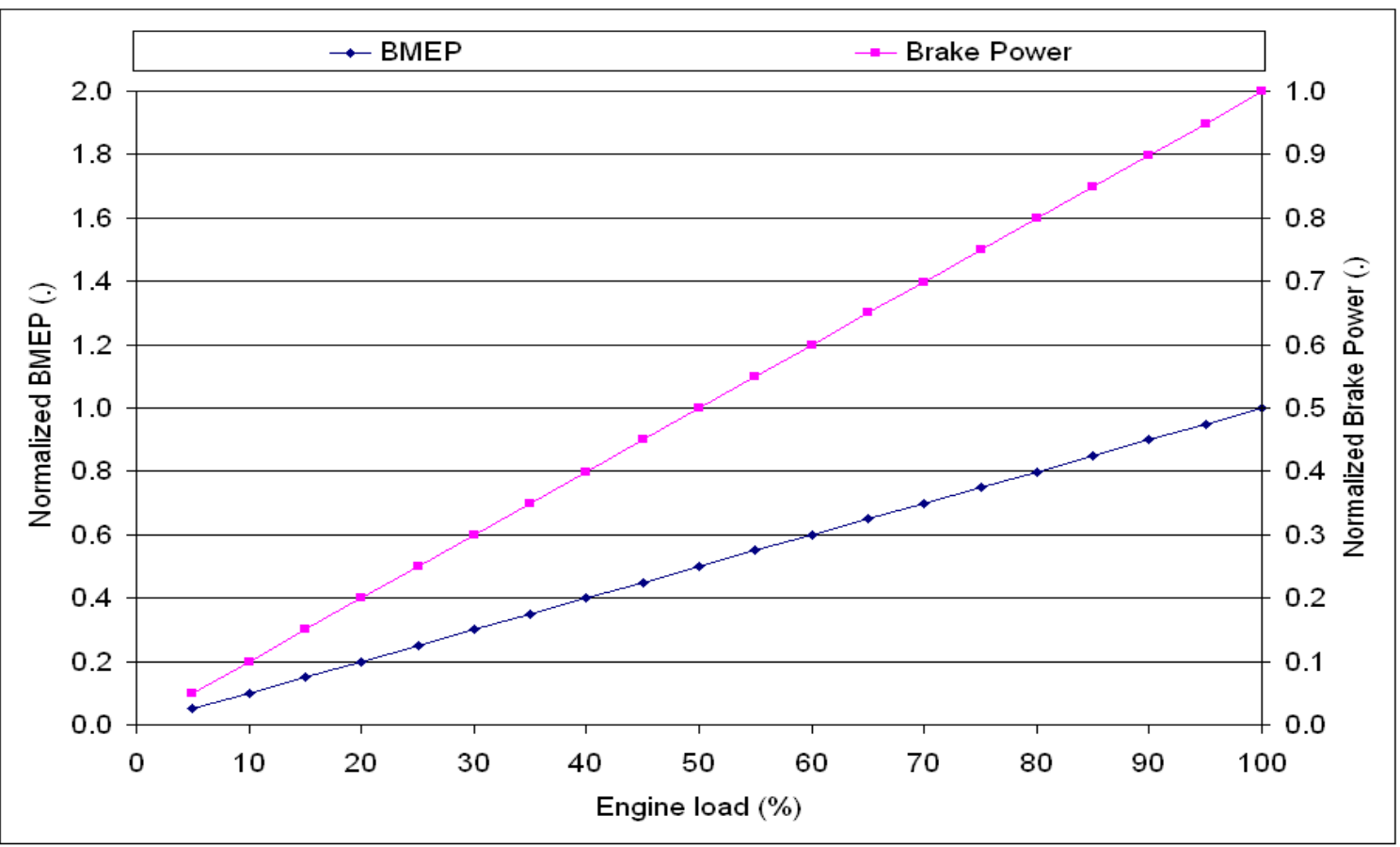

Figure E.1: Normalized BMEP and normalized brake power in DOC-only setup at $2200 \mathrm{rpm}$

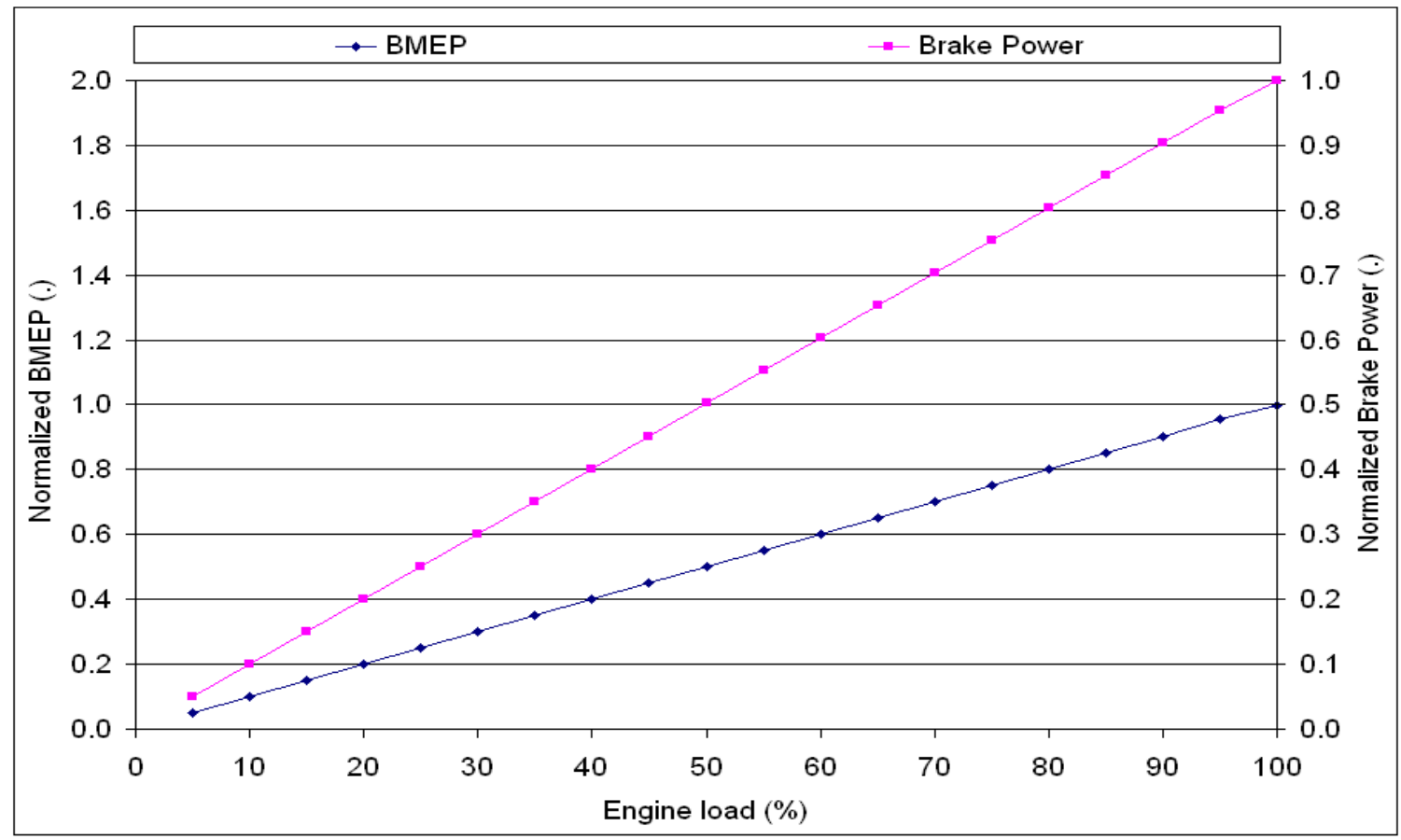

Figure E.2: Normalized BMEP and normalized brake power in DOC-only setup at $1650 \mathrm{rpm}$ 


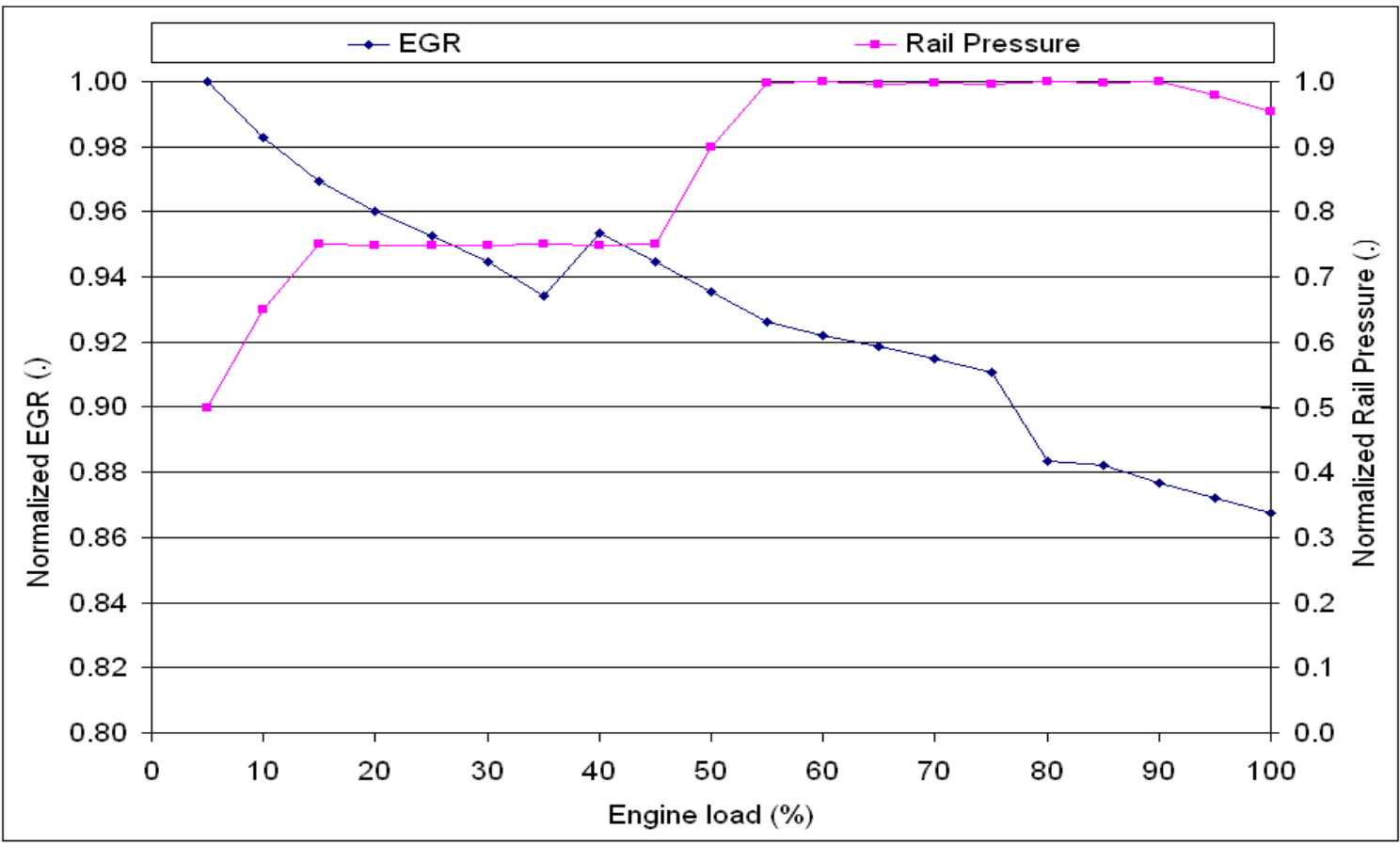

Figure E.3: Normalized Percentage EGR and normalized rail pressure in DOC-only setup at $2200 \mathrm{rpm}$

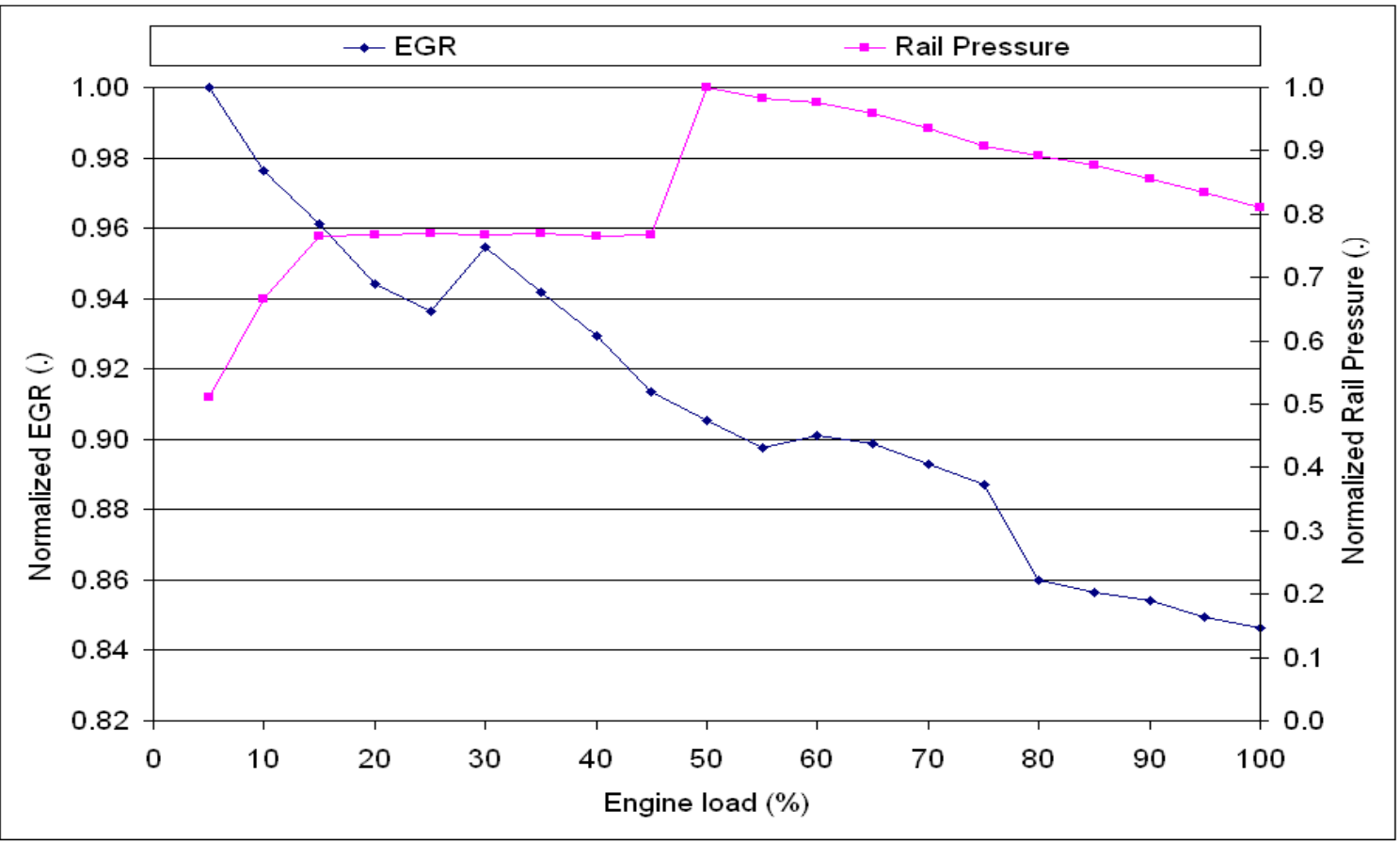

Figure E.4: Normalized Percentage EGR and normalized rail pressure in DOC-only setup at $1650 \mathrm{rpm}$ 


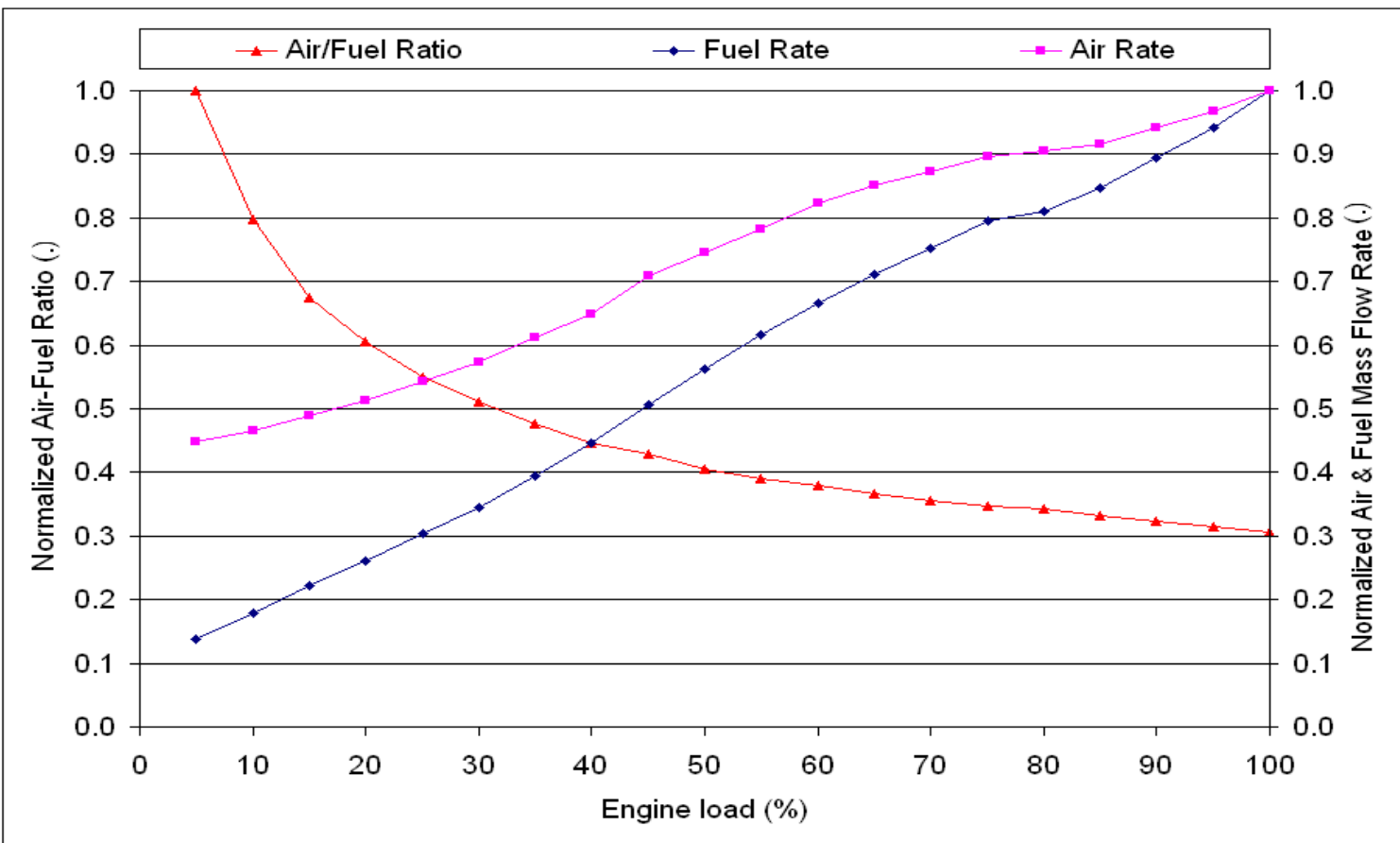

Figure E.5: Normalized air and fuel mass flow rates and normalized air/fuel ratio against percentage load in DOC-only setup at $2200 \mathrm{rpm}$

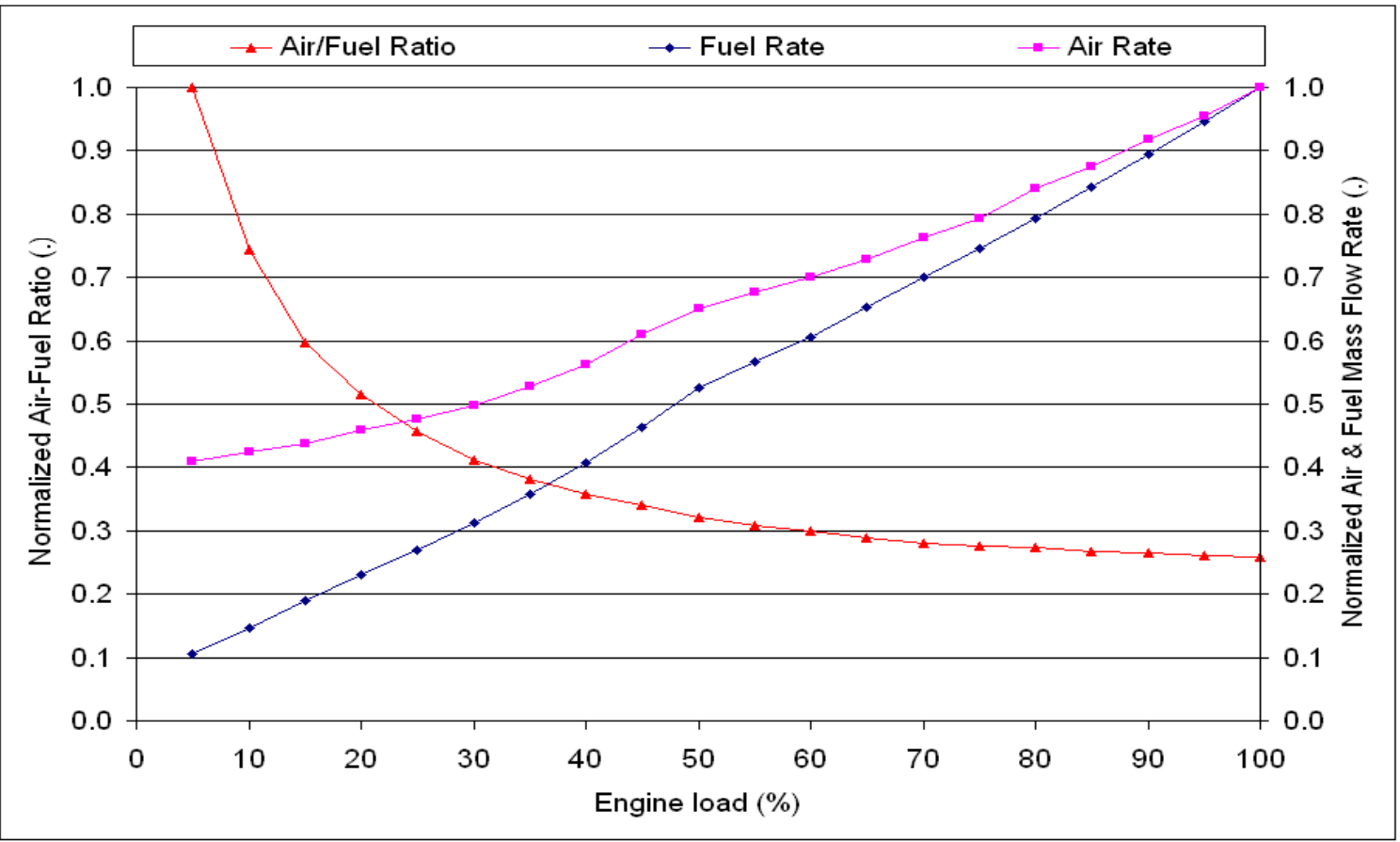

Figure E.6: Normalized air and fuel mass flow rates and normalized air/fuel ratio against percentage load in DOC-only setup at $1650 \mathrm{rpm}$ 


\section{Appendix $\mathrm{F}$}

\section{Experimental Setup - Schematics}

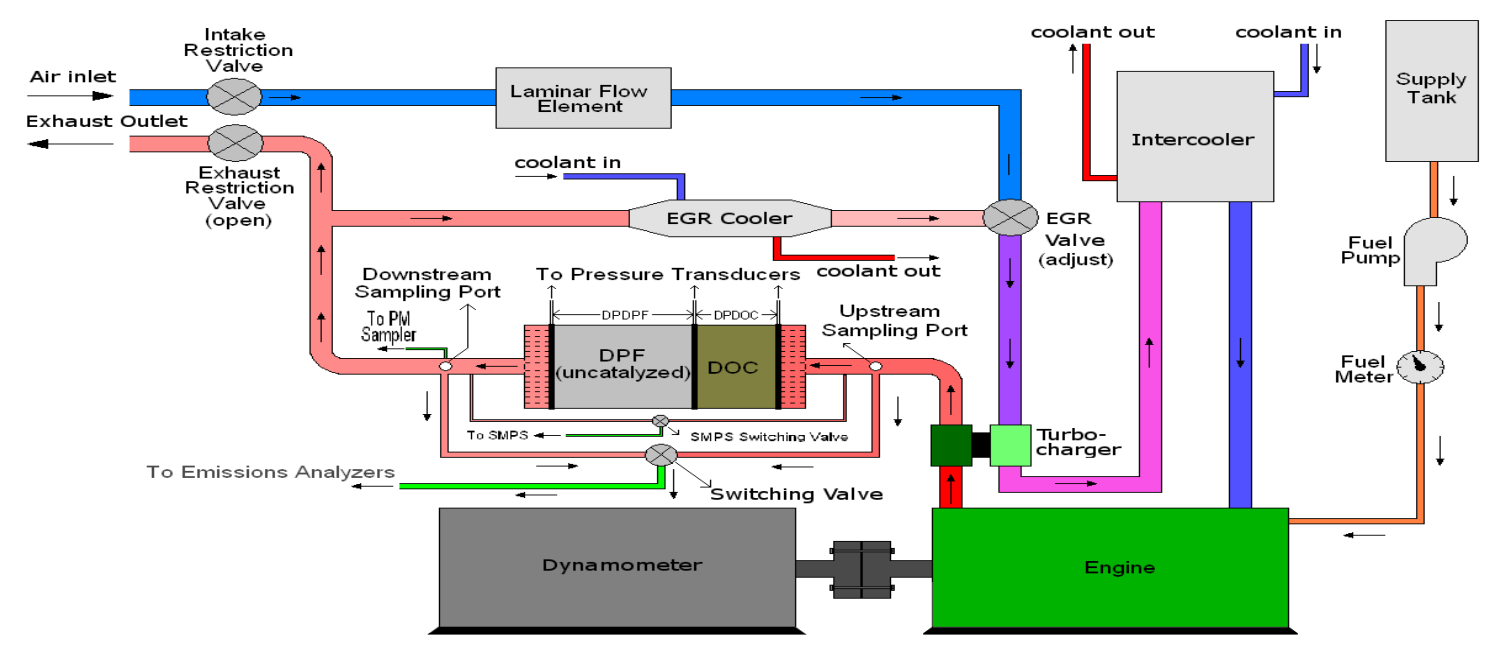

Figure F.1: Setup for DOC-only experiments 


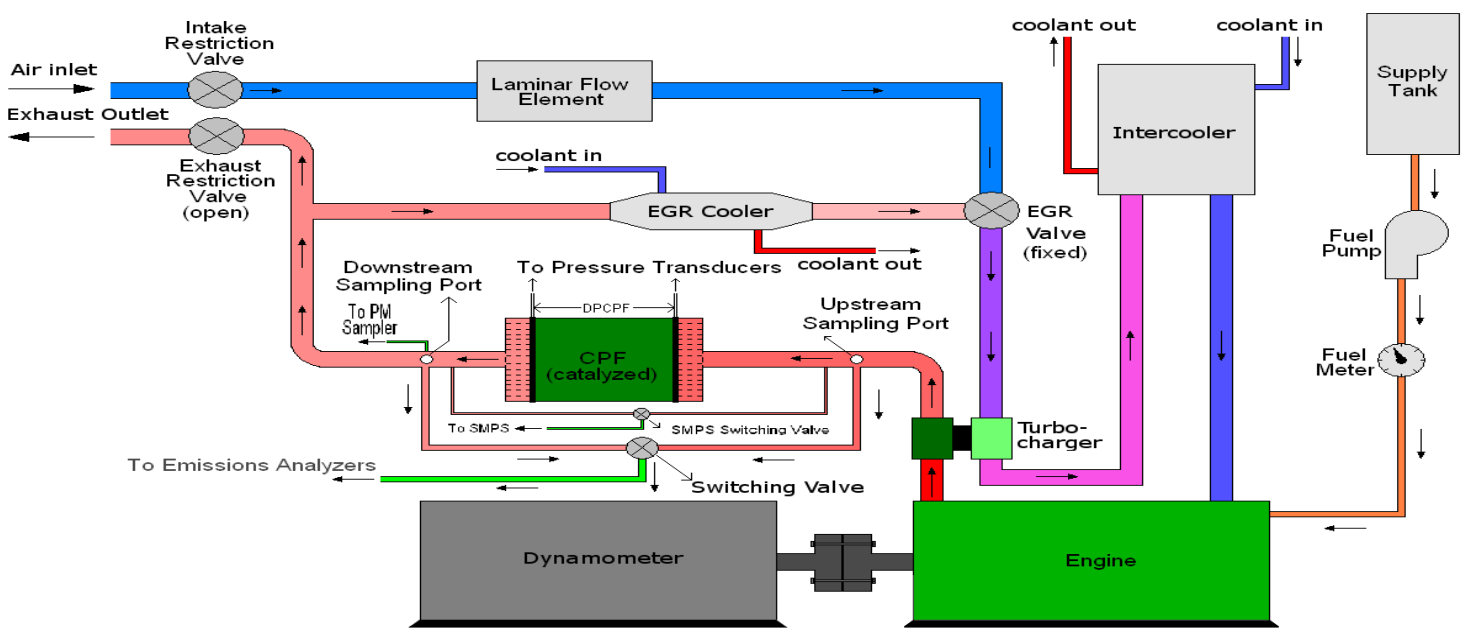

Figure F.2: Setup for CPF-only experiments

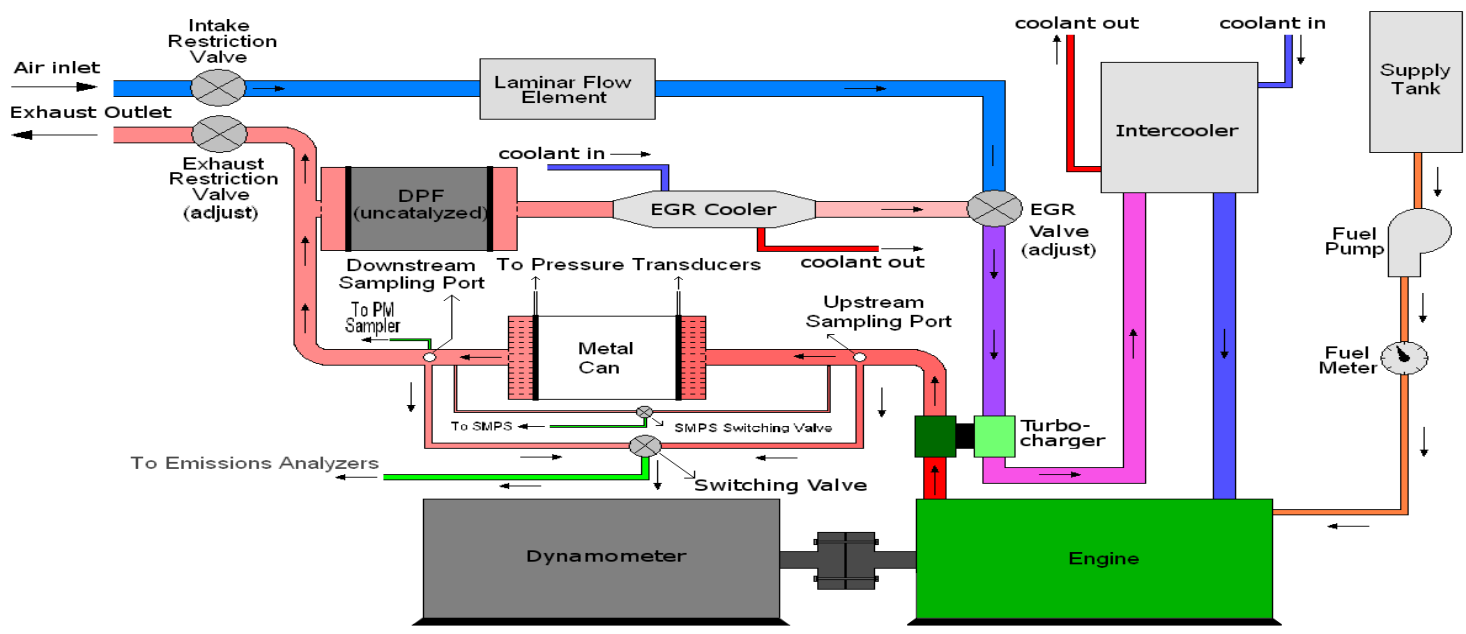

Figure F.3: Baseline setup for CPF-only experiments 


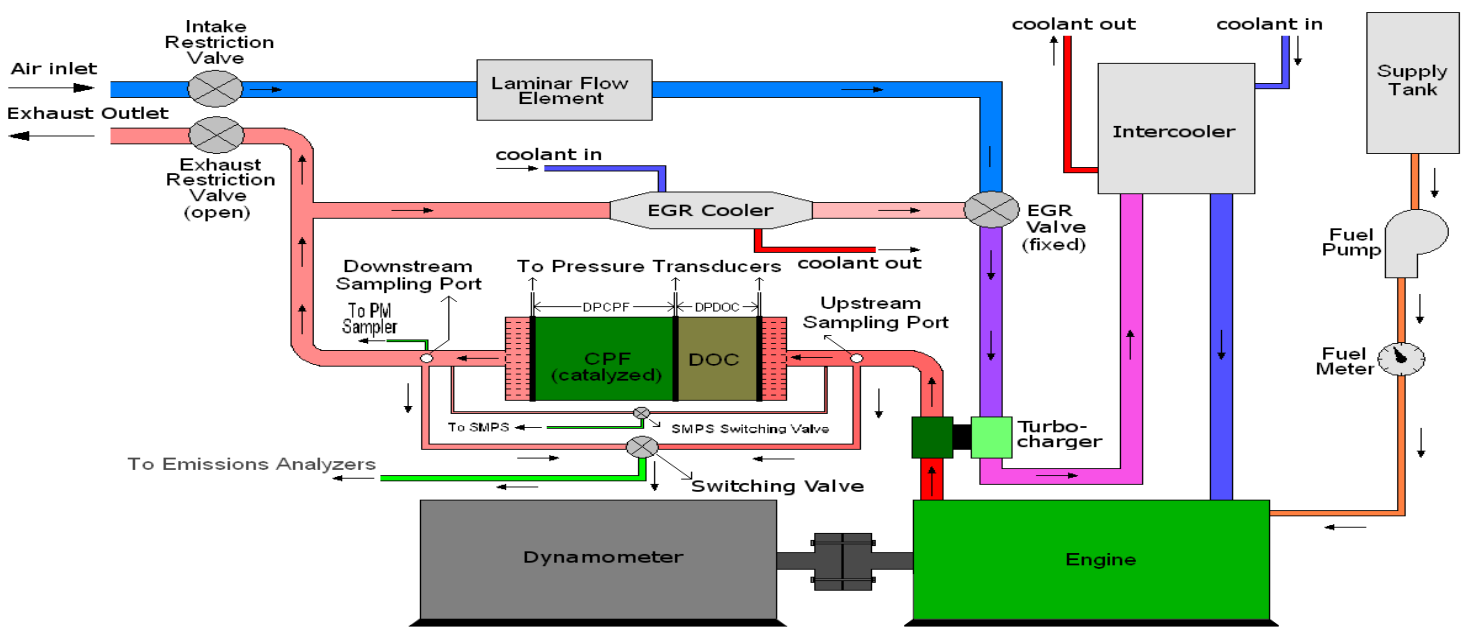

Figure F.4: Setup for CCRTß experiments

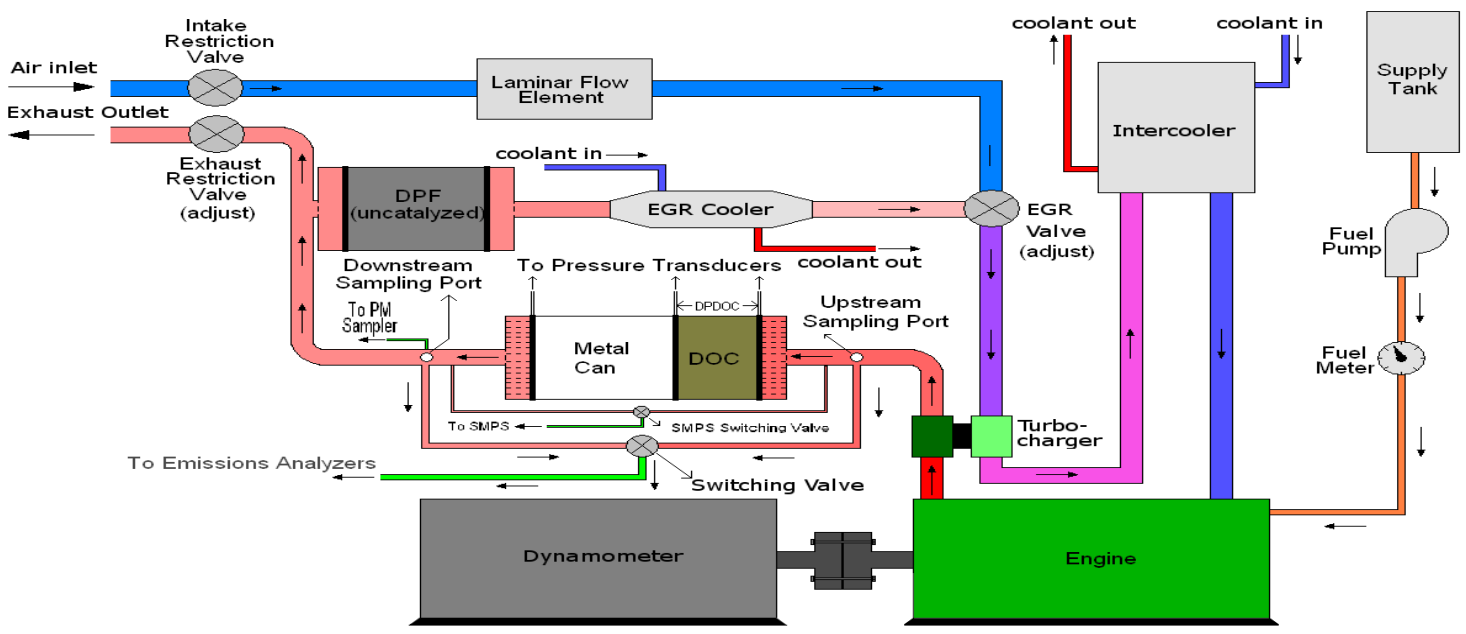

Figure F.5: Baseline setup for CCRT@ experiments 


\section{Appendix G}

\section{Analysis of the Particulate Filter Weight Gain Observed During Experiments}

During CPF-only and CCRT experiments conducted at $2200 \mathrm{rpm}$ and $1650 \mathrm{rpm}$, it was observed that in some cases, values for PM mass deposited obtained from the difference of filter pre-test and post-test weights were higher than expected. In some cases, values of PM mass deposited calculated were higher than the total CPF inlet PM calculated from baseline data. This led to the conclusion that filter weights measured were not accurate in all cases. An analysis of the weights of the two CPF units that were used in the experiments (labeled 'CPF 1' and 'CPF 2') was carried out to observe the changes in pre-test weights of the two filters used.

Filter post-test weights were observed to be increasing as the average temperature of the filter decreased from the average temperature gained during the loading. This could be caused by a weight gain due to moisture gain, from the cooling of the CPF. But as can be seen from Figures G.1 and G.2, a definite relationship between filter temperature differences and CPF weight gains could not be established. 


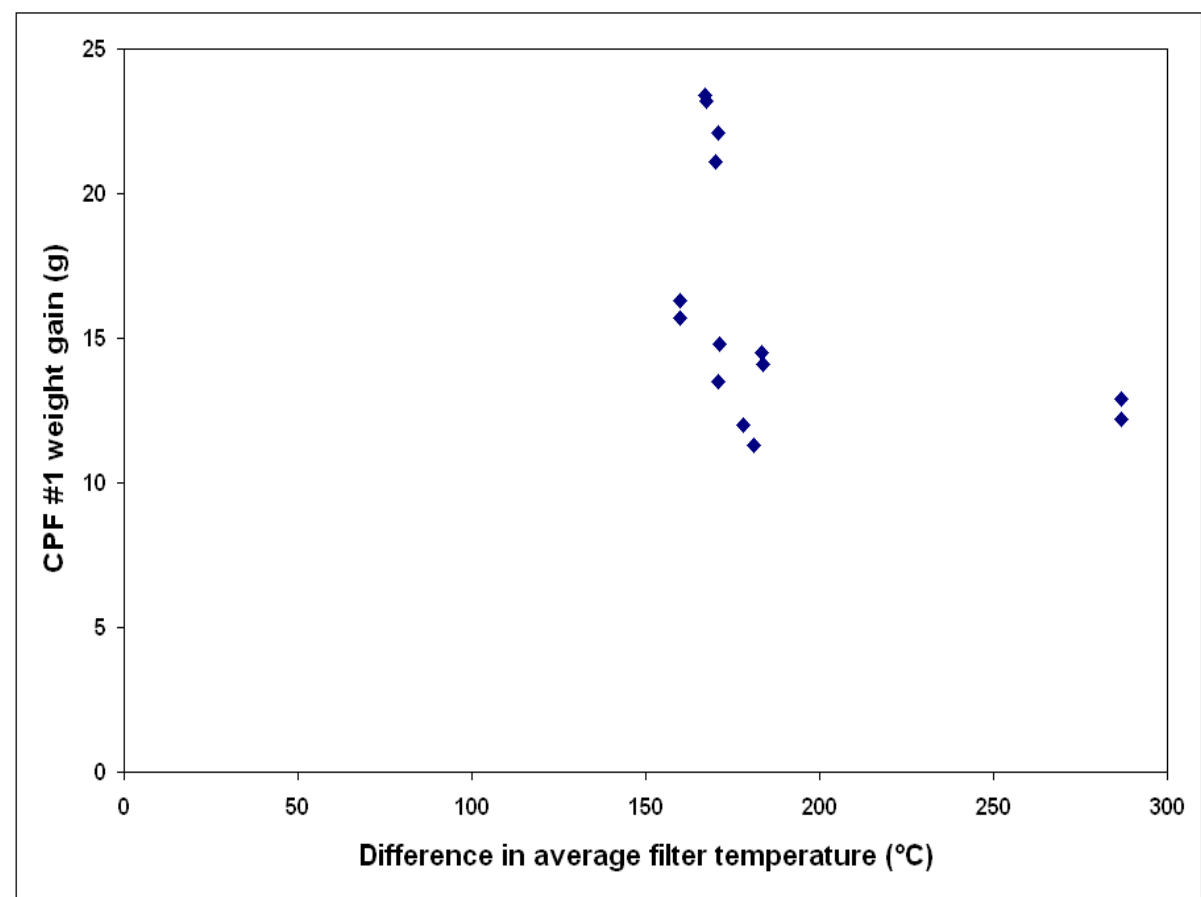

Figure G.1: CPF weight gain versus average filter temperature difference between measurements for CPF 1

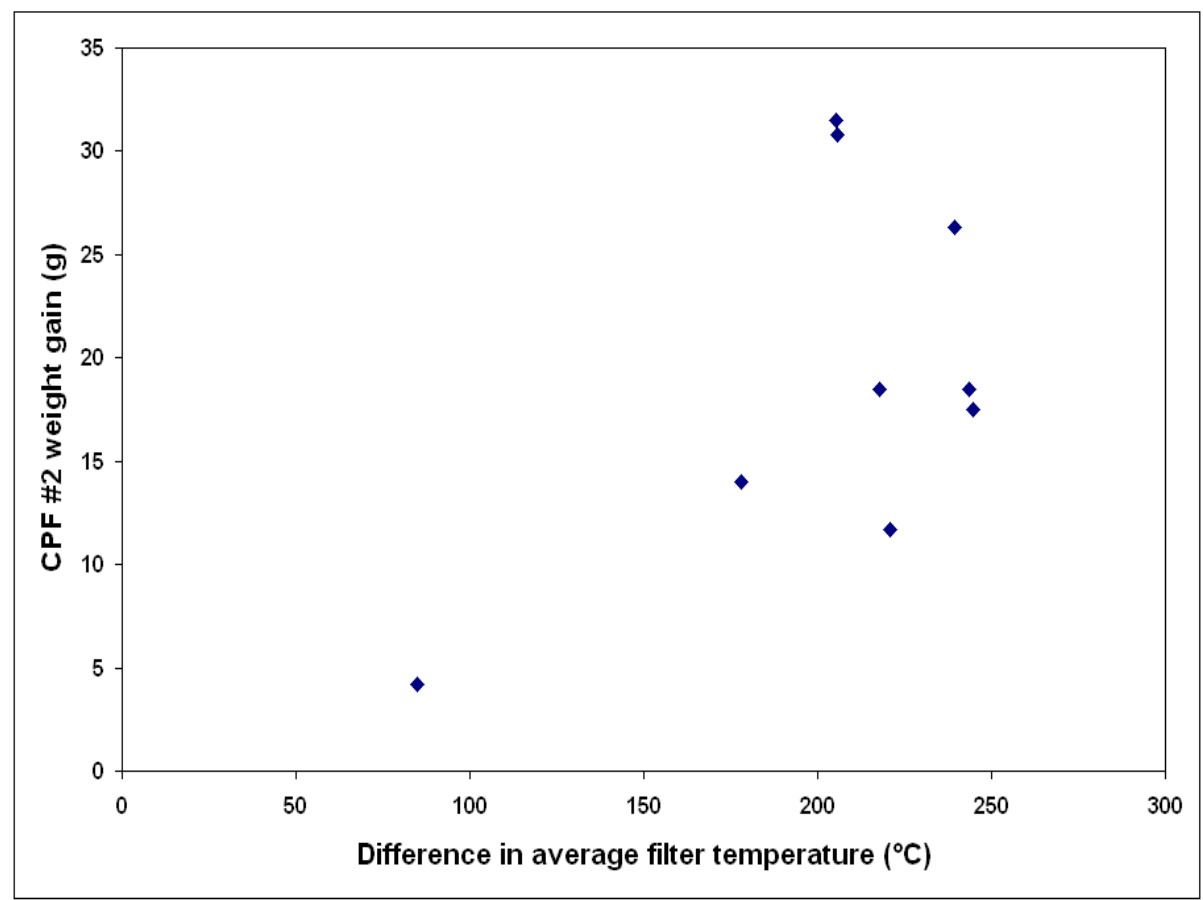

Figure G.2: CPF weight gain versus average filter temperature difference between measurements for CPF 2 
However, a study of filter pre-test weight gain versus number of days between measurements showed a definite trend of increasing weights with increasing number of days as the CPF was left exposed to the ambient for a greater amount of time (as shown in Figures G.3 and G.4).

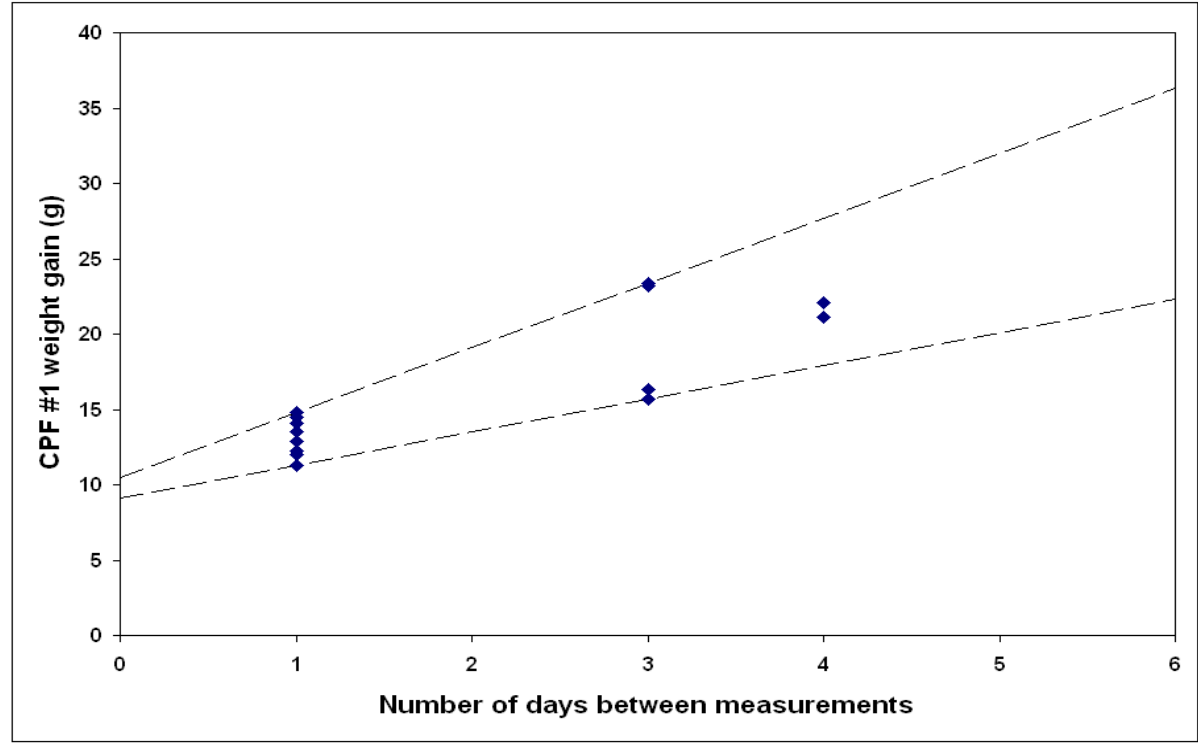

Figure G.3: CPF weight gain versus number of days between measurements for $\mathrm{CPF} 1$

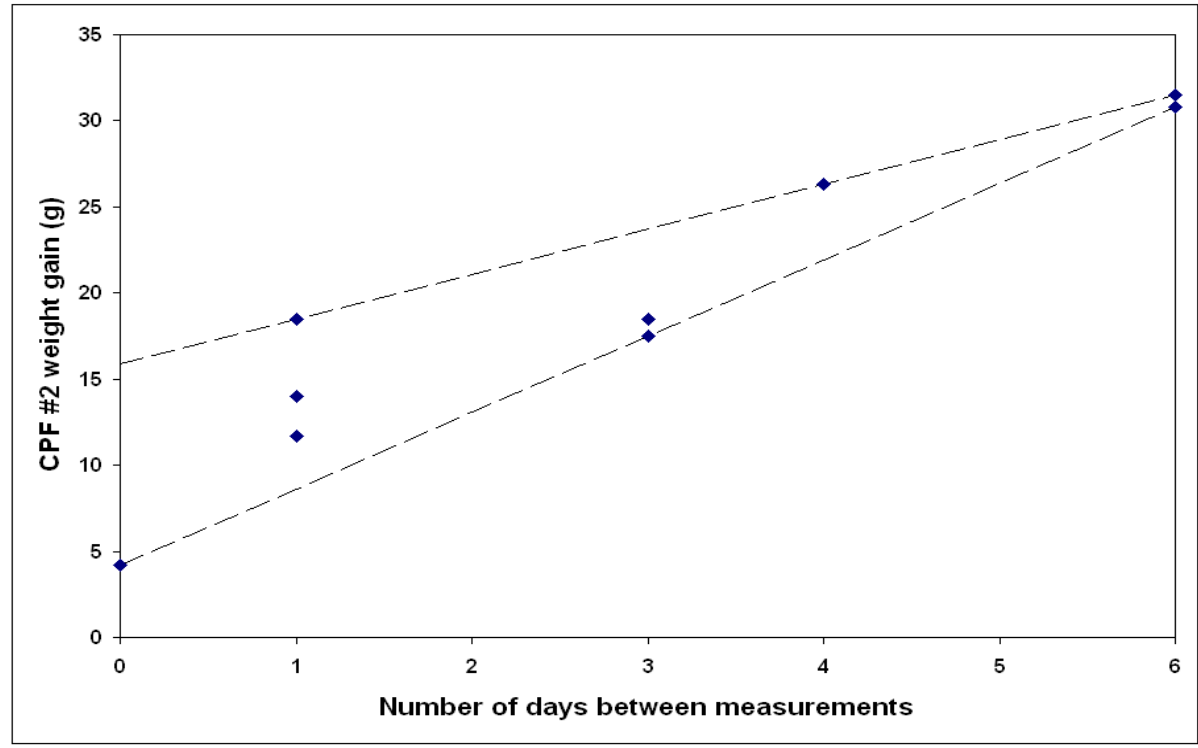

Figure G.4: CPF weight gain versus number of days between measurements for $\mathrm{CPF} 2$ 
Since the pre-test and post-test weights of the filter were taken on the same day, estimates from Table G.1 for CPF 1 and CPF 2 were taken corresponding to '0' days between measurements. This estimate combined with a 'temperature difference effect' would explain filter weight gains observed in low-load cases (specifically, the 25 and $50 \%$ load-cases) at $2200 \mathrm{rpm}$ and $1650 \mathrm{rpm}$.

Table G.1: Estimate of filter weight gain based on number of days between measurements

\begin{tabular}{|c|c|c|c|c|}
\hline & \multicolumn{2}{|c|}{ CPF 1} & \multicolumn{2}{|c|}{ CPF 2} \\
\hline 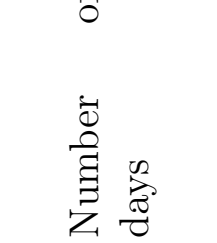 & 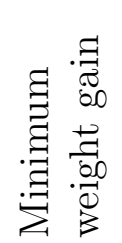 & 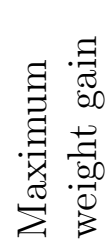 & 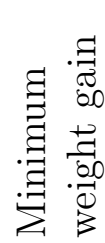 & 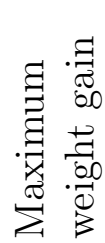 \\
\hline (Units) $\rightarrow$ & (g) & (g) & (g) & (g) \\
\hline 0 & 9.1 & 10.5 & 4.2 & 15.9 \\
\hline 1 & 11.3 & 14.8 & 8.6 & 18.5 \\
\hline 2 & 13.5 & 19.1 & 13.1 & 21.1 \\
\hline 3 & 15.7 & 23.4 & 17.5 & 23.7 \\
\hline 4 & 17.9 & 27.7 & 21.9 & 26.3 \\
\hline 5 & 20.1 & 32.0 & 26.4 & 28.9 \\
\hline 6 & 22.3 & 36.3 & 30.8 & 31.5 \\
\hline
\end{tabular}

From this estimate of the weight gain of the CPF, a correction to the mass deposited (to be applied to the cases believed to have had errors in measured values of PM mass deposited) was developed as shown in Table G.2. These estimates were used in the corrected percentage PM mass oxidized calculation used for calibration of the CPF model (Table 5.6). 
Table G.2: Mass corrections obtained from weight gain estimates

\begin{tabular}{|c|c|c|c|c|c|}
\hline 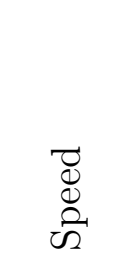 & 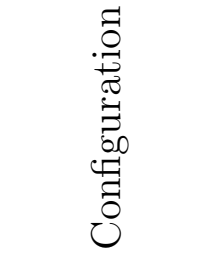 & $\begin{array}{l}\vec{\nabla} \\
\underset{\sigma}{0} \\
\stackrel{0}{\ominus}\end{array}$ & $\begin{array}{l}\dot{0} \\
z \\
{\left[\begin{array}{r}u \\
0\end{array}\right.}\end{array}$ & 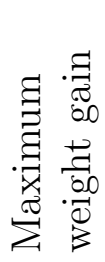 & 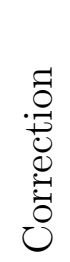 \\
\hline$(\mathrm{rpm})$ & & $(\%)$ & & (g) & (g) \\
\hline \multirow{8}{*}{2200} & \multirow{4}{*}{ CPF-only } & 25 & 1 & 10.5 & 3 \\
\hline & & 50 & 2 & 15.9 & 10 \\
\hline & & 75 & 1 & 10.5 & 0 \\
\hline & & 100 & 1 & 10.5 & 0 \\
\hline & \multirow{4}{*}{ CCRT@ } & 25 & 2 & 15.9 & 10 \\
\hline & & 50 & 1 & 10.5 & 0 \\
\hline & & 75 & 1 & 10.5 & 0 \\
\hline & & 100 & 2 & 15.9 & 0 \\
\hline \multirow{8}{*}{1650} & \multirow{4}{*}{ CPF-only } & 25 & 2 & 15.9 & 16 \\
\hline & & 50 & 2 & 15.9 & 0 \\
\hline & & 75 & 1 & 10.5 & 0 \\
\hline & & 100 & 1 & 10.5 & 0 \\
\hline & \multirow{4}{*}{ CCRTR } & 25 & 2 & 15.9 & 0 \\
\hline & & 50 & 1 & 10.5 & 0 \\
\hline & & 75 & 1 & 10.5 & 0 \\
\hline & & 100 & 1 & 10.5 & 0 \\
\hline
\end{tabular}

